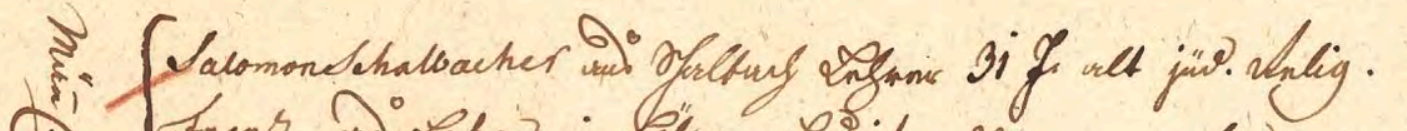

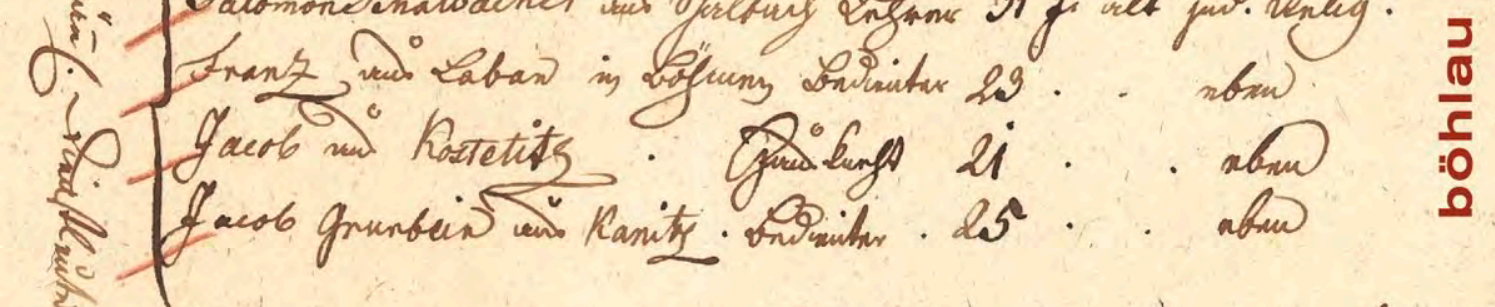

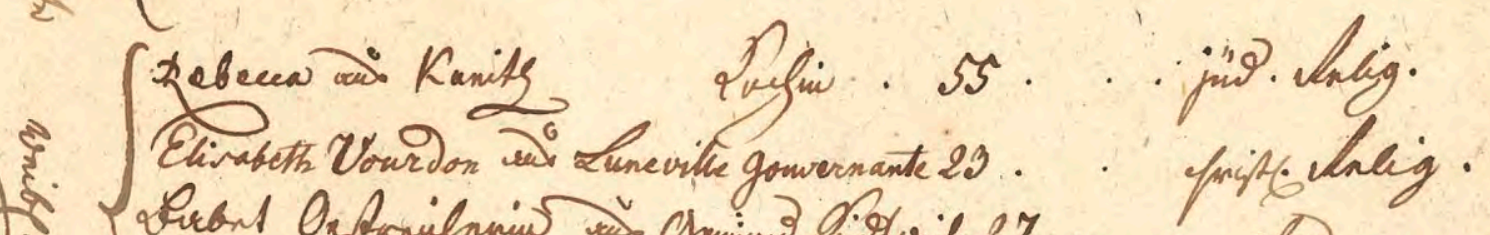

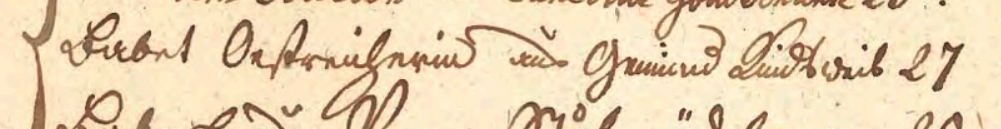

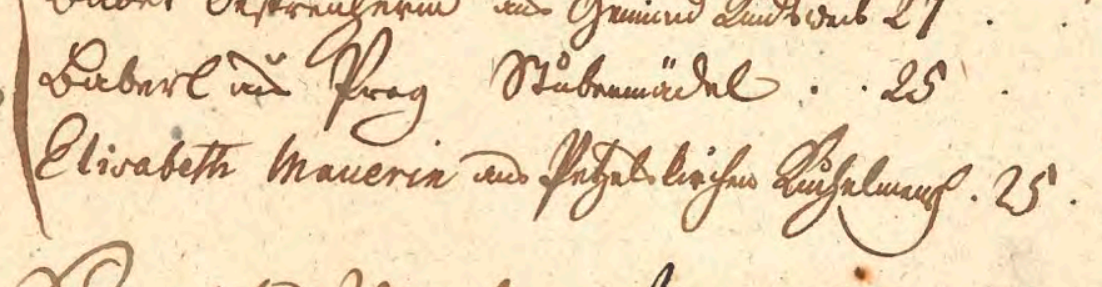

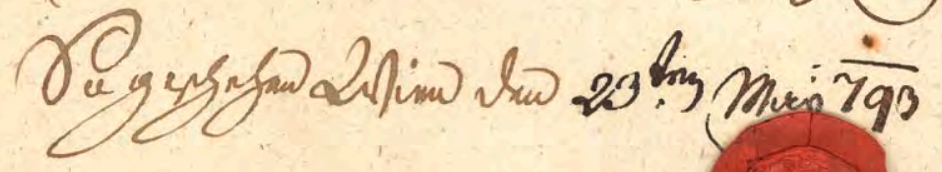

\title{
HEIMATRECHT UND STAATSBÜRGERSCHAFT ÖSTERREICHISCHER JUDEN
}

Vom Ende des 18. Jahrhunderts bis in die Gegenwart 
böhlau 
Studien zu Politik und Verwaltung

\author{
Herausgegeben von \\ Christian Brünner · Wolfgang Mantl · Manfried Welan
}

Band 108 
Hannelore Burger

\section{Heimatrecht und \\ Staatsbürgerschaft österreichischer Juden}

Vom Ende des 18. Jahrhunderts bis in die Gegenwart

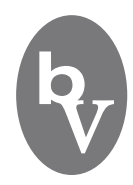

2014

Böhlau Verlag Wien · Köln · Graz 


\section{FWF $F_{\text {Derwsisenschatastsonds. }}$}

\section{Veröffentlicht mit Unterstützung des Austrian Science Fund (FWF): PUB 81-V18}

Bibliografische Information der Deutschen Nationalbibliothek:

Die Deutsche Nationalbibliothek verzeichnet diese Publikation in der Deutschen Nationalbibliografie; detaillierte bibliografische Daten sind im Internet über http://dnb.d-nb.de abrufbar.

\section{Umschlagabbildung:}

Teilansicht einer Familienliste, 1793

Archiv der Israelitischen Kultusgemeinde Wien, K1

(C) 2014 by Böhlau Verlag Ges.m.b.H., Wien Köln Weimar

Wiesingerstraße 1, A-1010 Wien, www.boehlau-verlag.com

Alle Rechte vorbehalten. Dieses Werk ist urheberrechtlich geschützt.

Jede Verwertung außerhalb der engen Grenzen des Urheberrechtsgesetzes ist unzulässig.

Korrektorat: Corinna Salomon, Wien

Satz: Michael Rauscher, Wien

Druck und Bindung: Prime Rate Kft., 1044 Budapest

Gedruckt auf chlor- und säurefreiem Papier

Printed in Hungary

ISBN 978-3-205-79495-0 


\section{Inhalt}

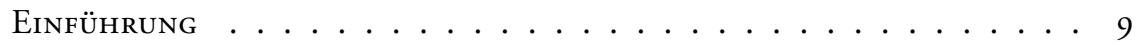

Von der Epoche des josephinischen Reformabsolutismus

Bis zum Ende des Neohbsolutismus . . . . . . . . . . . . . I 5

Die Frage der jüdischen Bürgerrechte in der Aufklärung . . . . . . . . I 5

Exkurs: Juden in den österreichischen Ländern vom Hochmittelalter bis in das

Zeitalter der Emanzipation . . . . . . . . . . . . . . I9

Die josephinische Zäsur . . . . . . . . . . . . . . . . . 26

Das böhmisch-mährische System der Familienstellen . . . . . . . . . . . . . 29

Das Toleranzpatent für die Juden Galiziens . . . . . . . . . . . . . . . . . . . 34

Anhaltende "Verschiedenheit des politischen Zustandes" . . . . . . . . . . 38

Die Vertretung der Tolerierten . . . . . . . . . . . . . . . . . . 39

Das Judenamt . . . . . . . . . . . . . . . . . . . . 40

Die Hofkanzlei als Hüterin der Toleranz . . . . . . . . . . . . . . . . . . . . . . . . . . 45

Taufen und Nobilitierungen . . . . . . . . . . . . . . . . . . . . . . . . . . . . . . . .

Die Kodifizierung des Staatsbürgerschaftsrechts . . . . . . . . . . . . 5 I

Die staatsbürgerliche Stellung der Juden im Vormärz

und das Auftauchen der Judenfrage . . . . . . . . . . . . . . . . . . . 53

Die bürgerliche Revolution von I 848 und die veränderte staatsbürgerliche

Stellung der Juden . . . . . . . . . . . . . . . . . . . . . . 59

Juden als österreichische Reichsbürger . . . . . . . . . . . . . . . . . . 62

Inklusion und Exklusion von Juden in der Zeit des Neoabsolutismus . . . . . 64

Das Heimatrecht der österreichischen Juden . . . . . . . . . . . . . . . 70

Die Sonderstellung der »türkischen" Juden . . . . . . . . . . . . . . . 74

Die Entwicklung von Heimatrecht und Staatsbürgerschaft

in der Epoche des Ausgleichs . . . . . . . . . . . . . . . . 77

Der Anteil der Juden an den Einbürgerungen . . . . . . . . . . . . . . . 77

Die Vermehrung der jüdischen Bevölkerung in Cisleithanien . . . . . . . . . 80

Die rechtliche Gleichstellung der Juden durch das Staatsgrundgesetz über

die allgemeinen Rechte der Staatsbürger im Dezember I 867 . . . . . . . . . 82

Rückkehr in die "verbotene Stadt» . . . . . . . . . . . . . . . . 83 
Paradoxe Fremde . . . . . . . . . . . . . . . 85

Die dualistische Verschärfung . . . . . . . . . . . . . . 86

Motive für den Erwerb von Heimatrecht und Staatsbürgerschaft . . . . . . 88

Heimatrecht und Staatsbürgerschaft jüdischer Frauen . . . . . . . . . . 990

Heimatrecht und soziale Frage . . . . . . . . . . . . . . 9I

Der Fall Dr. Hugo Stark . . . . . . . . . . . . . . . . . . . . 92

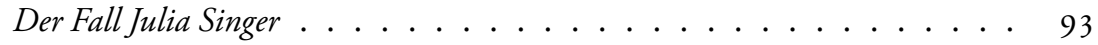

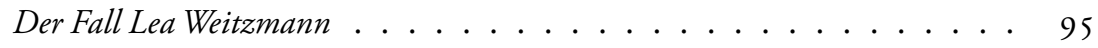

"Schutzgenossen" und "Untertanen de facto" . . . . . . . . . . . 96

Zur Ambivalenz von Heimatrecht und Staatsbürgerschaft . . . . . . . . 97

Die Nationalitätenkonflikte der Verfassungszeit und die

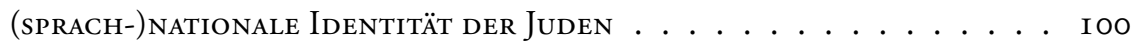

Kafkas Sprachen . . . . . . . . . . . . . . . . . I I00

Die Bedeutung von Bildung im Judentum . . . . . . . . . . . . . . I03

Sprache, Nationalität und Recht im Unterrichtswesen . . . . . . . . . . I0

Jüdische Kinder in den Mühlen des Nationalitätenkampfes . . . . . . . . . I I09

Der Anteil jüdischer Schüler am höheren Bildungswesen . . . . . . . . I I 2

Sprachen, Nationalitäten, Identitäten . . . . . . . . . . . . . . I I I4

Das mehrsprachige Unterrichtswesen in der Bukowina . . . . . . . I I 5

Der Verdacht gegen die Mehrsprachigkeit . . . . . . . . . . . I I6

Die Ethnisierung der Nationalitätenkonflikte . . . . . . . . . . . . . . I I 7

Die Wiederkehr der "Judenfrage" in der Epoche des Ausgleichs . . . . . . I I 9

Juden im ERsten WeltKrieg $\ldots \ldots \ldots \ldots \ldots \ldots \ldots$

Theorie und Praxis von Heimatrecht und Staatsbürgerschaft

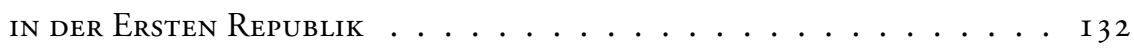

Die Aus- und Einbürgerungen des aUtoritären StändestaAtes . . . . I4I

Verfolgung, Vertreibung, Ausbürgerung, Vernichtung

WÄHREND DER NS-HERRSCHAFT . . . . . . . . . . . . . . I46

Die Implementierung der Nürnberger Gesetze in Österreich . . . . . . . . . I46

Signaturen der Vertreibung . . . . . . . . . . . . . I I52

Die Ausbürgerung und der Befehl zur "Endlösung" . . . . . . . I 55

Die Wiederherstellung der StaAtsbürgerschaft in der Zweiten

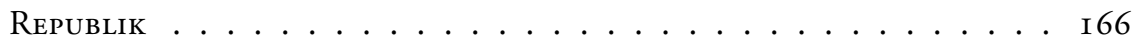


Der Fall Raviv . . . . . . . . . . . . . . . . . . . . . . . I772

StaAtenlosigkeit als Massenschicksal . . . . . . . . . . . . . I87

Der Fall Elias Canetti ． . . . . . . . . . . . . . . . . . . . . . . . . . I 88

"... durch Abstammung wie Wahlverwandtschaft ein Ostjude«.

Der Fall Manès Sperber . . . . . . . . . . . . . . . . . . . . . . . . . . 200

Semantische Nachbemerkungen ............. 2 I 3

VerZeICHNIS DER ARCHIVE . . . . . . . . . . . . . . . 222

LiteraturVERZEICHNIS . . . . . . . . . . . . . . . . . 223

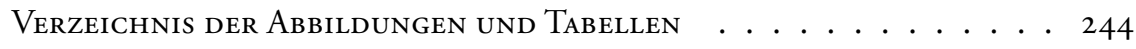

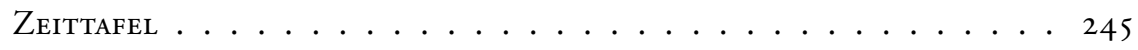

Register ........................ 264

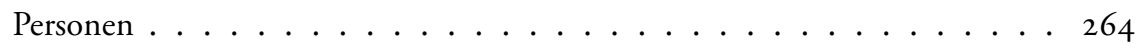

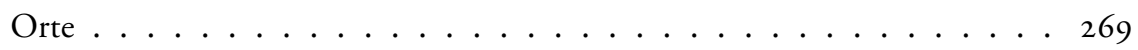

Sachen ....................... 27I 



\section{Einführung}

Die Bedeutung von Heimatrecht und Staatsbürgerschaft für die Emanzipation der Juden $^{1}$, d. h. ihre Inklusion in den Staatsverband durch Erlangung vollkommener rechtlicher und politischer Gleichstellung, blieb - wenngleich die Forschung sich in den letzten Jahrzehnten vermehrt dem besonderen Beitrag von Juden und Jüdinnen zur österreichischen Kultur und Wissenschaft gewidmet hat ${ }^{2}$ - bisher wenig bedacht. Heimatrecht und Staatsbürgerschaft, zwei gänzlich verschiedene Konzeptionen der Integration - die moderne staatsbürgerliche in den großen Raum der österreichischen Monarchie, die ältere heimatrechtliche in den engeren Raum der Gemeinde -, bestimmen noch weit über die Monarchie hinaus nicht nur den Rechtsstatus einer Person, sondern in hohem Maße auch deren Identität. Dies gilt im Besonderen für die österreichischen Juden, die nach einem sich über mehrere Generationen erstreckenden Transformationsprozess in religiöser, politischer und kultureller Hinsicht eher eine Vielheit differenter Gruppierungen als eine geschlossene Entität verkörperten. ${ }^{3}$

Vor der Folie der Entrechtung und Ausbürgerung der österreichischen Juden während der NS-Zeit wird an dieser Stelle versucht, gleichsam den Bogen zurückzuspannen und diskursanalytisch wie normativ und rechtspraktisch den umgekehrten Prozess einer stufenweisen Inklusion von Juden und - mit beträchtlichen Einschränkungen - Jüdinnen in Heimatrecht (politisches Domicil) und Staatsbürgerschaft der österreichischen Monarchie seit den josephinischen Reformen zu beschreiben. Hei-

1 Der Begriff Emanzipation meinte ursprünglich die Freilassung eines Sklaven (lateinisch: $e$ manu cipere); in der Neuzeit wurde er zuerst von irischen Katholiken in den 1820er-Jahren gebraucht (Catholic Emancipation), bevor ihn sich jene zu eigen machten, die für die Rechte der Juden eintraten. Weiterführend: Jacob Katz: Zur Assimilation und Emanzipation der Juden (Darmstadt 1982), S. $157 f$.

2 Stellvertretend für viele Neuerscheinungen sei hier der Band: Frank Stern/Barbara Eichinger (Hg.): Wien und die jüdische Erfahrung 1900-1938. Akkulturation - Antisemitismus - Zionismus (Wien/ Köln/Weimar 2009) genannt.

3 Vgl. Hildegard Kernmeyer/Klaus Hödl/Petra Ernst: Assimilation - Dissimilation - Transkulturation. Jüdische Identitäten in der Wiener und zentraleuropäischen Moderne, in: Moritz Csáky et al. (Hg.): Kultur - Identität - Differenz. Wien und Zentraleuropa in der Moderne (Innsbruck et al. 2004), S. 291-322. Siehe auch: Wolfgang Schmale/Martina Steer: Kulturtransfer in der jüdischen Geschichte (Frankfurt/Main 2006). 
matrecht und Staatsbürgerschaft werden von der gegenwärtigen Historiographie nicht nur als bedeutende Strukturelemente im Prozess der Territorialstaatswerdung erkannt - als Indikatoren für die Unterscheidung von Eigenem und Fremdem -, sondern als wichtige Elemente bei der Konstruktion von Individualität und personaler Identität. ${ }^{4}$ So bestimmt sich die Kategorie des Fremden bis Mitte des I9. Jahrhunderts nicht so sehr durch eine noch durchlässige und wenig kontrollierte Außengrenze (die Staatsgrenze), sondern vielmehr durch innere Grenzziehungen wie etwa den Besitz (bzw. Nichtbesitz) des politischen Domicils (später Heimatrecht) oder der Staatsbürgerschaft. ${ }^{5}$

Juden wurden und werden oft als ewig Fremde gesehen. Folgt man der älteren Literatur, so beschreibt sie die Juden des Mittelalters und der frühen Neuzeit in den Ländern des Heiligen Römischen Reiches als Fremde an sich, unterstanden sie doch, als Person und mit ihrem gesamten Besitz, der kaiserlichen oder königlichen Finanzkammer - waren frei verfügbares Eigentum des Landesherrn. ${ }^{6}$ Servi camere nostre, "unsere Kammerknechte", heißen sie in einem Privileg Kaiser Friedrichs II. aus dem Jahr I 238 - nur eine von unzähligen, ihre Anwesenheit wie ihre Lebensverhältnisse bis ins Kleinste regelnden, über Jahrhunderte fortgeschriebenen, erneuerten, verfeinerten, verschärften Judenordnungen. ${ }^{7}$ Innerhalb der bestehenden Rechtsordnung bildeten die Judenordnungen (Regale, Patente, Schützungen) ein Sonderrecht, ius odiosum, das Juden gleichzeitig privilegierte und diskriminierte, was zu der Vorstellung führte, Juden hätten in der mittelalterlichen und frühneuzeitlichen Staatenwelt als eine besondere Nation nach eigenen Gesetzen von der christlichen Bevölkerung getrennt gelebt. Neuere Forschungen betonen indes die strukturelle Mehrschichtigkeit der frühneuzeitlichen Rechtsordnung, in der die verschiedensten Gruppen mit unterschiedlichen Rechten und Freiheiten ausgestattet gewesen seien. Juden erscheinen darin nicht mehr als Fremdkörper in einer sonst vermeintlich geschlossenen Gesellschaft, sondern als aktive Teilnehmer am Rechtsgeschehen, als Subjekte und nicht bloß Objekte des Rechts. ${ }^{8}$ Darüber hinaus habe, so betont Friedrich Battenberg, die

4 Vgl. Charles Tilly (Hg.): Citizenship, Identity and Social History. International Review of Social History, Supplement 3 (1996).

5 Vgl. Hannelore Burger: Die Staatsbürgerschaft, in: Waltraud Heind/Edith Saurer (Hg.): Grenze und Staat. Paßwesen, Staatsbürgerschaft und Fremdengesetzgebung in der österreichischen Monarchie 1750-1867 (Wien/Köln/Weimar 2000), S. 88-172.

6 Vgl. Johann Evangelist Scherer: Die Rechtsverhältnisse der Juden in den deutsch-österreichischen Ländern (Leipzig 1901), S. 6.

7 Vgl. Klaus Lohrmann: Die Wiener Juden im Mittelalter. Geschichte der Juden in Wien, Bd. 1 (Wien 2000), S. 38ff sowie auch: derselbe et al.: Die Entwicklung des Judenrechtes in Österreich und seinen Nachbarländern, in: 1000 Jahre Österreichisches Judentum. Ausstellungskatalog (Eisenstadt 1982), S. 25-53, hier: S. 26.

8 Andreas Gotzmann/Stephan Wendehorst: Zwischen Kaiser, Landesherrschaft und Halacha. Zwi- 
Wiederbelebung des Römischen Rechts im Zuge des Humanismus (etwa eines Johannes Reuchlin) seit Mitte des I6. Jahrhunderts zur (Wieder-)Anerkennung der ursprünglichen Stellung von Juden als cives romani, als römische Bürger, geführt und damit allmählich zur Durchsetzung des Prinzips einer grundsätzlich unbeschränkten Teilhabe an der allgemeinen Untertanenschaft. ${ }^{9}$ Juden immer wieder zugeschriebene vermeintliche Eigenschaften wie Ortlosigkeit, ewige Wanderer (Ahasver-Motiv), Kosmopolitismus, Andersheit (Otherness) erscheinen vor dem Hintergrund der jüngeren Forschung obsolet. ${ }^{10}$ Es sind vielmehr die Setzungen des Rechts, seine Einschließungen und Ausschließungen, die darüber befinden, wer, zu einer bestimmten Zeit, an einem bestimmten Ort als zugehörig und einheimisch, bzw. als nicht zugehörig und fremd gilt. Die Geschichte der Staatsbürgerschaft ist deshalb immer auch und zuallererst eine Geschichte des Fremden. ${ }^{11}$

Aus dieser Einsicht folgt eine Forschungsperspektive, die sich dem Thema Staatsbürgerschaft gleichsam vom Rand her nähert, eine Perspektive, der der "Ausnahmefall« (jener der Juden) als Indikator für die Entwicklung der Staatsbürgerschaft insgesamt gilt. (Tatsächlich galt die Inklusion der Juden in die allgemeinen Rechte der Staatsbürger während des I9. Jahrhunderts als Gradmesser für die Reife eines Staates - als Ausweis guter Gouvernementalität.) Die Beschreibung des sich über mehr als ein Jahrhundert erstreckenden, steinigen, von vielen Rückschlägen gekennzeichneten Weges der Einbeziehung der Juden in die allgemeine Staatsbürgerschaft (vom exklusiven Judenregal über die Toleranz oder Familienstelle bis zur vollen Staatsbürgerschaft) ermöglicht zugleich auch einen neuen Blick auf den bisher wenig beleuchteten Akt der Ausbürgerung der Juden während der nationalsozialistischen Herrschaft. Die Ausbürgerung der österreichischen Juden und Jüdinnen zwischen I 938 und I94I war ein überaus komplexer, in mehreren Schüben ablaufender Prozess, der sich ähnlich wie im "Altreich«, doch zeitlich verschoben und bereits unter

schenräume als jüdische Rechts- und Handlungsspielräume. Einleitung zum Band: Juden im Recht. Neue Zugänge zur Rechtsgeschichte der Juden im Alten Reich, Zeitschrift für Historische Forschung, Beiheft 39 (2007), S. 1-11, hier: S. 2 und 4.

9 J. Friedrich Battenberg: Von der Kammerknechtschaft zum Judenregal. Reflexionen zur Rechtsstellung der Judenschaft im Heiligen Römischen Reich am Beispiel Johannes Reuchlins, in: Sabine Hödl et al (Hg.): Hofjuden und Landjuden. Jüdisches Leben in der Frühen Neuzeit (Berlin 2004), S. 65-91, hier: S. 83. Zur Stellung der Juden als cives romani vgl. auch: Peter Riesenberg: Citizenship in the Western Tradition (Chapel Hill/London 1992), S. 48 sowie Raph W. Mathisen: Perigrini, Barbari, and Cives Romani. Concepts of Citizenship and the Legal Identity of Barbarians in the Later Roman Empire. The American Historical Review 11.4 (2006) : 48 pars. 19 Juni 2012, htp:// www.historycooperative.org/journals/ahr/111.4/mathisen.html.

10 Vgl. Zygmunt Baumann: Moderne und Ambivalenz. Das Ende der Eindeutigkeit (Hamburg 1992), S. 80. Siehe dazu auch: Kernmeyer/Hödl/ Ernst, Assimilation, S. 291-322.

11 Vgl. Jacques Derrida: Von der Gastfreundschaft (Paris 1977), S. 57 und 101. 
dem Signum von Flucht und Vertreibung, ereignete. Dieser Prozess der Entrechtung und Entpersonalisierung stellt jedoch nicht bloß einen nationalsozialistischen Willkürakt dar, sondern die wie in einem Zeitraffer vorgenommene Umkehrung des Ende des I 8. Jahrhunderts einsetzenden Emanzipationsprozesses. ${ }^{12}$ Der auf den ersten Blick abstrus anmutende Verordnungswust der Nationalsozialisten entpuppt sich bei genauerer Analyse als geplante und systematische Rückführung der historischen »Judenemanzipation" mit ihren einzelnen Bausteinen: Öffnung der Schulen und Hochschulen, Einbeziehung in immer weitere Berufsfelder, Einbeziehung in die Militärpflicht, die allgemeine Steuerpflicht, Gewerbefreiheit, Grundbesitzfähigkeit, Freizügigkeit, Wahlrecht, Zeugenfähigkeit, Ehefähigkeit (mit christlichen Partnern). All dies wird apart und in Einzelschritten zurückgeführt, bis ein seiner personalen Würde beraubtes, unter kein Recht und keinen staatlichen Schutz mehr fallendes Wesen übrig blieb, welches der Vernichtung preisgegeben war. Nach nationalsozialistischer Logik war die Ausbürgerung der Juden (als vormals österreichische Staatsbürger, dann deutsche Staatsangehörige) ein zwingend gebotener Schritt. Er ging der Vernichtung mit Notwendigkeit voraus. Die Analyse der Elften Verordnung zum Reichsbürgergesetz vom 25. November I94I und ihrer Bedeutung im Hinblick auf die »Endlösung« nimmt in dieser Untersuchung deshalb einen besonderen Platz ein.

Der Begriff "österreichische Juden" wurde weitestmöglich gefasst: Gemeint sind nicht nur die Juden des deutschen Sprach- und Kulturraums, sondern ebenso die böhmischen, mährischen, ungarischen, italienischen, galizischen und bukowinischen Juden. Gemeint sind gleichermaßen Aschkenasen und Sepharden, orthodoxe, chassidische, rabbinische, assimilierte und glaubenslose Juden, Zionisten, Sozialisten und Kaisertreue, "West«- wie »Ostjuden«. Dabei zeigt sich das Judentum als ebenso vielgestaltig, fragmentiert und diversifiziert wie das Österreichische, das im Untersuchungszeitraum nach Umfang (des Staatsgebietes) und Begriff den größtmöglichen Wandlungen unterlag ${ }^{13}$ vom sich herausbildenden Territorialstaat des aufgeklärten Absolutismus im späten I 8. Jahrhundert über den Einheitsstaat des Neoabsolutismus, die duale Staatsform der österreichisch-ungarischen Monarchie, die Erste Republik, bis hin zur Auslöschung österreichischer Staatlichkeit in der Zeit der nationalsozialistischen Herrschaft und - nach dem Ende des Zweiten Weltkrieges - zu der wiedererrichteten Republik Österreich. Ständigen Transformationen aber, so wird zu

12 Ausführlicher zur Ausbürgerung: Hannelore Burger/Harald Wendelin: Vertreibung, Rückkehr und Staatsbürgerschaft. Die Praxis der Vollziehung des Staatsbürgerschaftsrechts an den österreichischen Juden, in: Staatsbürgerschaft und Vertreibung (= Veröffentlichungen der Österreichischen Historikerkommission 7), Zweiter Teil (Wien 2004), S. 239-501, hier: S. 267ff.

13 Siehe den einleitenden Aufsatz "Vom Umfang der österreichischen Geschichte« von Gerald Stourzh in dem gleichnamigen Band: Gerald Stourzh: Vom Umfang der Geschichte. Ausgewählte Studien 1990-2010 (Wien/Köln/Graz 2011), S 11-37. 
zeigen sein, unterliegt auch der Begriff der Staatsbürgerschaft selbst. ${ }^{14}$ Weder "das Jüdische», noch »das Österreichische«, noch »die Staatsbürgerschaft» sind als Konstanten zu denken, sondern als historisch gewordene, veränderliche, vielfach interdependente Phänomene.

Da der Begriff der Staatsbürgerschaft überwiegend männlich konnotiert ist und eine eigenständige, vom Vater oder Ehemann unabhängige Staatsbürgerschaft für Frauen noch bis weit in das 20. Jahrhundert gar nicht existierte ${ }^{15}$, erwies es sich überaus schwierig, generelle Aussagen über Heimatrecht und Staatsbürgerschaft von Frauen zu treffen. Dennoch zeigte es sich, dass es auch bei den Jüdinnen eigenberechtigte Frauen (Witwen, Gewerbetreibende) gab, die bei den Behörden etwa die Verlängerung ihrer »Toleranz«, später den Erwerb des Heimatrechtes bzw. der Staatsbürgerschaft selbständig beantragten - mehr jedenfalls, als es die Theorie der Staatsbürgerschaft, die seit Rousseau und Kant auf den freien, gleichen, selbstständigen männlichen Bürger verweist, erwarten ließ. ${ }^{16}$ Trotz des Ausschlusses von Frauen von vielen staatsbürgerlichen Rechten während des ganzen I9. Jahrhunderts und trotz starker Beschränkungen durch die sogenannten "familienrechtlichen Tatsachen" wird versucht, auch die Staatsbürgerschaft der jüdischen Frau sichtbar zu machen. Neben den jüdischen Frauen gilt ein besonderes Augenmerk der Studie den staatenlosen Juden (mit teilweise jahrzehntelanger Anwesenheit auf österreichischem Territorium). Ihnen widmen sich die drei Fallgeschichten am Ende des Buches.

Die Arbeit beruht auf Ergebnissen eines einjährigen gleichnamigen Forschungsprojekts, das vom Jubiläumsfonds der Österreichischen Nationalbank unterstützt wurde. Diesem gilt mein Dank. Ebenso eingeflossen sind Teilergebnisse einer gemeinsam mit Harald Wendelin und Dieter Kolonovits für die Österreichische Historikerkommission erstellten, unter dem Titel "Staatsbürgerschaft und Vertreibung" bereits früher publizierten Studie. ${ }^{17}$ Soweit es sich um Einzelergebnisse der genannten Forscher handelt, wurde dies jeweils ausgewiesen.

Mein ganz besonderer Dank gilt Waltraud Heindl-Langer (Wien) für die langjährige Unterstützung und Begleitung meiner Arbeit, für viele anregende Gespräche,

14 Vgl. Burger, Paßwesen und Staatsbürgerschaft, S. $95 \mathrm{f}$.

15 Maureen Healy spricht in diesem Zusammenhang von »Proto-Staatsbürgern«. Vgl. Maureen Healy: Vienna and the Fall of the Habsburg Empire. Total War and Everyday Life in World War I (Cambridge 2004), S. 10.

16 Vgl. Hannelore Burger: Zur Geschichte der Staatsbürgerschaft der Frauen in Österreich. Ausgewählte Fallstudien aus der ersten Hälfte des 19. Jahrhunderts, in: L'homme 10, 1 (1999), S. 38-44, siehe auch das Editorial des vorgenannten Heftes zum Thema "Citizenship» von Erna Appelt, S. $7 \mathrm{ff}$ sowie Erna Appelt: Geschlecht, Staatsbürgerschaft, Nation. Politische Konstruktionen des Geschlechterverhältnisses in Europa (Frankfurt/New York 1999).

17 Dieter Kolonovits/Hannelore Burger/Harald Wendelin: Staatsbürgerschaft und Vertreibung (= Veröffentlichungen der Österreichischen Historikerkommission 7) (Wien 2004). 
ihre Neugier, ihr Interesse am Thema und endlich für das sorgfältige Lesen des Manuskripts. Ebenso danke ich Benno Gammerl (Berlin), Svjatoslav Pacholkiv (Lemberg/Wien) und Harald Wendelin (Wien) für Anregungen, Kritik und Ermutigung sowie für die Lektüre teils auch früherer Fassungen des Manuskripts. Dass dieses Buch in der renommierten Reihe "Studien zu Politik und Verwaltung " erscheinen darf, ist mir eine besondere Freude und Ehre. Ich danke ihren Herausgebern, Christian Brünner und Wolfgang Mantl, ganz besonders aber Manfried Welan für sein langjähriges Interesse und seine Unterstützung. Den Mitarbeiterinnen und Mitarbeitern des Böhlau Verlages, Eva Reinhold-Weisz, Stefanie Kovacic und Corinna Salomon danke ich für die sorgfältige Betreuung und Lektorierung des Manuskripts sowie Michael Rauscher für die Umsicht bei der Drucklegung des Werkes. Letztere geschah mit Unterstützung des Austrian Science Fund (FWF). Auch dafür gebührt mein Dank. Nicht zuletzt danke ich Rudolf Burger (Wien), Richard Burger (Moskau) und Tamara Burger (Wien) für Rat, Hilfe und mannigfaltige Unterstützung während vieler Jahre. 


\section{Von der Epoche des josephinischen Reformabsolutismus bis zum Ende des Neoabsolutismus}

\section{Die Frage der jüdischen Bürgerrechte in der Aufklärung}

Ob Juden überhaupt Staatsbürger sein können, ist eine der zentralen Fragen der europäischen Aufklärung. ${ }^{18}$ Im Diskurs um die Bildung des modernen Nationalstaates wird sie in zweifacher Weise beantwortet: erstens durch das republikanische "westliche« (französische) Modell, zweitens durch das durch Herder und Fichte geprägte »östliche« (deutsche) Modell. ${ }^{19}$ Setzte das republikanische Modell - bekanntlich hatte die Nationalversammlung am 27. September I79I den französischen Juden die vollen Bürgerrechte (citoyenneté) unter der Bedingung zuerkannt, dass diese auf ihren Status als Gemeinde verzichteten - auf Assimilation und Integration ${ }^{20}$, so haftete dem deutschen Modell seit dem Hardenbergschen Edikt von I 8 I 2 der Charakter der Bewährung und Vorläufigkeit, gleichsam einer "Staatsbürgerschaft auf Probe«, an. ${ }^{21}$ Die Literatur beschreibt ersteres als inklusiv, letzteres überwiegend als exklusiv. ${ }^{22}$ Es wäre jedoch eine unzulässige Vereinfachung, den Umgang mit den in den österreichischen Ländern lebenden Juden und Jüdinnen - wie dies häufig geschieht - schlichtweg unter das deutsche Modell zu subsumieren. Ist schon das deutsche Modell, wie Andreas Fahrmeir gezeigt hat, äußerst differenziert ${ }^{23}$, so existierten in den einzelnen Kronländern der österreichischen Monarchie nicht nur die

18 Vgl. Hannah Arendt: Elemente und Ursprünge totaler Herrschaft (München 1986), S. $37 \mathrm{f}$.

19 Uli Bielefeld: Fremdenfeindlichkeit, kulturelle Diversifizierung und Homogenisierung, in: IKUS Lectures 3/4 (1992), S. 9-29, hier: S. 14. Zur Staatsbürgerschaft in den deutschen Staaten siehe insbesondere: Andreas Fahrmeir: Citizens and Aliens. Foreigners and the Law in Britain and the German States, 1789-1870 (New York/Oxford 2000).

20 Vgl. Esther Benbassa: Geschichte der Juden in Frankreich (Berlin/Wien 2000), S. 110f. Zum Modell der französischen, republikanischen Staatsbürgerschaft siehe auch: Cécile Laborde: Republican Citizenship and the Crisis of Integration in France, in: Richard Bellamy et al. (Hg.): Lineages of European Citizenship. Rights, Belongings and Participation in Eleven Nation-States (Houdmills/ New York 2004) S. 46-72.

21 Vgl. Milan Tvrdik: Die Emanzipation der jüdischen Kultur, in: Marek Nekula/Walter. Koschmal (Hg.): Juden zwischen Deutschen und Tschechen. Sprachliche, literarische und kulturelle Identitäten (München 2006), S. 203-216, hier: S. 204.

22 Vgl. Tilly, Citizenship, S. 9.

23 Fahrmeir, Citizens and Aliens, S. 30f. sowie ausführlicher in: Andreas Fahrmeir: Citizenship. The Rise and Fall of a Modern Concept (New Haven/London 2007). 
längste Zeit für Juden äußerst unterschiedliche staatsbürgerliche Rechte ${ }^{24}$, sondern nach dem Ausgleich von 1867 (im Rahmen der Doppelmonarchie Österreich-Ungarn) auch zwei gänzlich verschiedene, wenig miteinander kompatible Staatsbürgerschaftsmodelle. Darüber hinaus führt die unreflektierte Einschreibung in eine West/ Ost-Dichotomie, wie Benno Gammerl zu Recht festgestellt hat, implizit zu einer ahistorischen Betrachtungsweise von Staatsbürgerschaft, da sie nicht nur den Blick auf den imperialen Kontext verstellt, sondern auch auf die Transformationsprozesse, denen die verschiedenen Staatsbürgerschaftsmodelle im Laufe der Jahrhunderte unterlagen. ${ }^{25}$

Die Frage, von welchem Zeitpunkt an man von einer Staatsbürgerschaft der Juden in Österreich - oder umgekehrt von Juden und Jüdinnen als österreichischen Staatsbürger/innen - überhaupt sprechen kann, lässt sich kaum mit einem Datum beantworten. Wir gebrauchen heute im Allgemeinen den Begriff Staatsbürgerschaft nur dann, wenn, im Sinne etwa der klassisch gewordenen Studie von Thomas H. Marshall ${ }^{26}$, damit auch die vollen bürgerlichen, politischen und sozialen Rechte einhergehen. Bei einer solchen Betrachtungsweise wird allerdings übersehen, dass der Begriff Staatsbürger in Österreich zu einer Zeit aufkommt, als von bürgerlichen und politischen Rechten (in modernem Sinn) noch keine Rede ist. ${ }^{27}$ So verwendet etwa Carl Anton von Martini, der Schöpfer des "Westgalizischen Gesetzbuches«, den Begriff Staats-Bürger bereits wenige Jahre nachdem dieser durch Wieland und Kant populär geworden war. ${ }^{28} \mathrm{Im}$ Unterschied zu Preußen aber wird der anstelle des

24 Positiv wertet dies vor allem Rogers Brubaker, der sein favorisiertes Modell "wohlwollender Differenzierung«, jenseits der beiden Gegenmodelle ius soli und ius sanguinis, am ehesten in »der märchenhaft komplexen Welt des Habsburgerreiches« unmittelbar vor und nach dem Ersten Weltkrieg verwirklicht sieht. Rogers Brubaker: Staats-Bürger. Frankreich und Deutschland im historischen Vergleich (Hamburg 1994), S. 230. Zu den Transformationen des österreichischen Staatsbürgerschaftsmodells vgl. Burger, Staatsbürgerschaft, S. 171.

25 Benno Gammerl: Subjects, citizens and others: the handling of ethnic differences in the British and the Habsburg Empires (late nineteenth and early twentieth century), in: European Review of History - Revue européenne d'histoire, 16.4 (2009), S. 523-549, hier: S. 525 sowie ausführlicher in seiner Dissertation: Benno Gammerl: Untertanen, Staatsbürger und Andere. Der Umgang mit ethnischer Heterogenität im Britischen Weltreich und im Habsburgerreich 1867-1918 (= Kritische Studien zur Geschichtswissenschaft 189) (Göttingen 2010), S. 12.

26 Thomas H. Marshall: Bürgerrechte und soziale Klassen, hg. Elmar Rieger (= Theorie und Gesellschaft 22) (Frankfurt/Main 1992).

27 Zum Begriff „Staatsbürger« vgl. Paul-Ludwig Weinacht: „Staatsbürger«. Zur Geschichte und Kritik eines politischen Begriffs, in: Der Staat 8 (1969), S. 41-63.

28 "Jeder Staatsbürger ohne Unterschied des Ranges, des Standes oder Geschlechtes ist verpflichtet, die allgemeine Wohlfahrt des Staates durch genaue Befolgung der Gesetze möglichst befördern zu helfen.«, heißt es im »Urentwurf für ein allgemeines österreichisches Gesetzbuch« von 1797, kurz: "Westgalizisches Gesetzbuch" genannt, zit. nach: Hannelore Burger: Zum Begriff der österreichischen Staatsbürgerschaft. Vom josephinischen Gesetzbuch zum Staatsgrundgesetz über die allgemei- 
Abb. I: Joseph Freiherr von Sonnenfels (I733I8I7); Quelle: ÖNB/Wien, Bildarchiv

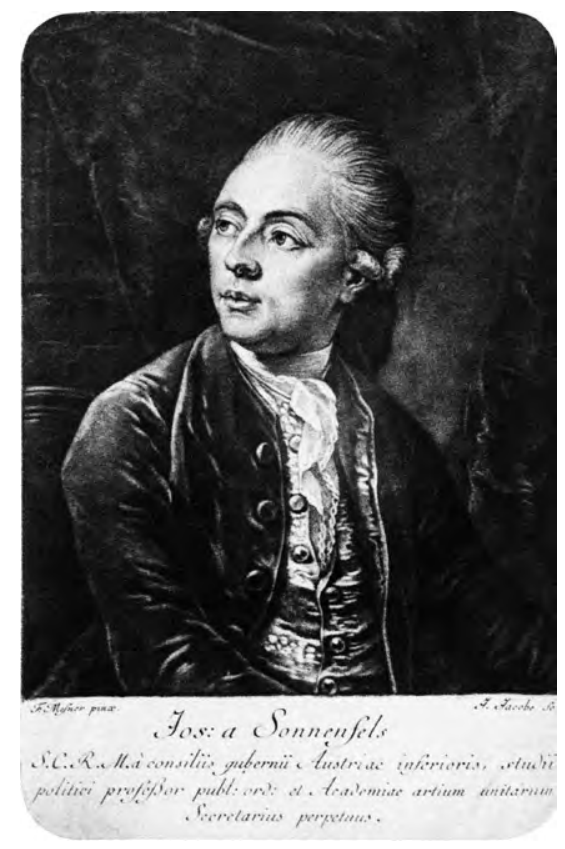

französischen Begriffs citoyen eingesetzte Begriff Staats-Bürger in der österreichischen Monarchie nicht subversiv von einem aufbegehrenden Bürgertum, sondern von den Staatseliten selbst gebraucht. Und er hat, vermittels seiner Apologeten (Martini, Sonnenfels, Zeiller), von Anfang an eine naturrechtlich-weltbürgerliche Konnotation. ${ }^{29}$ Für den kaiserlichen Rat Joseph von Sonnenfels (selbst ein getaufter Jude) war das "Vaterland « schlicht »das Land, worinnen man seinen Sitz genommen«, und die Staatsbürger waren "die Mitwohner dieses Landes« oder die "Zeitgenossen derselben Rechte « ${ }^{30}$ Trotz aller bestehenden ständischen Unterschiede wurde der neue Begriff "Staatsbürger« tendenziell auf alle Menschen angewandt. ${ }^{31}$ So formulierte Franz von Zeiller anlässlich des Erscheinens des Allgemeinen bürgerlichen Gesetzbuchs von I 8 I I : "Jeder, der sich keines Verbrechens schuldig gemacht hat, kann

nen Rechte der Staatsbürger, in: Thomas Angerer et al. (Hg.): Geschichte und Recht. Festschrift für Gerald Stourzh zum 70. Geburtstag (Wien/Köln/Weimar 1999), S. 207-224, hier: S. $216 f$.

29 Vgl. Waltraud Heindl: Bildung und Recht. Naturrecht und Ausbildung der staatsbürgerlichen Gesellschaft in der Habsburgermonarchie, in: Festschrift Stourzh, a.a.O., S. 183-206, insbesondere: S. 191.

30 Joseph von Sonnenfels: Über die Liebe des Vaterlandes (Wien 1771), S. $10 \mathrm{f}$.

31 Vgl. Michael Stolleis: Von den Rechtsnormen zur Rechtspraxis. Zur Rechtsgeschichte der Juden im Heiligen Römischen Reich Deutscher Nation, in: Andreas Gotzmann/Stephan Wendehorst (Hg.): Juden im Recht. Neue Zugänge zur Rechtsgeschichte der Juden im Alten Reich. Zeitschrift für Historische Forschung, Beiheft 39 (2007), S. 11-24, hier: S. 18 
die österreichische Staatsbürgerschaft und die damit verbundenen Personenrechte erwerben «. ${ }^{32}$ "Jeder", das bedeutete bei Zeiller: unabhängig von Stand, Herkunft, Geschlecht und Religion. Staatsbürgerschaft erweist sich im reform-absolutistischen Österreich als ein Begriff, der sich gegen ständische Ungleichheit, Adelsvorherrschaft und jeden Partikularismus richtete, nicht aber gegen Unselbstständige, Frauen oder Fremde an sich - wie es die Theorie der Staatsbürgerschaft seit Rousseau und Kant evoziert $^{33}$-, und auch nicht gegen Juden, sofern sich diese den aufklärerischen Vorstellungen des josephinischen Etatismus unterwarfen. ${ }^{34}$

Ein solcher Etatismus spiegelt sich etwa in den verschiedenen Toleranzpatenten für die österreichischen Juden seit I78 I. Diese wurden und werden als Meilensteine auf dem Weg zu einer gleichberechtigten Staatsbürgerschaft gewertet. ${ }^{35}$ So drückte der preußische Regierungsrat Christian Wilhelm von Dohm nach Erscheinen der ersten Toleranzpatente seine Genugtuung darüber aus, „dass die Juden in den k. k. Staaten in die Rechte der übrigen Bürger eingesetzt werden «. ${ }^{36}$ In seiner epochemachenden Schrift »Über die bürgerliche Verbesserung der Juden« hatte Dohm den "verderbten« Zustand der Juden »als Menschen und Bürger« nicht diesen selbst angelastet, sondern "der drückenden Verfassung, in der sie noch jetzt in den meisten Staaten« lebten, und die Regierungen aller Staaten aufgerufen, »die Juden zu dieser Gleichheit (mit allen Bürgern), zu dem Glück und der Nutzbarkeit, deren auch sie fähig sind, zu leiten. « ${ }^{37}$

Doch zu gleichberechtigten Staatsbürgern - wie sie etwa Protestanten mit dem Toleranzpatent vom I3. Oktober I78 I wurden - wurden die Juden noch lange nicht. Zwar wurde wiederholt - und besonders in der Einleitung zum Patent für die galizischen Juden vom Mai I 789 - der Grundsatz betont, dass sie »in Rechten sowohl als

32 Franz von Zeiller: Vortrag zur Einleitung in das bürgerliche Gesetzbuch vor der Hofkommission in Gesetzessachen vom 5. Juli 1810, Österreichisches Staatsarchiv, Allgemeines Österreichisches Verwaltungsarchiv, im Folgenden zitiert als: AVA, Bestand: Oberste Justiz, Fasc. ABGB, aus 1810, S. 23.

33 So hatte Kant «alles Frauenzimmer, und überhaupt jedermann, der nicht nach eigenem Betrieb, sondern nach der Verfügung anderer genötigt ist, seine Existenz (...) zu erhalten «, explizit aus der Staatsbürgerschaft ausgeschlossen, da jene der bürgerlichen Persönlichkeit entbehrten, ihre Existenz daher gleichsam nur inhärent sei. Immanuel Kant: Die Metaphysik der Sitten, in: Wilhelm Weischedel (Hg.): Werkausgabe, Bd. VIII (Frankfurt/Main 1982), S. 433.

34 Vgl. Burger, Begriff der österreichischen Staatsbürgerschaft, S. 217.

35 Hans Tietze: Die Juden Wiens [Wien/Leipzig 1933] (Nachdruck: Wien 1987), S. 117.

36 Christian Konrad Wilhelm von Dohm: Über die bürgerliche Verbesserung der Juden, Nachschrift [1781], Nachdruck: (Hildesheim/New York 1973), S. 152f. Auch Jacob Katz hebt hervor, dass Österreich das erste Land Europas gewesen sei, "das im Toleranzedikt Joseph II. 1782 das Recht der Juden auf Staatsbürgerschaft anerkannte«. Jacob Katz: Vom Vorurteil bis zur Vernichtung. Der Antisemitismus 1700-1933 (München 1989), S. 217.

37 Dohm, Bürgerliche Verbesserung, S. 148. Eine gründliche Analyse der Dohmschen Schrift findet sich in: Klaus L. Berghahn: Grenzen der Toleranz. Juden und Christen im Zeitalter der Aufklärung (Köln/Weimar/Wien 2000), S. 127. 
Pflichten vollkommen wie andere Untertanen angesehen « werden sollten, doch blieben ihnen nach wie vor wichtige Rechte wie das Bürger- und Meisterrecht, das Recht auf Haus- und Grundbesitz sowie das Recht auf Freizügigkeit verwehrt. Ungleichheiten, Diskriminierungen oder Sonderrechte existierten in je spezifischer Weise allerdings auch für andere Bevölkerungsteile, etwa für Frauen oder Adlige. Darüber hinaus standen Incolat und Indigenat ${ }^{38}$, "gemischte Untertanen« (»sujets mixtes»), Schutzgenossen und Untertanen de facto - alles Rechtsformen, die sich entweder aus alten Feudalverfassungen oder aus völkerrechtlichen Verträgen ableiteten ${ }^{39}$ - bis zum Ende der Monarchie einer allgemeinen und gleichen Staatsbürgerschaft, die spätestens mit dem Staatsgrundgesetz vom Dezember I 867 hätte durchgesetzt werden sollen, entgegen.

\section{EXKURS : JUdEN IN DEN ÖSTERREICHISCHEN LÄNDERN VOM Hochmittelalter bis in das Zeitalter der Emanzipation}

Der Status der Juden in den österreichischen Ländern war seit dem Mittelalter ein durch Ungleichheit und Differenz gekennzeichneter. Ihre Ansässigkeit in den einzelnen Ortsgemeinden wurde durch Schutzbriefe und Judenordnungen geregelt, Sonderrechte, die in je verschiedener Weise privilegierten und diskriminierten. So stellte etwa das Privileg Kaiser Friedrichs II. vom August I 238 die Juden Wiens - damals reichsunmittelbare Stadt - unter seinen Schutz und als "seine Kammerknechte« direkt unter die Hoheit der kaiserlichen Finanzkammer. ${ }^{40}$ Inhaltlich glich es einem zwei Jahre zuvor erlassenen allgemeinen Privileg für die Juden des Heiligen Römischen Reiches. Auch für die Wiener Juden galten somit die im Sachsenspiegel (und teilweise im Schwabenspiegel) aufgezeichneten Rechtsnormen. ${ }^{41}$ Als bald darauf der Babenberger Herzog Friedrich II. (der Streitbare) die rebellierende Stadt wieder unter seine Herrschaft brachte, stellte er das alte leopoldinische Stadtrecht wieder her und erließ noch am selben Tag, dem I. Juli I 244, eine neue Judenordnung, das sogenannte "Fridericianum «, das zum Vorbild für die meisten der späteren Judenordnungen werden sollte. ${ }^{42} \mathrm{Wie}$ in einem Geschäftskontrakt wurden darin Leistungen

38 Status, der aus dem Erwerb eines landtäflichen Gutes mit nachfolgender Einschreibung in die ständische Landtafel (Habilitation zu Lande) folgte.

39 Burger, Staatsbürgerschaft, in: Grenze und Staat, S. 103.

40 Abgedruckt in: Eveline Brugger/Birgit Wiedl: Regesten zur Geschichte der Juden im Mittelalter, Bd. 1 (Innsbruck/Wien/Bozen 2005), Nr. 20. Ein Jahr zuvor, 1237, hatte Friedrich II. in einem eigenen Patent bestimmt, dass die Juden in Wien keine Ämter bekleiden sollen. Ebenda, Nr. 17.

41 Siehe dazu: Lohrmann, Juden im Mittelalter, S. $36 \mathrm{ff}$.

42 Vgl. Kurt Schubert: Die Geschichte des österreichischen Judentums (Wien/Köln/Weimar 2008), S. 25 . 
und Gegenleistungen festgeschrieben. Unter den Schutzbestimmungen finden sich neben dem Tötungs- und Verletzungsverbot ein Schutz vor Zwangstaufe sowie der Schutz jüdischen Eigentums. Allen Christen, die einem Juden körperlichen Schaden zufügten, heilige Orte oder Sakralgegenstände schändeten oder jüdische Feiertage störten, drohte der Herzog schwere Strafen an. Die Verwüstung eines jüdischen Friedhofs sollte mit dem Tode bestraft werden. ${ }^{43}$

Als nach dem Aussterben der Babenberger der böhmische Herrscher Ottokar II. die Macht über die österreichischen Länder gewann, kam es I 254 zu einem Privileg für die Juden Böhmens, Mährens, Österreichs und der Steiermark, das im Wesentlichen den Bestimmungen des Fridericianums folgte. ${ }^{44}$ Die umfangreichen Förderungen und Begünstigungen durch den Landesherrn, die nicht nur zu einem Aufblühen der Judengemeinden von Wiener Neustadt, Tulln, Krems, Friesach und Klosterneuburg, sondern auch zu einer lebensweltlichen Angleichung von Christen und Juden führte, erregten jedoch alsbald das Missfallen der Kirche. I 267 erhob das Wiener Provinzialkonzil die größtmögliche soziale und gesellschaftliche Trennung von Christen und Juden - wie sie schon beim vierten Laterankonzil von I 2 I 5 gefordert wurden - zum Programm. Die kanonischen Bestimmungen dieses unter Führung von St. Stephan in Wien veranstalteten Konzils, das die Beziehungen von Juden und Christen bis ins Einzelne regeln wollte, beinhalteten unter anderem die Pflicht, den gehörnten Judenhut zu tragen, das Gebot, am Karfreitag, oder wenn das Sakrament des Altars auf den Straßen vorbeigetragen wurde, in den Häusern zu bleiben; das Verbot, christliche Dienstboten zu halten; das Verbot, öffentliche Ämter zu bekleiden; das Verbot des geschlechtlichen Verkehrs zwischen einem Juden und einer Christin; das Verbot, mit Christen gemeinsam zu essen, zu trinken und zu feiern; das Verbot, christliche Badehäuser aufzusuchen; das Verbot, unmäßige Zinsen zu nehmen sowie (für Christen) das Verbot, Fleisch und andere Speisen bei Juden zu kaufen. ${ }^{45}$ Die Canones von St. Stephan wurden nie Gesetz, und sie spiegeln auch kaum die Realität jener Zeit wider, prangern sie doch den nach Ansicht der Kirche viel zu lockeren gesellschaftlichen Verkehr zwischen Juden und Christen an. Doch finden sie sich nicht nur in verschiedenen Judenordnungen der frühen Neuzeit, sondern - sieben Jahrhunderte später - in wesentlichen Bestimmungen der nationalsozialistischen Rassengesetzgebung wieder (etwa im als Teil der Nürnberger Gesetze am I 5 . September 1935 erlassenen »Gesetz zum Schutze des deutschen Blutes und der deutschen Ehre«). ${ }^{46}$

43 Vgl. Lohrmann, Wiener Juden, S. 41.

44 Vgl. Jochen A. Fühner: Kaiser Maximilian I. und die Juden in den österreichischen Erblanden (= Mitteleuropäische Studien I) (Herne 2007), S. 19f.

45 Lohrmann, Wiener Juden, S. $142 \mathrm{f}$.

46 Vgl. Burger/Wendelin, Praxis, S. 283. 
Mit der Wahl Rudolfs von Habsburg zum deutschen König und Kaiser des Heiligen Römischen Reiches im Jahr I 273 begann die wechselvolle Geschichte der Juden unter der Herrschaft der Habsburger. Zunächst waren Rudolf und seine unmittelbaren Nachfolger - im Gegensatz etwa zu England, wo Juden zu eben dieser Zeit für Jahrhunderte vertrieben wurden - bemüht, möglichst günstige Rahmenbedingungen für die Zuwanderung und dauerhafte Ansiedlung von Juden in den habsburgischen Erbländern zu schaffen. Da Juden dem Herrscherhaus zunächst als Münzpräger, dann als Geldbeschaffer für seine umfangreichen politischen und wirtschaftlichen Unternehmungen immer unentbehrlicher wurden, waren die Habsburger bemüht, »ihre Juden" nach Kräften zu schützen und zu privilegieren, was u.a. dazu führte, dass die Residenzstadt Wien gegen Ende des I 4. Jahrhunderts eine der größten jüdischen Gemeinden Europas beherbergte. ${ }^{47}$

Die relative Sicherheit und der Wohlstand der österreichischen Judengemeinden im Hochmittelalter fand jedoch im Frühsommer I 420 ein jähes Ende. Das Gerücht, die Juden unterstützten die Hussiten (den damaligen Kriegsgegner) sowie die Beschuldigung der Hostienschändung ${ }^{48}$ (im Verein mit einer durch Theologen der Wiener Universität hervorgerufenen judenfeindlichen Stimmung ${ }^{49}$ ) führte zu Zwangstaufen, Folter, Enteignung, Ausweisung, und, ganz zuletzt, am I 2. März I42 I, zur öffentlichen Verbrennung von 2 ro jüdischen Männern, Frauen und Kindern - durchwegs Angehörige der gebildeten Oberschicht, die die Taufe noch immer verweigerten - auf der Erdberger Lände vor den Toren Wiens. Auch in Tulln, Langenlois und Krems starben Juden auf dem Scheiterhaufen. Jene etwa 800 Wiener Juden, denen die Flucht auf Booten donauabwärts gelungen war, siedelten sich später in Mähren und Ungarn an, wo sie Kaiser Sigismund, der Schwiegervater Herzog Albrechts, unter seinen Schutz nahm. ${ }^{50}$

47 Etwa fünf Prozent der damaligen Wiener Bevölkerung waren Juden. Vgl. Klaus Lohmann: Zwischen Finanz und Toleranz. Das Haus Habsburg und die Juden (Graz/Wien/Köln 2000), S. 15.

48 Der Prozess um die Ennser Hostienschändung von 1305 in Klosterneuburg wurde von den Chronisten offenbar nachträglich als eine der Ursachen für die Wiener Geserah angegeben. Birgit Wiedl: Konstruktion eines Verbrechens. Die angebliche Ennser Hostienschändung im Kontext der Judenverfolgung und -ermordung von 1420/21. Vortrag bei der Tagung des Instituts für jüdische Geschichte Österreichs "Taufe oder Tod?«. Die Vernichtung der Wiener Judenstadt 1420/21 im Spannungsfeld zwischen Theologie und Politik, 11. März 2011, Fakultätssitzungssaal der katholisch-theologischen Fakultät der Universität Wien.

49 Nach Klaus Wolf (Heidelberg) spielte die Agitation von Angehörigen der Wiener Theologischen Fakultät bei der Entstehung des Pogroms von 1420/21 eine bedeutende Rolle. Klaus Wolf: „Pey der äffinn ist dew Judenschül zu versten. Zum Judenbild in frühneuhochdeutschen Texten der Wiener Schule. Vortrag bei der Tagung »Taufe oder Tod?«a.a.O.

50 Lohrmann, Wiener Juden, S. 168. 
Vertreibungen und Ausweisungen von Juden, gefolgt von Wiederansiedlungen und Neuprivilegierungen, ziehen sich seit der Wiener Geserah (so der hebräische Name der ersten österreichischen Judenverfolgung von I420/2 I) durch die österreichische Geschichte. ${ }^{51}$ In der Regierungszeit Kaiser Maximilians waren in Niederösterreich immer neue jüdische Landgemeinden entstanden. ${ }^{52}$ Doch gegen Ende des I 5. Jahrhunderts verschlechterte sich die Situation der Juden im ganzen Reich dramatisch. Eine Welle des Antisemitismus, die ganz Europa erfasst hatte, sowie der wachsende Druck der Stände (dem Friedrich III. noch standgehalten hatte), führten zur Vertreibung der Juden aus Innerösterreich (Kärnten, Steiermark, Krain) in den Jahren I 496/97. ${ }^{53}$ Und die niederösterreichischen Landjuden mussten jetzt, wollten sie sich in Wien aufhalten, den gelben Flecken tragen. ${ }^{54}$

Auch im I6. Jahrhundert, dem Zeitalter der großen konfessionellen Auseinandersetzungen und Kriege, kam es im Reich immer wieder - häufig auf Antrag der zu dieser Zeit überwiegend protestantischen Stände - zu Ausweisungen von Juden. Doch mit einem Generalmandat bestätigte Kaiser Ferdinand I 529 erneut, »die Juden in Österreich bei ihren Freiheiten zu belassen «. ${ }^{55}$ Diese sogenannte "Judenschützung « bezog sich allerdings bloß auf eine kleine Anzahl "generalprivilegierter« Juden. Nur gegen hohe Steuern wurde einzelnen Juden der Aufenthalt in der Residenzstadt Wien erlaubt. I 57 I genehmigte Kaiser Maximilian II. die Ansiedlung von sieben weiteren privilegierten Familien. In Böhmen, Mähren und Ungarn hingegen war die Lage für Juden liberaler, hier durften sie etwa auch in bestimmten Handwerken, im Gewerbe und im Kleinhandel tätig sein.

Empfindlicher Geldmangel veranlasste Kaiser Rudolf II. im Jahr I 582, die sogenannte »Hofbefreiung « einzuführen, welche - gegen einen hohen Geldbetrag - Steuerfreiheit und das Aufenthaltsrecht in der Residenzstadt des Kaisers (damals Prag) gewährte. Anfang des I7. Jahrhunderts gab es in den österreichischen Ländern somit drei verschiedene Kategorien von Juden: hofbefreite Juden, Juden, die bei Hofbefreiten in Diensten standen, und fremde Juden. Letztere konnten jederzeit ausgewiesen

51 Die Ereignisse der Wiener Geserah (hebräisch: »katastrophales Verhängnis«), nach Martha Keil, das wohl grausamste Geschehen in der Geschichte der österreichischen Juden vor dem Holocaust, waren im März 2011 Gegenstand einer gemeinsamen Tagung des Instituts für die jüdische Geschichte Österreichs und der katholisch-theologischen Fakultät der Universität Wien. Die zitierten Beiträge sollen demnächst in einem Tagungsband publiziert werden.

52 In der frühen Neuzeit existierten über fünfzig jüdische Gemeinden in Niederösterreich. Vgl. Barbara Staudinger: "Gantze Dörffer voll Juden«. Juden in Niederösterreich 1496-1670 (Wien 2005), S. 16.

53 Einen Teil dieser innerösterreichischen Juden ließ Maximilian I. später in Marchegg, Zisterndorf und Eisenstadt ansiedeln.

54 Dekret aus 1511, vgl. Lohmann, 1000 Jahre, S. 37.

55 Seit 1526 König von Böhmen und Ungarn, ab 1556 Kaiser Ferdinand I. Abgedruckt in: Gershon Wolf: Geschichte der Juden in Wien 1156-1876 [Wien 1876] (Reprint 1974), S. 252f. 
werden. Ausweisungen - etwa unter Erzherzog Mathias im Jahr I6I I - und Neuprivilegierungen lösten einander auch das ganze I7. Jahrhundert hindurch ab. Dabei war die Situation in den einzelnen Kronländern äußerst unterschiedlich: Lebten in Innerösterreich nach 1496 überhaupt keine Juden mehr, kam es in Österreich unter der Enns (Niederösterreich) zu einer Konsolidierung bzw. Neuetablierung jüdischer Gemeinden an etwa fünfzig Orten, sodass der englische Arzt und Reisende Edward Brown in seinen Reiseerinnerungen erstaunt notierte: "gantze Dörffer voll Juden «. ${ }^{56}$

Auch in Wien bekamen die Juden schließlich die Möglichkeit der Wiederansiedlung. In einem Privileg von I 624 wies Kaiser Ferdinand II. ihnen das »Untere Werd « (auch: untere Wird), die heutige Leopoldstadt, als alleinige Wohnstatt zu. Voraussetzung für die Ansiedlung in der neuen Judenstadt war die Besitzfähigkeit, die ein weiteres Patent von 1632 regelte. Vor allem durch Zuzug aus Prag entwickelte sich aus den ursprünglich nur vierzehn Häusern des »Unteren Werd« rasch eine blühende Judengemeinde mit etwa 3000 Einwohnern, autonomer Verwaltung und einer beeindruckenden Infrastruktur. ${ }^{57}$ Doch eine Mischung aus wirtschaftlichem Neid und christlichem Aberglauben führte im Jahr I 670 unter Leopold I. wiederum zur Vertreibung der Juden aus Wien und Niederösterreich. ${ }^{58}$ Voraus ging dieser neuerlichen Austreibung eine genaue "Seelenerhebung«. Ende Juni I669 wurde von den in Wien wohnenden Juden ein innerhalb von acht Tagen einzureichendes Verzeichnis eingefordert, das neben einer Namensliste - betroffen waren I 346 Personen - und dem genauen Wohnort auch die geleisteten Steuern und Abgaben umfassen sollte. Derlei »Judenkonskriptionen« fanden seit Beginn des I 6 . Jahrhunderts in den böhmischen Ländern statt. Dienten sie ursprünglich rein fiskalischen Zwecken, so wurden sie im Falle Wiens auch zur Vorbereitung und Unterstützung der Vertreibung genutzt. ${ }^{59}$

Nach dieser leopoldinischen Austreibung wurde nur mehr sehr wenigen wohlhabenden Juden (den Hoffaktoren) der Aufenthalt in der Residenz erlaubt. Nur ein-

56 Zit. nach: Barbara Staudinger: Zur Geschichte der Juden in Niederösterreich 1496-1670/71, in: David - Jüdische Kulturzeitschrift, www.david.juden.at/kulturzeitschrift/61-65/63-Staudinger-htm.

57 Karl Artner et al. (Hg.): Die Leopoldstadt. Ein Heimatbuch (Wien 1937), S. $43 \mathrm{ff}$.

58 Die exakten Gründe hierfür sind bis heute ungeklärt. Neben einer judenfeindlichen Strömung am Wiener Hof (als Beleg dafür wird immer wieder das zurückgewiesene Geschenk einer silbernen Wiege durch die abergläubische Kaiserin genannt), Rivalitäten zwischen den kaiserlichen Räten und Judenfeindschaft der Wiener Bürgerschaft werden auch Vorgänge innerhalb der Judengemeinde selbst genannt: eine Steuerprüfung, ein Korruptionsprozess und ein Mordfall. Vgl. Peter Rauscher: Die Vertreibung der Juden aus Wien und Niederösterreich im Jahr 1670, Vortrag beim Symposium "Wiens jüdische Gemeinde im 17. Jahrhundert«, Wien, 24. Mai 2006; www.misrachi.atindex.php/ geschichte-der-juden-in-wien/49-symposium-wiens.

59 Anton Tantner: Ordnung der Häuser, Beschreibung der Seelen - Hausnumerierung und Seelenkonskription in der Habsburgermonarchie, phil. Diss. (Wien 2004), S. 19. 
zelne Häuser wie das des kaiserlichen Armeelieferanten Samuel Oppenheimer und seines Neffen Samson Wertheimer erhielten das Niederlassungsrecht in Wien. ${ }^{60} \mathrm{Da}$ rüber hinaus aber war die Politik der Habsburger im I7. Jahrhundert darauf gerichtet, die Zahl der in Wien ansässigen Juden so gering wie möglich zu halten. So beschränkten die Judenordnungen für Wien und Niederösterreich von I 72 I und I 723 das Aufenthaltsrecht immer nur auf das Haupt der Familie, dessen Frau und Kinder sowie die »unumgänglich notwendigen Bedienten «. ${ }^{61}$ Dennoch hielt der Zustrom "fremder" Juden nach Wien unvermindert an. Zwar wies eine unter Maria Theresia angeordnete Zählung im Jahr I752 nur zwölf Familien und insgesamt 452 legal ansässige Juden aus, doch die Zahl der tatsächlich anwesenden Juden dürfte erheblich höher gewesen sein. ${ }^{62}$

Noch Anfang des I 8. Jahrhunderts zielte die Politik der Habsburger auf Kontrolle und »Verminderung « der Juden. In diesem Kontext sind auch die »Familiantengesetze« von 1726 zu lesen, die durch drastische Ehebeschränkungen und eine exakt vorgegebene Zahl von »Familienstellen« (für Böhmen und Mähren) die Zahl der Juden konstant halten wollten. Barockfrömmigkeit und religiöse Intoleranz gegen Protestanten wie gegen Juden zeichneten die Herrschaftsperiode Karl VI. und seiner Tochter Maria Theresia aus. Die mit großer Grausamkeit verbundenen Judenausweisungen in Böhmen der Jahre 1744 bis I748 stießen bei den Judengemeinden in ganz Europa auf Empörung. Erstmals kam es zu einer Welle internationaler Solidarität. So trug nicht nur der englische Botschafter in Wien den energischen Protest König Georgs II. bei Maria Theresia vor ${ }^{63}$, sondern auch aus Kopenhagen und den Niederlanden kamen diplomatische Demarchen. ${ }^{64}$ Als bald darauf die nachteiligen wirtschaftlichen Folgen dieser Vertreibungen sichtbar wurden, kam es auf Druck der Prager Statthalterei im Zuge der Haugwitzschen Reformen zu

60 Ausführlicher dazu: Klaus Lohrmann: Zwischen Finanz und Toleranz. Das Haus Habsburg und die Juden (Graz/Wien/Köln 2000), S. 30f. Zur außergewöhnlichen Stellung Samuel Oppenheimers als Kriegskommissar vgl. Selma Stern/Marina Sassenberg: Die Hofjuden im Zeitalter des Absolutismus (= Schriftenreihe wissenschaftlicher Abhandlungen des Leo Baeck Instituts 64) (Tübingen 2001), S. 18

61 Johann Ludwig Barth-Barthenheim: Beiträge zur politischen Gesetzeskunde im österreichischen Kaiserstaate, Bd. 1, Politische Verfassung der Israeliten im Lande unter der Enns (Wien 1821), S. 17.

62 Tietze, Juden Wiens, S. 99.

63 Dan Diner spricht davon, dass seit dem Frieden von Utrecht 1713 dieses Eintreten zugunsten verfolgter und bedrohter Juden und Judenheiten auf der Bühne meines durch die großen Mächte politisch regulierten imperialen Raumes« erfolgt sei. Dan Diner: Synchrone Welten. Zeiträume jüdischer Geschichte (Göttingen 2005), S. 27.

64 Bericht über das Projekt: »Recht und Praxis der Religionsinterventionen im Europa der frühen Neuzeit" von Stephan Wendehorst im Rahmen des Jour Fixes an der Universität Wien zur "Geschichte der Juden in der Neuzeit", am 15. 11. 2012, mündliche Mitteilung. 
einer Veränderung der Politik gegenüber den Juden. Für vorläufig zehn Jahre wurde den reicheren Juden gegen eine hohe »Toleranzgebühr« die Rückkehr in das Prager Ghetto gestattet. ${ }^{65}$

Die harten Judenordnungen Maria Theresias von 1753 und 1764 fassten indes noch einmal alle, manchmal jahrhundertealten Bestimmungen der Ausgrenzung und Absonderung zusammen. Nur zögernd und in Einzelbestimmungen wurde die Tendenz spürbar, die Judengesetzgebung an die allgemeine Gesetzgebung anzugleichen. Und noch immer hing das Aufenthaltsprivileg davon ab, ob jemand »für das gemeine Wesen nützlich war", etwa durch »Anlegung einiger Fabriken« oder durch Zahlung der hohen Toleranzgebühren. ${ }^{66}$ Noch vor Erlassung der Judenordnung von 1753 wurde im Oktober 1752 in Wien eine gründliche Zählung aller Juden und Jüdinnen angeordnet. Zweck dieser Zählung - 452 jüdische Personen wurden erfasst - war die Überwachung und, wenn möglich, Verminderung der jüdischen Bevölkerung. Von jedem jüdischen Hausvater wurde jetzt eine quartalsweise einzureichende "Specification" aller in seinem Haus Wohnenden - und dazu zählten neben Frau und Kindern auch alle Bediensteten - eingefordert. Vierteljährliche Visitationen durch eigene Kommissare der niederösterreichischen Landesregierung sollten sicherstellen, dass die Zahl der erlaubten Dienstboten nicht überschritten wurde. Im Übertretungsfall war die Person auszuweisen. Diese vierteljährliche Meldepflicht, bei der jeder jüdische Hausvater die Namen seiner Frau, seiner Kinder, deren Alter sowie die im Hause wohnenden Dienstboten aufzulisten hatte, ging in die zweite maria-theresianische Judenordnung von 1764 ein. ${ }^{67}$ Die immer und immer wieder angeordneten Judenzählungen wurden, nach Anton Tantner, aber nicht nur gleichsam zum Pilotmodell für die ab I753/54 durchzuführende allgemeine »Seelenkonskription«, d.h. die systematische Erfassung der gesamten Bevölkerung für zivile und militärische Zwecke ${ }^{68}$, sondern waren darüber hinaus in Zusammenhang zu sehen mit jenem im Zeichen der Aufklärung stattfindenden Prozess der Disziplinierung, Überwachung und Kontrolle der Bevölkerung, die »jedem Individuum seinen Platz« (Michel Foucault) zuwies und am Ende den großen "Disziplinarraum" des modernen Territorialstaates entstehen ließ. ${ }^{69}$

65 Vgl. Stefan Plaggenborg: Maria Theresia und die Böhmischen Juden, in: Bohemia 39 (1998), S. 116, hier: S. $4 f$.

66 Tietze, Juden Wiens, S. 102.

$67 \mathrm{Vgl}$. Tantner, Seelenkonskription, S. 21.

$68 \mathrm{Vgl}$. ebenda, S. $149 \mathrm{f}$.

$69 \mathrm{Vgl}$. Wendelin, Schub und Heimatrecht, S. $176 \mathrm{f}$. 


\section{Die Josephinische Z̈̈sur}

In gewisser Weise markiert jedoch die Vertreibung der Prager Juden (I744) einen Wendepunkt in der habsburgischen Judenpolitik. Die allmählich sich durchsetzenden Ideen der Aufklärung wie auch die Säkularisierung der Staatsidee ließen es nicht länger zu, Untertanen aufgrund ihrer religiösen Zugehörigkeit auszugrenzen oder zu vertreiben. ${ }^{70}$ Zunehmend standen die bestehenden Sonderrechte und -pflichten der angestrebten Gleichförmigkeit in allen Staatsbelangen entgegen, und zunehmend setzten sich die Nützlichkeitserwägungen des herrschenden Utilitarismus auch in der Judengesetzgebung durch. Die noch bestehenden Judenordnungen schienen mit dem bereits in den ersten Jahren der Regierung Josephs II. proklamierten Grundsatz: "dass alle österreichischen Untertanen ohne Unterschied der Nation und Religion, sobald sie in den österreichischen Staaten aufgenommen und geduldet sind, an dem öffentlichen Wohlstande (...) gemeinschaftlich Anteil nehmen, eine gesetzmäßige Freiheit genießen und auf jedem ehrbaren Wege zur Erwerbung ihres Unterhaltes und Vergrößerung der allgemeinen Emsigkeit kein Hindernis finden sollen « ${ }^{71}$, kaum mehr vereinbar. In einem Handschreiben an den Obersten Kanzler Graf Blümegen erläuterte der Kaiser seine Grundsätze der Toleranz. Dabei wollte man das Ziel, nämlich die in seinen Erblanden "so zahlreichen Glieder der jüdischen Nation dem Staate nützlicher zu machen«, vor allem dadurch erreichen, dass man alle bisherigen Beschränkungen der Erwerbstätigkeit systematisch abbaute und alle »demütigenden und den Geist niederschlagenden Zwangsgesetze« beseitigte. Neben der Errichtung jüdischer Normalschulen empfahl Joseph II., jüdischen Kindern den Besuch der öffentlichen Schulen zu gestatten. Alle Studienzweige, mit Ausnahme der Theologie, sollten ihnen offen stehen, auch alle ihnen zuvor verschlossenen Berufe: neben der Landwirtschaft alle Arten von Handwerken sowie die freien Künste. Die Kehrseite dieses Assimilationsangebotes waren empfindliche Eingriffe in die religiöse und kulturelle Identität der Juden, vor allem die Beschränkung der hebräischen Sprache allein auf den Gottesdienst. Innerhalb einer Frist von zwei bis drei Jahren sollten die jeweiligen Landessprachen soweit erlernt werden, dass alle Verträge, Zeugnisse, Rechnungen, Handelsbücher etc. »bei Strafe der Nullität« in diesen ausgefertigt werden konnten. ${ }^{72}$

70 Vgl. Plaggenborg, Böhmische Juden, S. 4f.

71 Barth-Bathenheim, Gesetzeskunde 1, S. 19.

72 Handschreiben Josephs II. an den böhmischen Obersten und österreichischen Kanzler Graf Blümegen, zit. nach: Harm Klueting (Hg.): Der Josephinismus. Ausgewählte Quellen zur Geschichte der theresianisch-josephinischen Reformen (= Ausgewählte Quellen zur Geschichte der Neuzeit XIIa) (Darmstadt 1990), S. 241. Zu den Intentionen Josephs II. siehe auch: Lohrmann, Finanz und Toleranz, S. 39f. 
Noch vor der Erlassung des eigentlichen Toleranzpatentes für die Juden Niederösterreichs $^{73}$ (mit Wien) ergingen zahlreiche Einzelverordnungen, in denen der Kaiser versuchte, die »bürgerliche Stellung« der Juden zu verbessern. So wurde im Oktober I78 I angeordnet, den »bisher beobachteten Unterschied in der jüdischen Tracht und Kleidung (die gelben Bänder) ganz abzustellen. Den Juden solle »in Ansehung der Kleidertracht, wenn sie sich sonst ruhig und ordentlich aufführen, von niemandem etwas in Weg" gelegt werden. ${ }^{74}$ Wie alle Reformen Josephs II. erfolgten auch diese von oben und stießen bei der Bevölkerung auf wenig Verständnis. Um den Volksschulbesuch jüdischer Kinder in allen Erbländern durchzusetzen, ordnete er gleichsam mit einem Antirassismuserlass - an, dass die Juden "wie alle anderen $\mathrm{Ne}$ benmenschen « zu betrachten seien. Das »bei einigen, besonders bei niedrigdenkenden Leuten gegen die jüdische Nazion bisher beobachtete Vorurtheil einer Verächtlichkeit (...), das sogar zu sträflichen Exzessen Anlaß gegeben « habe, sei abzulegen. ${ }^{75}$

Doch als das Patent für die Juden Niederösterreichs am 2. Januar I782 - von den Wiener Juden mit Jubel begrüßt - endlich kundgemacht wurde, brach dieses keineswegs in allen Bereichen mit der bisherigen Judenpolitik. Bereits die Präambel zum Gesetzestext betonte, dass der höchste Wille keinesfalls dahingehe, »der in Wien wohnenden Judenschaft in Beziehung auf die äußere Duldung eine Erweiterung zu gewähren«, insbesondere sollte ihnen - im Gegensatz zu den Protestanten - auch in Hinkunft nicht gestattet sein, eine Gemeinde zu bilden, noch öffentliche Gottesdienste abzuhalten, noch eine Synagoge zu errichten. ${ }^{76}$ Ebenso war es nicht im

73 Zwischen 1781 und 1789 wurden acht verschiedene, die unterschiedlichen Bedingungen in den einzelnen Ländern berücksichtigende Toleranzdekrete für Juden erlassen, im Einzelnen:

Das Toleranzdekret die Juden Böhmens betreffend vom 19.10.1781.

Das Patent für die schlesischen Juden vom 15.12.1781.

Die Erneuerung der Privilegien der Juden der Lombardei, Ende Dezember 1781.

Das Toleranzpatent für die Juden Wiens und Niederösterreichs vom 2.1.1782.

Das Toleranzpatent für die Juden Mährens vom 13.2.1782.

Die »Sistematica gentis Judaicae regulatio« für die Juden Ungarns vom 31.3.1783.

Das vorläufige "Judensystem in Galizien« vom 27.5.1785.

Die »Judenordnung für Galizien« vom 7.5.1789.

Erst nach dem Tode Josephs II. erhielten im Jahr 1790 auch die Juden von Triest, Görz und Mantua ein Toleranzpatent von Leopold II., der die Toleranzpolitik seines Bruders fortsetzte. Vgl. Josef Karniel, Zur Auswirkung der Toleranzpatente für die Juden in der Habsburgermonarchie im josephinischen Jahrzehnt, in: Peter F. Barton (Hg.): Im Zeichen der Toleranz. Aufsätze zur Toleranzgesetzgebung des 18. Jahrhunderts in den Reichen Josephs II., ihren Voraussetzungen und ihren Folgen. Eine Festschrift. Wien 1981, S. 203-220, hier: S. 204 und 218. Eine kritische Edition aller die Juden betreffenden Toleranzpatente unter Federführung von Louise Hecht (Universität Olmütz/ Olomouci/Universität Wien) ist gegenwärtig in Vorbereitung.

74 Verordnung vom 12. Oktober 1781, zit. nach: Klueting, Josephinismus, S. 251.

75 Hofdekret für Böhmen vom 2. November 1781, zit. nach: Klueting, Josephinismus, S. 261.

76 Dies im Gegensatz zu den Sepharden, denen als türkischen Untertanen mit dem maria-theresiani- 
Sinn der neuen Verordnung, die Zahl der Juden "weder in Wien noch überhaupt in Unseren Staaten zu vergrößern, oder fremde ohne wichtige Ursachen und besondere für sie sprechende Verdienste herein zu ziehen $"{ }^{77}$ Überdies sollte für die Gewährung des Aufenthalts ein hohes "Toleranzgeld « eingehoben werden. ${ }^{78}$ Ausdrücklich wurde die Toleranz auf den "Hausvater", dessen Frau und die in seiner Versorgung stehenden Kinder beschränkt. Die Ansiedlung von Juden auf dem Land blieb ausschließlich wohlhabenden Fabrikinhabern vorbehalten. ${ }^{79}$ Dennoch öffnete das Patent den Juden viele bisher verschlossene Bereiche: Schule und Universität sollten ihnen offen stehen, alle sichtbaren Merkmale der Unterscheidung waren aufgehoben, ebenso die entehrende Leibmaut (eine Kopfsteuer). Insbesondere aber wurde ihnen gestattet, von nun an "alle Gattungen von Handwerken und Gewerben« bei christlichen Meistern zu erlernen (ohne damit allerdings das "Bürger- und Meisterrecht « zu erlangen). Zahlreiche weitere Verordnungen Josephs II., u. a. das Gebot, einen bestimmten Familiennamen und einen deutschen Vornamen zu führen (I787), die Heranziehung von Juden zum Militärdienst ( 1788$)^{80}$, die Erlaubnis, nach Absolvierung der Studien auch die Doktorwürde in den medizinischen und juridischen Fächern zu erlangen (I782) sowie die Erlaubnis zum Kauf von Staatsgütern (I789) ließen die tolerierten Juden, wie überzeugte Aufklärer meinten, »beinahe zu Vollbürgern « werden ${ }^{81}$, allerdings um den hohen Preis der Aufgabe ihrer spezifisch jüdischen Identität und Lebensweise, d. h. Emanzipation von der Religion wurde zunehmend zur Bedingung für Teilnahme an Staat und Gesellschaft. ${ }^{82}$ Wird heute das "antijüdische Potential«

schen Dekret vom 17. Juni 1778 die Eröffnung und Erhaltung einer Synagoge gestattet worden war. Siehe dazu: Ludwig August Frankl: Zur Geschichte der Juden in Wien (Wien 1853), S. 32.

77 Zit. nach: Klueting: Josephinismus, S. $275 \mathrm{f}$.

78 Die Toleranzsteuer betrug zwischen 20 und 200 Gulden pro Familie. Voraussetzung für den Erhalt der Toleranz in Wien war (ab 1786) der Nachweis eines Vermögens von 10000, ab 1807 sogar 60000 Gulden und/oder die Errichtung einer Fabrik oder die Erlangung des k. k. Großhandelsprivilegiums. Vgl. Ernst Mischler/Josef Ulbrich (Hg.): Österreichisches Staatswörterbuch. Handbuch des gesamten österreichischen öffentlichen Rechtes, Bd. 2 (Wien 1906), Stichwort: Die Juden, S. 950. Siehe dazu auch: Ludwig Bato, Die Juden im alten Wien (Wien 1928), S. 124.

79 Vgl. Staudinger, „Gantze Dörffer voll Juden«, S. 11.

80 Am 18. Februar 1788 entschied Joseph II., dass "die Juden auch zu dem Militärstande tauglich" seien. Diese zuerst in Galizien und nur für den Fuhrdienst kundgemachte Entscheidung wurde am 4. Juni 1788, auf alle anderen Kronländer ausgedehnt. Bald darauf durften Juden auch in der Infanterie dienen, und in den Napoleonischen Kriegen fielen alle Beschränkungen des Kriegsdienstes für Juden. Vgl. Erwin A. Schmidl: Juden in der k.(u.)k. Armee 1788-1918, in: (Studia Judaica Austriaca Bd. 11, Eisenstadt 1989), S. 35ff.

81 Vgl. Tietze, Wiener Juden, S. 118. Dazu auch: Julius H. Schoeps: „Du Doppelgänger, Du bleicher Geselle ...« Deutsch-jüdische Erfahrungen im Spiegel dreier Jahrhunderte 1700-2000 (Berlin/Wien 2004), S. 101.

$82 \mathrm{Vgl}$. Andreas Gotzmann, Eigenheit und Einheit. Modernisierungsdiskurse des deutschen Judentums der Emanzipationszeit (Leiden/Boston/Köln 2002), S. 216. 
der Aufklärung generell und das des Josephinismus im Besonderen gern betont ${ }^{83}$, so feierte das zeitgenössische Judentum die Toleranzdekrete noch hundert Jahre nach ihrem Erscheinen als Durchbruch zur Humanität und Befreiung aus mittelalterlicher Knechtschaft und sah in ihren Grundsätzen - vielleicht etwas überraschend viel »Übereinstimmung mit der israelitischen Religion ${ }^{84}$

\section{Das böhmisch-mährische System der Familienstellen}

Gänzlich verschieden von jenem in Wien und Niederösterreich war das »Judensystem« in Böhmen und Mähren. Hier zielten die sogenannten Familiantengesetze Kaiser Karls VI. insbesondere durch Ehebeschränkungen - nur der älteste Sohn erhielt die Erlaubnis, nach dem Tode des Vaters heiraten zu dürfen - und eine exakt vorgegebene Zahl von »Familienstellen « (für Böhmen 854I, für Mähren 5 I06) darauf $\mathrm{ab}$, die Zahl der Juden konstant zu halten. ${ }^{85}$ Hatten die Juden Böhmens und Mährens seit Beginn der Herrschaft Josephs II. Hoffnung geschöpft, dass das seit I 726 bestehende Familiantenwesen im Zeichen der Aufklärung endgültig verabschiedet werden würde, so sollte sie mit der Publizierung des Hofdekrets für die Juden Böh-

83 Etwa bei Adolf Gaisbauer in seiner Analyse des etwa zwei Jahrzehnte nach den Toleranzdekreten entstandenen Werkes des österreichischen Beamten Joseph Rohrer »Versuch über die jüdischen Bewohner der österreichischen Monarchie«. Adolf Gaisbauer: Das antijüdische Potential der Aufklärung und des Josephinismus, in: Aschkenas. Zeitschrift für Geschichte und Kultur der Juden (1996) 1, S. $163-182$.

84 So pries der Rabbiner und Prediger der Meisel Synagoge zu Prag, Dr. A. Stein, in seiner Festpredigt anlässlich der Feier des hundertsten Jahrestages der "Kundmachung des ersten der von Kaiser Josef II. gegebenen Gesetze zur Befreiung der Juden« am Azereth Fest des Jahres 5642 (1881) Joseph II. als "Repräsentanten der Humanität «, der »in der Religion der Humanität« (dem Judentum) unsterblich fortbestehen werde. Darauf hinweisend, wie rasch sich »die Widerspenstigkeit« der Kinder Israels gegen die neuen Gesetze gelegt habe, wie rasch die Landessprache die Muttersprache geworden sei und wie "brauchbar unsere Schulen die Jugend für jede Berufstätigkeit « gemacht hätten, fährt er fort: "Welcher Israelit in Österreich liebt nicht sein Vaterland, möchte nicht dienen dem Vaterlande, sterben für das Vaterland? - Und er möchte das nicht bloß, weil er Österreicher ist, er muss das, weil er Israelit ist, weil die Grundsätze der Humanität, von Kaiser Josef II. vor 100 Jahren eingeführt (...) übereinstimmen mit den obersten Grundsätzen der israelitischen Religion«. A. Stein: Der Mensch im Bilde Gottes. Festpredigt zur Feier des nach 100 Jahren wiederkehrenden Tages der Kundmachung des ersten der von Kaiser Josef II. gegebenen Gesetze zur Befreiung der Juden aus der mittelalterlichen Rechtlosigkeit (Prag 1881) (Sonderdruck), S. 12.

85 Zur Entstehung des Familianten-Systems siehe: Anna M. Drabek: Das Judentum der böhmischen Länder vor der Emanzipation (= Studia Judaica Austriaca X) (Eisenstadt 1984), S. 5-30. Zu den Juden in Böhmen und Mähren allgemein siehe auch: Ruth Kestenberg-Gladstein: Neuere Geschichte der Juden in den böhmischen Ländern (Tübingen 1969) sowie: Wilma A. Iggers: Die Juden in Böhmen und Mähren (München 1896). 
mens vom I9. Oktober I78 I gründlich enttäuscht werden. ${ }^{86}$ Trotz aller gewährten Erleichterungen blieb das verhasste System der Familienstellen bestehen. Brüsk wies der Kaiser eine von den Vorstehern der böhmischen jüdischen Gemeinde, Joachim Popper und Isaac Bobolc, unterzeichnete Petition, die Beschränkung der jüdischen Familien »ad numerum localem in Gemäßheit seiner Majestät allerhöchster Absichten aufzuheben « und ihnen - analog des Niederösterreichischen Toleranzpatentes zu erlauben, »unter den Christen zu domicilieren « ${ }^{87}$, mit der Bemerkung zurück, dass lediglich im Falle, dass »sehr gute Fabrikanten kommen, die sich auf dem Lande niederlassen wollen«, eine Ausnahme gemacht werden solle, im Übrigen aber der böhmischen Landesjudenschaft zu bedeuten sei, dass sie sich mit seiner früheren Verordnung begnügen solle. ${ }^{88}$

Das am I 3. Februar I 782 erlassene Toleranzpatent für die Juden Mährens brachte für diese zwar die Aufhebung bestehender Diskriminierungen, das überkommene Familienstellen-System blieb jedoch auch hier erhalten ${ }^{89}$, entsprach dieses doch durchaus den josephinischen Vorstellungen einer Erziehung der Untertanen, zwar nach den Prinzipien der Aufklärung, doch mit den Mitteln des Überwachens und Strafens, oder, zeitgenössisch gesprochen: der "Evidenzhaltung « und Kontrolle. ${ }^{90}$ Zahlreiche Petitionen und Beschwerden zielten vergeblich auf Änderung.

Wie außerordentlich streng das Familienstellen-System exekutiert wurde, belegt ein Gnadengesuch des mährischen Beamten Josef Richter, der darum bat, ihm eine durch das mährisch-schlesische Landesgubernium wegen in der Judengemeinde Lomnitz/Lomnice vorgefundenen »überzähligen Judenfamilien« verhängten Geldstrafe von ıoo Dukaten »allergnädigst nachzusehen«. Der Beamte führte zu seiner Entschuldigung an, dass er erst im März 1785 seinen Dienst zu Lomnitz angetreten habe und bisher verhindert gewesen sei, "die von seinem Vorgänger übernommenen 5I Familien gehörig nachzuzählen«. Bei der Einvernahme habe die betroffene Judengemeinde zu ihrer Entschuldigung angeführt, dass "aus Brotmangel und um ihr Leben zu erhalten« viele Lomnitzer Familien nach Ungarn und Polen gegangen,

86 Vgl. Stefi Jersch-Wenzel: Grundlagen der Judenemanzipation bis 1848 im östlichen Mitteleuropa: Politische Rechte, soziale Stellung und religiöse Strömungen, in: Jörg K. Hoensch et al. (Hg.) : Judenemanzipation, Antisemitismus, Verfolgung in Deutschland, Österreich-Ungarn, den Böhmischen Ländern und in der Slowakei (Tübingen 1999), S. 91-101, hier: S. 93.

87 AVA Inneres, Hofkanzlei IV T 8, Böhmen, Nr. 137 aus 1782.

88 Kaiserliche Resolution vom 15.2.1782, ebenda.

89 Text des Toleranzpatentes für die Juden Mährens vom 13. Februar 1782 in: Iggers, Juden in Böhmen und Mähren, S. $46 f$.

90 Vgl. dazu: Burger, Paßwesen, in: Grenze und Staat, S. 14. Zu den Transformationen des Josephinismus siehe auch: Franz Leander Fillafer: Das Josephinische Trauma und die österreichische Aufklärung, in: Andras F. Bálogh/Helga Mitterbauer (Hg.): Zentraleuropa - ein hybrider kultureller Kommunikationsraum (Wien 2006), S. 63-85. 
wovon allerdings einige, so der verantwortliche Beamte, wieder nach Mähren zurückgekommen seien, "welches die Überzähligkeit verursacht« habe. Der von der Hofkanzlei in Wien um ein Gutachten gebetene mährische Statthalter, Graf Ugarte, vertrat allerdings die Ansicht, dass der Bittsteller mit seinem Strafnachsichtsgesuche abzuweisen sei, da »die Bestrafung zur verfänglichen Warnung und Erziehung anderer Beamter und Gemeinden nötig sei«. Die Hofkanzlei ihrerseits schlug dem Kaiser vor, dem Beamten die Geldstrafe nachzusehen, dafür allerdings die jüdische Gemeinde Lomnitz umso mehr zu belangen, als diese vorsätzlich die Überzähligkeit verursacht habe. Bezüglich der Höhe der vorgesehenen Strafe empfahl die Hofkanzlei, statt ursprünglich roo nur 25 Dukaten zu verhängen, der Gemeinde aber deutlich zu machen, dass "keinem zweitgeborenen Sohn daselbst das Heiraten gestattet werden dürfe, bis sich die überzähligen Familien vermindert« hätten. Der Kaiser schloss sich dieser Auffassung an, forderte aber ausdrücklich dazu auf, dem Beamten des Lomnitzer Wirtschaftsamtes einen Verweis zu erteilen. ${ }^{91}$

Da die Zahl der Juden in Mähren trotz des restriktiven Überwachungssystems weiter wuchs und die Meldungen wegen »Überzähligkeit« an die Hofkanzlei kein Ende nahmen, entschloss sich Joseph II. im Jahr 1787, das mährische Judensystem teilweise zu reformieren. ${ }^{92}$ Mit seinem Patent vom 17. November 1787 ordnete er an, »die Anzahl der in dem Markgraftum Mähren unter dem Schutze der Landesregierung wohnenden Judenfamilien zu vermehren, und zum Besten derselben die bisher errichtete Familientaxe herabzusetzen«. Zugleich sollte "zur sicheren und leichteren Erhebung der übrigen Steuern« eine Abgabe auf Esswaren (Verzehrsteuer) eingeführt werden. Die Anzahl der Judenfamilien (bisher 5 I06) sollte sich auf 5400 erhöhen. Dem Gubernium kam die Aufgabe zu, die zusätzlichen Familienstellen unter den jüdischen Gemeinden verhältnismäßig aufzuteilen und für jede Gemeinde die Zahl der Judenfamilien genau festzusetzen. Die Gemeinden ihrerseits hatten darüber zu wachen, dass kein Jude eine Familienstelle bekam, der nicht alle zur Erlangung der Ehebewilligung vorgeschriebenen Bedingungen erfüllte und darüber hinaus bewiesen hatte, dass er das zur Erhaltung einer Familie nötige Vermögen besitze. ${ }^{93}$

Doch auch nach dieser Reform des mährischen Judensystems gelang es nachgeborenen Söhnen nur ausnahmsweise, eine der begehrten Familienstellen zu erwerben.

91 AVA Inneres, Hofkanzlei IV T 8, Mähren-Schlesien, Nov. 1787, ohne Zahl (Brandakt).

92 Zu den mährischen Juden vgl. Zdenka Stoklásková: Fremdsein in Böhmen und Mähren, in: Heindl/ Saurer (Hg.): Grenze und Staat, S. 665ff, sowie auch: Hannelore Burger: Juden zwischen Wien und Brünn, in: Lukáš Fasora et al. (Hg.): Brünn - Wien, Wien - Brünn. Landesmetropolen und Zentrum des Reiches im 19. Jahrhundert (Brünn 2008), S. 243-252.

93 Verneuertes Patent wegen Beschränkung der jüdischen Heiraten vom 18. September 1752. Kundgemacht mit Patent vom 17. November 1787, AVA Inneres, Hofkanzlei IV T 8, Mähren-Schlesien, ohne Zahl (Brandakt). 
Noch immer mussten viele Zweit- und Drittgeborene ihre mährische Heimat für immer verlassen. Häufig übersiedelten diese jüngeren Söhne in die nur wenige Kilometer entfernten oberungarischen (heute Slowakei) Judengemeinden, wo sie sich frei niederlassen, heiraten und eine Familie gründen konnten. ${ }^{94}$ Positiv wurden Gesuche um eine erledigte Familienstelle nur dann entschieden, wenn es, wie im Fall des Abraham Brand (sein älterer Bruder Jakob Brand hatte schon vor vielen Jahren nach Ungarn geheiratet und mittels eines Revers verkündet, nicht mehr in seine Heimat Mähren zurückkehren zu wollen), erstens keinen erstgeborenen Bewerber gab und zweitens der Gemeinde schon aus steuerlichen Gründen daran gelegen sein musste, eine erledigte Familienstelle mit einem möglichst vermögenden Bewerber nachzubesetzen. ${ }^{95}$

Trotz all dieser restriktiven Bestimmungen aber hatte der Inhaber einer böhmischen oder mährischen Familienstelle einen entscheidenden Vorteil : Er besaß das politische Domizil, das Heimatrecht, in seiner Gemeinde und war damit zweifelsohne Staatsbürger. Sein Status war damit grundsätzlich ein besserer als etwa der eines "hofbefreiten Juden« in Wien, dessen Aufenthaltstitel ausschließlich an sein Vermögen gebunden war. Folgerichtig bewarben sich viele der vermeintlich privilegierten Hofbefreiten, deren Aufenthalt nach dem Verlust ihres Vermögens prekär geworden war, um eine Familienstelle. So bat im Mai 1792 der Hofbefreite Bernhard Frankl in einem Majestätsgesuch, "gegen weitere Entrichtung der Inkolatssteuer sowie auch eines Beitrags zur jüdischen Contributions Cassa« so lange geduldet zu werden, bis er eine Familienstelle »ohne Nachteil eines anderen« erhalten könne. Betreffend eines Vermögensausweises erklärt er, dass er - sollte sein bisheriger Broterwerb, »die Salzund Militärverpflegslieferungen« aufhören - »die Jahrmärkte mit inländischen Fabrikaten« befahren wolle. Das Gubernium allerdings sprach sich gegen den weiteren Verbleib Bernhard Frankls aus, da es ihm, wie es in einem Gutachten heißt, "zwar gestattet worden sei, dass er als solcher hier belassen werden möge«, jedoch sei dem Kreisamt befohlen worden, darauf zu achten, dass "sobald er keine wirklichen Geschäfte mehr besorget, er auch sogleich von hier abgeschafft werde«. ${ }^{96} \mathrm{Al}$ s »fremdem Juden« drohte Bernhard Frankl (und seiner Familie) trotz seiner früheren Hofbefreiung, seines bereits 22-jährigen Aufenthalts in Mähren und seiner Verdienste als ehemaliger kaiserlicher Armeelieferant die Ausweisung.

Dass ein zweit- oder drittgeborener Sohn in den Genuss einer Familienstelle kam, kam selten, aber doch, vor. In einem Majestätsgesuch vom 27. April I795 bat der aus der mährischen Judengemeinde Triesch/Třešt stammende Großhändler Aron Weinberger "um Verleihung der durch den Tod seines Vaters erledigten

94 Ausführlicher dazu: Stoklásková, Fremdsein, S. 667.

95 AVA Inneres, Hofkanzlei IV T 8, Mähren-Schlesien, aus März 1792, ohne Zahl. 96 Ebenda, aus Juni 1792, ohne Zahl. 
Familienstelle und (als drittgeborener Sohn) um Nachsicht der vorschriftsmäßigen Eigenschaft«. Das um Stellungnahme gebetene Kreisamt in Iglau/Jíhlava berichtete, dass die Familienstelle seines Vaters bereits vergeben, aber eine andere noch frei sei, um welche sich allerdings schon vier Erstgeborene beworben hätten. Die Triescher Judengemeinde, in der es bereits dreizehn überzählige Familien gab, hatte sich gleichwohl für den Bittsteller erklärt, weil dieser »nebst seinen übrigen guten Eigenschaften« ein eigenes Haus und ein Vermögen von 2000 Gulden besitze. Aus der Erwägung, dass die Gemeinde »sehr im Vermögen herabgekommen« sei und viele verarmte Familien zu versorgen habe, trat das Kreisamt dafür ein, »dass dem Weinberger ... die Drittgeburt nachgesehen « und demselben gestattet werde, »bei künftiger Erledigung einer Familienstelle« sich um diese zu bewerben. ${ }^{97}$

Im seltenen Fall, dass sich ausländische Juden um eine mährische Familienstelle bewarben, war man besonders vorsichtig. Als der aus Philadelphia stammende, in einer Olmützer/Olomouc Handelsgesellschaft tätige Löwy Lyons (im Akt auch Lions) in einem Majestätsgesuch um eine Familienstelle bat, befand das zuständige Kreisamt, dass man in der Sache "zwar vollkommen einverstanden" sei, da die gesetzlichen Bestimmungen jedoch ausdrücklich vorsähen, »dass fremde Juden [...] ein

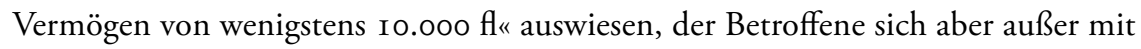
Wechselbriefen nur mit einem Schuldschein seines in Philadelphia zurückgelassen Bruders ausgewiesen habe, rate man dazu, abzuwarten, bis der Bittsteller eine mit seinem Vermögen in Verhältnis stehende Abgabe an den jüdischen Landesfonds und einen angemessenen Beitrag an die Gemeinde entrichtet habe. ${ }^{98}$

Nicht in jedem Fall allerdings waren es Wohlhabende, die das Aufenthaltsrecht in einer Gemeinde erwarben. Die für den religiösen Dienst in den mährischen Judengemeinden sowie auch die für den Schulunterricht jüdischer Kinder notwendigen Personen erhielten unabhängig von jedem Vermögen das Aufenthaltsrecht in ihrer Gemeinde. So bittet etwa die Proßnitzer/Prostějov Judengemeinde in einem Hofgesuch vom März I793, den Juden Ascher Singer als Normallehrer, Schulsinger und Gemeindeschreiber aufnehmen zu dürfen, was ihr umgehend gestattet wird.99

Bei aller Mühsal, die das Familiantenwesen für die betroffenen jüdischen Familien bedeutete, ist doch festzuhalten, dass der staatsbürgerliche Status der Juden in

97 Mit kaiserlichem Dekret vom 16. Mai 1795 wurde Aron Weinberger der gewünschte Dispens "aus Gnade« erteilt. Dem Bittsteller sei die erste »in Erledigung gehende Familienstelle zu Triesch« zu verleihen. Bis dahin sei er »mit seinem Heiratsgesuch zur Geduld« zu verweisen. AVA Inneres, Hofkanzlei IV T 8, Mähren-Schlesien, Nr. 76 aus Mai 1795.

98 Die kaiserliche Entschließung lautete dahingehend, "dass dem Juden Löwi Lions die Zusicherung auf eine in Zukunft erledigt werdende Familienstelle nach beigebrachtem Ausweis über sein Vermögen erteilt werden könne«. Ebenda, Nr. 47 aus Oktober 1792.

99 Ebenda, Nr. 134 aus März 1793. 
Mähren ein wesentlich besserer war als etwa jener der Juden in der Reichshaupt- und Residenzstadt Wien. Dies verdeutlicht eine Debatte innerhalb der Hofkanzlei, die sich anlässlich eines Toleranzgesuchs des Kupferstechers Jacob Wertheimer im Jahr I 807 entzündete. In dieser wurde ein Vorschlag der Polizeidirektion Niederösterreichs, die Zahl der Juden in Wien in ähnlicher Weise zu begrenzen wie in Böhmen und Mähren, mit dem Argument zurückgewiesen, dass die Gewährung der Toleranz in Wien »eine bloße Gnade sei, welche nach Umständen willkürlich widerrufen werden könne«, der Aufenthalt der Tolerierten deshalb »immer nur zeitlich und precär s sei und sie daher "in dieser Hauptstadt nicht einmal als wahre Untertanen anzusehen sind «. ${ }^{100}$ Während also eine Familienstelle auch das politische Domizil, das Heimatrecht, in der betreffenden Gemeinde, d. h. eine soziale Grundsicherung (die Armenversorgung aus der Contributionscassa der betreffenden Judengemeinde) sowie einen Schutz vor Abschiebung bedeutete, schützte der Erhalt der Toleranz in Wien niemanden davor, etwa im Verarmungsfall ausgewiesen zu werden. Endgültig aufgehoben wurde das Familiantenwesen in Böhmen und Mähren erst ein Jahr nach der bürgerlichen Revolution von I 848. ${ }^{101}$

\section{Das Toleranzpatent für die Juden Galiziens}

Ganz anders gestaltete sich die Situation für die über 200000 Juden Galiziens ${ }^{102}$, die nach der ersten Teilung Polens im Jahr 1772 zu habsburgischen Untertanen geworden waren. Die für viele Aufklärer "verstörende Erscheinung« der Masse armer galizischer Juden ${ }^{103}$ führte mit dem am 7 . Mai 1789 kundgemachten Patent zu einem radikalen Entwurf, der in vielen Punkten über die Patente für die niederösterreichischen, böhmischen und mährischen Juden hinauswies. ${ }^{104}$ Juden konnten

100 AVA Inneres, Hofkanzlei IV T 1, 32 aus Juli 1807.

101 Vgl. Eveline Brugger/Martha Keil/Albert Lichtblau (Hg.): Geschichte der Juden in Österreich (Wien 2007), S. 456.

$102 \mathrm{Zu}$ den Gründen für die stark voneinander abweichenden Zahlen der Volkszählungen zwischen 1773 und 1780 im Hinblick auf die Juden siehe: Svjatoslav Pacholkiv: Social Implications of the Incorporation of Galicia into the Habsburg Realm, in: Harald Heppner, Peter Urbanitsch, Renate Zedinger (Hg.): Social Change in the Habsburg Monarchy (Bochum 2011), S. 61-81, hier: S. 62.

103 Siehe dazu: Larry Wolff: Inventing Eastern Europe. The Map of Civilization on the Mind of the Enlightenment (Stanford, Calif. 1994), S. 29.

104 »Patent. Kraft welchen den Juden alle Begünstigungen und Rechte der übrigen Untertanen gewähret sind«, Patent vom 7. Mai 1789. AVA Inneres, Hofkanzlei IV T 1. Klaus Lohrmann macht anhand des galizischen Patents deutlich, dass die Toleranzpolitik einer dynamischen Entwicklung unterlag. Lohrmann, Finanz und Toleranz, S. 65. Zur Geschichte der Juden in Galizien vgl. Heiko 


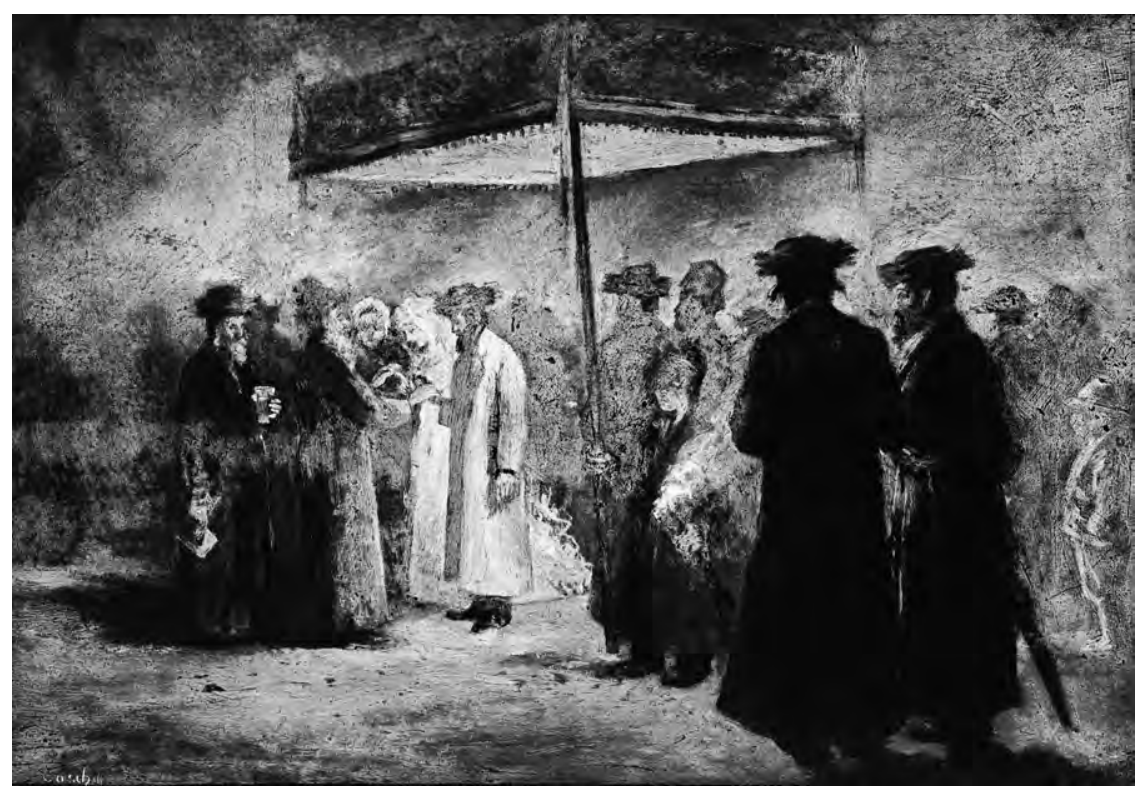

Abb. 2: Jüdische Trauungszeremonie in Galizien, Gemälde von Moritz Coschell;

Quelle: ÖNB/Wien, Bildarchiv

nicht nur zu Vorstehern gemischtkonfessioneller Gemeinden gewählt werden (und wurden dies, wie das Beispiel Brody zeigt, auch) ${ }^{105}$, sondern, etwa als Ärzte, in den Staatsdienst aufgenommen werden. Die am Land sich ansiedelnden Juden sollten ihren Lebensunterhalt durch Landwirtschaft und Handwerk - Bereiche, die ihnen zuvor verschlossen gewesen waren - verdienen können. ${ }^{106}$ Umgekehrt wandten sich zahlreiche Bestimmungen des Patents gegen aus der Halacha, dem jüdischen Religionsgesetz, begründete Traditionen: Heiratsregeln, Kleiderordnungen, Rabbinatsgerichtsbarkeit.

Hatte sich Maria Theresia noch damit begnügt, die Juden Galiziens bloß als ein "fiskalisches Element« zu betrachten und in ihrer Judenordnung vom I6. Juni 1776

Haumann: Geschichte der Ostjuden (München 1999), S. 167ff, siehe auch: Alex Hofmeister: Die Juden in der ukrainischen Geschichte, in: Österreichische Osthefte, 42 (2000), S. 262-271.

105 Börris Kuzmany hat in seiner Dissertation überzeugend dargelegt, dass die Juden in Brody, der wohl jüdischsten Stadt Galiziens, nicht nur das Stadtbürgerrecht erlangen und an der Gemeindeverwaltung paritätisch partizipieren konnten, sondern sogar lange Zeit den Bürgermeister stellten. Vgl. Börris Kuzmany: Brody. Eine galizische Grenzstadt im langen 19. Jahrhundert (Wien/Köln/ Weimar 2011), S. 132ff.

106 Vgl. Wolfgang Häusler: Zur historischen Situation des Ostjudentums, in: Ilona Slawinski/Joseph P. Strelka (Hg.): Die Bukowina. Vergangenheit und Gegenwart (Bern 1995), S. 13-34, hier: S. 22. 
lediglich die bisherige Kopfsteuer durch eine »Toleranzsteuer« ersetzt (wobei der zu zahlende Betrag verdoppelt wurde), die Autorität der autonomen jüdischen Gemeinden, der Kahalim, jedoch unangetastet gelassen ${ }^{107}$, hob ihr Sohn Joseph II. die fiskalischen und politischen Funktionen der 64 galizischen Kahalverwaltungen ausdrücklich auf, ebenso wie die autonome jüdische Gerichtsbarkeit. ${ }^{108}$ Juden hatten sich fortan in allen öffentlichen Angelegenheiten an die Kreisämter bzw. an das galizische Landesgubernium zu wenden. Ebenfalls in die neue Ordnung aufgenommen wurde die Militärpflicht der Juden. Gegenüber einer früher erlassenen Bestimmung wurde Juden nun auch die Möglichkeit gegeben, nicht bloß im Fuhrwesen, sondern auch in der Infanterie zu dienen. ${ }^{109}$

Darüber hinaus führte das josephinische Patent anstelle der aufgehobenen Gewerbe- und Vermögenssteuer einen »Koscherfleischaufschlag" ein. Und statt der früher üblichen Steuer auf die Ehebewilligung wurde angeordnet, dass zur Erlangung des »Eheconsenses" die Vorlage eines Zeugnisses einer israelitischen Normalschule vorzulegen sei. ${ }^{110}$ Die Lehrer dieser von Herz Homberg, dem jüdischen Aufklärer und Schwiegersohn Moses Mendelssohns, begründeten Schulform sollten "zugleich als Übersetzer der Gemeinde« tätig sein und waren »in Eidespflicht zu nehmen«. Die dahinterstehende Absicht war, die überwiegend Jiddisch sprechenden galizischen Juden und Jüdinnen allmählich zu Trägern einer deutschen Bildungsschicht zu formen. ${ }^{111}$ Die deutschsprachigen jüdischen Volksschulen, an denen im Geist der Aufklärung unterrichtet wurde, scheiterten jedoch. Sie wurden I 806 wieder aufgelöst und mit dem allgemeinen Schulwesen vereinigt. ${ }^{112}$ Das von Herz Homberg entwickelte Lehrbuch Bne Zion (Söhne Zions) aber blieb weiterhin für die Erlangung des jüdischen Ehekonsenses verbindlich.

Gegen die Einführung des »neuen Judensystems« in Galizien, welches viele Jahre lang vorbereitet worden war, waren seitens des galizischen Landesguberniums zahlreiche Vorbehalte geäußert worden. Eine I785 unter dem Vorsitz des Grafen Gallenberg eingesetzte Kommission hatte 257 galizische Judengemeinden sowie den Oberlandesrabbiner individualiter protocollando einvernommen. Das Guber-

107 Vgl. Pacholkiv, Social Implications, S. 78.

108 Mit Patent vom 17. Mai 1785, bestätigt im Toleranzpatent vom 7. Mai 1789. Vgl. Svjatoslav Pacholkiv: Die Politik des aufgeklärten Absolutismus und die Judengemeinden Galiziens, in: Frühneuzeit-Info, 22 (2011), Heft $1+2$, S. 75-89, hier: S. 84.

109 Schmidl, Juden in der k.(u.)k. Armee, S. 37.

110 Vgl. Pacholkiv, Politik des aufgeklärten Absolutismus, S. 85.

111 Vgl. ebenda.

112 Gründe für die mit kaiserlichem Dekret vom 26.6.1806 erfolgte Auflösung waren u. a. "pronapoleonische Sympathien« der Lehrerschaft und zu geringe Unterweisungen in Religion. Vgl. Dirk Sadowski: Haskala und Lebenswelt: Herz Homberg und die jüdischen deutschen Schulen in Galizien 1782-1806 (Göttingen 2010), S. 377. 
nium wendete u. a. ein, "dass die Juden Conscription nach ganz anderen Direktiven eingerichtet werden« müsse, da bei der gewöhnlichen Militärkonskription (vor der insbesondere orthodoxe Juden in Massen flohen) keine Zeit bliebe, "versteckte Handlungen«, wie etwa "clandestine Heiraten«, zu entdecken. Grundsätzlich gab das Gubernium in seinem Bericht vom Juli I 785 zu bedenken, dass manche der angeordneten Maßnahmen zu Problemen führen könnten, »die in der Entfernung gering scheinen, in der Nähe aber groß werden«. Der galizische Statthalter wollte sich nicht dem Vorwurf aussetzen, "aus Furcht geschwiegen [zu haben], da, wo es Zeit und Pflicht war, zu reden und zwar in einer Sache, deren gründliche Kenntnis man um so mehr von uns fordern kann, als sie ganz lokal ist, und nach keinem fremden Maßstab beurteilt werden kann «. ${ }^{113}$ Joseph II. jedoch befand die Betrachtungen des Guberniums als »nicht von Wichtigkeit«. Ungemein wichtiger war, nach Meinung des Kaisers: „die Juden allen übrigen Landeseinwohnern so viel immer möglich gleich zu halten «. Die Konskriptionsbücher seien deshalb »auf nämliche Art für die Juden wie für die Christen zu führen«. Im Übrigen habe sich die Landesstelle "genauestens an die Weisungen zu halten «. ${ }^{114}$ Trotz vieler Einwände und Vorschläge des Guberniums, die der Diversität des galizischen Judentums (ein Nebeneinander von orthodoxem Rabbinertum, Chassidismus und Maskilim) gerecht zu werden versuchten, wurde der ursprüngliche Patententwurf nur marginal verändert. ${ }^{115}$ Seinen letzten Schliff erhielt er im Mai I789, als der Kaiser befahl, ihn »im Stil vom Hofrat v. Sonnenfels berichtigen « zu lassen. ${ }^{116}$ Jeder Unterschied, heißt es dann in der Präambel zur Kundmachung des Patentes vom 7. Mai I789, „den die Gesetzgebung bisher zwischen christlichen und jüdischen Unterthanen beobachtet hat", sei aufzuheben, »und den in Galizien wohnenden Juden alle Begünstigungen und Rechte zu gewähren, deren sich unsere übrigen Unterthanen zu erfreuen haben «. ${ }^{117}$

Die Wirksamkeit des josephinischen Toleranzpatents war überaus ambivalent. Führte es auf der einen Seite zu einer rechtlichen und staatsbürgerlichen Gleichstellung und zur Anhebung des Bildungsstandes der mehrheitlich armen jüdischen Bevölkerung Galiziens, so griff es auf der anderen Seite in vielfach grober und unsensibler Weise in das seit der Zeit der polnischen Könige autonome jüdische Ge-

113 Bericht des Galizischen Landesguberniums »über dasjenige, was wegen der Einführung des neuen Juden-Systems veranlasset worden« vom 11. Juli 1785. AVA Inneres, Hofkanzlei IV T 1, Nr. 131 aus August 1785.

114 A.h. Resolution, ebenda.

115 Unter anderem kam es zur Umwandlung von vorgesehenen Geldstrafen in Arrest- bzw. Leibesstrafen, da man wegen der Armut der galizischen Juden "nicht auf Einbringung der Geldbußen hoffen« konnte. AVA Inneres, Hofkanzlei IV T 1, Nr. 270 aus Mai 1789.

116 Resolution zum Vortrag der Hofkanzlei vom 28. März 1789, ebenda.

117 AVA Inneres, Hofkanzlei IV T 1, Patent vom 7. Mai 1789. 
meindeleben ein. Viele der angeordneten Maßnahmen scheiterten, wie es der galizische Statthalter vorausgesehen hatte, am beharrlichen Widerstand vor allem armer galizischer Landjuden. Aus Angst vor Katholisierung weigerten sich viele, ihre Kinder in die neu errichteten "Normalschulen« zu schicken. Vor allem die Buben besuchten weiterhin den Cheder oder die traditionellen Talmud-Thoraschulen. Die Ansiedlung jüdischer Bauern in eigens errichteten jüdischen Kolonien, etwa in Neu-Sandez/Novy Sasz, scheiterte nicht zuletzt, wie Svjatoslav Pacholkiv nachweist, am "stummen Widerstand der Beamten und Gutsherren vor Ort «. ${ }^{118}$ Und »die Aufhebung aller Unterscheidungen hinsichtlich der Kleidung " musste auf Bitten orthodoxer Juden von Kaiser Leopold II. ausdrücklich wieder aufgehoben werden ${ }^{119}$, ebenso wie die allgemeine Militärpflicht, die man durch die Möglichkeit des Loskaufens abmilderte. ${ }^{120}$

\section{Anhaltende »Verschiedenheit des politischen Zustandes»}

Dessen ungeachtet entspann sich noch im Jahr des Erscheinens des galizischen Patentes zwischen den Hofstellen eine lebhafte Diskussion darüber, ob das weitreichende galizische Judensystem auch in anderen Erblanden eingeführt werden solle. Die niederösterreichische Regierung wehrte sich dagegen mit dem Argument, dass seine Anwendung auf Niederösterreich ganz unzweckmäßig sei, da »die meisten Anordnungen des galizischen Patents, so weit sie nämlich auf die Einrichtungen bei den Gemeinden, Bestellung der Obrigkeiten, auf Synagogen und ihren Gottesdienst Bezug haben, in Österreich unter der Enns bei der bestehenden Verfassung nicht anwendbar« seien, weshalb man "auch in Ansehung der übrigen Gegenstände» einstimmig erachte, dass man von einer Kundmachung des galizischen Patents oder auch nur einiger seiner Artikel für Niederösterreich absehen solle. Die Hofkanzlei hob in ihrem Vortrag hervor, dass man die meisten Anordnungen schon deshalb nicht auf die niederösterreichische Situation übertragen könne, weil in Wien bereits "alle Unterscheidungen zwischen den Kleidern ganz aufgehoben, und die Juden bei politischen und Rechtsbehörden mit den Christen in allen Stücken gleichgehalten" seien. Die galizische Judenordnung sei zum einen wegen des "Unterschieds in der Verfassung « nicht anwendbar, zum anderen aber »wegen der hierlandes ohnehin schon bestehenden Vorschriften

118 Svjatoslav Pacholkiv: Das Werden einer Grenze, in: Heindl/Saurer (Hg.): Grenze und Staat, S. 519620, hier: S. 600.

119 A.F. Pŕ́bram (Hg.): Quellen und Forschungen zur Geschichte der Juden in Deutsch-Österreich, Bd. VIII, Urkunden und Akten zur Geschichte der Juden in Wien, Erste Abteilung, Bd. 2 (Wien/ Leipzig 1918), S. 283.

120 Leopold II. erlaubte jüdischen Rekruten den Loskauf vom Militärdienst gegen die Zahlung von 30 Gulden. Vgl. Schmidl, Juden in der k.(u.)k. Armee, S. 41. 
ganz überflüssig «. ${ }^{121}$ Somit blieb es hinsichtlich der Rechtsverhältnisse der Juden in den einzelnen Kronländern bei einer anhaltenden "Verschiedenheit im politischen Zustand «. Diese begründete sich - im zeitgenössischen Urteil josephinisch gesinnter Beamter - allerdings bloß noch aus den "Religionsbegriffen und Volksvorurteilen", die man hoffte, bald zum Verschwinden zu bringen. ${ }^{122}$

Wieder anders lagen die Verhältnisse in den italienischen Städten: Aus der Intention heraus, die Hafenstadt Triest zu einem internationalen Freihandelszentrum zu machen, waren Juden dort umfangreiche wirtschaftliche, religiöse und rechtliche Begünstigungen gewährt worden. Schon 1746 hatte Maria Theresia den Triester Juden erlaubt, eine Gemeinde zu bilden. Statthalter Graf Zinzendorf beförderte nach Kräften die Ansiedlung von Protestanten und Juden in Triest und Görz/Gorizia. Das Privileg Maria Theresias für die Triester Juden von I77 I bildete dann auch eine der Grundlagen für die Toleranzgesetzgebung Josephs II. - mit Ausnahme der Erlaubnis der Gemeindebildung. Von einem Handschreiben des Kaisers vom I3. Mai I78 I, mit dem er die Juden Triests dazu aufforderte, ihre Kleidung den allgemeinen Gepflogenheiten anzupassen, ihre Bildung zu verbessern sowie bürgerliche Berufe zu ergreifen, sahen sich diese fast verhöhnt. All das hatten die Juden Triests nämlich längst schon getan.

\section{Die Vertretung der Tolerierten}

Trotz aller noch immer bestehenden Einschränkungen der bürgerlichen Rechte - vor allem hinsichtlich des Grundbesitzrechts und der Freizügigkeit - und trotz aller lokalen Verschiedenheiten eröffneten die Patente Josephs II. für die Juden nicht nur neue Möglichkeiten gesellschaftlicher Partizipation, sondern ließen erstmals ein Gefühl der Zugehörigkeit aufkommen, eine Möglichkeit, sich, wie Hans Tietze meint, »mit allen Mitbürgern eins zu fühlen«. ${ }^{123}$ Dabei wurde die Judengesetzgebung zunehmend auch international als Barometer für die Reife eines Staates, für Rechtsstaatlichkeit, für gute Gouvernementalität gesehen. ${ }^{124}$ Die gewählten Vertreter der Juden traten dann auch, sich auf die Patente berufend, zunehmend selbstbewusster für ihre Rechte ein

121 AVA Inneres, Hofkanzlei IV T 1, Nr. 226 aus Dezember 1789.

122 Barth-Barthenheim: Gesetzeskunde Bd. 1, S. 30. Siehe dazu auch: Albert Lichtblau: Als hätten wir dazugehört. Österreichisch-jüdische Lebensgeschichten aus der Habsburgermonarchie (Wien/ Köln/Weimar 1999), S. 32.

123 Tietze, Juden Wiens, S. 130.

124 Wolf, Juden in Wien, S. 98. Der französische Soziologe Pierre Birnbaum bezeichnet den Zugang zur Staatsbürgerschaft als "the central hallmark of legal emanicipation«. Pierre Birnbaum/Ira Katznelson: Emancipation and the Liberal Offer, in: dieselben ( $\mathrm{Hg}$.): Paths of Emancipation. Jews, States, and Citizenship (Princeton, New Jersey 1995), S. 3-36, hier: S. 4. 
(insbesondere nachdem diese nach dem Tod Josephs II. wieder empfindlich eingeschränkt wurden). So reagierte Kaiser Leopold II. auf eine "Bittschrift der hiesigen Judenschaft« wegen eines im Druck erschienenen »für selbe sehr kränkenden Circulars» mit dem Auftrag an den niederösterreichischen Regierungspräsidenten Grafen von Sauer, »sogleich ein anderes für diese Nazion nicht kränkendes Circular» zu entwerfen und dieses noch vor der Kundmachung seinem Sohn, dem Erzherzog Franz, zur Genehmigung vorzulegen. ${ }^{125}$ Das neue Selbstbewusstsein der Juden als Staatsbürger war es auch, das - als es im Jahr I792 zur Wiedereinführung der von Joseph II. abgeschafften Bollettentaxe ${ }^{126} \mathrm{kam}$ - zu einer umfangreichen Beschwerdeschrift der Wiener Tolerierten an die Niederösterreichische Landesregierung führte. Im Sinne des Toleranzpatentes forderten die neu gewählten Vertreter der Wiener Juden unter anderem das Recht zum Ankauf und Besitz von Staatsgütern, das Recht, auf dem Lande zu wohnen und dort Grund zu erwerben, das Recht, ein Gewerbe zu betreiben, die Zulassung zu öffentlichen Ämtern, die Entfernung der diskriminierenden Aufschrift "für Juden, Sesselträger und Fiaker« sowie die Unterlassung der Adressierung "an den Juden N.N. «bei amtlichen Schriftstücken. ${ }^{127}$

\section{Das Judenamt}

Nur die letzten beiden Begehren wurden umgehend erfüllt. Über die übrigen Forderungen und darüber, wie die "Masse der inländischen und fremden Juden « künftig zu behandeln sei, wurde ein Gutachten bei der niederösterreichischen Landesregierung in Auftrag gegeben. Eine seitens der Bittsteller eher ungewollte Konsequenz dieser Petition war der Vorschlag der niederösterreichischen Regierung, "wegen der zunehmenden Zahl der Juden und um den Toleranzerlässen künftig mehr Zuverlässigkeit zu geben«, für alle Belange der Judenschaft ein eigenes "Judenamt« zu errichten. ${ }^{128}$ Kaiser Franz II. stimmte im Staatsrat zunächst nur zögernd zu: »Mit dem von der Regierung und der Kanzlei eingerathenen Judenamt kann ein Versuch gemacht werden, wovon Mir nach dem Verlauf eines Jahres der Erfolg anzuzeigen, inzwischen aber das dazu erforderliche Personal nur provisorisch anzustellen ist. « ${ }^{129}$ In einer

125 AVA Inneres, Hofkanzlei IV T 1, Nr. 160 aus März 1791.

126 Eine Art Leibmaut, die nichtansässige Juden für ein ein- bis höchstens vierzehntägiges Aufenthaltsrecht in Wien zu zahlen hatten. Vgl. Ludwig Bato: Die Juden im alten Wien (Wien 1928), S. 123.

127 Vgl. Wolf, Juden in Wien, S. 98.

128 AVA Inneres, Hofkanzlei IV T 1, Nr. 254 aus Juli 1792.

129 HHStA, Protokolle des Staatsrats 1792, Nr. 3268. Nach einem Probelauf von einem Jahr war der "Erfolg" dem Kaiser anzuzeigen. Das betreffende Circular an sämtliche Hofräte trägt die Unterschrift Joseph von Sonnenfels'. AVA Inneres, Hofkanzlei IV T 1, Nr. 254 aus Juli 1792. 
Abb. 3: Polizeiverordnung vom 25. März I8Io; Quelle: WStLA, Israelitische Kultusgemeinde

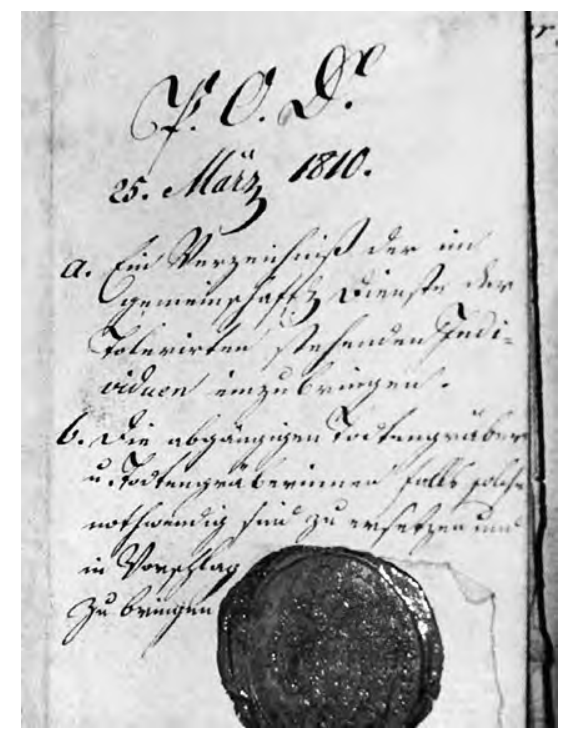

Evaluierung des Judenamtes durch die niederösterreichische Regierung vom November 1793 heißt es, dass das Bestreben der neuen Behörde zunächst dahin gegangen sei, "die sich hier unbefugt aufhaltenden Juden zu erfahren, aufzufinden, und sie unter die öffentliche Aufsicht zu ziehen; dann aber die fremden hier eintretenden Juden zur ordentlichen Meldung und Abnahme der Papierzettel zu bringen «. ${ }^{130}$ Beigefügt war dem Bericht an die Hofkanzlei ein Formular für die sogenannte Bollette (eine Art Abreißzettel), mit der sich fremde Juden, d. h. nicht in Wien ansässige Juden, einen auf vierzehn Tage begrenzten Aufenthalt in der Residenzstadt kaufen konnten - eine Maßnahme, die als besonders entwürdigend empfunden wurde.

$\mathrm{Zu}$ den weiteren Aufgaben des Judenamtes gehörte die Aufsicht über die »Familienlisten«, die seit I 787 von jeder in Wien tolerierten Familie zu führen waren und die fortan bis zum I 5 . Mai jedes Jahres dem Judenamt vorgelegt werden mussten. Darüber hinaus suchte das Judenamt, im Verein mit der niederösterreichischen Polizei, »eingeschlichene Personen « aufzuspüren. Zu diesem Zweck wurden Razzien selbst in den vornehmsten tolerierten Häusern durchgeführt. Jede Familienliste enthielt genaue Angaben über den Tolerierten selbst (Grund der Toleranz, deren Dauer, Adresse, Alter, Herkunft, Beschäftigung), dessen Ehefrau und Kinder, im

130 Vortrag des Directorii in Cameralibus Publico Politici, wegen Errichtung einer Judenkommission vom 28. November 1793; anwesend: Oberster Directorialminister Graf v. Kollowrath, Hofkanzler Graf v. Rottenhan, Hofräte: Greiner, Colloredo, v. Strobl (der spätere Referent im Judenamt). Für die niederösterreichische Regierung: Graf v. Pergen. AVA Inneres, Hofkanzlei IV T 1, Nr. 267 aus November 1793. 
Hause wohnende Dienstboten und Dienstbotinnen: Kutscher, Köchinnen, Kindermädchen, Lehrer. Das Judenamt überprüfte und protokollierte die Angaben und reklamierte gegebenenfalls einzelne Personen aus den Listen heraus, wie im Fall des Wiener Tolerierten Elias Drach, der seine Toleranz im Jahre I 783 ursprünglich auf eine Großhandelskonzession erhalten hatte, im Jahr i 800 allerdings nur mehr "als Inhaber des Indignats auf das Frauenbad " (ein kultisches Amt) aufscheint, toleriert auf jeweils zwei Jahre, gegen eine jährlich zu entrichtende Toleranzsteuer von 60 Gulden. Im Jahr 1799 beanstandete die Polizeioberdirektion, dass neben seiner Gattin, seiner verwitweten Mutter, seinen fünf Kindern sowie einer Köchin und einer Kindsmagd auch ein Individuum namens Karl Pressburger »ohne Bestimmung der Diensteigenschaft « in der Liste geführt werde. Elias Drach replizierte, dass Karl Pressburger schon bei seinem verstorbenen Herrn Vater in Dienst gestanden sei und er nach dem Tode desselben den verwitweten Mann, dessen Kinder in Ungarn lebten, zu sich genommen habe. ${ }^{131}$

Der 27-jährige Baumwollhändler Emanuel Engel, dessen verstorbener Vater Maximilian seit $\mathrm{I78}$ I auf unbestimmte Zeit toleriert worden war, musste im Jahr I 803 die Anwesenheit seiner verwitweten siebzigjährigen Mutter, Mariana Engel, in seinem Haushalt am Bauernmarkt rechtfertigen. Es seien zwar seit ihrer zuletzt erhaltenen Toleranz bereits drei Jahre verstrichen, doch habe sie auf die Ausfertigung des ihr in Aussicht gestellten neuen Dekrets bereits vor geraumer Zeit ein Schutzgeld bezahlt. Ihren Unterhalt bestreite sie aus dem geringen Nachlass ihres verstorbenen Gatten sowie aus einem kleinen Papierhandel. ${ }^{132}$ Und der fünfzigjährige, aus Kittsee stammende Großhändler Isac Figdor, der seit I 8 I 8 in Wien toleriert war, wandte sich im Mai I 8 I9 mit einer Petition an die niederösterreichische Landesregierung, in welcher er um die "gnädige Bewilligung« bat, seinen ältesten Sohn samt Frau und zwei kleinen Kindern in seiner Familienliste anführen zu dürfen. Er begründete sein Ansuchen damit, dass er selbst viel reise, "um den Einkauf der Wolle zu besorgen", sodass er einen Gehilfen notwendig habe, auf den er sich verlassen und dem er sein Geschäft anvertrauen könne. Nicht minder notwendig sei es, »seine Schwiegertochter hier behalten zu dürfen, da seine Frau wegen ihrer geschwächten Gesundheit und Alter deren Hilfe nicht entbehren« könne. Isac Figdor hoffte, dieser Gnade nicht unwürdig zu sein, da seine Familienliste sonst "ganz rein von fremden Subjecten « sei. ${ }^{133}$

Eine weitere Möglichkeit, in Wien einen zeitlichen, auf die Dauer des kultischen Amtes begrenzten Aufenthalt zu erlangen, war der sogenannte "gemeinschaftliche

131 Archiv der Israelitischen Kultusgemeinde Wien, K1, Elias Drach, 1787-1810, hier: 1799.

132 Ebenda, Maximilian Engel, 1787-1847, hier: 1803.

133 Ebenda, Isac Figdor, 1819-1847, hier: 1819. Im Jahr 1847 umfasste die Familienliste des k. k. priv. Großhändlers Isac Figdor 22 Personen. 


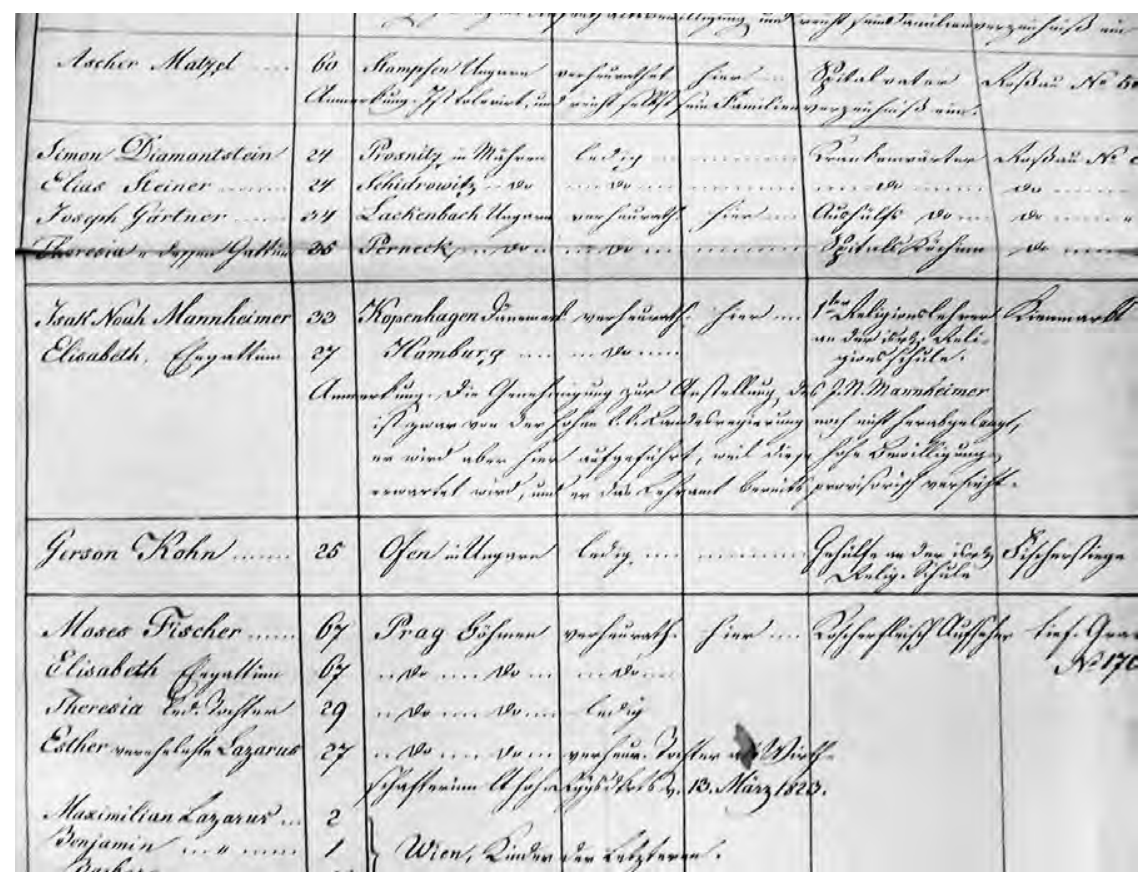

Abb. 4: Verzeichnis der in Gemeinschaftlichen Diensten der hiesigen Wiener Tolerierten stehenden Individuen (I828); Quelle: WStLA, Israelitische Kultusgemeinde

Dienst«. Auch über diese Personengruppe mussten, nach einer Verordnung vom 25. März I 8 Io, genaueste Verzeichnisse geführt werden. ${ }^{134}$ Zum Personenkreis der im gemeinschaftlichen Dienst der Wiener tolerierten Juden Stehenden gehörten ein Aktuar (Schreiber), der Vorsteher des jüdischen Spitals (Spitalsvater), ein Spitalsarzt und ein Wundarzt (Chirurg), zwei Krankenwärter, eine Spitalsköchin sowie für den religiösen Dienst: ein Ansager, ein Vorbeter, ein Religionslehrer, ein Gehilfe an der Religionsschule, ferner der Aufseher des Frauenbades, ein Koscherfleischaufseher, drei Schächter, acht Totengräber und ebenso viele Totenwäscherinnen. ${ }^{135}$ Einige der im "gemeinschaftlichen Dienst « Stehenden, vor allem Ärzte wie Zacharias Wertheim, „Spitalsphysicus« im Jahr I 826, waren unabhängig von ihrem Dienst Inhaber einer Toleranz, alle anderen wurden nur für die Dauer ihres Amtes geduldet. ${ }^{136}$

134 Anlass für die Verordnung war die Nachbesetzung der notwendigen Totengräber und Totenwäscherinnen. Verordnung der Polizeioberdirektion v. 25. März 1810. Archiv der Israelitischen Kultusgemeinde Wien, K1, 1810.

135 Verzeichnisse der in Gemeinschaftlichen Diensten der hiesigen Tolerierten stehenden Individuen, 1810-1847. Archiv der Israelitischen Kultusgemeinde Wien, K1.

136 In den Verzeichnissen der in Gemeinschaftlichen Diensten der Wiener Tolerierten Stehenden finden 
In einigen Fällen gelang es Juden, deren Toleranz aus ökonomischen Gründen nicht mehr verlängert worden war, durch die Antretung eines Amtes im gemeinschaftlichen Dienst ihren Aufenthalt in Wien zu sichern (so im Fall des Elias Drach). Doch im Allgemeinen sorgte das Judenamt dafür, dass verarmte Juden rigoros abgeschoben wurden. Die noch bis ins Jahr I795 möglich gewesenen Toleranzen auf Lebenszeit hörten ganz auf. Toleranzen wurden fortan nur mehr auf maximal drei Jahre vergeben. In manchen Fällen hob das Judenamt bestehende Toleranzen eigenhändig auf. ${ }^{137}$ Die Vertreter der Wiener Juden protestierten wiederholt, doch vergeblich, gegen Willkür und die Verschlechterung ihrer Aufenthaltsbedingungen. In einer Petition vom November 1796 forderten sie erstens: die Aufhebung der Gebühr für die Aufenthaltsbollette von 30 Kreuzer, zweitens: die Zusicherung, »keine Verordnung in Judensachen" ohne Hinzuziehung der Vertreter der Judenschaft kundzumachen, drittens: dass »die tauglichen Religionsgenossen zu allen öffentlichen Bedienstungen ohne Rücksicht auf die Religion angestellt werden«, viertens : „dass ihnen gestattet werde, gleich den Christen alle Gattungen Realitäten an sich zu bringen « und fünftens: „die jüdischen Doktoren der Medizin und der Rechte, welche auf irgendeiner inländischen Universität graduiert sind, in die bestehenden Witwensozietäten «138 aufzunehmen. In der Stellungnahme der Hofkanzlei heißt es zu Punkt eins, dass, $\mathrm{da}$ »die Verfassung Österreichs neben jenen, die hier geduldet werden, nun einmal nicht geeignet sei, weitere Juden aufzunehmen«, es "ganz billig sei, dass die auf kurze Zeit hierher kommenden Juden eine verhältnismäßige Zahlung leisten«. Zu Punkt drei der Bittschrift gibt der Referent (Hofrat von Greiner) zu bedenken, »dass gar kein Gesetz bestehe, welches die Juden von öffentlichen Ämtern ausschließe«, es daher ganz überflüssig sei, eine schriftliche Versicherung zu geben. Zwar sei nicht zu leugnen, so Greiner, dass ihre Jugend »in allen wissenschaftlichen Fächern gründliche Kenntnis sich zu erwerben befleißigt ist«, jedoch könne man die Meinung nicht

sich so prominente Namen wie der damals 33-jährige spätere Wiener Oberrabbiner Isaak Noah Mannheimer (im Akt auch: Isak Noa), der im Jahr 1826, zusammen mit seiner aus Hamburg stammenden Ehefrau Elisabeth, aus Kopenhagen nach Wien kam, um hier zunächst provisorisch als erster Religionslehrer seinen Dienst zu versehen. (Im Verzeichnis des Jahres 1826 findet sich die Anmerkung, dass zwar "die Genehmigung zur Anstellung des I.M. Mannheimer von der hohen Landesregierung noch nicht herabgelangt« sei, doch »er das Lehramt bereits provisorisch versieht«.) Ebenso findet man den aus Hohenems kommenden Kantor Salomon Sulzer, der mit Hofdekret vom 22. Juli 1827 als erster Vorbeter bestellt wurde. Verzeichnisse derer in Gemeinschaftlichen Diensten der hiesigen Tolerierten stehenden, 1826 und 1833. Archiv der Israelitischen Kultusgemeinde Wien, K1. Die Bitte der Vertreter der Wiener Judenschaft an das Judenamt, eine Aufenthaltsbollette für den "Vorzeiger" Sulzer gratis auszufolgen, findet sich abgedruckt in der Dokumentation: Hanoch Avenary et al. (Hg.) : Kantor Salomon Sulzer und seine Zeit (Sigmaringen 1985), S. IV-VI.

137 Vgl. Max Grunwald, History of the Jews in Vienna (Philadelphia 1936), S. 137.

138 Eine Art Pensionskassa für die Hinterbliebenen. 
teilen, dass sie »folglich in größerer Menge angestellt« werden müsse, da erstens die Juden »ihrer Religionsbräuche wegen zu vielen Ämtern gar nicht anwendbar« seien, und zweitens durch solche Anstellungen »die Nachkömmlinge wieder geduldet werden « müssten (gemeint ist die daraus resultierende Erhöhung der Gesamtzahl der Tolerierten), was unausweichlich zur »Überschwemmung des hiesigen Platzes« führen müsse. ${ }^{139}$

\section{Die Hofkanzlei als Hüterin der Toleranz}

Über die bis zum Revolutionsjahr I 848 bestehende Institution des Judenamtes urteilt etwa der jüdische Historiker Gershon Wolf, dass diese Institution keinen anderen Zweck gehabt habe, "als die Juden zu erniedrigen und zu demütigen und die Beamten daselbst zu bereichern «. ${ }^{140}$ Der Begriff der Toleranz wurde dabei vollkommen pervertiert. ${ }^{141}$ Hatte sich dieser in der Epoche Josephs II. von seinen ehemals negativen Konnotationen gelöst und meinte schlicht Duldung ${ }^{142}$, so wurde er zunehmend zu einem Synonym für »Beamtenwillkür und Gehässigkeit«. ${ }^{143}$ Umgekehrt gab es in der Hofkanzlei, wo der josephinische Geist nach wie vor lebendig war - oft gegen das Judenamt, die Polizeidirektion und die niederösterreichische Statthalterei -, ein Bemühen, die Rechte der Juden zu wahren und das ursprüngliche Ziel einer Annäherung der Juden an die übrige Bevölkerung und ihrer Erziehung zu "nützlichen Staatsbürgern « auf gesetzlichem Wege umzusetzen. ${ }^{144}$ Dabei wird die Hofkanzlei zur Hüterin der Toleranzpatente. Wenn in zahlreichen Berichten der niederösterreichischen Regierung immer wieder auf die "schädliche Vermehrung der Juden pflichtgemäß aufmerksam « gemacht, vor deren »Geschmeidigkeit«, »Arglist»,

139 Franz II. erteilte am 17. November 1796 das Placet. AVA Inneres, Hofkanzlei IVT 1, aus November 1796.

140 Wolf, Geschichte der Juden, S. 101.

141 Zur Genesis des Begriffs »Toleranz« vgl. Frank Surall: Juden und Christen - Toleranz in neuer Perspektive. Der Denkweg Franz Rosenzweigs in seinen Bezügen zu Lessing, Harnack, Baeck und Rosenstock-Huessy (Gütersloh 2003), S. 14ff.

142 Vgl. Peter F. Barton: Der lange Weg zur Toleranz, in: Peter F. Barton (Hg.), Im Lichte der Toleranz. Aufsätze zur Toleranzgesetzgebung des 18. Jahrhunderts in den Reichen Joseph II., ihren Voraussetzungen und ihren Folgen. Eine Festschrift (Wien 1981), S. 11-32.

143 Wolfgang Gasser: Neues aus der »Stadt der Toleranz«. Tolerierte und getaufte Juden, Da Ponte und Mozart, in: Werner Hanak (Hg.) : Lorenzo da Ponte. Aufbruch in die Neue Welt. Katalog zur gleichnamigen Ausstellung (Ostfildern 2006), S. 63-80, hier: S. 79. Siehe dazu derselbe: Jüdische DienstbotInnen in Wien - von den napoleonischen Kriegen, dem Biedermeier bis zur 1848-Revolution (Wien 2001).

144 Tietze, Juden Wiens, S. 134. Zum Erziehungsparadigma vgl. auch: Simone Lässig: Jüdische Wege ins Bürgertum (Göttingen 2004), S. 68f. 
»unersättlicher Gewinnsucht « gewarnt und die oberste Behörde dazu auffordert wird, »dieser Gattung Leute, die wegen ihrer prekären Existenz in dieser Hauptstadt nicht einmal als wahre Untertanen anzusehen sind, dennoch aber auf gleichen Schutz und eben dieselben Rechte Anspruch machen, die nötigen Schranken« zu setzen, repliziert die Hofkanzlei trocken, "dass I 3 I Familien, die, wenn man ro Personen auf eine durchschnittliche rechnet, zwischen 1300 und I 400 Seelen ausmachen, für die Central- und Hauptstadt der Monarchie und für eine christliche Popularität von beinahe 300 ooo Seelen, noch keine besondere der Aufmerksamkeit würdige Zahl sei«. ${ }^{145}$ Dennoch weist auch die Hofkanzlei immer wieder darauf hin, dass »die hiesige Toleranz der Juden eine bloße Gnadensache« und "die Gestattung ihres Aufenthaltes immer nur zeitlich und prekär« sei. ${ }^{146}$ Dass dieser prekäre Status auch für die wohlhabendsten Familien galt, belegt die Geschichte des Hauses Rothschild, deren Angehörige trotz ihrer Funktionen als Bankiers des Hauses Habsburg, als Diplomaten und Vermittler, Bauherren, Schiffseigner (Österreichische Lloyd) und Finanziers wichtiger Eisenbahnprojekte die längste Zeit als Fremde in Wien leben mussten. So residierte Salomon Rothschild, der Begründer des österreichischen Hauses Rothschild, Vertrauter Metternichs (und Vermittler im delikaten diplomatischen Geschäft der Eheanbahnung zwischen Napoleon und Erzherzogin Marie Louise) bei seinen Aufenthalten in Wien als Gast im Hotel "Zum Römischen Kaiser«. Selbst der Ankauf eines entlegenen Rittergutes in Mähren scheiterte zunächst am Widerstand des mährischen Adels. Erst I 843 erhielt er die kaiserliche Genehmigung, vererbbaren ländlichen Grundbesitz in Mähren und Schlesien zu erwerben. ${ }^{147}$

Ganz besonders prekär war der Status der Hinterbliebenen eines verstorbenen Tolerierten, deren Behandlung und fallweise Abschiebung zu zahllosen Beschwerden führte. Als die Hofkanzlei im Jahr I 807 noch einmal die Grundsätze über die Behandlung der Angehörigen verstorbener Tolerierter in Wien kundmachte und dabei zwar empfahl, "gegen die hinterlassenen Witwen und Kinder nicht mit zu großer Strenge« zu verfahren, aber dennoch darauf beharrte, "dass die hiesige Toleranz eine bloße Gnadensache sei, worauf keine jüdische Familie einen Anspruch " habe ${ }^{148}$, blieb vielen Juden und Jüdinnen - wollten sie nicht riskieren, abgeschoben zu werden - nur mehr die Taufe.

145 AVA Inneres, Hofkanzlei IV T 1, Nr. 32 aus Juli 1807.

146 Ebenda.

147 Frederic Morton: Die Rothschilds. Porträt einer Dynastie (Wien/München 2004), S. 89, 93 u. 95.

148 AVA Inneres, Hofkanzlei IV T 1, ohne Zahl, aus Mai 1807. 


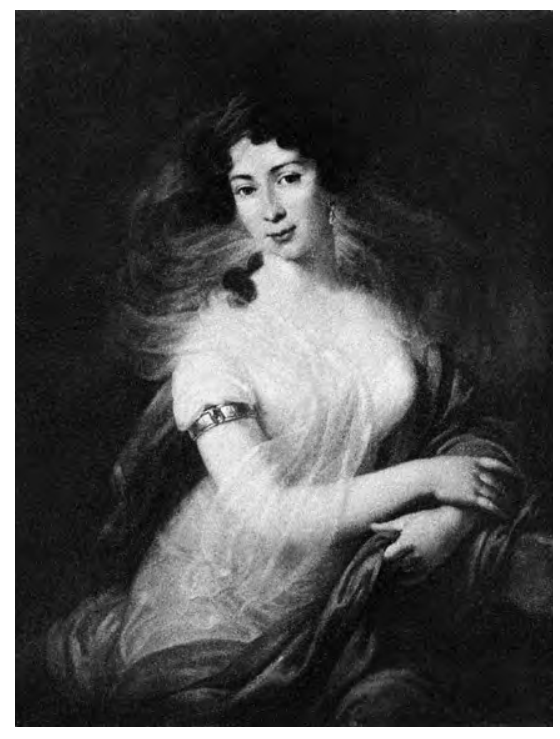

Abb. 5: Franziska (Fanny) Freifrau von Arnstein, geb. Itzig (I758-I8I8);

Quelle: ÖNB/Wien, Bildarchiv

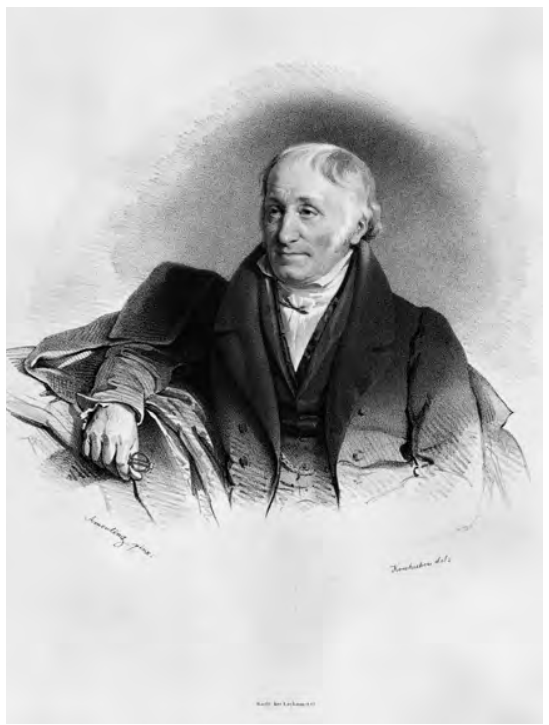

Abb. 6: Bernhard Freiherr von Eskeles (I753-I839); Quelle: ÖNB/Wien, Bildarchiv

\section{Taufen und Nobilitierungen}

Die hohe Zahl von Konversionen bei Juden und Jüdinnen, vor allem zu Beginn des I9. Jahrhunderts ${ }^{149}$, verdankt sich somit nicht so sehr den gesellschaftlichen Transformationsprozessen, etwa der zunehmenden Konfessionalisierung, einer allgemeinen Säkularisierung oder, umgekehrt, einer Retheologisierung (man denke an die romantische Mode des Katholizismus: bekannte Konvertiten waren etwa Friedrich Schlegel und seine jüdische Frau Dorothea, eine Tochter Moses Mendelssohns, die seit I 808 in Wien lebten), sondern vielmehr der prekären staatsbürgerlichen Existenz selbst Angehöriger der reichsten und kultiviertesten jüdischen Häuser. Die Familienlisten, in denen jede Taufe vermerkt und der Getaufte anschließend aus der Liste gestrichen wurde, zeigen gerade für diese Jahre eine empfindliche Ausdünnung. Zwar blieb etwa der führende jüdische Bankier Bernhard von Eskeles, Sohn eines mährischen Rabbiners, selbst dem Judentum treu, doch seine Frau und alle seine Kinder

149 Durchschnittlich betrug er im ersten Jahrzehnt des 19. Jahrhunderts 12 Prozent, im Jahr 1802 sogar 14 Prozent. Vgl. Anna Staudacher: Jüdisch-protestantische Konvertiten in Wien 1782-1914, Teil 1 (Frankfurt/Main et al. 2004), S. 193, Anm. 89. 
traten zum Christentum über. ${ }^{150}$ Zur Ikone des neuen, transkulturellen, hybriden Lebensstils der Wiener Tolerierten aber wurde Fanny von Arnstein (Tochter des Berliner Bankiers Daniel Itzig und Ehefrau Baron Nathan von Arnsteins), die nicht nur einen der glanzvollsten Wiener Salons führte, sondern sogar als Taufpatin eines Kindes aufscheint (eigentlich eine Unmöglichkeit, es sei denn, sie hatte sich, was manche vermuten, heimlich taufen lassen, ganz so wie ihre Tochter Henriette Pereira). ${ }^{151}$

Dass die Taufe - und damit die augenblickliche Erlangung vollständiger staatsbürgerlicher Gleichstellung (Grundbesitz- und Ämterfähigkeit, vor allem aber das uneingeschränkte Aufenthalts- und Niederlassungsrecht) - nicht bloß eine Angelegenheit der Wohlhabenden und Gebildeten war, belegt der Fall Josefa Karpeles. Im August I 8 Io legte die aus Mähren stammende Hebamme Beschwerde bei der Hofkanzlei gegen ihre geplante Abschiebung aus Wien an den Ort ihrer "politischen Zuständigkeit“ (Nikolsburg/Mikulov), ein. Nach einem Bericht der niederösterreichischen Regierung hatte man versucht, Josefa Karpeles, nachdem sie ihre Ausbildung zur Hebamme abgeschlossen hatte (für deren Dauer allein sie in Wien geduldet war), in ihre Heimat zurückzuweisen, was nur wegen der "ungünstigen Jahreszeit « aufgeschoben worden war. Als Josefa Karpeles den Ernst ihrer Lage erkannte, habe sie, so der Polizeibericht, "plötzlich den Wunsch geäußert, nach eingeholtem hinlänglichen Religionsunterricht getauft zu werden«. Da der niederösterreichische Statthalter, Graf Saurau, nun vermutete, dass hinter ihrer Bekehrung nur »listige Absicht « stecke, forderte er ihr ein Revers ab, in dem sie versichern musste, sich nach empfangener Taufe von Wien zu entfernen. Gleichzeitig empfahl er der Hofkanzlei, das Gesuch der Bittstellerin abzuweisen. Diese allerdings hob die Entscheidung der niederösterreichischen Regierung auf und gestattete der Hebamme Josefa Karpeles im August I 8 Io "den Aufenthalt in Wien und die Ausübung ihrer Kunst «. ${ }^{152}$

In gewisser Weise kam die Taufe einem Einbürgerungsverfahren gleich, musste doch vor jedem Taufakt die Bewilligung der staatlichen Behörden eingeholt werden, welche die notwendigen Erhebungen über familiäre Verhältnisse, Studienfortgang,

150 Archiv der Israelitischen Kultusgemeinde Wien, K1, Familienliste Eskeles .

151 Vgl. Staudacher, Konvertiten 1, S. $192 \mathrm{f}$.

152 „Durch Ablegung des Judentums und Empfang der Taufe hat die geprüfte Hebamme Josefa Karpeles aufgehört, den in Rücksicht der Juden bestehenden Polizeivorschriften unterworfen zu sein und von diesem Augenblicke an einen begründeten Anspruch auf alle Rechte erworben, welche den übrigen Untertanen im Staate zukommen, unter welchen Rechten es vorzüglich gehört, solch einen Aufenthaltsort und einen anständigen Erwerbszweig nach Gutbefinden zu wählen. Der Regierung ist daher ausrichten zu lassen, dass sie ein nur auf Juden gehöriges Gesetz auf die Getauften (...) anwenden will. Ebenso handlungswidrig war ihre Abforderung eines Reverses, wodurch sich die Josefa Karpeles selbst für den Fall, wenn sie getauft werden würde, verbindlich machen musste, in ihren Geburtsort Nikolsburg zurückzukehren, welches (...) daher als ganz willkürlich angesehen werden muß."AVA Inneres, Hofkanzlei IV T 1, Nr. 111 aus August 1810. 
Vermögensverhältnisse und den Leumund des Taufbewerbers vornahmen. Erst nach erfolgter Bewilligung durch die niederösterreichische Landesregierung konnte der Taufbewerber, oder die Taufbewerberin, einen etwa sechswöchigen Taufunterricht antreten. ${ }^{153}$ Nach empfangener Taufe hörten Jüdinnen und Juden auf, den für sie geltenden Sondergesetzen unterworfen zu sein. Sie hatten, wie es in einem Dekret der Hofkanzlei heißt, »von diesem Augenblick einen begründeten Anspruch auf alle Rechte erworben, welche den übrigen Untertanen im Staate zukommen«. ${ }^{154}$

Politische Rechte waren damit selbstverständlich nicht gemeint. Diese waren bis Mitte des I9. Jahrhunderts ausschließlich dem Adel vorbehalten. Der Akt der Nobilitierung allein verhalf allerdings auch noch nicht zu politischen Rechten. Erst die Mitgliedschaft in einer Adelskurie (die Einschreibung in die Landtafel) sicherte ein gewisses politisches Mitspracherecht. Juden erschienen in den Ständeregistern zunächst nur vereinzelt, wie etwa der Armeelieferant Abraham Wetzlar, der 1776 zum Katholizismus konvertierte und ein Jahr darauf als Baron Carl Abraham Wetzlar von Plankenstern nobilitiert und in die niederösterreichische Landtafel eingeschrieben worden war. ${ }^{155}$ In der Epoche nach den Toleranzedikten wurden schließlich immer mehr erfolgreiche jüdische Bankiers und Großhändler in den Adelsstand erhoben. Viele der Neuadeligen ließen sich unmittelbar vor oder bald nach der Standeserhebung taufen. Doch etwa ein Viertel der geadelten Judenfamilien des Vormärzes blieb ihrer Religion treu. ${ }^{156}$ Einer der Gründe für die Taufe Nobilitierter war die damit verbundene Möglichkeit des Erwerbs von Grundbesitz, der Juden sonst verwehrt war (eine Ausnahme bildete der Erwerb staatseigener Güter - sehr oft ehemaliger Kirchenbesitz -, den Joseph II. mit einem Dekret vom 24. September I 789 dem Inhaber des Böhmischen Tabakmonopols, Israel Hönig, nobilitiert I 789 als Edler von Hönigsberg, gestattet hatte).

Der zunehmende Erwerb von Grundbesitz durch wohlhabende (getaufte) Juden sowie ihre sich abzeichnende Verschmelzung mit dem Adel durch Nobilitierungen, Taufen, Heiraten und gesellschaftlichen Umgang führte bald schon zum Widerstand bei Teilen des niederen Adels. So gab sich die Kurie der Ritter (die niedere der beiden Adelskurien im niederösterreichischen Landtag) am 27. April I 808 ein neues

153 Da eine Taufe jedenfalls eine mehrwöchige Anwesenheit in der Residenzstadt erforderte, erfreute Wien sich in jenen Jahren eines regelrechten Tauftourismus.Vgl. Staudacher, Konvertiten 1, S. 61.

154 Hofkanzleidekret vom 30.8.1810, abgedruckt in: J.L.E. Graf von Barth-Barthenheim: Politische Verfassung der Israeliten im Lande unter der Enns, und insbesondere in der k. k. Haupt- und Residenzstadt Wien (Wien 1821), S. 357.

155 Sein ältester Sohn, Baron Raimund Wetzlar von Plankenstern sollte zum Förderer, Freund und zeitweiligen Quartiergeber Wolfgang Amadeus Mozarts werden. Vgl. Wolfgang Gasser: Neues aus der »Stadt der Toleranz«, in: Lorenzo da Ponte, a.a.O, S. $72 \mathrm{f}$.

156 Hanns Jäger-Sustenau: Die geadelten Judenfamilien im vormärzlichen Wien, phil. Diss. (Wien 1950), S. 65. 


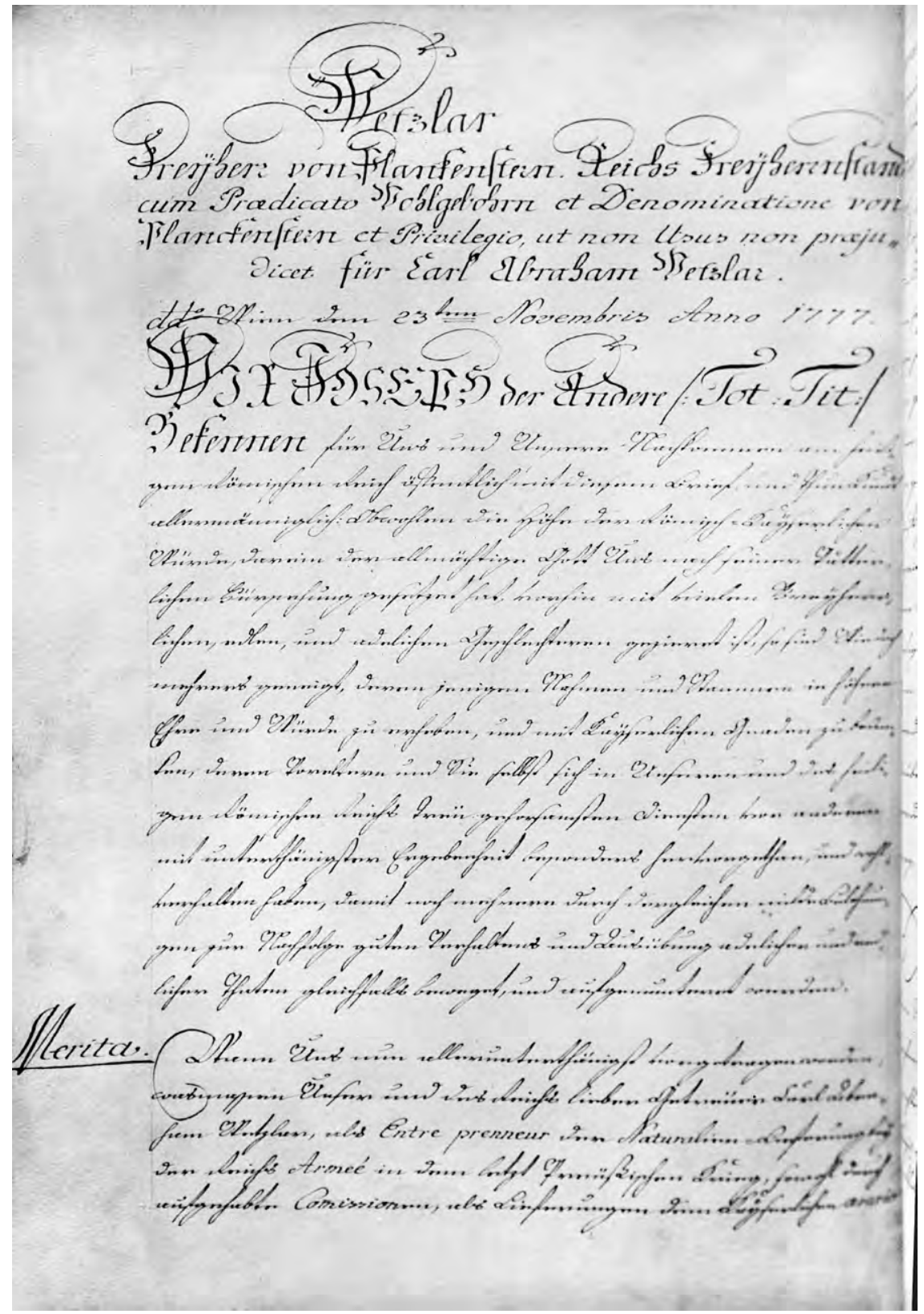

Abb. 7: Erhebung des Karl Abraham Wetzlar zum Reichsfreiherrn von Planckenstein durch Kaiser Joseph II. im Jahr I777. Nobilitierungsurkunde; Quelle: ÖNB/Wien, Bildarchiv 
Abb. 8: Israel Hönig von Hönigsberg, nobilitiert I789; Quelle: ÖNB/Wien, Bildarchiv

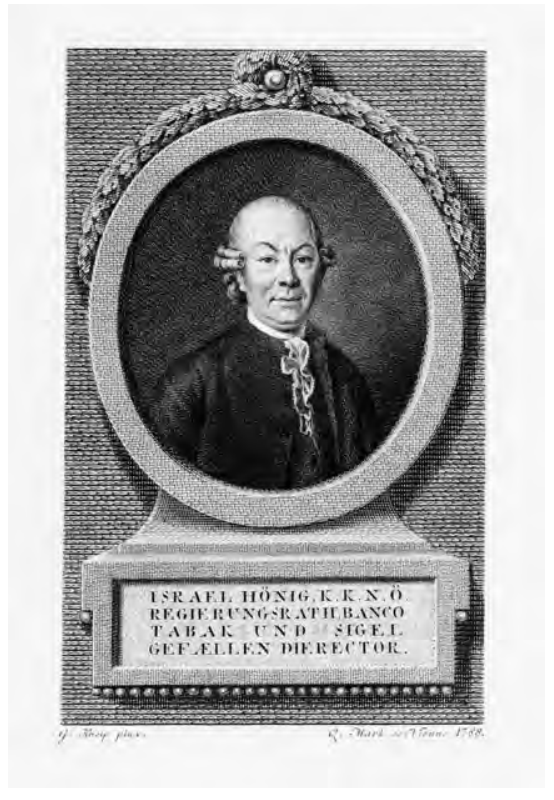

Statut, welches Personen jüdischer Abstammung, und zwar auch dann, wenn sie getauft waren, die Mitgliedschaft versagte. Unmittelbar vor dem letzten Krieg gegen Napoleon, der einen Schub patriotischer Gefühle ausgelöst hatte, erlassen, scheint das niederösterreichische Ritterstandsstatut im Kontext einer bestimmten Auffassung von Nation zu stehen, die, wie William D. Godsey betont, nach der Niederlage gegen Frankreich in den deutschen Ländern virulent geworden war und die Juden tendenziell vom Prozess der Nationsbildung ausschloss. ${ }^{157}$ Kaiser Franz I. ignorierte jedoch den Protest der Stände und setzte die Politik der Nobilitierung von Juden, die sein Onkel Joseph II. begonnen hatte, unbeirrt fort. ${ }^{158}$

\section{Die Kodifizierung des Staatsbürgerschaftsrechts}

$\mathrm{Zu}$ größerer Rechtssicherheit für die österreichischen Juden trug zweifellos das Erscheinen des Allgemeinen bürgerlichen Gesetzbuches am I. Juni I 8 I I bei. Ist die unifizierende und nivellierende, "gleichförmig« machende Funktion des ABGB oft

157 William D. Godsey: Nation, Government, and 'Anti-Semitism` in early Nineteenth-Century Austria, in: The Historical Journal, 51, 1 (2008), S. 49-85, hier: S. 49 und 72.

158 Godsey, Nation, Government, and ‘Anti-Semitism‘, S. 70. Nach Hanns Jäger-Sustenau erfolgten bis 1848115 Erhebungen von Juden in den Adelsstand. Jäger-Sustenau, Geadelte Judenfamilien, S. 65. 
betont worden, so ist unübersehbar, dass die nun kodifizierte Staatsbürgerschaft zu einem bedeutenden Element im Transformationsprozess von einer monarchischen Union von Ständestaaten hin zu einem einheitlichen Territorialstaat wurde. ${ }^{159}$ Erstmals waren nun für den Geltungsbereich des ABGB genaue Bestimmungen über den Erwerb der österreichischen Staatsbürgerschaft getroffen worden. Danach konnte die Aufnahme in die österreichische Staatsbürgerschaft entweder durch Abstammung: "Die Staatsbürgerschaft ist Kindern eines österreichischen Staatsbürgers durch die Geburt eigen " $(\$ 28)$ oder durch bestimmte Handlungen (ipso facto) erfolgen, nämlich »durch einen in diesen Staaten vollendeten zehnjährigen ununterbrochenen Wohnsitz« (die bloße Ersitzung), »durch Eintretung in einen öffentlichen Dienst« oder "durch Antretung eines Gewerbes, dessen Betreibung die ordentliche Ansässigkeit im Lande notwendig macht « (\$ 29). ${ }^{160}$ Ausschließungen hinsichtlich des Standes, der Religion oder ethnischen Zugehörigkeiten fanden sich nicht im Gesetz. ${ }^{161}$ Grundsätzlich hatten die Autoren des bürgerlichen Gesetzbuches Juden vom Erwerb der Staatsbürgerschaft keineswegs ausschließen wollen ${ }^{162}$, hatte doch Franz von Zeiller, Referent der Revisions-Hofkommission, dem Gesetzeswerk einen naturrechtlich konnotierten, weltbürgerlichen Schliff gegeben. Doch führten die noch immer geltenden Sonderrechte hinsichtlich Niederlassungs-, Grundbesitz- oder Gewerbefähigkeit für Juden implizit zur Unmöglichkeit, auf diese Weise die Staatsbürgerschaft zu erwerben.

Es gab allerdings noch eine weitere Möglichkeit, die Naturalisation zu erlangen. $\$ 30$ des Gesetzes bestimmte, dass auch »ohne Antretung eines Gewerbes oder Handwerkes und vor verlaufenen zehn Jahren (...) die Einbürgerung bei den politischen Behörden angesucht, und von denselben, nachdem das Vermögen, die Erwerbsfähigkeit und das sittliche Betragen des Ansuchenden« geprüft worden waren, verliehen werden könne. ${ }^{163}$ Diese Möglichkeit stand grundsätzlich auch Juden offen. Doch auch in diesem Fall war vor der Aufnahme in die Staatsbürgerschaft jedenfalls

159 Vgl. Martin P. Schennach: Der "Österreicher" als Rechtskonstrukt? Zur Formierung einer österreichischen Staatsbürgerschaft in der ersten Hälfte des 19. Jahrhunderts, in: Zeitschrift für Neuere Rechtsgeschichte 33 (2011), S. 152-176, hier: S. 175.

160 Allgemeines bürgerliches Gesetzbuch für die gesammten deutschen Erbländer der österreichischen Monarchie (ABGB), (= Kropatscheksche Sammlung) (Wien 1811), S. $257 f$.

161 Vgl. Rolf Grawert: Staat und Staatsangehörigkeit. Verfassungsgeschichtliche Untersuchung zur Entstehung der Staatsangehörigkeit (Berlin 1973), S. 146.

162 Als »relatively inclusive« bewertet Ulrike von Hirschhausen das imperiale Staatsbürgerschaftsrecht der Monarchie nach dem Erscheinen des ABGB. Ulrike von Hirschhausen: From imperial inclusion to national exclusion: Citizenship in the Habsburg monarchy and in Austria 1867-1923, in: European Review of History - revue européenne d'histoire, Vol. 16/4 (August 2009), S. 551-574, hier: S. 553.

163 Ebenda. 
die Toleranz bzw. eine Familienstelle zu erwerben. Waren Juden im Besitz der Toleranz, so geschah, wie ein Praktiker des Staatsbürgerschaftsrechtes, Johann Vesque von Püttlingen, betont, »ihre Aufnahme in die Staatsbürgerschaft wie bei anderen Ausländern« auch. ${ }^{164}$

\section{Die staAtsbürgerliche Stellung der Juden im Vormärz Und das Auftauchen der "Judenfrage«}

Die Entwicklung der staatsbürgerlichen Rechte der Juden in den einzelnen Ländern der österreichischen Monarchie verlief bis zum Vormärz derart unterschiedlich, dass ein gründlicher Kenner der Materie, Salo Baron, urteilen konnte: Im Einzelnen habe im Kaiserstaat »eine derart große Vielgestaltigkeit der Gesetzgebung" geherrscht, "wie sie nicht einmal unter den Staaten des übrigen Deutschlands « bestanden habe. ${ }^{165}$ Dort war es insbesondere nach der Niederlage Napoleons in allen zuvor von Frankreich annektierten Ländern - in denen Juden vollkommen gleichgestellt gewesen waren - zu erheblichen Rückschritten hinsichtlich der Judengesetzgebung gekommen. Selbst wenn Juden mancherorts bereits den Kern der neuen bürgerlichen Gesellschaft ausmachten, konnte das nicht darüber hinwegtäuschen, dass ihre staatsbürgerliche Stellung in den meisten deutschen Staaten noch immer äußerst prekär war. Als dann Preußen im März I 8 I 2 seine Juden zu Inländern und Staatsbürgern machte und ihnen nahezu alle bürgerlichen Rechte gewährte, ${ }^{166}$ regten sich in allen Staaten - so auch in Österreich - Hoffnungen auf eine vollständige staatsbürgerliche Gleichstellung der Juden im Zuge einer allgemeinen europäischen Lösung im Rahmen des Wiener Kongresses. ${ }^{167}$

164 Johann Vesque von Püttlingen: Die gesetzliche Behandlung der Ausländer in Österreich (Wien 1842), S. 29. Siehe auch: Barth-Barthenheim, Politische Administration 1, S. $63 \mathrm{f}$.

165 Salo Baron: Die Judenfrage auf dem Wien Kongreß (Wien/Berlin 1920), S. 20. Ähnlich argumentierend wie Baron in Bezug auf die preußischen Länder: Ludwig von Rönne/Heinrich Simon: Die früheren und gegenwärtigen Verhältnisse der Juden in den sämmtlichen Landestheilen des Preußischen Staates (Breslau 1943).

166 Bis zum Ende des Vormärzes kam es allerdings auch in Preußen wieder zu erheblichen Rückschritten in der Judengesetzgebung. Vgl. Dieter Gosewinkel: Einbürgern und Ausschließen. Die Nationalisierung der Staatsangehörigkeit vom Deutschen Bund bis zur Bundesrepublik Deutschland (= Kritische Studien zur Geschichtswissenschaft Bd. 150) (Göttingen 2003), S. 76.

167 Das Auftreten der Juden auf dem Wiener Kongress war allerdings ein uneinheitliches und, wie Stephan Wendehorst betont, teilweise vormodernes. So berief sich etwa die Israelitische Gemeinde zu Frankfurt am Main in einer Bittschrift vom 10. Oktober 1814 - gegen die Bedrückungen des Frankfurter Magistrats - auf den »unmittelbaren Schutz Seiner Kaiserlichen Majestät«, beschworen Huldigungsformeln, das alte Reichsrecht sowie ihre von der christlichen Gemeinde zu Frankfurt "ganz abgesonderte Existenz" (abgedruckt in: Johann Ludwig Klüber (Hg.): Acten des Wiener 


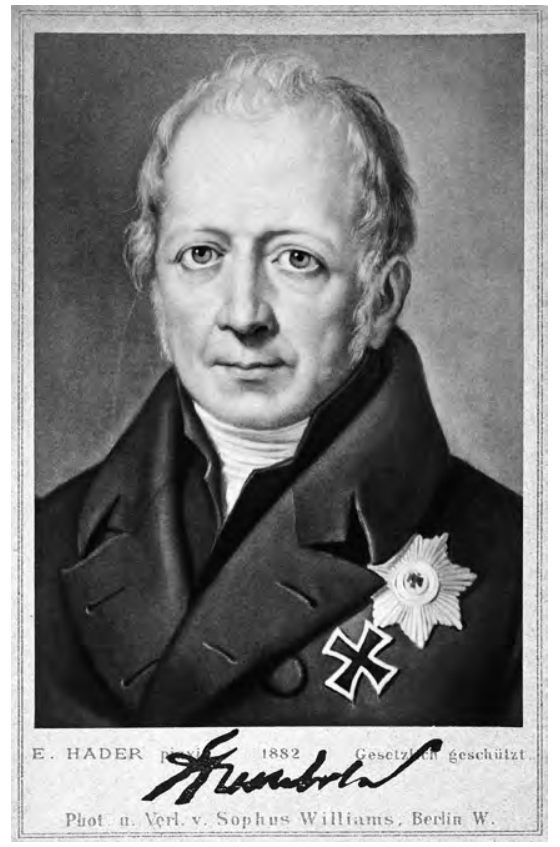

Abb. 9: Wilhelm von Humboldt (I767-1825); Quelle: ÖNB/Wien, Bildarchiv

Diese hohen Erwartungen waren vor allem durch Wilhelm von Humboldt, dem eigentlichen Urheber der Judenemanzipation in Preußen, geweckt worden. Wilhelm, wie auch sein jüngerer Bruder Alexander, galten von früher Jugend an als leidenschaftliche Vorkämpfer für eine uneingeschränkte Gleichberechtigung der Juden. Halbheiten waren ihre Sache nicht. Der von Zeitgenossen häufig vertretenen Auffassung, jeder Emanzipation habe erst die moralische Besserung der Juden vorauszugehen, trat Wilhelm mit der Bemerkung entgegen, der Staat sei kein Erziehungs-, sondern ein Rechtsinstitut. ${ }^{168}$ Im April I 8 I 4 hatte Wilhelm von Humboldt ein mémoire préparatoire zur Einsetzung eines Redaktionskomitees für die Verfassung des Deutschen Bundes vorgelegt, in dem die »vollständige Gleichheit aller Konfessio-

Congresses in den Jahren 1814 und 1815, Bd. 16 (Erlangen 1816), S. 397). In dieser "vormodernen Politik « wie auch in der Tatsache, dass die Juden kein anerkanntes Völkerrechtssubjekt waren, sieht Stephan Wendehorst die Ursache für das Scheitern der Frage der staatsbürgerlichen Gleichstellung der Juden auf dem Wiener Kongress. "Die Frankfurter Juden auf dem Wiener Kongress", Statement Stephan Wendehorsts anlässlich des 1. Workshop zur Internationalen Geschichte: „Mitwirkung ohne Teilnahme? Zu Gesprächs- und Verhandlungskulturen am Wiener Kongress" des Instituts für Neuzeit und Zeitgeschichtsforschung (INZ) der Österreichischen Akademie der Wissenschaften in Wien,am 25. Jänner 2013.

168 Zit. nach: Baron, Judenfrage, S. 83. 
nen« angekündigt wurde. ${ }^{169}$ Gegen diese (implizit die Juden einschließende) Formulierung erhob vor allem der bayerische Bevollmächtigte, Fürst Wrede, Einspruch. ${ }^{170}$ Doch am Vorabend des Wiener Kongresses war selbst Staatskanzler Metternich der Ansicht, dass die jüdischen Glaubensgenossen berechtigt seien, "die Bestimmung ihrer Verhältnisse und Rechte nach liberalen Grundsätzen von dem hier versammelten Kongress zu erwarten «. ${ }^{171}$ Ein diesbezüglicher Gesetzesentwurf, der bereits die Zustimmung Österreichs und Preußens gefunden hatte, scheiterte jedoch am Widerstand kleinerer Staaten, und es blieb bloß bei einer unbestimmten Aufforderung an die Bundesversammlung in Artikel i 6 der Bundesakte:

Die Bundesversammlung wird in Beratung ziehen, wie, auf eine möglichst übereinstimmende Weise, die bürgerliche Verbesserung der Bekenner des jüdischen Glaubens in Teutschland zu bewirken sey, und wie insbesondere denselben der Genuß der bürgerlichen Rechte, gegen die Uebernahme aller Bürgerpflichten, in den Bundesstaaten verschafft und gesichert werden könne. Jedoch werden die Bekenner dieses Glaubens, bis dahin, die denselben von den einzelnen Bundesstaaten bereits eingeräumten Rechte erhalten. ${ }^{172}$

Die Wiener Juden waren tief enttäuscht, hatten doch ihre Vertreter, Nathan von Arnstein, Bernhard von Eskeles und Leopold von Herz, bereits am I I. April i 8 I 5 in einer Bittschrift den Kaiser ersucht, ihre Belange stärker zu unterstützen. Nach dem für sie so enttäuschenden Ergebnis des Wiener Kongresses wandten sie sich neuerlich mit einer Bittschrift an den Kaiser, in der sie für eine gesamtstaatliche Behandlung aller Juden der Monarchie - gegenüber einer bloß länderweisen Lösung - plädierten. Tatsächlich befahl Franz I. seinen Hofstellen, „Grundsätze einer gleichmäßigen und liberalen Behandlung der Juden im Gesamtstaate« auszuarbeiten. ${ }^{173}$ Die Schwierigkeiten, auf welche die anempfohlene Gleichmäßigkeit der Gesetzgebung stoßen musste, schienen der Mehrheit der Beamten in den Hofstellen jedoch unüberwindlich. Hofrat Karl von Widmann (Referent für Judensachen in der Hofkanzlei) erinnerte in einem Vortrag an den anlässlich der Debatten um das böhmische Judensystem im Jahr I795 formulierten Grundsatz, »das Universum der

169 Ebenda, S. 73.

170 Ebenda, S. 75.

171 Zit. nach: Edward Timms: The Pernicious Rift: Metternich and the Debate about Jewish Emancipation at the Congress of Vienna, in: Leo Baeck Institute Year Book XLVI (2001), S. 3-17, hier: S. 11.

172 Deutsche Bundesakte vom 8. Juni 1815, zit. nach: www.verfassungen.de/de/de06-66bundesakte 15-i.htm.

173 Tietze, Juden Wiens, S. 145. 
Judenschaft unschädlich, die Individuen aber nützlich zu machen«. Diese Absicht, resümierte Widmann seine vergleichende Analyse der Judensysteme in den einzelnen Kronländern, sei - insbesondere im Hinblick auf Galizien - noch keineswegs erfüllt. Widmann gab zu bedenken, dass die Juden »sich den übrigen Staatsbürgern in einigen Provinzen mehr, aber noch nirgends ganz angeschlossen « hätten. Es könne ihnen daher noch nicht der volle Anspruch auf alle staatsbürgerlichen Rechte zugestanden werden. Zwar sei er weit davon entfernt, "sie als ewige Fremdlinge in der bürgerlichen Gesellschaft anzusehen «, plädiere jedoch dafür - habe der Staat es sich nun einmal zum Ziel gesetzt, "sie als nützliche Glieder desselben in die Reihe der Staatsbürger treten« zu lassen -, diesen Übergang »nicht plötzlich, sondern nur allmählich und stufenweise und in jederzeit zu modifizierenden Verfahren zu gestalten. ${ }^{174} \mathrm{Ei}$ nige Hofräte sprachen sich indes für eine sofortige "vollkommene Gleichstellung der Juden mit den übrigen Staatsbürgern« aus, darunter Anton von Roschmann, der in einem Separatvotum vom 7. November I 8 I 8 sowohl für ein Grundbesitzrecht als auch für die volle Ämterfähigkeit der Juden eintrat. Roschmann, in der Hofkanzlei u. a. Mitglied der Militärverpflegungskommission, sah nicht ein, warum ein Jude dem Staat, "für dessen Verteidigung er in den Reihen der Krieger blutet und fällt«, nicht auch als öffentlicher Beamter dienen könne. ${ }^{175}$

Auch Freiherr Andreas von Stift - einer der großen Fürsprecher der Juden - äußerte im Verlauf der Enquete über die Judenreform der Jahre I 8 I7/ I 8 die Meinung, "das einzige Mittel gegen alle beklagten Übelstände sei, den Juden die Grundbesitzfähigkeit zu geben «. ${ }^{176} \mathrm{Zu}$ einem solchen Schritt aber konnte sich die Landesregierung nicht entschließen. Eine I 82 I von Graf Barth-Barthenheim herausgegebene Gesetzessammlung drückte zwar in der Einleitung emphatisch das Bemühen um Gleichmäßigkeit aus, doch spiegelte sie zugleich die nach wie vor bestehenden gesetzlichen Ungleichheiten für Israeliten, etwa in Passangelegenheiten, bei der Eidesablegung oder hinsichtlich des Aufenthaltsrechts auf dem flachen Lande, wider. Vor allem aber betont die Gesetzessammlung die Unterschiede zwischen Tolerierten, zeitlich Tolerierten und Nichttolerierten (fremden Juden). ${ }^{177}$ Zwar betonte der Vizekanzler der Hofkanzlei, Freiherr Franz von Pillersdorf, im Februar i 833 - auf ausländische Kritik reagierend - "er wünsche den Zeitpunkt beschleunigt zu sehen, wo den Juden, ebenso wie sie zu den Bedürfnissen des Staatsverbandes beitragen und

174 Vortrag der Hofkanzlei (Referent Karl v. Widmann) v. 29. Dezember 1818, abgedruckt in: Př́bram, Urkunden und Akten II, S. 279ff.

175 Seperatvotum von Anton Leopold von Roschmann, ebenda, S. 298f.; weitere Seperatvoten existieren von Hofrat Franz v. Fradeneck und Hofrat Franz v. Stuppan.

176 Zit. nach: Tietze, Juden in Wien, S. 139.

177 Johann Ludwig Barth-Bartenheim: Politische Verfassung der Israeliten im Lande unter der Enns. Beiträge zur politischen Gesetzeskunde in den österreichischen Kaiserstaaten, Bd. 1 (Wien 1821). 
das gemeinschaftliche Wohl zu fördern verpflichtet und berufen sind, auch an den Vortheilen dieses Verbandes teilnehmen, und dadurch zuverlässigere und nützlichere Glieder dieses Vereines werden, als jemals unter dem Bestande von Ausnahmen und Ausschließungen zu erwarten ${ }^{178}$ sei. Doch dies änderte an der »staatsbürgerlichen Nullität des Judentums« - wie ein anderer Vertreter der Hofkanzlei sich ausdrückte wenig.

Was sich in diesen Diskussionen spiegelt, ist die vor allem in den deutschen Ländern - und hier vornehmlich in Preußen - immer eindringlicher geführte Debatte um die sogenannte jüdische Frage, (später: "Judenfrage«). ${ }^{179}$ Die Einlösung von John Lockes berühmtem Toleranzpostulat: "If we consider a human being a human being, neither pagans, Muslims, nor Jews can be excluded from the republic of civil rights ${ }^{180}$, scheiterte zum einen daran, dass eine solche republic of civil rights unter den deutschen Staaten nirgends zu finden war, zum anderen, dass auch die aufgeklärtesten Geister nicht von der Vorstellung einer der Mehrheit gleichgestellten Minderheit ausgingen, sondern von einem Aufgehen der jüdischen Minderheit in einem christlichen Mehrheitsstaat, wobei Emanzipation zunehmend als eine Art kollektiver Erziehungsprozess des Judentums vorgestellt wurde, der endgültig erst mit der Konversion zum Christentum abgeschlossen wäre. ${ }^{181}$

Ihren Höhepunkt fand die Debatte um die "Judenfrage«, an der sich seit den I 83 oer-Jahren zahlreiche, teils anonyme Autoren beteiligten, in der berühmten Kontroverse zwischen dem Junghegelianer Bruno Bauer und seinem früheren Schüler Karl Marx. Bruno Bauer hielt in einem zuerst I 842 in den »Deutschen Jahrbüchern für Wissenschaft und Kunst« erschienenen Aufsatz, "Die Juden-Frage«, das Streben der Juden nach gleichberechtigten Staatsbürgerrechten in einem christlichen Staat für vergeblich. »Bürger wollen die Juden im christlichen Staat werden?«, rief er aus, um dann empört fortzufahren: „Fragt doch erst, ob dieser (der christliche Staat) Bürger und nicht nur Untertanen kennt ... «182 Wahre Emanzipation sei, nach Bauer,

178 Zit. nach: Wolf, Juden, S. 140.

179 Um 1750 tauchte the jewish question zuerst in England auf. Der Begriff meinte zunächst, Juden den Landerwerb zu gestatten. 1790 diskutierte die Nationalversammlung in Frankreich die Frage der gesetzlichen Gleichstellung der Juden unter dem Titel: la question sur les juifs. Noch nach dem Wiener Kongress verwendeten Befürworter und Gegner der Judenemanzipation die Begriffe jüdische Frage oder Judenfrage in neutraler Weise, erst nach der Gründung des Deutschen Kaiserreichs 1871 erhielt der Begriff Judenfrage eine antisemitische Konnotation.

180 John Locke: Ein Brief über Toleranz (engl.-deutsch). Übersetzt und eingeleitet von Julius Ebbinghaus (Hamburg 1996), S. 19.

181 Vgl. Frank Surall: Juden und Christen - Toleranz in neuer Perspektive. Der Denkweg Franz Rosenzweigs in seinen Bezügen zu Lessing, Harnack, Baeck und Rosenstock-Huessy (Gütersloh 2003), S. 49.

182 Bruno Bauer: Die Judenfrage (Braunschweig 1843), S. 20. 
nur dann möglich, wenn sich die Juden ihres Judentums durch Konversion entledigten. Auch die Bemühungen von Reformjuden, das Judentum nur noch als Privatsache, als eine Konfession unter anderen, zu betrachten, lehnte er ab. Als einzige Lösung sah Bauer einen radikalen Laizismus (verbunden mit einer wissenschaftlichen Weltanschauung) in einem säkularen Staat nach französischem Vorbild.

Karl Marx hingegen ließ in seiner zwei Jahre später erschienenen Rezension der Bauerschen Abhandlung das Recht auf Religionsfreiheit als ein allgemeines Menschenrecht durchaus gelten. Auch die (wenngleich unvollkommene) politische Emanzipation der Juden in einem christlichen Staat hielt Marx grundsätzlich für möglich. Der Widerspruch, in welchem sich der Anhänger einer besonderen Religion mit seinem Staatsbürgertume befinde, sagt Marx, sei »nur ein Teil des allgemeinen weltlichen Widerspruchs zwischen dem politischen Staat und der bürgerlichen Gesellschaft«. Die Vollendung des christlichen Staates sei der Staat, »der sich als Staat bekennt und von der Religion seiner Glieder" gänzlich abstrahiere. Doch die Emanzipation des Staates von der Religion könne, so Marx, "nicht die Emanzipation des wirklichen Menschen von der Religion« sein. Und gegen Bauer gewendet fährt er fort: Weil die Juden sich politisch emanzipieren können, ohne sich »vollständig und widerspruchslos vom Judentum loszusagen, darum ist die politische Emanzipation selbst nicht die menschliche Emanzipation. ${ }^{183}$ Erst wenn der wirkliche individuelle Mensch den abstrakten Staatsbürger in sich zurücknehme und als individueller Mensch in seinem empirischen Leben, in seiner individuellen Arbeit, in seinen individuellen Verhältnissen, Gattungswesen geworden sei, erst wenn der Mensch seine 'forces propres` als gesellschaftliche Kräfte erkannt und organisiert habe und daher die gesellschaftliche Kraft nicht mehr in der Gestalt der politischen Kraft von sich trennte, erst dann sei »die menschliche Emanzipation vollbracht «. ${ }^{184}$

Beantwortet, wie Marx glaubte, war die "Judenfrage« damit noch lange nicht. Allein zwischen 1873 bis zum Ende des Jahrhunderts erschienen etwa 500 Schriften, die sich für oder gegen die politische Emanzipation der Juden, d.h. ihre Gleichstellung mit allen anderen Staatsbürgern, aussprachen. Alle diese Schriften und Pamphlete bezogen sich überwiegend auf die Verhältnisse im Deutschen Reich (die Juden der österreichisch-ungarischen Monarchie blieben, mit Ausnahme der Schriften von Nathan Birnbaum und Theodor Herzl unbedacht), wobei Juden zunehmend als Hindernis bei der (deutschen) Nationsbildung angesehen wurden. Im Zuge dieser Debatte bekam der ursprünglich neutrale Begriff Judenfrage eine immer deutlichere antisemitische Konnotation.

183 Karl Marx: Zur Judenfrage, in: Karl Marx/Friedrich Engels, Werke, Bd. 1 (Berlin 1974), S. 361 (Hervorhebungen im Original).

184 Ebenda, S. 370 (Hervorhebungen im Original). 


\section{Die bürgerliche Revolution von i 848 und die Veränderte StaAtsbürgerliche Stellung der Juden}

I789, I 848, I9I7: die Daten der großen europäischen Revolutionen, spielen in der Geschichte der Emanzipation der Juden eine bedeutende Rolle - im Falle der »bürgerlichen Revolution" von I 848 eine durchaus ambivalente. War das Jahr I 848 zumindest in der ersten Phase von meist antikapitalistisch motivierten pogromartigen Ausschreitungen gegen Juden geprägt, so ist doch unübersehbar, dass erstmals Juden in großer Zahl als politisch Handelnde und, in Einzelfällen, als herausragende Akteure der Revolutionsbewegung auftraten. ${ }^{185}$ Benjamin Kewall, ein jüdischer Hauslehrer und Journalist, beschrieb diese Ambivalenz in seinem die Revolutionsjahre I 848/49 begleitenden Tagebuch: "Ich habe die Zeit der Auferstehung Österreichs mit Freuden begrüßt, weil ich die Erlösung der Juden von schwerem Drucke hoffte, wie bitter wurde ich jedoch enttäuscht! Die entfesselten Leidenschaften suchten sich oft gegen wehrlose Juden Luft zu machen, wie dies in Prag, Pressburg und anderswo geschah. «186 An anderer Stelle berichtete er hoffnungsfroh von den Bürgern, »deren Reich jetzt gekommen ${ }^{187}$ sei und meinte damit auch die jungen Juden, die, wie er selbst, die gesamte bürgerliche Bewegung mitgetragen hatten, ja in gewisser Weise ihren Kern bildeten. In Wien waren dies vor allem jüdische Studenten und junge Akademiker, die sich der revolutionären Bewegung anschlossen, allen voran die Ärzte Adolph Fischhof und Joseph Goldmark. Fischhof, der junge Sekundararzt im Allgemeinen Krankenhaus, hatte in seiner berühmten improvisierten Rede im Hof des niederösterreichischen Landhauses, am I 3. März I 848, als erster die Forderungen der Revolution artikuliert. Juden befanden sich unter den Mitgliedern der "Akademischen Legion« und der Nationalgarde (unter ihnen der Dichter und Journalist Ludwig August Frankl), Juden waren unter den ersten Toten der Märzrevolution genauso wie unter den standrechtlich Hingerichteten des Oktoberaufstandes. ${ }^{188}$

Da Glaubens- und Gewissensfreiheit wie auch Gleichheit vor dem Gesetz zu den zentralen Programmpunkten der 48er-Bewegung gehörten, verführte dies manche zu der Annahme, die Emanzipation der Juden würde sich mit der Durchsetzung die-

185 Reinhard Rürup: Der Fortschritt und seine Grenzen. Die Revolution von 1848 und die europäischen Juden, in: Dieter Dowe et al (Hg.) : Europa 1848. Revolution und Reform (= Politik- und Gesellschaftsgeschichte Bd. 48) (Bonn 1998), S. 985-1005, hier: S. 997. Siehe dazu auch: Ernst Wangermann: 1848 und die Emanzipation der Juden im Habsburgerreich, in: Chilufim - Zeitschrift für jüdische Kulturgeschichte (1/2006), S. 59-85.

186 Wolfgang Gasser, Erlebte Revolution 1848/49. Das Wiener Tagebuch des jüdischen Journalisten Benjamin Kewall (Wien/München 2010), S. 169.

187 Ebenda, S. 169.

$188 \mathrm{Zu}$ den Toten der Märztage gehörten der Technikstudent Karl Heinrich Spitzer und der Webergeselle Bernhard Herschmann, hingerichtet wurde der jüdische Journalist Hermann Jellinek. 
ser Prinzipien quasi von selbst erledigen. Jüdische Aktivisten bemühten sich - wohl auch unter dem Eindruck antisemitischer Ausschreitungen -, die Judenfrage gerade nicht zu einem zentralen Thema zu machen. So mahnte der Prediger des Wiener Tempels, Isaak Noah Mannheimer, anlässlich einer ökumenischen Feier zu Ehren der Märzgefallenen:

Unter den ersten, die das Wort ergriffen und geführt in den stürmischen Tagen, waren die Juden! ... Jetzt nichts für uns! Kein Wort von "Judenemanzipation", wenn andere es nicht sprechen für uns! Wir haben genug 30 Jahre lang ... gebeten um Recht und Menschlichkeit ... Erst das Recht des Menschen zu leben, zu atmen, zu denken, zu sprechen; erst das Recht des Bürgers, des edlen, freien; nachher kommt der Jude! ... Wir sind die Leidenden in jedem Falle. Wo die rohe Gewalt einbricht, bricht sie gegen uns ein; wo die Gewalt der Herrschaft regiert, regiert sie gegen uns. ${ }^{189}$

Zwar war nun die Glaubens- und Gewissensfreiheit ebenso wie die Gleichstellung der Konfessionen in der nach der Märzrevolution erlassenen Verfassung vom 25. April I 848 (die sogenannte Pillersdorfsche Verfassung) erstmals garantiert worden, auch anerkannte die Aprilverfassung die Juden als Staatsbürger und gewährte ihnen das aktive und passive Wahlrecht zum Reichsrat, doch die Aufhebung aller für Juden noch immer geltenden Beschränkungen wurde ausdrücklich der Entscheidung des sich konstituierenden Reichstages vorbehalten. In dessen Grundrechtsentwurf, den der Verfassungsausschuss in einer erster Lesung Ende September I 848 behandelte, hieß es in $\$$ I7: "Die Religionsverschiedenheit begründet keinen Unterschied in den Rechten und Pflichten der Staatsbürger. ${ }^{190}$ Als jedoch wegen der zunehmenden Unruhen in Wien der Reichstag nach dem mährischen Kremsier/Kromeříž verlegt werden sollte, beschloss man am letzten Sitzungstag in Wien, dem 5. Oktober I 848, im Rahmen einer Budgetdebatte lediglich die Aufhebung aller den Juden auferlegten Steuern.

Nach der blutigen Niederschlagung der zweiten Phase der Revolution, im Oktober I 848, setzte die neue Regierung unter Fürst Felix von Schwarzenberg in der Frage der Gleichstellung der Juden zunächst den Kurs der vorherigen Regierung fort. Als jedoch im November im Ministerrat ein Antrag auf Zulassung eines Juden zum Gerichtsdienst eingebracht wurde, sprach sich Justizminister Bach gegen die Gewährung des Gesuchs aus, mit der Begründung, dass man der Emanzipation

189 Zit. nach: Walter Grab: Der deutsche Weg der Judenemanzipation 1789-1938 (München/Zürich 1991), S. 120.

190 Alfred Fischel: Die Protokolle des Verfassungsausschusses über die Grundrechte. Ein Beitrag zur Geschichte des österreichischen Reichstags vom Jahre 1848 (Wien/Leipzig 1912), Anhang, S. 185. 
Abb. Io: Isaak Noah Mannheimer (1793-I865); Quelle: ÖNB/Wien, Bildarchiv

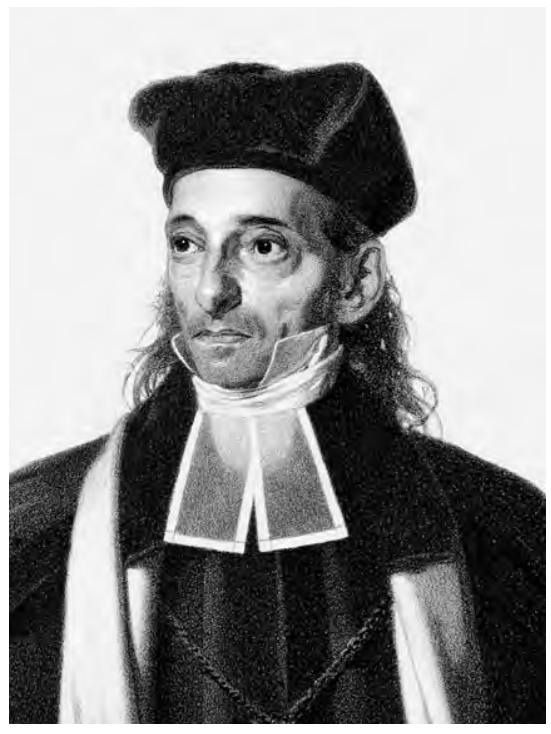

der Juden nicht vorgreifen, sondern diese dem inzwischen in Kremsier tagenden Reichstag überlassen wolle. ${ }^{191}$ In der letzten Fassung des Kremsierer Grundrechtskatalogs - wohl die vornehmste der österreichischen Verfassungsurkunden - war postuliert worden : "Vor dem Gesetz sind alle Staatsbürger gleich«. Daraus folgte, dass die »öffentlichen Ämter und [der] Staatsdienst« für »alle dazu befähigten gleich zugänglich " sein sollten ${ }^{192}$, doch der emphatisch vorgetragene Gleichheitsgrundsatz - die Isonomie - schloss weder Frauen noch Juden selbstverständlich mit ein. ${ }^{193}$ Im Gegenteil entwickelte sich auf dem Kremsierer Reichstag eine zunehmend antisemitische Stimmung. Und bevor $\$$ I7, der die Frage der bürgerlichen Gleichstellung der Juden hätte behandeln sollen, umfassend hatte diskutiert werden können, lösten kaiserliche Truppen den Reichstag gewaltsam auf, und anstelle des Kremsierer Verfassungsentwurfes trat nun die sogenannte »oktroyierte Märzverfassung" der Regierung Schwarzenberg. Diese allerdings gewährte mit einem eigenen Patent die volle Gleichberechtigung aller Konfessionen und damit die rechtliche Gleichstellung der

191 Die Protokolle des Österreichischen Ministerrates 1848-1867, II. Abteilung/Band 2, Das Ministerium Schwarzenberg, bearbeitet von Thomas Kletečka/Anatol Schmied-Kowarzik (Wien 2005), Einleitung, S. XXXI. sowie ÖMProt. II/1, Das Ministerium Schwarzenberg, bearbeitet von Thomas Kletečka, Nr. 3, MR, Wien, 15. Dezember 1848, S. 117.

192 Fischel, Grundrechte, S. 198.

193 Vgl. Gerald Stourzh: Die Grundrechte in der Paulskirche und im Kremsierer Reichstag, in: derselbe: Der Umfang der österreichischen Geschichte. Ausgewählte Studien 1990-2010 (Wien/ Köln/Graz 2011), 69-85, S. 72 
Juden. ${ }^{194}$ Die Emanzipation der Juden war also, wie Walter Grab nüchtern feststellt, gerade nicht ein »Ergebnis des revolutionären Erbes von I 848 «. Sie war keineswegs auf demokratischem Wege durchgesetzt ${ }^{195}$, sondern von oben dekretiert worden und möglicherweise deshalb - wie der Wiener Prediger Isaak Noah Mannheimer befürchtet hatte - umso leichter wieder rücknehmbar. ${ }^{196}$

Auch Benjamin Kewalls Empfindungen waren zwiespältig, als er am Morgen des 7. März I 849 die aufgeregten »Menschenhaufen« beobachtete, die sich an allen Straßenecken zusammenrotteten, um die neueste Proklamation der kaiserlichen Regierung zu diskutieren: "Der Reichstag ist aufgelöst, die neuen Kammern werden aus einem Ober- und Unterhause bestehen, die Juden sind emanzipiert«. Am Nachmittag hätten sich die Gemüter dann beruhigt, da, wie er schreibt, „die vielen liberalen Punkte der Verfassung« die »reichen Bürger und Juden« versöhnt hätten. ${ }^{197}$ Für sich selbst aber sah Kewall vor allem die Gefahr einer Ausweisung aus Wien, sollten doch bald nach dem Erlass der oktroyierten Märzverfassung Juden, die in Wien kein Heimatrecht besaßen (und dazu gehörte auch der im mährischen Polná geborene und heimatberechtigte Journalist), aus der Stadt abgeschoben werden. In seinem Tagebuch notierte er unter dem 27. April I 849: »Heute muß jeder auf einen Zettel seine Beschäftigung, Geburtsort und Religion angeben und dies durch den Hausherrn der Polizei zukommen lassen, damit diese in ihrer hohen Weisheit erwägt, wer fortgejagt werden soll oder nicht. Es scheint berechnet zu sein, sich einer großen Zahl Juden zu entledigen. So wie denn überhaupt die Fremden aufs Korn genommen werden sollen ...«198

\section{Juden Als ÖSTERREICHISChe ReICHSbÜRGeR}

Dennoch: Obwohl die Märzverfassung von I 849 eine "oktroyierte«, d. h. von der Regierung eingesetzte, war und nach dem kühnen Verfassungsentwurf von Kremsier

194 Kaiserliches Patent 151 »über die durch die konstitutionelle Staatsform gewährleisteten politischen Rechte« vom 4. März 1849.

195 Grab, Judenemanzipation, S. 26.

196 Vgl. Lohrmann, Finanz, S. 206; zu Mannheimer siehe auch: Marsha L. Rozenblit: Jewish Identity and the Modern Rabbi: The Cases of Isak Noa Mannehimer, Adolf Jellinek, and Moritz Güdemann in Nineteenth-Century Vienna, in: Leo Baeck Institute Year Book XXXV (1990), S. 103131, hier: S. 104-110.

197 Gasser, Erlebte Revolution, S. 341.

198 Ebenda, S. 369. Ein Schicksal, das ihn wenige Jahre später tatsächlich ereilt habe dürfte. Sein Biograph und Herausgeber des Tagebuchs, Wolfgang Gasser, vermag zwar keine genauen Ursachen für Kewalls plötzliche Rückkehr nach Polná anzugeben, sieht dahinter jedoch ein »einschneidendes, traumatisches Erlebnis«, das alle Chancen in seinem Leben zunichte gemacht habe. Vgl. Gasser, Erlebte Revolution, S. 132 
viele enttäuschte, wird das "allgemeine österreichische Reichsbürgerrecht", das nun selbst in den ungarischen Ländern galt, oft als die "vollkommenste Ausformung" des österreichischen Staatsbürgerschaftsrechts gepriesen. ${ }^{199}$ Die Staatsrechtslehre der späten Monarchie sieht mit der Reichsbürgerschaft von I 849 das verwirklicht, wonach schon die Autoren des Allgemeinen bürgerlichen Gesetzbuches gestrebt hätten: die Zurückweisung jeglichen Partikularismus, die Aufhebung jeder besonderen Landeszugehörigkeit, die Verwirklichung des modernen Einheitsstaates. ${ }^{200}$ Franz von Stadion hatte zwar bewusst vieles, was im Entwurf von Kremsier enthalten war, in die Verfassung einfließen lassen, doch vor dem Volk als der "Gesamtheit der Staatsbürger « - so die Formulierung im Kremsierer Grundrechtskatalog - schreckte er zurück. Ersatzweise und im Sinne eines strengen Zentralismus dekretierte er, dass in keinem Kronlande "zwischen seinen Angehörigen und jenen eines anderen Kronlandes ein Unterschied im bürgerlichen und politischen Rechte, im Rechtsverfahren und in der Verteilung der öffentlichen Lasten « bestehen solle. ${ }^{201}$ Aus liberaler Sicht bedeutete das Reichsbürgerrecht des Frühkonstitutionalismus einen Fortschritt, eine Wende hin zum modernen Verfassungsstaat. Auch die österreichischen Juden begrüßten es emphatisch, erklärte doch der $₫$ I der Märzverfassung, dass der Genuss der bürgerlichen und politischen Rechte vom Religionsbekenntnis unabhängig sei. ${ }^{202}$ Zwar waren von Seiten der Konservativen (vor allem Karl Friedrich Freiherr v. Kübeck) Bedenken gegen die implizite Einbeziehung von Juden in den Artikel über die Glaubens- und Gewissensfreiheit erhoben worden, doch die Mehrheit des Kabinetts war von der Notwendigkeit einer prinzipiellen Anerkennung der Emanzipation - wenn auch aus unterschiedlichen, nicht immer edlen Motiven - überzeugt. ${ }^{203}$ Die faktische Umsetzung sollte mit einem besonderen Reichsgesetz geregelt werden, mit dessen Vorbereitung Justizminister Schmerling betraut wurde. Darüber hinaus wurde im Ministerrat vom 29. März I 849 positiv entschieden, dass "Juden nunmehr zum Besitze von Häusern qualifiziert seien «. ${ }^{204}$ Mit der Grundbesitzfähigkeit hatten

199 Siehe Rudolf v. Herrnritt: Handbuch des österreichischen Verfassungsrechtes (Tübingen 1909), S. 79.

200 Josef Fritz Redlich: Das österreichische Staats- und Reichsproblem, Bd. I (Leipzig 1929), S. $341 \mathrm{ff}$.

$201 \mathrm{Vgl}$. Burger, Staatsbürgerschaft, S. 162f.

202 Vgl. Edmund Bernatzik: Österreichische Verfassungsgesetze (Wien 1911), S. 39ff.

203 Justizminister Bach warnte: "Wenn man die Juden als Parias behandelt, so hat man es mit einer sehr gefährlichen Klasse von Menschen zu tun. Sie haben das große Wort in der Presse, in den Volksversammlungen und viele Geldmittel zur Disposition. "Die Protokolle des Österreichischen Ministerrates 1848-1867. ÖMRProt II./1, Regierung Schwarzenberg, bearbeitet von Thomas Kletečka (Wien 2002), Nr. 20 v. 20. Februar 1849.

204 Eine diesbezügliche Anfrage der Niederösterreichischen Landesregierung wurde durch Justizminister Alexander Bach mit Hinweis auf die Bestimmungen des $\$ 1$ der österreichischen Grundrechte bejaht. ÖMRProt II/1, bearbeitet von Thomas Kletečka (Wien 2005), Nr. 39, v. 29. März 1849. 
sie de facto das volle Bürgerrecht erreicht. Am 3. April I 849 richteten die Wiener Juden eine Dankadresse an Kaiser Franz Joseph. Dieser erwiderte den Dank mit einem Handbillet, das an die Vertreter der »israelitischen Gemeinde von Wien« adressiert war (womit er implizit auch die bisher verweigerte Fähigkeit der Juden zur Gemeindebildung anerkannte). ${ }^{205}$

\section{InKLusion und ExkLusion von Juden in DeR Zeit des Neoabsolutismus}

Die neuen Prinzipien konfessioneller Gleichberechtigung wurden zu Beginn der Regierung Schwarzenberg durchaus noch umgesetzt. Im September I 849 fiel der "politische Ehekonsens« für Juden, d. h. die vor jeder jüdischen Eheschließung einzuholende Zustimmung des Kreisamtes bzw. der zuständigen Landesstelle. ${ }^{206}$ Und Justizminister Anton v. Schmerling befürwortete in einer Denkschrift betreffend die Gleichberechtigung der Juden vom I 8 . November I 849 ausdrücklich die Aufhebung von $\$ 64$ des Allgemeinen bürgerlichen Gesetzbuches, wonach Ehen zwischen Christen und Juden verboten waren. ${ }^{207}$ Im Laufe des Jahres I 8 50/5 I fielen weitere einschränkende Bestimmungen: Juden wurden zur Richteramtsprüfung zugelassen, die neue Notariatsverordnung sah keinerlei Beschränkungen hinsichtlich der Konfession mehr vor, und in einer »Pulververschleißordnung « wurde eine Juden ausschließende Klausel gestrichen. ${ }^{208}$ Doch am 3 I. Dezember I 85 I - knapp nach dem in Frankreich erfolgten Staatsstreich - wurde die neue Verfassung mit kaiserlichem Patent (dem sogenannte Silvesterpatent) sistiert. Was diese Aufhebung der Verfassung hinsichtlich der Rechte der Juden bedeutete, war zunächst unklar. Als eine Frankfurter Zeitung berichtete, dass in Österreich ein Gesetz über die politische Stellung der Israeliten vorbereitet würde, stellte Außenminister Graf Buol-Schauenstein im Ministerrat die Frage, wie man der großen Beunruhigung unter den österreichischen Juden begegnen wolle. Innenminister Bach entgegnete, dass die Verfassung vom 4. März I 849 alle Staatsbürger in ihren Rechten gleichstelle, wodurch früher bestandenen Beschränkungen für Juden aufgehoben worden seien. Durch die allerhöchs-

205 Vgl. Wolf, Juden, S. 153.

206 Verordnung der niederösterreichischen Landesregierung vom 11. September 1849. Ausführlicher dazu: Heinrich Jaques: Denkschrift (Wien 1859), S. XVIIIf. Zu den Besonderheiten des bürgerlichen Eherechts in Bezug auf Juden, insbesondere hinsichtlich der Ehehindernisse, der Ungültigkeit von Ehen, bei Scheidung und Trennung vgl. Ignaz Graßl: Das besondere Eherecht der Juden in Österreich nach den $\$ \$ 123-136$ des allgemeinen bürgerlichen Gesetzbuches (Wien 1838).

207 Vgl. Wolf, Juden, S. 153.

208 Vgl. Jaques, Denkschrift, S. XXI. 
ten Verfügungen vom 3 I. Dezember I 85 I (über die Sistierung der Verfassung) sei über die Judensache nichts entschieden worden, und so stelle sich die Frage, "wie die Juden zu behandeln und ihre mittlerweile geschlossenen Geschäfte über den Besitz etc. zu ordnen seien, was alles den Behörden vielfältige und peinliche Verlegenheiten verursache. " Man beschloss daraufhin, als Entgegnung einen »beruhigenden Artikel « in »irgendeine Zeitung einrücken zu lassen «, in welchem zu versichern sei, dass nach Abschluss aller Verhandlungen bezüglich die Ordnung der Judensache »mit Zuversicht erwartet werden könne«, dass eine künftige Gesetzgebung "allen Rücksichten der Humanität und der Gerechtigkeit entsprechen « werde. ${ }^{209}$ Ein solcher Artikel erschien allerdings ebenso wenig wie das befürchtete Gesetz. ${ }^{210}$

Im Ausland wurde die neue restriktivere Judenpolitik Österreichs schon sehr bald wahrgenommen; sie scheint mitursächlich dafür gewesen zu sein, dass Österreich I 853 in London beim Versuch einer Kapitalaufnahme scheiterte. ${ }^{211}$ Zwar blieb das Recht auf Grundbesitz, das der Gemeinderat der Residenzstadt Wien bestrebt war, sofort aufzuheben, zunächst erhalten, auch hatte der Kaiser noch am 29. Juli seiner Regierung "die Verhandlung über die Regulierung der staatsbürgerlichen Verhältnisse der Israeliten mit tunlicher Beschleunigung« zur »besonderen Pflicht« gemacht ${ }^{212}$, doch eine Verordnung vom 2. Oktober I 853 bestimmte schließlich, dass der in den einzelnen Kronländern vor der Verfassung von I 849 bestehende Rechtszustand hinsichtlich der Grundbesitzfähigkeit von Juden wieder herzustellen sei. ${ }^{213}$

209 ÖMProt III/1, Das Ministerium Buol-Schauenstein, bearbeitet von Waltraud Heindl (Wien 1975), MK Nr. 61 vom 13. November 1852, S. $318 f$.

210 Ebenda, Fußnote 5.

211 ÖMProt. III/4, Das Ministerium Buol-Schauenstein, bearbeitet von Waltraud Heindl (Wien 1987), Einleitung S. XVIII.

212 Ah. Entschließung zum Vortrag Bachs v. 6. Juni 1853. "Bis Ich über die im Zuge befindlichen Verhandlungen in Absicht auf die Regulierung der staatsbürgerlichen Verhältnisse der Israeliten gesetzgebende Beschlüsse zu fassen in der Lage bin, halte Ich es den Umständen entsprechend, die in den verschiedenen Kronländern Meine Reiches vor dem Jahre 1848 bestandenen Bestimmungen des Bürgerlichen Gesetzbuches oder, wo solches nicht in Kraft war, der allgemeinen Gesetze modifizierenden politischen Verordnungen über die Besitzfähigkeit der Israeliten provisorisch in Wirksamkeit treten zu lassen, wobei die von den Israeliten bis dahin und in der Zwischenzeit erworbenen und als rechtmäßig anzusehenden Realbesitzungen ungestört zu bleiben hätten. (...) Ich mache es Ihnen übrigens zur besonderen Pflichte, die Verhandlungen über die Regulierung der staatsbürgerlichen Verhältnisse der Israeliten mit tunlichster Beschleunigung zum Abschluß zu bringen ...« Zit. nach: ÖMProt. III/2, Nr. 156 Ministerkonferenz v. 3. September 1853, S. 309. Ähnlich lautend auch: Handschreiben Kaiser Franz Josephs an den Minister des Innern Bach v. 29. Juli 1853, zit. nach: Wolf, Juden, S. $156 \mathrm{f}$.

213 Kaiserliche Verordnung v. 2. Oktober 1853 über die provisorische Wirksamkeit der vor dem Jahre 1848 bestandenen, die Besitzfähigkeit der Israeliten beschränkenden Vorschriften. Reichsgesetzblatt für das Kaisertum Österreich RGBl. Nr. 190/1853. Dazu auch: ÖMProt. III/2, Nr. 163 v. 4. Oktober 1853. 
In Wien mussten Juden jetzt, wollten sie Grundbesitz erwerben, ein Majestätsgesuch einreichen und »besondere Verdienste" geltend machen. Das bedeutete, dass österreichische Juden gegenüber ausländischen schlechter gestellt waren, da es beispielsweise preußischen jüdischen Untertanen sehr wohl gestattet war, in Wien Haus- und Grundbesitz zu erwerben. ${ }^{214}$

Tatsächlich war der Rechtszustand der Juden (nach Kronländern differenziert) bis zum Jahr I 859 etwa jener, wie er vor der Revolution von I 848 bestanden hatte ${ }^{215}$, d. h. viele der alten Sonderrechte traten wieder in Kraft. Juden wurden durch Gesetz oder durch die Rechtspraxis vom Staatsdienst ausgeschlossen ${ }^{216}$, in ihrer Freizügigkeit stark eingeschränkt und das Grundbesitzrecht blieb ihnen versagt. Bereits erworbene Güter und Häuser durften zwar behalten, doch nicht vererbt werden. Nach und nach wurden seitens der Landesregierungen die alten, Juden exkludierenden Gesetzesbestimmungen - teilweise durch Republikation alter Dekrete - wieder in Kraft gesetzt. So hatte etwa die Böhmische Statthalterei eine fragwürdige Entscheidung bezüglich der Stellung christlicher Dienstboten bei Juden getroffen, die unter den Juden sowie bei in- und ausländischen Presseorganen für Empörung sorgte, sodass der Kaiser der Statthalterei einen Bericht abverlangte und mit allerhöchster Entschließung vom 23. November I 853 bestimmte, »dass keine Länderstelle in Judensachen Verordnungen ohne Zustimmung des Ministeriums des Inneren erlassen dürfe. «217 Auch in Galizien und Ungarn hatten die Statthalterei bzw. die Komitatsbehörde ein Hofdekret von I 8 I7 republiziert, wonach es Juden verwehrt war, christliche Dienstboten zu halten, ein Topos, der sich in vielen alten Judenordnungen fand und über Jahrhunderte fortgeschrieben worden war. ${ }^{218}$ Trotz des kaiserlichen Verbots ließen einzelne Landesregierungen immer mehr überwunden geglaubte Juden exkludierende Verordnungen wieder aufleben, sodass I 855 Innenminister Bach die Unterbehörden sogar ausdrücklich darauf hinweisen musste, dass diese aufgehoben und Juden sehr wohl Gemeindeangehörige und »österreichische Staatsbürger»

214 Vgl. Wolf, Juden, S. 158.

215 Von der geringen Bedeutung der bürgerlichen Revolution von 1848 für die Emanzipation der Juden ist u. a. Werner Mosse überzeugt. Vgl. Werner E. Mosse: From »Schutzjuden« to "Deutsche Staatsbürger Jüdischen Glaubens«. The Long and Bumpy Road of Jewish Emancipation in Germany, in: Birnbaum/Katznelson, Paths of Emancipation, a.a.O., S. 59-93, hier: S. 83f.

216 So wurde im Ministerkonferenz vom 4. Oktober 1853 beschlossen, die zahlreich eingegangenen Ansuchen um Aufnahme in den Staatsdienst seitens »Individuen jüdischen Glaubens« bis zu einer endgültigen kaiserlichen Verfügung über diesen Gegenstand nicht nachzukommen, »aber auch bis zum Bekanntwerden der diesfälligen Ah. Befehle nicht definitiv zurückzuweisen«. ÖMProt. III/2, Nr. 156 v. 3. September 1853, S. 309.

217 ÖMProt. III/2, Nr. 154 v. 20. August 1853, Fußnote 10.

218 Jacques, Denkschrift, S. XCVI. 
seien. ${ }^{219}$ Der spätere Reichsratsabgeordnete Heinrich Jaques, der als junger Rechtsanwaltskandidat im Jahr I 859 jenes, wie er sagte, "schmerzensschwere Stück österreichischer Rechtsgeschichte« zusammengefasst hat, befand über die Zeit des Neoabsolutismus, »dass die Praxis in allen nur irgend dem Gesetze nach zweifelhaften, ja selbst in nahezu unzweifelhaften Fällen gegen die Juden entschieden habe, dass man z. B. bei keiner politischen, bei keiner Justizbehörde im ganzen Kaiserreiche auch nur in den niedersten Beamtenstellen (...) einen Juden angestellt finden wird «. ${ }^{20}$

Erst der verlorene Krieg gegen Italien im Jahr I 859 ließ den Neoabsolutismus obsolet erscheinen. Innere Reformen und die allmähliche Rückkehr zu verfassungsmäßigen Zuständen, vor allem aber ständiger Druck aus dem Ausland, brachten den Juden allmählich ihre Rechte zurück. Zwar konnte sich die Regierung nicht zu einer vollkommenen Gleichstellung der Juden, wie sie etwa Joseph Wertheimer in seiner im Herbst I 859 veröffentlichten Schrift: "Die Regelung der staatsbürgerlichen Stellung der Juden in Österreich « forderte, entschließen, doch setzte sie immerhin kleine Schritte in die richtige Richtung. Ende Oktober I 89 sprach sich die Mehrheit der Ministerkonferenz für die Rücknahme des in Galizien (und Ungarn) für Juden bestehenden Verbots, christliche Dienstboten zu beschäftigen, aus. Innenminister Gołuchowski, der ehemalige Statthalter von Galizien, hatte das Gesetz zunächst mit dem Argument verteidigt, »christliche Dienstboten würden bei Juden demoralisiert und der christlichen Religion entfremdet«. Doch als Ministerpräsident Rechberg in der Ministerkonferenz vom 29. Oktober I 859 von den »immerwährenden Angriffen der in- und ausländischen Presse, denen Österreich in dieser Frage ausgesetzt sei«, berichtete, wurde das Verbot auf Antrag des Innenministers schließlich aufgehoben. ${ }^{221}$ Im Vortrag Gołuchowskis wurde die Aufhebung vor allem mit wirtschaftlichen und sozialen Argumenten begründet. Da man Juden jetzt vermehrt als Gewerbetreibende gewinnen wolle (eine neue Gewerbeordnung war in Vorbereitung), schließe das ein Verbot, christliche Dienstboten zu beschäftigen, geradezu aus. ${ }^{22}$ Weiters erfolgte unter der Regierung Rechberg: die Aufhebung aller Sonderbestimmungen betreffend die Eheschließung von Juden im Allgemeinen bürgerlichen Gesetzbuch ${ }^{223}$; die Aufhebung des Verbots des Aufenthalts von Juden in Bergbaustädten und -orten Ungarns und Böhmens ${ }^{224}$; die Aufhebung von Gewerbebeschränkungen für Juden im Apotheken-, Mühlen-, Brauerei-, Brennerei-

219 Vgl. Wolf, Juden, S. 158.

220 Jaques, Denkschrift, S. XCVII.

221 Ministerratskonferenz vom 29. Oktober 1859. ÖMProt. IV/1, Das Ministerium Rechberg, bearbeitet von Stefan Malfèr (Wien 2003), Einleitung, S. LVIIIf.

222 Ebenda, S. LX.

223 MK v. 29.10.1859/VII und am 1.11.1859/IV.

224 MK v. $17.11 .1859 / \mathrm{V}$. 
und Schankgewerbe (in Zusammenhang mit der neuen Gewerbeordnung) und die Aufhebung des Aufenthaltsverbots außerhalb von Städten für Galizien und die Bukowina. ${ }^{225}$

Die wohl wichtigste Reform aber war die Beseitigung des Realitäten- und Grundbesitzverbotes für Juden. Diese war in mehreren Ministerkonferenzen heftig und kontrovers diskutiert worden. Im September I 859 war ein Gesetz erschienen, wonach die kaiserliche Regierung eine noch in Ungarn, Kroatien und Slavonien bestehende Beschränkung des Niederlassungs- und Grunderwerbsrechtes für Protestanten (den 26. ungarischen Diätal-Artikel aus dem Jahr I79I) aufhob, und darüber hinaus ihren Wunsch verkündete, dass auch "die Ausschließung der Protestanten aus Tirol nunmehr ihr Ende nehme«. ${ }^{226}$ Dies führte zu einer öffentlichen Debatte darüber, ob nun auch Juden das Niederlassungsrecht an allen Orten sowie der Realitätenbesitz zu gestatten sei. Einer Juden immer wieder vorgehaltenen unpatriotischen, kosmopolitischen, gar revolutionären Gesinnung könne am ehesten dadurch begegnet werden, argumentierte etwa Heinrich Jaques, dass man ihnen den Grundbesitz, in dem die Wurzel der Heimatliebe liege, gestatte. ${ }^{227}$ In der Ministerkonferenz wurde das Thema ebenfalls ausführlich erläutert. Unterrichtsminister Thun konnte sich zwar den Erwerb städtischer Immobilien durch Juden vorstellen, nicht aber den Erwerb landtäflicher (adliger) und bäuerlicher Güter. Finanzminister Bruck warnte jedoch zum wiederholten Male vor dem Einfluss der Juden auf den »öffentlichen Kredit« und vor den zu befürchtenden negativen Konsequenzen im Falle einer Aufrechterhaltung des Realitätenbesitzverbotes auf die österreichischen Finanzoperationen. ${ }^{228}$ Budgetnöte und die Befürchtung negativer Reaktionen der internationalen Finanzmärkte gaben

225 MK v. 17.11.1859/V.

226 Zit. nach: Jaques, Denkschrift, S. 11.

227 Ebenda, S. 25.

228 Finanzminister Bruck bemerkte in der Ministerkonferenz vom 31. Dezember 1859, dass für das abgelaufene Verwaltungsjahr noch ein Abgang von 70 Millionen Gulden zu decken und das Erfordernis des laufenden sicherzustellen sei. Dies könne nur durch eine "Kreditoperation" geschehen. Er habe aber mit seinen Anträgen gezögert, weil zur Erleichterung der Durchführung noch eine sehr wichtige Maßnahme der Regierung fehle, und zwar, »die Zulassung der Juden zum Realbesitz«. Der Einfluss der Juden auf den öffentlichen Kredit sei bekannt. Würden sie in ihren gerechten Erwartungen getäuscht, so sei auf ihre Mitwirkung für eine österreichische Finanzoperation nicht zu rechnen. Der Finanzminister bat daher "um baldigste und liberalste Erledigung und gab zu Bedenken, dass die daraus sich ergebenden vereinzelten Übelstände und Nachteile gering seien, gegenüber »der Aufrechterhaltung größerer Beschränkungen des Judenbesitzes für unsern Kredit im In- und Auslande." ÖMProt. IV/1, Das Ministerium Rechberg, hg. Stefan Malfèr (Wien 2003), Protokoll Nr. 87 vom 31. Dezember 1859, S. 350 und Einleitung, S. LX. Diese vermeintliche "Ubiquität in Zeit und Raum« nährte, nach Dan Diner, "Vorstellungen über die vorgebliche Allmacht « der Juden und nistete sich »in den Kern dessen ein, was man Antisemitismus nennt«. Diner, Synchrone Welten, S. 30. 
schließlich den Ausschlag dafür, dass sich Ende Dezember I 859 die Ministerkonferenz darauf einigte, Juden den Besitz von Grund und Realitäten in Niederösterreich, Böhmen, Mähren und Schlesien, dem Küstenland und Dalmatien sowie in Ungarn zu gestatten. In Galizien und der Bukowina sollte der Besitzerwerb vom Bildungsgrad abhängig gemacht werden (trotz des Einwandes des Justizministers, dass eine solche Einschränkung, Realeigentum zu erwerben, wohl noch nirgendwo, »weder in Österreich noch anderwärts«, bestanden habe.) ${ }^{229}$ Der Finanzminister Bruck verteidigte jedoch die Gesetzesvorlage, weil »die Unterscheidung nach der erworbenen Bildung ein (An)sporn für die Jugend « sein werde, besitzfähig zu werden, allerdings sollten auch jene Juden, die »im k. k. Militär gedient haben« bezüglich der Besitzfähigkeit "gleich den christlichen Untertanen « behandelt werden. ${ }^{230}$ In den übrigen Kronländern Tirol, Salzburg, Oberösterreich, Kärnten, Krain und der Steiermark sollten jedoch Beschränkungen hinsichtlich der Grundbesitzfähigkeit aufrecht bleiben. Nachdem Finanzminister Bruck den zögernden Kaiser zweimal in dieser Sache bedrängt hatte ${ }^{231}$, unterschrieb Franz Joseph im März I 860 das neue Gesetz über die Zulassung von Juden zum Realitäten- und Grundbesitzerwerb. ${ }^{232}$

Eine weitere wichtige, Juden inkludierende Regelung wurde schließlich im Jahr I 863 beraten und beschlossen: die Zulassung von Juden zum Notariat. Am 5. Oktober 1863 berichtete Justizminister Ritter von Hein im Ministerrat, dass das Herrenhaus gegenwärtig über einen Gesetzesentwurf berate, wonach die in der Notariatordnung vom 2I. Mai I 855 implizit enthaltene Ausschließung von Juden vom Notariat (der entsprechende Paragraph lautete: "Zur Erlangung einer Notariatstelle wird erfordert, dass der Bewerber österreichischer Staatsbürger, 24 Jahre alt, der christlichen Religion zugetan [...] sei«) aufgehoben werden solle. Das Abgeordnetenhaus habe dem Antrag (des Abgeordneten Dr. Mühlfeld) bereits zugestimmt. Der Vorsitzende, Staatsratspräsident Erzherzog Rainer, versicherte, dass auch vom Regierungsstandpunkte dem Antrag nicht entgegenzutreten sei, "weil eine Besorgnis, dass der jüdische Notar bei konfessionellen Akten mit Christen in eine schiefrige (sic!) Lage geraten könnte, unbegründet sei." Daraufhin einigte man sich im Ministerrat, dass man dem Antrag des Herrenhauses nicht entgegentreten werde. ${ }^{233}$ Wenige Tage später, am I 4. Oktober I 863, erklärte sich die judizielle Kommission des Herrenhauses mit der vom Abgeordnetenhaus angenommenen Änderung des Paragraphen 7 der Notariatordnung vom 2 I. Mai I 855 einverstanden. In der darauffolgenden Debatte

229 Einleitung, S. LX.

230 MK v. 31. Dezember 1859/IV. Nr. 87, S. $348 f$.

$231 \mathrm{MK}$ v. 1.2.1860/III und MK v. 9.2.1860/V.

232 Einleitung, S. LX.

233 Ministerrat vom 5. Oktober 1863, ÖMProt. VI, Die Ministerien Erzherzog Rainer und Mensdorff, bearbeitet von Thomas Kletečka/Klaus Koch (Wien 1989), Nr. 401. 
im Herrenhaus stellte der Abgeordnete Leo Graf Thun einen einschränkenden Zusatzantrag, der $\$ 7$ nur insoweit außer Kraft setzen wollte, als bloß in Orten, »deren Bevölkerung teilweise aus Juden besteht, auch Juden zu Notaren ernannt werden können«. Dieser von Kardinal Josef Rauscher (Inhaber einer Virilstimme im Herrenhaus) unterstützte Antrag blieb jedoch in der Minderheit, sodass der Gesetzentwurf des Abgeordnetenhauses vom Herrenhaus schließlich unverändert in dritter Lesung angenommen wurde. Die kaiserliche Sanktion erhielt das Gesetz am I 3. November I 863. In der »allerhöchsten Entschließung « fügte Kaiser Franz Joseph allerdings einschränkend hinzu: „Es ist jedoch mein Wille, dass in denjenigen Kronländern, in welchen keine Israeliten ansässig sind, Bewerbern dieses Religionsbekenntnisses keine Notariatstelle verliehen werden. «234

\section{Das Heimatrecht der österreichischen Juden}

Eine eigentümliche Färbung erhielt das österreichische Staatsbürgerschaftsrecht durch seine enge Verknüpfung mit einem anderen, viel älteren Rechtsinstitut, dem Heimatrecht. ${ }^{235}$ Das Heimatrecht (vor I 849 "politisches Domicil«) gehörte zu den Grundelementen altösterreichischer Staatlichkeit. Es war lange Zeit die erste und einzige normative Grundlage für die Unterscheidung von Einheimischen (Untertanen/Staatsbürgern) und Fremden. Zurück geht es auf das Jahr I 552, als König Ferdinand (später Kaiser Ferdinand I.) mit einer Verordnung die Gemeinden für die Versorgung ihrer Armen verantwortlich machte. Seine staatsrechtliche Ausgestaltung erfuhr das Gemeindeprinzip in der Zeit des theresianisch-josephinischen Reformabsolutismus, als es im Interesse der Durchsetzung des modernen Territorialstaates notwendig schien, »jedem Individuum seinen Platz« zuzuweisen. In eine Vielzahl von Konskriptions-, Bettler- und Schubverordnungen flossen seit Mitte des I 8. Jahrhunderts armenrechtliche, sozialfürsorgerische, polizeiliche, militärische und bevölkerungspolitische Ordnungsvorstellungen ein, die zu einer nie zuvor dagewesenen Disziplinierung und Territorialisierung der Bevölkerung führen. Sesshaftigkeit wurde zum Gebot, "fremde« Bettler und Vaganten wurden erbarmungslos abgeschoben, einheimische versorgt. Dabei wurde die Gemeinde zum einzigen Ort, wo man heimisch (zuständig) war, von wo man nicht abgeschoben werden konnte und von dem man im Verarmungsfall erwarten durfte, erhalten zu werden. ${ }^{236}$

234 Ebenda, Fußnote 6 und RGBl. Nr. 94/1863.

235 Vgl. Harald Wendelin, Das Heimatrecht, in: Heindl/Saurer (Hg.): Grenze und Staat, S. 195-230. 236 Eine Hofentschließung vom 16. November 1754 listet drei Kategorien von Menschen auf, die im Verarmungsfall Anspruch auf Versorgung durch ihre Heimatgemeinde haben:

»a) diejenigen Personen, welche sich in einem anderen Erblande ansässig gemachet, das Bürgerrecht 
Auch hier stellt sich zunächst die Frage, ab wann man von einem Heimatrecht für Juden überhaupt sprechen kann, waren doch diese in ihrer Niederlassungsfreiheit - wie oben beschrieben - die längste Zeit hindurch äußersten Restriktionen unterworfen. Nach einem Hofkanzleidekret vom ı. Jänner I 82 I bewirkte allerdings die Erteilung der Toleranz bzw. einer Familienstelle, wie Friedrich Swieceny ausdrücklich festhielt, sehr wohl »den Erwerbstitel der Ortszuständigkeit und die Quelle, aus der alle Glieder der mit diesem Schutze ausgestatteten Familie das Heimatrecht für sich schöpfen«, was bedeutete, dass Juden, die an einem Ort beständig toleriert waren, auch "zu dessen einheimischer Bevölkerung zu zählen« waren. Jene Juden, die nur eine zeitweise und periodisch zu erneuernde Tolerierung genossen, gehörten hingegen zur Bevölkerung jenes Ortes, wo sie selbst oder ihre Familie im Besitz einer Familienstelle waren. ${ }^{237}$

Da die Toleranz jedoch nur gegen eine jährlich zu entrichtende hohe Gebühr vergeben wurde ${ }^{238}$, blieb die Aufnahme in den Gemeindeverband in der Praxis nur sehr wohlhabenden Juden vorbehalten. Zahllose Dekrete regelten in restriktiver Weise die Niederlassung von Juden und Jüdinnen (Witwen), deren Toleranz abgelaufen war, von jüngeren Söhnen, die nicht im Besitz einer Familienstelle waren, von jüdischen Ärzten, Waisen etc. ${ }^{239}$ Erst in den I 83oer-Jahren wurde die Praxis liberaler. Den Ortsgemeinden und Städten blieb es nun selbst überlassen, über die Ansiedlung von Juden zu entscheiden. ${ }^{240}$

Leitendes Prinzip des Heimatrechts war es, dass grundsätzlich jeder Staatsbürger einer und nur einer Gemeinde angehören sollte. Erworben wurde das Heimatrecht

ordentlich erworben oder als unbehauste Innwohner ihr Gewerbe oder Profession getrieben oder so gestaltig bis zur erfolgten Mühseligkeit (Verarmung) die gemeine Last mitzutragen geholfen haben, b) jene, welche entweder bei einer Gemeinde oder bei Privaten an einem Orte durch 10 Jahre in Diensten gestanden sind,

c) solche, die zwar ebenfalls 10 Jahre in einem andern als ihrem Geburtslande entweder durch Dienstleistung oder auf eine andere Art ihr Brot erworben, jedoch durch dies Zeit nicht an einem, sondern mehreren Orten des Landes sich aufgehalten haben«. Zit. nach: Ingobert Goldemund/ Kurt Ringhofer/Karl Theuer: Das österreichische Staatsbürgerschaftsrecht (Wien 1969), S. 568.

237 Friedrich Swieceny: Das Heimatrecht in den österreichischen Kronländern mit constituierten Ortsgemeinden (Wien 1861), Einleitung $₫ 18$.

238 Über die Erteilung der Toleranz in Wien und Niederösterreich vgl. Barth-Barthenheim, Gesetzeskunde, S. $40 \mathrm{f}$.

239 Franz Tobias Herzog: Sammlung der Gesetze über das politische Domizil im Kaiserthume Österreich (Wien 1837), S. $120 \mathrm{ff}$.

240 »Diejenigen Juden, welche sich in dem Falle des $\$ 51$ des Judenpatents vom J. 1797 befinden, kann der Aufenthalt außer dem Orte der Familie, zu der sie gehören, nur dann gestattet werden, wenn die Obrigkeit des Ortes, wo sie sich anzusiedeln wünschen, ihre Zustimmung gibt, was auch von den Städten zu gelten hat.", Hofentschließung vom 18. März 1835, zit. nach: Herzog, Politisches Domizil, S. $172 \mathrm{f}$. 
zu allererst durch Geburt. Fremde erwarben es entweder durch einen zehnjährigen ununterbrochenen Aufenthalt oder durch Verehelichung (bei Frauen), durch Antretung des Bürger- und Meisterrechtes, Ankauf eines Grundstückes oder Antretung eines öffentlichen Dienstes. ${ }^{241}$ Von den letzten drei Erwerbsarten waren Juden bis I 849 grundsätzlich ausgeschlossen, sodass sie de facto nur nach dem Erwerbsgrund des zehnjährigen ununterbrochenen Aufenthalts das Heimatrecht in einer Stadtgemeinde erwerben konnten.

Spätestens mit der Einführung des Allgemeinen Bürgerlichen Gesetzbuches im Jahr I 8 I I trat neben das Heimatrecht die Staatsbürgerschaft als neues, wesentlich umfassenderes Instrument der Bestimmung von Zugehörigkeit und Einheimischsein. Das Nebeneinander zweier verschiedener Konzeptionen der Integration, der »modernen« staatsbürgerlichen in den großen Raum der österreichischen Monarchie und der älteren heimatrechtlichen in den engen Raum der Gemeinde, bestimmte fortan nicht nur den Rechtsstatus einer Person, sondern in hohem Ausmaß auch deren Identität. In der Praxis führte dieses Nebeneinander zweier unterschiedlicher Rechtsinstrumente zu zahlreichen Ungereimtheiten und Unschärfen. ${ }^{242}$ Obwohl staatsrechtlich ein klares Primat der Staatsbürgerschaft über das Heimatrecht postuliert war ${ }^{243}$, hatte diese in der Alltagspraxis eine ungleich geringere Bedeutung als das die konkreten Lebensverhältnisse der Menschen viel stärker berührende Heimatrecht.

Mit dem nach der Bürgerlichen Revolution von I 848 - allerdings bloß vorübergehend - sich durchsetzenden liberalen Konstitutionalismus gewann das Heimatrecht zusätzlich Terrain gegenüber der Staatsbürgerschaft. Die freie Gemeinde wurde zum Baustein der neuen politischen Ordnung. "Zum Staatsbürgertume muss man durch das Gemeindebürgertum kommen«, lautete eines der Grundprinzipien der (oktroyierten) Märzverfassung und des provisorischen Gemeindegesetzes von I 849. ${ }^{244}$ Nach den neuen gesetzlichen Bestimmungen konnte die Aufnahme ausdrücklich, d.h. durch Gemeindebeschluss oder stillschweigend - nach jetzt bloß vierjährigem Aufenthalt - erfolgen. ${ }^{245}$ Das provisorische Gemeindegesetz von I 849

$241 \mathrm{Vgl}$. Wendelin, Heimatrecht S. $198 \mathrm{f}$.

242 Ebenda, S. 215.

243 Nach Joseph Ulbrich ist »die österreichische Staatsbürgerschaft durchaus das primäre Verhältnis, das Heimatrecht ist ein sekundäres Verhältnis, welches an die Voraussetzung der Staatsbürgerschaft gebunden ist«. Joseph Ulbrich: Das österreichische Staatsrecht (Tübingen 1904), S. 95.

244 Jiří Klabouch: Die Gemeindeverwaltung in Österreich 1948-1918 (Wien 1986), S. 32.

245 "Die Aufnahme in den Gemeindeverband erfolgt entweder: a) durch förmlichen Gemeindebeschluß oder b) stillschweigend durch Duldung eines ohne Heimatschein oder mit einem bereits erloschenen Heimatschein sich durch vier Jahre ununterbrochenen in der Gemeinde aufhaltenden, die österreichischen Staatsbürgerschaft besitzenden Fremden, endlich c) bei Frauenpersonen durch die Verehelichung mit einem Gemeindegliede." $₫ 12$ des provisorischen Gemeindegesetzes v. 17. März 1849, RGBl. Nr. 70/1849, zit. nach: Goldemund, Staatsbürgerschaft, S. 588. 
galt - entsprechend dem Grundsatz der Märzverfassung, dass der Genuss der bürgerlichen und politischen Rechte vom Religionsbekenntnis unabhängig sei ( I $_{\text {) }}$ - auch für die österreichischen Juden. Da wenige Tage später Juden auch die Haus- und Grundbesitzfähigkeit zugestanden wurde (siehe oben), konnten Juden nun das volle Bürgerrecht in einer Gemeinde erlangen. Die alten Judenordnungen waren damit aufgehoben.

Die Bestätigung der Aufnahme durch die Gemeinde erfolgte mittels des mit dem provisorischen Gemeindegesetz eingeführten Heimatscheins. Der Heimatschein wurde für seinen Besitzer (oder seine Besitzerin) fortan nicht nur zum Beweismittel der "Zuständigkeit«, sondern auch zum Ausweis seiner/ihrer Identität. Darüber hinaus erfüllte er zahlreiche weitere Funktionen, darunter die eines Inlandsreisepasses. ${ }^{246}$ Mit der Heimatrechtsgesetzgebung nach I 849 erfolgte insgesamt eine staatsrechtliche Schließung. Seit dem Gemeindegesetz von I 859 galt: „Nur Staatsbürger können das Heimatrecht erwerben. Jeder Staatsbürger soll in einer Gemeinde heimatberechtigt sein «. ${ }^{247}$ Weiters wurde bestimmt, dass das Heimatrecht nicht mehr, wie zuvor, stillschweigend durch vierjährigen Aufenthalt erworben wurde, sondern nur noch nach ausdrücklichem Beschluss des Gemeindeausschusses. Allerdings bestand, wenn der Bewerber (oder in seltenen Fällen die Bewerberin) alle Bedingungen erfüllte, ein Rechtsanspruch auf Einbürgerung, und es gab - im Falle der Verweigerung - eine Berufungsinstanz. ${ }^{248}$ Wegen der mit dem Heimatrecht verbundenen armenrechtlichen Versorgungsansprüche wehrten sich Gemeinden jedoch immer häufiger, mittellose Neubürger aufzunehmen. Zunehmend wurde seitens der Gemeinden ein Ausweis von Vermögen gefordert, eine Bedingung, die ein Hofkanzleidekret von I 8 I 6 einst ausdrücklich zurückgewiesen hatte. ${ }^{249}$ Zudem verloren Juden nach der Aufhebung der oktroyierten Märzverfassung wieder das Grundbesitzrecht und damit eine wesentliche Möglichkeit, das Heimat- und Bürgerrecht in einer Ortsgemeinde zu erwerben.

Eine weitere Reform des Heimatrechts im Jahr I 863 verwirklichte eine Grundforderung des liberalen Bürgertums, nämlich »die völlige Freiheit der Gemeinde, den Kreis ihrer Angehörigen zu bestimmen «. ${ }^{250}$ Zwar änderte sich an den bestehenden Erwerbsarten kaum etwas, doch mit $\$ 8$ des Gesetzes wurde (außer bei Geburt und Heirat) jeder Rechtsanspruch ausgeschlossen. ${ }^{251}$ Somit hatten die Gemeinden die

246 Vgl. Swieceny, Heimatrecht S. 44-47.

$247 \$ 2$ des Gemeindegesetzes von 1859, zit. nach: Goldemund, Staatsbürgerschaft, S. $603 f$.

$248 \$ 39$ des Gemeindegesetzes vom 24. April 1859, RGBl. Nr. 58/1859.

249 Vgl. Burger, Staatsbürgerschaft, S. 165.

250 RGBl. Nr. 105/1863. Vgl. Klabouch, Gemeindeverwaltung, S. 69.

251 "Das Heimatrecht wird durch ausdrückliche Aufnahme in den Heimatverband erworben. Über das Ansuchen hierum entscheidet mit Ausschluß jeder Berufung die Gemeinde.«, $₫ 8$ des Heimat- 
Freiheit, Personen, die ihnen, aus welchen Gründen immer, nicht genehm waren, vom »Recht des ungestörten Aufenthalts und dem Anspruch auf Armenversorgung « auszuschließen. Eine "Ersitzung« des Heimatrechts war nun nicht mehr möglich. Zwar galt nach wie vor der staatsrechtliche Grundsatz, dass das Heimatrecht bloß eine notwendige Ergänzung der Staatsbürgerschaft sei und man im Streitfall die Entscheidung über diese keinesfalls den Gemeinden selbst überlassen dürfe, doch in der Realität kam den Gemeinden große Macht bei der Ausstellung bzw. Verweigerung von Heimatscheinen zu. ${ }^{252}$ Eine Konsequenz war, dass die wachsende Zahl der Arbeiter in den Industriegemeinden praktisch nie das Heimatrecht (und damit eine wenn auch nur rudimentäre soziale Absicherung) an ihren Aufenthalts- und Arbeitsorten erlangen konnte, was sie dem Druck einer möglichen Abschiebung an den Ort ihrer formalen Heimatzuständigkeit aussetzte. Die Tendenz, Armen das Heimatrecht zu verweigern, galt stärker noch bei Juden. Allerdings hatte sich deren Rechtsstellung insgesamt inzwischen dadurch verbessert, dass ihnen im Jahr I 860 nicht nur das Grundbesitzrecht zurückgegeben, sondern mit der liberalen Gewerbeordnung von I 859 - die die alte Zunftordnung abschaffte - auch der Zugang zu ihnen zuvor verschlossenen Berufen gewährt worden war (eben diese Gewerbeordnung von I 859 wird rund zwanzig Jahre später von antisemitischen Handwerkern und Gewerbetreibenden als »legislativer Sündenbock« benutzt werden und wurde damit zu einem Baustein des modernen Antisemitismus der frühen I 88oer-Jahre). ${ }^{253}$ $\mathrm{Ab}$ den I 86oer-Jahren unterlagen Juden dann, was die Erlangung des Heimatrechts anbelangt, denselben - vor allem sozialen - Ausschließungsgründen wie alle anderen Bewerber auch.

\section{Die Sonderstellung der "türkischen « Juden}

Eine der Möglichkeiten für Juden, sich den zahlreichen »Bedrückungen« zu entziehen, war - neben der Konversion zum Christentum - die Annahme der türkischen (osmanischen) Staatsbürgerschaft. Eine der Paradoxien im österreichischen Staatsbürgerschaftsrecht bestand nämlich darin, dass fremde Juden - insbesondere aber solche, die »in der Bothmäßigkeit« der Hohen Pforte standen, d. h. osmanische Untertanen waren - in vielerlei Hinsicht größere Freiheiten genossen als tolerierte österreichische Juden. Die Freiheiten der »türkischen Handelsleute« - meist

rechtsgesetz von 1863 (HRG 1863), RGBl. Nr. 105/63, zit. Nach: Goldemund, Staatsbürgerschaftsrecht, S. 518.

252 Vgl. Burger, Staatsbürgerschaft, S. 165.

253 Vgl. John W. Boyer: Karl Lueger (1844-1910). Christlichsoziale Politik als Beruf (= Studien zu Politik und Verwaltung 93) (Wien/Köln/Weimar 2010), S. 30. 
sephardische Juden, deren Vorfahren einst im Zuge der Reconquista aus Spanien vertrieben und ins Osmanische Reich eingewandert waren - gingen auf die zahlreichen wechselseitigen Begünstigungsklauseln in den Friedensverträgen von Karlowitz ( I 699), Passarowitz ( I 7 8), Belgrad (I739) und Sistova (I 79I) zurück. Insbesondere garantierte der Friede von Passarowitz den Untertanen beider Reiche Freizügigkeit im jeweils anderen Staatsgebiet. So genossen die sephardischen, »türkischen« Juden in Österreich weitgehend Religionsfreiheit, gründeten eigene Gemeinden in Triest/ Trieste/Trst und Wien, errichteten Synagogen und Bethäuser nach eigenem Ritus (in Wien den architektonisch eindrucksvollen, im maurisch-orientalischem Stil gehaltenen Tempel in der Zirkusgasse) und waren in mancherlei Hinsicht grandiose Mittler zwischen Orient und Okzident. ${ }^{254}$

Grundsätzlich war es den türkischen Händlern - Muslimen, Juden oder »Rajas ${ }^{255}$ - möglich, die österreichische Staatsbürgerschaft zu erwerben, auch wenn die Pforte einen solchen Übertritt nach dem Frieden von Sistova vom August I79I nicht mehr anerkannte und in Österreich der Grundsatz galt, dass »bei Erteilung der Staatsbürgerschaft an türkische Untertanen nur sparsam vorgegangen « werden solle. ${ }^{256}$ Mussten sich muslimische Untertanen der Hohen Pforte vor einem Übertritt »in die österreichische Bothmäßigkeit« taufen lassen, so war dies bei Juden nicht erforderlich. ${ }^{257} \mathrm{Im}$ Allgemeinen handelte es sich bei den seltenen Ansuchen um Erlangung der Naturalisation um bereits länger in Österreich ansässige Großhändler, die die Erweiterung ihres Großhandelspatents um Waren anstrebten, die weder österreichischer noch türkischer Herkunft waren und die dazu die österreichische Staatsbürgerschaft benötigten. (Für alle anderen war es jedoch günstiger, die osmanische Staatsangehörigkeit zu behalten, da sie sonst bestimmte - vor allem passrechtliche - Vorteile verloren hätten).

Immer häufiger kam jedoch der umgekehrte Fall vor, dass österreichische Juden, die nicht im Besitz einer Familienstelle waren oder deren Toleranz nicht verlängert worden war, in die Türkei auswanderten, dort ottomanische Untertanen wurden und später mit einem türkischen Pass (Teskères) nach Österreich zurückkehrten, um auf diese Weise ein unbeschränktes Aufenthaltsrecht in Österreich zu erwerben. ${ }^{258}$

254 Vgl. Die Türken in Wien. Geschichte einer jüdischen Gemeinde. Jüdisches Museum Wien (Hg.). Katalog zur gleichnamigen Ausstellung (Wien 2010), siehe auch: N.M. Gelber: The Sephardic Community in Vienna, in: Jewish Social Studies, 10 (1948), S. 359-396.

255 Nichtmuslimische Untertanen der Hohen Pforte.

256 Hofdekret v. 12. Februar 1807, zit. nach: Vesque, Behandlung, S. 27.

257 Vgl. Christina Kaul: Die Rechtsstellung der türkischen Juden in Wien auf Grund der österreichisch-türkischen Staatsverträge, Diplomarbeit (Salzburg 1990), S. $74 f$.

258 Vgl. Stoklásková, Fremdsein in Böhmen und Mähren, in: Heindl/Saurer (Hg.): Grenze und Staat, S. 673. 
Hintergrund dieser Praxis waren die Reformen der sogenannten »Tanzimatzeit«, die insgesamt eine Annäherung des Osmanischen Reiches an die bürgerlichen Freiheitsund Rechtsverhältnisse der westlichen Staatenwelt brachten. Innerhalb dieser Reformbestrebungen war in den Jahren I 839, I 856 und I 876 die Gleichstellung aller osmanischen Untertanen ohne Unterschied der Religionszugehörigkeit verfügt worden. Eine Intention hinter dieser Erhebung von Christen und Juden zu im Prinzip gleichberechtigten osmanischen Staatsbürgern war es, den europäischen Mächten die Möglichkeit zu entziehen, sich unter dem Vorwand des Schutzes ihrer christlichen Glaubensgenossen in die inneren Angelegenheiten des Osmanischen Reiches einzumischen - ein Ziel, das allerdings nicht erreicht wurde. ${ }^{259}$ Dem rechtlich oft ungeklärten Status »türkischer Juden« (sie konnten entweder osmanische Untertanen, österreichische Staatsbürger oder österreichische "Schutzgenossen« sein) ist es zuzuschreiben, dass sich die in Österreich ansässigen Sepharden oft gleichzeitig als loyale Untertanen des Sultans wie des österreichischen Kaisers fühlten, was sich auf der symbolischen Ebene etwa in der Ausstellung der Porträts beider Herrscher im Vorraum des prächtigen sephardischen Tempels in Wien ausdrückte.

259 Barbara Haider-Wilson: Die Habsburgermonarchie und das Heilige Land 1842-1917. Schutzmachtpolitik, katholisches »Jerusalem-Milieu« und Volksfrömmigkeit, phil. Diss. (Wien 2007), S. 118. 


\title{
Die Entwicklung von Heimatrecht und Staatsbürgerschaft in der Epoche des Ausgleichs
}

\author{
Der Anteil der Juden an den Einbürgerungen
}

Am 5. August I 878 erschien der 42-jährige, im ungarischen Szilar-Balhás (Komitat Veszprém) geborene Fächermacher Josef Wertheimer vor dem Magistrat der Reichshaupt- und Residenzstadt Wien, legte eine übersetzte und beglaubigte Urkunde über seine Entlassung aus der »königlichen ungarischen Staatsbürgerschaft « vor und gelobte, nachdem er über »die Wichtigkeit der erhaltenen Wohltat und der mit der Staatsbürgerschaft verbundenen Vorzüge« seitens eines Magistratsbeamten belehrt worden war, "von nun an als Untertan dem Allerdurchlauchtigsten Fürsten und Herrn, Franz Josef I., Kaiser von Österreich « treu und gehorsam zu sein, und »die bestehenden Gesetze genau beobachten, und überhaupt alle Pflichten und Verbindlichkeiten eines getreuen österreichischen Untertanen pünktlich" erfüllen zu wollen. Nach diesem wenig spektakulären Treueschwur (galt dieser doch dem gleichen Herrn, dem Josef Wertheimer immer schon ein treuer Untertan gewesen war, mit dem Unterschied, dass es sich für ihn dabei bisher um den König von Ungarn gehandelt hatte) erhielt er wenige Tage später eine Urkunde, die ihm bestätigte, dass er nunmehr »überall als österreichischer Staatsbürger und in Wien heimatberechtigt anzusehen und zu behandeln« sei. Mit ihm zugleich eingebürgert worden waren seine Frau und seine vier bereits in Wien geborenen Kinder. Josef Wertheimer war, wie viele andere Juden auch, im »Ausgleichsjahr" I 867 nach Wien gekommen, hatte zunächst als Handwerker und Einkäufer gearbeitet und in Mariahilf zur Untermiete gewohnt. Im Jahr I 873 hatte er hier ein Haus erworben und eine Fächerfabrik errichtet. Inzwischen beschäftigte er in seinem Unternehmen vier Gehilfinnen. Es verwundert kaum, dass der Vorsteher des sechsten Wiener Gemeindebezirks das Ansuchen des „tüchtigen und rechten Geschäftsmannes« um Aufnahme in den Gemeindeverband wärmstens befürwortete. ${ }^{260}$ Am gleichen Tag wie Josef Wertheimer erhielt auch der aus Breslau gebürtige, 35-jährige Kaufmann Salomon Cohn, zusammen mit seiner Ehefrau Camilla und seinen beiden in Wien geborenen Söhnen, nachdem er seine Entlassungsurkunde aus der preußischen Staatsangehörigkeit vorgelegt hatte, die österreichische Staatsbürgerschaft. ${ }^{261}$

260 Wiener Stadt- und Landesarchiv (im Folgenden zitiert als WStLA), Hauptreg. P Nr. 47231/1878. 261 WStLA, Hauptreg. P Nr. 15067/1878. 
Zehn Jahre nach dem Ausgleich mit Ungarn und dem Staatsgrundgesetz über die allgemeinen Rechte der Staatsbürger vom 21. Dezember I 867 stieg die Zahl der in den österreichischen Staatsverband aufgenommenen Juden stetig an. Ab I88o erreichte ihr Anteil an den Eingebürgerten stets Werte zwischen 20 und 35 Prozent, im Spitzenjahr I 888 sogar 35, o I Prozent ${ }^{262}$ - ein Trend der bis zur Jahrhundertwende ungebrochen anhält.

\begin{tabular}{|c|c|c|c|c|c|c|c|c|c|}
\hline \multicolumn{5}{|c|}{ ES WURDEN JUDEN } & \multicolumn{5}{|c|}{ ES WURDEN JUDEN } \\
\hline \multirow{4}{*}{ 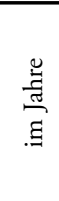 } & \multicolumn{2}{|c|}{ in den } & \multirow{2}{*}{\multicolumn{2}{|c|}{ aus dem }} & \multirow{4}{*}{ 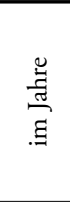 } & \multicolumn{2}{|c|}{ in den } & \multicolumn{2}{|c|}{ aus dem } \\
\hline & \multicolumn{2}{|c|}{ österreichischen Staatsverband } & & & & \multicolumn{4}{|c|}{ österreichischen Staatsverband } \\
\hline & \multicolumn{2}{|c|}{ aufgenommen } & \multicolumn{2}{|c|}{ entlassen } & & \multicolumn{2}{|c|}{ aufgenommen } & \multicolumn{2}{|c|}{ entlassen } \\
\hline & absolut & $\begin{array}{l}\text { prozen- } \\
\text { tualiter }\end{array}$ & absolut & $\begin{array}{l}\text { prozen- } \\
\text { tualiter }\end{array}$ & & absolut & $\begin{array}{l}\text { prozen- } \\
\text { tualiter }\end{array}$ & absolut & $\begin{array}{l}\text { prozen- } \\
\text { tualiter }\end{array}$ \\
\hline 1885 & 771 & 28,22 & 218 & 6,23 & 1895 & $\begin{array}{r}946 \\
(683)\end{array}$ & 26,76 & $\begin{array}{c}257 \\
(188)\end{array}$ & 9,56 \\
\hline 1886 & $\begin{array}{r}741 \\
(540)\end{array}$ & 21,59 & $\begin{array}{l}290 \\
(202)\end{array}$ & 7,13 & 1896 & $\begin{array}{r}659 \\
(476)\end{array}$ & 20,62 & $\begin{array}{c}243 \\
(171)\end{array}$ & 7,56 \\
\hline 1887 & $\begin{array}{l}1225 \\
(834)\end{array}$ & 33,49 & $\begin{array}{c}185 \\
(124)\end{array}$ & 4,63 & 1897 & $\begin{array}{r}616 \\
(447)\end{array}$ & 16,10 & $\begin{array}{c}281 \\
(186)\end{array}$ & 9,11 \\
\hline 1888 & $\begin{array}{l}1187 \\
(818)\end{array}$ & 35,01 & $\begin{array}{c}224 \\
(151)\end{array}$ & 5,94 & 1898 & $\begin{array}{r}293 \\
(210)\end{array}$ & 10,32 & $\begin{array}{c}291 \\
(205)\end{array}$ & 8,17 \\
\hline 1889 & $\begin{array}{r}794 \\
(587)\end{array}$ & 26,36 & $\begin{array}{l}196 \\
(127)\end{array}$ & 6,68 & 1899 & $\begin{array}{l}113 \\
(63)\end{array}$ & 4,41 & $\begin{array}{l}354 \\
(231)\end{array}$ & 7,96 \\
\hline 1890 & $\begin{array}{r}580 \\
(411)\end{array}$ & 24,37 & $\begin{array}{c}173 \\
(116)\end{array}$ & 5,92 & 1900 & $\begin{array}{r}175 \\
(115)\end{array}$ & 8,21 & $\begin{array}{c}341 \\
(237)\end{array}$ & \\
\hline 1891 & $\begin{array}{r}897 \\
(658)\end{array}$ & 26,46 & $\begin{array}{l}208 \\
(143)\end{array}$ & 6,07 & 1901 & $\begin{array}{r}230 \\
(147)\end{array}$ & 7,91 & $\begin{array}{l}390 \\
(272)\end{array}$ & 8,11 \\
\hline 1892 & $\begin{array}{r}787 \\
(573)\end{array}$ & $\begin{array}{l}26,73 \\
25,86\end{array}$ & $\begin{array}{c}237 \\
(168)\end{array}$ & 6,52 & 1902 & $\begin{array}{r}845 \\
(610)\end{array}$ & 15,59 & $\begin{array}{c}390 \\
(268)\end{array}$ & $\begin{array}{l}8,18 \\
7,62\end{array}$ \\
\hline 1893 & $\begin{array}{r}761 \\
(555)\end{array}$ & & $\begin{array}{c}242 \\
(173)\end{array}$ & 7,04 & 1903 & $\begin{array}{l}1102 \\
(812)\end{array}$ & 17,10 & $\begin{array}{c}352 \\
(245)\end{array}$ & 7,00 \\
\hline 1894 & $\begin{array}{r}688 \\
(484)\end{array}$ & 23,05 & $\begin{array}{c}213 \\
(158)\end{array}$ & 7,05 & & & & & \\
\hline
\end{tabular}

Tabelle I: Ein- und Ausbürgerungen von Juden in Österreich zwischen I885 und I903, nach Jacob Thon

So waren von im Zeitraum I 893 bis 1902 in den österreichischen Staatsverband aufgenommenen I 5968 Personen 5326 jüdischer (»mosaischer») Konfession - 33,35

262 Jacob Thon: Die Juden in Österreich. Veröffentlichungen des Bureaus für Statistik der Juden, Heft 4 (Berlin 1908), S. 49. 
Prozent (bei einem jüdischen Bevölkerungsanteil von nur 4,7 Prozent). ${ }^{263}$ Von diesen wiederum stammte die überwältigende Mehrheit, nämlich 448 I Personen, aus Ungarn, gefolgt von Russland (27I), Preußen (I70), Rumänien (I09). ${ }^{264}$

Was waren die Gründe für diesen - verglichen mit dem Ausland - hohen Anteil an Juden an den Einbürgerungen? Während etwa in Großbritannien in jenen Jahren eine Immigrationsdebatte geführt wurde, mit dem Ziel, die Einbürgerung insbesondere russischer jüdischer Pogromflüchtlinge zu verhindern ${ }^{265}$, und es, wie Eli Nathans gezeigt hat, auch in Preußen in den I88oer-Jahren nicht nur zur Ausweisung von etwa Io ooo polnischen und russischen Juden kam, sondern zugleich zu einer restriktiven, ethnisch exklusiven Staatsbürgerschaftspolitik gegenüber Polen im Allgemeinen und polnischen und russischen Juden im Besonderen ${ }^{266}$, sind dies in Österreich gerade jene Jahre, in denen der jüdische Anteil an den Einbürgerungen besonders hoch ist. Während die Immigration von Juden im Deutschen Kaiserreich ab Mitte der I 88oer-Jahre als "gefährlich und zu verhindern « angesehen wurde ${ }^{267}$, ließ sich ein ähnlicher Trend in Österreich - obwohl auch hier, insbesondere mit dem Erscheinen Georg Schönerers auf der politischen Bühne, ein rauer antisemitischer Ton eingezogen war - nicht feststellen. Die zahlreichen, seit Ende der Achtzigerjahre von Abgeordneten aller Kronländer initiierten Interpellationen, die auf ein Einwanderungsverbot für vornehmlich aus Russland kommende Juden zielten, blieben im Abgeordnetenhaus des österreichischen Reichsrats erfolglos. Alle diesbezüglichen Anträge wurden abgewiesen. ${ }^{268}$

263 Thon, Juden in Österreich, S. 53.

264 Thon, Juden in Österreich, S. 53. Erst nach der Jahrhundertwende wurde der jüdische Anteil an den Einbürgerungen geringer: 1909 ergingen von 1935 Aufnahmezertifikaten (samt Familienangehörigen 5952 Personen) 17,8 Prozent an jüdische Bewerber. Österreichisches Statistisches Handbuch für die im Reichsrate vertretenen Königreiche und Länder, 29 Jg. (1910), Tabelle 11, S. 34.

2651905 trat dann der restriktive "Aliens Act» in Kraft. Vgl. Gammerl, Untertanen, S. 228.

266 Nur innerhalb eines schmalen Zeitfensters Anfang der 1870er-Jahre waren in Preußen fremde Juden in nennenswerter Zahl eingebürgert worden. Vgl. Eli Nathans: The Politics of Citizenship in Germany. Ethnicity, Utility and Nationalism (Oxford/New York 2004), S. 111 und Tab. 4.3, S. 99. $\mathrm{Zu}$ den ethnischen Ausschließungen nach dem Staatsangehörigkeitsgesetz von 1913 vgl. Caitlin E. Murdock: The Politics of Belonging: Citizenship, Community, and Territory on the SaxonBohemian Frontier, 1918-1924, in: Austrian History Yearbook 43 (2012) S. 59-74.

267 Nathans, Politics of Citizenship, S. 123.

268 Etwa 1891 vom Abgeordneten Hauck und Genossen, 1897,1900 und 1901 vom Abgeordneten Schönerer und 1901 vom Abgeordneten Prochazka. Vgl. Gammerl, Untertanen, S. 81f. und Fußnote 28 . 


\section{Die Vermehrung der jüdischen Bevölkerung in Cisleithanien}

Ganz allgemein ist nach I 867 ein sprunghaftes Anwachsen der jüdischen Bevölkerung zu bemerken. War die Bevölkerung Österreichs (Cisleithaniens, oder, korrekt: "der im Reichsrat vertretenen Königreiche und Länder«) im Jahr I 880 seit der letzten Zählung um 7,9 Prozent, so war die jüdische Bevölkerung gleich um 22,9 Prozent gewachsen. ${ }^{269}$ Für Wien waren die Zahlen noch bemerkenswerter. Hier betrug der Anstieg der jüdischen Bevölkerung gegenüber der vorherigen Zählung gleich 8I, I Prozent (42 708 Personen), gegenüber einem Wachstum der Gesamtbevölkerung von nur I7, I Prozent. ${ }^{270}$ Insgesamt erreichte der jüdische Bevölkerungsanteil in Wien jetzt Io,6 Prozent. ${ }^{271}$

Zwar wird bis heute immer wieder die Ungenauigkeit bzw. Unvergleichbarkeit der Ergebnisse der verschiedenen Zählungen hervorgehoben, die zum einen daraus resultiere, dass die Volkszählungen vor I 880 vorwiegend zum Zwecke der militärischen Konskription durchgeführt wurden - der sich orthodoxe Juden in Galizien aus religiösen Gründen oft zu entziehen suchten -, zum anderen einmal die tatsächlich anwesende Bevölkerung, dann wieder nur die einheimische (heimatberechtigte) Bevölkerung erhoben wurde, doch trotz dieser Inkonsistenzen bleibt, wie der Statistiker Gustav Schimmer feststellt, »die ganz abnorme Zunahme der Juden noch immer auffallend $«{ }^{272}$

Das bis zur Jahrhundertwende starke Wachstum der jüdischen Bevölkerung, aber auch die in anderen Bereichen für Juden ermittelten Zahlen (geringere Säuglingssterblichkeit, geringere Tuberkuloseerkrankungen), kurz das "außerhalb jeden Verhältnisses « Stehende der jüdischen Daten ${ }^{273}$, führte nicht nur zu Spekulationen bezüglich relevanter sozialer und wirtschaftlicher Faktoren, sondern auch bezüglich anderer Hygiene- und Gesundheitsstandards, abweichender Familienstrukturen, religiöser Traditionen etc., sodass es nach der Jahrhundertwende sogar zur Gründung eines eigenen »Bureaus für jüdische Statistik « mit Sitz in Berlin kam. ${ }^{274}$

269 Vgl. Gustav A. Schimmer: Die Juden in Österreich nach der Zählung vom 31. Dezember 1880 (Wien 1881), S. 4.

270 Thon, Juden, S. 9.

271 In absoluten Zahlen: 72588 Personen. Nach der Eingemeindung der Wiener Vororte im Jahr 1890 sank ihr Prozentanteil auf 8,6 Prozent (118 495 Personen). Vgl. Wolfdieter Bihl: Die Juden, in: Adam Wandruszka/Peter Urbanitsch (Hg.) : Die Habsburgermonarchie 1848-1918, Bd. III/2, Die Völker des Reichs (Wien 1980), S. 880-948, hier: S. 884.

272 Schimmer, Statistik, S. 5.

273 Schimmer, Statistik, S. 7.

274 Sein erster Direktor war Arthur Ruppin. Vgl. Kernmayer, Assimilation, Dissimilation, Transkulturation, in: Csáky (Hg.) Kultur - Identität - Differenz, S. 1-17, hier: S. 12. 


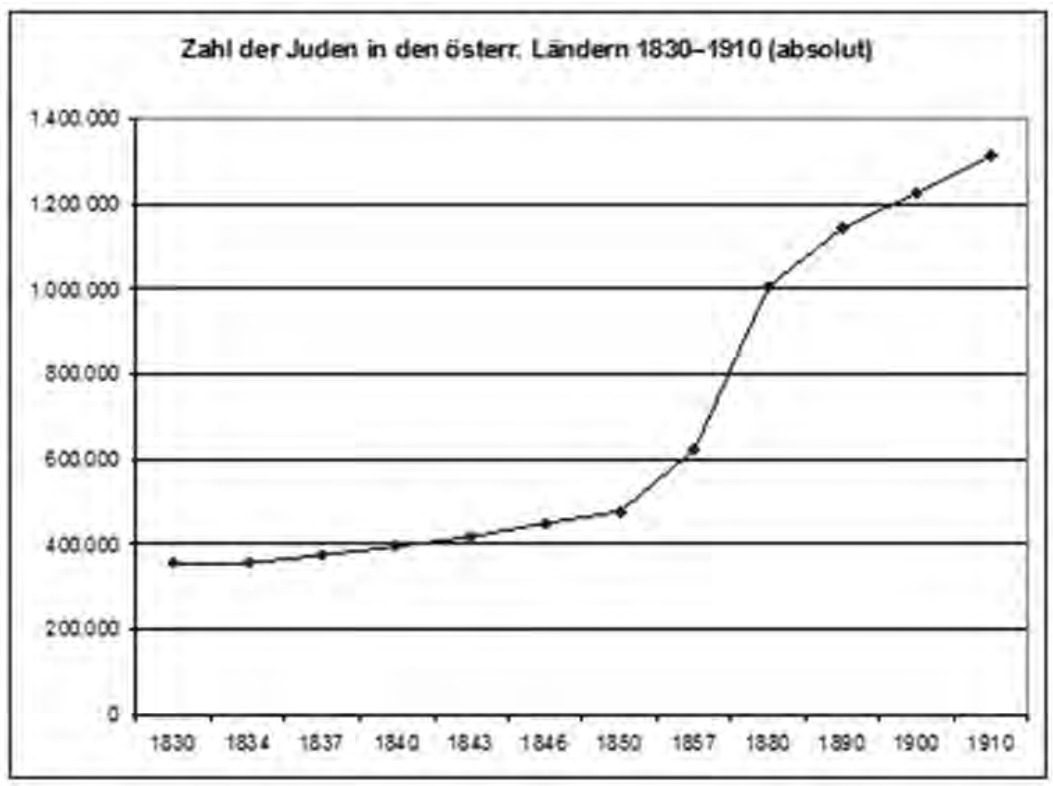

Abb. II: Zahl der Juden in den österreichischen Ländern I830-I9I0, nach Thon

Lässt sich die Vermehrung der jüdischen Bevölkerung an der Peripherie des Reiches in Galizien um I9,2 Prozent (absolut um I Io 678 Personen), in der Bukowina um 4I Prozent (etwa 20000 Personen) ${ }^{275}$ - noch mit dem Zuzug aus dem nahen Ausland, vor allem von Pogromflüchtlingen aus Russland, erklären, so verdankt sich der Anstieg der Juden in Wien nicht so sehr dem Zuzug aus dem Ausland, sondern einer gewaltigen Binnenmigration. Das explosionsartige Anwachsen der Metropolen im letzten Drittel des I9. Jahrhunderts war ein allgemeines europäisches Phänomen. Auch das kosmopolitisch gewordene Wien der I 870er- und I 88oer-Jahre verdankte seine Größe, wie Hans Tietze feststellt, keineswegs nur dem jüdischen Zuzug. Dennoch hätten Urbanisierung und Modernisierung (etwa die Schleifung der Basteien und der Bau der Ringstraße) sowie die durch den Liberalismus ausgelöste wirtschaftliche Dynamik ganz besonders Juden angezogen. ${ }^{276}$ Diesen wurde dann häufig eine "größere Beweglichkeit «"277, ein immer schon vorhandener Wandertrieb (gleichsam als »ewiger Ahasver«) als Identitätsmoment unterstellt. ${ }^{278}$ Übersehen wird dabei,

275 Thon, Juden, S. 9.

276 Tietze, Juden Wiens, S. 215.

277 Vgl. Thon, Juden, S. 50.

278 Zum Ahasver-Mythos siehe: Lovis M. Wambach: Ahasver und Kafka. Zur Bedeutung der Judenfeindschaft in dessen Leben und Werk (Heidelberg 1993), S. 5 ff. Kritisch dazu: Kernmayer-Hödl, Assimilation, S. 6. 
dass die »erhöhte Mobilität« von Juden in der zweiten Hälfte des I9. Jahrhunderts nicht so sehr durch eine wie auch immer geartete "Wanderlust « ausgelöst wurde, sondern vielmehr durch Verfolgungen und Pogrome sowie die in vielen Staaten noch immer vorhandene äußerst prekäre staatsbürgerliche Stellung von Juden.

\section{Die rechtliche Gleichstellung der Juden durCh das StaAtsgrundgesetz ÜBer die Allgemeinen Rechte der StaAtsbürger} im Dezember i 867

Mit dem Inkrafttreten der Dezemberverfassung von I 867 hatte sich die rechtliche Stellung der Juden in Österreich grundsätzlich verändert. Fast zwanzig Jahre nach der gescheiterten Revolution von I 848 war den Juden die uneingeschränkte Gleichberechtigung mit allen anderen Staatsbürgern gewährt worden. ${ }^{279}$ Die "jüdische Frage«, jener den Werten der Aufklärung und des Deutschen Idealismus verpflichtete Diskurs, wie er sich in der gesamten intellektuellen Community von Mendelssohn, Fichte, Lessing, Hegel, Herder und Humboldt bis hinauf zu Bruno Bauer und Karl Marx während eines halben Jahrhunderts entfaltet hatte ${ }^{280}$, schien damit (für die österreichische Monarchie) endgültig beantwortet zu sein. Die Antwort lautete nicht länger mehr: Teilhabe an Staat und Gesellschaft nach vorangegangener Emanzipation, d. h. allmähliche Transformation des Judentums durch Aufklärung und Bildung (bis hin zu seinem vollständigem Verschwinden) ${ }^{281}$, sondern die Antwort hieß jetzt, in der zweiten Hälfte des I9. Jahrhunderts und unter den Bedingungen einer liberalen Verfassung und des Ausgleichs mit Ungarn: Gleichheit vor dem Gesetz

279 Artikel 1 des Staatsgrundgesetzes lautet: „Für alle Angehörigen der im Reichsrate vertretenen Königreiche und Länder besteht ein allgemeines österreichisches Staatsbürgerrecht.« RGBl. Nr. 142/ 1867. Michael Brenner weist darauf hin, dass die österreichischen Juden schon vier Jahre bevor Bismarck im Zuge der Reichseinigung die deutschen Juden den übrigen Staatsangehörigen gleichstellte, die Gleichberechtigung erlangt hätten. Michael Brenner: Vom Untertanen zum Bürger, in: Michael Brenner et al.: Deutsch-Jüdische Geschichte in der Neuzeit, Bd. 2 (Emanzipation und Akkulturation) (München 1996), S. 260-355, hier: S. 320.

280 Zur »Judenfrage« siehe u. a. Tamás Ungvári: The Jewish Question` in Europe. The Case of Hungary (New York 2000), S. 9ff sowie: Ulrich Wyrwa: Juden in der Toskana und in Preußen im Vergleich (= Schriftenreihe wissenschaftliche Abhandlungen des Leo Baeck Instituts 67) (Tübingen 2003), S. $430 \mathrm{ff}$.

281 Zum ambivalenten Verhältnis des Deutschen Idealismus zum Judentum siehe vor allem die Studie von Micha Brumlik: Deutscher Geist und Judenhass (München 2002), dazu auch: Jacob Katz: Vom Vorurteil bis zur Vernichtung. Der Antisemitismus 1700-1933 (München 1989), S. 57ff sowie jüngst: Christoph Schulte: Moses Mendelssohn, die jüdische Aufklärung und der Pluralismus im modernen Judentum, in: Eveline Goodman-Thau/Fania Oz-Salzberger (Hg.): Das jüdische Erbe Europas (Berlin/Wien 2005), S. 77-91. 
(Artikel 2), Freizügigkeit und Niederlassungsfreiheit (Artikel 6), volle Glaubens- und Gewissensfreiheit (Artikel I 4) ${ }^{282}$ - kurz: full citizenship. Alle Besonderheiten und Partikularismen, alle alten Beschränkungen auf bestimmte Berufsfelder und Siedlungsräume waren damit beseitigt. ${ }^{283}$ Aus einst bloß Tolerierten waren Staatsbürger und (mit starken, vor allem familienrechtlichen Einschränkungen) Staatsbürgerinnen mit gleichen Rechten und Pflichten geworden. Wenige Tage später wurde auch in der transleithanischen Reichshälfte (Ungarn) mit Artikel I7 des ungarischen Verfassungsgesetzes - sein Schöpfer war der liberale jüdische Staatsrechtler Joseph von Eötvös - die rechtliche Gleichstellung der Juden durchgesetzt. ${ }^{284}$

\section{RüCKkehr IN Die "Verbotene Stadt «}

Eine fast unmittelbare Folge der durch das Staatsgrundgesetz gewährten Freizügigkeit (Artikel 6) war eine gewaltige jüdische Migrationsbewegung. Tausende strömten aus allen Teilen der Monarchie vor allem in die Metropolen Wien und Budapest. Das in der älteren Literatur manchmal favorisierte Modell einer Ost-Westwanderung der Juden, d. h. einer überwiegenden Migration aus den jüdischen »Kernländern« Galizien und Bukowina ${ }^{285}$, erweist sich allerdings - zumindest für die ersten beiden Jahrzehnte nach dem Ausgleich - als nicht zutreffend. Bereits Leopold Moser fand in seiner Untersuchung der Grabinschriften des Währinger jüdischen Friedhofs heraus, dass ein Großteil der Zuwanderer aus den oberungarischen (heute: slowakischen) Gemeinden Bösing/Pezinok/Bazin, Geiring, Holitsch/Holič, Joka Korompa/Krompachy, Kuklov/Kukló, Groß-Magendorf/Velký Mager sowie den früheren Wiedertäufergemeinden Senitz und Sobotiz) kam, alles Gemeinden, die nahe der (nieder)österreichischen Grenze lagen, deren Hausierer und Händler schon früher in lebhaftem Handel mit Wien gestanden seien und »deren Einwohnerschaft sich in der Mehrzahl aus Nachkommen mährischer Juden zusammensetzte«. ${ }^{286}$ Die noch unabgeschlossene jüngste Untersuchung des »Gräberbuchs« des Währinger Friedhofs bestätigt

\footnotetext{
282 RGBl. Nr. 142/1867.
}

283 Vollendet wurde die Emanzipation der Juden durch die Interkonfessionellen Gesetze sowie die sogenannten Maigesetzte des Jahres 1868.

$284 \mathrm{Vgl}$. Gerald Stourzh: The Age of Emancipation and Assimilation - Liberalism and its Heritage, in: Hanni Mittelmann/Armin A. Wallas (Hg.): Österreich-Konzeptionen und jüdisches Selbstverständnis. Identitäts-Tranfigurationen im 19. und 20. Jahrhundert (Tübingen 2001), S. 11-28, hier. S. $11 \mathrm{f}$.

285 Vgl. Anson G. Rabinbach: The Migration of Galician Jews to Vienna, 1857-1880, in: The Austrian History Yearbook, Bd. 9 (1975), S. 42-54.

286 Leopold Moser: Spaziergänge, in: P. Steines (Hg.): Studien und Skizzen zur Geschichte der Juden in Österreich (Wien 1994), S. 48-59, hier: S. $56 f$. 
diesen Befund und weist bei etwa einem Sechstel der in den Jahren I784-I880 in Währing bestatteten Juden und Jüdinnen einen Geburtsort in Mähren aus. ${ }^{287}$ Marsha Rozenblit spricht anhand der Analyse von Geburts- und Heiratsdaten der Wiener Juden von drei sich überlappenden Wellen jüdischer Zuwanderung: einer böhmischmährischen, einer ungarischen und einer galizischen. ${ }^{288}$ Und zuletzt bestätigt auch meine Analyse der Wiener Einbürgerungsprotokolle die schon bei Ivar Oxaal und Walter Weitzmann ausgesprochene Vermutung, dass es sich bei der jüdischen Zuwanderung nach Wien überwiegend um eine kleinräumige, sich aus dem unmittelbaren "Hinterland « speisende handelt. ${ }^{289}$ Nach diesen Einbürgerungsprotokollen stammt ein Großteil der jüdischen Migranten aus jener schmalen, halbmondförmigen Sichel, die sich aus den autonomen Judengemeinden Südmährens, den oberungarischen (westslowakischen) und den sieben ungarischen (burgenländischen) Gemeinden bildete. ${ }^{290}$ Darüber hinaus wird aus den Protokollen deutlich, dass es sich in vielen Fällen um eine Remigration (manchmal der zweiten oder dritten Generation) von in der Toleranzepoche wegen Nichtbesitzes oder Nichtverlängerung der »Toleranz«, wegen Fehlens einer Familienstelle (bei Juden aus Böhmen und Mähren) oder wegen „Überzähligkeit« zur Migration nach Ungarn gezwungener Juden handelt. ${ }^{291}$ Häufig waren die vermeintlichen Neu-Wiener schon vor ihrer endgültigen Niederlassung in vielfältiger Weise mit Wien verbunden. So existierten bis I 848 die "Platzsteher", meist Textilhändler, die sich während der Woche in Wien aufhielten und ihren Geschäften nachgingen, um am Freitag zu ihren Familien nach Pressburg/Bratislava oder einer der »sieben Gemeinden« zurückzukehren. ${ }^{292} \mathrm{Zu}$ ihnen mag auch der I85 I in

287 Tina Walzer: Mährische Juden in Wien 1784-1874. Ein Forschungsbericht, in: David - Jüdische Kulturzeitschrift, www.david.juden.at/kulturzeitschrift.

288 Marsha L. Rozenblit: The Jews of Vienna, 1867-1914: Assimilation and Identity (Albany, 1983), S. 21; deutsche Ausgabe: Die Juden Wiens 1867-1914. Assimilation und Identität (Wien/Köln/ Graz 1988), S. 43.

289 Ivar Oxaal/Walter R. Weitzmann: The Jews of Pre-1914 Vienna. An Exploration of Basic Sociological Dimensions, in: Leo Baeck Institute Year Book XXX (1985), S. 393-432. Von mir untersucht wurde der Bestand Einbürgerungsprotokolle im Wiener Stadt- und Landesarchiv, Hauptreg. P 1.

290 Die sogenannten "Sieben Heiligen Gemeinden« (hebräisch: Scheva Kehillot) waren jüdische Ansiedlungen auf Esterházy'schem Grund und setzten sich zusammen aus: Kittsee, Frauenkirchen, Eisenstadt, Mattersburg, Kobersdorf, Lackenbach und Deutschkreutz. Vgl. J. Reiss (Hg.) : Aus den sieben Gemeinden. Ein Lesebuch über Juden im Burgenland (Eisenstadt 1997).

291 Dies ergab sich u. a. aus dem häufigen Auseinanderfallen von Geburtsort und "politischer Zuständigkeit« (Heimatrecht), etwa wenn, wie im Falle Jakob Kaposi, der Geburtsort in Leipnik/Lipník, Mähren, lag, die politische Zuständigkeit aber in Pucho/Trenscsin (Ungarn) gegeben war (WStLA, Hauptreg. P1, Nr. 9023/86), oder, im Falle des Samuel Rosenberg, der 1842 in Nikolsburg/Mikulov geboren wurde, aber im Jahr 1884, als er sich um die österreichische Staatsbürgerschaft bewarb, in Bonyhad, Ungarn, zuständig war. WStLA, Hauptreg. P 11, Nr. $37740 / 84$ (viele weitere Fälle).

292 Vgl. Elisabeth Campagner: Judentum, Nationalitätenprinzip und Identität. Die jüdische Revolu- 
Pressburg geborene Kleiderhändler Daniel Bettelheim gehört haben, der am I 5 . Februar I 887, nach über zwanzigjähriger Anwesenheit in Wien, zusammen mit seiner Frau Helene und seinen fünf Kindern in die österreichische Staatsbürgerschaft und den Gemeindeverband der Stadt Wien aufgenommen wurde. ${ }^{293}$ Bettelheim war dort angekommen, wo er immer schon gewesen war - in einer für Juden lange Zeit verbotenen Stadt. ${ }^{294}$

\section{Paradoxe Fremde}

Nach dem Ausgleich kommt es, motiviert durch das durch das Staatsgrundgesetz gegebene Versprechen von Gleichberechtigung, Freizügigkeit und Rechtsicherheit, zu einem Zurückströmen dieser Ausgewiesenen und „Überzähligen« (bzw. deren Kindern), von denen manche einst mit dem harten Zwangsmittel des Schubs aus Wien entfernt worden sein mögen. ${ }^{295}$ Im Prinzip kamen diese Remigranten jetzt als gleichberechtigte Staatsbürger, frei, sich überall niederzulassen, ein Gewerbe zu treiben oder Grundbesitz zu erwerben. Doch durch die für das österreichische Staatsbürgerschaftsrecht konstitutive Verknüpfung von Staatsbürgerschaft und Heimatrecht wurden sie in Wien abermals zu »Fremden«. So besaßen im Jahr I 869 von den 40230 in Wien ansässigen Juden nur etwa die Hälfte (20 500) die österreichische (cisleithanische) Staatsbürgerschaft und bloß 4800 das Heimatrecht der Gemeinde Wien. ${ }^{296}$ Bedenkt man, dass zwischen I 870 und I 9 I o allein über I I 000 Juden von der ungarischen in die österreichische Reichshälfte wechselten ${ }^{297}$, so verwundert es

tionspresse von 1848 (= Europäische Hochschulschriften 986) (Frankfurt/Main et al. 2004), S. 30, siehe dazu auch: Sigmund Mayer: Ein jüdischer Kaufmann. 1831 bis 1911 (Leipzig 1911), S. 210.

293 WStLA, Hauptreg. P 1, Nr. 229591/86. Dies würde auch den überproportional hohen Anteil an Pressburgern bei den Einbürgerungen und Heimatrechtserwerbungen in Wien erklären.

294 Mit Ausnahme der tolerierten Juden war fremden Juden der Aufenthalt in Wien bis 1848 nur gegen Entrichtung einer Leibmaut gestattet. Siehe oben und Israel Jeiteles: Die Kultusgemeinde der Israeliten in Wien (Wien 1873), S. 7.

295 Der Anteil der Juden am »Wiener Hauptschub«, d. h. an der vierzehntägig stattfindenden, militärisch begleiteten Sammelabschiebung in die Heimatgemeinde der Betroffenen, betrug Mitte des 19. Jahrhunderts 8,4 Prozent, wobei die meisten (etwa drei Viertel) nach Ungarn abgeschoben wurden. Vgl. Harald Wendelin: Schub und Heimatrecht, in: Waltraud Heindl/Edith Saurer (Hg.), Grenze und Staat. Passwesen, Staatsbürgerschaft, Heimatrecht und Fremdengesetzgebung in der österreichischen Monarchie 1750-1865 (Wien/Köln/Weimar 2000), S. 302, Tabelle 7.

296 Von den "Ausländern« kamen 17500 aus der ungarischen Reichshälfte. Von diesen waren nur 2800 in Wien heimatberechtigt. Vgl. Schimmer, Statistik, S. 2, siehe auch: Tietze, Juden Wiens, S. 204. Eine noch genauere Analyse der heimatberechtigten Juden Wiens liefert Jeiteles, Kultusgemeinde, S. 67 .

297 Vgl. Bihl, Juden, S. 888. 
kaum, dass Juden sowohl unter den »Heimatlosen« und »Ausländern« als auch den Eingebürgerten über Jahrzehnte einen sehr hohen Prozentsatz ausmachten. Um die Jahrhundertwende war Wien in Europa die Stadt mit dem drittgrößten Anteil an jüdischen Einwohnern ${ }^{298}$, doch viele von ihnen blieben ohne österreichische Staatsbürgerschaft und/oder ohne Heimatrecht in Wien ${ }^{299}$, was im Falle von Subsistenzlosigkeit (Besitz- oder Erwerbslosigkeit) erneut die Ausweisung in die Heimatgemeinde (den Ort der "politischen Zuständigkeit«) bedeuten konnte - ein Schicksal, das sie allerdings mit vielen nichtjüdischen, vor allem aus den slawischen Teilen der Monarchie kommenden Migranten und Migrantinnen teilten. ${ }^{300}$

\section{Die dualistische Verschärfung}

Die oft doppelte Fremdheit ungarischer Juden (im heimatrechtlichen und/oder staatsbürgerschaftsrechtlichen Sinn) in der österreichischen Reichshälfte erfuhr im Jahre I 879 noch eine wesentliche Verschärfung, als sich Ungarn in Ausübung seiner staatlichen Autonomie ein modernes Staatsbürgerschaftsgesetz gab, das sich in seinen Prinzipien eher am französischen Modell und teilweise am deutschen Gesetz über die Reichs- und Staatsangehörigkeit von I 870 orientierte als an den österreichischen Gesetzesbestimmungen. ${ }^{301}$ Diese dualistische Verschärfung führte nicht nur zu einer wechselseitigen staatsrechtlichen Schließung, sondern auch zu zahlreichen Ungereimtheiten und Kuriosa in der Praxis der Staatsbürgerschaftsgesetzgebung. So ließ das ungarische Staatsbürgerschaftsgesetz im Gegensatz zum österreichischen (cisleithanischen) grundsätzlich Doppelstaatsbürgerschaften zu, sodass es für einen

298 Michael John: Mosaik, Schmelztiegel, Weltstadt Wien. Migration und multikulturelle Gesellschaft im 19. und 20. Jahrhundert, in: WIR. Zur Geschichte und Gegenwart der Zuwanderung nach Wien (Wien 1996), S. 137-144, hier: S. 139.

299 Von der um 1900 in Cisleithanien lebenden etwa eine halbe Million "Ausländern" waren 15,89 Prozent jüdischer Konfession. Von diesen 78841 ausländischen Staatsbürgern - die meisten davon lebten in Wien - waren wiederum etwa drei Viertel (59682 Personen) ungarische Staatsangehörige. Vgl. Thon, Juden, S. 50.

300 Während in Galizien, dem Kronland mit dem höchsten jüdischen Bevölkerungsanteil, von 1000 Einwohnern 838 heimatberechtigt waren, besaßen, nach der Volkszählung von 1890, in Wien (Niederösterreich) von 1000 Personen nur noch 415 das Heimatrecht in Wien. Erst nach der Jahrhundertwende ließen eine rigoros gehandhabte Abschiebepraxis auf der einen und die Heimatrechtsreform von 1905 auf der anderen Seite die Zahl der Personen ohne Heimatrecht geringer werden. Vgl. Wendelin, Schub, S. 227.

301 Gesetzesartikel L: 1879 über den Erwerb und Verlust der ungarischen Staatsbürgerschaft. Text und Genesis dieses Artikels in: Emanuel Milner: Die österreichische Staatsbürgerschaft und der Gesetzesartikel L: 1879 über den Erwerb und Verlust der ungarischen Staatsbürgerschaft (Tübingen 1880), S. 3 . 
Ungarn möglich war, zugleich ungarischer und Staatsbürger »der im Reichsrat vertretenen Königreiche und Länder « zu sein, nicht aber umgekehrt. ${ }^{302}$

Das ungarische Staatsbürgerschaftsgesetz von I 879 dürfte somit ein wesentlicher Grund für den seit den I 88 oer-Jahren besonders hohen Anteil ungarischer Juden an den Einbürgerungsverfahren in der österreichischen Reichshälfte sein. ${ }^{303}$ Viele derjenigen, die nach dem Ausgleich, teilweise aber schon in den frühen I 86oer-Jahren als nach dem Ende des Neoabsolutismus die jetzt auch Juden gewährte Gewerbefreiheit, das Grundbesitzrecht und der Zugang zu zuvor verbotenen Berufen (Notariat, Apotheker) eine Chance zu Aufstieg und Erfolg boten - nach Wien gekommen waren, fanden sich nun nicht mehr nur im heimatrechtlichen Sinn als "Fremde«, sondern staatsrechtlich als "Ausländer" behandelt und sahen, um ihre erfolgreiche Integration nicht zu gefährden, spätestens jetzt den Zeitpunkt gekommen, die österreichische Staatsbürgerschaft zu beantragen. Zwar wurden die Angehörigen der beiden Reichshälften wechselseitig im Allgemeinen nicht als Ausländer bezeichnet (und empfanden sich in dem meisten Fällen wohl auch nicht als solche ${ }^{304}$ ), doch hatte das österreichische Innenministerium anlässlich einer ungarischen Beschwerde verfügt, dass ungarische Staatsbürger bei der Aufnahme in eine österreichische Gemeinde (der Erteilung des Heimatrechts) "wie andere Auswärtige« zu behandeln seien. ${ }^{305}$

Aus Ungarn stammende Juden hatten sich also dem gleichen komplizierten Aufnahmeverfahren zu unterziehen wie andere Ausländer auch. Als der 33-jährige, in Gyömrö (Ungarn) geborene, ledige jüdische Handelsagent Gabriel Spitzer im Februar I 883 um Aufnahme in die österreichische Staatsbürgerschaft ansuchte, zog dies ein langwieriges Verwaltungsverfahren nach sich. Dem bei seiner Einvernahme vor dem Magistrat der Stadt Wien aufgenommen Protokoll lässt sich entnehmen, dass Spitzer bereits seit dem Jahr I 866, also seit I 6 Jahren, ununterbrochen in Wien, und zwar im zweiten Bezirk ansässig war, sein Gewerbe dort ausübte, aber noch immer nach Budapest "zuständig" (heimatberechtigt) war. Nachdem der Vorsteher seines Wohnbezirks dem Bittsteller nach "gepflogenen Erhebungen« bescheinigt, "sich in geordneten Verhältnissen" zu befinden und dessen Gesuch befürwortet hatte, erfolgte am I. August I 884 die Zusicherung der Aufnahme in den Gemeindeverband der Stadt Wien. Die notwendige Entlassung aus dem ungarischen Staats-

302 Vgl. Milner, Österreichische Staatsbürgerschaft, S. 83.

303 Zwischen 1893 und 1902 wurde insgesamt 5326 Personen jüdischer Konfession die österreichische Staatsbürgerschaft erteilt. 4481 davon stammten aus Ungarn. Umgekehrt wurden 1510 Juden aus dem österreichischen Staatsverband nach Ungarn entlassen. Vgl. Thon, Juden, S. 53.

304 Thon bezeichnet die in Cisleithanien lebenden ungarischen Juden zu Recht als "Bindeglied " zwischen den beiden immer weiter auseinanderdriftenden Reichshälften. Vgl. Thon, Juden, S. 50.

305 Erlass des Ministeriums des Innern vom 7. Dezember 1870, Zl. 15 115, zit. nach: Milner, Österreichische Staatsbürgerschaft, S. 91. 
verband verzögerte jedoch den Vorgang. Erst am I7. August I 885, rund ein Jahr später, konnte Spitzer seine von einem beeideten Gerichtsdolmetscher übersetzte und durch einen Anwalt beglaubigte Entlassungsurkunde vorlegen. Seine Aufnahme in den Gemeindeverband Wien erfolgte gleichzeitig mit der Verleihung der österreichischen Staatsbürgerschaft am I 5 . Oktober I 885 (rund zweieinhalb Jahre nach der Antragstellung) ${ }^{306}$ - ein außergewöhnlich langes Verfahren. In der Regel betrug die Frist zwischen Entlassung aus dem ungarischen und Aufnahme in den österreichischen Staatsverband vier Wochen bis ein halbes Jahr. Im Einzelfall konnten sich jedoch die Beschaffung der notwendigen Dokumente, ihre Übersetzung, Beglaubigung und Überbeglaubigung als schwierig und kostenintensiv erweisen. Dazu war es notwendig, dass die "politische Zuständigkeit " einwandfrei feststand, bzw. durch die Herkunftsgemeinde (nicht notwendigerweise die Geburtsgemeinde) anerkannt worden war. Im Gegensatz zur cisleithanischen Gesetzeslage - wonach die Staatsbürgerschaft durch Auswanderung spätestens nach fünf Jahren unweigerlich verloren war - erfolgte in Ungarn die Entlassung aus der Staatsbürgerschaft nur aufgrund eines ausdrücklichen Gesuchs und nicht aufgrund einer beabsichtigten oder bereits erfolgten Auswanderung. Unwirksam wurde eine ausgesprochene Entlassung, wenn der Betroffene innerhalb eines Jahres keine andere Staatsbürgerschaft erworben hatte. ${ }^{307}$

Motive für den Erwerb von Heimatrecht und Staatsbürgerschaft

Ein weiteres Motiv für den Erwerb der österreichischen Staatsbürgerschaft liegt im Artikel 3 des Staatsgrundgesetzes, welcher den Eintritt in ein öffentliches Amt vom Besitz der österreichischen Staatsbürgerschaft abhängig machte. »Jeglicher Staatsdienst" - sei er zivil oder militärisch - durfte nur mehr von Inländern bekleidet werden. ${ }^{308}$ Die Berufung an eine österreichische Hochschule etwa war jetzt notwendig mit der vorgängigen Aufnahme in den österreichischen Staatsverband

306 WStLA, Hauptreg. P 11, Nr. 77278/84.

307 Emanuel Milner siehe darin ein starkes "Behalteelement« mit der Absicht, »die Staatsgenossen, wenn sie schon dem Staatsverband nicht zu erhalten waren, doch so leicht als möglich wieder zu gewinnen«. Milner, Österreichische Staatsbürgerschaft, S. 82.

308 Die ursprüngliche Fassung des ersten Absatzes von Artikel 3 des Staatsgrundgesetzes lautete: „Die öffentlichen Ämter sind für alle dazu befähigten Staatsbürger gleich zugänglich«. Auf Antrag des jüdischen Abgeordneten Ignaz Kuranda, der eine Diskriminierung jüdischer Staatsbürger fürchtete, wurde der Zusatz "für alle dazu befähigten" in der Sitzung des Verfassungsausschusses vom 21. September 1867 gestrichen. Vgl. Barbara Haider: Die Protokolle des Verfassungsausschusses des Reichsrates vom Jahre 1867, Fontes Rerum Austriacarum. Österreichische Geschichtsquellen, Zweite Abteilung, Diplomataria et Acta, Band 88 (Wien 1997), S. 119. 
verbunden. ${ }^{309}$ So beantragte etwa der aus Sebes-Kellemes (Ungarn) stammende Alexander Strakosch nach bereits zwanzigjährigem Aufenthalt in Wien im März I 886 die österreichische Staatsbürgerschaft, um eine Professur für Rhetorik am Konservatorium der Stadt Wien antreten zu können ${ }^{310}$, ebenso der 3 I-jährige, nach Deutschkreuz zuständige, Advokaturanwärter Dr. Markus Blau, der sich um eine Stelle als Verteidiger in Strafsachen beworben hatte. ${ }^{311}$

Für selbständig Tätige war die Staatsbürgerschaft zur Ausübung ihres Berufes grundsätzlich keine Voraussetzung. So finden sich unter den erfolgreichsten jüdischen Unternehmerpersönlichkeiten - etwa Angehörigen der Familie Ephrussi solche, die trotz jahrzehntelangen Aufenthalts in Wien und oft unter Beweis gestellter Loyalität zum Kaiserhaus ihre ausländische Staatsbürgerschaft behielten. ${ }^{312}$ Dennoch finden sich unter den Einbürgerungswerbern auch sehr viele Selbständige wie Anwälte und Mediziner, etwa der aus Budapest stammende praktische Arzt und Herausgeber der Wiener medizinischen Blätter, Dr. Wilhelm Schlesinger, der nach 25-jährigem Aufenthalt in Wien, zusammen mit seiner Ehefrau Emma und seinen fünf in Wien geborenen Kindern, am 24. Februar I 887 die österreichische Staatsbürgerschaft erhielt. ${ }^{313}$ In diesem, wie in vielen anderen Fällen, scheint die Motivation für die Beantragung der Staatsbürgerschaft nicht so sehr in der eigenen Person, sondern vielmehr in der rechtlichen und sozialen Absicherung der Kinder gelegen zu haben, war doch mit dem Staatsbürgerschaftserwerb immer auch der Erwerb des Heimatrechts in einer österreichischen Gemeinde und damit eine armenrechtliche Grundversorgung sowie der Schutz vor Abschiebung verbunden.

Neben Ärzten, Anwälten und Fabrikanten finden sich in den Protokollen aber auch viele traditionelle Handwerksberufe: Schneider, Tapezierer, Schumacher, Pfeifenschneider etc. Der hohe Anteil von Selbständigen an den Einbürgerungen von Juden verdankt sich dem Umstand, dass nach dem Staatsgrundgesetz Juden zwar grundsätzlich alle Ämter offen standen, doch ein ungeschriebenes Gesetz es wollte,

309 Genauer dazu: Hannelore Burger, Passwesen und Staatsbürgerschaft, in: Heindl/Saurer (Hg.) Grenze und Staat, S. 127.

310 WStLA, Hauptreg. P 11, Nr. 54836/86.

311 WStLA, Hauptreg. P 1, Nr. 59960/85.

312 Edmund de Waal schildert in seiner Familiengeschichte der Ephrussi (einer ursprünglich aus Odessa stammenden Familie, die eines der erfolgreichsten Bank- und Handelshäuser Europas führte) »Der Hase mit den Bernsteinaugen«, dass das österreichische Familienoberhaupt, Viktor Ephrussi, erst im Jahr 1914, zu Beginn des Ersten Weltkrieges, als 84-Jähriger den Zaren um seine Entlassung aus der russischen Staatsangehörigkeit bat und österreichischer Staatsbürger wurde, und zwar aus Sorge vor einer eventuellen Einziehung seines Sohnes zum Militärdienst in Russland. Edmund de Waal: Der Hase mit den Bernsteinaugen. Das verborgene Erbe der Familie Ephrussi (Wien 2011), S. 186.

313 WStLA, Hauptreg. P 1, Nr. 199800/85. 
dass - bis auf Ausnahmen - nur getaufte Juden in den höheren Staatsdienst aufgenommen wurden. ${ }^{314} \mathrm{Ab}$ den I 88 oer-Jahren waren es jedoch nicht mehr nur Selbständige, sondern auch die mit der ökonomischen Entwicklung verbundenen neuen Angestellten: Handlungsgehilfen, Handlungsreisende, (Börsen-)Agenten etc., die um Aufnahme in die Staatsbürgerschaft ansuchten. Junge Wiener Juden der zweiten Generation wandten sich, wie Marsha Rozenblit feststellt, zunehmend vom Händler- und Kaufmannsberuf der Väter ab und wurden bevorzugt »Angestellte, Reisende und Manager ${ }^{315}$ - eine Tendenz, die sich auch in den Einbürgerungsprotokollen dieser Jahre widerspiegelt.

\section{Heimatrecht und StaAtsbürgerschaft jüdischer Frauen}

Das Sichtbarmachen von Frauen in der Einbürgerungsstatistik gestaltet sich überaus schwierig ${ }^{316}$, wurden Frauen doch im Allgemeinen als Angehörige (des Vaters, bzw. Ehemannes) lediglich mit eingebürgert. Aus den Einbürgerungsprotokollen (der männlichen Familienoberhäupter) erfahren wir den Namen, das Geburtsdatum und die "politische Zuständigkeit« der Ehefrau. Seltener als in der ersten Hälfte des I9. Jahrhunderts - noch I 833 waren in Niederösterreich (Wien) 26 Prozent aller Naturalisierten weiblich ${ }^{317}$ - wurden Frauen selbständig eingebürgert. In den wenigen eingesehenen Fällen handelt es sich um verwitwete selbständige Gewerbetreibende - so die nach Lackenbach (Burgenland/Ungarn) zuständige, im neunten Wiener Gemeindebezirk als Branntweinschänkerin tätige Amalie Herzl, die im Mai I 888, zusammen mit ihren drei Kindern, die österreichische Staatsbürgerschaft und das Heimatrecht in der Gemeinde Wien erhielt, ${ }^{318}$ oder die 46-jährige verwitwete Glasermeisterin Rosa Löwy, geb. Reisz, die im dritten Wiener Gemeindebezirk eine Glaserei betrieb und nach über zwanzigjährigem Aufenthalt in Wien, nach erfolgter Entlassung aus dem ungarischen Staatsverband, die österreichische Staatsbürgerschaft erhielt. ${ }^{319}$ In beiden Fällen scheint die soziale und rechtliche Absicherung

314 Noch bei der letzten Volkszählung im Jahr 1910 wurden für Wien im Öffentlichen Dienst nur 1045 männliche und 69 weibliche jüdische Bedienstete ausgewiesen, 8,6 Prozent, gegenüber 14,2 Prozent bei der nichtjüdischen Bevölkerung. Goldhammer, Die Juden Wiens, S. $50 \mathrm{f}$.

315 Während nach Rozenblit unter den männlichen jüdischen Heiratenden in Wien im Jahr 1870 noch die selbständigen Kaufleute mit 55,6 Prozent dominierten und sich nur 2,8 Prozent Handelsangestellte fanden, waren es um 1900 schon 29,6 Prozent Handelsangestellte und nur mehr 45,8 Prozent Kaufleute. Rozenblit, Juden, S. 59, Tabelle 3:2.

316 Vgl. Elisabeth Malleier: Jüdische Frauen in Wien 1816-1938 (Wien 2004), S. $19 f f$.

317 Vgl. Burger, Passwesen und Staatsbürgerschaft, S. $154 \mathrm{ff.}$

318 WStLA, Hauptreg. P 1, Nr. 305399/86.

319 WStLA, Hauptreg. P 1, Nr. 9609/81. 
der Kinder das Motiv für das späte Einbürgerungsbegehren gewesen zu sein. Nur ein einziger Fall wurde gefunden, in dem eine verheiratete Frau selbstständig die österreichische Staatsbürgerschaft erhielt (bzw. wieder erwarb) : die von ihrem ungarischen Ehemann, dem Schauspieler Emanuel Kanitz, getrennt lebende Sängerin Caroline Bettelheim. ${ }^{320}$

\section{Heimatrecht und soziale Frage}

Wiewohl für die Aufnahme in den Staatsverband keineswegs Bedingung (gefordert war lediglich die "polizeiliche Unbeanstandetheit«), finden sich in den protokollierten Einvernahmen genaue Angaben über das Vermögen des Staatsbürgerschaftswerbers (Haus- und Grundbesitz, Aktien, Renten, Warenwert oder Betriebskapitel); auch der Steuersatz und das Jahreseinkommen sind häufig ausgewiesen. Mit Ausnahme von jungen Akademikern, die, sofern polizeilich "unbeanstandet«, auch bei geringem Einkommen eingebürgert wurden ${ }^{321}$, scheint Armut das größte Hindernis für eine Aufnahme in die Staatsbürgerschaft, mehr allerdings noch in den Heimatverband der Gemeinde Wien, gewesen zu sein. So wurde etwa die Bewerbung des aus Jamnitz/Jemnice (Mähren) stammenden Zuckerbäckers Salomon Kohn um das Heimatrecht in Wien nicht nur wegen seines relativ kurzen Aufenthalts, sondern vor allem wohl wegen dessen »Vermögenslosigkeit« und wegen seiner »sieben Kinder» zurückgewiesen. ${ }^{322}$

Eine Verschärfung erfuhr das Heimatrecht, als im Zuge einer Gesetzesnovellierung im Jahr I 896 statt des vierjährigen, wie es das provisorische Gemeindegesetz von I 849 vorsah, wieder der zehnjährige Aufenthalt eingeführt wurde. Grundsätzlich sollte zwar jenen Staatsbürgern, welche sich über einen so langen Aufenthalt "freiwillig und ununterbrochen in der Gemeinde aufgehalten" hatten, das Heimatrecht "nicht versagt werden ${ }^{323}$, doch in der Praxis hatten Arme kaum eine Chance auf Aufnahme. Zunehmend wurde der Streit um das Heimatrecht Teil der sozialen Frage. So prangerte etwa der jüdische Anwalt Julius Ofner die Praxis wohlhabender Gemeinden an, Personen, welche über dreißig, vierzig Jahre, in manchen Fällen »ihr ganzes Leben in Österreich wohnen", makellos gelebt hatten, jedoch arm waren, die Erteilung des Heimatrechts zu verweigern. Zwar sei es niemals in der Intention des

320 Caroline Bettelheim leistete am 15. März 1888 den Staatsbürgerschaftseid (ohne Einbeziehung ihres Sohnes Gustav). WStLA, Hauptreg. P 1, Nr. 345223/86.

321 Etwa der Advokatur-Candidat Dr. Adolf Sonnenfeld. WStLA, Hauptreg. P 1, Nr. 113596/85.

322 WStLA, Hauptreg. P, Nr. 168765/1878.

$323 \S 2$ der Heimatrechtsnovelle vom 5. Dezember 1896, RGBl. Nr. 1896222, zit. nach: Goldemund/ Ringhofer/Theuer, Staatsbürgerschaftsrecht, S. 540. 
Gesetzgebers gelegen, weist Ofner nach, den Behörden ein freies Ermessen bei der Einbürgerung einzuräumen, doch zeige die Praxis, dass das Heimatrecht »stetig zum Nachteil bedürftiger, völlig makelloser Ausländer umgangen« werde. ${ }^{324} \mathrm{Da}$ jedoch während des ganzen I9. Jahrhunderts für die Gemeinden die Erteilung des Heimatrechts mit der Verpflichtung zur Armenfürsorge verbunden blieb, sorgten diese dafür, dass der Aufenthalt Fremder nur so lange geduldet wurde, als sie selbst für ihren Unterhalt Sorge tragen konnten. Im Falle ihrer Verarmung (»Subsistenzlosigkeit«) konnten sie weiterhin mittels des polizeilichen Zwangsmittels Schub in ihre zuständige Heimatgemeinde (zurück)befördert werden. So scheint bei vielen Ansuchen um die Staatsbürgerschaft die damit verbundene vorgängige Aufnahme in eine Gemeinde, also die Erlangung des Heimatrechts, die erste Motivation gewesen zu sein.

\section{Der Fall Dr. Hugo Stark}

Während das "mosaische Bekenntnis« nach dem Ausgleich niemals mehr (zumindest explizit) als Abweisungsgrund genannt wurde, scheint gegen Ende des Jahrhunderts neben dem Faktor Armut vor allem "politische Bedenklichkeit« ein Hindernis für die Aufnahme in den Staatsverband gewesen zu sein - so im Falle des jüdischen Arztes Dr. Hugo Stark, der gegen die mit Statthaltereierlass vom 24. Juli I 897 erfolgte Abweisung seines Einbürgerungsbegehrens Beschwerde eingelegt hatte. Dr. Stark, der zwar I 870 in Prag geborene worden, doch nach seinem Vater nach Pottornya Prekáska (Komitat Lipto) in Ungarn zuständig war, hatte sein ganzes Leben in Böhmen verbracht: hatte in Prag an der deutschen Karl Ferdinand Universität sein Studium absolviert und dort promoviert, war danach als Gemeinde- und Bezirksarzt in Bucher/Puchér, Bezirk Kapitz, tätig gewesen und sich seit Juni I 895 als praktischer Arzt in Karlsbad niedergelassen. Begründet hatte Hugo Stark sein Ansuchen damit, dass er in der diesseitigen Reichshälfte (Cisleithanien) seit seiner Geburt ununterbrochen gelebt, hier seine Ausbildung erhalten habe und dass alle seine mütterlichen Verwandten sowie alle Verwandten seiner Gattin, Rosa Steiner (Tochter des Prager Kaufmannes Emanuel Steiner) österreichische Staatsbürger seien, weiters, dass er hier seine Existenz gegründet und sein »dauerndes Berufsdomicil" genommen habe, und somit sein Wunsch, für sich und seinen (im Jahr der Antragstellung geborenen) Sohn die Staatsbürgerschaft und das Heimatrecht zu erwerben, "gewiss gerechtfertigt" sei.

Von der Gemeinde Schönlind/Krásná Lípa, Bezirk Falkenau, war ihm für den Fall der Erlangung der österreichischen Staatsbürgerschaft die Aufnahme in den Heimat-

324 Vgl. Julius Ofner: Die Entstehung des Justizhofdekrets vom 12. April 1833 über die Ersitzung der Staatsbürgerschaft, in: Juristische Blätter 23 (1905) Nr. 13, S. 157-160 und Nr. 14, S. 146-158. 
verband zugesichert worden. Der Böhmische Statthalter berichtete in seiner Stellungnahme an das Innenministerium, dass gegen Dr. Stark zwar »in sittlicher und materieller Rücksicht nichts Nachteiliges" vorliege, dieser allerdings Sozialist sei und »in dieser Richtung agitatorisch" wirke. Während seines Aufenthaltes in Karlsbad sei er polizeilich unbestraft geblieben, jedoch sei von Seiten der Staatsanwaltschaft in Eger gegen ihn Anklage wegen Vergehens gegen die öffentliche Ruhe und Ordnung erhoben worden. Dr. Stark sei früher in der Dallwitzer/Dalovicer Porzellanfabrik bei Karlsbad Fabriksarzt gewesen, habe jedoch »in Folge seiner Wütereien unter den Arbeitern" seinen Posten verloren. Stark sei »ein eifriger Anhänger der Sozialdemokratischen Partei und die Seele der sozialdemokratischen Bewegung in Karlsbad«. Wegen eines Aufruhrs sei er angeklagt, jedoch bei einer I 897 in Eger stattgefundenen Hauptverhandlung freigesprochen worden. Mit Rücksicht auf seine agitatorische Tätigkeit habe sich, so der Bericht des Statthalters, die Bezirkshauptmannschaft gegen seine Aufnahme in den österreichischen Staatsverband mit aller Entschiedenheit ausgesprochen. Für Dr. Stark spräche der Umstand, dass er durch die Bande der Familie, durch seine Herkunft, durch seinen Aufenthalt und seine Berufstätigkeit an den Staat, dessen Angehörigkeit er zu erwerben strebte, geknüpft erschien und dass er einen Sohn habe, dessen (deutschsprachige) Erziehung es diesem unmöglich machen würde, in Ungarn jemals sein Fortkommen zu finden. Der Statthalter beantragte dennoch die Abweisung der Beschwerde. Das Innenministerium schloss sich im Oktober I 897 - dem Höhepunkt der Badeni-Krise - dieser Auffassung an. Dr. Hugo Stark und damit auch seinem minderjährigen Sohn Gustav wurde aus ausschließlich politischen Gründen - nicht aber aus konfessionellen oder ethnischen die Aufnahme in die österreichische Staatsbürgerschaft versagt. ${ }^{325}$

Welche soziale und ökonomische Bedeutung der Staatsbürgerschaft, mehr aber noch dem Heimatrecht zukam, zeigen die zahlreichen Feststellungsverfahren, die vielfach auch Kinder oder andere unmündige Personen betrafen.

\section{Der Fall Julia Singer}

An einem Augusttag des Jahres I 888 war in Rohrbach, im Bezirk Lilienfeld, Niederösterreich, von der Gendarmerie ein etwa zehnjähriges Mädchen wegen »Ausweisund Subsistenzlosigkeit" aufgegriffen und vorläufig der Gemeinde zur Betreuung übergeben worden. Die eingeleiteten Nachforschungen, so ein Bericht des niederösterreichischen Statthalters an das Innenministerium, hätten mit Gewissheit ergeben, dass das Kind die am 26. Juli I 878 im Wiener Gebärhaus geborene uneheliche Toch-

325 AVA Inneres, Fasc. 8, Staatsbürgerschaft in genere, 1870ff, Karton 353, Nr. 32097/1897. Zum Fall Hugo Stark siehe auch: Gammerl, Untertanen, S. 87. 
ter der jüdischen Dienstmagd Anna Singer sei und Julia Singer heiße. Das Kind sei bald nach seiner Geburt zu einem Schneidermeister in M. (unleserlich) in Pflege gekommen und dort bis zur Erreichung des »Normalalters" (das Schuleintrittsalter) geblieben, dann nach Wien zurückgeschickt und vom Wiener Magistrat am 9. August I 888 der Pfandlerin Franziska Sedlaczek, in Wien-Hernals, zur Pflege übergeben worden. Das Mädchen sei jedoch noch am selben Tag von dort geflohen, herumgestreift, bis es schließlich in Rohrbach aufgegriffen wurde. Auf Anfrage der Gemeinde Rohrbach, was mit dem Mädchen geschehen solle, erwiderte der Wiener Magistrat, dass sie sich wegen der Heimbefürsorgung des Kindes an dessen Heimatgemeinde Kukló/Kuklov (im Akt Kuklo), im Pressburger Komitat, Ungarn, wenden möge. Die Annahme, dass Julia Singer nach Kukló zuständig sei, beruhe auf der Tatsache, dass deren Mutter, Anna Singer, bei ihrer Aufnahme in das Wiener Gebärhaus einen von der israelitischen Kultusgemeinde Kukló ausgestellten Heimatschein vorgewiesen habe. Die Gemeinde Rohrbach habe sich zunächst direkt an die Gemeinde Kukló und, als diese keine Antwort gab, an die Bezirkshauptmannschaft Lilienfeld gewandt, welche die Gemeinde Kukló zur Übernahme des Kindes und zum Ersatz der inzwischen für dasselbe erwachsenen Verpflegungskosten von fünfundzwanzig Tagsätzen verhalten habe.

Aus Mitteilungen der Landesgebär- und Findelanstalt ${ }^{326}$ ging hervor, dass Anna Singer die Anstalt insgesamt fünfmal aufgesucht und dort die unehelichen Kinder Juliana, Rudolf, Julia, Gisela, Gisela Nr. 2 und Wilhelmine geboren habe. Sie habe dabei jedes Mal einen Heimatschein, ausgestellt von der israelitischen Kultusgemeinde Kukló, vorgelegt, von wo auch die Gebärhauskosten aufgebracht worden seien. Der in Dojcs/Dojč), im ungarischen Komitat Neutra, ansässige Vater Anna Singers, Michael Singer, gab bei seiner Einvernahme vor der Bezirkshauptmannschaft an, er habe die Spiritusbrennerei erlernt und in Kukló, wo er als Branntweinbrenner beschäftigt war, die dort zuständige Franziska Kampi geheiratet. Im Jahre I 85 I sei er nach Dojcs übersiedelt, habe dann in verschiedenen ungarischen Gemeinden gearbeitet, bis er im Jahr I 863 nach Kukló zurückgekehrt sei, wo er sich als zuständig betrachte. Dass Kukló seine Gemeindangehörigkeit anerkannt habe, sei daraus zu erkennen, dass sie seinen Kindern zwecks Erlangung von Dienstbotenbüchern entsprechende Zuständigkeitszertifikate ausgestellt habe. Gegenwärtig lebe er wieder in Dojcs und zwar von der Mildtätigkeit seiner Kinder. Im Zuge eines Feststellungsverfahrens waren nun verschiedene ungarische Gemeinden, insbesondere Kukló, wiederholt aufgefordert worden, die Zuständigkeit des Michael Singer anzuerkennen, wozu aber keine zu bewegen gewesen war. Die Gemeinde Kukló be-

326 Zu dieser Institution siehe: Verena Pawlowsky: Mutter ledig, Vater Staat. Das Gebär- und Findelhaus in Wien 1784-1910 (Wien 2001). 
gründete ihre Weigerung damit, dass Michael Singer im Jahr I 864 von Dojcs, wo er zwanzig Jahre als Branntweinbrenner und Hauseigentümer gelebt habe, nach Kukló gekommen und dort nur eineinhalb Jahre geblieben, von dort aber nach Österreich (Cisleithanien) gegangen sei und auch jetzt wieder in Dojcs bei seinem dort ansässigen Sohn lebe. Die Gemeinde Dojcs wiederum behauptete, dass bei einer früheren Verhandlung festgestellt worden sei, dass Michael Singer das Heimatrecht in der niederösterreichischen Gemeinde Ringelsdorf erworben habe, da sein jüngster Sohn als Ringelsdorfer im 2 I. Jägerbataillon diene.

Die weiteren Ermittlungen ergaben, dass der einst in Ringelsdorf (Niederösterreich) ansässige Michael Singer im Jahre I 886 mit Urteil des Wiener Landesgerichts wegen Betruges mit drei Monaten Kerker bestraft und gegen ihn die Landesverweisung aus sämtlichen im Reichsrat vertretenen Königreichen und Ländern ausgesprochen worden war. In Vollziehung dieser Landesverweisung war Michael Singer am 30. Jänner I 887 nach Dojcs, Ungarn, abgeschoben worden. Der Fall endete damit, dass das österreichische Innenministerium die Akte Singer am 2 I. Juli I 894 - sechs Jahre nachdem in Niederösterreich ein verwirrtes Kind aufgegriffen worden war an das ungarische Ministerium des Innern mit der Bemerkung zurückstellte, dass "die österreichische Staatsbürgerschaft des Michael Singer und seiner Deszendenten« nicht anerkannt werden könne. ${ }^{327}$ Erst zwei Jahre später bestätigte das ungarische Ministerium des Innern die ungarische Staatsbürgerschaft des Michael Singer und seiner Nachkommen. Auf diese Weise wurde das in Wien geborene Mädchen Julia, das seine ungarische "Heimat « noch nie gesehen hatte, zur Ungarin. ${ }^{328}$

\section{Der Fall Lea Weitzmann}

Dass sich aus den sozialen Implikationen von Heimatrecht und Staatsbürgerschaft auch internationale Verwicklungen ergeben konnten, belegt der folgende Fall, der durch viele Instanzen, bis hin zum Verwaltungsgerichtshof, ausgetragen wurde. Im Mai 1890 beeinspruchte die Bezirkshauptmannschaft Brody im Rekursweg einen Erlass der galizischen Statthalterei, wonach die Stadtgemeinde Brody (Galizien) hätte verpflichtet werden sollen, an die französische Regierung einen Ersatz von 939 Gulden und 27 Cent an Verpflegungskosten, plus 584 Gulden an Transportkosten für die Geisteskranke Ettel Lea Weitzmann, geb. Marer, die in Frankreich in Spitalsbehandlung gewesen war, zu leisten. Der Beschwerde wurde jedoch mit Hinweis auf die zwischen Österreich und Frankreich bestehende Reziprozität hinsichtlich des Ersatzes von Kosten für die Verpflegung von Irrsinnigen in Spitälern sowie auf die

327 AVA Inneres, Fasc. 8, Staatsbürgerschaft in genere, 1870ff, Karton 353, Nr. 23148/1896.

328 Zum Fall Singer siehe auch: Gammerl, Untertanen, S. 55. 
Verpflichtung der Heimatgemeinde zur Armenpflege keine Folge gegeben und die Stadtgemeinde Brody zur Zahlung des Gesamtbetrages von I 523 Gulden und 30 Cent an die Regierung des französischen Staates verpflichtet. Gegen diesen Statthaltereierlass erhob nun die Stadtgemeinde Brody, vertreten durch ihren Anwalt Eduard Kornfeld, Beschwerde beim Verwaltungsgerichthof, mit der Begründung, dass die Verpflegungskosten für die Geisteskranke Ettel Lea Weitzmann nach den gesetzlichen Bestimmungen der galizische Landesfonds und keinesfalls die Gemeinde Brody zu tragen habe.

Das Erkenntnis des Verwaltungsgerichtshofs vom 2I. Jänner I 89I gab der Gemeinde Brody recht. Nach den Grundsätzen der Reziprozität stehe es außer Zweifel, erkannte das Gericht, dass die österreichische Regierung die den französischen Spitälern erwachsenen Kosten für die Verpflegung von Irrsinnigen, Findlingen und Unheilbaren zu ersetzen verpflichtet sei. Um jedoch dieser Reziprozität gerecht zu werden, sei es geboten gewesen, zu prüfen, "wer im Inlande nach inländischen Gesetzen die Kosten für die Verpflegung der Irrsinnigen in den Spitälern zu ersetzen verpflichtet erscheint «. Nach dem Gesetz vom I7. Februar I 864, mit welchem die Verpflegungsgebühren in öffentlichen Irrenanstalten geregelt wurden, sei dies der Landesgesetzgebung vorbehalten. Für Galizien sei ein solches Gesetz am 6. Januar I 875 erlassen worden, "dass den Ersatz der Verpflegskosten nicht der Heimatgemeinde auferlegt«, sondern dem Landesfonds. Die angefochtene Entscheidung, welche diese Verpflichtung der Heimatgemeinde Brody auferlegte, sei somit "als im Gesetz nicht begründet aufzuheben«. ${ }^{329}$

\section{"SChutzgenossen« UND »Untertanen De FaCto»}

Eine wichtige Funktion der Staatsbürgerschaft ist der Schutz der Staatsangehörigen im Ausland. Im Falle Österreich-Ungarns betraf dies jedoch nicht nur die im letzten Drittel des I9. Jahrhunderts sprunghaft anschwellende Masse der Auswanderer (unter denen sich stets ein hoher Anteil von Juden befand) sondern auch - dies eine Besonderheit des österreichischen Staatsbürgerschaftsrechts - die österreichischen Schutzgenossen und Untertanen de facto: in erster Linie (nichtmuslimische) Personen, die im osmanischen Hoheitsgebiet lebten, jedoch keine türkischen Staatsangehörigen waren und unter dem besonderen Schutz der österreichischen Konsuln standen, oder auch Staatsangehörige fremder, befreundeter Mächte, die in der Levante keine eigene Vertretung hatten sowie osmanische Untertanen, die bei einem k. u. k.

329 AVA Inneres, Fasc. 8, Staatsbürgerschaft in genere, 1870ff, Karton 356, Nr. 15038/1890 mit dem Erkenntnis des Verwaltungsgerichtshof vom 21.1.1891, Nr. 4935/91. 
österreichischen Konsulat oder der Internuntiatur (der österreichisch-ungarischen Botschaft) in Konstantinopel in Diensten standen. ${ }^{330}$ Administrative Grundlage für den Anspruch auf Schutz und Protektion bildeten von den Konsulaten zu führende Register, die sogenannten "Schutzlisten«. Allen in diesen Schutzlisten eingetragenen Personen gebührte grundsätzlich der gleiche diplomatische Schutz - ein Schutz, der auch den zahlreichen Juden in diesen Listen gewährt wurde. ${ }^{331}$ Eine besondere Bedeutung kam dabei dem I 849 gegründeten (Vize-)Konsulat in Jerusalem zu. Wenngleich es die Hauptaufgabe der insgesamt I 4 österreichischen Konsuln im »Heiligen Land « war, die katholischen Interessen wahrzunehmen und der christlichen Bevölkerung sowie den zahlreich ins Land strömenden christlichen Pilgern jeden erdenklichen konsularischen Beistand zukommen zu lassen, zeigte es sich von Beginn der konsularischen Tätigkeit an, dass die Zahl der christlichen Schutzgenossen gegenüber jener der jüdischen eine verschwindende Minderheit darstellte. Kein anderes Konsulat hatte so viele Juden auf seinen "Schutzlisten" wie das in Jerusalem. Waren es in den I $850 e r-J a h r e n$ noch etwa I 500 bis I 800 Personen, so erhöhte sich ihre Zahl im Jahrzehnt vor dem Ersten Weltkrieg auf ca. 600o. ${ }^{332}$ Wie Benno Gammerl gezeigt hat, lassen sich zumindest bis zum Ersten Weltkrieg bei der Behandlung der »Schutzgenossen« durch die k. u. k. Auslandsvertretungen keine Unterschiede hinsichtlich der ethnischen oder konfessionellen Zugehörigkeit feststellen. ${ }^{33}$

\section{Zur Ambivalenz von Heimatrecht und StaAtsbürgerschaft}

Empfanden die einen die Staatsbürgerschaft als hohes Gut und ihren manchmal unfreiwilligen Verlust als ideellen und materiellen Schaden - so im Falle des nach Hamburg ausgewanderten jüdischen Kaufmannes Markus Verschleisser, der in einem Rekurs gegen den ihm mitgeteilten Verlust der österreichischen Staatsbürgerschaft bat, das Wiederaufnahmeverfahren »mit großer Dringlichkeit« zu behandeln, da seine Geschäfte dadurch leiden und seinen Kindern »beim Schulbesuche Hindernisse in den Weg gelegt werden« würden ${ }^{334}$-, suchten sich andere der österreichischen Staats-

330 Josef v. Malfatti: Handbuch des Österreichisch-Ungarischen Consularwesens (Wien 1879), S. $132 \mathrm{f}$.

331 Benno Gammerl konstatiert, dass die k. u. k. Konsulate (untersucht wurden jene von Beirut, Tunis, Tripolis und Jerusalem) die in den Schutzlisten eingetragenen Personen "unabhängig von ihrer ethnischen und religiösen Identität« annähernd gleich behandelt hätten. Gammerl, Untertanen, S. 254.

332 Eliav, Mordechai, unter Mitarbeit von Barbara Haider (Hg.): Österreich und das Heilige Land. Ausgewählte Konsulatsdokumente aus Jerusalem 1849-1917 (Fontes rerum Austriacarum 2. Abt. 91, Wien 2000), S. 63, 32f.

333 Vgl. Gammerl, Untertanen, S. 254.

334 AVA Inneres, Fasc. 8, Staatsbürgerschaft in genere, 1870ff, Karton 355, Nr. 24903/91. 
bürgerschaft aus religiösen Gründen (vor allem wegen der mit der Staatsbürgerschaft verbundenen Verpflichtung zur Wehrdienstleistung) zu entziehen. So schlugen im Falle des in Lemberg/Lwów/L'viv ansässigen Aron Moses Taubes alle Bemühungen der galizischen Behörden um Feststellung seiner Staatsbürgerschaft fehl. Aron Moses Taubes, Sohn des Rabbiners Chaim Taubes, hielt sich selbst, laut protokollarischer Einvernahme vor der Bezirkshauptmannschaft Lemberg, für einen rumänischen Staatsangehörigen. Bei den Erhebungen über seine Stellungspflicht war festgehalten worden, dass er das Heimatrecht in Lemberg nicht besitze. Jahrelange Bemühungen um eine Verifizierung seiner behaupteten rumänischen Staatsbürgerschaft verliefen, da die rumänischen Behörden die Kooperation verweigerten, im Sande. Die »möglicherweise absichtlich verwirrenden Angaben« des Aron Moses Taubes machten, wie es in einem Bericht des galizischen Statthalters an das Innenministerium resignierend heißt, am Ende "weder die Stellung noch die Abschiebung möglich«.335

Zwar kamen derlei Verweigerungen aus religiösen Gründen bei orthodoxen galizischen Juden häufiger vor ${ }^{336}$, doch generell geht aus den eingesehenen Akten eher eine hohe Wertschätzung des Rechtgutes der Staatsbürgerschaft hervor. So suchte im Juni I9I 4 - knapp vor dem Ersten Weltkrieg - der seit vierzehn Jahren in Triest lebende Dr. Moritz (Maurizio) Augenfeld mit der Begründung um die österreichische Staatsbürgerschaft an, dass er durchaus nicht mehr die Absicht habe, nach Ungarn zurückzukehren, da seine "ältere Tochter hier in Triest angestellt« sei und er hoffe, die jüngere Tochter »eventuell in eine Staatsanstellung unterzubringen «. ${ }^{337}$

Die meisten der eingesehenen Protokolle jüdischer Bewerber und (ganz selten) Bewerberinnen um Aufnahme in einen Gemeindeverband (die Erlangung des Heimatrechts) und um Verleihung der österreichischen Staatsbürgerschaft drücken eine zunehmend selbstbewusste Haltung gegenüber den staatlichen Behörden aus. Die Erwerbung von Heimatrecht und Staatsbürgerschaft war nicht nur ein Indikator für Aufstieg und Erfolg, sondern auch ein Zeichen für Angekommensein, für gelungene Integration - für Verortung. Motive für die Anträge waren, neben dem erhofften leichteren Zugang zu Staatsämtern, vor allem die soziale und rechtliche Absicherung der Kinder sowie der Wunsch, nicht mehr als Fremde im eigenen Land leben zu müssen. Die häufig teuren und langwierigen Naturalisierungsverfahren ${ }^{338}$ bedeute-

335 AVA Inneres, Fasc. 8, Staatsbürgerschaft in genere, 1870ff, Karton 354, Nr. 13718/93.

336 AVA Inneres, Fasc. 8, Staatsbürgerschaft in genere, 1870ff, Karton 355, No. 3549/95, Bericht der Statthalterei in Lemberg betr. Heimatsache Felix Teitelbaum, u. a.

337 AVA Inneres, Staatsbürgerschaft, Fasc. 8, Staatsbürgerschaft in genere, 1914, Nr. 30.667.

338 Die Einbürgerung selber wurde am Tag der Eidesablegung mit 50 Kronen vergebührt (im Jahr 1878), diese Grundkosten verteuerten sich jedoch fallweise durch einzelne beizubringende übersetzte, beglaubigte und überbeglaubigte Dokumente, z. B. 15 Kronen für die beglaubigte Entlassungsurkunde aus der ungarischen Staatsbürgerschaft. 
ten im Erfolgsfall ein Zeichen der Anerkennung und sie vermittelten ein starkes $\mathrm{Zu}$ gehörigkeits- und Identitätsgefühl. Die Tatsache, dass Juden Heimatrecht und/oder Staatsbürgerschaft in vielen Fällen nicht durch Geburt und Abstammung, sondern durch bewusste Wahl erwarben, trug entschieden dazu bei, dass, wie Hannah Arendt befand, aus Fremden das Staatsvolk par excellence wurde. ${ }^{339}$ 


\title{
Die Nationalitätenkonflikte der Verfassungszeit und die (sprach-)nationale Identität der Juden
}

\author{
KafKas SpRachen
}

In der Erzählung »Das Stadtwappen« berichtet Franz Kafka über das mythische Projekt eines babylonischen Turmbaus, dass anfangs noch alles in leidlicher Ordnung gewesen sei, aber bald schon sei es zu Problemen gekommen: "Jede Landsmannschaft wollte das schönste Quartier haben, dadurch ergaben sich Streitigkeiten, die sich bis zu blutigen Kämpfen steigerten. Diese Kämpfe hörten nicht mehr auf.«340 Analysiert man, wie Marek Nekula das tut, die komplexen heraldischen Bezüge und setzt an Stelle des altertümlichen Wortes Landsmannschaft den Begriff der Nationalität ein, so wird hinter der düsteren Parabel Kafkas Heimatstadt Prag sichtbar. ${ }^{341}$ Doch wie bei jeder Geschichte Kafkas ist mehr als eine Lesart und ein Deutungsmuster möglich ${ }^{342}$, und so ließe sich darin auch das gesamte Staatsgebäude der österreichischen Monarchie erkennen, das in Kafkas Jugend von erbitterten Sprachenund Nationalitätenkämpfen erschüttert wurde und das von Zeitgenossen nicht selten mit dem Etikett Babylon bedacht wurde.

In seiner Schulzeit (von September I 889 bis Sommer I 893 besuchte Kafka die Volks- und Bürgerschule für Knaben in der Fleischmarktgasse ${ }^{343}$, vom September I 893 bis zur Matura im Juli I 90 I das k. k. Staatsgymnasium am Altstädter Ring)

340 Franz Kafka, Das Stadtwappen, in: Roger Hermes (Hg.): Franz Kafka, Erzählungen und andere ausgewählte Prosa (Frankfurt/Main 1996), S. 374-375.

341 Vgl. Marek Nekula: Franz Kafkas Sprachen und Identitäten, in: Marek Nekula/Walter Koschmal, Juden zwischen Deutschen und Tschechen. Sprachliche, literarische und kulturelle Identitäten. München 2006, S. 125-150. Das nachstehende Kapitel geht auf einen Vortrag zurück, der von mir beim Symposium "Sprache und nationale Identität in öffentlichen Institutionen der Kafka-Zeit» 2005 in Regensburg gehalten wurde und in einer kürzeren Version in dem vorgenannten Tagungsband unter dem Titel "Das mehrsprachige Unterrichtswesen der Verfassungszeit (1867-1918) und die sprachnationale Identität der Juden S. 151-163 abgedruckt wurde.

342 Vgl. Peter Demetz: Prag und Babylon. Zu Kafkas "Das Stadtwappen«, in: Böhmische Sonne, mährischer Mond. Essays und Erinnerungen (Wien 1996), S. 81-92.

343 Mehr als die Hälfte der Kinder dieser Schule ist »israelitischer « Konfession. Fast alle Kinder waren zweisprachig (dt. und böhmisch). Vgl. Schematismus der Allgemeinen Volkschule und Bürgerschulen in den im Reichsrathe vertretenen Königreichen und Ländern, K. k. Statistische Zentralkommission (Hg.) (Wien 1902), S. 248. 
Abb. I2: Franz Kafka (I883-I924); Quelle: ÖNB/ Wien, Bildarchiv

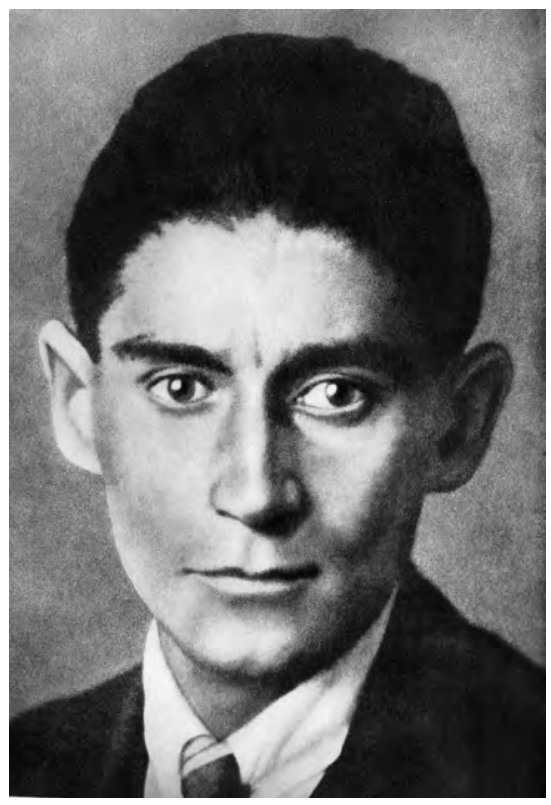

gehörten Konflikte bis hin zu Straßenkämpfen zwischen Schülern »deutscher« und Schülern »tschechischer« Schulen zum Alltag. Kafkas Bildungsgang ist gut belegt. Sowohl seine Volksschule wie auch das Gymnasium waren Schulen mit deutscher Unterrichtsprache und einem hohen Anteil an jüdischen Schülern. ${ }^{34}$ Zur Lektüre seiner Maturaklasse gehörten: Goethes Hermann und Dorothea, Schillers Braut von Messina, Kleists Prinz von Homburg, Grillparzers König Ottokars Glück und Ende, auch eine Redeübung Kafkas zum Torquato Tasso ist überliefert. Im Griechischen standen Platons Apologie und Sophokles Antigone auf dem Lehrplan. ${ }^{345}$ Es war der klassische humanistische Bildungskanon, der in der ganzen Monarchie, ob in Prag oder Wien, Lemberg/Lwów/L'viv oder Czernowitz/Černivci/Cernăuți, gleich verbindlich war gleich verbindlich, doch keineswegs überall mehr in der gleichen Sprache. Längst war Unterricht in der Muttersprache ein anerkanntes Prinzip, längst hatten die Nationalitäten sich ihren Anteil am Bildungswesen erobert, längst handelte es sich um deutsche Bildung in allen Sprachen. Kafka gehört in seiner Gymnasialzeit nicht mehr zu den guten Schülern. Die deutschen Gymnasien - in der Literatur von Musil über Zweig bis Torberg zur Genüge porträtiert - galten, verglichen mit den böhmischen, als be-

344 Zur Sprachwirklichkeit an den Prager Volksschulen siehe: Ingrid Fleischmann: Angaben zur Sprache in den Schulkatalogen der Prager Volksschulen, in: Marek Nekula et al. (Hg.): Franz Kafka im sprachnationalen Kontext seiner Zeit (Köln/Weimar/Wien 2007), S. 183-212.

345 Vgl. Roger Hermes et al. (Hg.): Franz Kafka, Eine Chronik (Berlin 1999), S. 25 sowie Hartmut Binder: Franz Kafka. Leben und Persönlichkeit (Stuttgart 1983). 
sonders hart, werden nicht selten als finstere Zwangsanstalten beschrieben. Auch in Kafkas Jugend gab es die Gestalt des unerbittlich strengen und gefürchteten Mathematik- und Physikprofessors, sein Name: Gustav Effenberger.

In Kafkas fünftes Gymnasialjahr, das Jahr I 897, fiel die Badeni-Krise - ein Höhepunkt des Nationalitätenkampfes. Tschechisch als »innere Amtssprache«, die zweisprachige Amtsführung aller Zivilbehörden und die unabdingbare Kenntnis beider Landessprachen für Beamte standen auf der politischen Agenda. Die Intention der Badenischen Sprachenverordnungen war, kurz gesagt, ein Mehr an Sprachgerechtigkeit für die tschechische Bevölkerung Böhmens und Mährens. Was jedoch auf den Erlass der Verordnungen folgte, war eine Orgie an Gewalt und politischer Dummheit. Antitschechische und antisemitische Pöbeleien im Abgeordnetenhaus und auf den Straßen führten zur Lähmung des Parlaments und am Ende in eine Staatskrise, die den von vielen als unvermeidlich gesehenen Untergang der Monarchie vorwegzunehmen schien. Nach der Entlassung des Ministerpräsidenten Graf Casimir Badeni ließen enttäuschte Tschechen ihre Wut vor allem an den Juden aus: "Nieder mit den Deutschen, nieder mit den Juden!« tönte der Ruf vor dem Deutschen Theater in Prag. Bei tagelang anhaltenden Ausschreitungen kam es zu Plünderungen vor allem jüdischer Geschäfte. Als die neue Regierung am 2. Dezember I 897 das Standrecht über Prag verhängte, waren drei Tote und viele Schwerverletzte zu beklagen. ${ }^{346}$

Das elterliche Geschäft am Altstädter Ring war von den Ausschreitungen nicht betroffen. Der Vater, Hermann Kafka, hatte schon bei der Volkszählung im Jahr I 890 Tschechisch als Umgangssprache für die Familie angegeben und - zumindest im geschäftlichen Bereich - sich dieser Sprache auch bedient. Sein Sohn nahm ab der dritten Volksschulklasse auf väterlichen Wunsch hin am Unterricht in der tschechischen Sprache teil ${ }^{347}$, nicht als »Freifach«, wie einige seiner Biographen meinen, sondern als relativ obligater Unterrichtsgegenstand. "Relativ obligat « bedeutete in der Sprache der Hochbürokratie - entsprechend dem im Artikel I9 des Staatsgrundgesetzes ausgesprochenen "Sprachenzwangsverbot « - die freiwillige Verpflichtung, am Unterricht in der zweiten Landessprache (in diesem Fall »Böhmisch«) teilzunehmen. Tatsächlich blieb Franz Kafka auch während seiner Gymnasialzeit dem relativ obligaten Unterrichtsfach Tschechisch treu. Obwohl zeitlebens mit seinen Tschechischkenntnissen unzufrieden, war er nicht zuletzt deshalb der tschechischen Sprache in Wort und Schrift unvergleichlich besser mächtig als viele seiner jüdischen Freunde ${ }^{348}$ - ein Umstand, der ihm bei seinem späteren beruflichen Werdegang

346 Zur Badeni-Krise siehe: Hannelore Burger/Helmut Wohnou: Eine "polnische Schufterei«? Die

Badenischen Sprachenverordnungen für Böhmen und Mähren 1897, in: Michael Gehlen/Helmut

Sickinger (Hg.) : Politische Affären und Skandale in Österreich (Wien/München 1995), S. 79-98.

347 Vgl. Binder, S. 126; Hermes, Kafka, S. 14.

348 Vgl. Binder, Kafka, S. 126. 
zugutekommen sollte, in den Jahren I907-1908 bei der Prager Niederlassung der Triester Versicherungsanstalt »Assicurazioni Generali« (in dieser Zeit lernte Kafka auch Italienisch), später bei der Arbeiter-Unfall-Versicherungs-Anstalt, in der zweisprachig amtiert wurde und unter deren Dach er im Kriegsjahr I 9 I 5 die Abwicklung der staatlichen Fürsorge für heimkehrende Soldaten (Kriegsbeschädigtenfürsorge) übernahm. ${ }^{349}$ Nicht zuletzt garantierten seine Tschechischkenntnisse sowie seine Loyalität gegenüber der jungen Tschechoslowakischen Republik seine bruchlose Weiterbeschäftigung bei der gleichen Anstalt nach I9 I 8. ${ }^{350}$

Franz Kafka war, nach den Zeugnissen seiner Biographen, ein überaus pflichtbewusster Beamter mit einem, wie ihm sein Freund Max Brod bescheinigte, unübertrefflichen Gerechtigkeitsgefühl. ${ }^{351}$ An den leidenschaftlichen Auseinandersetzungen seiner Zeit um Sprache und Nationalität, insbesondere in seiner Heimatstadt Prag, beteiligte er sich nicht. Seine Haltung dazu war gekennzeichnet von Abscheu und Distanz. Dennoch war er von der Intensität der Kämpfe, vom Riss, der bis in die eigene Familie reichte, tief betroffen. ${ }^{352}$ Viele seiner Texte, insbesondere die nachgelassenen Fragmente, spiegeln Gefangensein, Hoffnungslosigkeit und tiefe Agonie the agony of entrapment, wie William McCagg es genannt hat. ${ }^{353}$ Doch Kafkas fragile Existenz schuldet sich nicht nur dem Spannungsverhältnis zwischen den Nationalitäten, sondern ebenso sehr seiner prekären jüdischen Identität. Überliefert ist sein lebenslanges Schwanken zwischen Befreiungsversuchen einerseits und tiefer Hinwendung zum Judentum andererseits (seine Selbstcharakterisierung als "glaubensloser Jude«, seine Betroffenheit vom Elend der galizischen Flüchtlinge in Prag, sein Interesse am jiddischen Theater, seine Faszination durch den Chassidismus, dessen Mythen und Märchen er in seinen Texten verarbeitet). ${ }^{354}$

\section{Die Bedeutung von Bildung im Judentum}

Kafkas Bildungsgang war in gewisser Weise ein exemplarischer. Bildung wurde für die Epoche nach dem Ausgleich zu einem Schlüsselbegriff, und sie wurde zu einer Chiffre für den Aufstieg der Juden. Mit dem Inkrafttreten der Dezemberverfassung

349 Vgl. Binder, Kafka, S. $126 f$ sowie Hermes, Chronik, S. 14, 19.

350 Simona Svingrová: Tschechisch oder Deutsch? Auf dem Weg von Konkurrenz zu Dominanz. Zum Einsatz von innerer und äußerer Amtssprache in der Arbeiter-Unfall-Versicherungs-Anstalt im Prag der Kafka-Zeit (1908-1922), in: Marek Nekula et al. (Hg.): Kafka im sprachnationalen Kontext, a.a.O., S. 129-150, hier: S. 139.

351 Max Brod: Franz Kafka. Eine Biographie (Berlin 1954), S. 205.

352 Vgl. Nekula, Kafkas Sprachen und Identitäten, S. 135f.

353 William O. McCagg: A History of Habsburg Jews, 1670-1918 (Bloomington/Indianapolis 1989), S. $179 \mathrm{f}$.

354 Binder, Kafka, S. 468f. Siehe dazu auch: Wambach: Ahasver, S. 61ff. 
von I 867 veränderte sich der Charakter der österreichischen Staatsbürgerschaft grundlegend, ${ }^{355}$ bedeutete doch die Gewährung konkreter politischer Rechte - etwa des Wahlrechts - auch eine Schließung des Staates. Mit der Einführung des direkten (nicht aber allgemeinen) Wahlrechtes durch die Wahlrechtsreform der Regierung Auersperg im Jahr I 873, die in gewisser Weise den Abschluss der liberalen verfassungspolitischen Reformen bildete, waren Juden in allen vier Wählerkurien (faktisch allerdings nur in Kurie II : Städte und Märkte und Kurie III: Handels- und Gewerbekammern) wahlberechtigt, sofern sie mindestens Io Gulden direkte Steuern zahlten (was etwa bei I 2 Prozent der wahlfähigen Bevölkerung Cisleithaniens der Fall war, darunter auch Frauen, diese allerdings nur in der Wählerklasse I, dem Großgrundbesitz). Eine neue schärfere Grenze verlief nun zwischen Besitzenden und Nichtbesitzenden, zwischen Männern und Frauen, Inländern und Ausländern nicht aber mehr zwischen Christen und Juden.

Eine fast unmittelbare Folge des Staatsgrundgesetzes (und der Folgegesetzgebung) war, dass Juden in nie zuvor da gewesener Weise begannen, in allen Bereichen des öffentlichen Lebens zu partizipierten: in Kunst und Kultur, Medizin und Justiz, in der Wirtschaft und im Journalismus (einzig der Bereich des öffentlichen Dienstes der Staatsdienst - blieb ihnen durch ein ungeschriebenes Gesetz, das vorsah, nur getaufte Juden in den Staatsdienst aufzunehmen, weitgehend verschlossen). Zum Schlüssel dieser Partizipation aber wurde das Bildungswesen, eine allgemeine (nichtreligiöse) Schul- und Hochschulbildung. ${ }^{356}$ Bildung hat in der Tradition der Haskala, jener durch Moses Mendelssohn geprägten Form jüdischer Aufklärung, die Bedeutung von westlicher (deutscher) Kultur im Sinne des humanistischen Ideals, gepaart mit dem spezifisch jüdischen Aspekt eines moralischen Gebots. ${ }^{357}$ Danach wäre der Mensch ganz Mensch nur als ein gebildeter. Bildung im jüdischen Sinn ist daher immer auch eine religiöse Pflicht. ${ }^{358}$ Jüdische Kinder profitierten dann auch

355 Martin Schennach wies unlängst darauf hin, dass mit der Konstitutionalisierung des Kaiserstaates die Staatsbürgerschaft eine veränderte verfassungsrechtliche Bedeutung erfahren habe, da Staatsbürgerschaft nun im Bereich der Grundrechte angesiedelt worden sei. Vgl. Schennach, Österreicher als Rechtskonstrukt, S. 176.

356 Den engen Zusammenhang von Allgemeinbildung und Staatsbürgerschaft für die deutschen Staaten betont Ingrid Lohmann, in: dieselbe: Die Juden als Repräsentanten des Universellen. Zur gesellschaftspolitischen Ambivalenz klassischer Bildungstheorie, in: Pluralität und Bildung, Ingrid Gogolin et al. (Hg.) (Opladen 1998), S. 153-178. Zur Bedeutung von Bildung im (jüdischen) Bürgertum siehe auch: Gary B. Cohen: Education and Middle-Class Society in Imperial Austria 1848-1918 (West Lafayette/Indiana 1996), S. 147-148, 255-58, $278 \mathrm{f}$.

357 Zur Bedeutung von Bildung als Mittel der Integration von Juden ins Bürgertum siehe: Simone Lässig: Jüdische Wege ins Bürgertum (Göttingen 2004).

358 Vgl. Steven Beller: Patriotism and the National Identity of Habsburg Jewrey, 1860-1914, in: Leo Baeck Institute Year Book XVI (1996), S. 215-238, hier: S. $218 \mathrm{f}$. 
in besonderem Maße von den interkonfessionellen Volks- und Bürgerschulen mit staatlicher Schulaufsicht, wie sie nach dem Reichsvolksschulgesetz von I 869 überall zu errichten waren. Aufbau und Gestaltung des Bildungssystems erfolgte unter liberalem Vorzeichen unter dem Postulat der Gleichberechtigung. (Der Begriff der Gleichberechtigung löste jetzt den Begriff der Emanzipation, der in das semantische Feld der Julirevolution von I 830 gehört, ab: Gleichberechtigung der Sprachen, Gleichberechtigung der Nationalitäten, Gleichberechtigung der Konfessionen sind die großen Themen der Tagespolitik, noch kaum - und schon gar nicht im Unterrichtswesen - Gleichberechtigung der Geschlechter.)

\section{Sprache, Nationalität und Recht im Unterrichtswesen}

Das Grundrecht auf Wahrung und Pflege von Nationalität und Sprache - im »Völkerfrühling « des Vormärzes geboren - war mit Artikel I 9 des Staatsgrundgesetzes vom Dezember I 867 in den Verfassungsrang erhoben worden. Intendiert war damit der Schutz des Individuums, ein allgemeines Recht des Staatsbürgers, keinesfalls der Schutz eines Volksstammes oder gar einer Sprache. ${ }^{359}$ In liberaler Tradition war hier versucht worden, das nationale Bekenntnis dem religiösen gleichzustellen und damit der Nationalität eine ähnliche Stellung wie der Konfession einzuräumen. ${ }^{360}$

Auf die Gestaltung des österreichischen (cisleithanischen) Unterrichtswesens sollte Artikel I 9 den größten Einfluss haben. War mit dem ersten Absatz:

Alle Volksstämme des Staates sind gleichberechtigt, und jeder Volksstamm hat ein unverletzliches Recht auf Wahrung und Pflege seiner Nationalität und Sprache.

an die liberalen Postulate von Kremsier und die >Märzverfassung`von I 949 angeknüpft worden ${ }^{361}$, so wurde mit dem Absatz zwei:

359 Dass es im Zuge der Radikalisierung der Nationalitätenkämpfe und des Ethnisierungsprozesses späterer Jahrzehnte zu einer Veränderung des Verständnisses von citizenship kam, darauf hat in jüngster Zeit Gary B. Cohen aufmerksam gemacht. Gary B. Cohen: Citizenship and Nationality in Late Imperial Austria, in: Marija Wakounig/Wolfgang Müller (Hg.): Nation, Nationalität und Nationalismus im östlichen Europa. Festschrift für Arnold Suppan (Köln/Wien 2010), S. 201-224, 204.

360 Zur Genesis von Artikel 19 siehe: Gerald Stourzh: Die Gleichberechtigung der Nationalitäten in der Verfassung und Verwaltung Österreichs 1848-1918 (Wien 1985), S. 53ff, sowie auch: Hannelore Burger: Sprachenrecht und Sprachgerechtigkeit im österreichischen Unterrichtswesen 18671918 (= Studien zur Geschichte der Österreichisch-Ungarischen Monarchie 26) (Wien 1995), S. 37 .

361 Vgl. Gerald Stourzh: Die österreichische Dezemberverfassung von 1867, in: Wege zur Grund- 
Die Gleichberechtigung aller landesüblichen Sprachen in Schule, Amt und öffentlichem Leben wird vom Staate anerkannt.

in besonderem Maße dass Problemfeld der Unterrichtssprache berührt. Da hier keiner Sprache (etwa als Amts- oder Staatssprache) Priorität eingeräumt worden war, bedeutete das, dass erstens jede der in Cisleithanien anerkannten Landessprachen, d. h. Deutsch, Tschechisch, Polnisch, Ruthenisch, Slowenisch, Serbokroatisch, Italienisch, Rumänisch, Unterrichtssprache in jenen Kronländern sein konnte, in denen diese Sprache landesüblich war (also etwa Slowenisch in der Steiermark, Kärnten, Krain und dem Küstenland, Görz und Triest), und dass zweitens keiner Sprache allein aus Gründen der Staatsräson zukam, in allen Kronländern verpflichtend gelehrt zu werden.

Besonderen Sprengstoff aber barg der dritte Absatz des Artikels i9:

In den Ländern, in welchen mehrere Volksstämme wohnen, sollen die öffentlichen Unterrichtsanstalten derart eingerichtet sein, dass ohne Anwendung eines Zwanges zur Erlernung einer zweiten Landessprache jeder dieser Volksstämme die erforderlichen Mittel zur Ausübung in seiner Sprache erhält. ${ }^{362}$

Diese in zeitgenössischer Terminologie Sprachenzwangsverbot genannte Bestimmung führte in sprachpolitischer Hinsicht zu einem Paradigmenwechsel. Im Kern ging sie auf die am Verfassungsprozess beteiligten deutsch-böhmischen Abgeordneten zurück und zielte auf die Abschaffung des bis dahin verpflichtenden Tschechischunterrichts an den deutschen Gymnasien Böhmens und Mährens. ${ }^{363}$ Tatsächlich beschlossen der böhmische und wenig später alle anderen Landtage die Aufhebung aller Gesetzesbestimmungen, die die verpflichtende Erlernung einer zweiten Landessprache anordneten. ${ }^{364}$ Sehr bald aber schon sollte das "Sprachenzwangsgesetz« vor allem gegen die deutsche Sprache wirksam werden, die unter dem Druck der nichtdeutschen Nationalitäten zunehmend in die Defensive geriet.

Nach der Sanktionierung der vier Staatsgrundgesetze (Dezemberverfassung) kam es zu Beginn des Jahres I 868 zur Bildung des sogenannten »Bürgerministeriums« unter dem Fürsten Carlos Auersperg. Ihm gehörten bedeutende Liberale an, darunter auch getaufte Juden: Karl Giskra (Inneres), Julius Glaser (Finanzen), Ernst Berger (ohne Portefeuille). Es war dies, wie Sigmund Freud es einmal ausgedrückt hat,

rechtsdemokratie. Studien zur Begriffs- und Institutionengeschichte des liberalen Verfassungsstaates (Studien zu Politik und Verwaltung Band 29) (Wien/Köln 1989), S. 239-258, hier: S. 252 sowie: Haider, Protokolle, S. 119.

362 RGBl. Nr. 142/1867, zit. nach: Burger, Sprachenrecht, S. 37.

363 Vgl. Stourzh, Gleichberechtigung, S. 54.

364 Vgl. Burger, Sprachenrecht S. 38. 
die "hoffnungsfrohe Zeit des Bürgerministeriums", in der Liberalismus und Judentum, Deutschsein und Verfassungstreue beinahe zusammenfielen. ${ }^{365}$ Kernpunkte der Politik dieser Regierung waren der Kampf gegen das Konkordat, ein modernes Ehegesetz, die Einführung der allgemeinen Wehrpflicht (auch für Juden) mit dem Wehrgesetz I $868^{366}$ sowie die liberale Schulgesetzgebung. Radikale Veränderungen im Bereich des Unterrichtswesens, die im Kern auf Reformkonzepte der I 848er Zeit zurückgingen, wurden nun in rascher Folge umgesetzt. Bereits im Laufe des Jahres I 868 erfolgte der Umbau vom bisherigen Modell einer gemischten staatlich-kirchlichen hin zu einer vollständig weltlichen Schulaufsicht. ${ }^{367}$ So betonte das sogenannte "Schule-Kirche-Gesetz« die staatliche Schulaufsicht für alle Gegenstände des Unterrichts mit Ausnahme des Religionsunterrichtes. ${ }^{368}$ Darüber hinaus sah das Gesetz die Einrichtung unabhängiger Landes-, Bezirks- und Ortsschulräte vor, in denen die Vertreter aller Religionsgemeinschaften - auch der »israelitischen « - gleichberechtigt vertreten sein sollten. ${ }^{369}$

Besonders bemerkenswert ist das böhmische Schulaufsichtsgesetz von I 873, das vorsah, dass jeweils eigene Ortsschulräte für die Schulen deutscher wie für die Schulen tschechischer Unterrichtssprache zu errichten seien. In gleicher Weise wurden auch die Bezirksschulräte national getrennt. Hier waren Vorstellungen verwirklicht worden, wie sie von Adolph Fischhof, dem jüdischen Arzt und Haupt der Märzrevolution von I 848, in seiner berühmten Schrift „Österreich und die Bürgschaft seines Bestandes « entwickelt worden waren. ${ }^{370}$ Fischhof hatte als Mittel zum nationalen Frieden ein sogenanntes Kuriatvotum vorgeschlagen. ${ }^{371}$ Nachdem "das Gebiet der Schul- und Sprachgesetzgebung", wie Fischhof befand, "zum Haupttummelplatz nationaler Leidenschaften und Herrschaftsgelüste" geworden sei, sollte, nach seiner Vorstellung, die Abstimmung nach getrennten nationalen Kurien in den Landtagen und in den Vertretungs- und Verwaltungskörpern gemischter Orts- und Bezirksgemeinden zur Anwendung kommen. ${ }^{372}$ Im böhmischen Schulaufsichtsgesetz von

365 Vgl. Stourzh, Age of Emancipation, S. 15

3661872 dienten bereits 12471 jüdische Soldaten in der k. u.k. Armee, etwa 1,5 Prozent; 1902 erreichte mit 59 784, oder 3,9 Prozent, ihr Anteil einen Höhepunkt, damit war der jüdische Bevölkerungsanteil von 4,6 Prozent schon fast erreicht. Zahlen nach: Schmidl, Juden in der k.(u.)k. Armee, S. 57.

367 Vgl. Helmut Engelbrecht, Geschichte des österreichischen Bildungswesens, Band 4 (Wien 1986), S. 113.

368 Abgedruckt in Engelbrecht, Bildungswesen, S. 553.

369 Burger, Sprachenrecht, S. 41.

370 Vgl. Stourzh, Gleichberechtigung, S. 200f.

371 Vgl. Robert A. Kann: Das Nationalitätenproblem der Habsburgermonarchie, Bd. 2 (Graz/Köln 1964), S. $153 f$.

372 Adolf Fischhof: Österreich und die Bürgschaft seines Bestandes (Wien 1870), S. 138. 


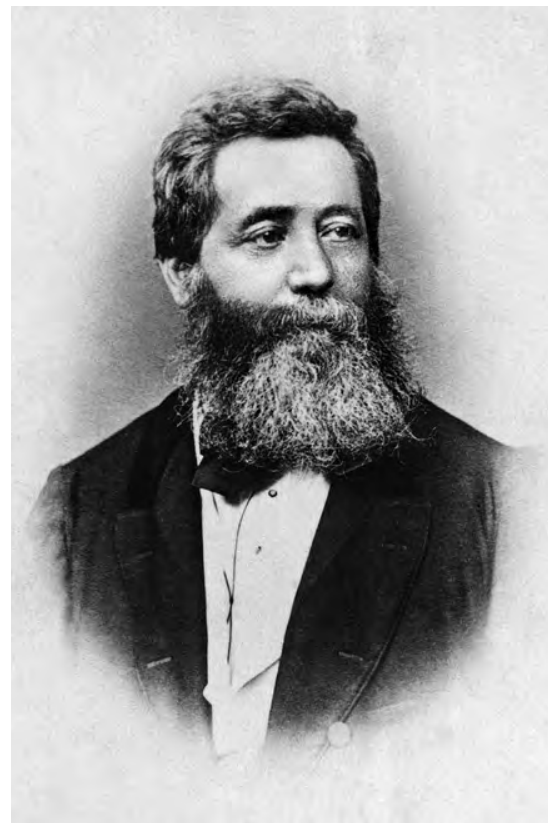

Abb. 13: Adolph Fischhof (I816-1893); Quelle: ÖNB/Wien, Bildarchiv

I 873 war, worauf Gerald Stourzh hingewiesen hat, mit diesem Modell erstmals ein Schutz vor nationaler Majorisierung gesetzt worden, doch das bedeutete auch lange vor der Teilung der Prager Universität - ein erster Schritt in Richtung einer kulturellen Segregation der Bevölkerung Böhmens.

Einen weiteren Meilenstein der liberalen Schulgesetzgebung stellte das von Adolf Beer, Alois Hermann und Julius Glaser ausgearbeitete Reichsvolksschulgesetz vom I4. Mai I 869 dar. Die fünfährigen Volks- und die dreijährigen Bürgerschulen waren als überkonfessionelle Gemeinschaftsschulen konzipiert worden, die allen Kindern, ohne Unterschied des Glaubens, des Standes oder Geschlechts gleiches Wissen vermitteln sollten. Gegen viele Widerstände seitens der Kirche wie des feudalen Großgrundbesitzes wurden die neuen Normen bis in die entferntesten Winkel des Reiches und bis hinein in Architektur und Design gleichförmig umgesetzt. Die "Neuschule«, wie sie von ihren Gegnern genannt wurde, führte nicht nur zu einer deutlichen Anhebung des allgemeinen Bildungsniveaus, verbunden mit einem Abbau des ungeheuren Bildungsgefälles zwischen Zentrum und Peripherie, Stadt und Land, sondern auch zu einer fortschreitenden Integration jüdischer Kinder in das öffentliche Schulwesen. ${ }^{373}$ Besuchten diese - vor allem die Buben - bisher bevorzugt

373 Vgl. Gustav Strakosch-Grassmann: Geschichte des Österreichischen Unterrichtswesens (Wien 1905), S. 269. 
eine jüdische Privatschule, den Cheder, so wuchs der Anteil von Kindern jüdischen Bekenntnisses an öffentlichen Schulen im Jahrzehnt nach I 880 um 54,5 Prozent. ${ }^{374}$

\section{Jüdische Kinder in den Mühlen des Nationalitätenkampfes}

Im Zuge der Umsetzung der neuen Gesetze kam es jedoch auch zur Schaffung einer neuen Schulform, die kaum in der Intention des Gesetzgebers gelegen sein dürfte: der Nationalitätenschule (auch »Minoritätsschule« genannt), eine Besonderheit des altösterreichischen Unterrichtswesens, die sich einerseits aus der Bestimmung des Reichsvolksschulgesetzes ergab, wonach Volksschulen von den Gemeinden überall dort zu errichten waren, wo nach einem fünfährigen Durchschnitt mehr als 40 Kinder in einem Umkreis von vier Kilometern vorhanden waren, andererseits aus den Erfordernissen des Absatz 3 des Artikel I9 des Staatsgrundgesetzes, des oben beschriebenen "Sprachenzwangsverbots«, die es notwendig machten, in gemischtsprachigen Gemeinden, sofern die Eltern dies wünschten, für jede der vorhandenen Nationalitäten Schulen mit je eigener Unterrichtssprache zu errichten. ${ }^{375}$ Unterstützt und angeheizt von den nationalen Schul- und Schutzvereinen kam es bald zu einem Krieg ganz besonderer Art, in der teilweise aus finanziellen Erwägungen - die Gemeinden mussten selbst für den Erhalt ihrer Schulen aufkommen -, hauptsächlich aber aus dem Grund der "Wahrung des nationalen Besitzstandes« mit allen Mitteln versucht wurde, die Errichtung einer Schule mit der Unterrichtssprache des nationalen Gegners zu verhindern.

Und immer wieder waren es gerade jüdische Kinder, die zwischen die Mühlsteine des Nationalitätenkampfes gerieten. So fällte im Jahr I 880 das Reichsgericht zwei aufsehenerregende Urteile. Beide betrafen das Volksschulwesen in Galizien. Beide betrafen Minderheiten. Mit ersterem wurde das Begehren ruthenischer (ukrainischer) Eltern nach einer Volksschule mit ruthenischer Unterrichtssprache in Lemberg durchgesetzt ${ }^{376}$, mit letzterem das Begehren der (überwiegend) jüdischen Bevölkerung Brodys gegen den Zwang, ihre Kinder in Volksschulen mit polnischer Unterrichtssprache schicken zu müssen. Die zweite Beschwerde - der Vertreter der Stadtgemeinde Brody war der bekannte jüdische Anwalt und Abgeordnete Heinrich Jaques - löste innerhalb des Unterrichtsministeriums eine heftige Kontroverse dar-

374 Wolfdieter Bihl: Die Juden in der Habsburgermonarchie 1848-1918, in: Zur Geschichte der Juden in den österreichischen Ländern der Habsburgermonarchie (= Studia Judaica Austriaca VIII) (Eisenstadt 1980), S. 7-121, hier: S. 48.

375 Burger, Sprachenrecht, S. 44.

376 Erkenntnis des Reichsgerichts Nr. 203 vom 19. Jänner 1880, zit. nach: Burger, Sprachenrecht, S. 126. 
über aus, ob die deutsche Sprache in Galizien überhaupt landesüblich und damit Unterrichtssprache sein könne. Das Reichsgericht jedoch befand, dass - wenn auch nur an einzelnen Orten - in Galizien die deutsche Sprache landesüblich sei. ${ }^{377}$ Ebenso wies das Gericht in seiner Erkenntnisbegründung die Ansicht zurück, die jüdischen Einwohner Brodys hätten kein Recht, sich zur deutschen Nationalität zu bekennen und die deutsche Sprache als ihre Sprache zu reklamieren. Nahezu alle jüdischen Einwohner Brodys, stellte das Gericht fest, bedienten sich der deutschen Sprache als ihrer "Mutter-, Familien- und Umgangssprache«, und somit könne es den Einwohnern von Brody als österreichische Staatsbürger nicht verwehrt werden, "nicht nur sich selbst als der deutschen Nationalität angehörig und die deutsche Sprache als ihre Sprache« zu erklären, sondern auch »für ihre schulpflichtigen Kinder die deutsche Sprache als Unterrichtssprache zu begehren«. ${ }^{378}$

Errichtet waren die beiden Volksschulen wegen des anhaltenden Widerstandes des galizischen Landesschulrats damit aber noch lange nicht. Während die Ruthenen Lembergs noch fünf Jahre lang auf ihre Volksschule warteten, mussten sich die Juden Brodys am Ende mit einer privaten, von der jüdischen Kultusgemeinde unterstützten Volksschule mit Öffentlichkeitsrecht begnügen. Sie wurde gemischtsprachig, mit deutscher und polnischer Unterrichtssprache eingerichtet. ${ }^{379}$ Da die galizische Landesregierung nur äußerst schleppend ihren schulpolitischen Verpflichtungen nachkam, waren es immer häufiger private Stiftungen, die die Lücken schlossen. Um die jüdischen Kinder machte sich besonders die I 889 gegründete »Baron HirschStiftung « verdient, die im Geiste der jüdischen Aufklärung, der Haskala ${ }^{380}$, wirkte und es sich zum Ziel gesetzt hatte, jüdische Kinder zu mündigen Staatsbürgern und $\mathrm{zu}$ »tüchtigen Handwerkern und Landwirten« - Bereiche, die ihnen zuvor verwehrt waren - heranzubilden. Die um die Jahrhundertwende existierenden rund zwanzig Baron Hirsch-Schulen waren säkular ausgerichtet; die meisten verfügten - wie jene in Kolomea/Kołomyja - über eine angeschlossene Lehrwerkstatt. Die Unterrichtssprache war für die Kinder, deren Muttersprache in Wahrheit meist das Jiddische war, in der Bukowina die deutsche und in Galizien die polnische. Deutsch wurde allerdings - was wegen des "Sprachenzwangsverbots« nur an Privatschulen möglich war - von der ersten Klasse an obligatorisch gelehrt. ${ }^{381}$

377 Erkenntnis des Reichsgerichts Nr. 219 vom 12. Juli 1880, zit. nach: Burger, Sprachenrecht, S. 128.

378 Ebenda, siehe auch: Stourzh, Gleichberechtigung, S. $75 \mathrm{ff}$.

379 Vgl. Burger, Sprachenrecht, S. 129. Dazu auch: Kuzmany, Brody, S. 216.

380 Zum Forschungsstand der Haskala siehe: Shmuel Feiner: "Wohl euch, die ihr eurer Gedanken wegen verfolgt seid! - Die gegenwärtige Erforschung der Haskala: Kultur der jüdischen Aufklärung in historischer Perspektive. Vorwort zu: Haskala im 18. Jahrhundert. TrumaH. Bd. 16, 2006, S. $1-17$.

381 Vgl. Burger, Sprachenrecht, S. $129 f$. 
Vor allem an der sogenannten Sprachgrenze wurden Gemeinden bei der Begründung von Schulen mit der Unterrichtssprache der Sprachminderheit von den sich nach I 880 konstituierenden nationalen Schulvereinen tatkräftig unterstützt. Unter den besonderen Bedingungen des österreichischen Sprachen- und Nationalitätenrechts begannen eine Vielzahl von Schutzvereinen sprachliche Grenzverteidigung bzw. nationale Besitzstandswahrung zu betreiben - allen voran der im Mai I 880 ausdrücklich als überparteilich gegründete, liberal ausgerichtete "Deutsche Schulverein«. Gehörten diesem - er zählte bereits ein Jahr nach seiner Gründung 30000 Mitglieder - anfangs noch viele Liberale und spätere Sozialdemokraten an, darunter auch Juden wie etwa Viktor Adler, so entwickelte sich diese größte zivilgesellschaftliche Vereinigung Österreichs später zu einer, wie Albert Fuchs feststellt, "Pflanzstätte des Rassendünkels«. ${ }^{382}$ Der Umstand nämlich, dass die von ihren Eltern bevorzugt in Schulen mit deutscher Unterrichtssprache geschickten jüdischen Kinder nicht unbedeutend zum sonst gefährdeten Bestand deutscher Schulen beitrugen (etwa in Eibenschitz/Ivancice), bewirkte, dass die Judenfrage im Deutschen Schulverein sehr bald präsent war. Wurde im Jahr I 882 die Forderung, keine Juden mehr in den Verein aufzunehmen, von Dr. Moritz Weitlof, dem ersten Obmann des Deutschen Schulvereins, noch energisch zurückgewiesen, kam es einige Jahre später zur Absplitterung der Antisemiten unter Führung von Georg Schönerer. Drei Jahre später wurde Schönerers Gegenverein wegen ständiger antislawischer und antisemitischer Hetze durch die Regierung Taaffe verboten. Daraufhin schlossen sich die Antisemiten dem Deutschen Schulverein wieder an und verstärkten somit die deutschnationalen und rassistischen Tendenzen. ${ }^{383}$

Doch auch seitens der tschechischen Schulvereine wurde immer wieder der Vorwurf erhoben, dass viele Schulen mit deutscher Unterrichtssprache ihre Existenz allein den jüdischen Kindern verdankten. Die häufige Zurückweisung ihrer Option, ihre Kinder auf Schulen mit deutscher Unterrichtssprache zu schicken - von deutscher Seite, weil sie Juden waren und von tschechischer Seite, weil sie sich als Deutsche bekannten -, macht das Dilemma jüdischer Eltern in diesem verhängnisvollen Krieg an der Sprachgrenze besonders deutlich. Dass dieser vielfach bloß von den Funktionären nationalistischer Vereine und Parteien geführt wurde, die Bevölkerung dieser Grenzregionen selbst aber weitgehend ihrer traditionellen Zweisprachigkeit treu blieb, darauf hat in jüngster Zeit Pieter Judson aufmerksam gemacht. ${ }^{384}$

382 Albert Fuchs: Geistige Strömungen in Österreich 1867-1918 (Nachdruck von 1949, Wien 1984), S. 193.

383 Gerhard Weidenfeller: VDA, Verein für das Deutschtum im Ausland. Allgemeiner Deutscher Schulverein (1881-1918) (= Europäische Hochschulschriften Reihe III, Bd. 66) (Bern/Frankfurt/ Main 1976), S. 114-117.

384 Pieter M. Judson: Guardians of the Nation? Activists on the Language Frontiers of Imperial Austria (Cambridge MA/London 2006), S. 19-65. 


\section{Der Anteil jüdischer Schüler am höheren Bildungswesen}

Dass das aufstrebende jüdische Bürgertum seine Söhne bevorzugt in Mittelschulen mit deutscher Unterrichtssprache - und hier wiederum in jene vom Typus des klassischen humanistischen Gymnasiums - schickte, ist durch die Forschungen Marsha L. Rozenblits und Steven Bellers gut belegt. Die Gründe dafür mögen im hohen Prestige dieser Lehranstalten zu suchen sein, wohl auch darin, dass sich jüdische Knaben aufgrund ihrer Erziehung, die das frühe Erlernen des Hebräischen implizierte, mit den hohen Ansprüchen in den klassischen Sprachen an den Gymnasien leichter taten, vor allem aber in den angestrebten Studienfächern Jus und Medizin, die den Weg in die freien Berufe ebneten. ${ }^{385}$

In Wien betrug, bei einem jüdischen Bevölkerungsanteil von rund so Prozent, der Anteil jüdischer Schüler an den Gymnasien und Realgymnasien vom Jahr I 875 an bis zur Jahrhundertwende ziemlich konstant 30 bis 35 Prozent, um dann wieder leicht abzusinken. An einzelnen Anstalten der Inneren Stadt, der Leopoldstadt und dem Alsergrund, waren bis zu vier Fünftel der Schüler jüdischer Konfession. ${ }^{386}$ Spitzenreiter war das Erzherzog-Rainer-Gymnasium im zweiten Wiener Gemeindebezirk mit einem Anteil von über 80 Prozent jüdischer Schüler. ${ }^{387}$ In Prag besuchten ebenfalls bemerkenswert konstant zwischen 1875 und I 91045 bis 46 Prozent jüdischer Schüler deutschsprachige Gymnasien und nur 3,8 Prozent tschechischsprachige. ${ }^{388}$ In der ungarischen Hälfte der Monarchie war bezüglich des jüdischen Anteils an Sekundarschulen eine ähnliche Entwicklung zu verzeichnen. ${ }^{389}$ Besonders hoch war der Anteil jüdischer Schüler an den evangelischen Gymnasien, wo sie regelmäßig die Majorität stellten. ${ }^{390}$

Allerdings verstellt der Fokus der Forschung auf das Zentrum und auf die bürgerlichen Eliten in den Städten den Blick nicht nur auf die Masse der armen Landjuden, deren Verhältnis zu ihrer Umgebungsbevölkerung noch wenig erforscht ist ${ }^{391}$, son-

385 So betrug im Jahr 1890 der Anteil jüdischer Medizinstudenten an der Wiener Universität 48 Prozent, jener der Jusstudenten 22 Prozent. Vgl. Steven Beller: Wien und die Juden 1867-1938 (Wien/Köln/Weimar 1993), S. 43, Tabelle 2.

386 Vgl. Rozenblit, Juden Wiens, S. 109.

387 Ebenda, Tabelle 5.1, S. 112.

388 Österreichische Statistik. Neue Folge 8.2, 1875, S. 48-55 und 1910, S. 52-55, sowie Rozenblit, Juden Wiens, S. 115.

389 Für die Jahre 1908-1914 beträgt er 34 Prozent. Vgl. Victor Kárady, The ^Smart Jew` in Pre-1919 Hungary. Educational Investments and Cultural Assimilation, Kakanienrevisited 29/09/2004 (www.kakanien.ac.at/beitr/fallstudie/VKarady1.pdf, S. 1-4).

390 Ebenda, S. 4.

391 Neuerdings dazu: Wilma A. Iggers: Geschichte einer ländlichen Familie zwischen Deutschen und Tschechen, in: Marek Nekula/Walter Koschmal (Hg.), Juden zwischen Deutschen und Tschechen. Sprachliche und kulturelle Identitäten 1800-1945 (München 2006), S. 19-32. 
dern auch für den bemerkenswerten Umbau, den das Unterrichtswesen in sprachnationaler Hinsicht in den letzten Jahrzehnten der Monarchie erfahren hat, büßten doch nach dem Ende der liberalen Ära Schulen mit deutscher Unterrichtssprache und zwar sowohl im Volks- als auch im Mittelschulbereich ihre zuvor dominante Stellung ein. Lagen bei den Volks- und Bürgerschulen die Zahl der deutschsprachigen Schulen im Schuljahr I 9 I 2/ I 3 mit 36,6 Prozent nur mehr knapp über dem deutschen Bevölkerungsanteil (in Cisleithanien 35,6 Prozent), so sanken bei den Gymnasien und Realgymnasien die Anstalten mit deutscher Unterrichtssprache von 60,3 Prozent im Schuljahr I 872/73 auf 42,6 Prozent im Schuljahr I913/I4; umgekehrt stieg der Anteil der Gymnasien etwa mit tschechischer Unterrichtssprache im gleichen Zeitraum von 17,2 auf 2 I Prozent (bei einem tschechischen Bevölkerungsanteil von 23 Prozent). ${ }^{392}$ Der Tendenz nach zeigte sich an Mittelschulen hinsichtlich der Unterrichtssprachen eine allmähliche Angleichung an die realen Bevölkerungsverhältnisse. Dabei erreichte der Anteil jüdischer Gymnasialschüler um I 880 seinen Höhepunkt, um dann ab I 900 wieder leicht abzusinken. ${ }^{393}$

Ursächlich für das Zurückgehen des Prozentsatzes jüdischer Schüler an den Mittelschulen deutscher Unterrichtssprache nach der Jahrhundertwende war zweifellos der Aufstieg der nichtdeutschen Nationalitäten in der konservativen Ära Taaffe, von denen sich eine nach der anderen ihren Anteil am Unterrichtswesen eroberte. Ein weiterer Grund dürfte im steigenden Antisemitismus zu suchen sein, auf den Juden zum einen mit Assimilation (zur jeweiligen Mehrheitsbevölkerung) oder Flucht aus dem Judentum (Konversionen, Austritte, Mischehen), zum anderen mit Hinwendung zum Nationaljudentum bzw. Zionismus reagierten, manchmal auch zum Internationalismus der Arbeiterbewegung. All das führte dazu, dass Juden, wie das Beispiel der Familie Kafka zeigt, ab den I 89oer-Jahren nicht selten einen Sprachwechsel (häufig allerdings bloß einen Wechsel des Bekenntnisses) vornahmen. ${ }^{394}$ Die Umgangssprachenzählungen (im Rahmen der Volkszählungen I 890 bis I910) zeigen deutlich, dass die einst so fest gefügte Klammer um Judentum und deutsche Kultur, Liberalismus und Fortschrittsglaube sich aufzulösen begann. So bekannten sich I 900 bereits 55,2 Prozent der Prager Juden zur tschechischen Umgangssprache. ${ }^{395}$ Ähnliche Tendenzen zeigten sich auch in Galizien, wo es I9 Io zu einer manifesten

392 Ebenda, Tabelle 4A, S. 256.

393 Vgl. Rozenblit, Juden Wiens, Tabelle 5.1, 5.2, S. $112 \mathrm{f}$.

394 Vgl. Nekular, Franz Kafkas Sprachen und Identitäten, S. 145f. Siehe dazu auch die eindrucksvolle Schilderung des Wechsels der Unterrichtssprache am ehemals deutschsprachigen k. k. Staatsgymnasiums in Brody ab dem Jahr 1896, in: Kuzmany, Brody, S. 222.

395 Emil Brix: Die Umgangssprachen in Altösterreich zwischen Agitation und Assimilation. Die Sprachenstatistik in den zisleithanischen Volkszählungen 1880 bis 1910 (= Veröffentlichungen der Kommission für neuere Geschichte Österreich 73) (Wien/Köln/Graz 1982), S. 438. 
Hinwendung der Juden zur polnischen Umgangssprache kam und knapp vor dem Ersten Weltkrieg selbst in der Bukowina, wo der Antisemitismus erst spät manifest wurde. ${ }^{396}$

\section{Sprachen, Nationalitäten, Identitäten}

Doch schon im Jahr I 874 waren anlässlich einer Debatte im Abgeordnetenhaus die Versuche deutschliberaler Abgeordneter, die Juden umstandslos den Deutschen zurechneten, entschieden zurückgewiesen worden. Gegen den Versuch, »eine Konfession zu irgend einem Motiv der Unterrichtssprache« zu gebrauchen, hatte sich damals der jüdische Abgeordnete Albert Mendelsburg gewandt. Mendelsburg wies darauf hin, dass die Juden Galiziens zum allergrößten Teil sich der polnischen Sprache bedienten und warnte davor, neben der nationalen Frage auch noch die religiöse Frage zu provozieren, indem man die Juden Galiziens als eine Nation hinstellte. Galizien, so Mendelburg, sei von Polen und Ruthenen bewohnt, zwischen ihnen lebten Juden. Die Juden seien als eine Konfession zu betrachten, von denen lediglich eine Minderheit deutscher Sprache sei. ${ }^{397}$ Damit war ein Motiv berührt worden, das noch jahrzehntelang den nationalitätenpolitischen Diskurs beschäftigen sollte, die Frage nämlich, ob die Juden Österreichs als eigene Nationalität gelten sollten. Sie sollte viele Jahre später - anlässlich der Debatten um den bukowinischen Ausgleich durch mehrere Erkenntnisse des Reichsgerichts verneint werden. ${ }^{398}$

Die Nichtanerkennung der Juden als Nationalität und die Nichtanerkennung des Jiddischen als Umgangssprache (und damit als Amts- oder Unterrichtssprache) erwies sich jedoch für die Juden Galiziens und der Bukowina kaum als Nachteil. Im Gegenteil lässt sich zeigen, dass Juden an dem, was heute "galizische Bildungsrevolution"

396 Vgl. Emil Brix, Umgangssprachen, S. 356.

397 Stenographische Protokolle des Abgeordnetenhaus, 43. Sitzung, 8. Session, 27. März 1874, S. 1532, zit. nach: Burger, Sprachenrecht, S. 70, siehe dazu auch: Harald Binder: Galizien in Wien. Parteien, Fraktionen und Abgeordnete im Übergang zur Massenpolitik (= Studien zur Geschichte der österreichisch-ungarischen Monarchie 29) (Wien 2005), S. 350.

398 In seinem Erkenntnis Nr. 1722 vom 26. Oktober 1909 wies das Reichsgericht eine Beschwerde des jüdischen Anwaltes Dr. Max Diamant aus Czernowitz wegen Verletzung des durch die Verfassung gewährleisteten Rechtes auf Wahrung und Pflege der Nationalität im Hinblick auf die jiddische Sprache mit dem Leitsatz zurück: »... die ganze historische Entwicklung der österreichischen Gesetzgebung in Ansehung dieser rechtlichen Stellung geht dahin, die Juden nicht als einen Volksstamm (eine Nationalität), sondern - als Bekenner der mosaischen Religion - als eine Religionsgesellschaft anzusehen und als solche zu behandeln. Hye-Hugelmann, Erkenntnisse, Nr. 1722, S. 772. Siehe dazu auch: Gerald Stourzh: Galten die Juden als Nationalität Altösterreichs? In: Anna M. Drabek et al. (Hg.), (= Studia Judaica Austriaca 10) (Eisenstadt 1984), S. 73-117. 
genannt wird, einen hohen Anteil hatten. Auch die gebildete jüdische Elite Wiens verdankte ihre Entstehung nicht zuletzt dem Zuzug jüdischer (mehrsprachiger) Studenten aus Galizien. ${ }^{399}$ Steven Beller erklärt den hohen Anteil jüdischer Mittelschüler und Studenten mit der - verglichen mit dem Katholizismus - deutlich anderen Bildungstradition des Judentums. So lernten Knaben schon im Alter von drei oder vier Jahren lesen. Sie besuchten den Cheder oder die Talmud-Thora-Schulen, in denen Hebräisch gelehrt wurde ${ }^{400}$, in zunehmendem Maße aber auch (und zwar zuerst die Mädchen) die öffentlichen Volksschulen mit polnischer Unterrichtssprache, später bevorzugt Mittelschulen mit deutscher oder polnischer Unterrichtssprache und waren ihren Mitschülern oft schon aufgrund ihrer Mehrsprachigkeit überlegen. ${ }^{401}$

\section{Das mehrsprachige Unterrichtswesen in Der Bukowina}

Auch in der Bukowina, dem ethnisch und sprachlich vielfältigsten Kronland mit dem höchsten jüdischen Bevölkerungsanteil, sprengte die Mehrsprachigkeit jüdischer Kinder oft genug die amtliche Statistik. Wie heute wieder in vielen europäischen Großstädten sah sich die Lehrerschaft in Czernowitz/Černivci/Cernăuți mit einer äußerst heterogenen, pluriethnischen und polyglossen Schülerpopulation konfrontiert. So gab es Kinder römisch-katholischer, griechisch-orthodoxer, griechischkatholischer (unierter), evangelischer und (mit 30,6 Prozent die stärkste Gruppe) jüdischer (mosaischer) Konfession. Mehr als die Hälfte der jüdischen Kinder, exakt 5 I,3 Prozent, sprach im Volksschulalter neben ihrer eigentlichen Muttersprache Jiddisch mindestens zwei, manche drei Landessprachen (Deutsch, Rumänisch, Ruthenisch) und 36 Kinder sogar alle vier landesüblichen Sprachen (mit Polnisch), wobei die Kenntnis des Hebräischen, das ein großer Teil der jüdischen Knaben im Cheder lernte, in den amtlichen Statistiken gar keine Berücksichtigung fand. ${ }^{402}$

Das bukowinische Landesschulgesetz trug der komplexen Bildungslandschaft in der Bukowina insofern Rechnung, als die Unterrichtssprache durch eine eigens eingesetzte Kommission, die die ethnisch-sprachlichen Verhältnisse vor Ort festzustellen hatte, bestimmt wurde. So existierten neben einsprachigen Volksschulen in allen

399 Jerzy Holzer: Aufklärung, Assimilation und moderne Identitäten. Jüdische Eliten in Galizien, Vortragsmanuskript, Juni 1992, S. 8f. sowie vom gleichen Autor: Zur Frage der Akkulturation der Juden in Galizien im 19. und 20. Jahrhundert, in: Jahrbücher für die Geschichte Osteuropas 37 (1989), S. 217-227.

400 Beller, Juden in Wien, S. 103.

401 Vgl. Burger, Sprachenrecht, S. 71.

402 Schematismus der Allgemeinen Volksschulen und Bürgerschulen in den im Reichsrathe vertretenen Königreichen und Ländern (Wien 1902), S. 749. 
Landes- und landesüblichen Sprachen auch Schulen, die gemischtsprachig, d. h. mit bis zu vier verschiedenen Unterrichtssprachen (deutsch-ruthenisch-rumänisch-polnisch), eingerichtet waren. ${ }^{403}$ Während an den einsprachigen Volksschulen eine der Landessprachen einen "relativ obligaten « Lehrgegenstand bildete, wurden an den gemischtsprachigen Volksschulen die Kinder entsprechend ihrer Muttersprache in getrennten Abteilungen unterrichtet. ${ }^{404}$ Auch das Modell des gemischtsprachigen Gymnasiums, das von dem slowenischen Pädagogen Joseph Šuman entwickelt worden war, war in der Bukowina häufiger anzutreffen. So wurde im Jahr I 895, um das überfüllte Staatsgymnasium von Czernowitz zu entlasten (ein Gymnasium mit bis zu 80 Prozent jüdischen Schülern), zunächst Parallelklassen mit ruthenischer, später auch mit rumänischer Unterrichtssprache eingerichtet, die nach der Jahrhundertwende in selbständige Gymnasien umgewandelt wurden. Für diese gemischtsprachigen Gymnasien, an denen ein Teil der Fächer in der Muttersprache der Schüler, die anderen Fächer in deutscher Sprache unterrichtet wurden, existierten sowohl eigene Lehrpläne, als auch eigene Schulbücher. ${ }^{405}$

Die Entwicklung der Bildungslandschaft in der Bukowina während der Verfassungszeit ist bemerkenswert, gehörte doch das ökonomisch noch immer rückständige Kronland mit einer Einwohnerschaft von nur knapp 800000 Menschen vor dem Ersten Weltkrieg zu den Ländern mit dem höchsten Anteil von Mittelschülern. Jüdische Schüler - und ganz zuletzt auch Schülerinnen - spielten dabei eine herausragende Rolle. Ihr Anteil erreichte im Schuljahr I 893/94 mit 43,3 Prozent den höchsten Stand. Knapp vor dem Ersten Weltkrieg (die absolute Schülerzahl hatte sich in dieser Zeit fast verdoppelt) war er (mit 39,6 Prozent) leicht gesunken. Neben den oben angeführten Gründen dürfte in der Bukowina auch die starke Auswanderungsbewegung, an der Juden ebenfalls einen hohen Anteil hatten, eine Rolle gespielt haben. ${ }^{406}$

\section{Der Verdacht gegen die Mehrsprachigkeit}

$\mathrm{Zu}$ Versuchen einer grundlegenden Umgestaltung dieses bemerkenswert mehrsprachigen Unterrichtswesens kam es, als - mit einiger Verspätung und in einer vergleichsweise milden Variante - der nationale Zeitgeist auch in der Bukowina einzog.

403 Vgl. Hannelore Burger: Mehrsprachigkeit und Unterrichtswesen in der Bukowina 1869-1918, in: Ilona Slawinski/Joseph P. Strelka (Hg.): Die Bukowina. Vergangenheit und Gegenwart (Bern et al. 1995), S. 93-125, hier: S. $101 \mathrm{f}$.

404 Burger, Bukowina, S. $101 \mathrm{f}$.

405 Burger, Bukowina, S. 108.

406 Ebenda, Tabelle 2B, S. 122. 
Ähnlich wie in Mähren nach dem Ausgleich von 1905 gab es in Zusammenhang mit den Verhandlungen zum bukowinischen Ausgleich I 909/ıo von deutschnationaler Seite Bestrebungen, einsprachige "Nationalschulen«, deren Besuch für die Czernowitzer Volksschüler verpflichtend sein sollte, durchzusetzen. Gegen die geforderte Nationalisierung des Volksschulwesens wurde insbesondere von jüdischer Seite Einspruch erhoben. In einer Sitzung des Landesschulrats wandte Dr. Josef Billig - unterstützt von Oberrabbiner Dr. Rosenfeld - ein, dass das Gesetz den Staatsbürgern in Anerkennung der sprachlichen Gleichberechtigung das Recht und nicht die Pflicht zuspräche, für ihre Kinder eine Schule mit der Unterrichtssprache ihrer Nationalität zu begehren. Am Ende der Landesschulratssitzung wurde schließlich - gegen die Vorstellungen des deutschnationalen Vertreters - beschlossen, dass es für die Eltern Czernowitzer Kinder keine Verpflichtung geben sollte, ihre Kinder für eine national homogene Klasse anzumelden. ${ }^{407}$

Was in dieser Debatte des bukowinischen Landesschulrats - ein Konzert von vier sehr verschiedenen deutschen Stimmen - deutlich wird, ist, dass der seit dem Vormärz erschallende Ruf nach einem Recht auf den Gebrauch der Muttersprache gegen Ende des Jahrhunderts sich geradezu in eine Pflicht kehrt, sich ausschließlich dieser zu bedienen. Betrachtet man den pädagogischen Diskurs dieser Zeit, so ist zu konstatieren, dass hier ein wahrer Prozess gegen Polyglossie, gegen »Mehr- und Vielsprecherei« geführt wurde, in der man - vor der jetzt geschichtsmächtig werdenden Folie der Sprachnation, wie sie im Anschluss an Herder, Humboldt und Fichte gedacht wurde ${ }^{408}$ - ein Zeichen der Dekadenz und eine Bedrohung des noch sehr filigranen Konstrukts der nationalen Identität erblickte. Die Sprache des Anderen wurde zunehmend zur Fremd-Sprache - zur Sprache des Feindes gar -, und Mehrsprachigkeit geriet immer schon unter Verdacht, ein Verdacht, der sich in besonderem Maße gegen Juden richtete und zwar gerade dann, wenn sie sich der deutschen Sprache bedienten.

\section{Die Ethnisierung der Nationalitätenkonflikte}

Die Durchführung der sogenannten nationalen Autonomie, die Einführung von national getrennten Wahlkatastern (I 905 in Mähren, I 9 Io in der Bukowina, I 9 I 4 in Galizien und, wie viele hofften, bald in ganz Cisleithanien), die damit verbun-

407 Vgl. Burger, Bukowina, S. $110 \mathrm{f}$.

408 In welcher Weise das philosophische Konzept der "sprachbestimmten Kulturnation« zum Exklusionsinstrument gegen Juden im Deutschen Reich gewendet wurde, beschreibt Arndt Kremer in seiner hervorragenden Dissertation: Arndt Kremer: Deutsche Juden - deutsche Sprache. Jüdische und judenfeindliche Sprachkonzepte und -konflikte 1893-1933 (Berlin 2007), S. $25 \mathrm{ff}$. 
dene Herausbildung von einsprachigen nationalen Bildungspyramiden (Ernest Gellner) (eine einsprachige Erziehung von der Volksschule bis zur Universität), wie sie in Böhmen und Mähren bereits realisiert worden waren, führte nicht nur zu einer zunehmenden Entfremdung der Nationalitäten, sondern auch zur Zurückdrängung von Mehrsprachigkeit. Da an Nationalität immer mehr materielle Rechte geknüpft wurden - eigene Schulen, Theater, Universitäten, Presse, Vereine, Wahlkataster - musste, um den Besitzstand einer Nation zu wahren, versucht werden, möglichst deutliche, vermeintlich wissenschaftliche Kriterien zur Bestimmung und Identifizierung von Nationalität zu finden. Gefordert war jetzt das nationale Subjekt. Seinem Wesen nach einsprachig, war es geeignet, gewachsene soziale und kulturelle Bindungen zu zerstören, dazu gehörten auch jene für die Bukowina beschriebenen mehrsprachigen Schul- und Unterrichtsformen. Nach dem Vorbild Böhmens und Mährens wurde der Anteil der gemischtsprachigen Volksschulen und utraquistischen (zweisprachigen) Gymnasien drastisch verringert. Und die viersprachigen Volksschulen wurden als »bukowinisches Kuriosum« zur Gänze abgeschafft. ${ }^{409}$

Darüber hinaus wurde in der Spätzeit der Monarchie in den Diskurs über die Bestimmung von Nationalität der durch Arthur de Gobineau und Houston Stewart Chamberlain populär gewordene Begriff der Rasse eingefügt. Geschichte wurde jetzt vornehmlich als Schauplatz von Rassenkämpfen gedeutet. Die neue Weltanschauung ließ Nationalitätenkonflikte nun nicht länger mehr als Ausdruck des Strebens nach Gleichberechtigung, nach Teilhabe am Staatsganzen erscheinen, sondern als einen naturgesetzlichen Prozess, an dessen Ende es nur Sieger und Besiegte geben konnte.

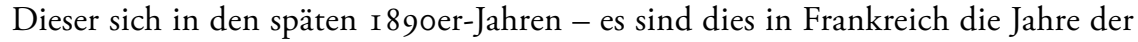
Dreyfus-Affäre und in Österreich jene der Badeni-Krise und des Hilsner-Prozesses brachten, wie Carl Schorske es genannt hat, den neuen Ton in die Politik, der die Entfremdung zwischen den Nationalitäten tiefer, den Kampf um den Besitzstand schärfer werden ließ. ${ }^{410}$ Schrille nationalistische, antislawische und antisemitische Töne drohten jenen auch von den österreichischen Juden getragenen Grundkonsens zu zerreißen, der in gewisser Weise zur Lebensgrundlage der Monarchie geworden war: die Anerkennung der Gleichberechtigung der Nationalitäten, die Anerkennung der Sprache des anderen als zu wahrendes und zu pflegendes Rechtsgut.

409 Vgl. Burger, Bukowina, S. 112.

410 Carl Schorske: Geist und Gesellschaft im Fin de Siècle (Frankfurt/Main 1982), S. 122. 


\section{Die Wiederkehr der »Judenfrage« in der Epoche des Ausgleichs}

Die auf das Staatsgrundgesetz folgende Epoche wurde und wird - im Hinblick auf die Situation der Juden - häufig als ein golden age beschrieben ${ }^{411}$, blieben doch, trotz wechselnder politischer Konstellationen und trotz des seit den I 88 oer-Jahren alle politischen und gesellschaftliche Felder durchdringenden Antisemitismus ${ }^{412}$, die politischen Rahmenbedingungen, was die staatsbürgerliche Stellung der Juden betrifft, unverändert. ${ }^{413}$ Manchmal wird diese Epoche als Verfassungszeit, manchmal auch als Epoche des Ausgleichs bezeichnet, wobei damit allererst der ungarische Ausgleich gemeint ist, der die staatsrechtliche Trennung der Monarchie in zwei wesensverschiedene Reichshälften: einen Nationalitätenstaat mit acht im Prinzip gleichberechtigten "Volksstämmen" (Cisleithanien) und einen Nationalstaat mit einem Staatsvolk (den Ungarn) und verschiedenen ethnischen Minderheiten (Transleithanien) ins Werk setzte. Doch sehr bald schon bezeichnete Ausgleich nicht länger mehr nur das filigrane Konstrukt der k. u. k. österreichisch-ungarischen Monarchie - bzw. die Staatskunst, die notwendig war, das alle zehn Jahre neu zu verhandelnde Ausgleichswerk zu erhalten -, sondern, unter dem Vorzeichen des Aufstiegs der nichtdeutschen Nationalitäten in der konservativen Ära Taaffe, wurde Ausgleich mit veränderten Konnotationen auch für Cisleithanien zu einem Code, der begann, alle Politikfelder zu durchdringen. Dabei ging es nicht mehr um staatsrechtliche Trennung, wie im Fall Österreich-Ungarn, sondern darum, das Streben der Nationalitäten nach Selbstverwaltung, nach größtmöglicher Autonomie, mit den Erfordernissen der Verfassung, näherhin den Bestimmungen des Artikels is (das Recht auf "Wahrung und Pflege von Nationalität und Sprache«) zu versöhnen.

Die Prinzipien dieser Ausgleichsbewegung (wobei hier nicht nur die politisch realisierten, also der mährische, bukowinische und, mit Einschränkung, der galizische Ausgleich, gemeint sind, sondern ebenso die gescheiterten böhmischen Ausgleichsversuche, wie auch die gedachten künftigen) reichen bis in den Vormärz zurück. Wenn der junge Karl Renner nach der Jahrhundertwende den Umbau der

411 Fred Stambrook: The Golden Age of the Jews of Bukowina 1880-1914 (= Center for Austrian Studies, Minneapolis, Working Paper 03-2, October 2003).

412 Der jüdische Reichsratsabgeordnete und Begründer der »Österreichischen Wochenschrift«, Dr. Joseph Bloch, beschreibt in mehreren in den 1880er-Jahren erschienenen Aufsätzen (und Reden) den Antisemitismus nicht mehr bloß als eine Idee, sondern als eine "Leidenschaft", eine "Leidenschaft, die sich entflammt und auflodert in jedem Hauche des öffentlichen Lebens«. Joseph S. Bloch: Der nationale Zwist und die Juden in Österreich (Wien 1886) (Separatdruck), S. 1.

413 Vgl. Stourzh, Age of Emanzipation, S. 17. Auch John Boyer weist in seiner Studie zu Karl Lueger darauf hin, dass selbst der populäre Wiener Bürgermeister, dessen programmatischer Antisemitismus ihn von Wahlsieg zu Wahlsieg führte, nie einen ernsthaften Versuch unternahm, die Wiener Juden ihrer Bürgerrechte zu berauben. Vgl. Boyer, Karl Lueger, S. 208. 
Monarchie zu einem modernen Nationalitätenstaat auf Grundlage der sogenannten personalen Autonomie forderte ${ }^{414}$, so griff er dabei auf Instrumente zurück, die er im Wesentlichen von Adolph Fischhof, dem jüdischen Arzt und Haupt der Märzrevolution von I 848 , übernommen hatte, der in seiner - bereits oben erwähnten - überaus populären Schrift »Österreich und die Bürgschaft seines Bestandes« eine Föderalisierung Cisleithaniens gefordert hatte, wobei ein sorgfältig ausgearbeitetes Nationalitätengesetz sowie das Instrument des Kuriatvotums dem "nationalen Frieden « dienen sollten. (»Kuriatvotum» meinte die gesonderte Abstimmung nach nationalen Kurien in den verschiedenen Verwaltungskörpern der Monarchie, insbesondere den Ortsund Bezirksgemeinden ${ }^{415}$ ).

Rund zwanzig Jahre später, im Vorfeld der Verhandlungen um einen böhmischen Ausgleich, bemerkte Fischhof stolz, dass sich seine Vorstellungen hinsichtlich der nationalen Abgrenzung der Bezirke, insbesondere aber das Kuriatvotum, »jenes Schild, das den nationalen Minoritäten sichere Deckung bietet«, überall durchgesetzt hätten. ${ }^{416}$ Doch als deutschböhmische Abgeordnete im Zuge der Ausgleichsverhandlungen nun auch die Teilung des böhmischen Landesschulrats in eine deutsche und eine tschechische Sektion verlangten, lehnt Fischhof dies schroff ab. Plötzlich warnte er davor, dass "der Deutsche» sich im »herrlichen Böhmerland« hermetisch hinter »einer mehrfachen Kette von Verschanzungen« abschließe. Und in fast Bolzanischer Diktion fragt er, ob denn »die Hebung der Schule, die Pflege der wichtigsten Kulturstätten des Landes, nicht ein gemeinsames Interesse, nicht eine solidarische Pflicht" sei? Es ist, als ahnte er, dass die von ihm selbst erdachten Instrumente am Ende nicht nur dahin führen könnten, die Völker nach dem Prinzip der »sicheren Zäune« von einander fern zu halten (um damit den nationalen Frieden zu sichern), sondern sie einander »immer mehr zu entfremden «. 417

Und noch knapp vor dem Ersten Weltkrieg - der mährische und der bukowinische Ausgleich waren politische Realität und die nationale Trennung von Institutionen längst Routine geworden - widmete der neugewählte Rektor der Universität Wien, der Verfassungsrechtler Edmund Bernatzik, seine Inaugurationsrede den rechtlichen Problemen der nationalen Autonomie. Nachdem letztere »ein politisches

414 Vgl. Rudolf Springer (Karl Renner): Grundlagen und Entwicklungsziele der Österreichisch-Ungarischen Monarchie (Wien/Leipzig 1906), siehe dazu auch: Robert Kann, Nationalitätenproblem, S. $162 f$.

415 Adolph Fischhof, Österreich und die Bürgschaft seines Bestandes (Wien 1870), S. 137f.

416 Adolph Fischhof: Der österreichische Sprachenzwist. Ein Wort aus Anlass der diesjährigen historischen Gedenktage (Wien 1888), S. 7. Eine Formulierung, die sehr nah an jenen »sicheren Zäunen« ist, wie sie etwa ein Michael Walzer für ethnische und religiöse Minderheiten im heutigen Amerika verlangt. Siehe: Michael Walzer: Über Toleranz. Von der Zivilisierung der Differenz (Hamburg 1998), S. 105 u. 123 f.

417 Vgl. Fischhof, Sprachenzwist, S. 34. 
Prinzip von unwiderstehlicher Stoßkraft" geworden, und es bereits zu einer "partiellen Ersetzung des bisher im öffentlichen Recht geltenden Territorialprinzips durch das Personalitätsprinzip« gekommen sei, stelle sich, so Bernatzik, das Problem, auf welcher rechtlichen Grundlage die nationale Trennung der Bevölkerung vorgenommen werden solle. ${ }^{418}$ Alle politischen Instrumente, die im Rahmen der Ausgleichsverhandlungen geschaffen worden seien, hätten einen empfindlichen Mangel: den Mangel feststellbarer Kriterien für die Zugehörigkeit zu einer Nationalität. ${ }^{419}$ Anlass für seine Intervention war die wenige Wochen zuvor ausverhandelte neue Landesund Landeswahlordnung für die Bukowina, die neben den fünf sozialen Wählerklassen ebenso viele nationale Kurien vorsah: eine ruthenische, eine rumänische, eine polnische, eine deutsche und - die eigentliche Sensation des Bukowina Ausgleichs eine jüdische. Zum Glück habe, so Bernatzik, die Regierung letztere zurückgewiesen, doch da ähnliche Reformen auch in Böhmen, Istrien und anderen Ländern zu erwarten seien, sei die Einführung nationaler Matriken (die Einschreibung der Bevölkerung in getrenntnationale Verzeichnisse) unabdingbar. Darüber hinaus müsse, meint Bernatzik, in einem Gesetz versucht werden, "Nationalität im objektiven und im subjektiven Sinne festzustellen ${ }^{420}$ Da nun in der Monarchie nur die Sprache als eindeutiges Zeichen der Nationalität anerkannt werde, hätte ein solches Gesetz eindeutig festzustellen, welche Sprachen und Nationalitäten durch Artikel I 9 geschützt seien, ob etwa Ladiner "mit den Italienern identisch" seien, oder, »ob Juden eine besondere Nationalität bilden - wenigstens jene Juden, welche sich als Nationalität bekennen wollen. « ${ }^{421}$ Für Bernatzik, der die »Kühnheit und Originalität« der mährischen Gesetze pries, war das Problem der Zuordnung von Juden in das neu geschaffene Instrument des Wahlkatasters jedenfalls nicht gelöst. Lange Zeit hatten sich die Juden dem "Nationalitätenzwist«, wie es der junge Floridsdorfer Rabbiner Dr. Joseph Bloch nannte, verweigert, in gewisser Weise schienen sie die einzig übriggebliebenen Österreicher zu sein, "Österreicher sans phrase«, wie es in einem Artikel der von Bloch gegründeten Österreichischen Wochenschrift hieß. ${ }^{422}$ Doch die immer bedrohlicheren Zeichen eines neuen Antisemitismus in den I 88oer-Jahren - zuerst im Deutschen Reich mit dem hässlichen Berliner Antisemitismusstreit und etwa zwei Jahre später mit der Rohling-Affäre in Österreich, weiters mit dem Linzer Programm,

418 Edmund Bernatzik, Über nationale Matriken (Wien 1910), S. 17.

419 Ebenda, S. 19.

420 Ebenda, S. 24.

421 Ebenda, S. 25.

422 In einem Leitartikel in der Ausgabe vom 20. Februar 1885 hieß es: „Wenn die österreichische Nationalität konstruiert werden könnte, so würden die Juden ihren Grundstock bilden«. Zit. nach: Jacob Toury: Troubled Beginnings: The Emergence of the Österreichisch-Israelitische Union, in: Leo Baeck Institute Year Book XXX (1985), S. 456-475, hier: S. 463. 
wo erstmals die Forderung des Ausschlusses von Juden erhoben worden war sowie den wüsten antisemitischen Tiraden Georg Ritter von Schönerers und Karl Luegers schufen ein Klima, das Joseph Bloch und andere liberale Juden an ihrer bisherigen Neutralität in allen nationalen Belangen zweifeln ließ, sodass es I 885 zur Bildung der »Österreichisch-Israelitischen Union«, einer Art Wählervereinigung und Schutzorganisation, $\mathrm{kam}^{423}$, die sich in besonderer Weise der Bekämpfung des Antisemitismus und der Wahrung der staatsbürgerlichen Rechte von Juden verpflichtet sah.

Längst schon war sie wieder da: die überwunden geglaubte »Judenfrage«. Theodor Herzl hatte sie - nach der Dreyfus-Affäre in Frankreich, die Ende der I 89oerJahre ganz Europa erschütterte - mit der zionistischen Option auf die Bühne der Weltpolitik gehoben. ${ }^{424}$ In seinem I 896 erschienenen Buch »Der Judenstaat « entfaltete er die Judenfrage als eine "nationale Frage«, die nur durch die Schaffung eines eigenen Staates für die Juden zu lösen sei. ${ }^{425}$ In Österreich-Ungarn kam es, von der Weltöffentlichkeit weniger bemerkt als in Frankreich, im Umfeld und als Nachspiel der Badeni-Krise, beinahe gleichzeitig zu einem heftigen Ausbruch von Antisemitismus: Vordergründig ein Konflikt zwischen Tschechen und Deutschen um die innere Amtssprache in Böhmen und Mähren, der die Monarchie in eine ihrer größten Staatskrisen führte, wurden in der letzten Phase der Auseinandersetzungen die antisemitischen Töne immer lauter. So verzeichnet etwa das stenographische Protokoll des Abgeordnetenhauses am 27. November I 897, als das Parlament zum letzten Mal zusammentrat, nach schweren Tumulten den Ruf: „Hinaus mit dem Juden Blumenstock! Der ist Schuld an allem!«426

Der Krakauer Jurist und enge Vertraute Badenis blieb nicht der Einzige, der als (getaufter) Jude zwischen die Mühlen des Nationalitätenkampfes geraten sollte. Während im Frankreich der Dreyfus-Affäre der Antisemitismus häufig gepaart war mit einem Antigermanismus (der sich aus dem Verlust von Elsass-Lothringen speiste), trat er in Österreich häufig zusammen mit einem Antislawismus auf (etwa bei Schönerer und Wolf, den krakeelenden Volksvertretern der »Alldeutschen «, oder beim späteren Wiener Bürgermeister Karl Lueger, der seinen Wahlkampf gleichermaßen mit antislawischen wie antisemitischen Parolen würzte). ${ }^{427}$ Auf tschechischer

423 Ebenda, S. 465.

424 Der Antisemitismus "wirkte auf mich«, bekannte Herzl damals, "wie wenn ich einen Schlag auf den Kopf bekommen hätte«. Vgl. Theodor Herzl: Zionistische Schriften (Berlin 1920), S. $256 f$.

425 Theodor Herzl, Der Judenstaat. Versuch einer modernen Lösung der Judenfrage [Leipzig/Wien 1896] (Zürich 2006).

426 Gemeint war der Kanzleidirektor des Parlaments, Heinrich Ritter von Halban Blumenstock. Vgl.: Hannelore Burger/Helmut Wohnout, Eine "polnische Schufterei«? - Die Badenischen Sprachenverordnungen für Böhmen und Mähren 1897, in: Michael Gehler/Hubert Sickinger (Hg.): Politische Affären und Skandale in Österreich (Wien/München 1995), S. 79-98.

427 Zur Eroberung Wiens durch die Antisemiten siehe: Boyer, Karl Lueger, S. 123ff. 
Seite machte sich allerdings auch die französische Variante geltend. In der sich jetzt national ausdifferenzierenden Gesellschaft wurden Juden zunehmend - wie es im Sprachgebrauch der Action Française hieß - zu Metöken, die, wie es dem jüdischen Abgeordneten Adolf Stránsky vorgeworfen wurde, weil sie Juden waren, »für die heiligsten Interessen der Völker (...) keinen Sinn und kein Verständnis« hätten. ${ }^{428}$

Wann immer in der Folgezeit Deutsche mit Tschechen und Tschechen mit Deutschen aneinander gerieten, waren es bevorzugt Juden, die dabei zu Schaden kamen. Als im Oktober I 899 alle Sprachenverordnungen sistiert wurden, kam es wieder zu schweren Unruhen in Prag und Brünn. Zum besonderen Opfer der Gewalt aber wurden die mährischen Juden. In mehreren Gemeinden kam es zu pogromartigen Exzessen gegen die jüdische Bevölkerung, die, wie Richard Charmatz zutreffend bemerkt, bisher »mehr zwischen den beiden Nationen als mit ihnen gelebt hatten «. ${ }^{429}$ Im gleichen Jahr erregte der Hilsner-Prozess weit über Böhmen hinaus die Öffentlichkeit. In einer nicht zuletzt durch das Erscheinen der Masse auf der politischen Bühne geschürten Hysterie kam es zu einer fatalen Verschmelzung von Nationalismus, Antisemitismus und den neuen Rassentheorien mit der mittelalterlichen Ritualmordlegende. ${ }^{430}$ Eine Folge dieses über Jahre sich erstreckenden Justizskandals war eine immer deutlichere Ethnisierung des Sprachen- und Nationalitätenkampfes. Weitmöglichste Trennung der Nationalitäten schien vielen politischen Akteuren der einzig gangbare Weg zu sein.

Dass es in Mähren - anders als in Böhmen - nach siebenjährigen Verhandlungen gelang, einen Ausgleich zwischen den Nationalitäten zu erzielen, wurde allgemein als ein Zeichen der Hoffnung empfunden. Der aus vier Teilgesetzen bestehende mährische Ausgleich: eine Landesordnung, eine Landeswahlordnung, ein Gesetz über den Gebrauch der Landessprachen bei den autonomen Behörden sowie ein Gesetz über die Organisation der Schulaufsichtsbehörden ${ }^{431}$ galt vie-

428 Stenographische Protokolle des Abgeordnetenhauses, XIII. Session, 18. Sitzung, 26. Oktober 1897, S. 961.

429 Richard Charmatz: Österreichs innere Geschichte von 1848 bis 1907, Bd. 2, Der Kampf der Nationen (Leipzig 1912), S. 138.

430 Der 22-jährige Schustergeselle Leopold Hilsner wurde des Ritualmordes an einer jungen Frau im ostböhmischen Polná beschuldigt und nach einem in ganz Europa aufsehenerregenden Prozess zum Tode verurteilt, von Kaiser Franz Joseph später zu lebenslanger Haft begnadigt. Der spätere erste Präsident der Tschechischen Republik Tomáš G. Masaryk regte mit öffentlich publizierten Stellungnahmen eine Revision des Hilsner-Prozesses an. Leopold Hilsner wurde nach 19-jähriger Haft in den letzten Tagen des Ersten Weltkrieges entlassen. Ausführlich zum Hilsner-Prozess siehe: Benno Wagner: Kafkas Polná. Schreiben jenseits der Nation, in: Marek Nekula (Hg.): Juden zwischen Deutschen und Tschechen im 19. und 20. Jahrhundert (Tübingen 2006), S. 151-172.

431 Grundlegend zum Gesetzeswerk des Mährischen Ausgleichs: Horst Glassl: Der Mährische Ausgleich (München 1967). 
len als das Ende eines sinnlosen Kampfes auf nationalem Gebiet und als "Beginn eines friedlichen Nebeneinanders der Nationalitäten im Interesse eines produktiven Wirtschaftslebens« ${ }^{432}$ Dabei hatten die Deutschmährer auf ihre bisher garantierte Mehrheit im Landtag zwar verzichtet, doch blieb ihr politischer Einfluss durch das Zugeständnis einer fixen Mandatsverteilung gesichert.

Bis heute gilt der mährische Ausgleich als hervorragendes Beispiel des Minderheitenschutzes. Kritische Einwände kamen in der jüngeren Historiographie zuerst von Gerald Stourzh, der vor allem in den Verfahren zur Feststellung "fassbarer Merkmale« nationaler Zugehörigkeit ein Alarmzeichen im Hinblick auf unheilvolle Entwicklungen im 20. Jahrhundert erblickt ${ }^{433}$, von Emil Brix, der im mährischen Ausgleich einen weiteren Schritt in Richtung einer »kulturellen Desintegration « von Deutschen und Tschechen erkennt ${ }^{434}$, von dem japanischen Historiker Toshiaki Kyogoku bezüglich der Auswirkungen der sogenannten Lex Perek, und von der amerikanischen Historikerin Tara Zahra, die den nationalen Kampf um die Kinder ins Zentrum ihrer Dissertation rückte. ${ }^{435}$

Für die mährischen Juden bedeutete der mit der Einschreibung in einen Wahlkataster verbundene Zwang zu einem nationalen Bekenntnis ein fast unlösbares Problem. Kulturell und sprachlich mehrheitlich den Deutschen verbunden, doch häufig beider Landessprachen mächtig, fühlten sie sich - etwa in ihrer Existenz als Kaufleute und Händler - ebenso ihren tschechischen Landsleuten verpflichtet. Machte nun ein Bekenntnis zum Deutschtum sie den tschechischen Mährern suspekt, so war ihre (häufige) Ambivalenz in nationalen Belangen den Deutschmährern verdächtig. ${ }^{436}$ Forderungen nach Schaffung einer eigenen jüdischen Wählerkurie waren bisher nur von der kleinen Gruppe mährischer Zionisten erhoben worden. Doch als die Regierung im November I 905 eine Wahlreform ankündigte ${ }^{437}$ und dabei die Möglichkeit, diese könne auf Grundlage von nationalen Kurien entstehen, andeu-

432 Alfred von Skene: Der nationale Ausgleich in Mähren 1905 (Wien 1910), S. 98.

433 Stourzh, Gleichberechtigung, S. 218.

434 Emil Brix: Mentalität ist gut - Die Teilung der Prager Universität 1882. Österreichische Osthefte, 30/3 (1988), S. 371-382, hier: S. 371.

435 Tara E. Zahra: Reclaiming Children fort the Nation: Germanization, National Ascription, and Democracy in the Bohemian Lands, 1900-1945. Central European History, 37,4 (2004), S. 501-543 sowie dieselbe: Kidnapped Souls. National Indifference and the Battle for Children in the Bohemian Lands, 1900-1948 (Ithaca/London 2008). Vgl. dazu auch: Hannelore Burger: Der Verlust der Mehrsprachigkeit. Aspekte des mährischen Ausgleichs, Bohemia, Bd. 34, Heft 1 (1993), S. 77-89.

436 Vgl. Sigmund Mayer: Ein jüdischer Kaufmann. 1831 bis 1911 (Leipzig 1911), S. 346f.

$437 \mathrm{Zu}$ den Motiven dieser Wahlreform siehe: Helmut Rumpler: Budapest - Wien - Fiume 1905. Die Entscheidung für die österreichische Wahlreform von 1907 im Kontext der Wende der europäischen Außenpolitik, in: Michael Svatos/Luboš Velek/Alice Velková (Hg.): Magister Noster. Festschrift in memoriam Prof. ph.Dr. Jan Havránek (Prag 2005), S. 493-506. 
tete (was sich allerdings nicht bewahrheitete), beschloss eine eilig einberufene gesamtösterreichische zionistische Konferenz am 3. Dezember I 905, den Kampf um eine jüdische Kurie für die Reichsratswahlen 1906 zum Programm zu erheben. ${ }^{438}$

Es war dies der eigentliche Eintritt der Zionisten in die österreichische Politik. In allen Kronländern wurden nun Versammlungen zum Thema "nationale Autonomie und die Juden « abgehalten. ${ }^{439}$ In Mähren war es besonders die »Freie zionistische Vereinigung für Mähren und Schlesien« mit Sitz in Proßnitz/Prostějov, die für den jüdischen Kataster warb, fürchtete sie doch, dass die Einschreibung der Juden in einen fremdnationalen Kataster (gemeint war der deutsche) wie eine Proskriptionsliste wirken und von den Tschechen zu Boykottzwecken missbraucht werden könnte. ${ }^{440}$ Die Mehrheit der mährischen Juden lehnte einen gesonderten jüdischen Kataster allerdings ab. Längst sei der moderne Jude nicht mehr bloß Jude, so Sigmund Mayer, Präsidiumsmitglied der Österreichisch-Israelitischen Union, sondern "fühle sehr wohl auch als Tscheche, Deutscher, Italiener." ${ }^{441}$ Als Liberaler sah Mayer allerdings eine ganz andere Gefahr: das in der Logik der Ausgleichsgesetzgebung liegende Proporzdenken. Dieses könne, so befürchtete Mayer, dazu führen, dass Juden eines Tages nur mehr entsprechend ihrem Bevölkerungsanteil an Mittelschulen und Universitäten partizipieren dürften, oder, dass »die Zahl der jüdischen Ärzte, Advokaten, Lehrer und Professoren, Bankbeamten« nach fixen Quoten festgesetzt werden würde. ${ }^{442}$ Mayer hielt die Idee des Wahlkatasters für eine kurzlebige. Sie vertrüge sich nicht mit den Grundsätzen der Verfassung und sei kein Heilmittel gegen Antisemitismus und Chauvinismus. Gegen diese Übel gäbe es nur eines: „das allgemeine, gleiche und direkte Wahlrecht. « ${ }^{443}$ Als ein Jahr später die Sozialdemokraten 86 Abgeordnete in den Reichsrat entsandten - eine Zahl, mit der nicht einmal sie selbst in ihren kühnsten Träumen gerechnet hatten - geschah dies nicht zuletzt auch mit den Stimmen liberaler Juden, von denen viele die Sozialdemokratische Partei für die letzte wirkliche Staatspartei hielten.

Doch die Idee des nationalen Katasters war mit der Einführung des allgemeinen gleichen (Männer-)Wahlrechts im Jahr 1906 keineswegs tot, war doch deren

438 Vgl. Adolf Gaisbauer: Davidstern und Doppeladler. Zionismus und jüdischer Nationalismus in Österreich 1882-1918 (Wien/Köln/Graz 1988), S. 178.

439 Ebenda, S. 179.

440 Gaisbauer, Davidstern, S. 177.

441 Mayer, Kaufmann, S. 350.

442 Ebenda, S. 349. Eine Befürchtung, die keineswegs absurd war, wurde doch im Jahr 1914 in einem Geheimabkommen zwischen Tschechen und Deutschen beschlossen, alle Subventionsleistungen und Aufträge der mährischen Landesregierung nach bestimmten ethnischen Quoten zu vergeben. Siehe dazu: Jiř́i Maliŕ, "Druhé« moravské vyrovnání z roku 1914, in: Der Mährische Ausgleich von 1905, a.a.O., S. 87-102.

443 Mayer, Kaufmann, S. 356. 
Verfechtern - allen voran Otto Bauer und Karl Renner - klar, dass dieses nicht vor nationaler Majorisierung schützte. Verwirklicht - und zwar in seiner komplexesten Form - wurde das Katasterwahlsystem noch einmal im Rahmen des Ausgleichs in der Bukowina. Anfang September 1909 legte der Bukowina Landtag der Regierung in Wien einen einstimmig beschlossenen Wahlreformentwurf vor, der auf Basis des alten Kurienwahlsystems fünf nationale Kataster vorsah, darunter einen jüdischen. ${ }^{444}$ Ausgearbeitet worden war das komplexe Wahlgesetz vom jungruthenischen Politiker Nikolaij Wassilko, von dem rumänischen Demokraten Aurel von Onciul und vom Gründer der nationaljüdischen Partei Benno Straucher. Neben Benno Straucher, der eine Art "Diaspora-Nationalismus" vertrat, fochten auch Nathan Birnbaum (der Schöpfer des Begriffs »Zionismus«) und der jüdische Rechtsanwalt Dr. Max Diamant für einen eigenständigen jüdischen Kataster. ${ }^{445}$ Tatsächlich war die Bukowina seit der Jahrhundertwende zu so etwas wie einem Experimentierfeld für eine eigenständige national-jüdische Politik geworden. ${ }^{446}$

Als die Details des Ausgleichswerks in der Öffentlichkeit bekannt wurden, erregte dies einerseits Begeisterung auf Seiten der Zionisten und nationalbewussten Juden, für die der jüdische Kataster »ein Stück Lösung der Judenfrage« bedeutete ${ }^{447}$, andererseits Erschrecken und Entsetzen auf Seiten der assimilierten Juden in Czernowitz wie in Wien. Letztere fürchteten nicht nur, dass die Anerkennung eines eigenen jüdischen Volksstammes die mit dem Staatsgrundgesetz errungene staatsbürgerliche Gleichberechtigung wieder gefährden könnte, sondern dass damit auch den Bestrebungen der Antisemiten, Assimilation und Integration rückgängig zu machen, Tür und Tor geöffnet werden könnte. ${ }^{448}$ Die Regierung in Wien reagierte auf die Ausgleichsvorlage mit einem Erlass, in der der bukowinischen Landesregierung eindringlich dargelegt wurde, dass die »Behandlung der jüdischen Bevölkerung als eigene Nation« mit den Grundsätzen der österreichischen Gesetzgebung unvereinbar sei. ${ }^{449}$ Die Enttäuschung auf nationaljüdischer und zionistischer Seite war groß. Die bukowinische Landesregierung behalf sich schließlich damit, dass die sich zur

444 Zum Ausgleich in der Bukowina siehe: Thomas Hensellek: Der Bukowina Ausgleich. Ein Erfolg in der politischen Praxis? In: Lukáš Fasora/Jiří Malír (Hg.): Der Mährische Ausgleich von 1905, a.a.O., S. 279-290.

445 Vgl. Gerald Stourzh: Der nationale Ausgleich in der Bukowina 1909/1910, in: Ilona Slawinski/ Joseph P. Strelka (Hg.) : Die Bukowina. Vergangenheit und Gegenwart (Bern et al. 1995), S. 35-52.

446 Vgl. David Rechter: A Nationalism of Small Things: Jewish Autonomy in Late Habsburg Austria, in: Leo Baeck Institute Year Book LII (2007), S. 87-109.

447 Neue Nationalzeitung vom 10. September 1909, zit. nach: Gaisbauer, Davidstern, S. 516.

$448 \mathrm{Vgl}$. Stourzh, Nationale Ausgleich, S. 46f.

449 Die Regierung anerkannte die jüdische Bevölkerung in ihrer Gesamtheit vielmehr »als staatlich anerkannte Religionsgesellschaft«. Erlass vom 4. Oktober 1909, zit. nach: Stourzh, Nationale Ausgleich, S. 48. 
deutschen Umgangssprache bekennende jüdische Bevölkerung auch der deutschen Wählerklasse zugeschlagen wurde, wobei die Wahlkreiseinteilung derart verändert wurde, dass im städtischen Bereich der jüdischen Majorität und der deutschen Minorität je ein Mandat gesichert sein sollte. Damit dürfte das Wahlsystem der Bukowina, wie Gerald Stourzh bemerkt, eines der kompliziertesten, wenn nicht das komplizierteste, in ganz Europa gewesen sein. ${ }^{450}$

War dem neuen Katasterwahlsystem in Mähren und der Bukowina zumindest insofern ein Erfolg beschieden, als es im Großen und Ganzen möglich wurde, Landtags- bzw. Reichsratswahlen ohne ständigen Nationalitätenhader abzuhalten, so zeigten sich die Probleme des Ausgleichs in beiden Kronländern schon sehr bald im sensiblen Bereich des Unterrichtswesens. In Mähren resultierten diese Probleme insbesondere aus $\$ 20$ des mährischen Schulerhaltungsgesetzes, der bestimmte, dass »in der Regel" nur solche Kinder in eine Volksschule aufgenommen werden dürften, "welche der Unterrichtssprache mächtig sind «. ${ }^{451}$ Die Intention der nach ihrem Schöpfer, dem alttschechischen Abgeordneten Dr. Václav Perek, sogenannten Lex Perek zielte darauf, eine Praxis zu unterbinden, die die Tschechen "Kinderfang" nannten und die darin bestand, in die deutschen Schulen, sofern die Eltern dies wünschten, auch Kinder aufzunehmen, die die deutsche Sprache nur mangelhaft oder gar nicht beherrschten. Ein Wahlrecht der Eltern, ihr Kind entweder auf eine Schule mit deutscher oder mit tschechischer Unterrichtssprache zu schicken, gestand der Gesetzgeber nur mehr ausnahmsweise und nur dann zu, wenn ein Kind beider Sprachen mächtig war. Diese äußerst umstrittene Gesetzesbestimmung wurde fünf Jahre später durch ein Erkenntnis des Verwaltungsgerichtshofs noch verschärft, das feststellte, dass durch die Sprache eines Kindes auch dessen Nationalität gekennzeichnet sei. Aus dieser in der österreichischen Gesetzgebung gänzlich neuen Gleichsetzung von Sprache und Nationalität leitete man nun ein folgenschweres Recht ab: das "Recht jedes Volksstammes auf seine Angehörigen « ${ }^{452}$

Die Gefahren, die in bestimmten Tendenzen der Ausgleichsgesetzgebung lagen, nämlich das allmähliche Abgehen vom bisher gültigen Prinzip der Option, d. h. eines subjektiven Bekenntnisprinzips, hin zu einer objektiven Bestimmung von Nationalität, sind nur vereinzelt erkannt worden. Immer mehr wurde die Fähigkeit für ein öffentliches Amt (etwa das eines Orts- oder Bezirksschulrat) an die Prüfung der Nationalität gebunden. Auf der Suche nach fassbaren Merkmalen der nationalen Zugehörigkeit sollte es in Zukunft sogar zulässig sein, »Handlungen aus dem privaten,

450 Stourzh, Nationale Ausgleich, S. 49 sowie Gleichberechtigung S. 235-238.

451 Mährisches Landesgesetzblatt Nr. 4 aus 1906. Zur Problematik des Schulausgleichs siehe: Stourzh, Gleichberechtigung, S. 214-222, sowie: Burger, Verlust der Mehrsprachigkeit, S. 77-89.

452 Erkenntnis des Verwaltungsgerichtshofs Nr. 7843/A vom 30. Dezember 1910, zit. nach: Burger, Verlust der Mehrsprachigkeit, S. 86. 
sozialen und öffentlichen Leben, welche sich als glaubwürdige und ernste Kundgebungen der nationalen Zugehörigkeit darstellen «, in die Prüfung einzubeziehen. ${ }^{453}$ Opfer dieser Obsession nach eindeutiger (wissenschaftlicher) Feststellung der Nationalität aber wurden vor allem Kinder im Volksschulalter, die anlässlich der Schuleinschreibung (oder auch anlässlich eines Schulwechsels) oft demütigenden Prüfungsverfahren ausgesetzt waren. Ging es vor dem mährischen Ausgleich vor allem um die Errichtung bzw. Verhinderung von Schulen mit der Unterrichtssprache des nationalen Gegners - insbesondere um die Errichtung sogenannter "Minoritätsschulen«, dem heikelsten Problem des Nationalitätenstreits überhaupt -, so ging es nach dem Ausgleich vornehmlich um die Zuweisung jedes einzelnen Kindes in die »richtige« Schule. Tschechische wie deutsche Ortsschulräte reklamierten nun Jahr für Jahr Kinder aus Schulen heraus, die, aus welchen Gründen immer, eine Schule des nationalen Gegners besuchen und ordneten die Überprüfung ihrer Sprachmächtigkeit, später auch ihrer Nationalitätszugehörigkeit an. Und nicht selten waren es gerade Kinder jüdischer Konfession, deren Nationalität in Zweifel gezogen wurde. So wies ein Verwaltungsgerichtshoferkenntnis vom 9. Februar I9 I I den Rekurs des böhmischen (tschechischen) Ortsschulrats gegen den Besuch des jüdischen - der deutschen wie der tschechischen Sprache mächtigen - Schülers Josef Bartosch der Volksschule Leipnik/Lipník nur deshalb zurück, weil es sich bei der Schule um eine Schule der politischen Israelitengemeinde ${ }^{454}$ Leipnik, »eine Gemeinde mit nur einer Schule und einer Unterrichtssprache« (in diesem Falle die deutsche) handelte und somit für den ortsansässigen »böhmischen « Schüler gar keine andere Wahl bestand. Im Ganzen aber bestätigte das Erkenntnis des Verwaltungsgerichtshofs den Leitsatz, wonach Ortsschulräte nicht allein Behörden im technischen Sinne seien, sondern Organe, die - entsprechend dem Geist des Mährischen Ausgleichs - berufen seien, „den Rechtsanspruch ihres Volksstammes in der Richtung zur Geltung zu bringen, dass die nach dem Gesetze den Schulen dieses Volksstammes angehörigen Kinder diesem nicht entzogen werden « dürften. ${ }^{455}$ Es war dies ein Krieg ganz besonderer Art, der von beiden Lagern gegen eine vermeintliche »Germanisierung «bzw. »Tschechisierung« ihrer Kinder geführt wurde. Die aggressiven Kampagnen, die über Jahrzehnte

453 Erkenntnis des Verwaltungsgerichtshofs Nr. 7846 vom 30. Dezember 1910, zit. nach: Burger, Verlust der Mehrsprachigkeit, S. 87.

454 Von den ursprünglich mit Patent vom 15. 2. 1789 geschaffenen 52 politischen Israelitengemeinden existierten nach dem provisorischen Gemeindegesetz von 184925 als autonome politische Gemeinden (mit eigener Verwaltung und eigenen Schulen) fort. Aufgelöst wurden die autonomen jüdischen Gemeinden in Mähren erst 1919. Vgl. Theodor Haas: Die Juden in Mähren. Darstellung der Rechtsgeschichte und Statistik unter besonderer Berücksichtigung des 19. Jahrhunderts (Wien 1908), S. 25.

455 Erkenntnis des Verwaltungsgerichtshofs vom 9. Februar 1911, Sammlung Budwinski Nr. 7988. 
mit höchster Intensität im Namen der Nation geführt wurden, verfolgten, wie Tara Zahra bemerkt, das Ziel »to nationalize even wider circles of nationally ambivalent children and families « ${ }^{456}$ - keineswegs immer erfolgreich: Gerade Eltern jüdischer Kinder (vor allem in Mähren) ließen sich nur schwer davon überzeugen, dass etwa Schulen deutscher Unterrichtssprache bzw. die Kenntnis der zweiten Landessprache ihre Kinder existentiell bedrohen bzw. ihren Charakter schädigen würde. ${ }^{457}$

Gewiss hat der Ausgleich (in Mähren 1905, in der Bukowina I910 und in Galizien I9I4) bewiesen, dass der Sprachenkampf grundsätzlich schlichtbar und die Nationalitätenfrage in Cisleithanien im Prinzip lösbar waren. Auch hinsichtlich einer

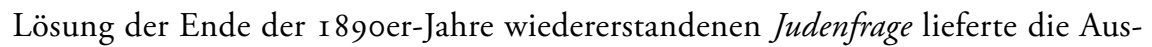
gleichsbewegung - zumindest für nationalbewusste oder zionistisch gesonnene Juden - durchaus kreative Lösungsansätze, doch für die Mehrheit der österreichischen Juden blieb der Ausgleich mit seinen Tendenzen des Zwangs zu einem nationalen Bekenntnis, der Entstehung homogener Nationalgesellschaften und des damit einhergehenden Verlusts von Mehrsprachigkeit und multiplen Identitäten ein Instrument von äußerster Ambivalenz. ${ }^{458}$ Die meisten Juden standen mehr zwischen den verschiedenen Nationalitäten als in ihnen, doch gleich welche Sprache sie sprachen, gleich welcher Nationalität sie sich (zeitweise) verbanden, gleich welcher politischen Partei sie sich zugehörig fühlten, fast alle Juden bewahrten dem österreichischen Staat mit seiner liberalen Verfassung, vor allem aber der Person des Kaisers als Garant ihrer Rechte, ihre unerschütterliche Loyalität. ${ }^{459}$

456 Zahra, Reclaiming Children, S. 503.

457 Tara Zahra: Kidnapped Souls. National Indifference and the Battle for Children in the Bohemian Lands, 1900-1948 (Ithaca/London 2008), S. 19.

458 Vgl. Hannelore Burger: Die »jüdische Frage« zwischen den Ausgleichsbewegungen in Mähren, der Bukowina und Galizien, in: Fasora/Malír : Der Mährische Ausgleich von 1905, a.a.O., S. 71-86. 459 Vgl. Cohen, Citizenship, S. 221. 


\section{Juden im Ersten Weltkrieg}

Das Staatsgrundgesetz von I 867 hatte, zusammen mit dem ein Jahr später verabschiedeten Wehrgesetz, nicht zuletzt auch die Einbeziehung der Juden in die allgemeine Wehrpflicht - eine staatsbürgerliche Pflicht par excellence - gebracht. Obwohl es, vor allem bei orthodoxen galizischen Juden, immer noch eine gewisse Anzahl gab, die versuchte, sich der Stellungspflicht zu entziehen, entsprach im letzten Jahrzehnt der Monarchie der Anteil der Juden in der k. u. k. Armee fast schon ihrem Bevölkerungsanteil. I 902 dienten 59784 jüdische Soldaten im Heer - 3,9 Prozent (bei einem jüdischen Bevölkerungsanteil von 4,6 Prozent). ${ }^{460}$ Da Juden seit I 867 auch die Kadettenschulen und Militärakademien besuchen durften, stieg der Anteil jüdischer Berufsoffiziere stetig an und sogar in der Generalität fanden sich vereinzelt Juden, darunter auch ein Marine-Konteradmiral und ein Generaloberstabsarzt. ${ }^{461}$ Besonders hoch war der jüdische Anteil an den Reserveoffizieren, wohl auch, weil das Tragen der Uniform als Symbol einer endgültigen Aufnahme in die christliche Mehrheitsgesellschaft galt. Mit Ausnahmen erwies sich das Offizierskorps, wie Erwin Schmidl gezeigt hat, gegenüber dem im zivilen Leben stetig anwachsenden Antisemitismus immun. ${ }^{462}$ Die multiethnische k. u. k. Armee mit ihren dreizehn Nationalitäten und zwölf Religionen war neben der Bürokratie zweifellos ein stabilisierendes Element im von endlosen Nationalitätenkämpfen zermürbten und in seinen Grundfesten erschütterten Reich.

Als im Herbst I9I4 der Erste Weltkrieg begann, war die Haltung der jüdischen Bevölkerung ambivalent. Zwar war der Anteil jüdischer Wehrpflichtiger, die um Befreiung vom Wehrdienst ansuchte oder der sich der Stellung zu entziehen suchte, wie der oben zitierte Fall des Aron Moses Taubes zeigt, unter orthodoxen galizischen Juden größer als bei anderen Religionsgemeinschaften, doch unter den eher säkularen Juden der übrigen Kronländer, vor allem bei den schon genannten Reserveoffizieren, war die (anfängliche) Kriegsbegeisterung genauso groß wie unter der übrigen Bevölkerung. Zu dieser Kriegsbegeisterung trug bei einigen noch eine Art »Kreuzzugsgedanke« bei, nämlich die Befreiung der russischen Juden, deren Schicksal im Zaren-

$460 \mathrm{Vgl}$. Schmidl, Juden in der k.(u.)k. Armee, S. 57.

461 Bis 1911 wurden 19 jüdische Offiziere in den Rang eines Generals erhoben, darunter elf Militärärzte. Vgl. István Deák: Der K.(u.) k. Offizier 1848-1918 (Wien/Köln/Weimar 1991), S. 213. 462 Ebenda, S. 69 u. 74. 
reich durch unzureichende staatsbürgerliche Rechte und dauernde Pogrome gekennzeichnet war. ${ }^{463}$ Maureen Healy wies unlängst darauf hin, dass in Kriegszeiten viele Staatsbürger - und zwar positiv wie negativ - ein geschärftes Bewusstsein für den Staat entwickeln, das vorher so nicht existiert hatte. ${ }^{464}$ Diese These trifft gewiss auch für die österreichischen Juden zu, von denen 300000 in den Jahren des Ersten Weltkrieges in der k. u. k. Armee dienten, wobei insbesondere den Reserveoffizieren große Bedeutung zukam, da in den ersten Kriegsmonaten eine enorme Zahl von Berufsoffizieren ihr Leben ließ, sodass diese sehr bald zum Einsatz kamen. In manchen Fällen mögen Juden den Krieg als eine Chance empfunden haben, nicht nur ihre staatsbürgerliche Verpflichtung zu erfüllen, sondern darüber hinaus auch ihre Loyalität, Treue und Zugehörigkeit zu diesem Staat unter Beweis zu stellen. ${ }^{465}$ Geholfen hat ihnen das freilich wenig. Je länger der Krieg dauerte, desto stärker wurden antisemitische Parolen wie die Rede vom »inneren Feind «, einer »fünften Kolonne» oder von den vom Krieg profitierenden Juden laut. ${ }^{466}$ So wurde Juden immer wieder unterstellt, statt Kriegsanleihen zu zeichnen, sich vom Kriegsdienst freizukaufen, sie wurden aller Arten von Verrat und Verschwörungen beschuldigt oder als Urheber mysteriöser Krankheiten verdächtigt. ${ }^{467}$ Etwa zehn Prozent aller Berufs- und Reserveoffiziere waren Juden ${ }^{468}$, über tausend (etwa 6,8 Prozent aller Offiziere) fielen. An Mut, Tapferkeit und Patriotismus ließen es die jüdischen Offiziere also - entgegen aller anderslautenden Behauptungen der Antisemiten - genauso wenig fehlen wie ihre übrigen Kameraden. Die Hälfte der jüdischen Berufsoffiziere und 7,2 Prozent der jüdischen Reserveoffiziere wurde mit einem Orden der dritten oder einer höheren Klasse ausgezeichnet ${ }^{469}$ - eine Tatsache, der anfänglich sogar die Nationalsozialisten Respekt zollten, als sie die jüdischen Teilnehmer des Ersten Weltkrieges, die sogenannten »Frontkämpfer«, auf Druck von Reichspräsident Hindenburg zunächst von einigen ihrer Verfolgungsmaßnahmen ausnahmen. ${ }^{470}$

463 Siehe dazu die hervorragende Studie von Marsha L. Rozenblit: Reconstructing a National Identity: The Jews of Habsburg Austria During World War (Oxford/New York 2001).

464 Healy: Vienna and the Fall, S. 10.

465 Rozenblit, National Identity, S. 9.

466 Belinda Davis: Experience, Identity, and Memory: The Legacy of World War I, in: The Journal of Modern History 75 (März 2003), S. 111-131, hier: S. 121f.

467 Healy, Vienna and the Fall, S. 83, 145 u. 301.

468 Ebenda, S. 84.

469 Ebenda, S. $84 \mathrm{f}$.

470 Noch bis etwa 1936 blieben jüdische dekorierte Teilnehmer des Ersten Weltkrieges von gewissen Diskriminierungen und Verfolgungen verschont. So waren wegen eines Einspruchs Hindenburgs „Frontkämpfer« und deren Hinterbliebene vom Gesetz zur Wiederherstellung des Berufsbeamtentums noch nicht betroffen. Vgl. Michael Berger: Eisernes Kreuz und Davidstern. Die jüdischen Soldaten in den deutschen Armeen (Berlin 2006). 


\section{Theorie und Praxis von Heimatrecht und Staatsbürgerschaft in der Ersten Republik}

Ein grundlegendes - in demokratischen Staaten heute selbstverständliches - Recht eines jeden Staatsbürgers und einer jeden Staatsbürgerin ist das allgemeine, gleiche, direkte und geheime Wahlrecht. Verwirklicht wurde es in Österreich - nun auch für Frauen - in der am I 2. November I9 8 ausgerufen Republik. Das am gleichen Tag erlassene »Gesetz über die Staats- und Regierungsform Deutschösterreichs« sah vor, die Wahlordnungen für das Parlament sowie alle Körperschaften auf Landes-, Kreis-, Bezirks- und Gemeindeebene nach dem Prinzip des »allgemeinen, gleichen, direkten und geheimen Stimmrecht aller Staatsbürger ohne Unterschied des Geschlechts « einzurichten. ${ }^{471}$ In der Folge wurde der Kreis der Wähler stark erweitert, indem erstens das Wahlalter von bisher 24 Jahren auf 20 Jahre gesenkt wurde (um Soldaten, die im Ersten Weltkrieg gedient hatten, die Möglichkeit politischer Partizipation zu geben) und zweitens nun auch Frauen das Wahlrecht, und zwar das aktive wie das passive, gewährt wurde. ${ }^{472} \mathrm{Als}$ am I6. Februar I9I9 die Wahlen zur konstituierenden Nationalversammlung stattfanden, konnten von ihrem Wahlrecht grundsätzlich nun alle Männer und (erstmals) Frauen jüdischen Bekenntnisses Gebrauch machen. Voraussetzung für die Ausübung des Wahlrechts allerdings war der Besitz der österreichischen Staatsbürgerschaft und der blieb vielen der sich im Staatsgebiet der neuen Republik aufhaltenden Juden und Jüdinnen aus nachstehenden Gründen vorbehalten.

Als die österreichisch-ungarische Monarchie am Ende des Ersten Weltkrieges zusammenbrach, bedeutete das für Millionen von Menschen den Verlust ihrer Staatsbürgerschaft. Für Juden und Jüdinnen sollte der Weg zur Erlangung einer neuen Staatsbürgerschaft in einem der Nachfolgestaaten ein häufig langwieriger und mühevoller Prozess werden. Nicht selten endete er in der Staatenlosigkeit. War das Staatsbürgerschaftsrecht der Monarchie - wie komplex und unübersichtlich es auch immer gewesen sein mag - vom Prinzip einer supra-ethnischen Neutralität geprägt

471 StGBl. Nr. 5/1918.

472 Vgl. Birgitta Bader-Zaar, Einführung des Frauenwahlrechts in Österreich, www.demokratiezentrum. org. Kathleen Canning spricht - allerdings mit Bezug auf die Weimarer Republik - vom Frauenwahlrecht als einem "gift to woman from revolution«. Kathleen Canning: "Bodies and Citizenship«, Beitrag zur Konferenz: "The Stakes of Citizenship: Bodies in the Aftermath of War and Revolution«, 1. April 2011, www.youtube, Kathleen Canning. 
gewesen, so folgten die Staatsbürgerschaftsrechte der neuen Republiken überwiegend einer nationalstaatlichen, ethnisch exklusiven Logik. ${ }^{473}$

Auch wenn die Frage der Staatsbürgerschaft ihre endgültige Regelung im Wesentlichen erst in den Staatsverträgen von St-Germain (I919) und Trianon (I920) fand, versuchten doch alle Nachfolgestaaten, ihr Territorium sowie ihre Staatsbürger und Staatsbürgerinnen zunächst selbst zu bestimmen. So erklärte sich die am I 2. November proklamierte »Republik Deutschösterreich« bloß einige Tage später zum Souverän über »das geschlossene Siedlungsgebiet der Deutschen innerhalb der bisher im Reichsrate vertretenen Königreiche und Länder« - ein Gebiet, das mit "Deutschböhmen« und »Deutsch-Südmähren« weit über das Territorium der späteren Republik Österreich hinausreichte. Gleichzeitig erhob sie Ansprüche auf alle "Deutschen« in den größeren Sprachinseln der Nachfolgestaaten Cisleithaniens und Westungarns, u. a. in den »deutschen Siedlungsgebieten« von Brünn, Iglau/Jíhlava und Olmütz/Olomouc. ${ }^{474}$

In einem ersten Entwurf für ein Staatsbürgerschaftsgesetz für die »Republik Deutschösterreich« war die Staatsbürgerschaft grundsätzlich von der Heimatberechtigung in einer auf dem Territorium der Republik gelegenen Gemeinde abhängig gemacht worden. ${ }^{475}$ Damit allerdings wären all jene Einwohner, die das Heimatrecht in einer Gemeinde eines anderen ehemaligen Kronlandes der Monarchie besaßen, automatisch zu Ausländern geworden, selbst dann, wenn sie schon immer im von der Republik beanspruchten Territorium gelebt hatten. Diese Personen hätten jedoch durchaus die Möglichkeit erhalten sollen, Staatsbürger zu werden, indem sie spätestens ein Jahr nach Inkrafttreten des Gesetzes die Zusicherung der Aufnahme in den Heimatverband einer deutschösterreichischen Gemeinde vorlegten. Bei dieser

473 Vgl. Gammerl, Untertanen, S. 328. Dietmar Müller spricht mit Bezug auf die rumänische Volksgruppe zutreffend davon, dass sich seit dem Berliner Kongress bis zur Pariser Friedenskonferenz Argumentationsmuster durchgesetzt hätten, »mit denen die eigene ethnische Gruppe (...) in einer ethnisch-ontologischen Alterität hauptsächlich zu den Juden des Landes konstruiert wurde«, an anderer Stelle von einem (rumänischen) "Nationscode« unter Ausschluss der Juden. Vgl. Dietmar Müller: Staatsbürger auf Widerruf. Juden und Muslime als Alteritätspartner im rumänischen und serbischen Nationscode. Ethnonationale Staatsbürgerschaftskonzepte 1878-1941 (= Balkanologische Veröffentlichungen 41) (Wiesbaden 2005), S. 211.

474 Staatserklärung vom 22. November 1918 über Umfang, Grenzen und Beziehungen des Staatsgebietes von Deutschösterreich, Staatsgesetzblatt für den Staat Deutschösterreich (StGBl) 1918/41. Vgl. Goldemund/Ringhofer/Theurer, Staatsbürgerschaftsrecht, Anm. 1, S. $413 \mathrm{f}$.

475 Der erste Entwurf für das Staatsbürgerschaftsgesetz der Republik Deutschösterreich stammt von Anfang November 1918. Zu den Debatten um Heimatrecht und Staatsbürgerschaft der Ersten Republik vgl. Margarete Grandner: Staatsbürger und Ausländer. Zum Umgang Österreichs mit den jüdischen Flüchtlingen nach 1918, in: Asylland wider Willen. Flüchtlinge in Österreich im europäischen Kontext seit 1914 (= Veröffentlichungen des Ludwig-Boltzmann-Institutes für Geschichte und Gesellschaft 25) (Wien 1995), S. 60-85, hier: S. 62. 
Regelung hatte man vor allem an die große Zahl von (deutschen) Beamten, Soldaten und Eisenbahnern in den Nachfolgestaaten gedacht, denen die Möglichkeit gegeben werden sollte, ihren Wohnsitz in der neuen Republik zu nehmen. In der diesbezüglich in der Nationalversammlung geführten Debatte stand jedoch nur ein Problem im Vordergrund, jenes nämlich, die Einbürgerung jüdischer, vor allem aus Galizien und der Bukowina stammender Kriegsflüchtlinge zu verhindern.

Bereits während des Krieges hatte sich eine beispiellose Hetzkampagne gegen »die Ostjuden« entfaltet, jene rund I 50 ooo vor der russischen Armee geflüchteten bzw. vom österreichischen Militär evakuierten Juden und Jüdinnen, von denen sich bei Kriegsende noch etwa 30000 in Wien aufhielten. ${ }^{476}$ Diente der Begriff "Ostjuden“ ursprünglich bloß einer sozialen, geographischen, kulturellen und religiösen Differenzierung, so erhielt er spätestens jetzt seine antisemitischen Konnotationen. ${ }^{477}$ Pogrome in Galizien (im Zuge der polnisch-ukrainischen Kämpfe) spülten im Winter I9I8/I 9 neue Flüchtlingswellen nach Österreich. Als Staatsbürger waren die als habsburgtreu stigmatisierten Juden in den Nachfolgestaaten wenig willkommen. Nicht zuletzt im Vertrauen auf ihre vermeintlich österreichische Staatsbürgerschaft flüchteten viele nach Wien, oft mit nicht viel mehr als ihrem Heimatschein. Dort aber waren sie plötzlich Ausländer. Einen Flüchtlingsstatus erhielten sie nicht zuerkannt $^{478}$, sodass mehr als I 7000 auf die Unterstützung öffentlicher und privater (vor allem jüdischer) Hilfsorganisationen angewiesen waren. ${ }^{479}$ Führende christlichsoziale oder deutschnationale Politiker agitierten gegen die jüdischen "Schmarotzer", die für die schlechte Versorgungslage, die Wohnungsnot und sogar für die militärische Niederlage verantwortlich gemacht wurden. ${ }^{480}$ Folgt man der in der Presse ausgetragenen Polemik, drängt sich der Eindruck auf, das Schicksal der Zweimil-

476 Beatrix Hoffmann-Holter: "Abreisendmachung«. Jüdische Kriegsflüchtlinge in Wien 1914 bis 1923 (Wien/Köln/Weimar 1995), S. 145.

477 Svjatoslav Pacholkiv: Die Ostjuden als Begriff in der Geschichte, in : „Ostjuden«-Geschichte und Mythos. Juden in Mitteleuropa (St. Pölten 2011), S. 2-11. Siehe dazu auch: Wolff: Inventing Eastern Europe, S. 29f; Auch David Brenner weist darauf hin, dass der Begriff „Ostjude« keineswegs immer einen negativen Klang gehabt habe, ja dass es in Deutschland während des Ersten Weltkrieges geradezu zu einer Idealisierung des »Ostjuden« gekommen wäre. David A. Brenner: Marketing Identities. The Invention of Jewish Ethnicity in Ost und West (Detroit 1998), S. 17f u.161f. Ausführlich behandelt den Begriff »Ostjuden« das Kapitel: "'durch Abstammung und Wahlverwandtschaft ein Ostjuder. Der Fall Manès Speber« in diesem Band, S. 200-212.

478 Vgl. Walter Mentzel: Weltkriegsflüchtlinge in Cisleithanien 1914-1918, in: Asylland wider Willen, a.a.O., S. 17-44, hier: S. 39.

479 Ausführlich dazu sowie zu den Veränderungen und Auseinandersetzungen, die sich dadurch innerhalb der Kultusgemeinde ereigneten: David Rechter, The Jews of Vienna and the First World War (London/Portland, Oregon 2001).

480 Eleonore Lappin: Juden in Wien. Zur Geschichte und Gegenwart der Zuwanderung in Wien, in: WIR (Wien 2000), S. 57-69, hier: S. 65. 


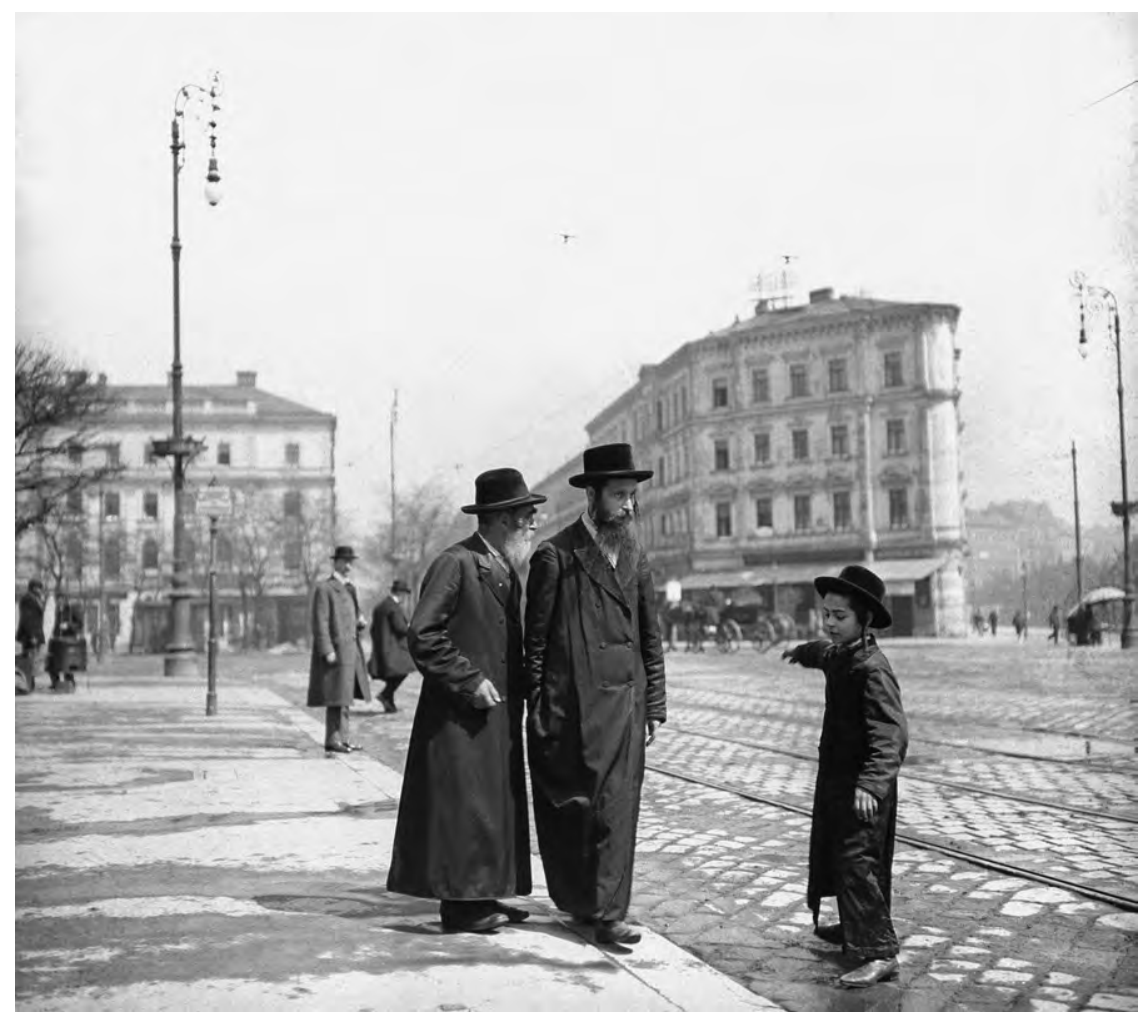

Abb. Is: Orthodoxe jüdische Flüchtlinge aus Galizien am Mathildenplatz (heute: Gaußplatz) in Wien-Brigittenau im April IgIs; Quelle: ÖNB/Wien, Bildarchiv

lionen-Metropole Wien sei allein von der "Abschaffung« der »Ostjuden « abhängig gewesen. ${ }^{481}$ Höhepunkt der Kampagne war ein - allerdings vergeblicher - Versuch des niederösterreichischen Landeshauptmanns Alfred Sever, alle Juden mittels Erlass auszuweisen. ${ }^{482}$

Die jüdischen Flüchtlinge spielten - genannt oder verschwiegen - eine bedeutende Rolle bei der Konstruktion der (deutsch-)österreichischen Staatsbürgerschaft in den Jahren I9I 8 bis I920. Unter dem Druck der öffentlichen Debatte waren sich bald Abgeordnete aller Parteien - auch sozialdemokratische, die für die Misere verantwortlich gemacht wurden - einig, dass eine Regelung gefunden werden musste, die es den jüdischen Flüchtlingen unmöglich machen sollte, ein Heimatrecht in

481 Beatrix Hoffmann-Holter: Jüdische Kriegsflüchtlinge in Wien, in: Asylland wider Willen, a.a.O., S. 45-59, hier: S. 53.

482 Der sogenannte „Sever-Erlaß« ist abgedruckt in: Grandner, Staatsbürger, S. 72. 
Wien zu erlangen. ${ }^{483}$ Ein von der Nationalversammlung am 27. November I9 I 8 beschlossener Entwurf für ein deutsch-österreichisches Staatsbürgerschaftsgesetz wollte die Erlangung der Staatsbürgerschaft überhaupt von einem vorher abzulegenden »Bekenntnis zur deutschen Nation « abhängig machen. ${ }^{484}$ Verlautbart wurde das Gesetz in dieser Form allerdings schon aus formalen Gründen nicht, da, wie Staatskanzler Renner scharfsinnig erkannte, es wegen der eklatanten Verletzung von Minderheitenrechten nicht nur die Empörung der ausländischen Presse hervorgerufen haben würde, sondern weil die Republik Deutschösterreich am Tage der Kundmachung des Gesetzes damit überhaupt keine Staatsbürger gehabt hätte. ${ }^{485}$ Renner gelang es schließlich, einen Gesetzesentwurf im Parlament durchzubringen, wonach allen im Gebiet der Republik Heimatberechtigten ipso jure die österreichische Staatsbürgerschaft zukommen sollte. $\$$ I des am 5. Dezember i9i 8 kundgemachten Gesetzes über das deutschösterreichische Staatsbürgerrecht verkündete dementsprechend: "Deutschösterreichische Staatsbürger sind alle Personen, die zur Zeit der Kundmachung dieses Gesetzes in einer Gemeinde der Deutschösterreichischen Republik heimatberechtigt sind «. ${ }^{486}$ Doch auch Personen, »die ihren ordentlichen Wohnsitz erst nach dem I. August I9I4 nach Deutschösterreich verlegt haben" (bzw. in Zukunft verlegen würden), sollten, sofern sie in einer außerhalb der Republik Deutschösterreich gelegenen Gemeinde des bisherigen Österreich heimatberechtigt gewesen waren, die Möglichkeit haben, durch Erklärung Staatsbürger zu werden, mit Ausnahme allerdings - so die Regelung in $\$ 2$ Absatz 2 des Gesetzes - "Dalmatiens, Istriens und Galiziens « ${ }^{487}$, also gerade jener ehemaligen Kronländer mit entweder geringem deutschen Bevölkerungsanteil bzw. (im Falle Galiziens) mit einem besonders hohen jüdischen Bevölkerungsanteil. Die Verhinderung der Einbürgerung von »Ostjuden« wurde von nun an zum Leitmotiv österreichischer Staatsbürgerschaftspolitik.

483 Darunter auch der liberale jüdische Abgeordnete Julius Ofner, der zehn Jahre zuvor engagiert für die Einbeziehung der »unteren Klassen« in das Heimatrecht gekämpft hatte, vgl. auch: Grandner, Staatsbürger, S. 63.

484 Svjatoslav Pacholkiv bringt dies in Zusammenhang mit einer neuerlichen Flüchtlingswelle nach dem Novemberpogrom in Lemberg, das nach dem Zusammenbruch der Monarchie von Teilen der polnischen Bevölkerung als eine Art Strafgericht an den Juden Lembergs wegen ihrer vermeintlichen Neutralität während der 21-tägigen ukrainischen Herrschaft verübt wurde. Vgl. Svjatoslav Pacholkiv: Vertraut und fremd zugleich, in: Alexandra Binnenkade et al. (Hg.) : Jüdisch-christliche Nachbarschaft in Warschau, Lengnau, Lemberg (Köln 2009), S. 180ff.

485 Grandner, Staatsbürger, S. 65.

486 Staatsgesetzblatt für den Staat Deutschösterreich (StGBI) 1918/91.

487 Zum Erwerb der Staatsbürgerschaft nach $\$ 2$ StbG 1918 siehe: Dieter Kolonovits: Rechtsfragen des Wiedererwerbs der österreichischen Staatsbürgerschaft durch Opfer des Nationalsozialismus (Vertriebene) nach österreichischem Staatsbürgerschaftsrecht, in: Staatsbürgerschaft und Vertreibung (= Veröffentlichungen der Österreichischen Historikerkommission 7), Erster Teil (Wien 2004), S. 7-238, hier: S. $41 \mathrm{f}$. 
Die dem Staatsbürgergesetz von I9 8 zugrundeliegenden Vorstellungen bildeten endlich auch die Grundlage für die im Rahmen der Pariser Friedensverhandlungen vorgenommene Abwicklung der altösterreichischen Staatsbürgerschaft. Die österreichische Delegation unter Führung Staatskanzler Renners schlug - entgegen einer von den Alliierten eingebrachten Vorlage - vor, dass grundsätzlich jeder Bürger der früheren österreichisch-ungarischen Monarchie jenem Staate angehören sollte, in dem sich die Gemeinde befand, in der er heimatberechtigt gewesen war. Darüber hinaus jedoch sollten sowohl »die Bewohner der strittigen und einer Volksabstimmung unterworfenen Gebiete« als auch »Personen fremder Rasse und Sprache« jenen Staat durch Option zur Heimat wählen können, »dem sie nach Rasse und Sprache angehören «. ${ }^{488}$ Nach langen Verhandlungen übernahmen die Siegermächte - unter Aufrechterhaltung des Prinzips der Reziprozität zwischen den Nachfolgestaaten schließlich weitgehend die österreichischen Vorschläge. Für alle Nachfolgestaaten der österreichisch-ungarischen Monarchie galt nun gleichermaßen ein Optionsrecht nach »Rasse und Sprache«. ${ }^{489}$ Der entsprechende Artikel 80 des Vertrages von StGermain-en-Laye vom Io. September I9I9 lautet:

Personen, die in einem zur ehemaligen österreichisch-ungarischen Monarchie gehörigen Gebiet heimatberechtigt und dort nach Rasse und Sprache von der Mehrheit der Bevölkerung verschieden sind, können innerhalb eines Zeitraumes von sechs Monaten nach dem Inkrafttreten des gegenwärtigen Vertrages für Österreich, Italien, Polen, Rumänien, den serbisch-kroatisch-slowenischen Staat oder die Tschechoslowakei optieren, je nachdem die Mehrheit der Bevölkerung dort aus Personen besteht, welche die gleiche Sprache sprechen und derselben Rasse zugehörig sind wie sie. ${ }^{490}$

Hinsichtlich der Durchführung der Option versprach der Brünner Vertrag vom 7. Juni I920, diese »in liberaler Weise« regeln zu wollen und insbesondere die Worte "par la race et la langue" (so der französische Originaltext) derart deuten zu wollen, dass »hauptsächlich die Sprache als wichtigstes Kennzeichen der Volkszugehörigkeit in Betracht gezogen werde. « ${ }^{491}$ In der Folge wurden tatsächlich Optionen von aus dem nunmehrigen Staatsgebiet der Tschechoslowakei stammenden österreichischen

$488 \mathrm{Zu}$ den französischen Gegenvorschlägen siehe Grandner, Staatsbürger, S. 69 und Fußnote 56.

489 Vgl. Grandner, Staatsbürger, S. 70.

490 Zit. nach Goldemund/Ringhofer/Theurer, Staatsbürgerschaftsrecht, S. 422ff (Hervorhebung nicht im Original). Siehe dazu: Kolonovits, Rechtsfragen, S. $47 \mathrm{ff}$.

491 Artikel 9 des Vertrages zwischen der Tschechoslowakischen Republik und der Republik Österreich über Staatsbürgerschaft und Minderheitsschutz vom 7. Juni 1920 („Brünner Vertrag«), BGBl 1921/163, zit. nach: Goldemund/Ringhofer/Theurer, Staatsbürgerschaftsrecht, S. $453 \mathrm{f}$. 
Juden in den meisten Fällen anerkannt. Im Allgemeinen genügte es, seine »Zugehörigkeit zum österreichischen Volke« zu bekennen und sich »mit Familien- und staatsbürgerlichem Leben ganz an Österreichs Verhältnisse angepasst« zu haben. ${ }^{492}$ Doch für aus Galizien und der Bukowina stammende Juden galten andere Regeln. Schon kurz vor dem Inkrafttreten des Staatsvertrags von St-Germain gingen auf der administrativ-praktischen und nach seinem Inkrafttreten auch auf der legistischen Ebene die Bemühungen fast aller politischen Kräfte dahin, zu einer solchen Interpretation des Artikel 80 zu gelangen, die die Anerkennung von Optionen von in Österreich verbliebenen "Ostjuden" unmöglich machen würde. So bestimmte eine Vollzugsanweisung des Innenministeriums vom 20. August I920, dass die Optanten »nach Rasse und Sprache zur deutschen Mehrheit der Bevölkerung " gehören sollten. ${ }^{493}$ Nur ausnahmsweise und im Falle von prominenten oder wohlhabenden Juden, wie etwa im Falle des Schriftstellers Joseph Roth, wurde bei aus den östlichen Gebieten der Monarchie stammenden Juden eine Option für Österreich anerkannt. ${ }^{494} \mathrm{Als}$ die Anmeldefrist für Optionen am I 5 . Jänner I 92 I zu Ende ging, waren viele Ansuchen unbearbeitet geblieben. Nach dieser Frist aber wurde es für auf dem Staatsgebiet der neuen Republik lebende, aus Galizien oder der Bukowina stammende Juden noch schwieriger, zur Anerkennung ihrer Optionen zu kommen. ${ }^{495}$ Denn mit einer Resolution des Plenums des österreichischen Nationalrats vom Io. März I92 I war die Regierung nicht nur aufgefordert worden, sich bei der Erledigung von Optionsansuchen "strengstens an die Bestimmungen des Artikel 80 des Staatsvertrages von St-Germain zu halten«, sondern auch »insbesondere der Forderung der Rassezugehörigkeit zur Mehrheit der österreichischen Bevölkerung gebührend Rechnung zu tragen « ${ }^{496}$ Zusammen mit einem Erkenntnis des Verwaltungsgerichtshofs vom 9. Juni I92 I, mit welchem das Optionsansuchen des aus Galizien stammenden Moses Dym wegen Nichterbringung des Beweises »der Zugehörigkeit zur deutschen Mehrheit der österreichischen Bevölkerung « abgewiesen worden war ${ }^{497}$, bildete

492 Lukas Langhoff: Staatsbürgerrecht und Heimatrecht in Österreich (Wien 1920), S. 22.

493 Zit. nach: Grandner, Staatsbürger, S. 75.

494 Vgl. Edward Timms: Citizenship and `Heimatrecht` after the Treaty of Saint-Germain, in : Austrian Studies V (1994), S. 158-168, hier: S. 163.

495 Gründlich untersucht wurde der gesamte Komplex der jüdischen Option in einer Dissertation von Oskar Besenböck: Die Frage der jüdischen Option in Österreich 1918-1992, phil. Diss. (Wien 1992).

496 Stenographische Protokolle des Nationalrates der Republik Österreich, 1920-1923. Wien 1923, S. 57 (Hervorhebung nicht im Original).

497 Die Mehrheit des Verwaltungsgerichtshofes war anlässlich des Falls Dym zu der Erkenntnis gelangt, dass "Rasse« eine dem Menschen "angestammte, ihm inhärente, durch physische und psychische Momente bestimmte und charakterisierte Eigenart dauernden Charakters« sei. Erkenntnis des Verwaltungsgerichtshofs vom 9. Juni 1921, zit. nach: Grandner, Staatsbürger, S. 79. 
diese Resolution die Grundlage für die nach dem deutschnationalen Innenminister Leopold Waber sogenannte »Wabersche Optionspraxis«, nach der Optionsansuchen von Juden unter Hinweis auf deren Rasse generell abzuweisen waren.

$\mathrm{Zu}$ einer grundlegenden Änderung des Staatsbürgerschaftsrechtes kam es durch die Bundesverfassung von I920, mit der die Republik Österreich als ein Bundesstaat eingerichtet wurde. Artikel 6 des Bundesverfassungsgesetzes unterschied zwischen einer Landes- und Bundesbürgerschaft, wobei jeder Landesbürger zugleich Bundesbürger sein sollte; eine Bundesbürgerschaft als solche - ohne zugleich Landesbürger zu sein - sah die Verfassung nicht vor. ${ }^{498}$ Dennoch gab es sie. Allerdings erklärte das Übergangsgesetz vom I. Oktober I 920 jene gar nicht so seltenen Fälle »heimatloser Bundesbürger«, die entweder durch Erklärung nach $₫ 2$ des Staatsbürgerschaftsgesetzes von I9I 8 oder durch Option nach dem Staatsvertrag von St-Germain Staatsbürger/Staatsbürgerin geworden waren, ohne dass sie vorher ein Heimatrecht in einer österreichischen Gemeinde erworben hatten, ausdrücklich zu Bundesbürgern oder -bürgerinnen. ${ }^{499}$

Eine gewisse - wenn auch vom Gesetzgeber nicht intendierte - Reparatur erfuhr die Praxis der Ausschließung von »Ostjuden« durch die Heimatrechtsnovelle des Jahres 1925 unter der Regierung Ramek. ${ }^{500}$ Diese war vom Willen getragen, die Zahl der noch immer heimatlosen Optanten zu verringern und das Prinzip durchzusetzen, wonach jeder Bundesbürger auch in jener Gemeinde seine rechtliche Heimat haben sollte, "in welcher er sich niedergelassen hat, lebt und wirkt ". ${ }^{501}$ In der Regierungsvorlage wird dazu ausgeführt, dass die Zahl der Heimatlosen, die schon zur Zeit der Monarchie nicht unbedeutend gewesen sei, seit dem Umsturze außerordentlich gewachsen sei, da wegen des Gesetzes vom 5. Dezember I9I 8 sowie durch Option und Rückfall auf Grund der Staatsverträge von St-Germain, Trianon und Brünn zahlreiche Personen wohl die österreichische Staatsangehörigkeit, nicht aber ein Heimatrecht erworben hätten. Mit der Novelle sollte nun heimatlosen Bundesbürgern, die ehemals in einer Gemeinde der österreichischen Monarchie heimatberechtigt gewesen waren, die Möglichkeit gegeben werden, das Heimatrecht in jener Gemeinde zu erlangen, "wo sie am I6. Juli 1920 (dem Tag des Inkrafttretens des Staatsvertrags von St-Germain) ihren ordentlichen Wohnsitz hatten«. Nach $₫ 3$ des Gesetzes hatten die »heimatlosen Bundesbürger» nun die Möglichkeit, innerhalb

498 Artikel 6 BVG 1920/BV Nov. 1925, abgedruckt in: Goldemund/Ringhofer/Theurer, Staatsbürgerschaftrecht, S. 6.

499 Übergangsgesetz vom 1. Oktober 1920, abgedruckt in: ebenda, S. 29. Vgl. auch: Kolonovits, Rechtsfragen, S. 65.

500 Rudolf Ramek war vom 20. November 1924 bis 20. Oktober 1926 Bundeskanzler.

501 Aus der Begründung der Heimatrechtsnovelle 1925, 359 BlgNR II GP. Vgl. Goldemund/Ringhofer/Theurer, Staatsbürgerschaftsrecht, Nr. 64, S. 554ff. 
dreier Monate »bei der Landesregierung eines Bundeslandes (zu) erklären, dass sie in diesem Bundeslande heimatberechtigt sein wollen «. ${ }^{502}$ Zwar war, laut Regierungsvorlage, mit letzterem vor allem dem Wunsch jener Bundesländer Rechnung getragen worden, die durch den Staatsvertrag von St-Germain Gebietsanteile verloren hatten und denen man mit diesem Gesetz die Chance geben wollte, sich ehemalige (deutsche) Landesangehörige zurückzuholen, doch bestand nun auch für bis dahin »heimatlos" gebliebene jüdische ehemalige Bewohner der österreichisch-ungarischen Monarchie zumindest theoretisch die Möglichkeit, das Heimatrecht - und damit auch die österreichische Landes- und Bundesbürgerschaft ${ }^{503}$ - in ihrer Wohnsitzgemeinde zu erwerben. ${ }^{504}$

502 Heimatrechtsnovelle 1925, §3, zit. nach: Goldemund/Ringhofer/Theurer, Staatsbürgerschaftsrecht, S. 560 .

$503 \$ 2$ des am 30. Juli 1925 kundgemachten Gesetzes über den Erwerb und Verlust der Landes- und Bundesbürgerschaft lautete: "Jeder in einer Gemeinde der Republik Österreich Heimatberechtigte ist Landesbürger jenes Landes, in dem die Gemeinde gelegen ist."Zit. nach: Goldemund/Ringhofer/Theurer, Staatsbürgerschaftsrecht, S. 390.

504 Vgl. Kolonovits, Rechtsfragen, S. 65f. 


\section{Die Aus- und Einbürgerungen des autoritären Ständestaates}

Wie weit verbreitet nicht nur antisemitisches Gedankengut, sondern auch antisemitische Handlungen, d. h. physische Übergriffe auf Juden, während der Dreißigerjahre, besonders aber seit Ausbruch der Weltwirtschaftskrise I 93 I waren, belegen die ständigen Protestresolutionen vor allem der Wiener Israelitischen Kultusgemeinde. Jahr für Jahr beobachtete und reklamierte die Kultusgemeinde Fälle schwerer Beeinträchtigungen und Verletzungen der Rechte von Juden, sodass sich Bundeskanzler Vaugoin und Außerminister Ignaz Seipel sogar gezwungen sahen, öffentlich zu erklären, "dass die Regierung selbstverständlich für die volle Wahrung der gesetzlichen Gleichberechtigung der Staatsbürger jüdischen Glaubens mit den anderen Staatsbürgern eintrete und dass sie Äußerungen, die das religiöse Empfinden oder das Ehrgefühl der Juden verletzen könnten, missbillige. ${ }^{505} \mathrm{Zu}$ heftigen antisemitischen Attacken und Ausschreitungen kam es, als im Mai I93 I die Creditanstalt - sie galt wegen ihrer früheren Verbundenheit mit dem Haus Rothschild als "jüdische Bank« - zusammenbrach und die Weltwirtschaftskrise Österreich mit voller Härte traf. Die Creditanstalt war keine gewöhnliche Großbank, sondern kontrollierte, wie David Landes bemerkt, "unmittelbar oder mittelbar zwei Drittel der österreichischen Industrie«; sie galt als Verkörperung eines »soliden Unternehmens «. ${ }^{506}$ Eine Folge dieses Zusammenbruchs war u.a. der Anstieg der Arbeitslosigkeit von etwa I 90000 auf 360000 Menschen innerhalb eines halben Jahres. Zum besonderen Problem wurden die ständigen Übergriffe seitens deutschnationaler Burschenschaftler oder illegaler Nationalsozialisten auf jüdische Studenten an den österreichischen Universitäten. Bereits im Juni I93 I hatte der Vorstand der Wiener Kultusgemeinde festgestellt, dass »die jüdische Studentenschaft auf akademischem Boden den organisierten, brutalen Gewaltakten einer rohen Übermacht wehrlos preisgegeben « sei, und "nirgends, insbesondere nicht bei den hiezu berufenen akademischen Behörden, Schutz finde. In einer Resolution vom I 8. November I93 I heißt es dann, dass "an der Schwelle eines Winters, der durch die zunehmende Arbeitslosigkeit und Hunger die schrecklichsten Schatten voraus wirft, in einer Zeit, in der alle maßgebenden Stellen bemüht sind (...), sich zu vereinter Hilfeleistung für die Unglücklichsten

505 Abgedruckt ebenda, S. 15.

506 David S. Landes: Der entfesselte Prometheus (Köln 1973), S. 347. 
und zur Aufrechterhaltung der Wirtschaft zusammenzuschließen«, die Wiener Universität »der Schauplatz von kulturwidrigen Vorgängen, von wüsten Hetzen und von brutalen Gewaltanwendungen gegen jüdische Studierende« sei. ${ }^{507}$ Ein Jahr später, im Oktober 1932, intervenierte das Präsidium der Kultusgemeinde, Dr. Alois Pick, Dr. Josef Löwenherz und Dr. Jakob Ornstein, durch persönliche Vorsprache bei Unterrichtsminister Dr. Anton Rintelen gegen die täglich an den Wiener Hochschulen begangenen Gewaltakte »hakenkreuzlerischer Massen gegen einzelne, wehrlose jüdische Studenten«. Der Minister missbilligte die »höchst bedauerlichen Vorfälle« und betonte, »dass er mit dem Rektor der Universität eingehend die nötigen Sicherheitsmaßnahmen « besprochen habe. ${ }^{508}$

Nach der Machtergreifung Hitlers im Deutschen Reich kam es im März 1933 in Österreich zur Auflösung des Parlaments und zur Bildung eines autoritären Regimes faschistischer Prägung unter Engelbert Dollfuß. Dieses richtete sich zunächst gegen die nationalsozialistische Bedrohung von außen wie innen - nicht gegen Juden. Die Verfassung vom I. Mai I934, die allerdings weder demokratisch legitimiert war, noch überhaupt jemals vollständig in Kraft trat ${ }^{509}$, versprach durchaus die Gleichberechtigung der Konfessionen, und die Vertreter der israelitischen Kultusgemeinde fanden dann auch in den korporatistischen Ständerepräsentationen ihren Platz. ${ }^{510}$ Jüdische Einrichtungen blieben unangetastet, auch die "Vaterländische Front« erlaubte Juden grundsätzlich den Beitritt. Doch die Zerschlagung der österreichischen Linken nach dem Februaraufstand 1934, das Verbot der Heimwehr und der sozialdemokratischen Partei, traf (da die sozialdemokratische Partei wegen des in allen anderen Parteien herrschenden Antisemitismus für Juden praktisch zur einzigen politischen Heimat geworden war) besonders viele Juden. Viele jüdische Sozialdemokraten und Kommunisten verloren ihren Arbeitsplatz und/oder wurden des Landes verwiesen. Doch es handelte sich um politische Ausschließungen, nicht um rassisch begründete. Im Gegenteil wurden gar nicht wenige der über 2000 jüdischen Flüchtlinge, die nach der Machtergreifung Hitlers in Deutschland nach Österreich geströmt waren - darunter zahlreiche Prominente jüdischer Abstammung wie Max Reinhardt, Bruno Walter, Franz Mehring, Alfred Polgar, Hermynia zur Mühlen oder Oskar Maria Graf - später durch die Regierung Schuschnigg eingebürgert oder

507 Bericht des Präsidiums und des Vorstandes der Israelitischen Kultusgemeinde Wien über die Tätigkeit in den Jahren 1933-1936 (Wien 1936), S. 12.

508 Ebenda, S. 13.

509 Helmut Wohnout: Die Verfassung 1934 im Widerstreit der unterschiedlichen Kräfte im Regierungslager, in: Ilse Reiter-Zatloukal et al. (Hg.): Österreich 1933-1938. Interdisziplinäre Annäherungen an das Dollfuß-/Schuschnigg-Regime (Wien/Köln/Weimar 2012), S. 17-30, hier: S. 30.

510 Vgl. Sylvia Maderegger: Die Juden im österreichischen Ständestaat 1934-1938. Veröffentlichungen des Historischen Instituts der Universität Salzburg (Wien 1973). 


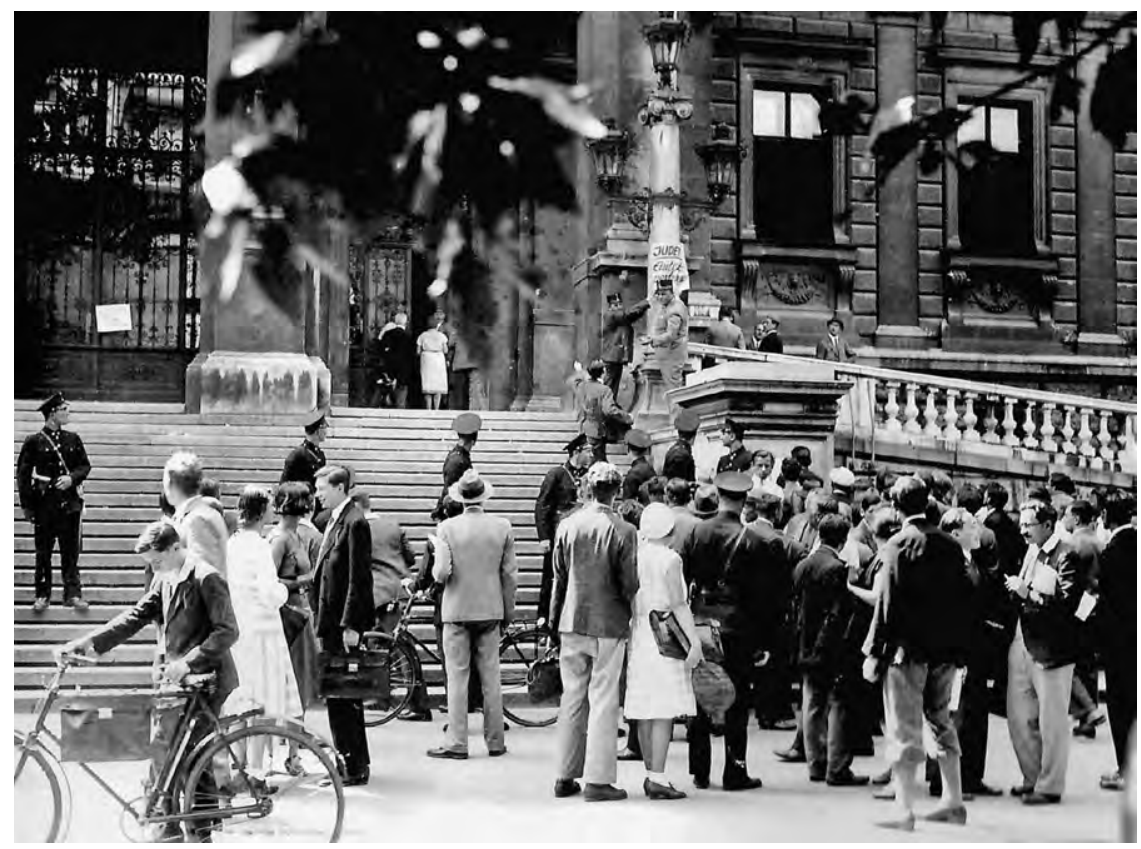

Abb. I4: Antisemitische Ausschreitungen an der Universität Wien I93I; Quelle: ÖNB/Wien, Bildarchiv

wiedereingebürgert. Einige waren im Staatsgebiet der Monarchie geboren oder mit Österreicherinnen verheiratet, so etwa Carl Zuckmayer, der zusammen mit seiner österreichischen Frau Alice seinen Wohnsitz bei Salzburg nahm und noch knapp vor dem »Anschluss« österreichischer Staatsbürger wurde. ${ }^{511}$ Die »Deutschlandemigranten «, von denen die meisten in bitterer Not lebten, wurden von der israelitischen Kultusgemeinde, die ihren Wohlfahrtsaufgaben durch Stiftungen und besondere Hilfsaktionen nachkam, tatkräftig unterstützt. ${ }^{512}$ Selbstbewusst verabschiedete die Kultusgemeinde nach dem Nürnberger Reichsparteitag und der Erlassung der Rassengesetze im Deutschen Reich in einer Plenarsitzung vom 24. September 1935 eine "Protestresolution gegen die Bedrückung und Entrechtung der Juden in Deutschland«. Darin hieß es:

511 Burger/Wendelin, Staatsbürgerschaft und Vertreibung, S. 277. Alle diese Einbürgerungen wurden nach dem "Anschluss" vom nationalsozialistischen Regime mit der ersten "Verordnung über die deutsche Staatsangehörigkeit im Lande Österreich« vom 3. Juli 1938, GBlÖ 1938/236, zurückgenomen.

512 Zwischen April 1933 und Juli 1936 beliefen sich die Ausgaben für die jüdischen Flüchtlinge aus dem Deutschen Reich auf rund 365000 Schilling. Bericht des Präsidiums, S. 25. 
"Die schwere Bedrückung und die unmenschliche, an das tiefste Mittelalter erinnernde Behandlung der jüdischen Bevölkerung in Deutschland, ihre soziale und politische Ächtung, der gegen sie systematisch geführte wirtschaftliche Vernichtungskampf und die Sanktionierung ihrer Entrechtung durch die Gesetzesbeschlüsse des Nürnberger Reichstages haben in der Wiener jüdischen Bevölkerung Mitgefühl und tiefste Entrüstung ausgelöst. Die Wiener Judenschaft protestiert gegen die zur Begründung der judenfeindlichen Maßnahmen vorgeschützten unwahren und böswilligen Anklagen. Sie richtet an das durch den Völkerbund repräsentierte Weltgewissen, an alle an der Spitze der Staaten stehenden verantwortlichen Männer den Appell, die gegen die Juden gerichteten deutschen Gesetze (...) zu verurteilen, und erklärt sich feierlich mit allen Bestrebungen solidarisch, die eine Beseitigung der der gesamten Judenschaft angetanen Schmach herbeiführen wollen. ${ }^{513}$

Noch - so beweist diese Resolution - existierte unter den Vertretern der österreichischen Juden ein Gefühl der Sicherheit und des Vertrauens in die eigenen staatlichen Institutionen, vor allem aber die große Sorge über die zunehmende Entrechtung der Juden im Deutschen Reich. Ein Jahr später kam es zu heftigen Zwistigkeiten zwischen der "jüdischnationalen" (zionistischen) Fraktion und den "vaterländisch fühlenden " Angehörigen der Wiener israelitischen Kultusgemeinde (zionistische Gruppierungen hatten bei den Wahlen 1932 die Mehrheit innerhalb der Kultusgemeinde erlangt). ${ }^{514}$ In einer Beschwerdeschrift vom 5. Februar I 936 hatten sich die »Vaterländischen« über den zunehmenden Einfluss »ausländischer Juden« (Juden ohne Heimatrecht in Wien) auf die Gebarungen der Kultusgemeinde beklagt und deren aktives Stimmrecht bestritten. Die Beschwerde, in der die "Zurückdrängung des Einflusses des in Österreich beheimateten positiv-religiös und vaterländisch fühlenden Teiles der Angehörigen der Wiener Israelitischen Kultusgemeinde« beklagt wurde, wurde jedoch mit einem Bescheid des Wiener Magistrats vom I 2. Juni 1936 mit dem Verweis auf $₫ 2$ des Statuts zurückgewiesen, wonach "jeder Israelit, der in Wien seinen ordentlichen Wohnsitz hat, ohne Rücksicht auf seine Heimatberechtigung und Staatsbürgerschaft der Wiener Kultusgemeinde« angehöre und »das aktive Wahlrecht « besitze. ${ }^{515}$

513 Bericht des Präsidiums, S. 16.

514 Vgl. Gerald Stourzh: An Apogee of Conversions: Gustav Mahler, Karl Kraus, and fin de siècle Vienna, in: From Vienna to Chicago and back. Essays on Intellectual History and Political Thought in Europe and America (Chicago/London 2007), S. 224-247, hier: S. 225.

515 Bericht des Präsidiums, S. 19f. Bei den Wahlen von 1936 zur Wiener Kultusgemeinde machten erstmals über die Hälfte der Wahlberechtigten von ihrem Wahlrecht Gebrauch. Vgl. Harriet Pass Freidenreich: Jewish Politics in Vienna 1918-1938 (Bloomington/Indianapolis 1991), S. VII und 272. 
Auch die zahlreichen Ausbürgerungen, die die Regierung Dollfuß aufgrund einer zum geltenden Bundesbürgerschaftsgesetz von 1925 erlassenen Verordnung tätigte, wonach der Verlust der Bundes- und Landesbürgerschaft dann eintreten sollte, "wenn ein Landesbürger im Ausland österreichfeindliche Handlungen unterstützt ${ }^{516}$, betrafen nicht etwa Juden, sondern zunächst rund Iooo nach der Machtergreifung Hitlers ins Deutsche Reich geflohene illegale Nationalsozialisten. Nach der gleichen Verordnung, die zuerst gegen Nationalsozialisten gerichtet war, wurden allerdings nach dem Bürgerkrieg vom Februar I 934 fast I 2000 politische Gegner des Austrofaschismus, vor allem Schutzbündler und Kommunisten, ausgebürgert. Unter diesen befanden sich auch zahlreiche Juden - wie etwa der Theoretiker des Austromarxismus Otto Bauer, der seine Wiener Landesbürgerschaft (und damit seine österreichische Bundesbürgerschaft) am 3. April 1934 verlor. Diese Ausbürgerungen erfolgten allerdings nicht aus rassistischen Gründen, sondern wegen der Gegnerschaft der Betroffenen zum autoritären Ständestaat. ${ }^{517}$ So blieb das Verhältnis vieler Juden zu den Regierungen des österreichischen Ständestaates ambivalent. Dass jedoch nicht alle mehr diesem letzten österreichischen Staat vertrauten, belegt die nüchterne Statistik. Während es in den I 89oer-Jahren einen stetigen Anstieg des Nettozuwachses der Wiener Kultusgemeinde (Summe der Geburten und Eintritte minus Summe der Sterbefälle und Austritte) gegeben hatte, mit einem Höhepunkt im Jahr I 896 (ein Zuwachs von 999 Personen), wird die Negativbilanz seit I 92 I immer größer und erreicht mit 21 83 Personen im Jahr I935 ihren höchsten Stand. ${ }^{518}$ Dieser Abgang ist aber nicht mehr nur in den natürlichen Sterbefällen, den Konversionen und Austritten (wobei etwa drei Viertel jener, die die Kultusgemeinde verließen, der katholischen oder protestantischen Kirche beitraten und ein Viertel konfessionslos blieb ${ }^{519}$ ) begründet, sondern in einer bereits beginnenden Auswanderungswelle, nicht zuletzt nach Palästina, welche von der zionistischen Fraktion innerhalb der Kultusgemeinde organisatorisch und finanziell unterstützt wurde.

516 Art. 1 der Verordnung vom 16. August 1933, BGBl 1933/369.

$517 \mathrm{Vgl}$. Burger/Wendelin, Staatsbürgerschaft und Vertreibung, S. $274 \mathrm{f}$.

518 Bericht des Präsidiums, Tabelle XIIIf.

519 Stourzh, Apogee of Conversions, S. 226. Siehe dazu auch: Philomena Leiter, Assimilation, Antisemitismus und NS-Verfolgung. Austritte aus der jüdischen Gemeinde in Wien 1900-1944, phil. Diss. (Wien 2003), S. 282ff. 


\section{Verfolgung, Vertreibung, Ausbürgerung, Vernichtung während der NS-Herrschaft}

\section{Die Implementierung der Nürnberger Gesetze in Österreich}

Seit dem Rücktritt der Regierung Schuschnigg in den Abendstunden des I I. März I938 und dem am nächsten Tag erfolgten Einmarsch der deutschen Armee - von einem Großteil der Bevölkerung enthusiastisch begrüßt - hatte Österreich als Staat aufgehört zu existieren. Mit einer Fülle von Erlässen, Verordnungen und Gesetzen seitens der neuen nationalsozialistischen Machthaber wurde in den nächsten Wochen und Monaten der am I 3. März von Hitler verkündete »Anschluss« Österreichs an das Deutsche Reich auch administrativ vollzogen (ein Prozess, der erst mit dem „Ostmarkgesetz« vom I. Mai I939, mit dem die letzten österreichischen Zentralstellen aufgelöst wurden, abgeschlossen war). ${ }^{520}$ Für die jüdischen Staatsbürger und Staatsbürgerinnen jedoch begann noch am Tage des "Anschlusses« mit Verhaftungen, Folter, Entlassungen aus dem Staatsdienst, Wohnungsverweisungen und Beraubungen eine Zeit unendlicher Demütigungen. Wer aber überhaupt als Jude gelten sollte, das war in diesen Tagen des Terrors und der wilden "Arisierungen« noch nicht klar.

"Ein Jude kann nicht Reichsbürger sein. Ihm steht ein Stimmrecht in politischen Angelegenheiten nicht zu; er kann ein öffentliches Amt nicht bekleiden «, heißt es in der Ersten Verordnung zum Reichsbürgergesetz, die in Österreich am 20. Mai I938, zweieinhalb Monate nach dem »Anschluss«, zusammen mit den übrigen »Nürnberger Gesetzen«: dem Reichsbürgergesetz und dem "Gesetz zum Schutze des deutschen Blutes und der deutschen Ehre«, kundgemacht wurde. ${ }^{521}$ Das Reichsbürger-

520 Die letzten österreichischen Behörden wurden bis 31. März 1940 aufgelöst. Artikel I des Gesetzes über die "Wiedervereinigung Österreichs mit dem Deutschen Reich« vom 13. März 1938 lautet: „Österreich ist ein Land des deutschen Reiches«. Zit. nach: Emmerich Tálos: Von der Liquidierung der Eigenstaatlichkeit zur Etablierung der Reichsgaue der »Ostmark«. Zum Umbau der politisch-administrativen Struktur, in: Emmerich Tálos et al. (Hg.) : NS-Herrschaft in Österreich. Ein Handbuch (Wien 2000), S. 55-72, hier: S. 56. Zu den innen- und außenpolitischen Implikationen des "Anschlusses« siehe den Symposiumsband: Gerald Stourzh/Birgitta Zaar (Hg.): Österreich, Deutschland und die Mächte. Internationale und Österreichische Aspekte des »Anschlusses« vom März 1938 (Wien 1990).

521 Gesetzblatt für Österreich 1938/150. Zur Durchführung der »Nürnberger Gesetze« in Österreich vgl.: Burger/Wendelin, Staatsbürgerschaft und Vertreibung, S. 283ff. Allgemein zu den »Nürnberger Gesetzen« siehe: Joseph Walk/Robert M.W. Kemper: Das Sonderrecht für die Juden im NS- 
gesetz differenzierte zwischen bloßen Staatsangehörigen und »Reichsbürgern«. Letztere (die Reichsbürgerschaft) gebührte nur jenen, die »deutschen oder artverwandten Blutes « waren, was die österreichischen Juden a priori ausschloss. Da allerdings das "vorläufige Reichsbürgerrecht« in Österreich gar nicht eingeführt wurde, erhielten zunächst alle vormaligen Österreicher (auch die österreichischen Juden und Jüdinnen) dieselbe »deutsche Staatsangehörigkeit«. ${ }^{522}$ Erst durch die materiellen Bestimmungen des "Blutschutzgesetzes" und die nachfolgenden Verordnungen zum Reichsbürgergesetz ${ }^{523}$ erfolgte für die österreichischen Juden die schrittweise Fragmentierung und Aushöhlung ihrer Staatsbürgerschaft. ${ }^{524}$ Als "Juden « im Sinne der Nürnberger Gesetze galten nun, entsprechend der Ersten Verordnung zum Reichsbürgergesetz, Personen, die entweder der jüdischen Religion angehörten oder die mindestens drei jüdische Großeltern hatten (bzw. zwei jüdische Großeltern und mit einem jüdischen Ehepartner verheiratet waren). "Mischlinge« ersten oder zweiten Grades, d.h. Personen, die bloß zwei oder einen jüdischen Großelternteil hatten, fielen nicht unter die Nürnberger Gesetze, ebenso sogenannte »Volljuden«, die mit einem "arischen « Partner verheiratet waren. ${ }^{525}$

Viele der neuen Bestimmungen erscheinen grotesk - etwa das Verbot des Hissens der neuen Reichsfahne für Juden -, doch waren sie weit davon entfernt, bloße Willkür oder Schikane zu sein. Die Nürnberger Gesetze entfalteten eine am Ende mörderische Logik des Blutes, mit der der Emanzipationsprozess der deutschen (und nach dem "Anschluss" 1938 auch der österreichischen) Juden systematisch und in Einzelschritten zurückgeführt werden sollte. So verbot das »Gesetz zum Schutze des deutschen Blutes und der deutschen Ehre« nicht bloß Eheschließungen wie auch außereheliche Beziehungen zwischen Juden und Nichtjuden, sondern bestimmte ferner, dass Juden weibliche Hausangestellte »deutschen oder artverwandten Blutes unter 45 Jahren in ihrem Haushalt nicht beschäftigen « dürften. ${ }^{526}$ Mit letzterem war - von der Öffentlichkeit eher unbemerkt - ein nicht unbedeutender Baustein der Judeneman-

Staat. Eine Sammlung der gesetzlichen Maßnahmen und Richtlinien, Inhalt und Bedeutung (F. Müller Verlag 1996), S. 129ff.

522 Vgl. Helfried Pfeifer (Hg.): Die Ostmark. Eingliederung und Neugestaltung. Historisch-systematische Gesetzessammlung nach dem Stande vom 16. April 1941 (Wien 1941), S. 172, Anmerkung 1.

523 Zum Reichsbürgergesetz wurden dreizehn Verordnungen erlassen, mit denen die stufenweise Entrechtung der Juden vorangetrieben wurde, in Österreich allerdings, durch die zeitliche Verschiebung oder aus inhaltlichen Gründen, nur zehn. Vgl. Burger/Wendelin, Staatsbürgerschaft und Vertreibung, S. 294.

524 Dieter Gosewinkel bezeichnet den Vorgang zutreffend als »Aushöhlung von innen her«. Gosewinkel, Einbürgern und Ausschließen, S. 376.

$525 \$ 5$ der Ersten Verordnung zum Reichsbürgergesetz, Gesetzblatt für Österreich 1938/150.

526 GBIÖ 1938/150 (später herabgesetzt auf 35 Jahre). 
zipation aufgehoben worden. ${ }^{527}$ Ähnlich verhielt es sich mit der am 3 I. Mai 1938 erlassenen »Verordnung zur Neuordnung des österreichischen Berufsbeamtentums «. 528 Strukturell entsprach sie einem im Deutschen Reich bereits zweieinhalb Jahre vor den Nürnberger Gesetzen, am 7. April I933, erlassenen »Gesetz zur Wiederherstellung des Berufsbeamtentums « und sah die Entlassung aller jüdischen Beamten aus dem Staatsdienst vor. De facto war dies bereits unmittelbar nach dem »Anschluss« geschehen. Tausende Beamte, die nicht auf Hitler vereidigt werden konnten oder wollten, waren sofort aus dem Staatsdienst entlassen, jüdische Richter und Staatsanwälte schon am I 5. März ihres Amtes enthoben worden. ${ }^{529}$ Mit diesem Gesetz war das seit dem I 3. bis Mitte des I9. Jahrhunderts in Österreich bestehende Ämterverbot für Juden wiederhergestellt worden ${ }^{530}$ - ein weiterer wichtiger Baustein der Judenemanzipation war gefallen. Auch die seit dem Hochmittelalter und (teilweise) in der frühen Neuzeit für Juden geltende Kennzeichnungspflicht (der gehörnte Judenhut, der "gelbe Flecken« oder die gelben Bänder), die durch das Toleranzedikt Joseph II. I 782 ausdrücklich aufgehoben worden war, wurde unter nationalsozialistischer Herrschaft wieder eingeführt. Am 23. Juli I 938 wurde eine besondere Kennkarte für Juden eingeführt, ab I7. August die Führung der »jüdischen Vornamen« Sara bzw. Israel, zusätzlich zum Vornamen, zur Pflicht gemacht, ab Anfang Oktober ein rotes "J « in die Reisepässe von Juden gestempelt. ${ }^{531}$ Vollendet wurde die Brandmarkung der Juden

527 Restriktive Bestimmungen hinsichtlich der Frage, ob und wie viele christliche Dienstboten in einem jüdischen Haushalt beschäftigt werden durften, fanden sich über Jahrhunderte in zahlreichen Judenordnungen. In Österreich waren sie zuerst 1267 durch das Provinzialkonzil von St. Stephan formuliert worden. Und noch in der Judenordnung Maria Theresias von 1764 hatte sich die Bestimmung gefunden, dass Juden außer einem Kutscher keine christlichen Bedienten im Haus halten durften. Mit dem Toleranzpatent ihres Sohnes Joseph II. von 1782 wurde ihnen dann »fürhin gestattet, so viel jüdische oder auch christliche Dienstleute zu halten als ihre Geschäfte fordern«. 1817 jedoch wurde das Verbot, christliche Ammen und Dienstboten in jüdischen Häusern zu halten, erneuert. Endgültig aufgehoben wurde es am 29. Oktober 1859 durch die liberale Regierung Rechberg.

528 GBIÖ 1938/160.

529 Vgl. Rosenkranz, Entrechtung, S. 373.

530 Bereits 1237 fand es sich im Wiener Stadtrecht. Auf ausdrücklichen Wunsch der Bürgerschaft hatte Kaiser Friedrich II. "getreu den Pflichten eines christlichen Fürsten« Juden von allen öffentlichen Ämtern ausgeschlossen mit der Begründung, dass »sie nicht die Amtsgewalt zur Bedrückung der Christen missbrauchen«. Ähnliche Bestimmungen fanden sich im Privilegium für die Wiener Neustädter Juden von 1239 und im Freiheitsbrief für die Juden Wiens von 1244 wieder. 1792 forderten die Wiener Tolerierten erstmals in einer Bittschrift an die Niederösterreichische Landesregierung die Zulassung zu öffentlichen Ämtern. Gewährt wurde sie ihnen (zumindest theoretisch) durch das Staatsgrundgesetz über die allgemeinen Rechte der Staatsbürger vom 21. Dezember 1867, wonach der Eintritt in ein öffentliches Amt nur mehr von der Erwerbung der österreichischen Staatsbürgerschaft abhängig gemacht wurde.

531 Vgl. Wolfgang Benz: Der Holocaust (München 1999), S. 24. 
Abb. I6: Träger des gelben Sterns nach der Verordnung vom I5. 9. I94I (Das Foto entstand zu Propagandazwecken für die NS-Presse); Quelle: ÖNB/Wien, Bildarchiv

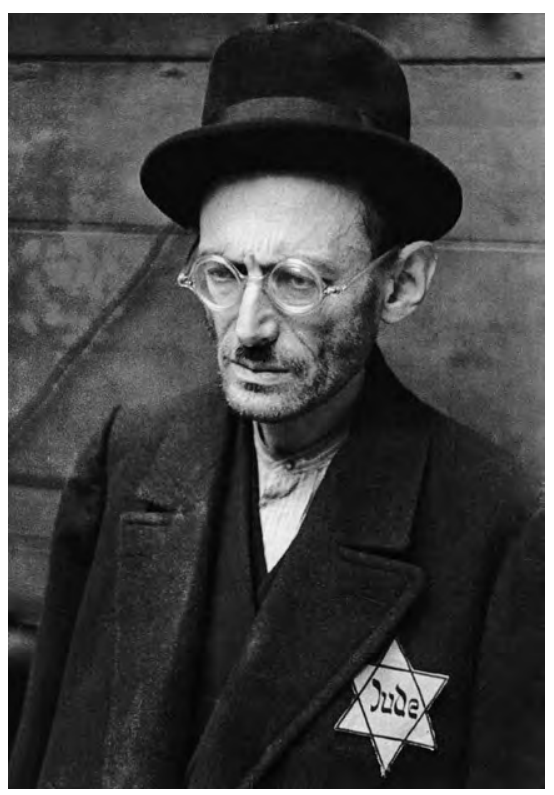

mit der am I 5. September I94I verordneten Pflicht, einen gelben Stern auf der Kleidung tragen zu müssen. Dieser Ausgrenzungs- und Entrechtungsprozess ist oft beschrieben worden, doch selten wurde auf die Systematik und die historischen Bezüge hinter dem Verordnungswust aufmerksam gemacht, selten die longue durée der von den Nationalsozialisten angeordneten Maßnahmen erkannt.

Mit zahlreichen weiteren Verordnungen, insbesondere den dreizehn Verordnungen zum Reichsbürgergesetz, wurden über Jahrhunderte hart erkämpfte staatsbürgerliche Rechte apart und nacheinander zurückgenommen, wie etwa die Zulassung zum Arztberuf 532 (die Approbationen jüdischer Ärzte erloschen am 30. September I938), zum Beruf des Zahnarztes, Tierarztes und Apothekers ${ }^{533}$, der Zugang zum Notariat und zum Anwalts- und Patentanwaltsberuf. ${ }^{534}$ Während es jedoch im

532 Die Vierte Verordnung vom 25. Juli 1938 war die erste, die zeitgleich in Österreich und dem übrigen Reich kundgemacht wurde. Sie schloss Juden grundsätzlich von der Ausübung des Arztberufs aus. Einzelnen Juden konnte das Reichsinnenministerium die Ausübung des Arztberufs gestatten, wenn diese ausschließlich Juden behandelten. Kundmachung des Reichsstatthalters in Österreich vom 25. Juli 1938. GBIÖ 1938/320.

533 Achte Verordnung zum Reichsbürgergesetz, kundgemacht in Österreich am 17. Januar 1939, GBIÖ 1939/106.

534 Mit der Fünften Verordnung zum Reichsbürgerschaftsgesetz vom 27. September 1938 wurde verfügt, dass jüdische Rechtsanwälte aus der Liste der Rechtsanwälte zu löschen waren. Eine Ausnahme wurde lediglich bei Anwälten gemacht, die Teilnehmer des Ersten Weltkrieges gewesen waren (Frontkämpfer). Kundmachung des Reichsstatthalters in Österreich vom 27. September 1938, 
Deutschen Reich nach der Verkündung der Nürnberger Gesetze im Mai I935 sogar zu einer gewissen Beruhigung gekommen war, da es dem nationalsozialistischen Staat durch das Verbot von Willkürakten und das Versprechen, dem Schutzverband des deutschen Volkes anzugehören, gelang, bei den Juden ein trügerisches Gefühl der Sicherheit zu erzeugen (sodass die Auswanderung zeitweise sogar zurückging), fiel die Implementierung der Nürnberger Gesetze in Österreich (im Mai I938) in die Zeit kurz nach dem Anschlusspogrom. Mit willkürlichen Verhaftungen, Plünderungen, wilden »Arisierungen" und ungeplanten Grausamkeiten sollte nun Schluss sein. Die im Mai gegründete »Vermögensverkehrsstelle« sorgte in Hinkunft für den geordneten Zwangsverkauf von Betrieben und Unternehmungen im Zuge einer nun legalen »Arisierung «. Bereits einen Monat zuvor war eine Verordnung in Kraft getreten, nach der alle Juden ab einem Vermögen von 5000 Reichsmark bis zum 30. Juni I $938 \mathrm{ihr}$ "gesamtes in- und ausländisches Vermögen anzumelden und zu bewerten« hatten. ${ }^{535}$ Ein ausgefeiltes Verwaltungsverfahren sorgte dafür, dass Juden, die sich zu einer Auswanderung entschlossen hatten, nach Abzug der »Reichsfluchtsteuer», angeblicher oder tatsächlicher Steuerrückstände sowie devisenrechtlicher Abzüge nur noch ein Bruchteil ihres Vermögens blieb. Da es schon wenige Tage nach Kundmachung der Nürnberger Gesetze in Wien im Rahmen der sogenannten »Mai-Aktion" erneut zu Verhaftungen, Verhören, Folterungen durch die Gestapo und zu Deportationen nach Dachau kam ${ }^{536}$, war jedoch an eine geordnete Auswanderung kaum mehr zu denken. Wer immer konnte, floh ins Ausland. Um diese Fluchtbewegung bürokratisch zu unterstützen und im nationalsozialistischen Sinne zu steuern, wurde am 20. August I 938 auf Veranlassung Reichskommissar Josef Bürckels die "Zentralstelle für jüdische Auswanderung« begründet. Hier entwickelte Adolf Eichmann sein »Wiener Modell«, eine Art bürokratisches Fließbandsystem, das die effiziente Abwicklung der »Auswanderung« garantierte. Bereits ein Jahr nach Erlass der Nürnberger Gesetze hatte fast die Hälfte der österreichischen Juden das Land verlassen. ${ }^{537}$

GBlÖ 1938/513. Die Sechste Verordnung schloss die jüdischen Patentanwälte aus. Kundgemacht in Österreich am 31. Oktober 1938, GBlÖ 1938/158.

535 Die Frist für die Anmeldung wurde später für deutsche Staatsangehörige bis 31. Juli, für ausländische Staatsangehörige bis 31. Oktober 1938 verlängert. Verordnung vom 26. April 1938, RGBl. I, 414f. und RGBl. I, $415 f$.

536 Vgl. Herbert Rosenkranz: Entrechtung, Verfolgung und Selbsthilfe der Juden in Österreich, in: Gerald Stourzh/Birgitta Zaar (Hg.): Österreich und die Mächte. Internationale und österreichische Aspekte des "Anschlusses" vom März 1938 (= Veröffentlichungen der Kommission für die Geschichte Österreichs 16) (Wien 1990), S. 367-417, hier: S. 383ff.

537 Nach einer im Auftrag Adolf Eichmanns in der Zentrale für jüdische Auswanderung erstellten graphischen Übersicht verließen in den ersten neunzehn Wochen nach dem "Anschluss« 34467 Juden das Land. Im Mai 1939 lebten nur noch 94530 Juden (im Sinne der Nürnberger Gesetze) in Österreich. Vgl. Burger/Wendelin, Staatsbürgerschaft und Vertreibung, S. 285. 
Von führenden Nationalsozialisten wurden die Nürnberger Gesetze als Staatsgrundgesetze des »Dritten Reiches«, als Teil einer »neuen Verfassung«, gerühmt, mit denen die Rechtsgrundlage geschaffen worden sei, die "Judenfrage« ein für allemal zu lösen. ${ }^{538}$ Die um wissenschaftliche Fundierung ringenden Kommentatoren, Wilhelm Stuckart und Hans Globke - sie gehörten zur Elite der deutschen Justiz -, verweisen auf den Grafen Gobineau, der »die Rassenfrage« als »alle anderen Probleme der Geschichte « beherrschend erkannte ${ }^{539}$, auf Houston Stewart Chamberlain, der in seinem einflussreichen Werk über "die Grundlagen des I9. Jahrhunderts « zur "Verpflichtung« aufgerufen hatte, die Juden als »fremdes Element in unserer Mitte zu erkennen " 540 , auf Alfred Rosenberg, der in seinem "Mythus des 20. Jahrhunderts" für eine Aussiedlung der Juden plädiert ${ }^{541}$, und auf Adolf Hitler selbst, für den »der Jude« seinem Wesen nach der Fremde war und der seine Vorstellungen hinsichtlich ihrer Ausscheidung aus der Staatsbürgerschaft bereits in "Mein Kampf« dargelegt hatte. ${ }^{542}$

Ihre Entstehung verdanken die »Nürnberger Gesetze« keinesfalls dem chaotischen Geschehen rund um den Reichsparteitag von 1935. Auch wenn sie in einer turbulenten Nacht flüchtig hingeworfen sein mögen, so handelt es sich bei ihren Mitverfassern, Bernhard Lösener und Wilhelm Stuckart, um in der Geschichte der Staatsbürgerschaft überaus kenntnisreiche Fachleute, die schon geraume Zeit mit der Ausarbeitung eines entsprechendes Gesetzes befasst gewesen waren. Die Nürnberger Gesetze schufen nicht zuletzt die Synthese von Rassenideologie und nationalsozialistischer Staatslehre. Und sie brachten endlich auch die Adaptierung des Staatsbürgerschaftsrechts an die nationalsozialistische Weltanschauung. Mit dem Reichbürgergesetz und dem "Blutschutzgesetz« (deren Einheit immer wieder beschworen wurde) sollte »das Eindringen weiteren jüdischen Blutes in den deutschen Volkskörper für alle Zukunft« verhindert werden. Darüber hinaus aber bedeuteten sie auf staatsrechtlichem Gebiet »die bewusste Überwindung des individualistischen Denkens« im liberalen Verfassungsstaat und die »Wiederanerkennung der organischen Lebensordnung dieser Welt«. Das »neue Reich« sollte kein Rechtsstaat

538 Wilhelm Stuckart/Hans Globke (Hg.) : Kommentar zur deutschen Rassengesetzgebung, Bd. 1.C., Erläuterungen zum Reichsbürgergesetz und Gesetz zum Schutze des deutschen Blutes und der Ehre (München/Berlin 1936), S. 47.

539 Arthur de Gobineau: Versuch über die Ungleichheit der Menschenracen [1853], Bd. 1 (Stuttgart 1922), S. XVI.

540 Houston Stewart Chamberlain: Die Grundlagen des Neunzehnten Jahrhunderts, Bd. 1 (München 1904), S. 329.

541 Alfred Rosenberg: Der Mythus des 20. Jahrhunderts. Eine Wertung der seelisch-geistigen Gestaltungskräfte unserer Zeit (München 1930), S. 632.

542 Vgl. Rainer Faupel/Klaus Eschen: Gesetzliches Unrecht in der Zeit des Nationalsozialismus (= Veröffentlichungen der Potsdamer Juristischen Gesellschaft 3) (Baden-Baden 1997), S. 18. 
mehr sein, sondern, so Wilhelm Stuckart, "der auf deutscher Sittlichkeit beruhende Weltanschauungsstaat «. ${ }^{543}$

\section{Signaturen der Vertreibung}

Ausbürgerung und nachfolgende Staatenlosigkeit waren im 20. Jahrhundert ein Massenschicksal - Signatur der Vertreibung schlechthin. Nahezu alle österreichischen Juden und Jüdinnen, die etwa I 20000 Vertriebenen wie auch die über 60000 Ermordeten, waren von ihr betroffen. "Und ich zögere nicht zu bekennen«, schreibt Stefan Zweig in seiner I 944 verfassten autobiographischen Studie »Die Welt von Gestern«, „dass seit dem Tage, da ich mit eigentlich fremden Papieren oder Pässen leben musste, ich mich nie mehr ganz als mit mir zusammengehörig empfand. "544 Zwar hatte er, der sich zur Zeit des »Anschlusses« Österreichs an das Deutsche Reich, im März 1938, bereits im Exil befand, von den englischen Behörden umstandslos "ein weißes Ersatzpapier, einen Staatenlosenpass" erhalten und einige Jahre später auch einen britischen Reisepass, doch das Gefühl, mit sich selbst nicht mehr identisch zu sein, "mit offenen wachen Augen im Leeren zu taumeln und zu wissen, dass man überall, wo man Fuß gefasst hat, zurückgestoßen werden kann « ${ }^{545}$, verließ ihn von da an niemals wieder - ein Gefühl, das er, schenkt man den zahlreichen Zeugnissen von Emigranten und Emigrantinnen Glauben, mit vielen anderen teilte.

Die Ausbürgerung (Expatriation) der österreichischen Juden während der NSHerrschaft war ein überaus komplexer, sich in mehreren Schüben ereignender Prozess, der sich ähnlich wie jener im "Altreich«, doch zeitlich verschoben, abspielte. Während die Ausbürgerung im Deutschen Reich bereits im Juni I933, also zu einem Zeitpunkt begonnen hatte, als eine Auswanderung grundsätzlich noch möglich war ${ }^{546}$, begann sie in Österreich erst im Juli 1939 mit der »Verordnung über die Aberkennung der Staatsangehörigkeit und den Widerruf des Staatsangehörigkeitserwerbs in der Ostmark " ${ }^{547}$, zu einem Zeitpunkt, als nach dem Novemberpogrom (der sogenannten »Reichskristallnacht«) bereits eine Massenflucht österreichischer Juden und Jüdinnen eingesetzt hatte. Auch griffen im Zuge der (Un)Rechtsangleichung

543 Wilhelm Stuckart: Nationalsozialismus und Staatsrecht, in: H.H. Lammers/Hans Pfundner (Hg.): Grundlagen, Aufbau und Wirtschaftsordnung des nationalsozialistischen Staates, Bd. 1, Gruppe 2 (Berlin o.J.), Loseblattsammlung, S. 13ff.

544 Stefan Zweig: Die Welt von Gestern (Frankfurt/Main 1966), S. 466.

545 Ebenda, S. 441.

546 Mit dem "Gesetz über den Widerruf von Einbürgerungen und die Aberkennung der deutschen Staatsangehörigkeit" vom 14. Juli 1933, dRGBl I, S. 480.

547 GBIÖ 1939/892. 
der österreichischen an die nationalsozialistische Gesetzgebung andere Rechtssphären ineinander als im Deutschen Reich. Waren es im "Altreich» die Staatsangehörigkeitsnormen der Weimarer Republik, so waren es in Österreich die Rechtsnormen der Ersten Republik, zum Teil aber auch noch jene der österreichisch-ungarischen Monarchie. Nach dem "Anschluss" Österreichs wurde nämlich keineswegs der gesamte Korpus des NS-Rechts automatisch wirksam. Insbesondere sollte sich die Überleitung des Staatsbürgerschaftsrechts als schwieriger erweisen als gedacht, sodass noch eine Zeit lang teilweise die alten Normen des österreichischen Bundesgesetzes von 1925 galten, ein föderatives Dreiebenen-Modell (bestehend aus Heimatrecht, Landes- und Bundesbürgerschaft ${ }^{548}$, das mit den einheitsstaatlichen Vorstellungen der Nationalsozialisten kaum kompatibel war. Zwar verkündete die erste »Verordnung über die deutsche Staatsangehörigkeit im Lande Österreich" vom 3. Juli I938, es gäbe "nur die deutsche Staatsangehörigkeit « ${ }^{549}$, doch Ein- und Ausbürgerungen wurden weiterhin nach dem Staatsbürgerschaftsgesetz von 1925 exekutiert, und erst ein Jahr später, mit der zweiten Verordnung vom 30. Juni I939, wurde das österreichische Recht vollständig eliminiert. ${ }^{550}$ Für immer beseitigt wurde mit dieser zweiten Verordnung auch das österreichische Heimatrecht ${ }^{551}$, jener Grundpfeiler österreichischen Rechts, der seine Wurzeln in den armenrechtlichen, sozialfürsorgerischen Vorstellungen der österreichischen Monarchie des I 8. Jahrhunderts hatte und der nun einem »modernen" nationalsozialistischen Fürsorgerecht weichen sollte. ${ }^{552}$

Grundsätzlich konnte eine Ausbürgerung durch Widerruf der Einbürgerung (Denaturalisation) oder durch Strafexpatriation (wegen vermeintlicher Verletzung der Treupflicht "gegen Reich und Volk«) erfolgen. ${ }^{553}$ Betroffen von der Strafexpatriation waren etwa I 400 ins Ausland geflohene österreichische Juden und Jüdinnen, darunter zahlreiche Künstler, Wissenschaftler und Intellektuelle, neben dem schon erwähnten Dichter Stefan Zweig der bekannte austromarxistische Ökonom Rudolf

548 Siehe dazu: Kurt Ringhofer: Strukturprobleme des Rechts (Wien 1966), S. $12 \mathrm{ff}$.

549 Entsprechend $\$ 1$ der Verordnung über die deutsche Staatsangehörigkeit vom 5. Februar 1934, zit. nach: Pfeifer, Ostmark, S. 123.

550 Vgl. Pfeifer, Ostmark, S. 124.

551 Artikel 2, $\$ 3$ der Zweiten Verordnung über die deutsche Staatsangehörigkeit im Lande Österreich bestimmte: "Das Gesetz vom 3. Dezember 1863, betreffend die Regelung der Heimatverhältnisse und seine Nachtragsgesetze treten mit Ablauf des 30. Juni 1939 außer Kraft.« Zit. nach: Pfeifer, Ostmark, S. 108, siehe auch: Ringhofer, Strukturprobleme, S. 14.

552 Die Gemeinden wurden allerdings verpflichtet, die »Heimatrollen« aufzubewahren, da der »Auszug aus der Heimatrolle« weiterhin als wichtiges Beweismittel für die Feststellung der Staatsangehörigkeit galt. Vgl. Pfeifer, Ostmark, S. 108, Anmerkung 1.

553 Nach dem "Gesetz über den Widerruf von Einbürgerungen und die Aberkennung der deutschen Staatsangehörigkeit" vom 14. Juli 1933, kundgemacht in der "Ostmark" am 11. Juli 1939. GBlÖ 1939/892. Siehe dazu: Gosewinkel, Einbürgern und Ausschließen, S. 376ff. 
Hilferding, die Schauspielerin und Gattin Bert Brechts, Helene Weigel, die Autorin Alice Henriette Zuckmayer, der Kinderpsychologe Bruno Bettelheim oder der Schriftsteller und nunmehrige Vorsitzende des "Komitees der Österreicher« in Großbritannien Friedrich Hertz. Sie alle erfuhren - wenn überhaupt - von ihrer strafweisen Ausbürgerung durch Anzeige im Deutschen Reichsanzeiger. ${ }^{554}$ Die Gründe für den Verlust ihrer Staatsbürgerschaft wurden ihnen nicht mitgeteilt. Ein Rechtsmittel gegen die Verfügung gab es nicht. Eine der Folgen der strafweisen Ausbürgerung war die Beschlagnahmung des gesamten Vermögens des/der Betroffenen durch die Geheime Staatspolizei zugunsten des Deutschen Reiches.

Die große Mehrheit der österreichischen Juden aber verlor ihre mit dem Anschluss Österreichs an das Deutsche Reich zwangsweise erworbene deutsche Staatsangehörigkeit erst mit der Elften Verordnung zum Reichsbürgergesetz vom 25. November I94I. ${ }^{555}$ Mit der Elften Verordnung verloren nicht nur jene ihre Staatsbürgerschaft, die sich bereits im Ausland aufhielten (und noch nicht strafweise ausgebürgert waren), sondern auch all diejenigen, die, wie der Gesetzgeber zynisch formulierte, künftig die »Verlegung des gewöhnlichen Aufenthalts ins Ausland " planten (was, da seit dem I 8. Oktober I94I jede Auswanderung von Juden verboten war, nur mehr den Vorgang der Deportation in die Konzentrationslager bedeuten konnte). ${ }^{556}$ Diese Elfte Verordnung ermöglichte nicht nur den sofortigen vollständigen Vermögensentzug - und vollendete somit den Raubzug am Vermögen der jüdischen Bürger und Bürgerinnen ${ }^{557}$-, sondern markierte darüber hinaus den

554 Vgl. Michael Hepp/Hans Georg Lehmann (Hg.): Die Ausbürgerung deutscher Staatsangehöriger 1933-45 nach den im Reichsanzeiger veröffentlichten Listen, Bd. 3, Liste der Geburtsorte und der letzten Wohnorte (München/New York/London 1985). In welchem Maße Emigranten und Emigrantinnen durch die Auslandsmissionen des Deutschen Außenministeriums überwacht wurden und in welcher Weise dieses am Prozess der Ausbürgerung deutscher und österreichischer Juden beteiligt war, wird in der umfangreichen Studie über das Deutsche Außenministerium, "Das Amt«, deutlich. Eckart Conze et al. (Hg.): Das Amt und die Vergangenheit. Deutsche Diplomaten im Dritten Reich und in der Bundesrepublik Deutschland (Hamburg 2010), S. 14ff.

$555 \$ 1$ Ein Jude, der seinen gewöhnlichen Aufenthalt im Ausland hat, kann nicht deutscher Staatsangehöriger sein. Der gewöhnliche Aufenthalt ist dann gegeben, wenn sich ein Jude im Ausland unter Umständen aufhält, die erkennen lassen, dass er dort nur vorübergehend verweilt.

$\$ 2$ Ein Jude verliert die deutsche Staatsangehörigkeit, wenn er beim Inkrafttreten dieser Verordnung seinen gewöhnlichen Aufenthalt im Ausland hat; mit dem Inkrafttreten der Verordnung wenn er seinen gewöhnlichen Aufenthalt später im Ausland nimmt, mit der Verlegung des gewöhnlichen Aufenthalts im Ausland.

$\$ 3$ (und alle weiteren Paragraphen der Elften Verordnung) zielen auf das Vermögen der Juden. RGBl. 133/1941. Ausführlicher dazu: Burger/Wendelin, Staatsbürgerschaft, S. $296 f f$.

$556 \$ 2$ der Elften Verordnung. RGBl. 1941/133.

557 Das Gesamtvermögen der österreichischen Juden wurde in einer Studie der Österreichischen Historikerkommission, die auf der Auswertung der "Verzeichnisse über das Vermögen der Juden nach dem Stande vom 27. April 1938«basiert, auf etwa 1,8 bis 2,0 Milliarden Reichsmark geschätzt. 
Endpunkt des langen und mit großer juridischer Finesse betriebenen Prozesses der Entrechtung und Depersonalisierung der Juden. 558

\section{Die Ausbürgerung und der Befehl Zur "Endlösung «559}

Unter dem Datum des I 2. Dezember I94I findet sich im Dienstkalender Heinrich Himmlers die knappe Eintragung: "Bis I9 h (Führerwohnung) «. ${ }^{560}$ Abweichend von den übrigen Eintragungen gibt es hier keine Tagesordnungspunkte, keine Teilnehmer, keinen Hinweis darauf, was sich an jenem Abend in den Privaträumen Hitlers in der Reichskanzlei ereignet hat. In Berlin hatte an diesem Tag eine Reichs- und Gauleitertagung sowie die Vereidigung Arthur Seyß-Inquarts stattgefunden (an der Himmler teilnahm), davor, um I I.50 Uhr, hatte er ein kurzes Gespräch mit dem Staatssekretär im Innenministerium, Wilhelm Stuckart, geführt. ${ }^{561}$ Handelt es sich bei der unscheinbaren Notiz, "Bis I 9 h Führerwohnung«, um ein Indiz für den Befehl Adolf Hitlers zur "Endlösung«, d. h. den Befehl, alle im Reichsgebiet und den besetzen Gebieten sich befindenden Juden planmäßig und mit industriellen Mitteln ermorden zu lassen?

Unser Wissen über den Holocaust ist auch heute noch - 50 Jahre nach dem Erscheinen von Raul Hilbergs "The Destruction of the European Jews" (mit dem die wissenschaftliche Erforschung des Holocausts überhaupt erst anhob) $)^{562}$ - fragmenta-

Vgl. Michael Pammer: Jüdische Vermögen in Wien 1938 (= Veröffentlichung der Österreichischen Historikerkommission 8) (Wien/München 2003), S. 143.

558 Der Begriff Depersonalisierung wird hier nicht im psychatrischen Sinne verwendet, sondern im Sinne der allgemeinen Folgen der gravierenden Einschränkung von Persönlichkeitsrechten. Durch eine Unzahl von demütigenden Polizeiverordnungen und eine totale Überwachung sollte das Alltagsleben von Juden derart eingeschränkt werden, dass die gewohnte Lebenspraxis verunmöglicht wurde. So wurden ab 15. November 1938 jüdische Kinder vom allgemeinen Schulbesuch ausgeschlossen, mit Kriegsbeginn am 1. September 1939 wurde Juden der Besitz von Rundfunkgeräten verboten, ab Dezember der Besitz und das Führen eines Kraftfahrzeuges, ab 19. Juli 1940 war der Besitz eines Telefons untersagt; die Haltung von Haustieren und das Benutzen von Leihbibliotheken wurde Juden ebenfalls verboten.

559 Erweiterte Fassung eines Vortrags beim 15. kulturanthropologisch-philosophischen Canetti-Symposium »Macht und Gewalt, im Herbst 2002, erstmals publiziert in: Hannelore Burger: Die Ausbürgerung der reichsdeutschen Juden und der Befehl zur "Endlösung«, in: John D. Pattillo-Hess/ Mario Smole (Hg.) : Macht und Gewalt (Wien 2003), S. 90-99.

560 Peter Witte et al (Hg.): Der Dienstkalender Heinrich Himmlers 1941/42 (= Hamburger Beiträge zur Sozial- und Zeitgeschichte, Quellen 3) (Hamburg 1999), S. 289.

561 Ebenda. Zur Rolle Himmlers bei der »Endlösung« vgl. Peter Longerich: Heinrich Himmler. Biographie (München 2008), S. 575 und 921.

562 In den USA erschien das Werk 1961; deutsche Erstausgabe: Raul Hilberg: Die Vernichtung der europäischen Juden (Berlin 1982); deutsche Taschenbuchausgabe in 3 Bänden (Frankfurt a. M. 1990). 
risch. Selbst über eine so fundamentale Frage wie jene nach dem Befehl zur »Endlösung" gab und gibt es bis heute keine gesicherten Erkenntnisse. In die dritte Runde geht nun schon jener Historikerstreit, der I 977 durch »Hitler's War«, ein Buch des britischen Holocaust-Leugners David Irving, ausgelöst worden war. Irving hatte darin behauptet, dass es nie einen ausdrücklichen Befehl Hitlers für die »Endlösung« gegeben habe, eventuelle Ermordungen von Juden seien gegen dessen Willen von Himmler und Goebbels durchgeführt worden ${ }^{563}$ - eine absurde These, die jedoch paradoxerweise befruchtende Wirkung auf die historische Forschung hatte. Auf mehreren Konferenzen und in zahlreichen Publikationen haben seither Intentionalisten und Funktionalisten (jene, die der Meinung sind, dass zu einem bestimmten Zeitpunkt die Entscheidung zum Mord an den europäischen Juden gefallen sei, und jene, die glauben, dass eine solche Entscheidung nie getroffen wurde) polemisch sich ausgetauscht, einander angenähert, sich wieder voneinander entfernt. Für letztere, die Funktionalisten, waren und sind es eher strukturelle Gründe, Sachzwänge gleichsam, die für den Holocaust verantwortlich sind: Wechselwirkungen etwa zwischen den verschiedenen nationalsozialistischen "Programmen « wie die Deportation der Juden an die Peripherie des Reiches einerseits, mit der gleichzeitigen Heimholung und versuchten Ansiedlung von Volksdeutschen andererseits.

Der vielleicht prononcierteste Vertreter der funktionalistischen Schule scheint heute Götz Aly zu sein, der, so wie vor ihm Martin Broszat, davon überzeugt ist, dass das Programm der Judenvernichtung bis zum Frühjahr 1942 aus Einzelaktionen heraus allmählich sich entwickelt habe und erst nach der Errichtung der Vernichtungslager bestimmenden Charakter erhielt. Nach Aly gibt es nicht den einen Befehl Hitlers zum Massenmord; es gäbe nur die falsche Annahme späterer Analytiker, die ungeheuerliche Tat müsse in einer völlig außergewöhnlichen Form beschlossen worden sein. ${ }^{564}$ Aly spricht von einer "vielfachen Aufforderung an alle Beteiligten«. Danach sei die "Endlösung " gleichsam »Teamwork" gewesen, ermöglicht nicht zuletzt durch den »Abbau von Hierarchien und bürokratischen Fesseln «. ${ }^{565}$ Hitler erscheint bei Aly nicht als "der unerbittliche Befehlshaber«, sondern als ein Politiker, der seinen Leuten freie Hand ließ, sie ermunterte, Phantasie zu entwickeln, um das

563 In einer zweiten, 1991 erschienenen Auflage wird der Holocaust dann mit keiner Zeile mehr erwähnt. Vergleiche dazu die detaillierte Schilderung des Irving-Prozesses in: Eva Menasse: Der Holocaust vor Gericht. Der Prozess um David Irving (Berlin 2000), S. 28.

564 Gemeint ist Eberhart Jäckel. Vgl. Götz Aly: "Judenumsiedlung«. Überlegungen zur politischen Vorgeschichte des Holocaust, in: Ulrich Herbert (Hg.) : Nationalsozialistische Vernichtungspolitik 1939-1945. Neue Forschungen und Kontroversen (Frankfurt a. M. o.J.), S. 67-97, hier: S. 94 u. 68.

565 Interview mit Götz Aly über NS-Vergangenheit und Holocaust in der Mitteldeutschen Zeitung vom 9. September 2002. 
unmöglich Erscheinende möglich zu machen. ${ }^{566}$ Ähnlich sieht es der israelische Historiker Yaakov Lozowick. Er siedelt die Initiative zur Ermordung der Juden bei den von ihm untersuchten Bürokraten des Reichssicherheitshauptamtes an. Auf niederer Rangebene seien in den Jahren 1940/4I Überlegungen, die auf Ermordung von Juden im großen Stil hinausliefen, bereits sehr weit gediehen und in Form von Vorschlägen nach oben weitergereicht worden. Dadurch habe man auf höchster Ebene gewusst, dass die Männer an der Front bereit waren, auch noch einen Schritt weiter zu gehen. Nach Lozowick bleibt vieles im Dickicht der Bürokratie verborgen, sodass es unmöglich erscheine, Urheber und Initiator der »Endlösung « zu identifizieren. ${ }^{567}$

Moderat intentionalistisch argumentiert hingegen der amerikanische Historiker Christopher Browning, der die Entscheidung Hitlers, die das Schicksal der europäischen Juden besiegelte, auf Anfang Oktober I94I datiert, wobei er von einem "stufenweisen, kontinuierlichen Entscheidungsprozess" ausgeht. ${ }^{568}$ Seinem Szenario zufolge erteilte Hitler (an Heydrich) Mitte Juli I94I den Auftrag zur Ausarbeitung eines Planes für die "Lösung der Judenfrage« und gab Anfang Oktober grünes Licht für die Ausführung der ihm vorgelegten Konzeption. In den darauf folgenden Monaten seien die ersten Schritte erfolgt. In den sich erweiternden Kreis der Eingeweihten der "Endlösung " wurden die Beamten des Auswärtigen Amtes und des "Ostministeriums" einbezogen. Die ersten Vernichtungsaktionen erfolgten dann im November I94I. Doch erst im Mai 1942 habe man mit dem systematischen Massenmord an den Reichsjuden begonnen. ${ }^{569}$ Soweit drei exemplarische Positionen einer nicht enden wollenden Kontroverse, die keineswegs bloß scholastischer Natur ist, hat sie doch, wie Browning zurecht sagt, zentrale Bedeutung für das Begreifen der Natur der NS-Herrschaft überhaupt. ${ }^{570}$

Für alle hier skizzierten Theorien gibt es gute Argumente, aber keinen empirisch belegbaren Beweis, etwa den eines Dokuments. Zunehmend setzen sich daher eher prozessuale Beschreibungen durch, in denen die Auffassung vertreten wird, dass sich die "Endlösung" auf so etwas wie eine Politik der Konsensbildung stützte, ${ }^{571}$ bis eine neue Generation von Holocaustforschern (der Wiener Hans Safrian, der holländische Historiker L. J. Hartog und der Berliner Historiker Christian Gerlach)

566 Götz Aly: „Endlösung«. Völkerverschiebung und der Mord an den europäischen Juden. (Frankfurt a. M. 1999), S. 306.

567 Yaacov Lozowick: Hitlers Bürokraten. Eichmann, seine willigen Vollstrecker und die Banalität des Bösen (Zürich/München 2000), S. 103.

568 Christopher R. Browning, Judenmord. NS-Politik, Zwangsarbeit und das Verhalten der Täter (Frankfurt a. M. 2001), S. 83.

569 Ebenda, S. 82.

570 Vgl. ebenda, S. 47.

571 Browning, Judenmord, S. 53. 
versuchte, durch penibles Zusammenführen und Abgleichen neuester Quellen: Telefonnotizen, Besprechungszettel, Terminkalender, Tagebücher usw., Fundstücke aus bis in die I990er-Jahre nicht zugänglichen Archiven, endlich doch einen Beweis für den Befehl Hitlers zur "Endlösung« zu liefern. Sie bewegten sich dabei in einem Zeitraum Frühjahr bis Herbst I94I, wobei sich der Herbst I94I als Schlüsselzeit herauszukristallisieren scheint, als Übergangsphase zwischen den noch unbestimmten Plänen der Vertreibung und Dezimierung, durch Umsiedlung (etwa nach Madagaskar), durch Treiben in die weißrussischen Sümpfe, durch Hunger und Kälte bis zu immer konkreter werdenden Vernichtungsplänen. Im Allgemeinen wird dabei vermieden, ein exaktes Datum anzugeben, mit Ausnahme von Christian Gerlach, der den I 2. Dezember I94I als vermutetes Datum für einen Befehl Hitlers zur Ermordung der europäischen Juden nennt. Die Tatsache, dass ein Befehl Hitlers bisher nicht gefunden wurde, dürfe, so Gerlach, nicht zu der Annahme verleiten, eine solche Entscheidung habe es nie gegeben. ${ }^{572}$

Gerlachs Chronologie und Beweisführung haben etwas durchaus Überzeugendes: Am 7. Dezember war der Angriff der Japaner auf Pearl Harbour erfolgt. Am I I. Dezember erklärte Hitler den USA den Krieg, so wie umgekehrt Präsident Roosevelt dem Deutschen Reich den Krieg erklärte. Damit aber war der Krieg zum Weltkrieg, aus einem geplanten "Blitzkrieg" war ein Zweifrontenkrieg mit allen führenden Weltmächten geworden. Schuld daran aber war, nach nationalsozialistischer Logik, nur eines: die "jüdische Weltverschwörung". Bereits am nächsten Tag, dem I 2. Dezember, vermutet Gerlach - gestützt auf die oben erwähnte Eintragung in Himmlers Dienstkalender - habe Hitler seine Entscheidung, die Juden (und zwar nun auch die »Reichsjuden", d.h. die deutschen und die ehemaligen österreichischen und tschechischen Juden) zu vernichten, im innersten Kreis bekannt gegeben. Als zweite Quelle führt Gerlach eine Tagebucheintragung Joseph Goebbels' an, wonach Hitler in einer langen Ansprache am Abend des I 2. Dezember vor den Spitzen der Partei auf seine berüchtigte Reichstagsrede vom 30. Januar I939 zurückgekommen sei: »Bezüglich der Judenfrage«, schreibt Goebbels, sei »der Führer entschlossen, reinen Tisch zu machen. Er hat den Juden prophezeit, dass, wenn sie noch einmal einen Weltkrieg herbeiführen würden, sie dabei ihre Vernichtung erleben würden. Dies ist

572 Christian Gerlach: Die Wannsee-Konferenz, das Schicksal der deutschen Juden und Hitlers politische Grundsatzentscheidung, alle Juden Europas zu ermorden, in: Krieg, Ernährung, Völkermord. Deutsche Vernichtungspolitik im Zweiten Weltkrieg (Zürich 2001), S. 79-152, hier: S. 147. Hermann Graml ist davon überzeugt, dass ein Befehl Hitlers »unverzichtbar" gewesen sei. Hermann Graml: Die Durchführung der "Endlösung", in: Rolf Steininger (Hg.): Der Umgang mit dem Holocaust (Wien/Köln/Weimar 1994), S. 31-44, hier: S. 39. Auch Peter Longerich spricht von einer ausdrücklichen Autorisierung der "Endlösung" durch Hitler. Siehe: Peter Longerich: Der ungeschriebene Befehl. Hitler und der Weg zur `Endlösung` (München 2001), S. $144 f$. 
keine Phrase gewesen. Der Weltkrieg ist da, die Vernichtung des Judentums muss die notwendige Folge sein $" .{ }^{573}$ In den darauffolgenden Tagen sei der Kreis der Eingeweihten allmählich ausgeweitet worden. Bis dahin - so die These Gerlachs - sei das Los der reichsdeutschen Juden (im Gegensatz zu dem der Juden in den besetzten Gebieten, mit deren Vernichtung bereits kurz nach dem Überfall auf die Sowjetunion begonnen worden war) noch nicht entschieden gewesen. ${ }^{574}$

Am I 8. Dezember - ein weiteres Datum aus Himmlers Dienstkalender - habe Hitler dem Reichsführer den ausdrücklichen Befehl erteilt, alle Juden »als Partisanen auszurotten «. ${ }^{575}$ (Mit Partisanen waren jetzt nicht mehr, wie bisher, solche in den besetzten Gebieten gemeint, sondern - als imaginierte Teilnehmer im »Weltkrieg« Juden als Partisanen im eigenen Land.) Ein weiteres Indiz für die These Gerlachs ist die Verschiebung der für Anfang Dezember geplanten (Wannsee-)Konferenz um gleich sechs Wochen auf den 20. Januar 1942. Das Protokoll der Wannsee-Konferenz gilt seit den Nürnberger Prozessen als wichtigstes Beweisstück zum geplanten, systematischen Genozid an den europäischen Juden. ${ }^{576}$ In jüngster Zeit wurde das enigmatische Dokument in seiner Bedeutung allerdings eher herabgestuft. Tatsächlich sei es bei der Wannsee-Konferenz nur mehr um die Einbindung der Spitzen der Bürokratie gegangen, um »Parallelisierung der Linienführung« (Heydrich), um Einhaltung der sprachlichen Codes sowie insbesondere um die Frage der Einbeziehung der Mischlinge ersten und zweiten Grades und der Juden in privilegierten Ehen die eigentliche Entscheidung zur Ermordung der, nach den Berechnungen Adolf Eichmanns, etwa I I Millionen Juden (jetzt einschließlich der reichsdeutschen), sei zu diesem Zeitpunkt längst gefallen gewesen. ${ }^{577}$

Einen urkundlichen Beweis für seine Theorie legt allerdings auch Gerlach nicht vor. Auch er vermeidet - und das ist ein Spezifikum der Debatte - den Begriff

573 Elke Fröhlich (Hg.): Die Tagebücher von Joseph Goebbels (29 Bände), Band 2, Teil II, bearbeitet von Angela Hermann (Berlin 2004), S. 498f, Eintragung unter dem 13.12.1941.

574 Gerlach, Wannseekonferenz, S. 143.

575 Gerlach, Wannseekonferenz, S. 116.

576 Mark Roseman nennt es "a deeply mysterious document «, the »Rosetta stone of Nazi murder«. Mark Rosemann: The Villa, the Lake, the Meeting. Wannsee and the Final Solution (London 2002), S. 2. Dan Diner spricht vom "absoluten Genozid", im Sinne eines "grundlosen, jenseits von Vernunft und Selbsterhaltungswillen« geplanten Völkermords. Dan Diner: "Über die Not des Vergleichs. Über Holocaust, Genozid und andere Massenverbrechen." Beitrag zur Internationalen Tagung der Österreichischen Akademie der Wissenschaften »Diesseits und jenseits des Holocaust. Aus der Geschichte lernen in Gedenkstätten«, am 15. September 2011 in Wien.

577 Gerlach, Wannseekonferenz, S. 125ff. Mark Roseman spricht davon, dass es Heydrich darum gegangen sei, so etwas wie shared complicity zu etablieren, insofern habe sich das Wannsee-Protokoll für einige der Protagonisten später als Falle erwiesen. Roseman, The Lake, S. 87. 
»Befehl«. Vorsichtig spricht er von einer "Grundsatzentscheidung « Hitlers. ${ }^{578}$ Andere nennen es »Durchführungs-Entscheidung « oder sprechen von einem Entscheidungsprozess. Das Wort »Befehl« taucht in aller Deutlichkeit nur bei Hannah Arendt auf. ${ }^{579}$ Der Mangel eines schriftlichen Dokuments bereitet ihr keine Verlegenheit. Sie geht vor allem sprachanalytisch vor, weist auf die Tarnsprache der Nazis hin, in welcher »Verlegung des Wohnsitzes« oder »Umsiedlung« die Deportation bedeutet und "Sonderbehandlung" oder »radikale Lösung « Mord. Die "Endlösung« - ein Euphemismus für Mord - war und blieb bis zuletzt »Geheimsache«, auch dann noch, als alle Parteistellen, Staatsämter, Eisenbahner usw. informiert waren. Diejenigen, die vom »Führerbefehl « ausdrücklich unterrichtet waren, avancierten zu "Geheimnisträgern «. ${ }^{500}$ Himmler selbst gab die Devise aus, dass über die »Endlösung der Judenfrage« öffentlich nie gesprochen werden dürfe, diese sei vielmehr "ein niemals geschriebenes und niemals zu schreibendes Kapitel unserer Geschichte ${ }^{581}$

Ein Geheimnis aber ist etwas, womit Historiker schon aus methodischen Gründen nur schwer umgehen können. Schweigen ist keine historische Kategorie. ${ }^{582}$ Doch auch die Sprache des Nationalsozialismus ist uns in Wahrheit kaum mehr verständlich. Zwar können wir - dank Wilhelm Klemperers Sammlung nazistischen Sprachgebrauchs - einzelne Vokabeln der »LTI«, der Lingua Tertii Imperii, entschlüs$\operatorname{seln}^{583}$, doch die Dichte des ideologischen Kontextes: Erlösungsglaube, Führerkult, Gefolgschaft, der alles durchdringende Biologismus, Rassismus und Antisemitismus ist Nachgeborenen kaum mehr nachvollziehbar. Geheimnisse haben in Demokratien nichts verloren. Gibt es sie doch, bleiben sie es - bei funktionierenden Medien und parlamentarischer Kontrolle - im Allgemeinen nicht lange. Nach Elias Canetti beruht nun die Macht eines Diktators zu einem Gutteil darauf, dass man ihm die Kraft des Geheimnisses zubilligt. Beratungen spielten sich in ganz kleinen Gruppen ab, die auf Geheimhaltung hin gebildet werden. Auf Verrat stünden die aller schwersten Sanktionen. Der Beschluss liege bei einem Einzelnen. Dieser kenne ihn selbst nicht,

578 Gerlach, Wannseekonferenz, S. 119.

579 Hannah Arendt: Eichmann in Jerusalem. Ein Bericht von der Banalität des Bösen (München/Zürich 1999), S. $168 f$.

580 Arendt, Eichmann, S. 170. Siehe dazu: Raul Hilberg: Die Quellen des Holocaust. Entschlüsseln und Interpretieren (Frankfurt a. M. 2002), S. 131ff.

581 Zit. nach: Aly, "Endlösung«, S. 394. Was nicht bedeutet, dass in der Öffentlichkeit gar keine Informationen über das Geschehen vorhanden waren. Peter Longerich bezeichnet dann auch die "Endlösung" als ein "öffentliches Geheimnis». Siehe: Peter Longerich, "Davon haben wir nichts gewusst!« Die Deutschen und die Judenverfolgung 1933-1945. München 2006, S. 201.

582 Vgl. dazu Lyotards Auseinandersetzung mit dem sogenannten »Faurisson-Argument«, in: JeanFrançois Lyotard: Der Widerstreit (München 1987), S. $35 \mathrm{ff}$.

583 Wilhelm Klemperer: LTI. Notizbuch eines Philologen [Berlin 1947] (Stuttgart 2010). 
bevor er ihn gefasst habe, doch »einmal gefasst, findet er als Befehl seine rasche Ausführung «. ${ }^{584}$ Das Geheimnis, sagt Canetti, ist »im innersten Kern der Macht «. ${ }^{585}$

Den oben zitierten Positionen im Historikerstreit um den Befehl zur "Endlösung « liegen - unausgesprochen - die verschiedensten machttheoretischen Vorstellungen zugrunde. Wer gegen den schon beinahe erreichten Konsens über strukturelle Sachzwänge weiter nach dem einen Befehl sucht, wird über eine andere Vorstellung von Macht verfügen als die Anhänger des funktionalistischen Ansatzes. Funktionalisten scheinen eine subjektlose, dezentrale Vorstellung von Macht zu haben, wie sie vorherrschend ist in einem Diskurs von Marx bis Foucault. Dass der Ausgangspunkt der Macht allein beim Souverän, beim Staat, zu finden sei, schien Michel Foucault ein überholtes historisches Konstrukt. Foucault hat auf die Vielfältigkeit von Machtbeziehungen aufmerksam gemacht. ${ }^{586}$ Die Macht durchdringe alle Körper. Man müsse sie als ein produktives Netz auffassen, das den ganzen sozialen Körper durchzieht, nicht so sehr als negative Instanz, deren Funktion in der Unterdrückung bestehe. ${ }^{587}$ Der klassische Machtbegriff hat sich, darauf weist auch Vilém Flusser hin, entscheidend verändert. Die moderne Macht begründe sich, so Flusser, auf dem Beherrschen bestimmter Codes und (Entscheidungs-)Methoden «. ${ }^{588}$ Weitergeführt wurde dieser Ansatz (allerdings ohne den zivilisationskritischen Ton Flussers) unter anderem von dem Globalisierungstheoretiker Manuel Castells. Nach Castells sei Macht in ihrer zentralisierten Erscheinungsform im Schwinden. Macht sei die Funktion eines endlosen Kampfes "um die kulturellen Codes der Gesellschaft«. Anstelle eines vertikalen Machtmodells vom Souverän oder dem Staat zu den einzelnen Subjekten erblickt Castells bloß horizontale Netzwerke. ${ }^{589}$

Verglichen mit diesen Positionen mutet Canettis Machtbegriff geradezu archaisch an. Macht ist bei ihm weder ort-, noch subjektlos, noch dezentriert. Elias Canetti untersucht Gewalt, Geheimnis, Befehl als zentrale Elemente der Macht. Dabei löst er den Befehl aus dem militärischen Kontext heraus und geht an seine anthropologischen Ursprünge, analysiert die Beziehung von Reiter, Pferd und Pfeil, von »Befehlsstachel « und "Befehlsangst«: die Angst (der Diktatoren) vor der Umkehrung des Befehls, jenem "Gefühl von Gefahr - dass alles, dem man befohlen hat, alles

584 Elias Canetti: Masse und Macht, Bd. 2 (Hamburg 1976), S. 24.

585 Ebenda, S. 17.

586 Michel Foucault: Dispositive der Macht. Über Sexualität, Wissen und Wahrheit (Berlin 1978), S. $110 \mathrm{f}$.

587 Ebenda, S. 35.

588 Vilém Flusser: Vermassung und Vernetzung, in: Der Stachel des Befehls, IV. Canetti-Symposium, John Pattillo-Hess (Hg.) (Wien 1992), S. 117-121, hier: S. 121.

589 Vgl. Manuel Castells: Das Informationszeitalter, Bd. 1: Der Aufstieg der Netzwerkgesellschaft (Opladen 2001). 
mit dem Tode Bedrohte lebt und sich erinnert -, Gefahr, in der man wäre, wenn die vielen mit dem Tode Bedrohten sich gegen einen zusammenschließen würden (...) dieses quälende, unversiegliche und unbegrenzte Gefühl von Gefahr bezeichne ich als Befehlsangst. "Sie sei am größten, sagt Canetti, bei »dem, der zuhöchst steht. An der Quelle des Befehls, in dem, der die Befehle aus sich heraus erteilt, der sie von niemand empfängt, der sie sozusagen selbst erzeugt, da ist die Konzentration von Befehlsangst die größte. "590 Wäre hier eine Begründung zu finden, warum Hitler am Ende alle Juden töten wollte, warum niemand überleben sollte, warum es keine Gnade - nach Canetti der höchste und konzentrierteste Akt der Macht - gab, auch nicht für die reichsdeutschen Juden, die eigenen Staatsbürger, deren Tod er - nach Einsicht von Gerlach und anderen - erst entschieden hat, als der Weltkrieg begann und die siegreiche Phase des Krieges im Osten zu Ende ging?

Was in den Analysen der Historiker, die sich in den letzten Jahren vor allem auf das Geschehen im Osten konzentrierten (auf die gigantischen Bevölkerungsverschiebungen und -vertreibungen, auf die verbrecherischen Planungen in Zusammenhang mit dem "Generalplan Ost « ${ }^{591}$ ), zu kurz zu kommen scheint, ist der Prozess der geplanten und systematischen Entrechtung der Juden, der knapp nach Beginn der NS-Herrschaft einsetzte, jene durch einzelne Rechtsakte betriebene stete Verwandlung, die auf Depersonalisierung zielte, solange, bis Juden nur mehr als »Ungeziefer» erschienen, das man straflos vernichten durfte. 592 „Die Juden sind die Läuse der zivilisierten Menschheit. Man muss sie irgendwie ausrotten «, schrieb Joseph Goebbels am 2. November I94I in sein Tagebuch. ${ }^{593}$ Bald darauf schritt man zur Tat. Dass die Juden "weg müssen«, darin war man sich jetzt einig, doch ob »bloß« die »Ostjuden« in den besetzten Gebieten, die man während des Kriegsgeschehens gefahrlos umbringen konnte, oder tatsächlich alle Juden, auch die eigenen Staatsbürger, alle, bis zum letzten Greis, bis zum letzten Kind, diese Frage scheint im Spätherbst I94I noch offen gewesen zu sein ${ }^{594}$, ebenso die Frage, wer als Jude gelten sollte. Hitler hat bis zuletzt an der mit den Nürnberger Gesetzen getroffenen Definition festgehalten, ebenso an den dort beschlossenen Ausnahmeregelungen (für mit "arischen«

590 Canetti, Masse und Macht, Bd. 2, S. 36.

591 Dazu: Hannelore Burger: Der Generalplan Ost und die `Bereinigung der Slowenenfrage‘, in: Valentin Oman/Karl Vouk (Hg.): DenkMal: Deportration 1942-2012, Katalog (Celovec/Klagenfurt 2012), S. 13-20.

592 Vgl. Elias Canetti: Die Provinz des Menschen. Aufzeichnungen 1942-1972 (Frankfurt a. M. 1991), S. 81.

593 Zit. nach:: Aly, »Endlösung«, S. 374.

594 Noch sei das Konzept, sagt Timothy Snyder, nicht klar umrissen gewesen, die Maschinerie nicht installiert, aber bestimmte Umrisse von Hitlers letzter Version der Endlösung seien bereits sichtbar gewesen. Timothy Snyder: Bloodlands. Europa zwischen Hitler und Stalin (München 2011), S. 220 . 
Partnern verheiratete, Teilnehmer des Ersten Weltkrieges) und jede Ausweitung auf Mischlinge ersten und zweiten Grades, wie sie etwa Heydrich vorgeschlagen hatte, abgewiesen - möglicherweise auch wegen der ausländischen Proteste, vor allem aber wohl deshalb, weil es sich (bei »Viertel-« oder »Halbjuden«) eben teilweise um »deutsches Blut handelte. Die nationalsozialistische (Blut-)Logik gebot zwingend, die auf reichsdeutschem Boden verbliebenen Juden auszubürgern, und zwar bevor sie in das Vernichtungsprogramm, das nun anstelle der bisherigen Vertreibungs- und Umsiedlungsprogramme getreten war, einbezogen wurden. Bei ihrer Ermordung durften Juden keine Deutschen mehr sein.

Im Folgenden soll hier die Chronologie des Herbstes I94I, wie sie durch die Aktenfunde der jüngeren Zeit gesichert erscheint, noch einmal aufgenommen und um einige Daten, die mir bedeutsam erscheinen, ergänzt werden. Am I7. September I 94I hatte Hitler, laut Eintragung in Himmlers Dienstkalender, die Deportation der deutschen, österreichischen und tschechischen Juden nach Osteuropa angeordnet. ${ }^{595}$ Mitte Oktober setzten die Massendeportation von "Reichsjuden« nach Osten ein. Am I 8. Oktober erfolgte das strikte Verbot der Auswanderung, was bedeutete, dass es kein Entkommen mehr gab. Anfang November befand sich das erste Vernichtungslager, Bełzec, im Distrikt Lublin, vor der Fertigstellung; ein Probebetrieb der Gaskammern wurde aufgenommen. Ab Mitte November zeigen die Quellen nun eine Verdichtung von Begegnungen, Besprechungen, Telefonaten: Am I6. November waren Himmler und Rosenberg gemeinsam bei Hitler. Am 17. telefonierte Himmler mit Heydrich wegen »Beseitigung der Juden«. ${ }^{596}$ Mehrmals in dieser Zeit traf Himmler mit Wilhelm Stuckart, Staatssekretär im Innenministerium, Mitschöpfer und Kommentator des Reichsbürgergesetzes, zusammen. Stuckart gegenüber reklamierte er seine alleinige Kompetenz in der "Lösung der Judenfrage«.597 Auf einem Besprechungsblatt notierte Himmler: "Judenfragen gehören zu mir«.598 Worüber haben die beiden noch gesprochen? Nach Christopher Browning bekam Stuckart »bei dieser Gelegenheit wesentlich mehr zu hören als Himmlers Pochen auf Zuständigkeiten«.599 Am Tag nach dem Gespräch Himmlers mit Stuckart, dem 25. November I94I, wurden erstmals alle Angehörigen der im litauischen Kaunas eintreffenden Transporte - darunter auch ein Transport aus Wien - sofort getötet

595 Vgl. Witte, Dienstkalender, S. 213.

596 Vgl, Gerlach, Wannseekonferenz, S. 164.

597 Stuckarts Vorschlag, die Juden für staatenlos zu erklären und sie legistisch als bloße "Schutzangehörige des Reiches « zu fassen, war der Erkenntnis geschuldet, dass das Innenministerium jede Kontrolle über die deportierten Juden verlieren würde, und ein Versuch, das Ministerium (und sich selbst) jeglicher Verantwortung zu entziehen. Vgl. Roseman, The Lake, S. 94.

598 Vgl. Witte, Dienstkalender, S. 274.

599 Vgl. Browning, Judenmord, S. 74. 
(bis dahin waren die deportierten "Reichsjuden« in den Ghettos von Łódź und Minsk interniert worden). ${ }^{600}$ Nach Browning bezeichnet das Datum des 25. November jenen point of no return, "an dem das NS-Regime offiziell die Linie überschritt", die das politische Programm für die Aussiedlung und Ermordung der deutschen Juden von seiner tatsächlichen Umsetzung trennte. ${ }^{601}$ Der 25 . November I 94I ist aber zugleich auch das Datum der Kundmachung der Elften Verordnung zum Reichsbürgergesetz, die, so ist zu vermuten, ebenfalls Gegenstand der Besprechung Himmlers mit Staatssekretär Stuckart gewesen war.

Tatsächlich beseitigte die Elfte Verordnung zum Reichsbürgergesetz alle einer »radikalen Lösung" noch entgegenstehenden Hindernisse. Ausbürgerung, Vermögensentzug, Enterbung und Deportation waren nun harmonisiert. Auf Anordnung des Reichssicherheitshauptamtes wurde darüber hinaus die Verfügungsgewalt von Juden über ihr bewegliches Vermögen aufgehoben. Damit waren die »rechtlichen" Voraussetzungen für die "Endlösung« geschaffen. Im Gegensatz zu den schon früher möglichen strafweisen Ausbürgerungen, die noch mit einem ordentlichen Verfahren durchgeführt und bescheidmäßig festgestellt werden mussten, war die Ausbürgerung nach der Elften Verordnung unmittelbar nach ihrem Inkrafttreten ipso facto wirksam. Festgestellt wurde sie in einem polizeilichen Verfahren, an dem der Reichsstatthalter, das Polizeipräsidium und die Geheime Staatspolizei beteiligt waren. Die Rechtsfolgen der Aberkennung der Staatsbürgerschaft waren so gewaltig - neben dem Vermögensverfall auch der Verlust von Versorgungs- und Hinterbliebenenansprüchen -, dass, wie in vielen anderen Bereichen auch, die Nationalsozialisten um Aufrechterhaltung des Scheins der Legalität ihrer Maßnahmen bemüht waren. Nach ihren eigenen Gesetzen konnte die Konfiskation des Vermögens nämlich erst dann vorgenommen werden, wenn der Aufenthaltsort bzw. das Datum der Ausreise (jetzt nur mehr die Deportation) amtlich festgestellt und die erfolgte Ausbürgerung an das Reichssicherheitshauptamt in Berlin weitergemeldet worden war. ${ }^{602}$

Wird die Elfte Verordnung von den meisten Historikern vor allem in Zusammenhang mit der Beraubung der Juden gesehen (dem Vermögensentzug) ${ }^{603}$, möchte ich hier ihren Charakter als Instrument im langen und mit unglaublicher juridischer Finesse betriebenen Prozess der Entrechtung und Depersonalisierung betonen. Er beginnt mit der Erklärung der Juden zu Staatsangehörigen minderen Rechts im Rah-

600 Vgl. Browning, Judenmord, S. 77 sowie auch Florian Freund/Hans Safrian: Die Verfolgung der österreichischen Juden 1938-1945. Vertreibung und Deportation, in: Emmerich Tálos et al. (Hg.): NS-Herrschaft in Österreich. Ein Handbuch (Wien 2000), S. 767-794, hier: S. 775.

601 Vgl. Browning, Judenmord, S. 77.

602 Vgl. Burger/Wendelin, Staatsbürgerschaft und Vertreibung, S. 47f.

603 Etwa bei Cornelia Essner: Die `Nürnberger Gesetzer oder die Verwaltung des Rassenwahns 19331945 (Paderborn/München 2002), S. 296ff u. 310. 
men der Nürnberger Gesetze vom I 5 . September 1935 (in Österreich kundgemacht am 20. Mai 1938). Es folgten (wie oben ausgeführt) die Kenntlichmachung ihrer Pässe mit einem J für Juden, das Diktat der Zusatznamen Sara und Israel, schließlich, mit Erlass vom I 5. September I 94 I, der Zwang, ein sie als Juden identifizierendes Zeichen, den gelben Stern, tragen zu müssen - ein weiterer Schritt der Sichtbarmachung und Absonderung. Der Prozess endete mit dem Entzug ihrer - wenn auch längst jeden materiellen Inhalts entkleideten - Staatsangehörigkeit im Zuge der Deportation in die Ghettos und Konzentrationslager. Mit einer I3. Verordnung zum Reichsbürgerschaftsgesetz am I. Juli I 943 wurden Juden dann unter bloßes Polizeirecht gestellt, d. h. es gab für sie keinerlei Rechtsinstanzen mehr. Damit war der »bürgerliche Tod» der deutschen und österreichischen Juden herbeigeführt. Erst jetzt, als sie ihres Personseins beraubt waren, ging man dazu über, sie systematisch zu ermorden. Mit der Staatsbürgerschaft verliert, nach Hannah Arendt, der Mensch viel mehr als einen bloßen Status, er verliert damit den Standort in der Welt, »durch den allein er überhaupt Rechte haben kann. ${ }^{604}$ Als jetzt Staatenlose waren Juden gleichsam vogelfrei. Ihre Unbezogenheit, ihre Weltlosigkeit wirkte, so Hannah Arendt, »wie eine Aufforderung zum Mord, insofern der Tod von Menschen, die außerhalb aller weltlichen Bezüge (...) stehen, ohne jede Konsequenzen für die Überlebenden bleibt«. ${ }^{605}$ Die Elfte Verordnung zum Reichsbürgergesetz vom 25. November I94I war ein Mordinstrument, genauso wie die Gaskammern, die zu jenem Zeitpunkt gerade in »Probebetrieb« gingen. Sie steht exakt am Wendepunkt von einer Politik der Vertreibung zu einer Politik der Vernichtung der Juden. Sie steht im Horizont der »Endlösung « - und sie bereitet diese vor.

604 Hannah Arendt: Elemente und Ursprünge totaler Herrschaft (München 1986), S. 461.

605 Ebenda, S. 470. 


\section{Die Wiederherstellung der Staatsbürgerschaft in der Zweiten Republik}

Die Aufhebung des Reichsbürgergesetzes samt allen seinen Verordnungen war eine der ersten Amtshandlungen der wiedererrichteten Republik Österreich unter ihrer "provisorischen Staatsregierung« Karl Renner. Mit Kundmachungen vom I 3. und vom 29. Mai 1945 wurden alle durch das nationalsozialistische Reich getätigten Ausbürgerungen ausdrücklich aufgehoben. Doch die Wiederherstellung der österreichischen Staatsbürgerschaft erwies sich als ein weit schwierigerer, sich über Jahre erstreckender Prozess. Mit dem Staatsbürgerschaftsüberleitungsgesetz und dem Staatsbürgerschaftsgesetz vom Juli 1945 wurde ein Rechtszustand wiederhergestellt, wie er bis zum "Anschluss« bestanden hatte, d. h. Staatsbürger und Staatsbürgerinnen der Zweiten Republik wurden zunächst all jene, die am I 3. März I 938 die österreichische Bundesbürgerschaft besessen hatten - was grundsätzlich auch alle im Ausland befindlichen Emigranten mit einschloss, gleichgültig ob sie bereit waren, zurückzukehren, oder nicht. Nicht berücksichtigt worden waren jedoch jene, die bereits eine neue Staatsbürgerschaft erworben hatten. Dies aber war bei etwa einem Drittel der während der NS-Diktatur vertriebenen und ausgebürgerten Juden der Fall. Viele von ihnen hatten, um nicht staatenlos - und damit im Zustand nahezu völliger Rechtlosigkeit - zu bleiben, bereits die Staatsbürgerschaft ihres Aufnahmestaates angenommen, wie etwa der Wirtschaftswissenschaftler Dr. Julius Fliegel, der bereits im Februar 1945 die US-amerikanische Staatsbürgerschaft erhielt ${ }^{606}$, und hatten damit (wissentlich oder unwissentlich) ihre österreichische Staatsangehörigkeit ein zweites Mal verloren - diesmal nicht nach nationalsozialistischem (Un-)Recht, sondern nach dem fiktiv geltenden österreichischen Bundesbürgerschaftsgesetz von I925. Zwar wurden für dieses Rechtsproblem in den Jahren I949, I 966 und 1973 Sondererwerbsmöglichkeiten geschaffen, doch erwiesen diese sich entweder wegen allzu kurzer Antragsfristen oder wegen der Bedingung der Aufgabe der fremden Staatsangehörigkeit bzw. der Bedingung einer Wohnsitzbegründung als vollkommen unzulänglich.

Der Verlust der österreichischen Staatsbürgerschaft hatte aber nicht nur symbolische und emotionale Bedeutung, sondern war durchaus auch von vermögens-

606 Austrian Heritage Collection, AR 10532, Hans Fliegel, Leo Baeck Institute/Jüdisches Museum Berlin, MF 503 - viele weitere Fälle. Siehe dazu auch: Burger/Wendelin, Staatsbürgerschaft und Vertreibung, Diagramm 15, S. 437. 
rechtlicher Relevanz. So war zwar im Bereich der materiellen Rückstellungen (überwiegend von Haus- und Grundbesitz im Rahmen der sieben Rückstellungsgesetze) keine Bindung an eine bestehende österreichische Staatsbürgerschaft gegeben, doch im Bereich der Opferfürsorgegesetze wie auch bei manchen sozialversicherungsrechtlichen Regelungen wirkte sich der Mangel der Staatsbürgerschaft negativ aus. "Amtsbescheinigungen« und »Opferausweise«, die Zugang zu bestimmten Wiedergutmachungsleistungen erwirkten, blieben allein österreichischen Staatsbürgern vorbehalten. Vertriebenen österreichischen Juden, die nach I 938 hatten fliehen müssen und später eine andere Staatsbürgerschaft angenommen hatten, blieb der Zugang zu Leistungen aus der Opferfürsorge verwehrt. ${ }^{607}$ Somit war gerade die zahlenmäßig größte Gruppe von Verfolgten des nationalsozialistischen Regimes von wesentlichen Hilfs- und Entschädigungsleistungen weitgehend ausgeschlossen. ${ }^{608}$ Doch auch im Bereich des Sozialversicherungsrechts (ASVG), etwa bei der Pensionsversicherung, ist der Besitz bzw. Nichtbesitz der Staatsbürgerschaft von unmittelbar finanzieller und sozialrechtlicher Relevanz. ${ }^{609}$

Dass eine Remigration österreichischer Juden nach 1945 nur vereinzelt stattfand, lässt sich - neben anderen Ursachen - auch auf die unübersichtliche und unzureichende Staatsbürgerschaftsgesetzgebung zurückführen. Verschiedene Untersuchungen kommen - mit leichten Modifikationen - zu dem Schluss, dass von den etwa I I o ooo überlebenden jüdischen Vertriebenen bis Ende I 947 nur etwa 5000 nach Österreich zurückkehrten. ${ }^{610}$ Unter diesen befanden sich jedoch rund 3000 Überlebende der Konzentrationslager sowie 800 Rückkehrer aus Shanghai, die gar keine andere Wahl hatten als nach Österreich zurückzukehren. ${ }^{611}$ Unter den etwa 1200 freiwilligen Remigranten waren viele alte, gesundheitlich geschwächte Menschen, die im Emigrationsland keine neue Existenz hatten aufbauen können, bzw. handelte es sich um Personen, die sich bereits vor 1938 oder in der Emigration politisch betätigt hatten, am Widerstand beteiligt oder für die Wiedererrichtung Österreichs

607 Vgl. Brigitte Bailer-Galander: Die Opfer des Nationalsozialismus und die sogenannte Wiedergutmachung, in: Emmerich Tálos et. al. (Hg.), NS-Herrschaft in Österreich (Wien 2000), S. 884-901, hier: S. $891 \mathrm{f}$.

608 Bailer-Galander, Opfer, S. 892.

609 Vgl. Walter J. Pfeil: Die Entschädigung von Opfern des Nationalsozialismus im österreichischen Sozialrecht (= Veröffentlichungen der Österreichischen Historikerkommission 29/1) (Wien/München 2004), S. 286ff.

610 Friederike Wilder-Okladek: The Return movement of Jews to Austria after the second World War (Den Haag 1969), siehe auch die Diagramme 9, 10 und 11 von Harald Wendelin, die die Zusammensetzung der Remigranten bis 1950 exakt aufschlüsseln, in: Burger/Wendelin, Staatsbürgerschaft und Vertreibung, S. 430f.

611 Vgl. Françoise Kreissler: Retour ou rapatriement de Shanghai? Spécificités des contextes politiques (1945-1949), in: Austriaca (2003), 56, S. 89-100. 
eingetreten waren und bereit waren - unter welchen Umständen immer - am Aufbau eines wiedererrichteten demokratischen Österreich mitzuwirken. Nur für diese kleine Gruppe gab es - wie groß auch immer die Schwierigkeiten ihrer Remigration gewesen sein mögen - hinsichtlich der Wiedererlangung ihrer Staatsbürgerschaft noch kein Problem. So erhielten etwa der Musikwissenschaftler Kurt Blaukopf und seine Frau Herta ${ }^{612}$, die Schriftsteller Hermann Hakel und Willi Verkauf-Verlon alle aus Palästina kommend - ihre österreichische Staatsbürgerschaft nach $₫$ I des Staatsbürgerschaftsgesetzes zurück. Die Staatsbürgerschaft durch Erklärung nach $₫ 2$ erwarben I947 u. a. die aus den USA zurückkommende Schriftstellerin Elisabeth Freundlich und der ebenfalls aus den USA kommende Ökonom Eduard März. ${ }^{613}$ Doch unter den wenigen Rückkehrern und Rückkehrerinnen scheiterte ein nicht unbeträchtlicher Teil an den in Österreich vorgefundenen Bedingungen und verließ resigniert oder verzweifelt die Heimat ein zweites Mal (was allerdings den endgültigen Verlust der Staatsbürgerschaft bewirkte).

Ein besonderes Problem - aus der Sicht der österreichischen Regierung - waren die sich in den von den Alliierten kontrollierten Lagern aufhaltenden jüdischen Displaced Persons. ${ }^{614}$ Zwar waren die wenigen Überlebenden der Konzentrationslager, die in DP-Lagern untergebracht waren, relativ rasch von den Alliierten repatriiert worden, doch sehr bald füllte ein nicht enden wollender Strom jüdischer (Pogrom-) Flüchtlinge aus Rumänien und anderen osteuropäischen Ländern aufs Neue die Lager. Bis Frühjahr I 954 dürften etwa 200000 osteuropäische Juden durch die 47 unter amerikanischem Schutz stehenden in Österreich befindlichen DP-Lager geschleust worden sein ${ }^{615}$, darunter auch der Dichter Paul Celan, der sich 1947 etwa ein Jahr in Wien aufhielt, davon einige Tage in einem DP-Lager. ${ }^{616}$ Diese erst nach dem Krieg geflüchteten Juden - viele davon staatenlos - wurden von der österreichischen Regierung nicht mehr als Displaced Persons anerkannt. Rund um die Lager entwickelte sich eine heftige antisemitische Agitation, und im österreichischen Mi-

612 Herta Blaukopf schreibt über diese Gruppe zutreffend: „Diejenigen Emigranten, die sofort zur Rückkehr ins befreite Österreich bereit waren, hatten zumeist diesen Entschluss am Tage ihrer Flucht aus dem nazibeherrschten Österreich gefasst«. Herta Blaukopf: Kurt Blaukopfs (musikalisches) Österreich-Verständnis, in: Austriaca (2003) 56, S. 131-146, hier: S. 131.

613 Vgl. Burger/Wendelin, Staatsbürgerschaft und Vertreibung, S. $370 f$.

614 Vgl. Burger/Wendelin, Staatsbürgerschaft und Vertreibung, S. $362 \mathrm{f}$.

615 Thomas Albrich: Zwischenstation des Exodus. Jüdische Displaced Persons und Flüchtlinge nach dem Zweiten Weltkrieg, in: Gernot Heiss/Oliver Rathkolb (Hg.): Asylland wider Willen. Flüchtlinge in Österreich im europäischen Kontext seit 1914 (= Veröffentlichungen des Ludwig-Boltzmann-Institutes für Geschichte und Gesellschaft 25) (Wien 1995), S. 122-139.

616 Christine Oertel: Flucht über Österreich. Jüdische Displaced Persons aus Osteuropa 1945-1949, in: Displaced. Paul Celan in Wien 1947/48. Katalog der gleichnamigen Ausstellung im Jüdischen Museum Wien (Frankfurt a. M. 2001), S. 36-45. 
nisterrat wurden beschämende Debatten um die Ernährung und die Arbeitsfähigkeit der DPs geführt. ${ }^{617}$ Waren die sogenannten »volksdeutschen « DPs zwar anfangs auch nicht willkommen, wurden jedoch später zügig und bevorrechtigt eingebürgert $^{618}$, so hatten die wenigen jüdische DPs, die in Österreich bleiben wollten, kaum eine Chance auf Einbürgerung. ${ }^{619}$

Mit der Wiederverlautbarung des Staatsbürgerschafts- und des Staatsbürgerschaftsüberleitungsgesetzes (samt zahlreichen Novellierungen) im Jahr I949 war für die österreichische Regierung die Restitution der Staatsbürgerschaft abgeschlossen. Während der folgenden sechzehn Jahre sollte es für ehemalige österreichische Staatsbürger keinerlei Möglichkeiten eines erleichterten Erwerbs der Staatsbürgerschaft mehr geben. In der Praxis allerdings wurden die zwischen 1945 und 1949 bestehenden Sondererwerbsmöglichkeiten für die Mehrheit der jüdischen Vertriebenen gar nicht relevant, da österreichische Auslandsvertretungen, bei denen sich Emigranten hätten informieren können, zu diesem Zeitpunkt in vielen Ländern noch gar nicht errichtet waren und eine Rückkehr vielfach schon aufgrund der bestehenden verkehrstechnischen oder politischen Reisebeschränkungen nur eingeschränkt möglich war.

Eines der Hauptprobleme der Praxis der österreichischen Staatsbürgerschaftsgesetzgebung aber bestand darin, dass der endgültige Verlust der österreichischen Staatsbürgerschaft nicht nach nationalsozialistischem, sondern nach genuin österreichischem Recht erfolgte. Während man nämlich auf Seiten der österreichischen Regierung mit der gewählten Form der Staatsbürgerschaftsüberleitung: Nichtigkeitserklärung aller während der NS-Zeit getätigten Ausbürgerungen plus der Rechtsfiktion eines Weiterbestehens früherer österreichischer Rechtsnormen in gewisser Weise versucht hatte, das Geschehene gleichsam ungeschehen zu machen, waren die vertriebenen österreichischen Juden mit den gar nicht fiktiven Folgen ihrer Ausbürgerung zu jedem Zeitpunkt konfrontiert. Wollten sie nicht staatenlos bleiben, sahen sie sich vielfach gezwungen, die Staatsbürgerschaft ihres Aufnahmestaates anzuneh-

617 Insbesondere in den Ministerratssitzungen vom 20. Mai, 29. Juli, 26. September 1947 und 16. März 1948, abgedruckt in: Robert Knight (Hg.): „Ich bin dafür, die Sache in die Länge zu ziehen«. Die Wortprotokolle der österreichischen Bundesregierung von 1945 bis 1952 über die Entschädigung der Juden (Wien/Köln/Weimar 2000), S. 128-145.

618 Im April 1954 passierte ein Gesetzesentwurf den Nationalrat, der die Vereinfachung des Staatsbürgerschaftserwerbs für Volksdeutsche zum Inhalt hatte. Bis dahin hatten, laut Innenminister Oskar Helmer, rund 114000 Volksdeutsche (mit Familienangehörigen 228000 Personen) die österreichische Staatsbürgerschaft erhalten. Burger/Wendelin, Staatsbürgerschaft und Vertreibung, S. 357. Siehe dazu auch: Tara Zahra: "Prisoners of the Postwar«: Expellees, Displaced Perrsons, and the Jews in Austria after World War II, in: Austrian History Yearbook XLI (2010), S. 191-215.

619 Nach einem Bericht der US-Botschaft in Wien an das State Department vom 2. April 1953 waren Ende 1952 erst 23 jüdische Displaced Persons in Österreich eingebürgert worden. Siehe: Albrich, Zwischenstation, S. 134. 
men. Damit aber hatten sie (nach dem fiktiv geltenden Bundesbürgerschaftsgesetz von I925) einen Verlusttatbestand gesetzt, der ihnen, kehrten sie erst nach I950 zurück, zum Verhängnis wurde. Die Betroffenen, wie etwa der in der Frage der Restitution der Staatsbürgerschaft engagierte Autor Albert Sternfeld, der anlässlich seiner Wiedereinbürgerung mit großer Bitterkeit feststellte, wie jeder beliebige Fremde (d. h. lange Wartefristen, Aufgabe der eigenen Staatsbürgerschaft, hohe Kosten) behandelt worden zu sein ${ }^{620}$, oder der Maler Oskar Kokoschka, dessen komplizierte Wiedereinbürgerung (Kokoschka weigerte sich beharrlich, sowohl einen Antrag zu stellen, als auch einen Wohnsitz zu begründen) zum Anlassfall für die Novellierung des Staatsbürgerschaftsgesetzes im Jahr I 973 wurde ${ }^{621}$, empfanden es als eine $\mathrm{Zu}$ mutung, um etwas ansuchen zu müssen, von dem sie annahmen, dass es ihnen, da gewaltsam genommen, selbstverständlich zustand: ihre österreichische Staatsbürgerschaft. Nach Harald Wendelin erhielten nach den Reformen im Jahr I965 und 1973 (als die Bedingung der Aufgabe der fremden Staatsbürgerschaft entfiel, dafür aber die Bedingung einer Wohnsitzbegründung eingeführt worden war) nur sehr wenige Personen die Staatsbürgerschaft zurück. ${ }^{622}$

Zwar gab es immer auch die Möglichkeit einer Einbürgerung im Staatsinteresse, d. h. im Ausland zu Ruhm gelangten ehemaligen Österreichern und Österreicherinnen wegen "besonderer Verdienste um die Republik« via Ministerratsbeschluss eine (Wieder-)Einbürgerung zu ermöglichen: etwa im Fall der Schriftstellerin Hilde Spiel, die I973 aufgrund ihrer Tätigkeit als Generalsekretärin des österreichischen Pen-Clubs eingebürgert wurde, im Fall des Philosophen Sir Karl Popper, der 1976 auf eigenen Antrag, doch ohne einen Wohnsitz zu begründen, die österreichische Staatsbürgerschaft zurückerhielt oder des Dichters Erich Fried, dem I980 die Verleihung der österreichischen Staatsbürgerschaft angetragen wurde, ohne dass er seine britische Staatsbürgerschaft hatte aufgeben müssen ${ }^{623}$, doch handelte es sich dabei um Einzelfälle Prominenter. Für die große Mehrheit der Vertriebenen erwies sich die Staatsbürgerschaftsgesetzgebung - so eine Rückkehr aus dem Exil überhaupt erwogen wurde - eher als ein Hindernis.

Schwerer aber als eine unübersichtliche und teilweise verfehlte Gesetzgebung aber wog, dass keinerlei politischer Wille erkennbar war, die vertriebenen österrei-

620 Albert Sternfeld: Betrifft: Österreich. Von Österreich betroffen (Wien/Köln/Weimar 2001), S. $252 \mathrm{fff}$.

621 Bundeskanzler Bruno Kreisky löste schließlich das Problem der "Wohnsitzbegründung«, indem er den Maler Oskar Kokoschka in seiner eigenen Wohnung anmeldete und ihm somit den verlangten Wohnsitz verschaffte. Ausführlich dazu Harald Wendelin, in: Burger/Wendelin, Staatsbürgerschaft und Vertreibung, S. $383 \mathrm{ff}$.

6221965 waren es 51, 1973283 Fälle. Burger/Wendelin, Staatsbürgerschaft und Vertreibung, S. 386 sowie Diagramm 3, S. 399.

$623 \mathrm{Vgl}$. Burger/Wendelin, Staatsbürgerschaft und Vertreibung, S. 388f. 
chischen Juden zurückzuholen. So wurden in den zahlreich geführten Debatten im österreichischen Ministerrat die in alle Welt verstreuten jüdischen Vertriebenen entweder gar nicht, oder wenn doch, dann als Fremde, als Angehörige einer anderen Nation, als die "Judenschaft « erwähnt, nicht aber als willkommene, erwünschte oder dringend benötigte Rückkehrer. Der - nach Durchsicht der Ministerratsprotokolle der Jahre I 946 bis I 980 - ernüchternde Befund lautet: Alle von den Regierungen getroffenen gesetzlichen Maßnahmen, die der Wiedereinbürgerung ehemaliger Österreicherinnen und Österreicher dienten, zielten intentional auf andere Gruppen als die vertriebenen österreichischen Juden ${ }^{624}$ : vor allem auf die Gruppe der aus politischen Gründen Verfolgten, auf die Gruppe der sogenannten »reichsdeutschen Frauen" (die ihre österreichische Staatsbürgerschaft durch Eheschließung mit einem Deutschen verloren hatten), bald auch auf (minderbelastete) ehemalige Nationalsozialisten. Profitierten die aus »rassischen Gründen« Verfolgten dennoch von einzelnen Gesetzesbestimmungen, geschah dies gleichsam aus Versehen.

Ein Bewusstsein dafür - und in der Folge eine veränderte Haltung gegenüber den österreichischen Überlebenden des Holocausts - entstand erst Anfang der I 99oerJahre, als es im Zuge der sogenannten "Waldheim-Krise« zu einem paradigmatischen Wechsel in der Betrachtung der österreichischen Nachkriegsgeschichte kam. Die zumindest partielle Aufgabe der sogenannten "Opferthese", das zunehmende Bewusstseins einer Gleichzeitigkeit von Opferstatus und Tätersein und einer zumindest "moralischen Mitverantwortung" - so die Formel in einer Erklärung Bundeskanzler Franz Vranitzkys vom 8. Juli I99 - Österreichs für das Schicksal seiner jüdischen Bevölkerung, hatte auf der politisch-praktischen Ebene u. a. eine neuerliche Novellierung des Staatsbürgerschaftsgesetzes im Jahr I 993 zur Folge. Erstmals konnten Vertriebene nun ihre verlorene österreichische Staatsbürgerschaft durch einfache Erklärung zurückerhalten, ohne Antragstellung, ohne Wohnsitzbegründung, vor allem aber ohne die erworbene Staatsbürgerschaft des Emigrationslandes aufgeben zu müssen. Von dieser Möglichkeit machten bis Ende 200 I I 838 Personen Gebrauch, rund Io Prozent aller Anspruchsberechtigten. ${ }^{625}$ Verglichen mit der geringen Zahl von Wiedereinbürgerungen in den vorangegangenen Jahrzehnten war dies zweifellos ein

624 Vgl. dazu auch: Sternfeld, Betrifft: Österreich, S. 250 f u. 272 sowie Robert Knight (Hg.): »Ich bin dafür, die Sache in die Länge zu ziehen. "Die Wortprotokolle der österreichischen Bundesregierung von 1945 bis 1952 über die Entschädigung der Juden (Wien 2000), S. 46ff.

625 Nach einer Berechnung von Harald Wendelin entsprechend den Angaben der Magistratsabteilung 61. Vgl. Burger/Wendelin, Staatsbürgerschaft und Vertreibung, S. 402 sowie Tabelle 1, S. 401. Danach sanken die Zahlen der nach $\$ 58 \mathrm{c}$ der Staatsbürgerschaftgesetznovelle 1993 Wiedereingebürgerten kontinuierlich ab. Im Jahr 2002 betraf diese Form des Staatsbürgerschaftserwerbs noch 42 Personen, im Jahr 2010 nur mehr zehn Personen. Quelle: Statistik Austria: Einbürgerungen 1994 bis 2010 nach $\$ 58$ c. 
Erfolg und ein Zeichen dafür, dass zumindest bei einem Teil der Vertriebenen über die inzwischen geleisteten materiellen Hilfen hinaus auch tatsächlich ein Bedürfnis nach Wiederherstellung ihrer Staatsbürgerschaft, auch nach so vielen Jahrzehnten, bestand.

Allerdings führte nicht in allen Fällen die Abgabe einer »einfachen Erklärung«, wie es der Gesetzgeber vorgesehen hatte, auch unmittelbar zum Wiedererwerb der österreichischen Staatsbürgerschaft. Manche Verfahren zogen sich jahrelang hin und offenbaren in all ihrer Komplexität Tiefenstrukturen der österreichischen Geschichte, die weit über die Zeit des Nationalsozialismus und der Ersten Republik hinausreichen. Einer dieser Fälle, der nicht nur die Tragödie einer ganzen Familie unter nationalsozialistischer Herrschaft, sondern darüber hinaus die schicksalhaften Folgen von Staatenlosigkeit unter zunächst altösterreichischem, dann nationalsozialistischem Vorzeichen in exemplarischer Weise enthüllt, soll hier rekonstruiert werden.

\section{Der Fall Raviv ${ }^{626}$}

Als Martha Raviv am ıo. Oktober 1995 in der österreichischen Botschaft in Tel Aviv ein dort aufliegendes Formular der Wiener Landesregierung unterschrieb, mit dem sie anzeigte,

»dass ich mich als österreichische/r Staatsbürger/in vor dem 9. Mai 1945 (und zwar im Jahre ...) ins Ausland (nach ...) begeben habe, weil ich Verfolgungen durch Organe der NSDAP oder der Behörden des Dritten Reiches mit Grund zu befürchten hatte/erlitten hatte bzw. weil ich wegen meines Eintretens für die demokratische Republik Österreichs Verfolgungen ausgesetzt war oder solche zu befürchten hatte ${ }^{627}$,

wobei sie in die erste Klammer das Datum ihrer Deportation, "August I943«, und in die zweite Klammer - nach einiger Irritation über die Formulierung »ins Ausland

626 Die Rekonstruktion des Falls Raviv basiert zum einen auf der 2001 im Rahmen der Untersuchungen der Österreichischen Historikerkommission ermöglichten Einsichtnahme in den in der Magistratsabteilung 61 der Wiener Landesregierung aufliegenden Einbürgerungsakt, MA 61 IV - R 361/95, R 29/99 F (eine erste Fallstudie wurde publiziert in Burger/Wendelin, Staatsbürgerschaft und Vertreibung, S. 408ff), zum anderen auf Gesprächen, die ich mit Martha Raviv und ihrer Schwester Niza (Cwetka) Falkenflik zwischen dem 5. und 11. Juli 2005 in Petah Tikva, Israel, führen durfte. Für ihre Gastfreundschaft sowie für die Möglichkeit, ihre private Dokumentensammlung einsehen zu dürfen, danke ich Martha Raviv. Beiden Schwestern danke ich für ihr Vertrauen und ihre Geduld bei der Beantwortung schwieriger und schmerzhafter Fragen.

627 Formular der Wiener Landesregierung, im Einbürgerungsakt Martha Raviv, MA 61 IV - R 361/95, R 29/99F. 
begeben « - »eingesperrt und verschickt« eingesetzt hatte, war die rechtskundige, gut über die neue Gesetzeslage informierte Anwältin und Notarin davon überzeugt, mit ihrer Anzeige ihre - vermeintlich verlorene - österreichische Staatsbürgerschaft wiedererlangt zu haben. Doch die Enttäuschung folgte auf dem Fuß. Am 2. Februar I 996 wurde Martha Raviv von der Österreichischen Botschaft in Tel Aviv im Auftrag der Wiener Landesregierung darüber informiert, dass ihre Anzeige nicht zum Wiedererwerb der österreichischen Staatsbürgerschaft geführt habe. Sie sei - gemäß den in Wien vorhandenen Unterlagen - nach ihrem Vater »in Polen heimatberechtigt « und habe sich somit nicht als österreichische Staatsbürgerin ins Ausland begeben - eine für Martha Raviv schockierende und zutiefst irritierende Mitteilung, war sie doch in dem Bewusstsein aufgewachsen, einer österreichischen Familie zu entstammen, von einer "polnischen Abstammung " war ihr nichts bekannt. Damit war Martha Raviv nicht allein. Nur 85 Prozent der aus Österreich vertriebenen Juden besaßen bei ihrer Flucht die österreichische Staatsbürgerschaft, der Rest, also immerhin Is Prozent, war entweder staatenlos oder besaß die polnische oder eine andere Staatsbürgerschaft. ${ }^{628}$ Hintergrund dieses wenig und oft nicht einmal den Kindern der Betroffenen bekannten Phänomens, war in vielen Fällen das sogenannte Optionsrecht, das, entsprechend Artikel 8o des Staatsvertrags von St-Germain vom ıo. September I9I9, grundsätzlich allen Bürgern der zerfallenen Monarchie ermöglichen sollte, für einen der Nachfolgestaaten zu optieren. Optionen von aus Galizien oder der Bukowina stammenden Juden allerdings wurden, wie oben beschrieben, seitens der Ersten österreichischen Republik, auch wenn sich die Optanten im Besitz eines Heimatscheins einer dortigen Gemeinde befanden, in den meisten Fällen nicht anerkannt, was zur Folge hatte, dass sie und ihre Familien staatenlos wurden und fortan in Österreich als »Fremde« lebten.

Auch Martha Raviv, die am 20. Januar 1936 in Wien als Tochter des Leon Juda Leib Falkenflik und seiner Frau Gena, geb. Sternberg, geboren worden war, ist ein solcher »Fall«. Beide Eltern stammten aus Galizien. Die 1902 in Sniatyn (heute Ukraine) geborene Gena Sternberg wuchs in einer wohlhabenden, sich der deutschen Kultur tief verbunden fühlenden Familie auf. Sie hatte ausschließlich deutschsprachige Schulen besucht, zunächst die Volksschule in Stanislau/Stanisławów/Stanyslav, später die "Alina«, eine Handelsschule in Wien. Der Vater, Leon Falkenflik, war I $897 \mathrm{im}$ nahe der russischen Grenze gelegenen Tłuste geboren worden. Wie auch der Großvater mütterlicherseits, Simon Sternberg, war er Teilnehmer des Ersten Weltkrieges gewesen. I9I7 wurde er verwundet und ausgezeichnet. Nach Abschluss seines Chemiestudiums heiratete er 1926 Gena Sternberg. Bald darauf ließ sich das Paar in Wien nieder. Als Chemiker und Kaufmann betrieb Leon Falkenflik eine

628 Vgl. Burger/Wendelin, Staatsbürgerschaft und Vertreibung, Diagramm 14, S. 435. 


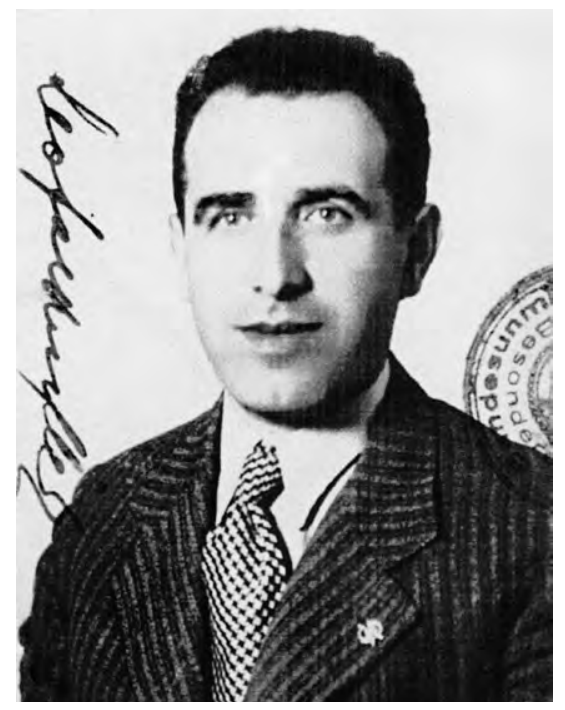

Abb. 17: Leon Falkenfik, September 1939; Quelle: Privatarchiv Martha Raviv

kleine Fabrik für Nahrungsmittelerzeugung im dritten Wiener Gemeindebezirk. Mit drei Angestellten erzeugte er nach eigenen Rezepturen Pflanzenfette, Suppenwürfel, Backpulver und Brauselimonade. Drei eingetragene Handelsmarken, darunter das Backpulver "Vindobona«, führten zu steigendem Wohlstand der kleinen Familie. I93 I übersiedelten die Falkenfliks mit ihrer damals vierjährigen Tochter Cwetka in die Pfefferhofgasse nahe der Wiener Urania. 1936 wurde eine zweite Tochter, Martha, geboren. Cwetka, die ältere der Schwestern erinnert sich an ein Kinderzimmer mit weißen Schleiflackmöbeln, an den großen grünen Kachelofen, an sonntägliche Ausflüge auf den Kahlenberg, an ihre Volksschule, in der sie das Lied vom lieben Augustin lernte, an Abenteuer auf dem Eislaufplatz, an Klavierstunden und Unterricht in "rhythmischen Ballett", kurz: an eine behütete Kindheit in einer liebevollen Familie in großzügigen, bürgerlichen Lebensverhältnissen. Nur durch ihre Religion unterschied sich ihr Leben von dem der anderen: Man hielt die jüdischen Feiertage, lebte koscher, der Vater besuchte die Synagoge, die Mutter betete mit den Kindern.

Den "Anschluss« im März I 938 erlebten die Schwestern noch nicht als einschneidendes Ereignis. Als staatenlose Juden - ein Status, der den Kindern jedoch nicht bewusst war - waren die Falkenfliks, wie auch alle ausländischen Juden, zunächst nicht von den "Arisierungen « betroffen. Cwetka erinnert sich nur, dass sie eine andere jüdische Familie, die ihre Wohnung bereits verloren hatte, bei sich aufnehmen mussten. Eine Weile noch besuchte sie das Gymnasium in der Novarragasse. Die Erzeugnisse der väterlichen Fabrik wurden über einen "arischen« Partner vertrieben. Sorgfältig bemühten sich die Eltern, ihre Kinder vor den täglichen Übergriffen und Grausamkeiten, die der Alltag für die Juden seit dem »Anschluss« bereithielt, zu schützen. Dass 
der Vater längst die Flucht der Familie vorbereitete, verzweifelt Möglichkeiten einer Emigration erkundete, war den Kindern nicht bewusst. Martha, damals zwei Jahre alt, erinnert sich daran, gern auf der Küchenbank am offenen Fenster gesessen und der Musik aus dem gegenüber gelegenen Restaurant gelauscht zu haben. Noch eine Zeit lang gab es für die Schwestern so etwas wie »Normalität« im Alltag.

Das änderte sich abrupt, als am I I. September I939 - also unmittelbar nach dem Überfall des Deutschen Reiches auf Polen - der Vater im Zuge einer von Reinhard Heydrich, damals Chef der Sicherheitspolizei und des Sicherheitsdienstes (SD), befohlenen reichsweiten Aktion gegen die staatenlosen Juden ${ }^{629}$, zusammen mit etwa tausend weiteren "polnischen Juden«, d. h. zumeist aus Galizien stammenden in Österreich ansässigen Juden ohne Staatsbürgerschaft oder mit ehemals polnischer Staatsbürgerschaft, in einer äußerst brutalen Polizeiaktion verhaftet und - nach einer Odyssee durch die überfüllten Wiener Gefängnisse - für etwa drei Wochen im Wiener Praterstadion interniert wurde. Dabei wurde Leon Falkenflik, zusammen mit 440 weiteren ausgewählten Gefangenen, zum Objekt einer großangelegten rassenbiologisch-anthropologischen Untersuchung. ${ }^{630}$ Die Gefangenen wurden fotografiert und vermessen, ihre biographischen und biometrischen Daten erhoben, es wurden Haarproben gesammelt, von den Gesichtern einiger Gefangener Gipsmasken genommen. Sinn dieser Aktion war es, Material über "polnische Juden« zu sammeln, um so anthropologische Aufschlüsse zum vom Nationalsozialismus postulierten Typus des »Ostjuden« zu gewinnen. Das Naturhistorische Museum hatte sich bereits im Mai 1939 mit einer großen Sonderausstellung über "Das körperliche und seelische Erscheinungsbild der Juden« zu einem zentralen ideologischen Thema des Nationalsozialismus hervorgetan. Dr. Joseph Wastl, der Kurator dieser Schau, ergriff die Gelegenheit, weiteres "schönes Material über polnische Juden« zu sammeln. ${ }^{631}$ Man arbeitete unter großem Zeitdruck. Schon bald sollte das Stadion wieder zu Sportzwecken genutzt werden. In weniger als einer Woche waren über 7 I 5 Fotos inventarisiert ${ }^{632}$, Zehntausende von Einzeldaten in Messblätter eingetragen, siebzehn Gipsmasken angefertigt worden. ${ }^{633}$ Der damals I 7-jährige Gershon Evan beschreibt

$629 \mathrm{Zu}$ den Hintergründen der Aktion vgl.: Yfaat Weiss: Deutsche und polnische Juden vor dem Holocaust. Jüdische Identität zwischen Staatsbürerschaft und Ethnizität 1933-1940 (München 2000), S. $194 \mathrm{ff}$ und S. 212.

630 Als einer der wenigen Überlebenden der Aktion berichtet Gershom Evan über die Wochen im Prater. Gershom Evan: Winds of Life. The Destinies of a Young Viennese Jew 1938-1958 (Riverside, Calif. 2000), S. 94.

631 Zur Karriere Joseph Wastls im "Dritten Reich" siehe auch: Ernst Klee: Deutsche Mediziner im Dritten Reich. Karrieren vor und nach 1945 (Frankfurt/Main, 2. Auflage 2001), S. 138.

632 Siehe: Volkhard Knigge/Jürgen Seifert (Hg.). Katalog zur Ausstellung: Vom Antlitz zur Maske. Weimar - Buchenwald 1939 (Weimar 1999), Eintrag unter Buchstabe F.

633 Claudia Spring: Vermessen, deklassiert und deportiert. Dokumentation zur anthropologischen 
die entwürdigende Prozedur genau. Wehgetan habe sie nicht, er hätte nur zu gern gewusst, so Evan sarkastisch, inwiefern er den Annahmen der Anthropologen entsprochen habe. ${ }^{634} \mathrm{Zu}$ einer "wissenschaftlichen « Auswertung des Experiments sollte es jedoch nie kommen. ${ }^{635}$

Als die Kommission ihre Arbeit am 30. September 1939 beendet hatte, waren die Vorbereitungen zur Räumung des Praters bereits getroffen worden. Leon Falkenflik wurde gemeinsam mit über tausend Mitgefangenen nach Buchenwald deportiert. Da die Baracken des vornehmlich politischen Häftlingen vorbehaltenen Konzentrationslagers bereits völlig überfüllt waren, wurden die Ankommenden in einem eilig errichteten Sonderlager, dem »Polenlager» (auch »kleines Lager" genannt), untergebracht. Von diesem »kleinen Lager « berichtet ein anderer Buchenwald-Überlebender, der Résistance-Kämpfer und Historiker Felix Kreissler, dass die Chancen, in diesem zu überleben, gering gewesen seien. ${ }^{636}$ Tatsächlich starben aufgrund der katastrophalen hygienischen Zustände im Lager sowie an den Folgen brutaler Zwangsarbeit im Steinbruch 3 I 8 der 440 anthropologisch untersuchten Männer bereits während der ersten Wochen nach der Deportation. ${ }^{637}$ Als Anfang Jänner I 940 eine Ruhrepidemie ausbrach, wurde aus Angst vor dem Übergreifen der Seuche auf die Stadt Weimar das Sonderlager aufgelöst. Für einige wenige Glückliche, darunter Gershon Evan, endete ihre KZ-Haft mit der Entlassung, die anderen Überlebenden, darunter Leon Falkenflik, wurden in das Hauptlager transferiert. Im Februar 1942 erhielt

Untersuchung an 440 Juden im Wiener Stadion im September 1939 unter der Leitung von Josef Wastl vom Naturhistorischen Museum Wien, in: Zeitgeschichte, 32. Jg., Heft 2 (März/April 2005), S. 91-110.

634 Evan: Winds of Life, S. 54.

635 Das gesamte Material fand sich im Zuge einer im Jahr 1998 ministeriell angeordneten Untersuchung wohlverwahrt in einer Kiste im Naturhistorischen Museum in Wien. Zwei engagierte junge Anthropologinnen nahmen sich schließlich der Bestände an und versuchten in einer kritischen Reflexion des eigenen Faches nicht nur eine wissenschaftstheoretische Einordnung der Experimente zu geben, sondern auch - sofern dies noch möglich war - durch Einbindung und Benachrichtigung der wenigen Überlebenden, bzw. deren Nachkommen, die während des Nationalsozialismus stattgehabte "Reduktion der Menschen zum Forschungsmaterial« aufzubrechen, die Person dahinter sichtbar zu machen und ihre Würde wiederherzustellen. Vgl. Margit Berner: "Judentypologisierungen « in der Anthropologie am Beispiel der Bestände des Naturhistorischen Museums, Wien, in: Zeitgeschichte, 32. Jg., Heft 2 (März/April 2005), S. 111-116. Im Jahr 1999 waren Teile des anthropologischen Materials im Rahmen einer vom israelischen Künstler Dani Karavan konzipierten Ausstellung "Vom Antlitz zur Maske« im Weimarer Schiller-Museum zu sehen. Katalog zur Ausstellung (Weimar 1999). Ich danke Claudia Spring für ihren Hinweis auf Leon Falkenflik als Opfer der Aktion gegen die staatenlosen Juden im Wiener Praterstadion.

636 Felix Kleissler: Un temoin principal de la barbarie du XXème siècle, in: Christine Lecerf/Hannelore Burger (Hg.): Corps blessés. Peines intimes autrichiennes, France/Autriche 14 (1991), S. 6390, hier: S. 68.

637 Vgl. Spring, Vermessen, S. 99. 


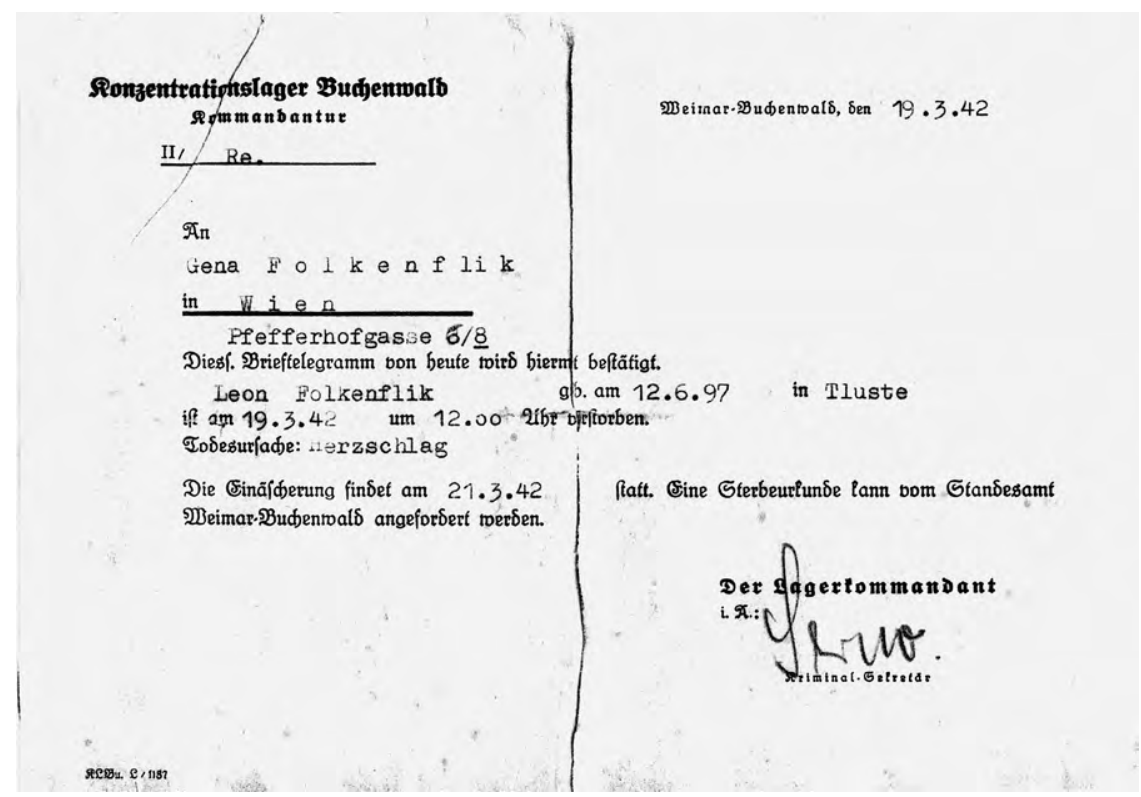

Abb. I8: Bescheinigung der Kommandantur des Konzentrationslagers Buchenwald über den Tod des Leon Falkenflik; Quelle: Privatarchiv Martha Raviv

seine Frau Gena den einzigen und letzten Brief ihres Mannes aus Buchenwald. Seine ganze Sorge galt darin der Gesundheit und dem Wohlergehen seiner Familie. Und noch immer klang Hoffnung aus den Zeilen, Hoffnung auf ein Überleben, auf ein Wiedersehen in Freiheit, auf eine "Übersiedlung« ins Ausland gar. Doch Leon Falkenflik wurde ein weiteres Mal selektiert. Im März I 942 wurden im Rahmen des Euthanasieprogramms der Nationalsozialisten dreißig der noch lebenden Männer aus der Gruppe jener, die einst im Praterstadion der anthropologischen Rassenforschung unterzogen worden waren, von sogenannten $\mathrm{T}_{4}$-Gutachtern selektiert und in verschiedene Euthanasieanstalten des Reiches eingewiesen. ${ }^{638}$ Leon Falkenflik starb am I9. März I942 in der Tötungsanstalt Bernburg/Saale. Seine Frau erhielt noch am selben Tag ein Brieftelegramm, ausgestellt von der Kommandantur des Konzentrationslagers Buchenwald, worin ihr mitgeteilt wurde, dass ihr Mann um I 2.00 Uhr verstorben sei. Die Todesursache sei »Herzschlag«. Die Einäscherung werde am 2 I. März I942 in Buchenwald stattfinden. Eine Sterbeurkunde könne sie anfordern. ${ }^{639}$

638 Ebenda, S. 100.

639 Dokumentensammlung Martha Raviv. 
Im Mai erhielt Gena Falkenflik die Asche ihres Mannes. Die Urne wurde im jüdischen Teil des Zentralfriedhofs beigesetzt.

Im November I939, kurz nach der Verhaftung und Deportation ihres Mannes, schickte Gena Falkenflik, die verzweifelt, doch vergeblich um die Freilassung ihres Mannes gekämpft hatte, ihre ältere, gerade zwölfährige Tochter Cwetka nach $\mathrm{Pa}$ lästina, in der Hoffnung, dass eine dort lebende Verwandte sie bei sich aufnehmen werde. Zu jung für die Jugend-Alijah reiste das Kind, versehen mit einer Schiffspassage und einem Palästina-Zertifikat, allein mit dem Zug vom Wiener Südbahnhof nach Triest. In Triest angekommen folgte sie dem Strom der Flüchtlinge und erreichte ein Schiff, das sie nach Haifa brachte. Eine Nacht lang blieb sie, da niemand sie abholte, allein auf dem Schiff. Als sie am nächsten Morgen an Land ging, war der Himmel über Palästina strahlend blau. Am Kai kauft sie eine Orange und traf dabei einen ehemaligen Lehrer und eine Mitschülerin, die ihr weiterhalfen. Die erste Zeit verbrachte sie in einer Unterkunft für Mädchen der zionistischen Organisation Betha Halozot. Bald ging sie wieder in die Schule. Später machte sie eine Ausbildung zur Krankenschwester (ein Beruf den Niza Falkenflik, wie sie sich später nannte, bis zu ihrer Pensionierung ausüben würde). Das Leben in Palästina war hart, doch es gefiel ihr. Sie wäre fast glücklich gewesen, wäre da nicht die drückende Ungewissheit über das Schicksal ihrer zurückgebliebenen Familie gewesen. Jahrelang erfuhr sie nichts. Erst im Juli I 944 erhielt sie ein Lebenszeichen der Mutter - ein Päckchen aus Frankreich. Es enthielt rote Schuhe und ein Seidentuch. Cwetka fühlte sich verlassener denn je, glaubte sie doch nun, dass Mutter und Schwester im sicheren Ausland und im Luxus leben. Nichts konnte unrichtiger sein.

Tatsächlich blieb Gena Falkenflik mit ihrer jüngeren Tochter Martha noch Jahre nach der Flucht Cwetkas in Wien. Anfänglich hatte sie wohl gehofft, dass ihr Mann bald aus der Haft entlassen werden würde. Martha erinnert sich, dass die Mutter den gelben Stern getragen hat und sie sich häufig bei den Behörden melden mussten. Im Herbst I94I, als sich in Wien die Gerüchte um die bevorstehende Deportation der Juden verdichteten, begann für Mutter und Tochter eine Zeit ständigen sich Versteckens. Aus ihrer Wohnung vertrieben, wanderten sie von Platz zu Platz. Einige wenige Menschen halfen der schönen Frau mit ihrer kleinen Tochter. Ein Polizeioffizier im Meldeamt, der eine falsche Bescheinigung ausstellte, eine Schneiderin, die Mutter und Tochter eine Nacht lang im Badezimmer verbarg, eine Nachbarin, die von den Produkten aus der väterlichen Erzeugung noch manches abzustoßen verstand, und jene, die sie über bevorstehende Deportationen informierten. Ihre Mutter habe alles daran gesetzt, so Martha Raviv, »Schlupfwinkel im bürokratischen Wirrwarr zu finden«. Einer dieser "Schlupfwinkel« war der Versuch, sich eine andere Staatsbürgerschaft zuzulegen, hätte doch eine fremde Staatsbürgerschaft unter Umständen lebensrettend sein können, da man Ausländern, auch ausländischen Juden, 
die Ausreise noch immer gestattete. So gelang es Gena Falkenflik, wie sich ihre Tochter erinnert, dank ihres ungewöhnlichen Charmes, ihre Staatsangehörigkeit zu verändern. In der Tat findet sich in einer Meldebestätigung der Bundespolizeidirektion Wien neben dem Namen Leon Falkenflik die Eintragung "Russland « - ein kleiner Sieg im täglichen Kampf ums Überleben. Denn nun stand Gena Falkenflik mit ihrer Tochter Martha unter dem Schutz des königlichen schwedischen Konsulats, das die Interessen der russischen Staatsangehörigen im ehemaligen Österreich wahrte. Tatsächlich gelang es ihr, einen Schutzbrief des Schwedischen Konsuls für sich und ihre Tochter zu erwirken. ${ }^{640}$ Als allerdings einen Monat später die deutschen Truppen die Sowjetunion überfielen, wurden sie damit zu feindlichen Ausländern und der schwedische Schutzbrief schien nur noch ein Stück Papier.

Martha erinnert sich daran, wie sie sich immer wieder vor Personen in SA- oder SS-Uniformen verstecken musste: »Wenn eine Tür aufging, konnte das unser Ende bedeuten. Ich wusste nur, ich darf mich nicht rühren. «Draußen fühlte sie sich freier. Da sie kaum als jüdisches Kind kenntlich war - um den gelben Stern tragen zu müssen, war sie zu jung -, bewegte sie sich viel im Freien, auch an Plätzen, die für Juden verboten waren, oft auf der Suche nach Nahrung. Im Alter von fünf Jahren es geschah in einem düsteren Wiener Stiegenhaus - wurde sie Opfer eines sexuellen Gewaltakts durch einen uniformierten Täter. Im Herbst 1942 wurde sie mit ihrer Mutter verhaftet und zunächst in ein Sammellager in der Malzgasse überführt. Martha erinnert sich an viele behinderte Kinder und daran, gemeinsam mit einem taubstummen Kind in einem Verschlag unter der Treppe gehaust zu haben. Nach drei Wochen wurden sie entlassen. Von jetzt an lebten sie in völlig überfüllten Sammelwohnungen im zweiten Wiener Gemeindebezirk, zunächst in der Große Mohrengasse, ab Februar 1943 in der Zirkusgasse.

Im August I943 - zu einem Zeitpunkt, als die Mehrzahl der Wiener Juden bereits deportiert worden war ${ }^{641}$ - wurden Mutter und Tochter erneut von der Gestapo verhaftet. Martha ergriff einen kleinen grünen Rucksack, den die Mutter für diesen Fall vorbereitet hatte. Er enthielt unter anderem ein Märchenbuch von Hans Christian Andersen und ihren Teddybär. Im Morgengrauen wurden sie in einen überfüllten Polizeiwagen, einen "grünen Heinrich«, gestoßen. Im Gefängnis an der Elisabeth-Promenade, der sogenannten Liesl, verbrachten Mutter und Tochter etwa einen Monat in Gestapo-Haft. Dann begann der Leidensweg der Deportation. Ein-

640 Schutzbrief des Königlich Schwedischen Konsulats vom 13. Juni 1942. Dokumentensammlung Martha Raviv.

641 Ende Oktober 1942 war die Deportation der Wiener Juden fast abgeschlossen. Es befanden sich nur mehr etwa 8300 Juden in der Stadt. Vgl. Jonny Moser: Die Katastrophe der Juden in Österreich 1938-1945, in: Der gelbe Stern in Österreich. Katalog und Einführung zu einer Dokumentation (= Studia Judaica Austrica V) (Eisenstadt 1977), S. $130 \mathrm{f}$. 
gepfercht in Viehwaggons oder auf langen Fußmärschen führte die "Reise« einer Gruppe von etwa zwanzig Personen, die als russische Staatsbürger galten, über Linz, Prag, Chemnitz, Leipzig zunächst nach Halle an der Saale. Ihre Reisebegleiter waren Hunger und Kälte, Schläge und Todesangst. Dazu die größte Angst des Kindes: die Drohung, man würde sie von ihrer Mutter trennen. Erlebten Mutter und Tochter im Polizeigefängnis von Prag bei allem Schrecken der Gefangenschaft noch manche menschliche Geste - eines Tages brachte eine Aufseherin einen Sack mit Obst, Brot und Süßigkeiten, den tschechische politische Gefangene für die Kinder in der Anstalt gesammelt hatten ${ }^{642}$-, so erlebten sie im Gefängnis von Halle eine Hölle an menschlicher Gemeinheit und Grausamkeit. Doch weder Schläge noch andere Übergriffe konnten die Würde und den Lebensmut der Gena Falkenflik brechen. Bei einem stundenlangen Appell in Hildesheim, einer weiteren Station ihrer Reise durch die Polizeigefängnisse, verlangte sie einen Sessel - nicht für sich, sondern für eine alte Frau, die umzufallen drohte - und erwarb sich dadurch die Achtung des Lagerkommandanten, der ihr bei der Weiterreise Medikamente zusteckte - ein begehrtes Tauschmittel, das sich als lebensrettend erweisen sollte, lebensrettend wie der schwedische Schutzbrief. Denn noch immer galten russischen Juden als politische Gefangene, die man eventuell würde austauschen können. Und darum ging die Reise nicht nach Osten - was den sicheren Tod bedeutet hätte -, sondern nach Westen.

Letzte Polizeistationen waren Hannover und Celle. Von dort wurden die Gefangenen eines Tages, im November I943, mit einem Lastwagen weitertransportiert. Wohin, wussten sie nicht. Martha saß vorn beim Fahrer an einem abgedunkelten Fenster. Durch ein kleines Loch der geschwärzten Scheibe blickte sie hinaus und beschrieb ihren Mitgefangenen die schöne herbstliche Landschaft. Dann erblickte sie plötzlich Baracken und Wachtürme, Scheinwerfer, Zäune und Kabel, sah Hunde, die nach Menschen schnappten - Menschen in Häftlingskleidung. Das Kind schwieg darüber, als fürchtete es die Panik der anderen. Sie waren angekommen: in Bergen Belsen. Als sie schließlich unter Schlägen und Schreien zum Appellplatz getrieben wurden, las sie in den Augen der Umstehenden so etwas wie Abschied und Bedauern. Es gab große und kleine Baracken, Baracken für Eltern mit Kindern, Kinder ohne Eltern etc. - die perverse Ordnung der Lager. Martha und ihre Mutter kamen in eine Baracke für polnische Juden. Martha wurde ein Mittelbett in einer dreistöckigen Lagerstatt zugewiesen, ihre Mutter erhielt das Bett darüber. Die Mutter konnte sich auf Polnisch verständigen, das Kind lernte rasch ein paar Brocken. Zum Chanukka-Fest im Dezember sang man polnische Lieder und erzählte den Kindern jüdische Sagen. Jeder Tag begann mit einem stundenlangen Appell, oft bei

642 "Crime and human rights in Pakrac Prison September/October 1943 as seen by a child ", Statement by Martha Raviv in Prag, August 2012. 
klirrender Kälte. Martha erinnert sich an den Hunger. Es gab Kartoffelschalen und ein Stück Brot. Kinder weinten stets nach Brot. Überlebt hat sie, davon ist sie noch heute überzeugt, nur durch das Opfer ihrer Mutter, die selbst unendlich hungerte, um ihr Kind am Leben zu erhalten. Als besonders traumatisches Erlebnis sind Martha Raviv die Desinfektionen in Erinnerung: „Man zog uns durch übermenschlich erhitzten Dampf oder dem Gefrierpunkt nahes Wasser. Ich wollte sterben, um die grauenhafte Hysterie und das Lachen jenseits der Mauer nicht hören zu müssen.« Fromme Juden beteten das Schma Israel (»Höre Israel! Gott unser Herr ist ein einiger, einziger Gott!«).

Ende Februar 1944 wurde die Gruppe der »russischen Juden« wiederum in einen Zug verfrachtet. Niemand wusste, wohin die Reise ging. Unterwegs wurde der Zug bombardiert, sprang aus den Gleisen, stand irgendwo die ganze Nacht. Martha kauerte eingehüllt in ein großes, mit Rosen bedrucktes russisches Tuch am Boden. Im Morgengrauen tauchte eine Rheinbrücke auf: Kehl. Die Räder rollten weiter, gen Westen, Richtung Straßburg, durch die Vogesen nach Vittel. Diesmal handelte es sich um ein Lager für arretierte Staatsbürger feindlicher Länder, überwiegend Briten und Amerikaner, die für den Gefangenenaustausch bestimmt waren. ${ }^{643}$ War Vittel vor dem Krieg vor allem berühmt für sein heilendes Wasser, so wurden seit I 940 in den prachtvollen alten Kurhotels des Städtchens Kriegsgefangene untergebracht, umzäunt von Stacheldraht, bewacht von der SS. Bei den internierten Juden handelte es sich um polnische, belgische und holländische Juden mit lateinamerikanischen Pässen. Gefangenenaustausch fand nur selten statt. Einmal, im März I 944, erhielten sechzig Insassen von Vittel Palästina-Zertifikate. Ausgetauscht wurden sie gegen palästinadeutsche Templer, die seit Jahrhunderten in geschlossenen Siedlungen im Mandatsgebiet lebten. Die Gruppe kam am ıo. Juli I944 in Haifa an. Einer von ihnen führte ein kleines Päckchen mit sich, das an Cwetka Falkenflik adressiert war. Es enthielt die roten Schuhe und das Seidentuch, verblichene "Luxusgüter", die ihre Mutter im Lager gegen jene Medikamente getauscht hatte, die sie einst vom Kommandanten von Hildesheim erhalten hatte.

Danach gingen die Züge nur noch in die Vernichtungslager. Am 29. April I 944 ging wieder ein Zug mit etwa 200 Gefangenen von Vittel ab. Über Drancy führte er direkt nach Auschwitz-Birkenau. Unter den Deportierten befanden sich zahlreiche polnische Rabbiner und Intellektuelle, die vom Warschauer Judenrat zunächst dadurch gerettet worden waren, dass man ihnen lateinamerikanische Pässe vermittelt hatte, darunter der Dichter Jizchak Katzenelson, der in den Besitz eines Passes von Honduras gekommen war. Katzenelson hatte die ganze Zeit im Lager an seinem später berühmt gewordenen Gedicht in jiddischer Sprache »Dos lied vunem ojsge-

643 Encyclopädie des Holocaust, Teil II, Israel Gutmann (Hg.), (Yad Vashem/Jerusalem 1990), S. 404. 
hargetn jidischn volk« geschrieben. Im Jänner I 944 war es fertig geworden. Gerettet wurde es von Freunden, die eine Abschrift mit nach Palästina nahmen. "So war der Anfang. Schrecken gabs vom allerersten Tage an. Der nächste brachte neues Leid, danach kam neue Qual. Und jeden Morgen geht es in der Früh wie irr von vorne los. Erst gestern so, heut so. /.../ ...der Tod ist hier ein Nimmersatt « ${ }^{644}$, heißt es in den ersten Versen des "Großen Gesangs vom ausgerotteten jüdischen Volk«. Jizchak Katzenelson und sein Sohn kamen im Mai 1944 in Auschwitz an. Beide fanden den Tod im Gas.

Martha und ihre Mutter blieben in Vittel. Von zwei englischen Katholikinnen, die eine Schule für die gefangenen Kinder organisierten, erhielt Martha Unterricht in Englisch und Kalligraphie. Beide Frauen wurden nach der Befreiung Nonnen. Im Juni I944, knapp nach dem D-Day, erlebten Mutter und Tochter, wie das Lager Vittel für zwei Tage von einer französischen Widerstandsgruppe befreit wurde. Da sie keinerlei Papiere hatte - die blieben in Bergen Belsen -, entschied sich Gena Falkenflik, im Lager zu bleiben. Tatsächlich kam die SS bereits nach zwei Tagen zurück. Endgültig befreit wurde Vittel am 23. Oktober I 944 von amerikanischen Soldaten.

Doch frei waren Gena und Martha Falkenflik noch lange nicht. Weitere lange Jahre in Lagern sollten folgen. Im Centre de réfugiés étrangers in La Bourboule erhielten sie ihre offizielle Anerkennung als Displaced Persons. Im Spätsommer 1945 wurden sie in ein DP-Lager des Roten Kreuzes nach Lourdes im Departement Hautes Pyrenées überstellt. Hier löste sich die Gruppe der »russischen Juden« allmählich auf. Doch für Gena Falkenflik und ihre Tochter gab es keine Heimat, in die sie zurückkehren konnten, und kein Land, das bereit gewesen wäre, sie aufzunehmen. Martha besuchte als einziges jüdisches Kind die Schule der Dominikanerinnen, wo sie Französisch lernte. Sie erinnert sich an die tiefe Bewunderung, die sie empfand, als sie die berühmte Grotte der Bernadette besuchte. Ende 1947 entschloss sich Gena Falkenflik, nach Israel zu gehen. Das war allein deshalb möglich, weil ihre nun zwanzigjährige Tochter Cwetka, deren staatsbürgerlicher Status in ihren Papieren als undefined angegeben wurde, inzwischen die palästinensische Mandatsbürgerschaft erworben und zugleich eine Bürgschaft für Mutter und Schwester geleistet hatte. Im Dezember I947, als das ersehnte Palästina-Zertifikat endlich eingetroffen war, brachte sie ein Schiff von Marseille nach Haifa.

In Israel begann für Mutter und Tochter mit dem Teudat Alijah ${ }^{645}$ ein neues Leben. Über das alte schwiegen beide. Beide waren außerstande, über ihre Erlebnisse

644 Jizchak Katzenelson: Dos lied vunem ojsgehargetn jidischn Volk (Großer Gesang vom ausgerotteten jüdischen Volk), übersetzt, herausgegeben und eingeleitet von Wolf Biermann (Köln 1994), S. 107.

645 Zertifikat über die Migration nach Israel. 
Abb. I9: Gena Falkenflik mit ihrer Tochter Martha in Israel 1948; Quelle: Privatarchiv Martha Raviv

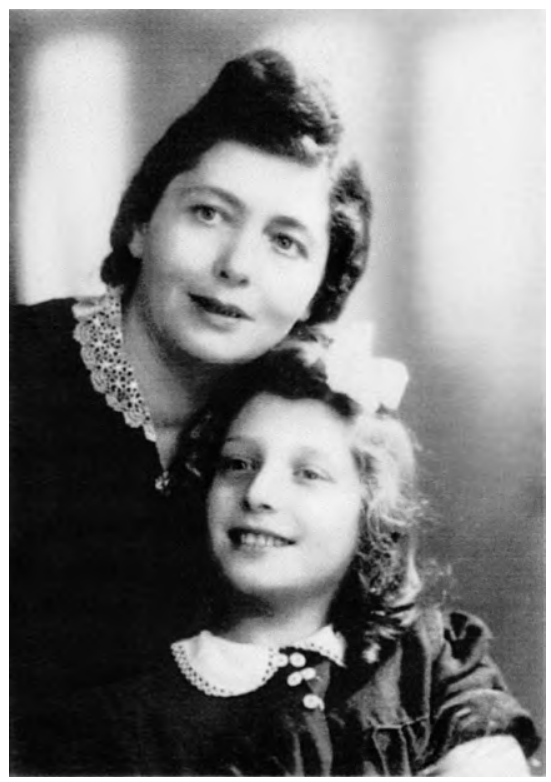

zu sprechen. I948 wurde der Staat Israel gegründet. In der Folge wurden sie israelische Staatsbürgerinnen. Martha ging zur Armee, arbeitete später als Lehrerin, studierte nebenbei Jus, wurde schließlich Anwältin. I957 heiratete sie den aus Kiew stammenden Wasserbauingenieur Chaim Raviv. Sie bekam drei Kinder, führte ein erfülltes Leben. Als I985 ihre Mutter infolge eines Diabetes schwer erkrankte, kam es zur Krise. Gena Falkenflik kehrte mental zurück in die Jahre der Verfolgung. Im Zimmer mit ihr aber war noch eine Gerettete, mit der sie alle Einzelheiten der Flucht und der nächsten Brotbeschaffung plante - ihre Tochter. »Ich wich nicht von ihrer Seite«, erinnert sich Martha, »durchlebte von neuem jede Phase der Schmach und der Verfolgung."

Nach dem Tod der Mutter begann Martha Raviv, gegenüber ihr Nahestehenden zum ersten Mal über die Zeit der Verfolgung zu sprechen. Später gelang es ihr, sich auch einem weiteren Kreis zu offenbaren. Doch es war kein heilsames Sprechen. Krankheiten stellten sich ein: Schlaflosigkeit, Konzentrationsschwierigkeiten, Migräne, immer wieder Bewusstlosigkeit - ein Herzfehler kam hinzu (ein Krankheitsbild, wie es sich nicht selten in den Biografien von Überlebenden der Shoah findet). Seit Oktober 1989 wird ihr seitens der israelischen Behörden eine Teilinvalidität als Folge der nationalsozialistischen Verfolgung anerkannt. Weder ihre Mutter noch sie selbst haben je irgendeine Entschädigung erhalten. Nur ihre Schwester Cwetka (Niza) Falkenflik erhält, da sie bei ihrer Flucht schon zwölf Jahre alt war, eine kleine Pension aus Österreich. 
Nach der für sie so überraschenden Ablehnung ihres Antrages durch die österreichischen Behörden bemühte sich Martha Raviv, weitere Beweismittel für ihre österreichische Staatsbürgerschaft vorzulegen. Doch alle ihre Belege und Argumente unter anderem eine Bescheinigung der deutschen Wiedergutmachungsbehörde, nach der der Vater "als Österreicher durch die Vereinigung Österreichs mit dem Deutschen Reich die deutsche Staatsangehörigkeit erworben hatte - erwiesen sich als ungeeignet. Das österreichische Staatsbürgerschaftsrecht stellt ausschließlich auf die "Abstammung" (ius sanguinis) ab. Für die österreichischen Behörden zählte deshalb einzig die Meldebestätigung (Auszug aus der »Heimatrolle») des Vaters, und diese bewies allein ein Heimatrecht in Tłuste, im Bezirk Zaleszczki (Polen) - eine Stadt, von der Martha Raviv noch nie in ihrem Leben gehört und die ihr Vater schon in früher Jugend verlassen hatte. Ein zehnjähriger Aufenthalt des Vaters in Wien vor I938 - der ersatzweise zur Inanspruchnahme bestimmter Leistungen aus dem Titel der Opferfürsorge führen hätte können - war auch nicht nachweisbar, da die Meldebestätigung das Jahr I93 I als erstes Aufenthaltsjahr in Wien auswies, und so kam es neuerlich zu einer Abweisung ihres Antrags. ${ }^{646}$ Doch Martha Raviv gab nicht auf. In ihrem Einspruch argumentierte die Anwältin schließlich mit dem Naturrecht. Und sie machte die Behörde auf die Möglichkeit von Ausnahmen aufmerksam. Sie, die als Minderjährige bis Herbst I943 - als Wien bereits »judenrein" gewesen war - hier unter unmenschlichen Bedingungen gelebt habe, sei ein solcher Fall. ${ }^{647}$ Doch eine Ausnahme wurde nicht gewährt.

Die dritte Abweisung ihres Ansuchens erfolgte im November I 997 durch die Wiener Landesregierung. Zwar unterliege es keinem Zweifel, wurde bedauernd mitgeteilt, dass sie dem Kreis jener Menschen angehöre, »die in der Zeit des Nationalsozialismus schwere Verfolgung erlitten« hätten, da sie jedoch Österreich im Jahr I943 nicht als Staatsbürgerin verlassen habe, läge eine der Voraussetzungen für einen Wiedererwerb durch Anzeige gemäß $\$ 58 \mathrm{c}$ des Staatsbürgerschaftsgesetzes hinsichtlich ihrer Person nicht vor. Ein anderer Erwerb der Staatsbürgerschaft komme nur auf dem »Verleihungsweg" in Betracht, und dieser setze einen zehnjährigen kontinuierlichen Hauptwohnsitz im Gebiet der Republik Österreich voraus. ${ }^{648}$ Martha Raviv - als Anwältin mit schwierigen und langwierigen Verfahren vertraut - war tief enttäuscht. Sie hatte den Aussagen Bundeskanzler Franz Vranitzkys anlässlich seines Staatsbesuchs I993, mit der Rückgabe der Staatsbürgerschaft eine Geste der

646 Schreiben des Amts der Wiener Landesregierung, MA 61 IV - R 361/95 F vom 12. Juni 1996, im Akt.

647 Schreiben M.R. an Botschaftssekretär Dr. Ulf Hausbrandt, beim Wiener Magistrat eingelangt am 26. November 1996, im Akt.

648 Schreiben des Amts der Wiener Landesregierung, MA 61 IV - R 361/95 F vom 3. November 1997, im Akt, meine Hervorhebung. 
Anerkennung gegenüber den Opfern setzen zu wollen, vertraut. Nach wie vor sieht sie Österreich als Heimat an, ist Österreich Teil ihrer Identität.

Bewegung in ihren Fall kam erst wieder ein Jahr später. Inzwischen war das österreichische Staatsbürgerschaftsgesetz neuerlich novelliert worden. Entsprechend $₫$ Io der Novelle sollte nun "Altösterreichern", die bei ihrer Flucht aus Österreich nicht im Besitz der österreichischen Bundesbürgerschaft gewesen waren, die Möglichkeit gegeben werden, die österreichische Staatsbürgerschaft zu erwerben. Unmittelbar nach Inkrafttreten der Novelle am I. Januar I 999 stellte Martha Raviv neuerlich ein Ansuchen um Erhalt der österreichischen Staatsbürgerschaft. In ihrem Begleitschreiben an den österreichischen Botschafter in Israel schrieb sie, dass sie bei einer Feier im November 1998 aus Anlass des Gedenkens an die "Kristallnacht (die Pogromnacht des 9. November I938) »mit zitternden Knien, erregt und gerührt« neben der Kerze im Ohel yizkor, der Gedenkstätte Yad Vashem, gestanden habe. Die Kranzniederlegung (durch den damaligen Botschafter Wolfgang Paul) sei für sie Symbol und Zeichen gewesen, dass es einen neuen österreichischen Staat gebe, der sich von jenem Österreich, das geschwiegen und seine Involviertheit in den Holocaust geleugnet habe, unterscheide. ${ }^{649}$

Doch auch dieses Verfahren gestaltete sich schwierig. Sie reiste nach Wien und legte im persönlichen Gespräch mit dem zuständigen Beamten neue Beweismittel vor $^{650}$, darunter ein Journalblatt des k. u. k. Kriegsspitals in Wien Grinzing, aus dem hervorging, dass ihr Vater dort im Dezember I9I7 acht Tage in Behandlung war, was seinen Status als "Altösterreicher « (im Sinne des neuen Gesetzes) beweise. ${ }^{651} \mathrm{Da}$ jedoch die Einbürgerung nach der Staatsbürgerschaftsgesetznovelle von I 998 Ermessenssache ist und somit kein Rechtsanspruch besteht, war es notwendig, die Stellungnahme des Innenministeriums einzuholen. In diesem herrschte jedoch - wie der Landesbehörde aus anderen Verfahren bekannt war - die Rechtsmeinung vor, dass Polen nicht zu den Nachfolgestaaten der ehemaligen österreichisch-ungarischen Monarchie zu zählen sei. ${ }^{652}$ Die Wiener Landesregierung, die die Brisanz dieser Rechtsauslegung durchaus erkannte - war sie doch vor allem mit Anträgen von jüdischen Vertriebenen, die aus dem ehemaligen Galizien (Polen) oder der Bukowina (nach

649 Neuerliches Ansuchen um Erhalt der österreichischen Staatsbürgerschaft durch Martha Raviv an die Österreichische Botschaft in Tel Aviv, in Übersetzung eingelangt in der Wiener Landesregierung am 19. Januar 1999, im Akt.

650 Niederschrift über die Amtshandlung vom 9.2.1999, im Akt.

651 »Vormerkblatt des k. u.k. Kriegsspitals, Wien XIX, Grinzing, betr. Leon Falkenflik« (Falkenflück geschrieben) vom 11.12.1917, im Akt.

652 Schreiben des Bundesministeriums für Inneres an das Amt der Wiener Landesregierung, MA $61 \mathrm{Zl}$. 66 020/20-III/12/99 v. 14. Januar 1999, in dem mitgeteilt wurde, dass in dieser Frage eine weitere gutachterliche Stellungnahme des Instituts für Zeitgeschichte der Universität Wien angefordert wurde. 
I 9 I 8 Rumänien, heute Ukraine) stammten (bzw. mit Anträgen von deren Nachkommen), konfrontiert -, fügte deshalb dem Staatsbürgerschaftsansuchen Martha Ravivs vorsorglich ein vom Institut für Zeitgeschichte der Universität Wien erstelltes Gutachten bei, in dem konstatiert wurde, dass Polen sehr wohl als Nachfolgestaat der österreichisch-ungarischen Monarchie anzusehen sei. ${ }^{653}$

Nachdem schließlich alle weiteren Erfordernisse einer Ermessenseinbürgerung erfüllt waren (das polizeiliche Führungszeugnis und der Einkommensnachweis erbracht sowie die Gebühren für die Einbürgerung bei der Amtskasse der österreichischen Botschaft eingezahlt), fertigte die Wiener Landesregierung am I4. Juli 1999 den »Bescheid über die Verleihung der Staatsbürgerschaft« aus. Das Gelöbnis, der Republik Österreich »als getreue Staatsbürgerin« angehören zu wollen, legte Martha Raviv im August 1999 in der österreichischen Botschaft in Tel Aviv ab.

653 Gutachten des Instituts für Zeitgeschichte der Universität Wien, Dr. Gustav Spann, vom 7.6.1999, im Akt. 


\section{Staatenlosigkeit als Massenschicksal}

Staatenlosigkeit war im 20. Jahrhundert ein Massenschicksal - Folge von Flucht, Vertreibung, Exil. ${ }^{654}$ Waren es Anfang des Jahrhunderts vor allem Armenier und russische Revolutionsflüchtlinge, die - als vom Völkerbund anerkannte und als Inhaber von Nansen-Pässen - so etwas wie die »Aristokratie unter den Staatenlosen « gebildet hatten, so waren es nach dem Ersten Weltkrieg vor allem jene, die durch den Untergang der österreichisch-ungarischen Monarchie wie auch des Osmanischen Reiches ihre Staatsbürgerschaft verloren hatten, darunter sehr viele Juden.

Der Prozess der Nationalstaatsbildung nach dem Zerfall der multinationalen Reiche schuf zusammen mit den Pariser Vorortverträgen von I919/20 ein Millionenheer von Heimatlosen, deren Nationalität bis zur Annahme einer neuen Staatsbürgerschaft (durch Option) völkerrechtlich als indéterminée galt. In den Dreißigerjahren vermehrten zuerst die Flüchtlinge des spanischen Bürgerkriegs die Zahl der Staatenlosen, und in der nationalsozialistischen Epoche waren es wieder vor allem Juden, die ihrer Staatsbürgerschaft in einem überaus komplexen, in mehreren Schüben vonstatten gehenden Prozess beraubt werden. Bereits 1939 waren annähernd 50 Prozent aller im Reichsgebiet lebenden Juden ohne Staatsbürgerschaft. ${ }^{65}$ Bei ihrer Ermordung waren fast alle (ehemals deutschen und österreichischen) Juden staatenlos. Erstmals im Jahr I954 gab es eine UN-Konvention zum Status staatenloser Personen; 196r folgte eine zweite Konvention zur Verminderung von Staatenlosigkeit. ${ }^{656}$ Als man 20 I I das fünfzigjährige Bestehen dieser Übereinkunft feierlich beging, belief sich, dem Hohen Flüchtlingskommissar der Vereinten Nationen zufolge, die Zahl der Staatenlosen allein in Europa noch immer auf etwa 590000 Personen weltweit sind es geschätzte I 2 Millionen Menschen. ${ }^{657}$

Die beiden nachstehenden Fallgeschichten stehen exemplarisch für die vielschichtigen Dimensionen und Probleme der Staatenlosigkeit. Die Betroffenen waren nie (Elias Canetti) bzw. nur wenige Jahre (Manès Sperber) österreichische Staatsbürger. In beiden Fällen resultierte ihre jahrzehntelange Staatenlosigkeit aus dem Untergang

654 Siehe dazu die grundlegende Studie: Gerald Daniel Cohen: In War's Wake: Europe’s Displaced Persons in the Postwar Order (Oxford 2011).

655 Martin Tarrab-Maslaton: Rechtliche Strukturen der Diskriminierung der Juden im Dritten Reich

(Berlin 1993), S. 55.

656 Abgedruckt in: Goldemund/Ringhofer/Theurer, Staatsbürgerschaftsrecht, S. 242f.

657 http://europa-redaktion.blogspot.com/2011/08. 
eines übernationalen Vielvölkerreiches: des Osmanischen Reiches im Falle Canetti, der österreichisch-ungarischen Monarchie im Falle Sperber. Beide hatten jahrzehntelang in Österreich gelebt und waren durch viele Schicksalsfäden mit diesem Staat verbunden. Und beide Fälle verdeutlichen, in welch hohem Maße die Probleme des Staatsbürgerschaftsrechtes und der Staatenlosigkeit in den Biographien von Menschen relevant werden können.

\section{Der Fall Elias Canetti 658}

Über Elias Canettis Staatsbürgerschaft sagt uns sein Biograph Sven Hanuschek: erst türkisch, dann staatenlos, dann britisch, »eigentlich aber Kosmopolit«. ${ }^{659}$ Geboren wurde Elias Canetti am 25. Juli 1905 in Rustschuk/Russe, einer Stadt im heutigen Bulgarien. Zur Zeit seiner Entstehung war Bulgarien, nach dem Willen des Berliner Kongresses, ein autonomes, dem Sultan gegenüber tributpflichtiges Fürstentum Teil des Osmanischen Reiches. I908 wurde es ein unabhängiges Königreich. Nach damaligem Selbstverständnis lag es außerhalb Europas. "Wenn jemand die Donau hinauf nach Wien fuhr«, erzählt Canetti, »sagte man, er fährt nach Europa, Europa begann dort, wo das türkische Reich einmal geendet hatte«. ${ }^{660}$

Wie die meisten Sepharden (Nachfahren der Ende des I 5 . Jahrhunderts aus Spanien vertriebenen Juden) waren die Canettis auch nach der Unabhängigkeit Bulgariens Untertanen des Sultans geblieben. Das hatte gute Gründe. Über I 50000 Juden waren einst aus Sepharad (so der hebräische Name für Spanien) geflohen, siedelten sich in Italien, Portugal und allen Mittelmeerstaaten an, zogen ihre Flucht-Spur entlang der nordafrikanischen Küste bis in das Osmanische Reich. Dort waren sie von Sultan Bayazid II. freundlich aufgenommen worden, der über die Dummheit der spanischen Könige nur spotten konnte, hatten diese doch, wie er meinte, ihre eigenen Länder beraubt und die seinen bereichert. ${ }^{661}$

Canettis Großvater Elias und dessen Brüder Abraham und Moisse waren in den 6oer-Jahren des I9. Jahrhunderts von Adrianopel nach Rustschuk gekommen (Abraham Canetti wurde später zum österreichisch-ungarischen Konsul ernannt). Auch der Großvater mütterlicherseits, Nissim Arditti - ein Sohn des angesehenen jüdi-

658 Der Text wurde von mir zuerst beim Internationalen Canetti-Symposium in Wien 2005 vorgetragen und in einer ersten Fassung unter dem Titel "Staatenlos. Die Verrätselung einer Biographie» veröffentlicht, in: John D. Pattillo-Hess/Mario R. Smole (Hg.) Elias Canetti - Chronist der Massen, Enthüller der Macht (Wien 2006), S. 83-96.

659 Sven Hanuschek: Elias Canetti. Biographie (München/Wien 2005), S. 511.

660 Elias Canetti: Die gerettete Zunge. Geschichte einer Jugend (Frankfurt a. M. 1992), S. 9.

661 Vgl. Hanuschek, Canetti, S. 35, siehe auch: Mordechai Arbell: Die Wanderung der Sepharden, in: 4. Internationales Theodor Herzl Symposium, Wien 8.-11.4.2002. Bericht (Wien 2002), S. 27-32. 


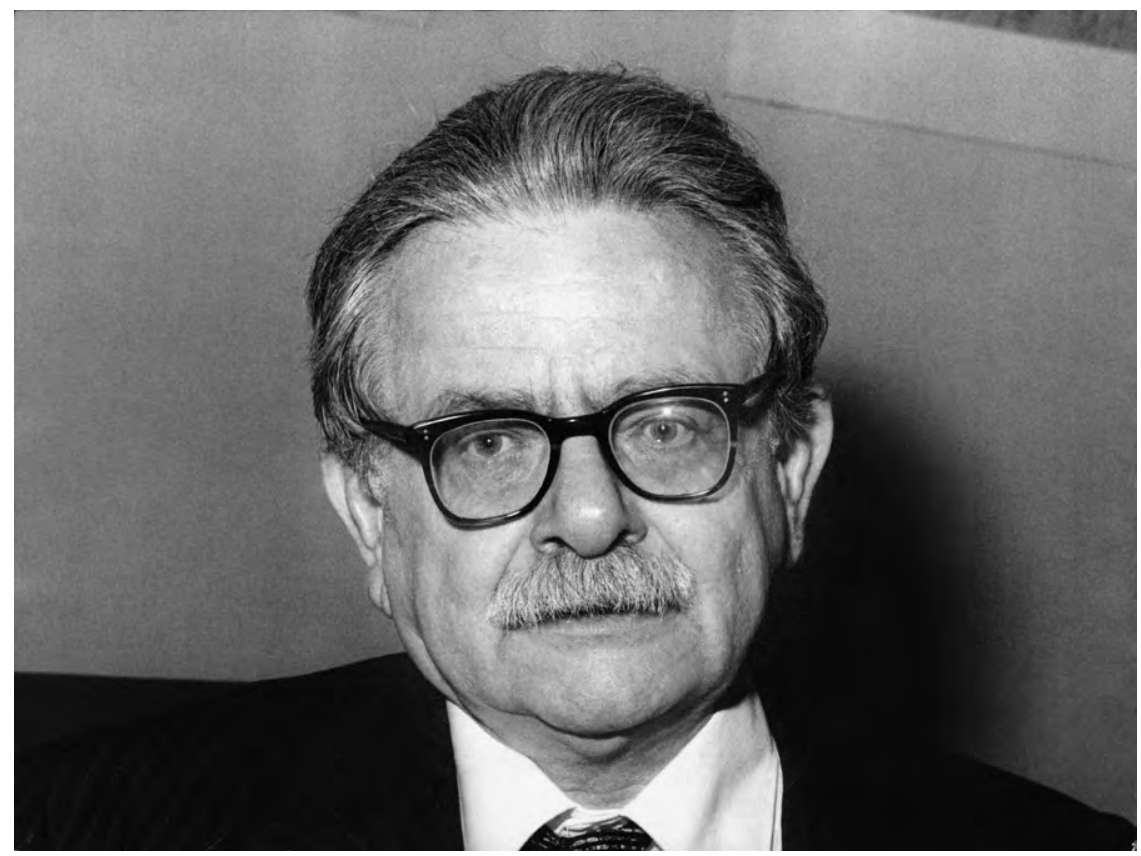

Abb. 20: Elias Canetti (1905-I994). Bei einer Lesung im Palais Pallfy; Quelle: ÖNB/Wien, Bildarchiv

schen Historikers und Aufklärers, Abraham ben Israel Rosanes, genannt Abir - kam aus Adrianopel. Alle drei Herkunftsfamilien - die Canettis, Ardittis und Rosanes spielten eine bedeutende Rolle in Rustschuk und unterhielten enge (Handels-)Beziehungen zur österreichischen Monarchie, engagierten sich aber auch innerhalb der neuen bulgarischen Gesellschaft. ${ }^{662}$ Sie bildeten ein weitläufiges Netzwerk in ganz Europa, waren kulturell vor allem nach Wien orientiert und blieben dennoch loyale Untertanen des Sultans. Das galt auch für Jacques und Mathilde Canetti, die Eltern von Elias. Als sie im Jahr I9 I I mit ihren drei Söhnen "nach Europa" gingen, taten sie das, wie Canetti betont, "mit türkischen Pässen«. Der türkischer Pass (teskère), in der rechten oberen Ecke versehen mit der Tugra, dem Namenszeichen des Sultans, versprach dem Reisenden damals Schutz und Sicherheit und wurde von allen europäischen Regierungen respektiert. ${ }^{663}$ Innerhalb des größten Teils der europäischen

662 Vgl. Wenzeslav Konstantinov: Elias Canetti - ein österreichischer Schriftsteller? Verwandlungen zwischen Rustschuk und Wien, in: Internet-Zeitschrift für Kulturwissenschaften Nr. 7 (September 1999), S. 3, www.inst.at/trans/7Nr/konstatinov7htm.

663 Vgl. Hannelore Burger: Passwesen und Staatsbürgerschaft, in: Grenze und Staat, S. 3-172, hier: S. 62 . 
Staatenwelt herrschte in der Zeit vor dem Ersten Weltkrieg Reisefreiheit. Ab Mitte des I9. Jahrhunderts waren laufend Maut-, Zoll- und Binnengrenzen und selbst die Kontrolle der Reisenden an den Außengrenzen aufgehoben worden. ${ }^{664}$ Stefan Zweig beschreibt mit Wehmut die nach dem Ersten Weltkrieg verloren gegangene Reisefreiheit seiner Jugend: "... die ganze Welt stand uns offen. Wir konnten reisen ohne Pass und Erlaubnisschein, wohin es uns beliebte, niemand examinierte uns auf Gesinnung, auf Herkunft, Rasse und Religion« ${ }^{665}$

Auch für die zunächst in Manchester sich niederlassende Familie Canetti war ihr ausländischer Pass kein Hindernis, nicht in England und auch nicht in Wien, wohin Mathilde Canetti mit ihren Söhnen nach dem frühen Tod ihres Mannes übersiedelte. Als Elias Canetti im September I9I3 im zweiten Wiener Gemeindebezirk eingeschult wurde, wurde er dort als »türkisch mosaisch" geführt, was eine reine Konfessionsbezeichnung war. ${ }^{666}$ Formal war er ein Ausländerkind - aber ein Fremder?

Der Aufenthalt türkischer Juden in der Habsburgermonarchie war seit dem I7. Jahrhundert durch die verschiedenen mit der Hohen Pforte geschlossenen Friedens- und Staatsverträge (Karlowitz I699, Passarowitz I7I8, Belgrad 1739 und Sistowa I79I)reglementiert. Sie enthielten umfangreiche Bestimmungen über die Behandlung der im jeweils anderen Hoheitsbereich sich aufhaltenden Staatsbürger: Handelsbestimmungen, Begünstigungsklauseln, Übertrittsbedingungen. ${ }^{667}$ Besonders detaillierte Bestimmungen hinsichtlich des Aufenthaltsrechtes enthielt ein im Jahre 1784 zwischen der Pforte und dem österreichischen Hof geschlossenes Abkommen, das sogenannte "Si(e)net« (Einverständnis), das Gleichbehandlung und Bewegungsfreiheit für Kaufleute vorsah. ${ }^{668}$ Grundsätzlich sah das Sienet auch vor, dass türkische Kaufleute in die österreichische Bothmäßigkeit übertreten, d. h. die österreichische Staatsangehörigkeit erwerben konnten, eine Möglichkeit, die allerdings nur sehr wohlhabenden osmanischen Untertanen offen stand. Im Allgemeinen war es jedoch für Juden günstiger, die osmanische Staatsangehörigkeit zu behalten. Eine der Paradoxien des österreichischen Staatsbürgerschaftsrechts bestand nämlich darin, dass fremde Juden - insbesondere osmanische Untertanen - in vieler Hinsicht größere Freiheiten genossen als ihre österreichischen Glaubensbrüder. Während die "türkischen Juden« (Sepharden) in Wien und Triest unbeschränktes Aufenthaltsrecht genossen, eine eigene jüdische Gemeinde unterhalten durften, deren Reichtum sich aus dem florierenden Orienthandel speiste (führende Familien waren die Ephrussi, Moreno, de Majo, Arditti, von deren Anwesenheit noch die prächtigen Gräber auf

664 Burger, Passwesen, S. 9.

665 Zweig, Welt von Gestern, S. 111.

666 Hanuschek, Canetti, S. 59.

667 Burger, Passwesen, S. 58.

668 Burger, Passwesen, S. 669f. 
dem jüdischen Teil des Währinger Friedhofs zeugen) ${ }^{669}$, bestimmte sich das Aufenthaltsrecht der Wiener Juden bis I 848 durch das Josephinische Toleranzpatent von I782, was bedeutete: Führung von Familienlisten, die Zahlung hoher Steuern und das regelmäßige Ansuchen um Verlängerung der Toleranz. Um sich all diesen »Bedrückungen« zu entziehen, kam es immer wieder vor, dass Wiener Juden, deren Toleranz nicht verlängert worden war, oder mährische Juden, die nicht im Besitz einer Familienstelle waren, in die Türkei auswanderten, dort osmanische Untertanen wurden und später mit einem türkischen Pass nach Österreich zurückkehrten, um auf diese Weise ein unbeschränktes Aufenthaltsrecht in Wien zu erwerben. ${ }^{670}$

Nun hatte zwar die sephardische Gemeinde, als Elias Canetti in Wien zur Schule ging, längst schon ihre einst privilegierte Existenz eingebüßt (auch wenn ihre im maurischen Stil errichtete Synagoge in der Zirkusgasse, die Canetti mit seinem Großvater besuchte, die prächtigste war), doch ein Abglanz der einstigen Stellung »türkischer Juden« war auch jetzt noch spürbar. Zwar waren ihre Privilegien inzwischen obsolet geworden, doch bestimmten diese nach wie vor ihr Lebensgefühl. So berichtet Canetti an keiner Stelle über Diskriminierung, weder als Ausländer noch als Jude, nur einmal über sein tiefes Erschrecken vor dem Elend galizischer jüdischer Flüchtlinge, die im Kriegsjahr I9 I 5/I6 massenhaft vor der russischen Front flüchteten und in Wien, vorzugsweise im zweiten Bezirk, Zuflucht suchten. Doch den Antisemitismus, der durch das Zuströmen verelendeter »Ostjuden« neue Nahrung erhielt, hat er, sofern er ihn wahrgenommen hat, noch sehr lange, darin seiner stolzen Mutter ähnlich, nicht auf sich bezogen.

Als Elias Canetti - nach den goldenen Jahren in der Schweiz und seinem Abitur in Frankfurt am Main - im Jahr I 924 nach Österreich zurückkehrte ${ }^{671}$, um in Wien auf Wunsch seiner Mutter Chemie zu studieren, war die Welt eine andere geworden. Die beiden transnationalen, multiethnischen Reiche - die Habsburgermonarchie wie auch das Osmanische Reich - existierten nicht mehr. Seine Rückkehr erfolgte in die junge Erste Republik, an deren pulsierendem intellektuellem und politischem Leben Canetti begeistert teilnahm. Bei einer Karl Kraus-Lesung im April I924 - einem der großen Wiener Events jener Zeit - lernte er seine zukünftige Frau Veza Taubner-Calderon kennen. Beide erkannten einander an ihren Namen sofort als gleiche, als Spaniolen. Die erste Frage, die sie an ihn richtete: "Sind Sie Schweizer?» traf ihn, nach eigenem Bekunden, tief. Canetti beantwortete sie mit einem »Leider nicht«. Mit dem einen Wort leider habe er mehr verraten, »als irgendein Mensch da-

669 Vgl. Tina Walzer: Weißbuch jüdischer Friedhöfe Österreichs (Wien 2002).

$670 \mathrm{Vgl}$. Heindl/Saurer, Grenze und Staat, S. 673.

671 Der Meldezettel vom 22. Juli 1924 weist ihn und seinen Bruder Georg (George) als »türkisch" aus. WStLA, Canetti. 
mals von mir wusste ${ }^{672}$ Canetti erklärte seine Betroffenheit durch die noch immer nicht verwundene Trennung von Zürich, dem unbeschwertesten Teil seiner Jugend. Doch Veza verstand die tiefere Bedeutung dieses »leider nicht« sofort. Für sie war die Frage keinesfalls Teil einer belanglosen Konversation. Sie bekannte, dass sie selbst gern Engländerin gewesen wäre. Der Dritte im Bund, ein österreichischer Freund, entgegnete verständnislos, man könne doch Shakespeare lieben, ohne darum "gleich Engländer zu sein«. »Alles Preziöse«, beschrieb Canetti die Szene, "war verschwunden, auch die Koketterie (...) Sie sprach von etwas, das ihr nah und wichtig war und setzte es ein gegen mein Wichtiges, das sie so rasch und leicht und doch gar nicht verletzend berührt hatte ${ }^{673}$

Was war dieses »Wichtige«, das beide für immer verbinden sollte? Es bestand in einem sehr nüchternen Problem, das in der Zeit der nun dominierenden Nationalstaaten eine nie gekannte Bedeutung erlangt hatte: ihr prekärer staatsbürgerlicher Status, die mangelnde Zugehörigkeit zu einer Nation. Veza Calderon war I 897 in Wien geboren worden, doch sie war keine Österreicherin, sondern besaß nach ihrer Mutter, Rachel Calderon, deren Familie zuletzt in Sarajevo ansässig gewesen war, einen jugoslawischen Pass. Elias Canetti, der die türkische Staatsangehörigkeit besessen hatte, war mit dem Zerfall des Osmanischen Reiches staatenlos geworden. ${ }^{674}$ Ein genaues Datum dafür gibt es nicht. Staatenlos wird eine Person entweder durch Ausbürgerung (Expatriation) oder durch Untergang eines Staates (Dismembration). Staatenlosigkeit ist ein völkerrechtlicher Status, der allerdings erst festgestellt werden muss (etwa, um einen Fremdenpass zu erlangen). Bis dahin gilt eine Person als "undefined subject" (nationalité indéterminée). Und genau das dürfte der Status Elias Canettis gewesen sein, als er die sieben Jahre ältere Veza am 29. Februar I 934 in Wien nach jüdisch-sephardischem Ritus heiratete, zu einem Zeitpunkt, als ihre Liebesbeziehung - nach Bekunden Canettis - bereits erloschen war. Diese gegen den Rat des Bruders erfolgte und vor der Mutter verheimlichte Eheschließung hatte

672 Elias Canetti: Die Fackel im Ohr. Lebensgeschichte 1921-1931 (München 1980), S. 86.

673 Canetti, Fackel, S. 86.

674 Eine Institutionalisierung der Staatsbürgerschaft war im Osmanischen Reich erst in der Phase seiner sogenannten "Neuordnung (tanzimat) im Jahr 1839 erfolgt, als - nicht zuletzt aufgrund des Drucks ausländischer Mächte - aus »tebaa« (Untertanen) Staatsangehörige mit Recht auf Leben, Eigentum und (allerdings erst nach der Verfassung von 1876) auch politischer Repräsentation wurden; darüber hinaus wurde die Rechtsgleichheit von Christen und Juden mit den Muslimen garantiert. Vgl. Günter Seufert: Die Türkei, der Libanon und Israel. Staatsbürgerschaft bei den drei seuropäischen` Erben des Osmanischen Reiches im muslimischen Vorderen Orient, in: Christoph Conrad/Jürgen Kocka (Hg.) : Staatsbürgerschaft in Europa. Historische Erfahrungen und aktuelle Debatten (Hamburg 2001), S. 216-239 sowie auch: Uri Davis: Democratization, Citizenship, Arab Unity and Palestinian Autonomy, in: N.A. Butenschon et al. (Hg.): Citizenship and the Middle East (Syrakus 2000), S. 225-245. 


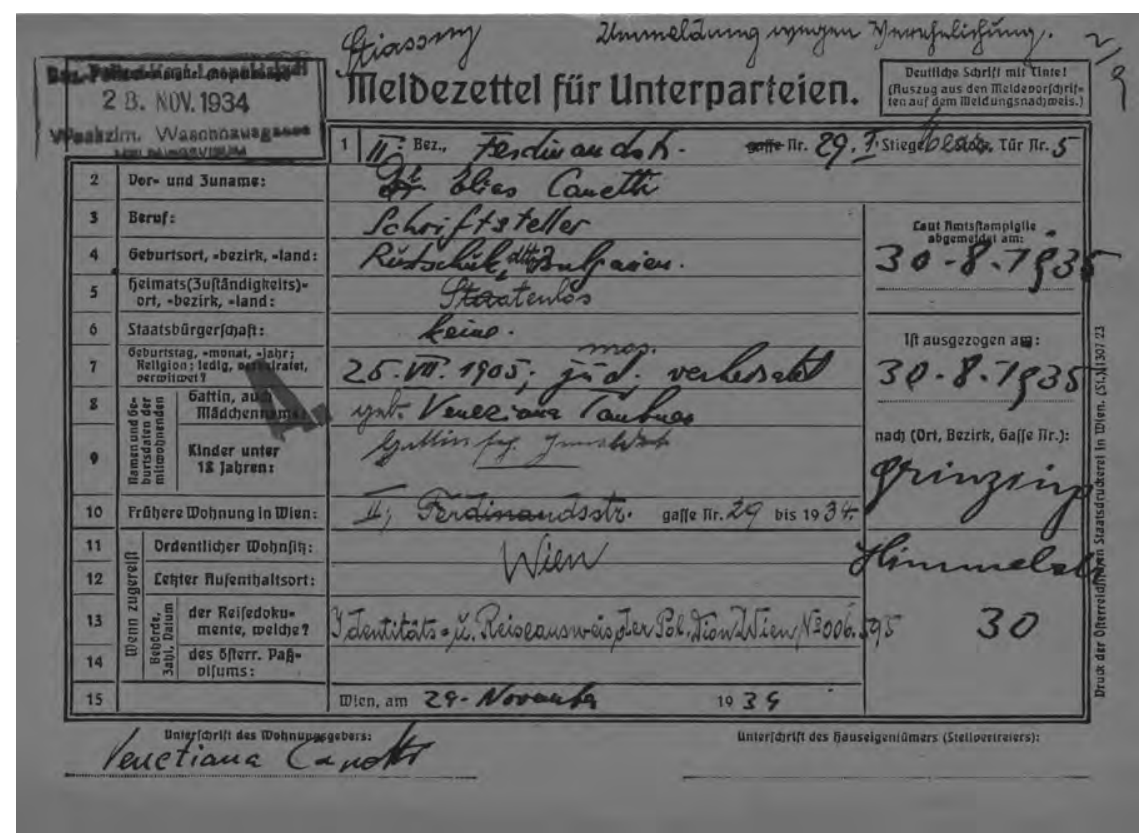

Abb. 2I: Meldezettel Dr. Elias Canetti (nach seiner Heirat erstmals als "Staatenlos a ausgewiesen.); Quelle:

Wiener Stadt- und Landesarchiv, Historische Meldeunterlagen, Prominentensammlung: Elias Canetti

vor allem einen Grund: Veza war, als freie Autorin der Arbeiterzeitung und jugoslawische Staatsbürgerin, nach dem Bürgerkrieg im Februar 1934 massiv von Abschiebung bedroht. Die Regierungen Dollfuß und Schuschnigg hatten bereits über I o ooo politische Gegner ausgebürgert: neben illegalen Nationalsozialisten vor allem ins Ausland geflohene Sozialdemokraten und Kommunisten. ${ }^{675}$ Politisch unliebsame Ausländer - zu denen auch Veza gehörte - wurden rigoros abgeschoben.

Wie Elias Canetti seinem Bruder George unter dem Siegel der Verschwiegenheit mitteilte, lag der wahre Grund für ihre Heirat also darin, dass Veza durch die Eheschließung ihre jugoslawische Staatsbürgerschaft verlieren und, wie er selbst, staatenlos werden würde. Die Gefahr ihrer Abschiebung war damit abgewendet. Da eine Zivilehe in Österreich zu dieser Zeit nur zwischen Konfessionslosen (als »Notzivilehe«) erlaubt war, ${ }^{676}$ sei eine Eheschließung, laut Canetti, nur im spaniolischen Tempel möglich gewesen (wofür Veza der Kultusgemeinde, die sie I93 I verlassen hatte,

675 Vgl. Burger/Wendelin, Vertreibung und Staatsbürgerschaft, S. 275.

676 Die generelle Einführung der Zivilehe erfolgte erst 1938, unter den Nationalsozialisten. Vgl. Gerald Stourzh: Zeit der Konversionen: Gustav Mahler, Karl Kraus und Wien im fin de siècle, in: Spuren einer intellektuellen Reise. Drei Essais (Wien/Köln/Weimar 2009), S. 61-102, hier: S. 64. 
erst wieder hatte beitreten müssen). ${ }^{677}$ Sie hätten dann ein wenig "spaniolisches Theater gespielt" und darüber einen Trauschein erhalten, der sie beide als staatenlos auswies. Für sich selbst sah Canetti darin allerdings auch einen Vorteil, da seine Staatenlosigkeit früher "eine sehr heikle Sache gewesen " sei und jedes weitere amtliche Dokument darüber ihm später leichter zu einer neuen Staatsbürgerschaft verhelfen könne. Niemand, so trug er seinem Bruder auf, dürfe von den wahren Gründen der Hochzeit erfahren. ${ }^{678}$

Tatsächlich weist das Stammblatt der Wiener Heimatrolle Elias Canetti als »staatenlos« aus. Da dieses erst am I 5. Februar I936 (zwei Jahre nach seiner Heirat) angelegt wurde ${ }^{679}$, stellt sich die Frage, ob Canetti zu jener Zeit versucht hat, die österreichische Staatsbürgerschaft zu erlangen? Theoretisch wäre dies möglich gewesen, war doch im Jahr 1925 eine Reform erfolgt, wonach die Erwerbung der Landes- und Bundesbürgerschaft schon nach vierjährigem ununterbrochenen Wohnsitz möglich sein sollte (vorher Io Jahre), allerdings erst dann, wenn dem Bewerber zuvor die Aufnahme in den Heimatverbrand einer Gemeinde zugesagt worden war. Hätte ein solches Ansuchen - gesetzt Canetti hätte sich darum bemüht - Aussicht auf Erfolg gehabt? Die staatsbürgerlichen Rechte der Juden waren - trotz weitverbreitetem Antisemitismus - in der sogenannten »Maiverfassung« des autoritären Ständestaates unangetastet geblieben. Nach der Machtergreifung Hitlers in Deutschland waren Tausende Flüchtlinge nach Österreich geströmt, darunter zahlreiche Prominente jüdischer Abstammung, u. a.: Theodor Adorno, Ernst Bloch, Max Reinhardt, Bruno Walter, Franz Mehring oder Alfred Polgar. Einige waren im Staatsgebiet der Monarchie geboren oder mit Österreicherinnen verheiratet. Gar nicht wenige wurden von der Regierung Schuschnigg eingebürgert. ${ }^{680}$ Grundsätzlich wäre es also auch für Elias Canetti, der sich nun bereits seit zwölf Jahren in Österreich aufhielt, möglich gewesen, die österreichische Landes- und Bundesbürgerschaft zu erlangen. Irgendeinen Rechtsanspruch konnte er - da er nicht im Staatsgebiet der Monarchie geboren war und somit nirgendwo ein Heimatrecht besaß - allerdings nicht geltend machend. Ebenso wenig konnte er gesicherte Lebensverhältnisse nachweisen, die wiederum Bedingung für den Erwerb des Heimatrechtes in Wien waren. Dass Canetti jedoch überhaupt die Möglichkeit einer Naturalisation durch den autoritären

$677 \mathrm{Zu}$ den Besonderheiten des jüdischen Eherechts und dem Heiratsverhalten von Juden nach dem Ersten Weltkrieg vgl. Marsha L Rozenblit: Jewish Courtship and Marriage in 1920s Vienna, in: Marion A. Kaplan/Deborah Dash Moore (Hg.): Gender and Jewish History (Bloomington, Indiana 2011), S. 88-103.

678 Brief E.C. an seinen Bruder George v. 10.2.1934 zit. nach Hanuschek. S. $265 f$.

679 GrundStammblatt Nr. 1230258 v. 15.2.1936, If. Nr. im Ausländerregister 62431, Magistratsabteilung 61, Wien, Heimatrolle. Vgl. Burger/Wendelin, Vertreibung und Staatsbürgerschaft, S. 323. 680 Ebenda, S. 277. 
Ständestaat in Erwägung gezogen haben sollte, ist unwahrscheinlich. Das gewaltsame Vorgehen des austrofaschistischen Regimes gegen die Arbeiterschaft, die Auslöschung der Sozialdemokratie und das Verbot der kommunistischen Partei waren ihm nicht gleichgültig. Dass sein früheres Idol Karl Kraus sich öffentlich für Dollfuß erklärte, war ihm Anlass für einen Bruch. ${ }^{681}$ Unter den gegebenen politischen Umständen scheint er es vorgezogen haben, staatenlos zu bleiben.

Nach dem Anschluss Österreichs an das nationalsozialistische Deutschland im März I 938 erwies sich Canettis Staatenlosigkeit zunächst als Vorteil. Mit den Nürnberger Gesetzen, die am 20. Mai 1938 in Österreich kundgemacht wurden, wurden alle österreichischen Juden »deutsche Staatsangehörige«. Die Canettis fallen - als Staatenlose - jedoch nicht unter die Nürnberger Gesetze. In ihrem Roman »Die Schildkröten"schildert Veza, die vom Antisemitismus viel stärker betroffen scheint als Canetti, eine Szene, in der die Protagonistin Eva ihren Mann (unschwer als C. zu erkennen) überredet, das Land zu verlassen: "Es schlagen jeden Tag neue Gesetze auf uns nieder, gegen Menschen mit schwarzen Haaren."Er versucht, sie zu beruhigen, doch Eva antwortet: "So kannst du denken, ... weil dich diese Blicke nicht treffen. Weil deine Züge zufällig slawisch sind und deine Augen hell. Aber ich - man hasst mich plötzlich. « ${ }^{682}$ Auch von den unmittelbar nach dem Anschluss beginnenden "Arisierungen « waren ausländische und staatenlose Juden zunächst nicht betroffen. Im Herbst 1938 verloren die Canettis dennoch ihre Wohnung in der Himmelstraße. Sie zogen in eine kleine Pension im I9. Bezirk und suchten nach einer Möglichkeit der legalen Ausreise. Veza schildert die Zeit des verzweifelten Wartens auf die Visa: „Die Angst herrscht jetzt im Herzen Europas, dessen Bewohner die `Liebenswürdigen` genannt wurden. Deren Häuser Geschichte waren. Deren Frauen Schubertlieder sangen. Die Angst trägt eine braune Uniform und die Swastika«. ${ }^{683}$ Nach dem Novemberpogrom, der sogenannten »Reichskristallnacht", gelang die Flucht. ${ }^{684}$ Im Gegensatz zu den einheimischen Juden, für die es viele bürokratische Hürden zu nehmen galt und hohe Vermögensabgaben (Reichsfluchtsteuer) fällig waren, hatten sie als Staatenlose neben den gültigen Reisepapieren nur eine "steuerliche Unbedenklichkeitsbescheinigung « vorzuweisen. ${ }^{685}$ (Nur ein Jahr später, im September I939, würden es gerade die staatenlosen und polnischen Juden sein, die die ersten Opfer systematischer Verfolgung und Vernichtung wurden. ${ }^{686}$ )

681 Elias Canetti: Das Augenspiel. Lebensgeschichte 1931-1937 (München 1985), S. 267

682 Veza Canetti: Die Schildkröten (München 1999) S. 13

683 Veza Canetti, Schildkröten, S. 28

684 Die polizeiliche Abmeldung erfolgte am 19. November 1938.

685 Vgl. Hanuschek, Canetti, S. 291

686 Weiss, Deutsche und polnische Juden, S. $194 f f$ und 212 sowie Spring, Vermessen, S. 91-110. 
Alle Berichte über die nationalsozialistische Epoche stammen von Veza. Elias Canetti schweigt darüber. Der dritte und letzte Teil seiner Biographie bricht mit Juni I 937 abrupt ab, endend mit dem Tod der Mutter. Seine Aufzeichnungen setzten erst wieder 1942 mit der »Provinz des Menschen« ein. Auffallend ist seine veränderte Haltung gegenüber dem Judentum. Sind die I 920er- und I 93oer-Jahre - wohl auch unter dem Einfluss Karl Kraus' - geprägt von einer Distanz zum Judentum (wiewohl Canetti im Gegensatz zu Kraus die Kultusgemeinde nie verlassen hat), geprägt vor allem auch vom Internationalismus der Arbeiterbewegung, so findet sich am Beginn der Aufzeichnungen des Jahres I 944 die berühmte Passage über die "größte geistige Versuchung « seines Lebens, die Versuchung, "ganz Jude zu sein«. Doch am Ende weist er diese Option zurück. Der Vernichtungsfeldzug gegen die Juden habe viele seiner Freunde veranlasst, sich »aus den Lockungen der vielen Völker« loszureißen, um am Ende »blind wieder zu Juden« zu werden. Die Toten aber sieht Canetti »auf allen Seiten«. Und er fragt: "Soll ich mich den Russen verschließen, weil es Juden gibt, den Chinesen, weil sie ferne, den Deutschen, weil sie vom Teufel besessen sind? Kann ich nicht weiterhin allen gehören, wie bisher, und doch Jude sein? "687 Sein Dazwischen-Sein verbietet ihm sich auf eine Seite zu schlagen. Einerseits froh über die Bomben der Alliierten, ist er zugleich entsetzt über die Zerstörung der deutschen Städte - seiner Städte. Es gelingt ihm nicht zu hassen. Weil er auch der Andere, auch der Feind ist? Die rätselhafteste Eintragung findet sich Anfang I945: "Wenn das Frühjahr kommt, wird die Trauer der Deutschen ein unerschöpflicher Brunnen sein, und es wird sie von den Juden nicht mehr viel unterscheiden. Hitler hat die Deutschen zu Juden gemacht, in einigen wenigen Jahren, und `deutsch` ist nun ein Wort geworden, so schmerzlich wie 'jüdisch « «. ${ }^{688}$

Eingeholt hat ihn die Versuchung, "ganz Jude zu sein", noch einmal - bei seiner Reise nach Marrakesch im Jahr I954. Beim Besuch der Mellah, des alten Judenviertels, begegnete er plötzlich Vertrautem: „Ich ging so langsam wie möglich vorüber und betrachtete die Gesichter. Ihre Verschiedenartigkeit war erstaunlich. Es gab Gesichter, die ich in anderer Kleidung für Araber gehalten hätte. Es gab leuchtende alte Juden von Rembrandt. Es gab katholische Priester von listiger Stille und Demut. Es gab Ewige Juden, denen die Unruhe über die ganze Gestalt geschrieben war. Es gab Franzosen. Es gab Spanier. Es gab rötliche Russen. (...) Ich dachte an Seelenwanderung. Vielleicht, sagte ich mir, muss jedes Menschen Seele einmal zum Juden werden, und nun sind sie alle hier: Keine erinnert sich daran, was sie früher war

687 Canetti, Provinz des Menschen, S. 61. Zur Ambivalenz Canettis siehe auch: Kristie A. Foell: Elias Canetti. Der unfreiwillige Jude, in: Dossier 25: Kurt Barsch/Gerhard Melzer (Hg.): Elias Canetti (Graz 2005), S. 126-135.

688 Canetti, Provinz des Menschen, S. 67. 
und selbst wenn es sich in den Zügen so deutlich verrät, dass ich, ein Fremder, es erkenne, glaubt jeder dieser Menschen doch fest daran, dass er in gerader Linie von den Leuten der Bibel abstammt. ${ }^{689}$ Er begegnete Elié, einem Namensvetter, wurde von dessen Familie freundlich aufgenommen und bekam neben anderen Köstlichkeiten eingemachte Früchte angeboten, wie sie seine Mutter zu machen pflegte. Höflich, aber bestimmt, wies er die Früchte zurück, "vielleicht«, wie er sagt, "weil sie mich zu sehr anheimelten«. Dann sprach er davon, dass seine Vorfahren aus Spanien gekommen seien und fragte, »ob es noch Leute in der Mellah gäbe, die das alte Spanisch sprächen«. Doch es gab niemanden mehr und nur wenige Alte wussten noch von der Flucht der Juden aus Spanien. ${ }^{690}$ Am Ende schienen ihm die Einwohner sogar ein wenig enttäuscht zu sein über sein Outing als »Israelit«. Vielleicht, meint er, »hätten sie sich den Fremden ganz fremd gewünscht«. ${ }^{691}$ Und so erwies sich sein erstes Gefühl des Angekommenseins als Illusion und wurde mit den »Stimmen von Marrakesch« zu einem Stück berührender Literatur.

Im Jahr I952 endlich sollte sich Vezas Traum doch noch erfüllen. Elias Canetti (und mit ihm seine Ehefrau) wurden britische Staatsbürger. Er hatte sich mit diesem Schritt Zeit gelassen. Erst nach dem Erscheinen der Blendung in England, seinem ersten großen Erfolg, und nach über dreißig Jahren der Staatenlosigkeit, entschloss sich Canetti zu diesem Schritt. Hatte er noch während des Krieges sich eher als österreichischer Exilant gefühlt und als solcher sich gemeinsam mit seinen Freunden Walter Hollitscher, Anna Mahler und Otto Erich Deutsch auch politisch engagiert gegen die Annexion Österreichs und für das Selbstbestimmungsrecht der österreichischen Nation ${ }^{692}$-, so war ihm das Exilland nun "Heimat " geworden. "Ich spüre», schreibt er in einem Brief an seine Freundin Marie-Louise von Motesiczky, "wie ich auf die Franzosen hier als Engländer reagiere, und nicht wie früher als Wiener, Schweizer oder Balkanese«. ${ }^{693}$ Und vielleicht entsprach ihm ja auch die britische Untertanenschaft (subjecthood) am ehesten, umfasste sie doch nicht nur das Commonwealth mit seinen zahllosen Völkerschaften, sondern - auch als europäischer Nationalstaat - immer schon eine Vielheit von Nationalitäten (die walisische, die schottische, die irische und die englische).

Seinen britischen Pass und seine Londoner Wohnung behielt Canetti auch nach dem Tod Vezas (1963) und seiner Heirat mit Hera Buschor (I97I). Im Jahr 1972 begründete das Paar in Zürich einen gemeinsamen Wohnsitz. Erst I988, nach dem

689 Elias Canetti: Die Stimmen von Marrakesch. Aufzeichnungen einer Reise (München 1968), S. 40.

690 Ebenda, S. 60.

691 Ebenda, S. 59.

692 So trägt eine Deklaration verschiedener Exilorganisationen von 1941 seine Unterschrift, auch unterstützte er eine Aktion des linken Flügels des "Austrian Centre«, vgl. Hanuschek, Canetti, S. 320. 693 Ebenda, S. 377. 
Tod seiner zweiten Frau, löste er seine Wohnung in London auf. Doch er blieb britischer Staatsbürger. Die Schweizer Staatsbürgerschaft erhielt er nie. Nur das Prozedere der jährlichen Verlängerung der Aufenthaltsbewilligung wurde für ihn nach einer Intervention eines Freundes beim Züricher Stadtpräsidenten - als im öffentlichen Interesse gelegen abgekürzt. ${ }^{694}$ Die Einbürgerung in der Schweiz zählt bekanntermaßen zu den schwierigsten. Neben der Bedingung eines zwölfährigen Aufenthalts existiert die Besonderheit des Gemeindebürgerrechts, das über den Vater weitergegeben wird, ohne dass eine persönliche Beziehung zum »Bürgerort « bestehen muss. Ein Fremder muss sich zuerst - darin gleicht es dem altösterreichischen Heimatrecht - um das Bürgerrecht einer Gemeinde bewerben. ${ }^{695}$ Jeder Schweizer ist zuallererst Bürger einer bestimmten Gemeinde, »Bürgerin von« oder »Originaire de«, wie es im Pass heißt. Damit ist der Bürgerort, wie Regina Wecker bemerkt, Teil der persönlichen Identität. ${ }^{696}$ Eine weitere Bedingung war bis in die I $980 e r-J a h r e ~ d i e$ Aufgabe der bisherigen Staatsbürgerschaft. Doppelte Staatsbürgerschaften wurden ebenso wie in Österreich - nicht geduldet. So blieb es für Elias Canetti am Ende in der Schweiz bloß bei einem Ehrengrab (auf dem Friedhof Witikon in Zürich) ${ }^{697}$ und in Österreich bei der Ehrenbürgerschaft der Stadt Wien. ${ }^{698}$

Dass das nationalstaatliche Modell der Staatsbürgerschaft, wie es sich in Europa nach dem Ersten Weltkrieg herausgebildet hat, für Menschen, die, wie Elias Canetti, vielen Welten angehörten, sich als viel zu eng erwies, ist evident. In seinem Nachlass finden sich dann auch Überlegungen zu einer Weltbürgerschaft: "Man wird, was man war, erst ganz in der Emigration, man sollte in mehreren sukzessiven Emigrationen leben, überall als Fremder angehen, nicht sehr erwünscht, zum Lernen in jedem Lebensalter gezwungen, so könnte man allmählich wirklich zum Weltbürger werden«. Canetti entwickelte ein Konzept verbundener Nationalitäten : Heimaten (im Plural) seien jene Länder, in denen man zumindest fünf Jahre gelebt habe. Man sei verpflichtet, die Sprache eines solchen Landes zu beherrschen, den Wohnsitz manchmal zu wechseln, dürfe aber, vom fünfzigsten Jahr an, sich ganz dort niederlassen, wo es einem am besten gefällt. Die Kinder müssten unter drei sichtlich verschiedenen Völkern aufwachsen. Einsprachige gelten als Idioten, »wie heutzutage

694 Vgl. Hanuschek, Canetti, S. 660.

$695 \mathrm{http}: / /$ switzerland.isyours.com.

696 Regina Wecker: »Ehe ist Schicksal, Vaterland ist auch Schicksal und dagegen ist kein Kraut gewachsen." Gemeindebürgerrecht und Staatsangehörigkeitsrecht von Frauen in der Schweiz 1798-1988, in: L'homme 1 (1999), S. 13-37, hier: S. 16.

697 Vgl. Hanuschek, Canetti, S. 660.

698 Die Ehrenbürgerschaft der Stadt Wien erhielt Elias Canetti am 26. April 1985, vgl. Hanns JägerSustenau: Die Ehrenbürger und Bürger ehrenhalber der Stadt Wien (Wien 1992), Nr. 143, S. 78. 
Dorftrottel, die nie aus ihrem Tal herausgekommen sind. ${ }^{699}$ Canetti, ein ironischer Kosmopolit?

Nicht ganz. Nationen waren ihm keineswegs gleichgültig. In "Masse und Macht» versucht er, ihnen auf den Grund zu kommen. Die alte Fichtesche Formel von der "Sprachnation « weist er zurück, ebenso Otto Bauers "Schicksalsgemeinschaft«. Canetti sieht die Nation als Modus der Masse, als ein Phänomen, das es allererst anzuerkennen gilt. Er versucht, sich ihr über die Symbole zu nähern und über diese ihr Eigentümliches zu bestimmen: das Meer für die Englische Nation, den Deich für die holländische, die Revolution für die französische. ${ }^{700}$ Canetti war, wie er sagt, »keiner von ihnen hörig, aber redlich und zutiefst an ihnen allen interessiert«. Man müsse "jede von ihnen geistig so in sich aufgehen lassen, als wäre man dazu verurteilt, ihr für einen guten Teil seines Lebens wirklich anzugehören «. ${ }^{701}$ Hier spricht nicht die Gleichgültigkeit des Kosmopoliten, auch nicht die Sicherheit eines Weltbürgers, sondern die Verletzlichkeit eines überaus fraglichen, fragmentierten, hybriden »Ichs", eines "Ichs", das in Wahrheit "aus vielen Figuren" besteht, wobei es ihm selbst verborgen bleibt, "welche dieser Figuren es jeweils ist, die aus ihm spricht, und warum eine die andere ablöst. ${ }^{702}$

Canetti kam vom äußersten Rand »nach Europa». Seine Zugehörigkeit musste er sich hart erkämpfen. Er tat es durch die Sprachen, von denen er eine nach der anderen lernte (meistens deren mehrere gleichzeitig), von denen sich ihm eine in die andere übersetzte. Ein »Vom-Rande-Kommen« bedeutet jedoch, worauf Jacques Derrida verweist, ein Offen-sein, ein »nicht mit sich selbst identisch sein«, bedeutet auch, aber nicht nur und nicht ausschließlich und "nicht durch und durch europäisch sein «. ${ }^{703}$ Vor einem "Durch-und-durch-europäisch-Sein« bewahrte ihn nicht zuletzt eine Philosophie (oder natürliche Religion), die ihn ein Leben lang begleitete: der Taoismus. Der Einfluss der taoistischen Philosophie auf Canettis Werk ist bislang wenig bemerkt worden. Doch schon auf den ersten Seiten der »Blendung « ist jenes Buch, das Kien, der Sinologe, einem »aufgeweckten Jungen« leiht, nicht zufällig eine kostbare Ausgabe des Taoisten Mong Tse. Warum sich Canetti den Chinesen "so nahe fühlte«, darüber können wir nur Vermutungen anstellen, hat er doch dazu nur wenige Stichworte hinterlassen. ${ }^{704}$ Nicht zuletzt dürfte es das Motiv der Ver-

699 Vgl. Hanuschek, Canetti, S. 334.

700 Vgl. Das Kapitel "Massensymbole der Nationen«, in: Elias Canetti, Masse und Macht, Bd. 1 (München, 2. Auflage 1976),, S. 185-196.

701 Canetti, Masse und Macht, Bd. 1 S. 185 f.

702 Elias Canetti: Die Fackel im Ohr, Lebensgeschichte 1921-1931 (Wien 1980), S. 182.

703 Jacques Derrida: Das andere Kap (Frankfurt a. M. 1992), S. 60.

704 Siehe neuerdings dazu die an der Heinrich Heine Universität Düsseldorf vorgelegte Dissertation von Yun Chen: Canetti und die chinesische Kultur, phil. Diss. (Düsseldorf 2005). 
wandlung gewesen sein, die vielfältigen Seinsformen, die Möglichkeit, auch Tier, zu sein, ein Vogel, ein Schmetterling. Am Taoismus habe ihn immer angezogen, »dass er die Verwandlung kennt und (sie) gutheißt« ${ }^{705}$

In gewisser Weise also scheint das Attribut der Staatenlosigkeit Elias Canetti, dem sephardischen Juden, dem Osmanen, Orientalen, Engländer, Österreicher, Europäer, durchaus entsprochen zu haben, seinem Dazwischen-Sein, seiner Hybridität, seiner »Ichlosigkeit«. Ein Verhängnis scheint er - anders als Hannah Arendt darin nicht gesehen zu haben, eher ein bürokratisches Ärgernis. Aus politischer Naivität, die Canetti gern unterstellt wird? Kaum. Ich denke, dass seine Jahrzehnte währende Staatenlosigkeit zwar keineswegs immer ein freiwillig gewählter Zustand gewesen war, doch im Innersten seinem Wunsch entsprochen hat, sich keiner Nation und keinem Staat ganz zu verbinden, einem zornigen, anarchistischen, aus tausendfacher Demütigung kommendem Widerspruch gegen Macht und Gewalt.

\section{"... durch Abstammung wie Wahlverwandtschaft ein Ostjude". Der Fall Manès Sperber ${ }^{706}$}

Er sei, so Manès Sperber zu Beginn einer Dankadresse anlässlich der Verleihung des Friedenspreises des Deutschen Buchhandels im Herbst I 983 in der Frankfurter Paulskirche, der zweite Laureat (nach Martin Buber), »der durch Abstammung wie Wahlverwandtschaft ein Ostjude« sei. ${ }^{707}$ Hatte sich Manès Sperber in früheren Jahren eher als Weltbürger und »skeptischen Humanisten «, als ketzerischen Sozialisten, Agnostiker oder allenfalls als »europäischen Juden« bekannt, so bestand er jetzt - wenige Monate vor seinem Tode - darauf, ein »Ostjude« zu sein - ein Begriff, dessen pejorative Konnotationen ihm nur allzu vertraut waren.

Als Manès Sperber am 5. Februar 1984 in Paris starb, herrschte bei seinen Nekrologen hinsichtlich seiner Nationalität heillose Verwirrung. In den in den europäischen Medien überaus zahlreich erschienenen Nachrufen wurde er bald als französischer, bald als (alt)österreichischer Schriftsteller, als »austrofrancese» (Corriere della Serra), als polnisch-jüdischer Schriftsteller oder als "écrivain autrichien, naturalisé français« (Le Quotidien de Paris) gewürdigt. Zwar wurde immer wieder auf die exis-

705 Canetti, Provinz des Menschen, S. 279.

706 Erweiterte Fassung eines Vortrags beim 14. Symposium Kulturraum Donau: Manès Sperber Dichtung gegen Tyrannis, 29./30. September 2006, in Wien.

707 Dankadresse des Preisträgers anlässlich der Verleihung des Friedenspreises des Deutschen Buchhandels am 16. Oktober 1983 in der Paulskirche, vorgetragen von Alfred Grosser. Nachlass Manès Sperber im Österreichischen Literaturarchiv (im Folgenden: ÖLA) in der Österreichischen Nationalbibliothek (ÖNB), Mappe 2/449. 


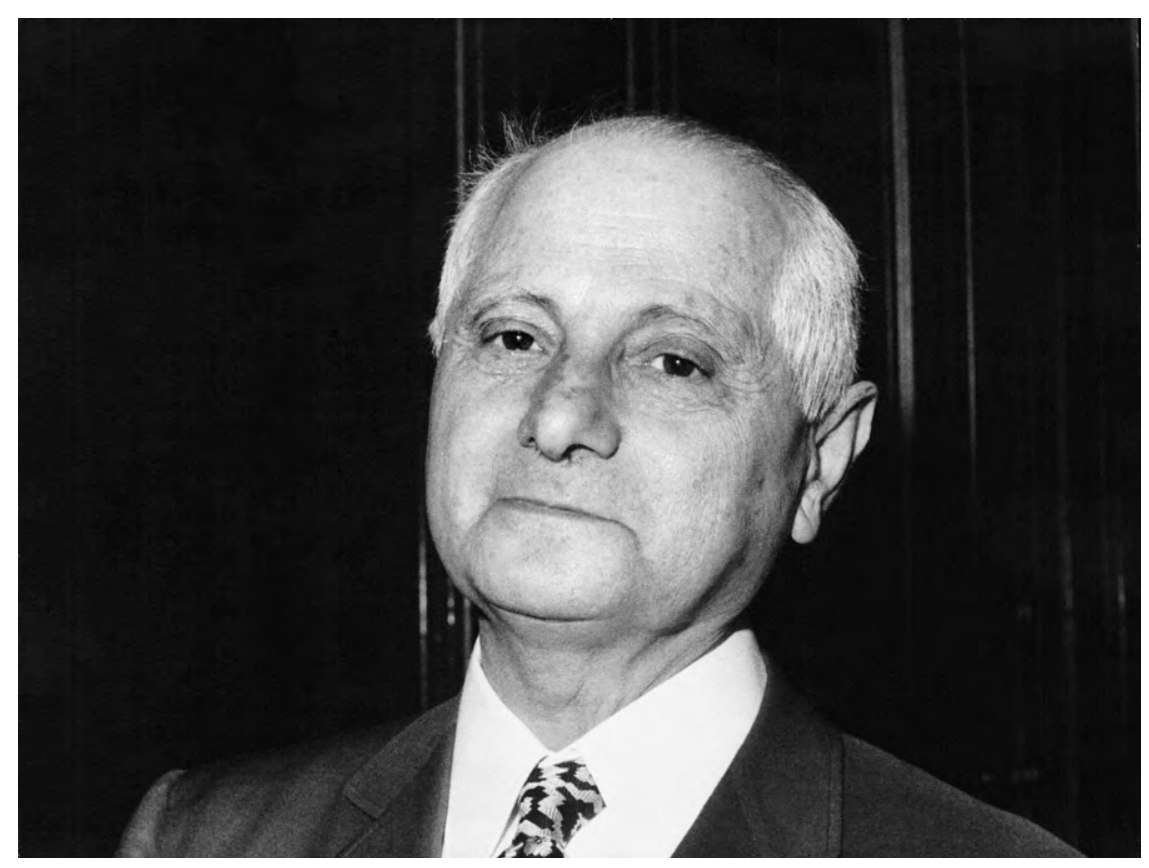

Abb. 22: Manès Sperber (I905-1984); Quelle: ÖNB/Wien, Bildarchiv

tentielle Heimatlosigkeit des »doppelt Exilierten« hingewiesen, doch die Tatsache seiner Jahrzehnte währenden Staatenlosigkeit blieb unerwähnt.

Es ist davon auszugehen, dass sich Manès Sperber der Paradoxie des Begriffs »Ostjude» durchaus bewusst war, der in Wahrheit ja eigentlich Westjuden bezeichnet, jene Juden nämlich, die im Hochmittelalter vor den mordenden, brandschatzenden, plündernden Heeren christlicher Kreuzfahrer aus ihren am Rhein gelegenen Gemeinden nach Osten geflohen waren, sich in den Weiten der slawischen Welt, vornehmlich in Litauen, Polen und Russland, angesiedelt hatten, um dort, mit ihren aus der rheinischen Heimat mitgebrachten Fähigkeiten und Fertigkeiten, nicht wenig zum wirtschaftlichen und kulturellen Aufschwung dieser Länder beizutragen. ${ }^{708}$ Nathan Birnbaum, der leidenschaftliche Vorkämpfer für die Anerkennung des Jiddischen als eigenständige Sprache, beschrieb die Ostjudenheit einmal »als eine große geschlossene, von jüdischen Lebensgesetzen bestimmte, in eigenen jüdischen Lebensformen sich realisierende Kulturgemeinschaft«, die sich in ihrer Einzigartigkeit von der Westjudenheit unterscheidet. ${ }^{709}$ Ost- und Westjuden unterschieden 
sich jedoch nicht nur kulturell und religiös, sondern auch hinsichtlich ihrer staatsbürgerlichen Stellung. Während »Westjuden« in der zweiten Hälfte des I9. Jahrhunderts im Großen und Ganzen die staatsbürgerliche Gleichheit erreicht hatten, blieben die "Ostjuden« noch lange in ihrer traditionellen Autonomie verhaftet. So erhielten etwa polnische Juden die vollen staatsbürgerlichen Rechte erst nach dem Ersten Weltkrieg durch die Bestimmungen des Versailler Vertrages, nicht nur als Individualrechte, sondern auch als Angehörige einer nationalen Minderheit. ${ }^{710}$ Sie bewegten sich damit in einem rechtlichen Rahmen, der ihren partikularen Interessen und ihrem Wunsch nach Autonomie Ausdruck verlieh. ${ }^{711}$

Sichtbarster Ausdruck ostjüdischer Autonomie und Authentizität aber war das Schtetl (Verkleinerungsform von jiddisch schtot, Stadt). Obwohl keineswegs alle Juden Osteuropas Schtetlbewohner waren, wurde das oft verklärte und idealisierte Bild des Schtetls nach dem Zweiten Weltkrieg zum Inbegriff des Verlustes ostjüdischer Lebensform. So lange es allerdings existierte, war es, wie Eva Hoffmann gezeigt hat, "weder Utopie noch Dystopie, sondern ein kohärentes und überraschend widerstandsfähiges soziales Gebilde " ${ }^{712}$ - so auch Zabłotow, die Stadt am Pruth, im südöstlichen Galizien an der äußersten Peripherie des Habsburgerreiches gelegen, das trotz aller Insignien altösterreichischer Staatlichkeit (einem Bezirksgericht, einer Finanzwache, einem Telegrafenamt, einer Eisenbahnstation, einer Baron-HirschSchule, einer Tabakfabrik) seinen der chassidischen Tradition verhafteten Charakter bewahrt hatte.

Manès Sperber hat der Welt, in die er hineingeboren worden war, ${ }^{713}$ im ersten Teil seiner Autobiographie, „Die Wasserträger Gottes«, ein Denkmal gesetzt: dem Ritual, das den Verlauf eines jeden Tages bestimmte, dem permanenten Gebet als Lebensform, dem Sinn für Gerechtigkeit, dem Streben nach Bildung, dem Witz

tities, S. 71. Zur Geschichte des Ostjudentums siehe: Heiko Haumann: Geschichte der Ostjuden (München 1999).

710 Dan Diner traf in einem Radiointerview die Unterscheidung: „Individualität und Staatsangehörigkeit« im Westen, "Ethnifizierung und Kollektivität« im Osten. Juden: Vormodern, modern, postmodern. Science.ORF.at, 19.11.2010. Siehe dazu auch Dan Diner: Synchrone Welten: Zeiträume jüdischer Geschichte (Göttingen 2005), S. 25.

711 Weiss, Deutsche und polnische Juden, S. 12.

712 Eva Hoffmann: Das Schtetl. Die Welt der polnischen Juden (München 2003), S. 24. Siehe dazu auch die berührenden Schilderungen ostjüdischer Lebenswelten in: Rabbi Berl Edelstein: Schabbatnachmittage im Obstgarten. Zerbrochene Welten meiner chassidischen Kindheit (Wien/Köln/ Weimar 1999).

713 Das Geburtsbuch des Israelitischen Matriken-Amtes in Zabłotow verzeichnet, dass dem Kaufmann David Mechel Sperber und seiner Ehegattin Jente Sperber, geborne Heger, aus Kolomea, am 12. Dezember 1905 in Zabłotow ein Sohn geboren worden war, der »am 19. Dezember 1905 beschnitten und ihm dabei der Vorname Manes Nussen beigelegt wurde«. Reproduktion des Geburtszeugnis, Nr. 1401744 v. 7.9.1936, Nachlass Sperber, ÖLA/ÖNB. 
und der Ironie, aber auch der Enge, dem Hunger, den unterernährten Kindern. Ein russischer Artillerieangriff im Herbst I9 I 5 , bei dem sich Sperber hinter einem Grabstein auf dem jüdischen Friedhof verbarg, beendete jäh die Kindheit: ein zerfetztes Pferd, ein toter Soldat wurden zum Urbild des Krieges, zur Quelle eines lebenslangen, leidenschaftlichen Pazifismus. Als die Front im Zuge der Kriegshandlungen mehrfach über Zabłotow hinwegging, floh die Familie über Mähren nach Wien, wo sie am 27. Juli i9 6 auf dem Franz-Josephs-Bahnhof ankam. Um den strengen Meldegesetzen zu entsprechen, begab sich der Vater, David Sperber, bereits am nächsten Tag auf das Polizeikommissariat des zweiten Wiener Gemeindebezirkes, der Leopoldstadt, um sich, seine Frau Jente und seine drei Söhne - unter Vorlage seines Heimatscheins - in der Lilienbrunngasse, dem langjährigen Domizil der Familie, anzumelden. ${ }^{714}$ Der Heimatschein wies ein Heimatrecht der Familie in Zabłotow, Galizien aus, was bedeutete, dass sie in Wien zwar als österreichische Staatsbürger, doch in heimatrechtlichem Sinn als Fremde lebten.

Wien - im zweiten Jahr des Ersten Weltkrieges - zeigte sich jedoch keineswegs als jener »leuchtende Kristall", als welchen der junge Manès die Haupt- und Residenzstadt des Reiches imaginiert hatte. Bitterer noch als der soziale Absturz, der tiefe Fall in die äußerste Armut, sei die alltägliche Erfahrung des Antisemitismus gewesen: Im Oktober I9 I6, am Tag des Attentats Friedrich Adlers auf den Außenminister Graf Stürgkh, drückte in der aufgewühlten Menge ein Fremder eine glühende Zigarette im Nacken des Elfährigen aus. Die Schule wurde für das begabte Kind zum Alptraum, zum Ort endloser Demütigungen. Rettung gab es nicht in der Religion gegen Gott hatte das Kind schon früh rebelliert, indem es zornig Steine in den Himmel warf -, sondern allein in der Literatur. Dostojewski wurde zur Lebensschule, die Leihbibliothek zur eigentlichen Bildungsanstalt.

Noch in das Jahr der Ankunft in Wien fiel am 21. November der Tod des alten Kaisers. Den elfährigen Manès ließ der prunkvolle Leichenzug, den er von der Dominikanerbastei aus beobachtet, gleichgültig - nicht so den Vater. Dieser schluchzte laut: "Mit ihm endet Österreich. Er ist ein guter Kaiser für uns gewesen; jetzt wird alles ungewiss. Für uns Juden ist das ein großes Unglück. « ${ }^{715}$ Für die Generation des Vaters war Franz Joseph der Garant ihrer staatsbürgerlichen Rechte, der »Beschützer gegen Willkür und Hass«. Erst Jahrzehnte später wurde auch für den Sohn der Kaiser zur »unantastbaren Institution«, deren Ende viel mehr als bloß den Tod eines Monarchen bedeutete. "Dass man ein Österreicher war», so Sperber, "hing

714 Die Meldezettel der Familie Sperber weisen ab 28. Juli 1916 als Wohnort Lilienbrunngasse 18/30, ab 27. November 1916 Lilienbrunngasse 8, im zweiten Wiener Gemeindebezirk aus. WStLA, Sperber.

715 Manès Sperber: Die Wasserträger Gottes. All das Vergangene (Frankfurt a. M. 1993), S. 36. 
mit diesem alten Mann zusammen, immer mehr mit ihm als mit dem Zufall von Geburtsort und Abstammung «. ${ }^{716}$

Tatsächlich verloren mit dem Zusammenbruch der österreichisch-ungarischen Monarchie im November I9 8 Millionen Menschen - darunter auch die Familie Sperber - ihre Staatsbürgerschaft. Hatten sie als Flüchtlinge in Wien zwar ohne Heimatrecht, doch als gleichberechtigte Staatsbürger gelebt, so wurde ihr Aufenthalt jetzt ein prekärer. Die »Republik Deutschösterreich« hatte sich am 22. November I9I 8 zum Souverän über »das geschlossene Siedlungsgebiet der Deutschen innerhalb der bisher im Reichsrate vertretenen Königreiche und Länder« erklärt. Darüber hinaus wurden Ansprüche auf alle "Deutschen" in den Nachfolgestaaten Cisleithaniens und Westungarns erhoben. ${ }^{717}$ Gleichzeitig schien es in den Debatten um das künftige Staatsbürgerschaftsgesetz nur ein Problem zu geben: die Einbürgerung der jüdischen, vor allem aus Galizien und der Bukowina stammenden Kriegsflüchtlinge zu verhindern. Bereits während des Krieges hatte sich eine beispiellose Kampagne gegen die »Ostjuden« jene seit Kriegsbeginn vor der russischen Armee geflüchteten, teilweise von der österreichischen Armee evakuierten jüdischen Flüchtlinge - entfaltet. Pogrome in Polen und der Ukraine brachten neue Flüchtlinge. Im Vertrauen nicht zuletzt in ihre österreichische Staatsbürgerschaft kamen sie nach Wien, oft mit nicht viel mehr als ihrem Heimatschein. Diese Flüchtlinge spielten - wie bereits erwähnt - eine beträchtliche Rolle bei der Konstruktion der österreichischen Staatsbürgerschaft in den Jahren I 9 I 8 bis I920. Die dem Staatsbürgerschaftsgesetz von I9 8 zugrundeliegenden Vorstellungen bildeten schließlich auch die Grundlage für die im Rahmen der Pariser Friedensverhandlungen vorgenommene Abwicklung der altösterreichischen Staatsbürgerschaft. Wie oben beschrieben sah der Artikel 80 des Vertrages von St-Germain-en-Laye vom Io. September I9 9 für die Bewohner aller Nachfolgestaaten der österreichisch-ungarischen Monarchie ein Optionsrecht nach "Rasse und Sprache vor. $^{718}$

Doch noch knapp vor dem Inkrafttreten des Staatsvertrags hatte der sozialdemokratische Landeshauptmann von Niederösterreich, Albert Sever, mit Erlass vom

716 Manès Sperber: Die Zeit in der sie lebten. Österreichische Juden unter Franz Joseph (Frankfurt a. M. 1970), S. 14.

$717 \$ 1$, StGBl 1918/40 und Staatserklärung vom 22. November 1918 über Umfang, Grenzen und Beziehungen des Staatsgebietes von Deutschösterreich, StGBl 1918/41.

718 "Personen, die in einem zur ehemaligen österreichisch-ungarischen Monarchie gehörigen Gebiet heimatberechtigt und dort nach Rasse und Sprache von der Mehrheit der Bevölkerung verschieden sind, können innerhalb eines Zeitraumes von sechs Monaten nach dem Inkrafttreten des gegenwärtigen Vertrages für Österreich, Italien, Polen, Rumänien, den serbisch-kroatisch-slowenischen Staat oder die Tschechoslowakei optieren, je nachdem die Mehrheit der Bevölkerung dort aus Personen besteht, welche die gleiche Sprache sprechen und derselben Rasse zugehörig sind wie sie." Zit. nach Goldemund/Ringhofer/Theurer, Staatsbürgerschaftsrecht, S. 422ff (Hervorhebung nicht im Original). Genauer dazu: Kolonovits: Rechtsfragen des Wiedererwerbs, S. $57 \mathrm{ff}$. 
9. September I9I9 versucht, alle Ostjuden auszuweisen, die nach Beginn des Erstens Weltkrieges nach Wien gekommen waren und kein permanentes Aufenthaltsrecht besaßen. Da jedoch der Sever-Erlass - vor allem aufgrund von Transportproblemen - scheiterte, versuchte man später auf legistischer Ebene zu einer solchen Interpretation des Artikel 80 zu gelangen, die eine Anerkennung von Optionen von in Österreich verbliebenen »Ostjuden« unmöglich machen würde. ${ }^{719}$ Mit einer Resolution des Plenums des österreichischen Nationalrats vom Io. März I92 I wurde die Regierung aufgefordert, bei der Erledigung von Optionsansuchen »insbesondere der Forderung der Rassezugehörigkeit zur Mehrheit der österreichischen Bevölkerung gebührend Rechnung zutragen «. ${ }^{720}$ Zusammen mit einem Erkenntnis des Verwaltungsgerichtshofs vom 9. Juni I92 I, mit welchem das Optionsansuchen des aus Lisko in Galizien stammenden Moses Dym wegen Nichterbringung des Beweises »der Zugehörigkeit zur deutschen Mehrheit der österreichischen Bevölkerung«abgewiesen wurde, ${ }^{721}$ bildete diese Resolution die Grundlage für die nach dem österreichischen Innenminister Leopold Waber sogenannte »Wabersche Optionspraxis», nach der Optionsansuchen von Ostjuden unter Hinweis auf deren Rasse generell abzuweisen waren.

Ob David Mechel Sperber, der Vater Manès Sperbers, unter jenen etwa 20000 Ostjuden war, die nach I9 9 für Österreich optiert hatten, ist ungewiss. Sicher ist, das beweisen die Meldezettel der Familie, dass David Sperber bis zum Ende der Ersten Republik für sich und seine Familie kein Heimatrecht in Wien - die Bedingung für den Eintritt in die österreichische Staatsbürgerschaft - erworben hatte. Der Republik Österreich galten sie als "polnische Juden«, waren Ausländer. Für den jungen Manès hatte dieser Tatbestand - wenn er davon überhaupt wusste - wenig Bedeutung. Seine Welt war eine übernationale: die der sozialistischen Versammlungen, der zionistischen Jugendbewegung. Er schloss sich dem linken Hashomer Hatzair an, verließ das Gymnasium, lebte, nach Konflikten mit dem Vater, von den Eltern getrennt in verschiedenen Untermieten, erwarb sich im Selbststudium eine umfassende Bildung. Im Sommer I92 I begegnete er Alfred Adler, dem charismatischen Begründer der Individualpsychologie. Er wurde einer seiner ersten Schüler und erlangte 1926 ein vom Meister selbst ausgestelltes Diplom für Heilpädagogik, das ihm

719 Vgl. Grandner, Staatsbürger, S. 75.

720 Stenographische Protokolle des Nationalrates der Republik Österreich. 1920-1923 (Wien 1923), S. 57, (Hervorhebung nicht im Original).

721 Die Mehrheit des Verwaltungsgerichtshofes war anlässlich des Falls Dym zu der Erkenntnis gelangt, dass "Rasse« eine dem Menschen "angestammte, ihm inhärente, durch physische und psychische Momente bestimmte und charakterisierte Eigenart dauernden Charakters« sei. Ein "anhaftender Zustand, der nicht willkürlich abgelegt und nicht nach Belieben verändert werden kann«. Erkenntnis des Verwaltungsgerichtshofs vom 9. Juni 1921, Z 2973, zit. nach Grandner, Staatsbürger, S. 79. 
eine berufliche Perspektive eröffnete. Im Alter von einundzwanzig Jahren begann Sperber, pädagogische und (individual)psychologische Vorträge zu halten, arbeitete mit Jugendlichen in Heimen, verkehrte in den Wiener Kaffeehäusern - vor allem im Herrenhof und im Siller, dem damaligen Hauptquartier der Adlerianer - und veröffentlichte einen ersten Essay über die individualpsychologische Methode Adlers.

Zu einem turning point in der Geschichte der Republik wie im persönlichen Leben Sperbers wurde der I 5. Juli 1927. Gemeinsam mit seinem kommunistischen Freund Alex Weissberg wurde er Augenzeuge jenes Fanals, das auf das berüchtigte Urteil von Schattendorf folgte: des Justizpalastbrandes. „Nichts setze Menschen so leidenschaftlich in Bewegung«, schrieb Sperber später über das Ereignis, das Österreich für einen Tag an den Rand einer Revolution bringen sollte, als das Gefühl, "wonach die Justiz die Gerechtigkeit und mit ihr die Opfer verhöhnt. «722 Das Geschehen vor dem "Palast des Unrechts" habe - und das hat er mit den ebenfalls Anwesenden Elias Canetti und Heimito von Doderer gemeinsam - nie aufgehört auf ihn zu wirken. ${ }^{723}$ Alle drei Augenzeugen sollten das Ereignis später in Literatur verwandeln, Sperber in seiner eindringlichen Parabel vom brennenden Dornbusch, die er seinem Epos »Wie eine Träne im Ozean« voranstellt.

Die Enttäuschung über die zögerliche Haltung der Sozialdemokratie und die Schwäche der österreichischen Kommunisten, wohl aber auch der Wunsch Alfred Adlers, einen Mann seines Vertrauens mit dem Aufbau der individualpsychologischen Schule in Deutschland zu betrauen, bewogen Sperber im Herbst 1927, nach Berlin zu gehen. Er reiste mit einem Pass, ausgestellt von der Wiener Polizeidirektion, der ihn als »staatenlos« auswies. In Berlin trat Sperber der Deutschen Kommunistischen Partei bei, widmete sich mit Eifer der Parteiarbeit, gründete zusammen mit Wilhelm Reich eine psychotherapeutische Praxis und hielt Vorträge über die sozialen Ursachen psychischer Störungen, unter anderem an der berühmten Marxistischen Arbeiterschule Masch, an der auch Georg Lukács, Willi Münzenberg, Bert Brecht, Walter Gropius und Albert Einstein unterrichteten. Sperbers parteipolitische Aktivitäten sowie die Begründung einer »Fachgruppe für dialektisch-marxistische Psychologie« (gemeinsam mit Alice Rühle-Gerstel, ihrem Mann Otto Rühle, Ilse Lang u.a.), deren Programm es war, Marxismus und Tiefenpsychologie zu verbinden, führten schließlich zur Krise und letztlich zum Bruch mit dem verehrten Lehrer Alfred Adler, der bestrebt war, seine Lehre vor jeder ideologischen Vereinnahmung zu bewahren. ${ }^{724}$

722 Manès Sperber: Die vergebliche Warnung (Frankfurt a. M. 1993), S. 148.

723 Sperber, Vergebliche Warnung, S. 154.

724 Vgl. Marta Marková: Auf ins Wunderland! Das Leben der Alice Rühle-Gerstel (Innsbruck 2007), S. 91. 
Am 5. August 1928 heiratete Manès Sperber in Wien die ebenfalls aus Galizien stammende Mirjam Reiter, eine Gefährtin aus der Hashomer-Zeit. Es folgten ausgedehnte Reisen in die Sowjetunion, I93 I eine dreimonatige Reise mit Mirjam zum Moskauer Weltpsychologenkongress, wo er unter anderem mit Nikolaij Bucharin und Béla Kun zusammentraf. Nach der Machtergreifung durch die Nationalsozialisten und der Ausschaltung der Kommunistischen Partei im Deutschen Reich lebte Sperber - von Abschiebung bedroht - in der Illegalität, wechselte ständig die Wohnung, hielt sich zuletzt in der bekannten Künstlerkolonie am Laubenheimer Platz auf, wo er, am I 5. März I933, in einer spektakulären Aktion, zusammen mit dem Journalisten Walter Zadek und dem Schriftsteller Theodor Balk u. a., von der Gestapo in "Schutzhaft" genommen wurde. ${ }^{725}$ Nach fünf Wochen Einzelhaft, die er als »Toter im Wartestand « erlebte, in ständiger Angst, ermordet oder auf der Flucht erschossen zu werden, wurde er am 20. April I933 nach Intervention des polnischen Botschafters plötzlich entlassen. (Hintergrund der diplomatischen Demarche: Für den polnischen Staat galt ein in einer galizischen Gemeinde ausgestellter Heimatschein oder Geburtsschein - analog den Bestimmungen des Versailler Vertrages noch als Nachweis der polnischen Staatsbürgerschaft. Erst I93 8 beschloss Polen ein Gesetz, mit welchem die im Ausland lebenden polnischen Juden ausgebürgert wurden.)

Sperber reiste über Prag nach Wien. Eine Heimkehr wurde es nicht. Zwar waren nach der Machtergreifung der Nationalsozialisten in Deutschland Tausende Flüchtlinge nach Österreich geströmt, auch Juden, und gar nicht wenige wurden später durch den autoritären Ständestaat eingebürgert, doch für den Kommunisten Sperber war dieser Weg versperrt. Mit seiner Frau reiste er Ende April I 933 nach Zagreb, im Auftrag der Komintern und betraut mit der Aufgabe des Aufbaus einer kommunistischen Jugendorganisation in Jugoslawien. Ein jugoslawischer Polizeibericht aus dieser Zeit bezeichnet Sperber als: "polnischer Jude, um dreißig Jahre alt, Flüchtling aus Deutschland, Mensch von zweifelhafter Vergangenheit, gibt sich als Professor der Individualpsychologie aus. Es ist bekannt, dass er in Russland als Lehrer tätig war. Es wird angeraten den Genannten unter rigorose Bewachung zu stellen «. ${ }^{726}$

Im Oktober 1934 folgte Manès Sperber wieder einem Ruf der Komintern, diesmal nach Frankreich. ${ }^{727}$ In Paris arbeitete er zusammen mit Arthur Koestler und Otto Bihalji-Merin am Aufbau des Instituts zum Studium des Faschismus in Frankreich INFA (Institut pour l'Etude du Fascisme), einer Art Clearingstelle der Komin-

725 Marcus G. Patka/Mirjana Stancic (Hg.): Die Analyse der Tyrannis. Manès Sperber 1905-1984, Katalog zur Ausstellung des Jüdischen Museums der Stadt Wien (Wien 2006), S. 69.

726 Stancic, Manès Sperber, S. 250.

727 Die Abmeldung von der elterlichen Wohnung Lilienbrunngasse 8 erfolgte am 17.10.1934; Pass der Wiener Polizeidirektion No. 2508, s t a a t e $\mathrm{n}$ lo s. WStLA, Sperber. 
tern. Zugleich beteiligte er sich an den politischen Aktivitäten seines Mentors Willi Münzenberg, der für die Komintern einen wahren Medienkonzern aufbaute. Nach zunehmenden Zweifeln und unter dem Eindruck des zweiten Moskauer Schauprozesses verließ Manès Sperber im Oktober 1937 die Kommunistische Partei. Als einen seiner Gründe gab er an, dass inzwischen viele seiner vertrauten Freunde in den Gefängnissen der Sowjetunion sich befänden, von deren Unschuld er überzeugt sei. Den Bruch mit der Partei erlebte er als »Fall ins Nichts« - und als tödliche Gefahr: "mit allen Fibern fühle ich es, mit meinem ganzen Bewusstsein weiß ich es: es ist das gefährlichste Jahr meines Lebens. So gefährlich, dass ich nicht weiß, ob ich es überleben werde «. ${ }^{728}$ Einige Monate später, im Herbst 1937, schrieb er den berühmten Essay "Zur Analyse der Tyrannis« und lieferte damit - noch vor Hannah Arendt und Elias Canetti - ein erstes Modell des Totalitarismus.

Im März I938 wurde er am Radio Zeuge des Aufmarsches der Massen am Heldenplatz, hörte die Heilrufe, erlebte von ferne den Untergang Österreichs. Nach dem Überfall Hitlers auf Polen und dem Beginn des Zweiten Weltkrieges meldete sich Manès Sperber noch im September I939 - auch, um der drohenden Internierung zu entgehen - als Freiwilliger bei der französischen Fremdenlegion. Heroisch war die Zeit in der Legion nicht. In »Wie eine Träne im Ozean « beschrieb er die Lächerlichkeit der militärischen Übungen, die kümmerliche Ausrüstung, die Verrohung der Sprache, die Langeweile in elenden Quartieren. In dieser Zeit kam es für Sperber zu einer Wiederbegegnung mit den "Ostjuden«, für die er sich - viele von ihnen sind Analphabeten oder der französischen Sprache nicht mächtig - als Lohnbriefschreiber betätigte. Nicht wenige von ihnen hatten sich - staatenlos wie Sperber - zur Legion verpflichtet, weil sie hofften, nach ihrer Demobilisierung die im Rekrutierungsgesetz versprochene französische Staatsbürgerschaft zu erhalten. Erst knapp vor der französischen Kapitulation, im Juni I940, wurde die Einheit in Rückzugsgefechte verwickelt. Da es die Statuten der Fremdenlegion verboten, sich in Gefangenschaft zu begeben, vermied Sperber jeden Schlaf: "I was determined to kill myself if the moment should arrive that we could no more escape. ${ }^{729}$

Nach seiner Demobilisierung am I 5 . August I 940 in Fuveau, hinter Grenoble, erfuhr er beim Hilfskomitee für Emigranten in Marseille, dass er sich auf einer Auslieferungsliste der Gestapo befand und es für ihn keine Möglichkeit der Ausreise aus Frankreich gab. Ein »Danger Visum« für die USA wurde ihm - möglicherweise aufgrund einer negativen Intervention seines ehemaligen Parteifreundes Hans Sahl ebenfalls verweigert. Seine Demobilisierungsurkunde verhalf ihm immerhin zu Lebensmittelmarken und zu einer halblegalen Existenz in der freien Zone Frankreichs.

728 Manès Sperber, Diese Einsamkeit so dicht, ÖLA/ÖNB, NL Teil II/37.

729 Ebenda, ÖLA/ÖNB, NL Teil II/37. 
Es war eine Zeit der Flucht - nicht nur vor den Deutschen : Sein Freund und Mentor Willi Münzenberg, der 1938 ebenfalls mit der Kommunistischen Partei gebrochen hatte, wurde in einem Wald in Südfrankreich tot aufgefunden, ermordet von ehemaligen Genossen. In der Figur des Lagrange setzte ihm Manès Sperber ein spätes Denkmal. »Es waren«, ließ er einen Genossen sagen, „wirre Zeiten, man rechnete mit den Verrätern ab, den Kollaborateuren«. Man habe mit ihm »kurzen Prozess gemacht ${ }^{730}$

Im September I 942 - inzwischen hatten auch im freien Süden die Deportationen von Juden begonnen - gelang Sperber mit Jenka, seiner zweiten Frau, und ihrem drei Monate alten Sohn Dan, die Flucht über einen Alpenpass in die Schweiz - mit einem falschen französischen Identitätsausweis, der ihn als Elsässer auswies. Erst I 943 - seine Lage hatte sich inzwischen insofern gebessert, als er mit seiner Familie von dem evangelischen Pastor Adolf Maurer aufgenommen worden war, er schreiben, wenn auch nicht publizieren konnte - erfuhr Sperber von einem TreblinkaFlüchtling (Hermann Kesten) von der Verfolgung und Ermordung der Juden in den Ghettos und Schtetl des Ostens. Was der in marxistischer Analyse geschulte Sperber nicht hatte wahrhaben wollen, dass das nationalsozialistische Programm, entgegen jeder "Kapitallogik«, auf die Vernichtung (nicht mehr bloß ökonomische Ausbeutung) der europäischen Juden zielte, wurde nun zur "unfassbaren Gewissheit«. (Dass die "Endlösung « auch sein eigenes Schtetl, Zabłotow, besonders früh und besonders grausam getroffen hatte, wusste er damals noch nicht. ${ }^{731}$ )

Im September I945 - Sperber war mit einem Repatriierungszug in Frankreich eingetroffen - gab es ein Wiedersehen mit André Malraux, dem Freund aus der Zeit der Résistance (inzwischen Informationsminister in der provisorischen Regierung Charles de Gaulles, zuständig unter anderem für die Entnazifizierungsmaßnahmen in der französischen Zone des besetzten Deutschlands). I 946 wurde er von Malraux mit einer besonderen Mission betraut. Mit einem provisorischen Pass ausgestattet reiste Sperber als »Beauftragter für den kulturellen Wiederaufbau« nach Mainz. Hier sollte er - so sein Auftrag - ein Zeitschriftenprojekt zur demokratischen Erziehung der Deutschen entwickeln: die »Umschau«. Nach dem Scheitern des Umschau-Projekts trat Sperber, wieder auf Vermittlung Malraux', als Lektor beim Pariser Verlag

730 Manès Sperber: Wie eine Träne im Ozean (Wien 1961), S. 1021.

731 In der Nacht auf den 22. Dezember 1941 waren 900 Juden aus Zabłotow aus der Stadt geführt worden und nach Aushebung eines Massengrabes erschossen und verbrannt worden. Die verbliebenen Juden (viele davon Frauen und Kinder) wurden am 11. April 1942 in das Ghetto von Kolomea/Kołomyja deportiert (darunter auch Sperbers Großmutter). Die Liquidation des Ghettos von Kolomea erfolgte im Januar 1943 (Sperbers Großmutter verhungerte, da man sie vergaß). Encyclopaedia Judaica, in 26 Bänden (Jerusalem/New York 1971ff), Bd. 16, Eintrag Zabłotov v. 13.5.1978. 
Calmann-Lévy ein, zuständig für die Übersetzung ausländischer Literatur, darunter die Herausgabe des Tagebuchs der Anne Frank.

I 949 kann als das Jahr des eigentlichen Beginns von Sperbers literarischer Karriere gelten. Mit »Der verbrannte Dornbusch« entstand der erste Teil seiner stark autobiographisch getönten Komintern-Saga »Wie eine Träne im Ozean«. Daneben schrieb er ungezählte Beiträge für den »Sender Freies Berlin« und die »Stimme Amerikas«, arbeitete mit Arthur Koestler an einer Charta für Menschenrechte, wurde Mitinitiator des ersten »Kongresses für kulturelle Freiheit« in Berlin (der später in Verdacht geriet, eine CIA-Schöpfung zu sein), entfaltete in diesem Zusammenhang in den I960er- und I970er-Jahren eine starke Reisetätigkeit nach Berlin und Wien, reiste mehrfach nach Israel und in die USA.

Nach dem großen Erfolg seines Romans, der zuerst in Teilen auf Französisch publiziert wurde und 1960 auf Deutsch erschien, stellten sich Ehrungen und Preise ein: 1975 der renommierte Büchner Preis der Deutschen Akademie für Sprache und Dichtung in Darmstadt, I 977 der große Österreichische Staatspreis für Literatur, I983 der Friedenspreis des Deutschen Buchhandels. In seinen Dankesreden wurde Sperber immer mehr zum leidenschaftlichen Europäer, hoffte auf ein baldiges Ende des Totalitarismus in Osteuropa, hoffte auf ein den USA ebenbürtiges, vereintes demokratisches freies Europa. Dass er den Fall der Berliner Mauer, den Zusammenbruch des sowjetischen Imperiums, den Demokratisierungsprozess in den mittel-osteuropäischen Staaten und ihren Eintritt in die Europäische Union nicht mehr erlebte, gehört zur Tragik seines Lebens, eines Lebens, das von scharfen Brüchen, Trennungen, Glaubensverlusten gekennzeichnet war. Manès Sperber wurde oft als der "Romancier des Exils« gesehen, für den es, wie für seinen Helden Denis Faber (Dojno), »keine Heimkehr" gab. ${ }^{732}$ Er selbst hat seine fundamentale »Heimatlosigkeit«, sein »lebenslanges Exil« vielfach zum Thema gemacht, beschwört häufig das Bild des ewigen Wanderers, der Ausschau hält nach den »Hügeln hinter den Hügeln« - nach einem neuen Land. Dieses Ahasver-Motiv verdeckt nur eines: den Tatbestand seiner beinahe lebenslangen Staatenlosigkeit. Manès Sperber hat, wie so viele andere auch, darüber geschwiegen, hat - als überzeugter Internationalist - vielleicht sogar versucht, daraus eine Tugend zu machen. Nur allzu konsequent erscheint es dann, dass die Gruppe, die Gemeinschaft, die Partei zur eigentlichen Heimat wurde. "Nicht allein sein ist viel wichtiger« als Recht haben, lässt er einen seiner Romanhelden einmal sagen. Doch als sich am Ende alle Gemeinschaften, alle Gruppen, alle Parteien als Illusion erweisen, wird es ein Sturz ins Bodenlose, ein Sturz »Tiefer als der Abgrund «. ${ }^{733}$

732 Vgl. Sperber, Träne im Ozean, S. 645.

733 So eine Kapitelüberschrift in "Wie eine Träne im Ozean«. 
Wie Jenka Sperber in ihrem Essay über das letzte Jahr Sperbers schreibt, befiel ihn im Jahr 1952 (nach der Vollendung seiner Romantrilogie) ${ }^{734}$, eine schwere Depression, die später in einer Angina pectoris mündete. Einen möglichen Grund nennt er selbst in »Churban oder die unfassbare Gewissheit «. Für Manès Sperber bestand im Sommer 1952 kein Zweifel mehr, dass Stalin fortsetzte, was vor dreihundert Jahren von Bogdan Chmelnitzkij begonnen worden war. "In den sowjetischen Zeitungen hetzt man gegen die 'Kosmopoliten`, indem man ihre jüdische Abstammung enthüllt. Leute ohne Ausweis, als solche bezeichneten die Pogromisten seinerzeit die Juden. Der Ausdruck wird nun wieder verwandt und kehrt in der offiziellen Sprache immer wieder. (...) Nach dem Churban lebten in der Sowjetunion noch eine Million Juden. Das autoritäre Regime kann ihre Existenz nicht dulden, weil es ist, was es ist. Und weil sie, die Juden, geblieben sind, die sie immer waren. (...) Ob man ihre Vernichtung "mit der Notwendigkeit begründen wird, die Kosmopoliten ohne Vorfahren, die Individuen ohne Reisepass endgültig zu beseitigen, um das Komplott der trotzkistisch-zionistischen Verschwörer in den Satellitenstaaten zu verhindern - gleichviel. Die Juden können in der Sowjetunion zugrunde gehen, fast ohne Geräusch. « ${ }^{735}$

Als Manès Sperber dies im Juni 1952 schrieb, zur Zeit des Korea-Krieges und am Höhepunkt des Kalten Krieges, war er noch immer ohne Ausweis. Zwar wies ihn schon 1946 ein Dokument - jener Ordre de Mission, mit dem ihn Malraux in das besetzte Deutschland schickt - als »Franzose« aus, doch handelte es sich dabei um einen Pass der provisorischen Regierung. Naturalisiert wurde Sperber in Frankreich erst im Jahr I960. Was erklärt sein langes Zögern? Könnte es sein, dass es die Nation, der er angehören wollte, allein angehören konnte, noch nicht gab, dass Sperber, wie Jean Pierre Condere vermutet, trotz seiner Liebe zu Frankreich auf das Kommen eines europäischen Passes gewartet habe ${ }^{736}$ Sperber selbst schreibt im dritten Band seiner Autobiographie, ohne das Faktum seiner Einbürgerung in Frankreich zu erwähnen: "Seit langem war ich kein Emigrant mehr; die Hälfte des Lebens lag hinter mir, es war Zeit, dass da, wo ich lebte, für mich hier werde und jeder andere Ort dort«. Er hatte für sich nun auch die Frage der Sprache gelöst, wurde ein zweisprachiger Schriftsteller, schrieb die Romane deutsch und die Essais französisch. ${ }^{737}$

734 Vgl. Stancic, Manès Sperber, S. 521, sowie Jenka Sperber: Sein letztes Jahr (München 1985).

735 Manès Sperber: Mein Judesein, in: Churban oder Die unfassbare Gewissheit (Wien/München/ Zürich 1979), S. $109 f$.

736 »... malgré son amour de la France, ne peut se prendre pour un Français. Son arrangement intime, c'est d'avoir imaginé un passeport européen dont il serait l'unique détenteur«. Jean Pierre Condere in: L'Express v. 25.11.1983, S. 87.

737 Manès Sperber: Bis man mir Scherben auf die Augen legt. All das Vergangene. Band 3 (Frankfurt a. M. 1977), S. 364. 
Keiner der Überlebenden seiner Familie kehrte nach Österreich zurück. Seine Eltern und Brüder waren, wie er sagt, »keine Engländer geworden«, aber »Briten, das heißt Staatsbürger des United Kingdom «. ${ }^{738}$ Manès Sperber wurde - voll Melancholie und unendlichem Heimweh nach Wien - Bürger der Republik Frankreich.

In den zahlreichen Interviews seiner letzten Jahre gab Sperber an, jeden Glauben an ein Absolutes verloren zu haben, ein »Leben im Zweifel zu leben«. Doch sei er immer auf der Seite der "Wasserträger " geblieben, "und auch um ihrethalben, auch deshalb habe ich gebrochen «. ${ }^{739}$ Für die Ungläubigen dieses Jahrhunderts (des zwanzigsten) habe es nur eine Hoffnung gegeben: eine sozialistische Gesellschaft, die allen Menschen das gleiche Maß an Recht, Freiheit und Schutz vor materiellem Elend gewährleistet. Der Menschheit von heute sei diese ungeheure Hoffnung vergiftet, zerschlagen worden. Es sei schwer, zu leben ohne Hoffnung. Es sei auch schwer, ohne ein Absolutes zu leben. Als glaubensloser Jude galt es ihm, wie er einmal sagte, "so zu leben, dass für den Messias ein ausreichender Grund entsteht zu kommen «. ${ }^{740}$ Wovon Sperber nicht sprach, vielleicht nicht sprechen konnte, war, dass es sehr wohl einer Instanz bedarf, die dieses "gleiche Recht für alle«, welches er erträumte, auch tatsächlich garantiert, und dass diese Instanz - solange der Messias denn ausbleibt nur ein Staat sein kann.

738 Ebenda, S. 366.

739 Manès Sperber im Gespräch mit Wendelin Schmidt-Dengler, Katalog, S. 86.

740 Ebenda. 


\section{Semantische Nachbemerkungen}

"Dass lässt mich darüber nachdenken, was es bedeutet, sich einem Ort zugehörig zu fühlen. Charles starb als Russe in Paris. Viktor hielt das für falsch; er war fünfzig Jahre lang ein Russe in Wien, dann Österreicher, dann Bürger des Deutschen Reichs, dann staatenlos. Elisabeth behielt fünfzig Jahre lang in England die niederländische Staatsbürgerschaft. Und Iggi war Österreicher, dann Amerikaner, dann ein in Japan lebender Österreicher. Man assimiliert sich, aber einen Ort muß es geben, wo man hingehen kann. Man hält den Pass bereit. Man behält etwas Privates. «Mit diesen Sätzen beendet Edmund de Waal seinen Roman »Der Hase mit den Bernsteinaugen «, mit welchem er seiner Familie, den aus Russland stammenden Ephrussi, ein grandioses Denkmal setzte. ${ }^{741}$ Hier wie in den vorstehenden drei biographischen Fallstudien: Martha Raviv, Elias Canetti, Manès Sperber wird deutlich, wie sehr Heimatrecht und Staatsbürgerschaft oder, umgekehrt, ihr Verlust, Leben und Identität von Menschen - in gleich welcher Staatsform - prägen konnten.

Heute scheint die Bedeutung von Staatsbürgerschaft im Schwinden begriffen zu sein. Veränderte Lebensentwürfe und Karriereverläufe, Lebensphasen in mehreren Staaten, gemischtnationale Ehen und Familien sowie Metastaatsbürgerschaften wie die »Unionsbürgerschaft« der Europäischen Union scheinen das herkömmliche, an den Nationalstaat gebundene Staatsbürgerschaftsmodell gleichsam von innen her aufzusprengen. Trotz gegenläufiger nationalstaatlicher Strategien sei ein »Leichterwerden« der Staatsbürgerschaft (»Lightening of Citizenship»), gibt sich Christian Joppke überzeugt, unvermeidlich. ${ }^{742}$ Längst schon werden Fragen einer multinationalen oder transnationalen Staatsbürgerschaft diskutiert - dies vor allem deshalb, weil sich Staat und Gesellschaft einem neuen Typus von Migration gegenübersehen, d.h. einer Migrantengeneration, die sich aus den verschiedensten Gründen nur bedingt oder gar nicht mehr integrieren kann oder will. ${ }^{743}$ Bemerkenswert an

741 De Waal, Hase, S. 325.

742 Christian Joppke: The Inevitable Lightening of Citizenship, in: European Journal of Sociology 51 (1) (2010), S. 9-32.

743 Nina Glick Schiller/Linda Basch/Christina Blanc Szanton: Transnationalismus: Ein neuer analytischer Rahmen zum Verständnis von Migration, in: Heinz Kleger (Hg.): Transnationale Staatsbürgerschaft (Frankfurt a. M. 1997) S. 81-108; siehe dazu auch die Studie von: Gökce Yurdakul/ Michal Bodemann: Staatsbürgerschaft, Migration und Minderheiten (Wiesbaden 2010) sowie die 
dieser Diskussion ist, dass von jüdischer Seite die Möglichkeit einer transnationalen Staatsbürgerschaft in der Vergangenheit eher verneint wurde. So wies der französische Intellektuelle Raymond Aron im Jahr I973 darauf hin, dass die Staatsbürgerschaft wechselseitige Rechte und Pflichten beinhalte - allen voran die Wehrpflicht und sie deshalb sogar »in ihrer Quintessenz national « sei. ${ }^{744}$ Und Hannah Arendt plädierte in ihren Werk »Elemente und Ursprünge totaler Herrschaft« eindringlich für einen Primat der Staatsbürgerrechte (und den Nationalstaat als Garanten derselben) gegenüber vermeintlich universalen, in Wahrheit aber - ohne diesen staatlichen Garanten - bedeutungslosen Menschenrechten. ${ }^{745}$ „Die Juden meiner Generation können nicht vergessen ", so noch einmal Raymond Aron, "wie zerbrechlich diese Menschenrechte wurden, als sie nicht mehr mit den (Staats)Bürgerrechten einhergingen. ${ }^{746}$ In den letzten Jahren zeichnet sich jedoch so etwas wie ein Primat der Menschenrechte ab. Diese werden jetzt nicht mehr nur in einzelnen nationalen Verfassungen, etwa durch Grundrechtskataloge, garantiert, sondern in zahllosen supranationalen Rechtsabkommen kodifiziert und konkretisiert. Durch die antidiskriminatorische und appellative Tätigkeit von "Non-Governmental Organisations" seien sie, so Gerald Stourzh, im Bewusstsein der Weltöffentlichkeit präsenter denn je. ${ }^{747}$ Internationalisierung und Globalisierung haben nicht zuletzt auch zu einer gewissen Ent-grenzung des Rechts geführt - davon ist das Staatsbürgerschaftsrecht nicht ausgenommen.

Bezeichnete der Begriff Staatsbürger bisher eine Person, die - um eine alte Formel des Allgemeinen bürgerlichen Gesetzbuches von I 8 I I aufzunehmen - im »vollen Genuß der bürgerlichen Rechte« ist, so haben die vorgenannten Entwicklungen dazu geführt, dass in vielen Staaten immer mehr Menschen von diesem vollen Genuß der bürgerlichen Rechte ausgeschlossen sind. Zwar sind die sichtbaren Außengrenzen eines Staates - zumindest in Europa - überall im Schwinden, doch neue, unsichtbare Grenzen tun sich auf in allen Ländern zwischen Staatsbürgern und Nichtstaatsbürgern, zwischen Inländern und »Fremden«, Fremden mit Teilrechten und Fremden mit geringen Rechten. Alle diese Entwicklungen führten in letzter Zeit dazu, dass von den verschiedensten rechtsphilosophischen, soziologischen und

gedruckte Dissertation von David Reichel: Staatsbürgerschaft und Integration. Die Bedeutung der Einbürgerung für MigrantInnen (Wiesbaden 2011).

744 Raymond Aron: Kann es eine multinationale Staatsbürgerschaft geben?, in: Kleger, Transnationale Staatsbürgerschaft, S. 24-41 sowie Einleitung zu diesem Band, S. 21.

745 Arendt, Ursprünge, S. 453ff. Eine Position, die allerdings auch viel Kritik erfahren hat, etwa, dass Arendt nie einen Weg aus dem "Trauma" der Staatenlosigkeit gewiesen habe und gegenüber der Durchsetzbarkeit von universalen Standards der Menschenrechte zu pessimistisch eingestellt gewesen sei. Siehe: Cohen, In War's Wake, S. 89.

746 Raymond Aron, zit. nach: Kleger, Transnationale Staatsbürgerschaft, S. 21.

747 Stourzh, Die Gleichheit alles dessen, S. 282. 
politologischen Positionen aus versucht wurde, den Begriff Staatsbürgerschaft neu zu bestimmen, seine semantischen Grenzen neu auszuloten.

Staatsbürgerschaft erwies sich in der Geschichte als ein Instrument territorialer, sozialer und ökonomischer Schließung (T. H. Marshall). Staatsbürgerschaft als Begriff erscheint daher immer im Modus von Inklusion und Exklusion. Mit neuen Denkansätzen : radikaldemokratischen, liberalen, kommunitaristischen, ökologischen, feministischen oder welt/erd/bürgerlichen versucht man gegenwärtig die alten Schließungen aufzubrechen. ${ }^{748}$

Die Fragen etwa, ob es eine europäische Staatsbürgerschaft geben könne, solange die politische Öffentlichkeit nationalstaatlich bestimmt bleibt, ob differenzierte, fragmentierte, postnationale Staatsbürgerschaften denkbar seien ${ }^{749}$, ja, ob eines Tages auch Tiere und Pflanzen in eine Theory of citizenship einbezogen werden könnten, werden gegenwärtig kontrovers diskutiert. ${ }^{750}$ Ein Wahlrecht für Hunde, Bienen und Erdbeeren, wie Carolyn Christov-Bakargiev es unlängst forderte, scheint dann keineswegs mehr bloß Ausdruck künstlerischer Exzentrik zu sein, sondern einer nachhumanistischen Ethik, die, angesichts des ökologischen Zustandes der Welt, zunehmend Zuspruch erfährt. ${ }^{751}$

Dabei löst sich die alte semantische Klammer um Staatsbürgerschaft und nationale Identität, wie Jürgen Habermas befindet, allmählich auf. ${ }^{752} \mathrm{Neu}$ ist dieser Befund allerdings nicht, ebenso wenig wie seine immer wieder erhobene Forderung nach einer Weltbürgerschaft. Bereits in den späten I 940er-Jahren hatten bedeutende

748 Exemplarisch seien genannt: Etienne Balibar: Die Grenzen der Demokratie (Hamburg 1992); John Rawls: Der Vorrang der Grundfreiheiten, in: derselbe, Die Idee des politischen Liberalismus. Aufsätze 1978-1989 (Frankfurt a. M. 1992), S. 159-254; Charles Taylor: Multikulturalismus und die Politik der Anerkennung (Frankfurt a. M. 1993); Will Kimlicka: Multicultural Citizenship. A Liberal Theory of Minority Rights (Oxford/New York 1995); Michael Walzer: Zivile Gesellschaft und amerikanische Demokratie (Frankfurt a. M. 1996); Drucilla Cornell: The Philosophy of the Limit: System Theory and Feminist Legal Reform, in: dieselbe et al. (Hg.): Deconstruction and the Possibility of Justice (New York/London 1992); Janna Thompson: Justice and World Order (London/New York 1992); Bart van Steenbergen: The Condition of Citizenship (London 1994), F. Stewart: Citizens of Planet Earth, in: G. Andrew (Hg.): Citizenship (London 1991).

749 Jean-Marc Ferry: Die Relevanz des Postnationalen und Charles Taylor: Was ist die Quelle kollektiver Identität? sowie Jean-Marc Ferry: Europäische Identität und europäischer Bürgerstatus. Anmerkungen zum Gipfel von Maastricht, alle in: Nicole Dewandre/Jacques Lenoble (Hg.): Projekt Europa. Postnationale Identität: Grundlage für eine europäische Demokratie? (Berlin 1994), S. 30-41, S. 42-46 u. S. 111-118.

750 Sue Donaldson/Will Kimlicka: Zoopolil. A Political Theory of Animal Rights (Oxford/New York 2011), S. $50 \mathrm{ff}$.

751 Carolyn Christov-Bakargiev, Interview vom 31.5.2012 in: www.sueddeutsche.de/kultur/documenta-leiterin-carolyn-christov-bakargiev.

752 Habermas, Jürgen: Staatsbürgerschaft und nationale Identität. Überlegungen zur europäischen $\mathrm{Zu}$ kunft, in: Dewandre/Lenoble, Projekt Europa, S. 11-29, hier: S. 12. 
Intellektuelle, darunter Albert Einstein, Bertrand Russell, Bernhard Shaw, John dos Passos und Aldous Huxley, in einem offenen Brief an den damaligen Generalsekretär der Vereinten Nationen, Trygve Lie, eine world citizenship für die Millionen von staatenlosen Menschen nach dem Zweiten Weltkrieg gefordert. Die Unterzeichneten verlangten - allerdings vergeblich -, dass die Staatenlosen nicht verpflichtet werden sollten, sich um eine Nationalisierung in einem bestimmten Nationalstaat zu bewerben. "By sheer force of events they have acquired the feeling of belonging to a community larger than one nation. Ideed, History made them citizens of the world, and they should be treated as such « $^{753}$ - ein Aufruf, der bloße Utopie bleiben sollte. Im Gegenteil drifteten die einzelnen historisch gewachsenen Staatsbürgerschaftsrechte immer weiter auseinander. Neuere rechtsvergleichende Studien weisen immer wieder auf die Unvereinbarkeit der höchst unterschiedlichen Staatsbürgerschaftskonzeptionen im europäischen Raum hin: auf die Dichotomie von Code civil und preußischem Allgemeinen Landrecht und die mit diesen Kodizes verbundenen Rechtsbegriffe ius soli und ius sanguinis (ein »Recht des Bodens " und ein "Recht des Blutes") - auf eine vermeintlich fortschrittliche und eine vermeintlich rückschrittliche Konzeption von Staatsbürgerschaft. ${ }^{754}$ Die Staatsbürgerschaftskonzeptionen der »Vielvölkerreiche« erfahren dagegen erst in jüngster Zeit einige Aufmerksamkeit, und man beginnt, die besondere Bedeutung von Staatsbürgerschaft für multinationale/multiethnische Staaten zu erkennen. Was die Menschen in einem multinationalen Staat bindet, konstatiert etwa T. K. Oommen in einer komparatistischen Studie für Großbritannien und Indien, »is common citizenship«, wobei er Staatsbürgerschaft als den Kitt zwischen den differenten ethnischen und kulturellen Entitäten auffasst. ${ }^{755}$

Es wurde in dieser Studie nicht versucht, das eine Modell österreichischer Staatsbürgerschaft zu liefern, das sich umstandslos in eine europäische Matrix einschreiben ließe. Die Praxis des Staatsbürgerschaftsrechts in der österreichischen Monarchie war - wie in jedem anderen Staat auch - eine Praxis der Einschließungen und Ausschließungen. Diese wurde im Laufe der historischen Entwicklung, wie gezeigt, einmal aufgeklärt-physiokratisch, absolutistisch, neoabsolutistisch-

753 Zit. nach: Cohen, In War's Wake, S. 91.

754 Brubaker: Staats-Bürger; Julia Kristeva: Fremde sind wir uns selbst (Frankfurt a. M. 1990), S. 104ff.; Rogers Brubaker: Einwanderung und Nationalstaat in Frankreich und Deutschland, in: Der Staat 28 (1989) 1-30; Reinhart Koselleck: Preußen zwischen Reform und Revolution. Allgemeines Landrecht, Verwaltung und soziale Bewegung von 1791 bis 1848 (= Schriftenreihe des Arbeitskreises für moderne Sozialgeschichte 7) (Stuttgart 1967), S. 53-77; Christoph Conrad/ Jürgen Kocka (Hg.): Staatsbürgerschaft in Europa: historische Erfahrungen und aktuelle Debatten (Hamburg 2001).

755 T.K. Oommen: Citizenship, Nationality and Ethnicity. Reconciling Competing Identities (Cambridge 1997), S. 45. 
zentralistisch, dann konstitutionell-dualistisch bzw. konstitutionell-differentialistisch gehandhabt, zu keiner Zeit allerdings - auch nicht in der Spätzeit der Monarchie, als ethnisierende Tendenzen sich auch in der Praxis des Staatsbürgerschaftsrechts breitmachten - konnte der ursprüngliche »Geist der Gesetze«, den Franz von Zeiller in seinen Vorträgen und Kommentaren zum "Allgemeinen bürgerlichen Gesetzbuch « eindrucksvoll dargelegt hat, in dem sich physiokratische, naturrechtliche und kantianisch-weltbürgerliche Grundsätze widerspiegeln, völlig verleugnet werden. ${ }^{756}$

Die frühneuzeitlichen Begriffe "Bürger" (civis) und "Untertan" (subditus) hatten über Jean Bodin, Samuel Pufendorff und Hugo Grotius schon früh Eingang in die österreichische Naturrechtslehre, insbesondere bei Carl Anton von Martini, gefunden. ${ }^{757}$ Dass auch der Begriff Staatsbürger im österreichischen Rechtswesen überraschend früh auftaucht, darauf wurde eingangs schon hingewiesen: »Jeder Staatsbürger ohne Unterschied des Ranges, des Standes oder Geschlechtes ist verpflichtet die allgemeine Wohlfahrt des Staates durch genaue Befolgung der Gesetze möglichst befördern zu helfen «, heißt es etwa in jenem »Ur-Entwurf " für ein österreichisches allgemeines Gesetzbuch, das unter dem Namen »Westgalizisches bürgerliches Gesetzbuch «(WGGB) I 797 kundgemacht wurde 758 - nur wenige Jahre nachdem der Begriff »Staats-Bürger« durch Wieland populär geworden war und durch Kant seine vorläufige Prägung gefunden hatte. ${ }^{759}$ Eine Definition des Begriffs Staatsbürger allerdings findet sich in jenem Westgalizischen Gesetzbuch ebenso wenig wie in dem durch zwei große Revisionen gegangenen, inhaltlich wie formal stark veränderten, mit Patent vom I. Juni I 8 I I kundgemachten Allgemeinen bürgerlichen Gesetzbuch (ABGB). Mit diesem wurden zwar erstmals in seinem Geltungsbereich genaue Be-

756 Franz v. Zeiller, Vortrag zur Einleitung in das bürgerliche Gesetzbuch vom 5. Juli 1810 vor der Hofkommission in Gesetzessachen, Allgemeines Österreichisches Verwaltungsarchiv, Wien (AVA), Bestand Oberste Justiz, Fasc. ABGB, aus 1810 (Brandakt), S. 23.

757 Siehe dazu: Manfred Riedel: Stichwort: Bürger, Staatsbürger, Bürgertum, in: Otto Brunner/Werner Conze/Reinhart Koselleck (Hg.): Geschichtliche Grundbegriffe. Historisches Lexikon zur politisch-sozialen Sprache in Deutschland, Bd. 1 (Stuttgart 1973), S. 672-718.

758 Zit. nach: Julius Ofner (Hg.): Der Ur-Entwurf und die Berathungs-Protokolle des Österreichischen Allgemeinen bürgerlichen Gesetzbuches, Bd. 1 (Wien 1889), S. IV.

759 Wieland hatte bereits im September des Revolutionsjahrs 1789 im "Teutschen Merkur" nach einem Äquivalent für Citoyen gesucht und dafür das deutsche Wort Staats-Bürger eingesetzt. Kant hat den Begriff zuerst in seiner Schrift „Über den Gemeinspruch: Das mag in der Theorie richtig sein, taugt aber nicht für die Praxis« (erschienen 1793 in der "Berlinischen Monatsschrift«) verwendet: "Derjenige nun, welcher das Stimmrecht in dieser Gesetzgebung hat, heißt ein Bürger (citoyen, d.i. Staatsbürger, nicht Stadtbürger, bourgeois)."(Wilhelm Weischedel (Hg.): Werkausgabe Bd. XI (Frankfurt am Main ${ }^{2} 1964$ ), S. 151); zwei Jahre später, 1795, verwendete er den Begriff bereits ohne Unterscheidung zwischen aktiven und passiven Staatsbürgern. Immanuel Kant: Zum ewigen Frieden, Wilhelm Weischedel (Hg.): Werkausgabe Bd. XI, S. 204. 
stimmungen über Erwerb und Verlust der österreichischen Staatsbürgerschaft erlassen, doch umsonst suche man, klagte der Verfasser der ersten Monographie »Über die Österreichische Staatsbürgerschaft « Gotthart von Buschmann, »nach einer ausdrücklichen Begriffsbestimmung«. Mangels dieser bliebe, so Buschmann, gar nichts anderes übrig, "als die Begriffe aus dem Geist der Gesetzgebung« abzuleiten. ${ }^{760}$

Staatsbürger und Staatsbürgerschaft waren Ende des I 8. Jahrhunderts im Allgemeinen noch subversive Begriffe. Sie enthielten, wie Reinhart Koselleck bemerkt, ein Versprechen, das Versprechen, dass anstelle einer überkommenen Standesgesellschaft eine Gesellschaft formal gleichberechtigter Staatsbürger treten solle. ${ }^{761}$ In der österreichischen Monarchie allerdings wurden die neuen Begriffe keineswegs subversiv von einem sich formierenden aufbegehrenden Bürgertum gebraucht, sondern in aufklärerischer Absicht von den josephinischen Eliten selbst. Staatsbürger und Staatsbürgerschaft wurden - aufgeladen mit allem josephinischen Pathos - rasch zu Kampfbegriffen, die sich gegen Ständeherrschaft und jeden Partikularismus richteten. Dabei war man sich der schwierigen Gratwanderung bei der Übernahme der "französischen Ideen« durchaus bewusst. So verteidigte etwa Joseph v. Sonnenfels die Übernahme des Begriffs Bürger in seine Staatslehre mit der Bemerkung, dass sich seiner ja nicht unbedingt "Empörer und Sklaven « annehmen müssten, sondern eben Bürger. „Denn warum soll in dem Mißbrauche eingeräumt sein, den Sinn eines Wortes verdächtig zu machen oder zu entstellen, das bis jetzt immer einen Menschen bezeichnet hat, der unter dem unmittelbaren Schutze der öffentlichen Verwaltung die Rechte der gesellschaftlichen Vereinigung genießt und nur Gesetzen und dem Organe der Gesetze, dem Oberhaupt des Staates, untertan ist. " ${ }^{762}$

Eine weitere Schwierigkeit des Umgangs mit den Begriffen Staatsbürger und Staatsbürgerschaft (im altösterreichischen Kontext) liegt darin, dass sie nicht nur im Zeitablauf der hier beschriebenen Epoche, sondern auch in der diese Epoche interpretierenden staatswissenschaftlichen Literatur ihre Bedeutung stark veränderten. So wurde das "allgemeine österreichische Reichsbürgerrecht « der oktroyierten Märzverfassung von I 849, das jetzt auch für die ungarischen Länder gelten sollte, oft als die "vollkommenste Ausformung " des österreichischen Staatsbürgerschaftsrechts gepriesen. ${ }^{763}$ Die Staatsrechtslehre der späten Monarchie sah mit der Reichsbürgerschaft von I 849 das verwirklicht, wonach schon die Autoren des Allgemeinen bürgerlichen

760 Gotthard von Buschmann: Über die österreichische Staatsbürgerschaft (erste Auflage 1833, Wien $\left.{ }^{2} 1841\right)$, S. 10.

761 Reinhart Koselleck: Vergangene Zukunft. Zur Semantik geschichtlicher Zeiten (Frankfurt a. M. 1979), S. 111.

762 Joseph v. Sonnenfels, Handbuch der inneren Staatsverwaltung, Bd. 1 (Wien 1798), S. XXX.

763 Rudolf v. Herrnritt: Handbuch des österreichischen Verfassungsrechtes (Tübingen 1909), S. 79. 
Gesetzbuches vergeblich gestrebt hatten: die Zurückweisung jedes Partikularismus, die Aufhebung jeder besonderen Landeszugehörigkeit, die Verwirklichung des modernen Einheitsstaates. ${ }^{764}$

Einheitlichkeit, Gleichförmigkeit und Allgemeinheit blieben auch dann das Ideal, als nach dem Ausgleich von I 867 die Monarchie in zwei wesensverschiedene Reichshälften geteilt wurde, wobei sich Ungarn in Konsequenz des Dualismus ein modernes, nach französischem Vorbild »in einem Guß « geschaffenes Staatsbürgerrecht gab. ${ }^{765}$ Für das für die österreichische Reichshälfte am 2 I. Dezember I 867 verkündete »allgemeine Staatsbürgerrecht « blieb das angekündigte Gesetz über die besonderen Bedingungen, unter welchen die Staatsbürgerschaft erworben und verloren wird, jedoch aus. ${ }^{766}$ Das österreichische (cisleithanische) Staatsbürgerschaftsrecht existierte also weiterhin in einer Vielzahl von Einzeldekreten, die teils vor, teils nach und in Ergänzung zum Allgemeinen bürgerlichen Gesetzbuch von I 8 I I erlassen worden waren. Auch standen die beschriebenen älteren Rechtsformen Incolat und Indigenat, "gemischte Untertanen" (sujets mixtes), Schutzgenossen und Untertanen de facto bis zum Ende der Monarchie einer allgemeinen und gleichen Staatsbürgerschaft, wie sie mit dem Staatsgrundgesetz vom Dezember I 867 eigentlich hätte durchgesetzt werden sollen, entgegen. Das von einer älteren Staatswissenschaft beklagte Zufällige und Unbestimmte der historischen Rechtsentwicklung ${ }^{767}$ barg allerdings auch eine Chance, die Chance nämlich, nicht nach einem Prinzip handeln zu müssen; dies ermöglichte einen Rechtspragmatismus, der der altösterreichischen Gesetzgebung überhaupt eigen ist. ${ }^{768}$ Die Tatsache jedenfalls, dass das österreichische Staatsbürgerschaftsrecht in seiner Entwicklung vom Ende des I 8. Jahrhunderts bis zum Ende der Monarchie in seinem Kern durch das Zivilrecht, das Allgemeine bürgerliche Gesetzbuch bestimmt wurde, "dem zugleich verbindlichsten, freiesten und sanftesten Gesetz « ${ }^{769}$, bedeutete auch, dass es alle Elemente des »natürlichen Privatrechtes«: Gleichberechtigung und Gleichbehandlung, Freiwilligkeit und Vertragsfreiheit - zumindest als Versprechen - in sich enthielt. (Ralph W. Mathisen wies unlängst mit

764 Josef Fritz Redlich: Das österreichische Staats- und Reichsproblem, Bd. I (Leipzig 1929), S. $341 \mathrm{ff}$. 765 Milner: Gesetzartikel L: 1879, S. 104.

766 »Das Gesetz bestimmt, unter welchen Bedingungen das österreichische Staatsbürgerrecht erworben, ausgeübt und verloren wird«, lautete der zweite Absatz des Artikel 1, zit. nach: Goldemund/Ringhofer/Theurer, Staatsbürgerschaftsrecht, S. 35.

767 Vgl. Fritz Karminski: Zur Codifikation des österreichischen Staatsbürgerschaftsrechtes (Wien 1887), S. 4.

$768 \mathrm{Zu}$ den philosophischen Grundlagen des Rechtspragmatismus in Österreichs vgl. Michael Benedikt: Natürliches Privatrecht und bürgerliche Souveränität. Franz v. Zeilers Kantrezeption in Österreich, in: derselbe (Hg.): Verdrängter Humanismus - verzögerte Aufklärung, Bd. 1 (Wien 1992), S. 659-708, hier: S. 690f.

769 Benedikt, Natürliches Privatrecht, S. 707. 
Bezug auf die heutigen Debatten um Staatsbürgerschaft und Weltbürgerrecht darauf hin, dass es im Römischen Reich der Zugang und Gebrauch des ius civile, des Zivilrechts, war - und nicht Ethnizität oder Religion -, der letztlich darüber entschied, wer Bürger, cives romani, war und wer nicht. ${ }^{770}$ )

Eine weitere Besonderheit des österreichischen Staatsbürgerschaftsrechts war neben der beschriebenen engen Verknüpfung mit dem Heimatrecht -, dass es ab I 867 auch Bestandteil des Grundrechtskatalogs der Verfassung war: „Für alle Angehörigen der im Reichrate vertretenen Königreiche und Länder besteht ein allgemeines österreichisches Staatsbürgerrecht", lautete Artikel I des Staatsgrundgesetzes. $\mathrm{Zu}$ diesen Grundrechten gehörte neben dem Gleichheitsgrundsatz (Artikel 2), der Freizügigkeit (Artikel 4), der Glaubens- und Gewissensfreiheit (Artikel I4) auch die Anerkennung der Verschiedenheit von Ethnizität und Sprache. Zwar war mit dem im Artikel I9 des Staatsgrundgesetzes ausgesprochenen Grundrecht auf »Wahrung und Pflege von Nationalität und Sprache« sowie der "Gleichberechtigung aller landesüblichen Sprachen « - nicht die jüdische »Nationalität« und schon gar nicht eine jüdische Sprache, das Jiddische etwa, gemeint (gemeint war vielmehr in liberaler Tradition ein individuelles Freiheitsrecht, ein Recht des Staatsbürgers), doch der in Verfassungsrang erhobene Rechtsgrundsatz ethnischer und sprachlicher Neutralität des Staates kam indirekt auch den Juden zugute.

Es scheint ganz ohne Zweifel, dass es die Inkorporation der Juden in dieses Modell der österreichischen Staatsbürgerschaft war (im Verein mit einem nunmehr uneingeschränkten Zugang zu einem jetzt säkularen und überkonfessionellen Bildungswesen), die den im I8. Jahrhundert begonnenen Emanzipationsprozess vollendete und den jüdischen Staatsbürgern und - mit großen Einschränkungen, aber zunehmend auch - Staatsbürgerinnen eine nie dagewesene Teilhabe in allen Bereichen gesellschaftlichen, politischen, wirtschaftlichen und kulturellen Lebens sicherte wobei das hier beschriebene komplexe Modell der Staatsbürgerschaft wohl auch zur Pluralität und Vielfalt des österreichischen Judentums insgesamt beitrug, das einmal als (Bei-)träger und Speerspitze der Moderne, als Kern (oder Submenge) des neuen Bürgertums oder auch als Bewahrer traditioneller Lebensformen, als »Residuen einer Vormoderne« (Dan Diner) in Erscheinung trat.

Die Versuche, dieses Modell zu zerstören - bereits in der Phase einer radikalen Ethnisierung aller Lebensbereiche in der späten Monarchie und später in der Anfangsphase der Ersten Republik - sind hier ausführlich beschrieben worden. Doch erst während der Zeit der nationalsozialistischen Herrschaft in Österreich wurden mit der Eliminierung des Heimatrechts durch die Zweite Verordnung zum Reichsbürgergesetz vom 30. Juni I 939 die letzten Reste dieses Modells endgültig ausge- 
löscht. Früh hatte eine nationalsozialistische Staatswissenschaft gegen das »irregeleitete Denken in römisch-rechtlichen und später liberalistisch-demokratischen Begriffen, die nur den Einzelmenschen und seine Interessen sahen " polemisiert. ${ }^{771}$ "Der Nationalsozialismus bedeutet«, schrieben Wilhelm Stuckart und Hans Globke in ihrem bekannten Kommentar zu den »Nürnberger Gesetzen«, »eine Abkehr von dem liberalistischen Grundsatz von der Gleichheit aller «. ${ }^{772 ~}$ "Ein Jude kann nicht Reichsbürger sein. Ihm steht ein Stimmrecht in politischen Angelegenheiten nicht zu; er kann ein öffentliches Amt nicht bekleiden«, heißt es dann in der Ersten Verordnung zum Reichsbürgergesetz ${ }^{773}$, die den Prozess der Entrechtung und Entpersonalisierung der Juden einleitete. Von da an, bis zum endgültigen Entzug der Staatsbürgerschaft mit der Elften Verordnung zum Reichsbürgerschaftsgesetz am 25. November I94I dauerte es noch einige Jahre - vom Verlust der Staatsbürgerschaft bis zum Beginn des Mordprogramms, der »Endlösung«, dann bloß noch wenige Tage.

771 Bernhard Lösener: Staatsangehörigkeit und Reichsbürgerrecht, in: H.H. Lammers/Hans Pfundner (Hg.): Aufbau und Wirtschaftsordnung des nationalsozialistischen Staates, Bd. 1 Gruppe 2, Loseblattsammlung (Berlin o.J.), S. 4.

772 Stuckart/Globke (Hg.): Kommentar, S. 3.

773 Gesetzblatt für Österreich 1938/150. 


\section{Verzeichnis der Archive}

Österreichisches Staatsarchiv

Allgemeines Verwaltungsarchiv (AVA):

Bestand: Inneres, Hofkanzlei IV T I I $765 \mathrm{ff}$

Bestand: Inneres, Hofkanzlei IV T I I 8ooff

Bestand: Inneres, Hofkanzlei IV T 8 I $787 \mathrm{ff}$

Haus-, Hof- und Staatsarchiv, Wien

Bestand: Staatsrat $1783 \mathrm{ff}$

Wiener Stadt- und Landesarchiv

Bestand: Hauptregistratur P, PI I 878ff

Bestand: Heimatrolle, MA 6I

Archiv der jüdischen Kultusgemeinde Wien

Bestand: KI, Familienlisten

Bestand: Tätigkeitsberichte der IKG

Archiv der Gedenkstätte Yad Vashem, Jerusalem

Diverse Bestände über österreichische und staatenlose Juden

Leo Baeck Institute, LBI Berlin

Mikroverfilmte Bestände des LBI New York

Österreichisches Literaturarchiv

in der Österreichischen Nationalbibliothek, Wien 


\section{Literaturverzeichnis}

Albrich, Thomas: Zwischenstation des Exodus. Jüdische Displaced Persons und Flüchtlinge nach dem Zweiten Weltkrieg, in: Gernot Heiss/Oliver Rathkolb (Hg.): Asylland wider Willen. Flüchtlinge in Österreich im europäischen Kontext seit I 9I 4 (= Veröffentlichungen des Ludwig-Boltzmann-Institutes für Geschichte und Gesellschaft 25) (Wien 1995), S. I22-I39.

Allgemeines bürgerliches Gesetzbuch für die gesammten deutschen Erbländer der österreichischen Monarchie (Wien I 8 I I).

Aly, Götz: »Judenumsiedlung«. Überlegungen zur politischen Vorgeschichte des Holocaust, in: Ulrich Herbert (Hg.) : Nationalsozialistische Vernichtungspolitik 1939-1945. Neue Forschungen und Kontroversen (Frankfurt a. M. o.J), S. 67-97.

Aly, Götz: »Endlösung«. Völkerverschiebung und der Mord an den europäischen Juden (Frankfurt a. M. I999).

Andrews, Geof (Hg.): Citizenship (London I99I).

Appelt, Erna: Geschlecht, Staatsbürgerschaft, Nation. Politische Konstruktionen des Geschlechterverhältnisses in Europa (Frankfurt/New York 1999).

Arbell, Mordechai: Die Wanderung der Sepharden, in: 4. Internationales Theodor Herzl Symposium, Wien 8.-II.4.2002, Bericht (Wien 2002).

Arendt, Hannah: The Origins of Totalitarism (New York 1958), deutsche Ausgabe: Elemente und Ursprünge totaler Herrschaft (München I986).

Arendt, Hannah: Eichmann in Jerusalem. Ein Bericht über die Banalität des Bösen (München/Zürich I999).

Aron, Raymond: Kann es eine multinationale Staatsbürgerschaft geben?, in: Heinz Kleger (Hg.): Transnationale Staatsbürgerschaft (Frankfurt a. M. 1997), S. 24-4I.

Artner, Karl et al. (Hg.): Die Leopoldstadt. Ein Heimatbuch (Wien 1937).

Avenary, Hanoch: Kantor Salomon Sulzer und seine Zeit (Sigmaringen I985).

Bader-Zaar, Birgitta: Einführung des Frauenwahlrechts in Österreich, www.demokratiezentrum.org.

Bader-Zaar, Birgitta: Frauenbewegung und Frauenwahlrecht, in: Helmut Rumpler/Peter Urbanitsch (Hg.): Die Habsburgermonarchie I 848-19 1 8, Band 8, Teil I (Politische Öffentlichkeit und Zivilgesellschaft), Kapitel VII/C (Wien 2008), S. I005-1027.

Bailer-Galander, Brigitte: Die Opfer des Nationalsozialismus und die sogenannte Wiedergutmachung, in: Emmerich Tálos et al. (Hg.): NS-Herrschaft in Österreich (Wien 2002), S. 884-902.

Balibar, Etienne: Die Grenzen der Demokratie (Hamburg 1992).

Baron, Salo: Die Judenfrage auf dem Wien Kongreß (Wien/Berlin I920).

Barth-Barthenheim, Johann Ludwig: Politische Verfassung der Israeliten im Lande unter der 
Enns (= Beiträge zur politischen Gesetzeskunde im österreichischen Kaiserstaate I) (Wien I $82 \mathrm{I})$.

Barton, Peter F.: Der lange Weg zur Toleranz, in: Peter F. Barton (Hg.): Im Lichte der Toleranz. Aufsätze zur Toleranzgesetzgebung des I 8. Jahrhunderts in den Reichen Joseph II., ihren Voraussetzungen und ihren Folgen. Eine Festschrift (Wien I98I), S. I I-32.

Bato, Ludwig: Die Juden im alten Wien (Wien I928).

Battenberg, J. Friedrich: Von der Kammerknechtschaft zum Judenregal. Reflexionen zur Rechtsstellung der Judenschaft im Heiligen Römischen Reich am Beispiel Johannes Reuchlins, in: Sabine Hödl et al. (Hg.) : Hofjuden und Landjuden. Jüdisches Leben in der Frühen Neuzeit (Berlin 2004), S. 65-91.

Bauer, Bruno: Die Judenfrage (Braunschweig I 843).

Baumann, Zygmunt: Moderne und Ambivalenz. Das Ende der Eindeutigkeit (Hamburg 1992).

Beller, Steven: Patriotism and the National Identity of Habsburg Jewrey, I 860-I 91 4, in: Leo Baeck Institute Year Book XVI (1996), S. 2 I 5-238.

Beller, Steven: Wien und die Juden I 867-1938 (Wien/Köln/Weimar 1993).

Benbassa, Esther: Geschichte der Juden in Frankreich (Berlin/Wien 2000).

Benedikt, Michael: Natürliches Privatrecht und bürgerliche Souveränität. Franz v. Zeillers Kantrezeption in Österreich, in: derselbe (Hg.) : Verdrängter Humanismus - verzögerte Aufklärung, Bd. I (Wien I992), S. 659-708.

Benz, Wolfgang: Der Holocaust (München 1999).

Berger, Michael: Eisernes Kreuz und Davidstern. Die jüdischen Soldaten in den deutschen Armeen (Berlin 2006).

Berghahn, Klaus L.: Grenzen der Toleranz. Juden und Christen im Zeitalter der Aufklärung (Köln/Weimar/Wien 2000).

Bernatzik, Edmund: Österreichische Verfassungsgesetze (Wien I9I I).

Bernatzik, Edmund: Über nationale Matriken (Wien I9ro).

Berner, Margit, »Judentypologisierungen« in der Anthropologie am Beispiel der Bestände des Naturhistorischen Museums Wien, in: Zeitgeschichte 32.2 (2005), S. I I I-I I 6.

Besenböck, Oskar: Die Frage der jüdischen Option in Österreich 1918-1992, phil. Diss. (Wien I992).

Bielefeld, Uli: Fremdenfeindlichkeit, kulturelle Diversifizierung und Homogenisierung, in: IKUS Lectures 3+4 (1992), S. 9-29.

Bihl, Wolfdieter: Die Juden in der Habsburgermonarchie I848-191 8, in: Zur Geschichte der Juden in den österreichischen Ländern der Habsburgermonarchie (= Studia Judaica Austriaca VIII) (Eisenstadt I980), S. 7-I 21.

Bihl, Wolfdieter: Die Juden, in: Adam Wandruszka/Peter Urbanitsch (Hg.) : Die Habsburgermonarchie I 848-ı 9 8, Bd. III/2: Die Völker des Reichs (Wien I980), S. 880-948.

Binder, Harald: Galizien in Wien. Parteien, Fraktionen und Abgeordnete im Übergang zur Massenpolitik (= Studien zur Geschichte der österreichisch-ungarischen Monarchie 29) (Wien 2005).

Binder, Hartmut: Franz Kafka. Leben und Persönlichkeit (Stuttgart 1983).

Birnbaum, Pierre/Ira Katznelson (Hg.): Paths of Emancipation. Jews, States, and Citizenship (Princeton/New Jersey I995). 
Birnbaum, Nathan: Die nationale Wiedergeburt des jüdischen Volkes in seinem Lande als Mittel der Judenfrage (o.O. I893).

Birnbaum, Nathan: Was sind Ostjuden? (Wien I916).

Blaukopf, Herta: Kurt Blaukopfs (musikalisches) Österreich-Verständnis, in: Austriaca 56 (2003), S. I 3 I-I 46.

Bloch, Joseph Samuel: Der nationale Zwist und die Juden in Österreich (Wien I 886).

Boyer, John W.: Karl Lueger (1844-19ro). Christlichsoziale Politik als Beruf (= Studien zu Politik und Verwaltung 93) (Wien/Köln/Weimar 2010).

Brenner, David A.: Marketing Identities. The Invention of Jewish Ethnicity in Ost und West (Detroit 1998).

Brenner, Michael et. al.: Deutsch-Jüdische Geschichte in der Neuzeit, Bd. 2: Emanzipation und Akkulturation, 1780-187 I (München 1996).

Brix, Emil: Die Umgangssprachen in Altösterreich zwischen Agitation und Assimilation. Die Sprachenstatistik in den zisleithanischen Volkszählungen I 880 bis I9 Io (= Veröffentlichungen der Kommission für neuere Geschichte Österreich 73) (Wien/Köln/Graz I982).

Brix, Emil: Mentalität ist gut - Die Teilung der Prager Universität I882, in: Österreichische Osthefte 30.3 (I988), S. 37I-382.

Brod, Max: Franz Kafka. Eine Biographie (Berlin 1954).

Browning, Christopher R.: Judenmord. NS-Politik, Zwangsarbeit und das Verhalten der Täter (Frankfurt a. M. 200I).

Brubaker, Rogers: Staats-Bürger. Frankreich und Deutschland im historischen Vergleich (Hamburg 1994).

Brubaker, Rogers: Einwanderung und Nationalstaat in Frankreich und Deutschland, in: Der Staat 28 (1989), S. I-30.

Brugger, Eveline/Birgit Wiedl: Regesten zur Geschichte der Juden im Mittelalter, Bd. I (Innsbruck/Wien/Bozen 2005).

Brugger, Eveline/Martha Keil/Albert Lichtblau (Hg.) : Geschichte der Juden in Österreich (Wien 2007).

Brumlik, Micha: Deutscher Geist und Judenhass (München 2002).

Brunner, Otto/Werner Conze/Reinhart Koselleck (Hg.): Geschichtliche Grundbegriffe. Historisches Lexikon zur politisch-sozialen Sprache in Deutschland, Bd. I (Stuttgart 1973).

Buchenwald. Vom Antlitz zur Maske, in: Volkhard Knigge/Jürgen Seifert (Hg.): Wien. Weimar. Buchenwald I939 (Weimar I999).

Burger, Hannelore: Der Verlust der Mehrsprachigkeit. Aspekte des mährischen Ausgleichs, in: Bohemia 34.I (1993), S. 77-89.

Burger, Hannelore: Sprachenrecht und Sprachgerechtigkeit im österreichischen Unterrichtswesen I 867-I91 8 (= Studien zur Geschichte der Österreichisch-Ungarischen Monarchie 26) (Wien I995).

Burger, Hannelore/Helmut Wohnout: Eine "polnische Schufterei«? Die Badenischen Sprachenverordnungen für Böhmen und Mähren I 897, in: Michael Gehlen/Helmut Sickinger (Hg.): Politische Affären und Skandale in Österreich (Wien/München I995), S. 79-98.

Burger, Hannelore: Mehrsprachigkeit und Unterrichtswesen in der Bukowina I869-1918, 
in: Ilona Slawinski/Joseph P. Strelka (Hg.): Die Bukowina. Vergangenheit und Gegenwart (Bern et al. I995), S. 93-125.

Burger, Hannelore: Zum Begriff der österreichischen Staatsbürgerschaft. Vom josephinischen Gesetzbuch zum Staatsgrundgesetz über die allgemeinen Rechte der Staatsbürger, in: Thomas Angerer et al. (Hg.): Geschichte und Recht. Festschrift für Gerald Stourzh zum 70. Geburtstag (Wien/Köln/Weimar I 999), 207-224.

Burger, Hannelore: Zur Geschichte der Staatsbürgerschaft der Frauen in Österreich. Ausgewählte Fallstudien aus der ersten Hälfte des I9. Jahrhunderts, in: L’homme ı.. (I999), S. 38-44.

Burger, Hannelore: Die Staatsbürgerschaft, in: Waltraud Heindl/Edith Saurer (Hg.): Grenze und Staat. Passwesen, Staatsbürgerschaft, Heimatrecht und Fremdengesetzgebung in der österreichischen Monarchie (I750-I867) (Wien/Köln/Weimar 2000), S. 88-I72.

Burger, Hannelore/Harald Wendelin: Vertreibung, Rückkehr und Staatsbürgerschaft. Die Praxis der Vollziehung des Staatsbürgerschaftsrechts an den österreichischen Juden, in : Staatsbürgerschaft und Vertreibung (= Veröffentlichungen der Österreichischen Historikerkommission 7) (Wien 2004), S. 239-50I.

Burger, Hannelore: Die Ausbürgerung der reichsdeutschen Juden und der Befehl zur »Endlösung«. Anmerkungen zu einem Historikerstreit, in: John D. Pattillo-Hess/Mario R. Smole (Hg.): »Macht und Gewalt» (Wien 2003), S. 90-99.

Burger, Hannelore: Sprachen und Sprachpolitiken. Niederösterreich und die Bukowina im Vergleich, in: Endre Hárs et al. (Hg.): Zentren, Peripherien und kollektive Identitäten in Österreich-Ungarn (Tübingen/Basel 2006), S. I I I-I 28.

Burger, Hannelore: Staatenlos. Die Verrätselung einer Biographie, in: John D. Pattillo-Hess/ Mario R. Smole (Hg.): Elias Canetti. Chronist der Massen, Enthüller der Macht (Wien 2006), S. 83-96.

Burger, Hannelore: Die »jüdische Frage« zwischen den Ausgleichsbewegungen in Mähren, der Bukowina und Galizien, in: Lukáš Fasora et al. (Hg.): Der Mährische Ausgleich von I 905. Möglichkeiten und Grenzen für einen nationalen Ausgleich in Mitteleuropa (Brünn 2006), S. 7 I-86.

Burger, Hannelore: Juden zwischen Wien und Brünn, in: Lukáš Fasora et al. (Hg.): Brünn Wien, Wien - Brünn. Landesmetropolen und Zentrum des Reiches im I9. Jahrhundert (Brünn 2008), S. 243-252.

Burger, Hannelore: Der Generalplan Ost und die `Bereinigung der Slowenenfrage`, in: Valentin Oman/Karl Vouk (Hg.): DenkMal: Deportation I942-2012, Katalog (Celovec/ Klagenfurt 20 I 2), S. I3-20.

Buschmann, Gotthard von: Über die österreichische Staatsbürgerschaft (erste Auflage I 833, Wien ${ }^{2}$ I 84I).

Canetti, Elias: Die Stimmen von Marrakesch. Aufzeichnungen einer Reise (München I968).

Canetti, Elias: Masse und Macht, 2 Bände (München 1976).

Canetti, Elias: Die Fackel im Ohr. Lebensgeschichte I92 I-I93 I (München 1980).

Canetti, Elias: Die Provinz des Menschen. Aufzeichnungen I942-1972 (Frankfurt am Main 1991).

Canetti, Elias: Die gerettete Zunge. Geschichte einer Jugend (Frankfurt a. M. I992). 
Canetti, Elias: Das Augenspiel. Lebensgeschichte I93 I-1937 (München 1985).

Canetti, Veza: Die Schildkröten (München I999).

Canning, Kathleen: "Bodies and Citizenship«, Beitrag zur Konferenz: »The Stakes of Citizenship: Bodies in the Aftermath of War and Revolution«, I. April 20 I I, www.youtube, Kathleen Canning.

Castells, Manuel: Das Informationszeitalter, Bd. I : Der Aufstieg der Netzwerkgesellschaft (Opladen 200I).

Chamberlain, Houston Stewart: Die Grundlagen des Neunzehnten Jahrhunderts, Bd. I (München 1904).

Campagner, Elisabeth: Judentum, Nationalitätenprinzip und Identität. Die jüdische Revolutionspresse von I848 (= Europäische Hochschulschriften 986) (Frankfurt a. M. 2004).

Charmatz, Richard: Österreichs innere Geschichte von I 848 bis I 907, Bd. 2: Der Kampf der Nationen (Leipzig I9I2).

Chen, Yun: Canetti und die chinesische Kultur, phil. Diss. (Düsseldorf 2005).

Christov-Bakargiev, Carolyn: Interview vom 3 I.5.20 I 2 in: www.sueddeutsche.de/kultur/ documenta-leiterin-carolyn-christov-bakargiev.

Cohen, Gerald Daniel: In War's Wake: Europe's Displaced Persons in the Postwar Order (Oxford 20II).

Cohen, Gary B.: Education and Middle-Class Society in Imperial Austria I 848-1918 (West Lafayette/Indiana I996).

Cohen, Gary B: Citizenship and Nationality in Late Imperial Austria, in: Marija Wakounig/ Wolfgang Müller (Hg.): Nation, Nationalität und Nationalismus im östlichen Europa. Festschrift für Arnold Suppan (Köln/Wien 20 Io), S. 20 I-224.

Conrad, Christoph/Jürgen Kocka (Hg.) : Staatsbürgerschaft in Europa: historische Erfahrungen und aktuelle Debatten (Hamburg 200I).

Conze, Eckart et al. (Hg.): Das Amt und die Vergangenheit. Deutsche Diplomaten im Dritten Reich und in der Bundesrepublik Deutschland (Hamburg 2010).

Cornell, Drucilla: The Philosophy of the Limit: System Theory and Feminist Legal Reform, in: dieselbe et al. (Hg.): Deconstruction and the Possibility of Justice (New York/London 1992).

Davis, Belinda: Experience, Identity, and Memory: The Legacy of World War I, in: The Journal of Modern History 75 (März 2003), S. I I I-I 3 I.

Davis, Uri: Democratization, Citizenship, Arab Unity and Palestinian Autonomy, in: N.A. Butenschon et al. (Hg.): Citizenship and the Middle East (Syrakus 2000), S. 225-245.

Deák, István: Der K.(u.)k. Offizier I 848-I91 8 (Wien/Köln/Weimar I99I).

Demetz, Peter: Prag und Babylon. Zu Kafkas »Das Stadtwappen«, in: Böhmische Sonne, mährischer Mond. Essays und Erinnerungen (Wien 1996), S. 8 I-92.

Derrida, Jacques: Von der Gastfreundschaft (Paris I977).

Derrida, Jacques: Das andere Kap (Frankfurt a. M. I992).

De Waal, Edmund: Der Hase mit den Bernsteinaugen. Das verborgene Erbe der Familie Ephrussi (Wien 201 I).

Dewandre, Nicole/Jacques Lenoble (Hg.): Projekt Europa. Postnationale Identität: Grundlage für eine europäische Demokratie? (Berlin 1994).

Diner, Dan: Gedächtniszeiten: über jüdische und andere Geschichten (München 2003). 
Diner, Dan: Synchrone Welten. Zeiträume jüdischer Geschichte (Göttingen 2005).

Dohm, Christian Konrad Wilhelm von: Über die bürgerliche Verbesserung der Juden [I78 I], Hildesheim/New York 1973).

Donaldson, Sue/Will Kimlicka: Zoopolil. A Political Theory of Animal Rights (Oxford/New York 20II).

Drabek, Anna Maria: Das Judentum der böhmischen Länder vor der Emanzipation (= Studia Judaica Austriaca X) (Eisenstadt I984), S. 5-30.

Edelstein, Rabbi Berl: Schabbatnachmittage im Obstgarten. Zerbrochene Welten meiner chassidischen Kindheit (Wien/Köln/Weimar 1999).

Eliav, Mordechai: Das österreichische Konsulat in Jerusalem und die jüdische Bevölkerung (= Studia Judaica Austriaca Bd. X) (Eisenstadt I984).

Eliav, Mordechai, unter Mitarbeit von Barbara Haider (Hg.): Österreich und das Heilige Land. Ausgewählte Konsulatsdokumente aus Jerusalem I 849-I9I7 (= Fontes rerum Austriacarum 2. Abt. 9I) (Wien 2000), S. 63, $32 \mathrm{f}$.

Encyclopädie des Holocaust, Teil II, Israel Gutmann (Hg.) (Yad Vashem/Jerusalem I990).

Encyclopaedia Judaica in 26 Bänden (Jerusalem/New York I97Iff).

Engelbrecht, Helmut: Geschichte des österreichischen Bildungswesens, 4 Bände (Wien I986).

Essner, Cornelia: Die `Nürnberger Gesetze` oder die Verwaltung des Rassenwahns 1933-1945 (Paderborn/München 2002).

Evan, Gershom: Winds of Life. The Destinies of a Young Viennese Jew I938-1958 (Riverside, Calif. 2000).

Fahrmeir, Andreas: Citizens and Aliens. Foreigners and the Law in Britain and the German States, I789-1870 (New York/Oxford 2000).

Fahrmeir, Andreas: Citizenship. The Rise and Fall of a Modern Concept (New Haven/London 2007).

Faupel, Rainer/Klaus Eschen: Gesetzliches Unrecht in der Zeit des Nationalsozialismus (= Veröffentlichungen der Potsdamer Juristischen Gesellschaft 3) (Baden-Baden I 997).

Feiner, Shmuel: »Wohl euch, die ihr eurer Gedanken wegen verfolgt seid!« - Die gegenwärtige Erforschung der Haskala: Kultur der jüdischen Aufklärung in historischer Perspektive. Vorwort zu: Haskala im i 8. Jahrhundert, TrumaH i6 (2006), S. I-I7.

Ferry, Jean-Marc: Die Relevanz des Postnationalen in: Nicole Dewandre/Jacques Lenoble (Hg.): Projekt Europa. Postnationale Identität: Grundlage für eine europäische Demokratie? (Berlin I994), S. 30-4I.

Ferry, Jean-Marc: Europäische Identität und europäischer Bürgerstatus. Anmerkungen zum Gipfel von Maastricht, in: Nicole Dewandre/Jacques Lenoble (Hg.): Projekt Europa. Postnationale Identität: Grundlage für eine europäische Demokratie? (Berlin I994), S. I I III 8 .

Fillafer, Franz Leander: Das Josephinische Trauma und die österreichische Aufklärung, in: Andras F. Bálogh/Helga Mitterbauer (Hg.) : Zentraleuropa - ein hybrider kultureller Kommunikationsraum (Wien 2006), S. 63-85.

Fischel, Alfred: Die Protokolle des Verfassungsausschusses über die Grundrechte. Ein Beitrag zur Geschichte des österreichischen Reichstags vom Jahre I 848 (Wien/Leipzig I9I2), Anhang. 
Fischhof, Adolph: Österreich und die Bürgschaft seines Bestandes (Wien I 870).

Fischhof, Adolph: Der österreichische Sprachenzwist. Ein Wort aus Anlass der diesjährigen historischen Gedenktage (Wien I 888).

Fleischmann, Ingrid: Angaben zur Sprache in den Schulkatalogen der Prager Volksschulen, in: Marek Nekula et al. (Hg.) : Franz Kafka im sprachnationalen Kontext seiner Zeit (Köln/Weimar/Wien 2007), S. I 83-2 I 2.

Flusser, Wilhelm: Vermassung und Vernetzung, in: John D. Pattillo-Hess (Hg.): Der Stachel des Befehls (Wien I 992), S. I I7-I 2 I.

Foell, Kristie A.: Elias Canetti: Der unfreiwillige Jude, in: Kurt Barsch/Gerhard Melzer (Hg.): Dossier 25: Elias Canetti (Graz 2005), S. I26-135.

Foucault, Michel: Dispositive der Macht. Über Sexualität, Wissen und Wahrheit (Berlin I978).

Frankl, Ludwig August: Zur Geschichte der Juden in Wien (Wien I 853).

Fraupel, Rainer/Klaus Eschen: Gesetzliches Unrecht in der Zeit des Nationalsozialismus (= Veröffentlichungen der Potsdamer Juristischen Gesellschaft 3) (Baden-Baden 1997).

Freidenreich, Harriet Pass: Jewish Politics in Vienna I9I 8-1938 (Bloomington/Indianapolis I991).

Freund, Florian/Hans Safrian: Die Verfolgung der österreichischen Juden 1938-1945. Vertreibung und Deportation, in: Emmerich Tálos et al. (Hg.): NS-Herrschaft in Österreich. Ein Handbuch (Wien 2000), S. 767-794.

Fröhlich Elke (Hg.) : Die Tagebücher von Joseph Goebbels (29 Bände), Band 2/Teil II, bearbeitet von Angelika Hermann (Berlin 2004).

Fuchs, Albert: Geistige Strömungen in Österreich I867-1918 (Nachdruck von 1949, Wien I984).

Fühner, Jochen A.: Kaiser Maximilian I. und die Juden in den österreichischen Erblanden (= Mitteleuropäische Studien I) (Herne 2007).

Gaisbauer, Adolf: Davidstern und Doppeladler. Zionismus und jüdischer Nationalismus in Österreich I882-I91 8 (Wien/Köln/Graz I988).

Gaisbauer, Adolf: Das antijüdische »Potential« der Aufklärung und des Josephinismus, in: Aschkenas. Zeitschrift für Geschichte und Kultur der Juden I (1996), S. I63-I82.

Gammerl, Benno: Subjects, citizens and others: the handling of ethnic differences in the British and the Habsburg Empires (late nineteenth and early twentieth century), in: European Review of History - Revue européenne d'histoire I6.4 (August 2009), S. 523-549.

Gammerl, Benno: Untertanen, Staatsbürger und Andere. Der Umgang mit ethnischer Heterogenität im Britischen Weltreich und im Habsburgerreich I 867-1918 (= Kritische Studien zur Geschichtswissenschaft I 89) (Göttingen 2010).

Gasser, Wolfgang: Jüdische DienstbotInnen in Wien - von den napoleonischen Kriegen, dem Biedermeier bis zur I 848-Revolution (Wien 200I).

Gasser, Wolfgang: Neues aus der »Stadt der Toleranz«. Tolerierte und getaufte Juden, Da Ponte und Mozart, in: Werner Hanak (Hg.): Lorenzo da Ponte. Aufbruch in die Neue Welt. Katalog zur gleichnamigen Ausstellung (Ostfildern 2006), S. 63-80.

Gasser, Wolfgang: Erlebte Revolution I 848/49. Das Wiener Tagebuch des jüdischen Journalisten Benjamin Kewall (Wien/München 2010). 
Gelber, N.M.: The Sephardic Community in Vienna, in: Jewish Social Studies ro (I 948), S. 359-396.

Gerlach, Christian: Die Wannsee-Konferenz, das Schicksal der deutschen Juden und Hitlers politische Grundsatzentscheidung, alle Juden Europas zu ermorden, in: Krieg, Ernährung, Völkermord. Deutsche Vernichtungspolitik im Zweiten Weltkrieg (Zürich 200I), S. 79-1 52. Glassl, Horst: Der Mährische Ausgleich (München 1967).

Glick Schiller, Nina/Linda Basch/Christina Blanc Szanton: Transnationalismus: Ein neuer analytischer Rahmen zum Verständnis von Migration, in: Heinz Kleger (Hg.) : Transnationale Staatsbürgerschaft (Frankfurt a. M. 1997), S. 8I-I08.

Gobineau, Arthur de: Versuch über die Ungleichheit der Menschenracen [1853], Bd. I (Stuttgart 1922), S. XVI.

Godsey, William D.: Nation, Government, and ‘Anti-Semitism` in early Nineteenth-Century Austria, in: The Historical Journal 51.I (2008), S. 49-85.

Goldemund, Ingobert/Kurt Ringhofe/Karl Theurer (Hg.): Das österreichische Staatsbürgerschaftsrecht (Wien 1969).

Gosewinkel, Dieter: Einbürgern und Ausschließen. Die Nationalisierung der Staatsangehörigkeit vom Deutschen Bund bis zur Bundesrepublik Deutschland (= Kritische Studien zur Geschichtswissenschaft I 50) (Göttingen 2003).

Gotzmann, Andreas: Eigenheit und Einheit. Modernisierungsdiskurse des deutschen Judentums der Emanzipationszeit (Leiden/Boston/Köln 2002).

Gotzmann, Andreas/Stephan Wendehorst: Zwischen Kaiser, Landesherrschaft und Halacha: Zwischenräume als jüdische Rechts- und Handlungsspielräume. Einleitung zum Band: Juden im Recht. Neue Zugänge zur Rechtsgeschichte der Juden im Alten Reich, Zeitschrift für Historische Forschung, Beiheft 39 (Berlin 2007), S. I-I I.

Grab, Walter: Der deutsche Weg der Judenemanzipation 1789-1938 (München/Zürich I991).

Graml, Hermann: Die Durchführung der »Endlösung«, in : Rolf Steininger (Hg.) : Der Umgang mit dem Holocaust (Wien/Köln/Weimar I994), S. 3 I-44.

Grandner, Margarete: Staatsbürger und Ausländer. Zum Umgang Österreichs mit den jüdischen Flüchtlingen nach I9r 8, in: Gernot Heiss/Oliver Rathkolb (Hg.): Asylland wider Willen. Flüchtlinge in Österreich im europäischen Kontext seit I9I 4 (= Veröffentlichungen des Ludwig Boltzmann-Institutes für Geschichte und Gesellschaft 25) (Wien I995), S. $60-85$.

Graßl, Ignaz: Das besondere Eherecht der Juden in Österreich nach den $\$ \$$ I 23-I 36 des allgemeinen bürgerlichen Gesetzbuches (Wien I 838).

Grawert, Rolf: Staat und Staatsangehörigkeit. Verfassungsgeschichtliche Untersuchung zur Entstehung der Staatsangehörigkeit (Berlin 1973).

Grunwald, Max: History of the Jews in Vienna (Philadelphia 1936).

Haas, Theodor: Die Juden in Mähren. Darstellung der Rechtsgeschichte und Statistik unter besonderer Berücksichtigung des I9. Jahrhunderts (Wien 1908).

Habermas, Jürgen: Staatsbürgerschaft und nationale Identität. Überlegungen zur europäischen Zukunft, in: Dewandre/Lenoble, Projekt Europa, S. I I-29.

Haider, Barbara: Die Protokolle des Verfassungsausschusses des Reichsrates vom Jahre I867, 
(= Fontes Rerum Austriacarum. Österreichische Geschichtsquellen, Zweite Abteilung, Diplomataria et Acta 88) (Wien I997).

Haider-Wilson, Barbara: Die Habsburgermonarchie und das Heilige Land I 842-1917. Schutzmachtpolitik, katholisches "Jerusalem-Milieu« und Volksfrömmigkeit, phil. Diss. (Wien 2007),

Hanuschek, Sven: Elias Canetti. Biographie (München/Wien 2005).

Häusler, Wolfgang: Zur historischen Situation des Ostjudentums, in: Ilona Slawinski/Joseph P. Strelka (Hg.): Die Bukowina. Vergangenheit und Gegenwart (Bern I995), S. I334 .

Haumann, Heiko: Geschichte der Ostjuden (München 1999).

Healy, Maureen: Vienna and the Fall of the Habsburg Empire. Total War and Everyday Life in World War I (Cambridge 2004).

Heindl, Waltraud: Bildung und Recht. Naturrecht und Ausbildung der staatsbürgerlichen Gesellschaft in der Habsburgermonarchie, in: Thomas Angerer et al. (Hg.): Geschichte und Recht. Festschrift für Gerald Stourzh zum 70. Geburtstag (Wien/Köln/Weimar 1999), S. I 83-206.

Heindl, Waltraud/Edith Saurer (Hg.): Grenze und Staat. Passwesen, Staatsbürgerschaft, Heimatrecht und Fremdengesetzgebung in der österreichischen Monarchie (I750-I867) (Wien/Köln/Weimar 2000).

Hensellek, Thomas: Der Bukowina Ausgleich - ein Erfolg in der politischen Praxis? In: Lukáš Fasora et al. (Hg.) : Der Mährische Ausgleich von 1905: Möglichkeiten und Grenzen für einen nationalen Ausgleich in Mitteleuropa (Brünn 2006), S. 279-290.

Hepp, Michael/Hans Georg Lehmann (Hg.): Die Ausbürgerung deutscher Staatsangehöriger I933-45 nach den im Reichsanzeiger veröffentlichten Listen, Band 3: Liste der Geburtsorte und der letzten Wohnorte (München/New York/London I985).

Herbert, Ulrich (Hg.) : Nationalsozialistische Vernichtungspolitik 1939-1945. Neue Forschungen und Kontroversen (Frankfurt a. M. o.J).

Hermes Roger et al. (Hg.): Franz Kafka. Eine Chronik (Berlin I999).

Herrnritt, Rudolf von: Handbuch des österreichischen Verfassungsrechtes (Tübingen I 909).

Herzl, Theodor: Der Judenstaat. Versuch einer modernen Lösung der Judenfrage [Leipzig/ Wien I 896] (Zürich 2006).

Herzl, Theodor: Zionistische Schriften (Berlin 1920).

Herzog, Franz Tobias: Sammlung der Gesetze über das politische Domizil im Kaiserthume Österreich (Wien I 837).

Hilberg, Raul: Die Vernichtung der europäischen Juden, 3 Bände (Berlin I982ff).

Hilberg, Raul: Die Quellen des Holocaust. Entschlüsseln und Interpretieren (Frankfurt a. M. 2002).

Hirschhausen, Ulrike von: From imperial inclusion to national exclusion: citizenship in the Habsburg monarchy and in Austria I867-1923, in: European Review of History - Revue européenne d'histoire I6.4 (August 2009), S. 55 I-574.

Hoffmann, Eva: Im Schtetl. Die Welt der polnischen Juden (München 2003).

Hoffmann-Holter, Beatrix: Jüdische Flüchtlinge in Wien, in: Gernot Heiss/Oliver Rathkolb (Hg.) : Asylland wider Willen. Flüchtlinge in Österreich im europäischen Kontext seit 
I 9 I 4 (= Veröffentlichungen des Ludwig Boltzmann-Institutes für Geschichte und Gesellschaft 25) (Wien I995), S. 45-59.

Hoffmann-Holter, Beatrix: „Abreisendmachung«. Jüdische Kriegsflüchtlinge in Wien I9I4I923 (Wien/Köln/Weimar I995).

Hofmeister, Alex: Die Juden in der ukrainischen Geschichte, in: Österreichische Osthefte 42 (2000), S. 262-27I.

Holzer, Jerzy: Zur Frage der Akkulturation der Juden in Galizien im 19. und 20. Jahrhundert, in: Jahrbücher für die Geschichte Osteuropas 37 (1989), S. 2 17-227.

Iggers, Wilma A: Die Juden in Böhmen und Mähren (München I 896).

Iggers, Wilma A.: Geschichte einer ländlichen Familie zwischen Deutschen und Tschechen, in: Marek Nekula/Walter Koschmal (Hg.): Juden zwischen Deutschen und Tschechen. Sprachliche und kulturelle Identitäten I800-1945 (München 2006), S. I9-32.

Jäger-Sustenau, Hanns: Die geadelten Judenfamilien im vormärzlichen Wien, phil. Diss. (Wien I950).

Jäger-Sustenau, Hanns: Die Ehrenbürger und Bürger ehrenhalber der Stadt Wien (Wien 1992).

Jaques, Heinrich: Denkschrift (Wien I 859 ).

Jeiteles, Israel: Die Kultusgemeinde der Israeliten in Wien (Wien I 873).

Jersch-Wenzel, Stefi: Grundlagen der Judenemanzipation bis I 848 im östlichen Mitteleuropa:

Politische Rechte, soziale Stellung und religiöse Strömungen, in : Jörg K. Hoensch et al. (Hg.) : Judenemanzipation, Antisemitismus, Verfolgung in Deutschland, Österreich-Ungarn, den Böhmischen Ländern und in der Slowakei (Tübingen I999), S. 9I-IOI.

John, Michael: Mosaik, Schmelztiegel, Weltstadt Wien. Migration und multikulturelle Gesellschaft im I9. und 20. Jahrhundert, in: WIR. Zur Geschichte und Gegenwart der Zuwanderung nach Wien (Wien I996), S. I37-I44.

Joppke, Christian: The Inevitable Lightening of Citizenship, in: European Journal of Sociology 51.I (2010), S. 9-32.

Judson, Pieter M.: Guardians of the Nation? Activists on the Language Frontiers of Imperial Austria (Cambridge MA/London 2006).

Kafka, Franz: Das Stadtwappen, in: Roger Hermes (Hg.): Franz Kafka. Erzählungen und andere ausgewählte Prosa (Frankfurt a. M. 1996), S. 374-375.

Kann, Robert A.: Das Nationalitätenproblem der Habsburgermonarchie, 2 Bände (Graz/Köln I964).

Kant, Immanuel: Die Metaphysik der Sitten, in: Wilhelm Weischedel (Hg.): Werkausgabe, Bd. VIII (Frankfurt a. M. I982).

Kant, Immanuel: Über den Gemeinspruch: »Das mag in der Theorie richtig sein, taugt aber nicht für die Praxis«, in: Wilhelm Weischedel (Hg.): Werkausgabe, Bd. XI (Frankfurt a. M. ${ }^{2}$ I964).

Kant, Immanuel: Zum ewigen Frieden, in: Wilhelm Weischedel (Hg.): Werkausgabe, Bd. XI (Frankfurt a. M. ${ }^{2}$ I964).

Kárady, Victor: The 'Smart Jew in Pre-1919 Hungary. Educational Investments and Cultural Assimilation, Kakanienrevisited 29/09/2004 (www.kakanien.ac.at/beitr/fallstudie/VKaradyi.pdf). 
Karminski, Fritz: Zur Codifikation des österreichischen Staatsbürgerschaftsrechtes (Wien I 887).

Karniel, Josef: Zur Auswirkung der Toleranzpatente für die Juden in der Habsburgermonarchie im josephinischen Jahrzehnt, in: Beter F. Barton (Hg.): Im Zeichen der Toleranz. Aufsätze zur Toleranzgesetzgebung des I 8. Jahrhunderts in den Reichen Joseph II, ihren Voraussetzungen und ihren Folgen. Eine Festschrift (Wien I98I), S. 203-220.

Katz, Jacob: Zur Assimilation und Emanzipation der Juden (Darmstadt 1982).

Katz, Jacob: Vom Vorurteil bis zur Vernichtung. Der Antisemitismus 1700-1933 (München I989).

Katzenelson, Jizchak: Dos lied vunem ojsgehargetn jidischn Volk (Großer Gesang vom ausgerotteten jüdischen Volk), übersetzt, herausgegeben und eingeleitet von Wolf Biermann (Köln I994).

Kaul, Christina: Die Rechtsstellung der türkischen Juden in Wien auf Grund der österreichisch-türkischen Staatsverträge, Diplomarbeit (Salzburg I990).

Kernmeyer, Hildegard/Klaus Hödl/Petra Ernst: Assimilation - Dissimilation - Transkulturation. Jüdische Identitäten in der Wiener und zentraleuropäischen Moderne, in: Moritz Csáky et al. (Hg.) : Kultur - Identität - Differenz. Wien und Zentraleuropa in der Moderne (Innsbruck et al. 2004), S. 29I-322.

Kestenberg-Gladstein, Ruth: Neuere Geschichte der Juden in den böhmischen Ländern (Tübingen 1969).

Kimlicka, Will: Multicultural Citizenship. A Liberal Theory of Minority Rights (Oxford/New York 1995).

Klabouch, Jiří: Die Gemeindeverwaltung in Österreich I948-I918 (Wien I986).

Klee, Ernst: Deutsche Mediziner im Dritten Reich. Karrieren vor und nach 1945 (Frankfurt a. M. 200I).

Kleger, Heinz (Hg.): Transnationale Staatsbürgerschaft (Frankfurt a. M. 1997).

Klemperer, Wilhelm: LTI. Notizbuch eines Philologen [Berlin 1947] (Stuttgart 2010).

Klüber, Johann Ludwig (Hg.): Acten des Wiener Congresses in den Jahren I 8 I 4 und I 8 I 5 , Bd. I6 (Erlangen I8I6).

Klueting, Harm: (Hg.): Der Josephinismus. Ausgewählte Quellen zur Geschichte der theresianisch-josephinischen Reformen (= Ausgewählte Quellen zur Geschichte der Neuzeit XIIa) (Darmstadt I990).

Knight, Robert (Hg.) : »Ich bin dafür die Sache in die Länge zu ziehen.«Die Wortprotokolle der österreichischen Bundesregierung von 1945-I952 über die Entschädigung der Juden (Wien 2000).

Knigge Volkhard/Jürgen Seifert (Hg.): Vom Antlitz zur Maske. Wien. Weimar. Buchenwald 1939. Katalog (Weimar 1999).

Kolonovits, Dieter: Rechtsfragen des Wiedererwerbs der österreichischen Staatsbürgerschaft durch Opfer des Nationalsozialismus (Vertriebene) nach österreichischem Staatsbürgerschaftsrecht, in: Staatsbürgerschaft und Vertreibung (= Veröffentlichungen der Österreichischen Historikerkommission 7), Erster Teil (Wien 2004), S. 7-238.

Konstantinov, Wenzeslav: Elias Canetti - ein österreichischer Schriftsteller? Verwandlungen 
zwischen Rustschuk und Wien, in: Internet-Zeitschrift für Kulturwissenschaften 7 (September 1999), www.inst.at/trans/7Nr/konstatinov7htm.

Koselleck, Reinhart: Preußen zwischen Reform und Revolution. Allgemeines Landrecht, Verwaltung und soziale Bewegung von I79I bis I 848 (= Schriftenreihe des Arbeitskreises für moderne Sozialgeschichte 7) (Stuttgart 1967), S. 53-77.

Koselleck, Reinhart: Vergangene Zukunft. Zur Semantik geschichtlicher Zeiten (Frankfurt a. M. 1979).

Kreissler, Felix: Un témoin principal de la barbarie du XXème siècle, in: Christine Lecerf/ Hannelore Burger (Hg.): Corps blessés. Peines intimes autrichiennes. France/Autriche I4 (I99I), S. 63-90.

Kreissler, Françoise: Retour ou rapatriement de Shanghai? Spécificités des contextes politiques (1945-1949), in: Austiaca 56 (2003), S. 89-100.

Kremer, Arndt: Deutsche Juden - deutsche Sprache. Jüdische und judenfeindliche Sprachkonzepte und -konflikte I893-I933 (Berlin 2007).

Kristeva, Julia: Fremde sind wir uns selbst (Frankfurt a. M. I990).

Kuzmany, Börries: Brody. Eine galizische Grenzstadt im langen I9. Jahrhundert (Wien/Köln/ Weimar 20I I).

Laborde, Cécile: Republican Citizenship and the Crisis of Integration in France, in: Richard Bellamy et al. (Hg.): Lineages of European Citizenship. Rights, Belongings and Participation in Eleven Nation-States (Houdmills/New York 2004).

Landes, David S.: Der entfesselte Prometheus (Köln I973).

Langhoff, Lukas: Staatsbürgerrecht und Heimatrecht in Österreich (Wien I920).

Lappin, Eleonore: Juden in Wien. Zur Geschichte und Gegenwart der Zuwanderung in Wien, in: WIR, Zur Geschichte und Gegenwart der Zuwanderung nach Wien (Wien 2000), S. $57-69$.

Lässig, Simone: Jüdische Wege ins Bürgertum (Göttingen 2004).

Leiter, Philomena: Assimilation, Antisemitismus und NS-Verfolgung. Austritte aus der jüdischen Gemeinde in Wien 1900-1944, phil. Diss. (Wien 2003).

Lichtblau, Albert: Als hätten wir dazugehört. Österreichisch-jüdische Lebensgeschichten aus der Habsburgermonarchie (Wien/Köln/Weimar 1999).

Lösener, Bernhard: Staatsangehörigkeit und Reichsbürgerrecht, in: H.H. Lammers/Hans Pfundner (Hg.): Aufbau und Wirtschaftsordnung des nationalsozialistischen Staates, Bd. I Gruppe 2, Loseblattsammlung (Berlin o.J.).

Lohmann, Ingrid: Die Juden als Repräsentanten des Universellen. Zur gesellschaftspolitischen Ambivalenz klassischer Bildungstheorie, in: Ingrid Gogolin et al. (Hg.) : Pluralität und Bildung (Opladen I 998), S. I 53-178.

Lohrmann, Klaus: Die Wiener Juden im Mittelalter. Geschichte der Juden in Wien, Bd. I (Wien 2000).

Lohrmann, Klaus: Zwischen Finanz und Toleranz. Das Haus Habsburg und die Juden (Graz/ Wien/Köln 2000).

Lohrmann, Klaus: Die Entwicklung des Judenrechtes in Österreich und seinen Nachbarländern, in: Iooo Jahre Österreichisches Judentum. Ausstellungskatalog (Eisenstadt I982), S. $25-53$. 
Longerich, Peter: Der ungeschriebene Befehl. Hitler und der Weg zur `Endlösung` (München 200I).

Longerich, Peter: „Davon haben wir nichts gewusst!« Die Deutschen und die Judenverfolgung 1933-1945 (München 2006).

Longerich, Peter: Heinrich Himmler. Biographie (München 2008).

Lozowick, Yaacov: Hitlers Bürokraten. Eichmann, seine willigen Vollstrecker und die Banalität des Bösen (Zürich/München 200o).

Lyotard, Jean-François: Der Widerstreit (München 1987).

Maderegger, Sylvia: Die Juden im österreichischen Ständestaat I934-I938. Veröffentlichungen des Historischen Instituts der Universität Salzburg (Wien 1973).

Malfatti, Josef v.: Handbuch des Österreichisch-Ungarischen Consularwesens (Wien I 879).

Maliř, Jiří: "Druhé« moravské vyrovnáni z roku I9I4, in: Lukáš Fasora et al. (Hg.): Der Mährische Ausgleich von 1905: Möglichkeiten und Grenzen für einen nationalen Ausgleich in Mitteleuropa (Brünn 2006), S. 87-102.

Malleier, Elisabeth: Jüdische Frauen in Wien I 8 I6-1938 (Wien 2004).

Marková, Marta: Auf ins Wunderland! Das Leben der Alice Rühle-Gerstel (Innsbruck 2007).

Marshall, Thomas: Bürgerrechte und soziale Klassen (= Theorie und Gesellschaft 22) (Frankfurt a. M. 1992).

Marx, Karl: Zur Judenfrage, in: Karl Marx - Friedrich Engels, Werke, Bd. I (Berlin 1974).

Mathisen, Ralph W.: Perigrini, Barbari, and Cives Romani. Concepts of Citizenship and the Legal Identity of Barbarians in the Later Roman Empire. The American Historical Review I I.4 (2006) : 48 pars. I9 Juni 20I 2, htp://www.historycooperative.org/journals/ahr/ I I I.4/ mathisen.html.

Mayer, Sigmund: Ein jüdischer Kaufmann. I83 I bis I9I I (Leipzig I9I I).

McCagg, William O.: A History of Habsburg Jews, I670-191 8 (Bloomington/Indianapolis I989).

Menasse, Eva: Der Holocaust vor Gericht. Der Prozess um David Irving (Berlin 2000).

Mentzel, Walter: Weltkriegsflüchtlinge in Cisleithanien I914-1918, in: Gernot Heiss/Oliver Rathkolb (Hg.): Asylland wider Willen. Flüchtlinge in Österreich im europäischen Kontext seit I9I4 (= Veröffentlichungen des Ludwig Boltzmann-Institutes für Geschichte und Gesellschaft 25) (Wien I995), S. 45-49.

Milner, Emanuel: Die österreichische Staatsbürgerschaft und der Gesetzesartikel L: I 879 über den Erwerb und Verlust der ungarischen Staatsbürgerschaft (Tübingen I880).

Mischler, Ernst/Josef Ulbrich (Hg.): Österreichisches Staatswörterbuch. Handbuch des gesamten österreichischen öffentlichen Rechtes, Bd. 2 (Wien I906).

Morton, Frederic: Die Rothschilds. Porträt einer Dynastie (Wien/München 2004).

Moser, Jonny: Die Katastrophe der Juden in Österreich 1938-1945, in: Der gelbe Stern in Österreich. Katalog und Einführung zu einer Dokumentation (= Studia Judaica Austrica V) (Eisenstadt 1977).

Moser, Leopold: Spaziergänge. Studien und Skizzen zur Geschichte der Juden in Österreich (Wien 1994).

Mosse, Werner E.: From »Schutzjuden« to »Deutsche Staatsbürger Jüdischen Glaubens«. The Long and Bumpy Road of Jewish Emanicipation in Germany, in: Birnbaum/Katznelson 
(Hg.): Paths of Emancipation, Jews, States, and Citizenship (Princeton/New Jersey 1995), S. 59-93.

Müller, Dietmar: Staatsbürger auf Widerruf. Juden und Muslime als Alteritätspartner im rumänischen und serbischen Nationscode. Ethnonationale Staatsbürgerschaftskonzepte I 878-I94I (= Balkanologische Veröffentlichungen 4I) (Wiesbaden 2005).

Murdock, Caitlin E.: The Politics of Belonging: Citizenship, Community, and Territory on the Saxon-Bohemian Frontier, 1918-1924, in: Austrian History Yearbook 43 (2012), S. 59-74.

Nathan, Paul: Das Problem der Ostjuden (Berlin 1926).

Nathans, Eli: The Politics of Citizenship in Germany. Ethnicity, Utility and Nationalism (Oxford/New York 2004).

Nekula, Marek: Franz Kafkas Sprachen und Identitäten, in: Marek Nekula/Walter Koschmal (Hg.): Juden zwischen Deutschen und Tschechen. Sprachliche, literarische und kulturelle Identitäten (München 2006), S. I 25-I 50.

Oertel, Christine: Flucht über Österreich. Jüdische Displaced Persons aus Osteuropa 1945I949, in: Displaced. Paul Celan in Wien I947/48. Katalog der gleichnamigen Ausstellung im Jüdischen Museum Wien (Frankfurt am Main 200I), S. 36-45.

Österreichisches Staatswörterbuch. Handbuch des gesamten österreichischen öffentlichen Rechtes, Ernst Mischler/Josef Ulbrich (Hg.), Bd. 2. (Wien I 906), Stichwort: Die Juden.

Österreichische Statistik. Neue Folge (Wien 1975 und Wien I910).

Österreichisches Statistisches Handbuch für die im Reichsrate vertretenen Königreiche und Länder, 29. Jahrgang (1910).

Ofner, Julius: Die Entstehung des Justizhofdekrets vom I2. April I 833 über die Ersitzung der Staatsbürgerschaft, in: Juristische Blätter 23 (I905) I 3, S. I 57-I60 und I4, S. I46-I 58.

Ofner, Julius (Hg.): Der Ur-Entwurf und die Berathungs-Protokolle des Österreichischen Allgemeinen bürgerlichen Gesetzbuches, Bd. I (Wien I889).

Oommen, T.K.: Citizenship, Nationality and Ethnicity. Reconciling Competing Identities (Cambridge 1997).

Oxaal, Ivar/Walter R. Weitzmann: The Jews of Pre-I9I4 Vienna. An Exploration of Basic Sociological Dimensions, in: Leo Baeck Institute Year Book XXX (1985), S. 393-432.

Pacholkiv, Svjatoslav: Das Werden einer Grenze, in: Waltraud Heindl/Edith Saurer (Hg.): Grenze und Staat. Passwesen, Staatsbürgerschaft, Heimatrecht und Fremdengesetzgebung in der österreichischen Monarchie 1750-1867 (Wien/Köln/Weimar 2000), S. 519620.

Pacholkiv, Svjatoslav: Vertraut und fremd zugleich, in: Alexandra Binnenkade et al. (Hg.) : Jüdisch-christliche Nachbarschaft in Warschau, Lengnau, Lemberg (Köln 2009), S. I80-198.

Pacholkiv, Svjatoslav: Die Ostjuden als Begriff in der Geschichte, in : „Ostjuden« - Geschichte und Mythos. Juden in Mitteleuropa (St. Pölten 20 I I), S. 2-I I.

Pacholkiv, Svjatoslav: Social Implications of the Incorporation of Galicia into the Habsburg Realm, in: Harald Heppner/Peter Urbanitsch/Renate Zedinger (Hg.): Social Change in the Habsburg Monarchy (Bochum 20II), S. 6I-8I.

Pacholkiv, Svjatoslav: Die Politik des aufgeklärten Absolitismus und die Judengemeinden Galiziens, in: Frühneuzeit-Info 22.I+2 (201 I), S. 75-89. 
Pammer, Michael: Jüdische Vermögen in Wien 1938 (= Veröffentlichungen der Österreichischen Historikerkommission 8) (Wien/München 2003).

Patka, Marcus G./Mirjana Stancic (Hg.) : Die Analyse der Tyrannis. Manès Sperber I905I984. Katalog des Jüdischen Museums der Stadt Wien (Wien 2006).

Pawlowsky, Verena: Mutter ledig, Vater Staat. Das Gebär- und Findelhaus in Wien I784I9I0 (Wien 200I).

Pfeifer, Helfried (Hg.): Die Ostmark. Eingliederung und Neugestaltung. Historisch-systematische Gesetzessammlung nach dem Stande vom I6. April I94I (Wien I94I).

Pfeil, Walter J.: Die Entschädigung von Opfern des Nationalsozialismus im österreichischen Sozialrecht (= Veröffentlichungen der Österreichischen Historikerkommission 29/I) (Wien/München 2004).

Plaggenborg, Stefan: Maria Theresia und die Böhmischen Juden, in: Bohemia 39 (I998), S. I-I6.

Př́bram, A.F. (Hg.): Quellen und Forschungen zur Geschichte der Juden in Deutsch-Österreich, Bd. VIII: Urkunden und Akten zur Geschichte der Juden in Wien, Erste Abteilung, Bd. 2 (Wien/Leipzig I9I 8).

Die Protokolle des Österreichischen Ministerrates I 848-1867. ÖMProt., III/I, Das Ministerium Buol-Schauenstein, bearbeitet von Waltraud Heindl (Wien 1975).

Die Protokolle des Österreichischen Ministerrates I 848-I 867. ÖMProt., III/2, Das Ministerium Buol-Schauenstein, bearbeitet von Waltraud Heindl (Wien I 979).

Die Protokolle des Österreichischen Ministerrates I 848-I867. ÖMProt., III/4, Das Ministerium Buol-Schauenstein, bearbeitet von Waltraud Heindl (Wien 1987).

Die Protokolle des Österreichischen Ministerrates I 848-I867. ÖMProt., II/I, Das Ministerium Schwarzenberg, bearbeitet von Thomas Kletečka (Wien 2002).

Die Protokolle des Österreichischen Ministerrates I 848-I867. ÖMProt., II/2, Das Ministerium Schwarzenberg, bearbeitet von Thomas Kletečka/Anatol Schmied-Kowarzik (Wien 2005).

Die Protokolle des Österreichischen Ministerrates I848-I 867. ÖMProt., IV/I, Das Ministerium Rechberg, bearbeitet von Stefan Malfèr (Wien 2003).

Die Protokolle des Österreichischen Ministerrates I 848-I867. ÖMProt., VI, Die Ministerien Erzherzog Rainer und Mensdorff, bearbeitet von Thomas Kletečka/Klaus Koch (Wien I989).

Rabinbach, Anson G.: The Migration of Galician Jews to Vienna, I 857-1880, in: The Austrian History Yearbook 9 (1975), S. 42-54.

Rauscher, Peter: "Die Vertreibung der Juden aus Wien und Niederösterreich im Jahr I670", Vortrag beim Symposium »Wiens jüdische Gemeinde im I7. Jahrhundert«, Wien, 24. Mai 2006, ungedruckt.

Rawls, John: Der Vorrang der Grundfreiheiten, in: derselbe: Die Idee des politischen Liberalismus. Aufsätze 1978-1989 (Frankfurt a. M. 1992), S. I 59-254.

Rechter, David: The Jews of Vienna and the First World War (London/Portland, Oregon 200I).

Rechter, David: A Nationalism of Small Things: Jewish Autonomy in Late Habsburg Austria, in: Leo Baeck Institute Year Book LII (2007), S. 87-I09. 
Redlich, Josef Fritz: Das österreichische Staats- und Reichsproblem, Bd. I (Leipzig 1929).

Reichel, David: Staatsbürgerschaft und Integration. Die Bedeutung der Einbürgerung für MigrantInnen (Wiesbaden 20II).

Reiss, J. (Hg.): Aus den sieben Gemeinden. Ein Lesebuch über Juden im Burgenland (Eisenstadt I997).

Riedel, Manfred: Bürger, Staatsbürger, Bürgertum, in: Otto Brunner/Werner Conze/Reinhart Koselleck (Hg.): Geschichtliche Grundbegriffe. Historisches Lexikon zur politisch-sozialen Sprache in Deutschland, Bd. I (Stuttgart I973), S. 672-7 I 8.

Riesenberg, Peter: Citizenship in the Western Tradition (Chapel Hill/London 1992).

Ringhofer, Kurt: Strukturprobleme des Rechts (Wien 1966).

Rönne, Ludwig von/Heinrich Simon: Die früheren und gegenwärtigen Verhältnisse der Juden in den sämmtlichen Landestheilen des Preußischen Staates (Breslau 1943).

Roseman, Mark: The Villa, the Lake, the Meeting. Wannsee and the Final Solution (London 2002).

Rosenberg, Alfred: Der Mythus des 20. Jahrhunderts. Eine Wertung der seelisch-geistigen Gestaltungskräfte unserer Zeit (München I930).

Rosenkranz, Herbert: Entrechtung, Verfolgung und Selbsthilfe der Juden in Österreich, in : Gerald Stourzh/Birgitta Zaar (Hg.): Österreich und die Mächte. Internationale und österreichische Aspekte des »Anschlusses« vom März 1938 (= Veröffentlichungen der Kommission für die Geschichte Österreichs I6) (Wien 1990), S. 367-417.

Rozenblit, Marsha L.: The Jews of Vienna, 1867-1914: Assimilation and Identity (Albany I983), deutsche Ausgabe: Die Juden Wiens I867-I9I4. Assimilation und Identität (Wien/ Köln/Graz 1988).

Rozenblit, Marsha L.: Jewish Identity and the Modern Rabbi: The Cases of Isak Noa Mannheimer, Adolf Jellinek, and Moritz Güdemann in Nineteenth-Century Vienna, in: Leo Baeck Institute Year Book XXXV (1990), S. 103-13 I.

Rozenblit, Marsha L.: Reconstructing a National Identity: The Jews of Habsburg Austria During World War (Oxford/New York 200r).

Rozenblit, Marsha L.: Jewish Courtship and Marriage in I92os Vienna, in: Marion A. Kaplan/ Deborah Dash Moore (Hg.): Gender and Jewish History (Bloomington 20 I I), S. 88-103.

Rumpler, Helmut: Budapest - Wien - Fiume I905. Die Entscheidung für die österreichische Wahlreform von 1907 im Kontext der Wende der europäischen Außenpolitik, in: Michael Svatos et al. (Hg.) : Magister Noster. Festschrift in memoriam Prof. PhDr. Jan Havránek (Prag 2005), S. 493-506.

Rürup, Reinhard: Der Fortschritt und seine Grenzen. Die Revolution von I 848 und die europäischen Juden, in: Dieter Dowe et al. (Hg.) : Europa I 848. Revolution und Reform (= Politik- und Gesellschaftsgeschichte 48) (Bonn I998), S. 985-1005.

Sadowski, Dirk: Haskala und Lebenswelt: Herz Homberg und die jüdischen Schulen in Galizien 1782-1806 (Göttingen 2010).

Schematismus der Allgemeinen Volksschulen und Bürgerschulen in den im Reichsrathe vertretenen Königreichen und Ländern (Wien I902).

Scherer, J.E.: Die Rechtsverhältnisse der Juden in den deutsch-österreichischen Ländern (Leipzig I90I). 
Schimmer, Gustav A.: Die Juden in Österreich nach der Zählung vom 3 I. Dezember I 880 (Wien I88I).

Schmale, Wolfgang/Martina Steer: Kulturtransfer in der jüdischen Geschichte (Frankfurt Main 2006).

Schmidl, Erwin A.: Juden in der k.(u.)k. Armee I788-I9I8, (= Studia Judaica Austriaca Bd. I I) (Eisenstadt I989).

Schoeps, Julius H.: „Du Doppelgänger, Du bleicher Geselle ...«. Deutsch-jüdische Erfahrungen im Spiegel dreier Jahrhunderte I700-2000 (Berlin/Wien 2004).

Schorske, Carl: Geist und Gesellschaft im Fin de Siècle (Frankfurt a. M. 1982).

Schubert, Kurt: Die Geschichte des österreichischen Judentums (Wien/Köln/Weimar 2008).

Schulte, Christoph: Moses Mendelssohn, die jüdische Aufklärung und der Pluralismus im modernen Judentum, in: Eveline Goodman-Thau/Fania Oz-Salzbrger (Hg.): Das jüdische Erbe Europas (Berlin/Wien 2005), S. 77-91.

Seufert, Günter: Die Türkei, der Libanon und Israel. Staatsbürgerschaft bei den drei reuropäischen Erben des Osmanischen Reiches im muslimischen Vorderen Orient, in: Christoph Conrad/Jürgen Kocka (Hg.): Staatsbürgerschaft in Europa. Historische Erfahrungen und aktuelle Debatten (Hamburg 200I), S. 216-239.

Skene, Alfred von: Der nationale Ausgleich in Mähren r905 (Wien I9 Io).

Snyder, Timothy: Bloodlands. Europa zwischen Hitler und Stalin (München 20 I I).

Sonnenfels, Joseph von: Über die Liebe des Vaterlandes (Wien I77I).

Sonnenfels, Joseph von: Handbuch der inneren Staatsverwaltung, Bd. I (Wien I798).

Sperber, Jenka: Sein letztes Jahr (München I 985 ).

Sperber, Manès: Die Wasserträger Gottes. All das Vergangene (Frankfurt a. M. 1993).

Sperber, Manès: Die vergebliche Warnung (Frankfurt a. M. 1993).

Sperber, Manès: Bis man mir Scherben auf die Augen legt. All das Vergangene (Frankfurt a. M. 1977).

Sperber, Manès: Wie eine Träne im Ozean (Wien I96I).

Sperber, Manès: Die Zeit in der sie lebten. Österreichische Juden unter Franz Joseph (Frankfurt a. M. 1970).

Sperber, Manès: Mein Judesein, in: Churban oder die unfassbare Gewissheit (Wien/München/Zürich 1979).

Sperber, Manès: Die vergebliche Warnung (Frankfurt a. M. I993).

Spring, Claudia: Vermessen, deklassiert und deportiert. Dokumentation zur anthropologischen Untersuchung an 440 Juden im Wiener Stadion im September 1939 unter der Leitung von Josef Wastl vom Naturhistorischen Museum Wien, in: Zeitgeschichte 32.2 (März/April 2005), S. 91-I IO.

Springer, Rudolf (Pseudonym für Karl Renner): Grundlagen und Entwicklungsziele der Österreichisch-Ungarischen Monarchie (Wien/Leipzig 1906).

Stambrook, Fred: The Golden Age of the Jews of Bukowina, I880-1914 (= Centre for Austrian Studies, Minneapolis, Working Paper 03-2) (October 2003).

Staudacher, Anna: Jüdisch-protestantische Konvertiten in Wien I782-I9I4, Teil I (Frankfurt a. M. 2004).

Staudinger, Barbara: Zur Geschichte der Juden in Niederösterreich I 496-I670/7I, in: Da- 
vid - Jüdische Kulturzeitschrift, www.david.juden.at/kulturzeitschrift/6I-65/63-Staudinger-htm.

Staudinger, Barbara: „Gantze Dörffer voll Juden«. Juden in Niederösterreich I 496-I670 (Wien 2005).

Staudinger, Barbara: Juden als »Pariavolk« oder »Randgruppe«? Bemerkungen zu Darstellungsmodellen des christlich-jüdischen Verhältnisses in der Frühen Neuzeit, in: Wiener Zeitschrift zur Geschichte der Neuzeit 4.I (2004), S. 8-25.

Steenbergen, Bart van: The Condition of Citizenship (London 1994).

Stein, A.: Der Mensch im Bilde Gottes. Festpredigt zur Feier des nach roo Jahren wiederkehrenden Tages der Kundmachung des ersten der von Kaiser Josef II. gegebenen Gesetze zur Befreiung der Juden aus der mittelalterlichen Rechtlosigkeit (Prag I 88I) (Sonderdruck), S. I 2.

Stein, Harry: Juden in Buchenwald I937-1942, Gedenkstätte Buchenwald (Hg.) (Weimar I992).

Stern, Frank/Barbara Eichinger (Hg.): Wien und die jüdische Erfahrung I900-1938. Akkulturation - Antisemitismus - Zionismus (Wien/Köln/Weimar 2009).

Stern, Selma/Marina Sassenberg: Die Hofjuden im Zeitalter des Absolutismus (= Schriftenreihe wissenschaftlicher Abhandlungen des Leo Baeck Instituts 64) (Tübingen 200I).

Sternfeld, Albert: Betrifft: Österreich. Von Österreich betroffen (Wien/Köln/Weimar 200I). Stewart, F.: Citizens of Planet Earth, in: Geof Andrews (Hg.): Citizenship (London I991).

Stoklásková, Zdenka: Fremdsein in Böhmen und Mähren, in: Waltraud Heindl/Edith Saurer (Hg.): Grenze und Staat. Paßwesen, Staatsbürgerschaft, Heimatrecht und Fremdengesetzgebung in der österreichischen Monarchie I750-1867 (Wien 2000), S. 62 I-720.

Stolleis, Michael: Von den Rechtsnormen zur Rechtspraxis. Zur Rechtsgeschichte der Juden im Heiligen Römischen Reich Deutscher Nation, in: Andreas Gotzmann/Stephan Wendehorst (Hg.) : Juden im Recht. Neue Zugänge zur Rechtsgeschichte der Juden im Alten Reich, Zeitschrift für Historische Forschung, Beiheft 39 (2007), S. I I-24.

Stourzh, Gerald: Galten die Juden als Nationalität Altösterreichs? (= Studia Judaica Austriaca го) (Eisenstadt I984), S. 73-I I7.

Stourzh, Gerald: Die Gleichberechtigung der Nationalitäten in der Verfassung und Verwaltung Österreichs I848-I918 (Wien I985).

Stourzh, Gerald: Die österreichische Dezemberverfassung von 1867, in: Wege zur Grundrechtsdemokratie. Studien zur Begriffs- und Institutionengeschichte des liberalen Verfassungsstaates (= Studien zu Politik und Verwaltung 29) (Wien/Köln I 989), S. 239-258.

Stourzh, Gerald: The Age of Emancipation and Assimilation - Liberalism and its Heritage, in: Hanni Mittelmann/Armin A. Wallas (Hg.): Österreich-Konzeptionen und jüdisches Selbstverständnis. Identitäts-Tranfigurationen im 19. und 20. Jahrhundert (Tübingen 200I), S. I I-28.

Stourzh, Gerald: Der nationale Ausgleich in der Bukowina I909/ı 9 Io, in: Ilona Slawinski/ Joseph P. Strelka (Hg.): Die Bukowina. Vergangenheit und Gegenwart (Bern et al. 1995), S. 35-52.

Stourzh, Gerald: Zeit der Konversionen: Gustav Mahler, Karl Kraus und Wien im fin de siècle, in: derselbe: Spuren einer intellektuellen Reise. Drei Essais (Wien/Köln/Weimar 2009), S. 6I-I02. 
Stourzh, Gerald: Die Grundrechte in der Paulskirche und im Kremsierer Reichstag, in: derselbe: Der Umfang der österreichischen Geschichte. Ausgewählte Studien I990-20 Io (Wien/Köln/Graz 20 I I), S. 69-85.

Stourzh, Gerald/Birgitta Zaar (Hg.): Österreich, Deutschland und die Mächte. Internationale und Österreichische Aspekte des »Anschlusses« vom März I 938 (Wien I990).

Strakosch-Grassmann, Gustav: Geschichte des Österreichischen Unterrichtswesens (Wien I905).

Stuckart, Wilhelm: Nationalsozialismus und Staatsrecht, in: H.H. Lammers/Hans Pfundner (Hg.): Grundlagen, Aufbau und Wirtschaftsordnung des nationalsozialistischen Staates, Bd. I, Gruppe 2, Loseblattsammlung (Berlin o.J.).

Stuckart, Wilhelm/Hans Globke (Hg.): Kommentar zur deutschen Rassengesetzgebung, Bd. I.C.: Erläuterungen zum Reichsbürgergesetz und Gesetz zum Schutze des deutschen Blutes und der Ehre (München/Berlin 1936).

Surall, Frank: Juden und Christen - Toleranz in neuer Perspektive (Gütersloh 2003).

Svingrová, Simona: Tschechisch oder Deutsch? Auf dem Weg von Konkurrenz zu Dominanz. Zum Einsatz von innerer und äußerer Amtssprache in der Arbeiter-Unfall-VersicherungAnstalt im Prag der Kafka-Zeit (1908-1922), in: Marek Nekula et al. (Hg.): Franz Kafka im sprachnationalen Kontext seiner Zeit. Sprache und nationale Identität in öffentlichen Institutionen der böhmischen Länder (Köln/Weimar/Wien 2007), S. I29-1 50.

Swieceny, Friedrich: Das Heimatrecht in den österreichischen Kronländern mit constituierten Ortsgemeinden (Wien I86I).

Tálos, Emmerich: Von der Liquidierung der Eigenstaatlichkeit zur Etablierung der Reichsgaue der »Ostmark«. Zum Umbau der politisch-administrativen Struktur, in: derselbe et al. (Hg.): NS-Herrschaft in Österreich. Ein Handbuch (Wien 2000), S. 55-72.

Tantner, Anton: Ordnung der Häuser, Beschreibung der Seelen - Hausnummerierung und Seelenkonskription in der Habsburgermonarchie, phil. Diss. (Wien 2004).

Tarrab-Maslaton, Martin: Rechtliche Strukturen der Diskriminierung der Juden im Dritten Reich (Berlin 1993).

Taylor, Charles: Multikulturalismus und die Politik der Anerkennung (Frankfurt a. M. 1993).

Taylo, Charles: Was ist die Quelle kollektiver Identität? In: Dewandre/Lenoble, Projekt Europa, S. $42-46$.

Thompson, Jana: Justice and World Order (London/New York 1992).

Thon, Jacob: Die Juden in Österreich. Veröffentlichungen des Bureaus für Statistik der Juden, Heft 4 (Berlin I908).

Tietze, Hans: Die Juden Wiens [Wien/Leipzig 1933] (Nachdruck: Wien 1987).

Timms, Edward: Citizenship and $>$ Heimatrecht after the Treaty of Saint-Germain, in: Austrian Studies V (1994), S. I 58 -I 68.

Timms, Edward: The Pernicious Rift: Metternich and the Debate about Jewish Emancipation at the Congress of Vienna, in: Leo Baeck Institute Year Book XLVI (200I), S. 3-17.

Tilly, Charles (Hg.): Citizenship, Identity and Social History, International Review of Social History, Supplement 3,1996.

Toury, Jacob: Troubled Beginnings: The Emergence of the Österreichisch-Israelitische Union, in: Leo Baeck Institute Year Book XXX (London I985), S. 456-475. 
Die Türken in Wien. Geschichte einer jüdischen Gemeinde. Katalog der Ausstellung, Jüdisches Museum Wien (Hg.) (Wien 2010).

Tvrdik, Milan: Die Emanzipation der jüdischen Kultur, in: Marek Nekula/Walter Koschmal (Hg.): Juden zwischen Deutschen und Tschechen. Sprachliche, literarische und kulturelle Identitäten (München 2006), S. 203-2 I6.

Ulbrich, Joseph: Das österreichische Staatsrecht (Tübingen 1904).

Ungvári, Tamás: The Jewish Question in Europe. The Case of Hungary (New York 2000).

Vesque von Püttlingen, Johann: Die gesetzliche Behandlung der Ausländer in Österreich (Wien I842).

Wagner, Benno: Kafkas Polná. Schreiben jenseits der Nation, in: Marek Nekula/Walter Koschmal (Hg.): Juden zwischen Deutschen und Tschechen. Sprachliche, literarische und kulturelle Identitäten (München 2006), S. I 5 I-I72.

Walk, Joseph/Robert M.W. Kemper: Das Sonderrecht für die Juden im NS-Staat. Eine Sammlung der gesetzlichen Maßnahmen und Richtlinien, Inhalt und Bedeutung (Heidelberg 1996).

Walzer, Michael: Über Toleranz. Von der Zivilisierung der Differenz (Hamburg 1998).

Walzer, Michael: Zivile Gesellschaft und amerikanische Demokratie (Frankfurt a. M. 1996).

Walzer, Tina: Weißbuch jüdischer Friedhöfe Österreichs (Wien 2002).

Walzer, Tina: Mährische Juden in Wien I784-1874. Ein Forschungsbericht, in: David - Jüdische Kulturzeitschrift, www.david.juden.at/kulturzeitschrift.

Wambach, Lovis M.: Ahasver und Kafka. Zur Bedeutung der Judenfeindschaft in dessen Leben und Werk (Heidelberg I993).

Wangermann, Ernst: i 848 und die Emanzipation der Juden im Habsburgerreich, in: Chilufim - Zeitschrift für jüdische Kulturgeschichte, I (2006), S. 59-85.

Wecker, Regina: „Ehe ist Schicksal, Vaterland ist auch Schicksal und dagegen ist kein Kraut gewachsen." Gemeindebürgerrecht und Staatsangehörigkeitsrecht von Frauen in der Schweiz I798-1988, in: L’homme I (1999), S. I3-37.

Weidenfeller, Gerhard: VDA, Verein für das Deutschtum im Ausland. Allgemeiner Deutscher Schulverein (I98I-I9I8) (= Europäische Hochschulschriften Reihe III, Bd. 66) (Bern/ Frankfurt am Main 1976).

Weinacht, Paul-Ludwig: "Staatsbürger«. Zur Geschichte und Kritik eines politischen Begriffs, in: Der Staat 8 (1969), S. 4I-63.

Weiss, Yfaat: Deutsche und polnische Juden vor dem Holocaust. Jüdische Identität zwischen Staatsbürgerschaft und Ethnizität 1933-1940 (München 2000).

Wendelin, Harald: Schub und Heimatrecht, in: Waltraud Heindl/Edith Saurer (Hg.): Grenze und Staat. Paßwesen, Staatsbürgerschaft, Heimatrecht und Fremdengesetzgebung in der österreichischen Monarchie 1750-1865 (Wien/Köln/Weimar 2000), S. I95-230.

Wilder-Okladek, Friederike: The Return movement of Jews to Austria after the second World War (Den Haag 1969).

Witte, Peter et. al.: Der Dienstkalender Heinrich Himmlers I94I/42 (= Hamburger Beiträge zur Sozial- und Zeitgeschichte, Quellen, 3) (Hamburg 1999).

Wohnout, Helmut: Die Verfassung 1934 im Widerstreit der unterschiedlichen Kräfte im Regierungslager, in: Ilse Reiter-Zatloukal et al. (Hg.) : Österreich 1933-1938. Interdiszip- 
linäre Annäherungen an das Dollfuß-/Schuschnigg-Regime (Wien/Köln/Weimar 20 I2), S. $17-30$.

Wolf, Gershon: Geschichte der Juden in Wien I I 56-I 876 [Wien I 876] (Reprint 1974).

Wolff, Larry: Inventing Eastern Europe. The Map of Civilization on the Mind of the Enlightenment (Stanford, Calif. 1994).

Wyrwa, Ulrich: Juden in der Toskana und in Preußen im Vergleich (= Schriftenreihe wissenschaftliche Abhandlungen des Leo Baeck Instituts 67) (Tübingen 2003).

Yurdakul, Gökce/Michal Bodemann: Staatsbürgerschaft, Migration und Minderheiten (Wiesbaden 20I0).

Zahra, Tara E.: Reclaiming Children for the Nation: Germanization, National Ascription, and Democracy in the Bohemian Lands, I900-1945. Central European History 37.4 (2004), S. 50I-543.

Zahra, Tara: Kidnapped Souls. National Indifference and the Battle for Children in the Bohemian Lands, 1900-1948 (Ithaca/London 2008).

Zahra, Tara: »Prisoners of the Postwar«: Expellees, Displaced Perrsons, and the Jews in Austria after World War II, in: Austrian History Yearbook XLI (2010), S. I 9 I-2 I 5.

Zeiller, Franz v.: Vortrag zur Einleitung in das bürgerliche Gesetzbuch vom 5. Juli I 8 I o vor der Hofkommission in Gesetzessachen, Allgemeines Österreichisches Verwaltungsarchiv, Wien (AVA), Bestand Oberste Justiz, Fasc. ABGB, aus i 8 I o (Brandakt).

Zweig, Stefan: Die Welt von Gestern (Frankfurt a. M. I966). 


\title{
Verzeichnis der Abbildungen und Tabellen
}

\author{
Abb. I Joseph Freiherr von Sonnenfels \\ Abb. 2 Jüdische Trauungszeremonie in Galizien \\ Abb. 3 Polizeiverordnung vom 25. März I 8 Io \\ Abb. 4 Verzeichnis in Gemeinschaftlichen Diensten Stehender \\ Abb. 5 Franziska (Fanny) Freifrau von Arnstein \\ Abb. 6 Bernhard Freiherr von Eskeles \\ Abb. 7 Nobilitierungsurkunde \\ Abb. 8 Israel Hönig von Hönigsberg \\ Abb. 9 Wilhelm von Humboldt \\ Abb. Io Isaak Noah Mannheimer \\ Abb. I I Zahl der Juden in den österreichischen Ländern \\ Abb. I 2 Franz Kafka \\ Abb. I 3 Adolf Fischhof \\ Abb. I4 Antisemitische Ausschreitungen I93 I \\ Abb. I 5 Orthodoxe jüdische Flüchtlinge I9 I 5 \\ Abb. I6 Träger des gelben Sterns \\ Abb. I7 Leon Falkenflik \\ Abb. I 8 Todesbescheinigung \\ Abb. I9 Gena Falkenflik mit Tochter Martha \\ Abb. 20 Elias Canetti \\ Abb. 2 I Meldezettel des Elias Canetti \\ Abb. 22 Manès Sperber
}

Tabelle I : Ein- und Ausbürgerungen von Juden in Österreich zwischen I 885 und I 903 


\section{Zeittafel}

\begin{tabular}{|c|c|c|c|}
\hline & Politische Geschichte & $\begin{array}{l}\text { Innere Entwicklung, } \\
\text { Verwaltung } \\
\text { und Verfassung }\end{array}$ & $\begin{array}{l}\text { Gesetze und Verordnungen } \\
\text { Juden betr., insb. Heimatrecht } \\
\text { u. Staatsbürgerschaft }\end{array}$ \\
\hline $1220-50$ & Friedrich II., r.-dt. Kaiser & & \\
\hline 1238 & & & $\begin{array}{l}\text { Privileg f. d. Juden der reichs- } \\
\text { unmittelbaren Stadt Wien }\end{array}$ \\
\hline $1230-46$ & Friedrich II., ö. Herzog & & (Kammerknechtschaft) \\
\hline $1273-91$ & $\begin{array}{l}\text { Rudolf v. Habsburg, dt. } \\
\text { König }\end{array}$ & & $\begin{array}{l}\text { "Fridericianum" (1244) } \\
\text { Provinzialkonzil v. St. Ste- }\end{array}$ \\
\hline $1404-39$ & Albrecht V., ö. Ehz. & & phan in Wien (1267) \\
\hline $1419-36$ & Hussitenkriege & & Schutzbrief (1407) \\
\hline $1493-1519$ & Maximilian I. & & Vertreibung d. Juden aus \\
\hline $1526-64$ & Ferdinand I. & $\begin{array}{l}\text { Reichskammergericht } \\
\text { (1495), Hofrat, Hof- } \\
\text { kammer und Hofkanzlei }\end{array}$ & $\begin{array}{l}\text { Wien (Wiener Geserah) } \\
\text { 1420/21 } \\
\text { Ausweisungen aus Tirol, }\end{array}$ \\
\hline $1576-1612$ & Rudolf II. & (1498) & Kärnten und Steiermark \\
\hline $1612-19$ & Matthias & Hofstaatsordnung (1527): & Generalmandat "Judenschüt- \\
\hline $1618-48$ & Dreißigjähriger Krieg & Geheime Rat, Hofrat, Hof- & zung« (1529) \\
\hline 1619-37 & Ferdinand II. & kanzler, Hofkammer & Hofbefreiung (1582) \\
\hline $1658-1705$ & Leopold I. & Bettler- und Armenverord- & Wiederansiedlung \\
\hline 1669 & Friede v. Karlowitz & $\begin{array}{l}\text { nung } 1552 \text { (Grundlage für } \\
\text { das spätere Heinatrecht) }\end{array}$ & $\begin{array}{l}\text { Privileg f. d. "Unteren Werd» } \\
(1624)\end{array}$ \\
\hline $1705-11$ & Joseph I. & & $\begin{array}{l}\text { Leopoldinisches Privilegium } \\
1659\end{array}$ \\
\hline $1711-40$ & Karl VI. & & Vertreibung aus Wien und \\
\hline 1713 & Pragmatische Sanktion & & $\begin{array}{l}\text { allgemeines Ansiedlungsver- } \\
\text { bot }(1670 / 71)\end{array}$ \\
\hline 1718 & Friede von Passarowitz & & Privilegien für Oppenheimer \\
\hline 1739 & Friede von Belgrad & & $\begin{array}{l}\text { + Wertheimer } \\
\text { Nach Friedensvertrag v. Pas- } \\
\text { sarowitz kommt es zu Nie- } \\
\text { derlassungen sephardischer } \\
\text { Juden in Wien und Triest. } \\
\text { Judenverordnung f. Wien u. } \\
\text { Niederösterreich (1721/23) } \\
\text { Familiantengesetz f. Böhmen } \\
\text { und Mähren (1726) }\end{array}$ \\
\hline $1740-80$ & $\begin{array}{l}\text { Maria Theresia. Ehz. Ö, } \\
\text { Königin v. Ungarn }\end{array}$ & & \\
\hline $1740-42$ & $\begin{array}{l}\text { Erster Schlesischer Krieg: } \\
\text { Österreich verliert Ober- u. } \\
\text { Niederschlesien }\end{array}$ & & \\
\hline
\end{tabular}




\begin{tabular}{|c|c|c|c|}
\hline & Politische Geschichte & $\begin{array}{l}\text { Innere Entwicklung, } \\
\text { Verwaltung } \\
\text { und Verfassung }\end{array}$ & $\begin{array}{l}\text { Gesetze und Verordnungen } \\
\text { Juden betr., insb. Heimatrecht } \\
\text { u. Staatsbürgerschaft }\end{array}$ \\
\hline 1742 & & $\begin{array}{l}\text { Haus-, Hof- und Staats- } \\
\text { kanzlei }\end{array}$ & \\
\hline $1742-44$ & $\begin{array}{l}\text { Zweiter Schlesischer } \\
\text { Krieg: Schlesien bleibt bei } \\
\text { Preußen }\end{array}$ & & $\begin{array}{l}\text { Ausweisung aller Juden } \\
\text { aus Prag } 1744 \text { (später Um- } \\
\text { wandlung in zehnjährige } \\
\text { Duldung) }\end{array}$ \\
\hline $1745-65$ & $\begin{array}{l}\text { Franz I. Stephan (v. Loth- } \\
\text { ringen), r.-dt. Kaiser }\end{array}$ & & \\
\hline 1748 & $\begin{array}{l}\text { Erbfolgekriege gegen Bay- } \\
\text { ern u. Preußen; Friede von } \\
\text { Aachen: Parma u. Piacenza } \\
\text { an Bourbonen }\end{array}$ & & \\
\hline 1749 & & $\begin{array}{l}\text { Verwaltungsreform (Haug- } \\
\text { witz): Oberstes Verwal- } \\
\text { tungsorgan: Directorium } \\
\text { in publicis et cameralibus; } \\
\text { Oberste Justizstelle; Guber- } \\
\text { nien und Kreisämter }\end{array}$ & \\
\hline 1753 & Kaunitz wird Staatskanzler & $\begin{array}{l}\text { Kommission zur Reform } \\
\text { des Codex Theresianius } \\
\text { (Zivilgesetz) eingesetzt. }\end{array}$ & Judenordnung \\
\hline 1754 & & $\begin{array}{l}\text { Bettlerschubs- und Ver- } \\
\text { pflegspatent v. 15. No- } \\
\text { vember betr. Versorgung } \\
\text { von Armen durch die } \\
\text { Heimatgemeinde (Beginn } \\
\text { des Heimatrecht) }\end{array}$ & \\
\hline $1756-63$ & Siebenjähriger Krieg & & \\
\hline $1760-61$ & & $\begin{array}{l}\text { Verwaltungsreform: Staats- } \\
\text { rat, Vereinigte böhmisch- } \\
\text { österreichische Hofkanzlei, } \\
\text { Hofkammer; Hofrechen- } \\
\text { kammer }\end{array}$ & \\
\hline 1763 & $\begin{array}{l}\text { Friede zu Hubertusburg: } \\
\text { Verlust Schlesiens, Rest: } \\
\text { "Österreichisch Schlesien« }\end{array}$ & & \\
\hline 1764 & & & Judenordnung \\
\hline $1765-90$ & $\begin{array}{l}\text { Joseph II., r.-dt. Kaiser, } \\
\text { Mitregent in Österreich } \\
\text { (seit } 1780 \text { Alleinregent) }\end{array}$ & & \\
\hline 1771 & & & Privilegium für $\mathrm{d}$. Juden \\
\hline 1772 & $\begin{array}{l}\text { Erste Teilung Polens: } \\
\text { Lodomerien u. Galizien } \\
\text { (ohne Krakau) fallen an } \\
\text { Österreich }\end{array}$ & & Triests \\
\hline 1775 & Erwerb der Bukowina & & \\
\hline
\end{tabular}




\begin{tabular}{|c|c|c|c|}
\hline & Politische Geschichte & $\begin{array}{l}\text { Innere Entwicklung, } \\
\text { Verwaltung } \\
\text { und Verfassung }\end{array}$ & $\begin{array}{l}\text { Gesetze und Verordnungen } \\
\text { Juden betr., insb. Heimatrecht } \\
\text { u. Staatsbürgerschaft }\end{array}$ \\
\hline 1776 & & & Judenordnung $\mathrm{f}$. Galizien \\
\hline $1778-79$ & $\begin{array}{l}\text { Bayerischer Erbfolgekrieg; } \\
\text { Friede von Teschen: Inn- } \\
\text { viertel an Ö. }\end{array}$ & & \\
\hline $1780-90$ & $\begin{array}{l}\text { Alleinregierung Joseph II. } \\
\text { Staatskanzler Kolowrat }\end{array}$ & & \\
\hline 1781 & & $\begin{array}{l}\text { Toleranzpatent v. } 13 . \\
\text { Oktober: Protestanten } \\
\text { erhalten Freiheit der } \\
\text { Religionsausübung. Unter- } \\
\text { tanenpatent: Aufhebung } \\
\text { der Erbuntertänigkeit d. } \\
\text { Bauern (1.11.) }\end{array}$ & $\begin{array}{l}\text { Patent v. 12. Oktober hebt } \\
\text { alle »Judenzeichen« auf. } \\
\text { Hofdekret f. d. Juden Böh- } \\
\text { mens (19.10.) }\end{array}$ \\
\hline 1782 & & $\begin{array}{l}\text { Josephinische Verwal- } \\
\text { tungsreform: „Vereinigte } \\
\text { Hofstellen« (Hofkanzlei + } \\
\text { Hofkammer); Ungarn: Un- } \\
\text { garische Hofkanzlei, Komi- } \\
\text { tatsverfassung aufgehoben; } \\
13 \text { Gubernien }\end{array}$ & $\begin{array}{l}\text { Toleranzpatent v. 2. Jänner } \mathrm{f} \text {. } \\
\text { d. Juden Wiens und Nieder- } \\
\text { österreichs. } \\
\text { Erlaubnis der Absolvierung } \\
\text { der medizinischen und juri- } \\
\text { dischen Studien. } \\
\text { Toleranzpatent f. d. Juden } \\
\text { Mährens v. 13.2. }\end{array}$ \\
\hline 1783 & & & $\begin{array}{l}\text { "Sistematica gentis Judaicae } \\
\text { regulatio« (Toleranzpatent } \\
\text { für die Juden Ungarn) 31.3. }\end{array}$ \\
\hline 1784 & Scheldesperre & $\begin{array}{l}\text { "Si(e)ned" (Einverständnis) } \\
\text { zwischen Hoher Pforte } \\
\text { u. Österreich regelt Han- } \\
\text { delsverkehr u. Passbestim- } \\
\text { mungen }\end{array}$ & \\
\hline 1785 & & & Vorläufiges Judensystem in \\
\hline 1786 & & $\begin{array}{l}\text { Josephinisches Gesetzbuch } \\
\text { (JGB) }\end{array}$ & Galizien \\
\hline 1787 & & & $\begin{array}{l}\text { Reform des mährischen } \\
\text { Judensystems }\end{array}$ \\
\hline $1788-89$ & Letzter Türkenkrieg & & Militärdienst f. Juden \\
\hline 1789 & $\begin{array}{l}\text { Ausbruch der Französi- } \\
\text { schen Revolution }\end{array}$ & & $\begin{array}{l}\text { Toleranzpatent für die Juden } \\
\text { Galiziens v. } 7.5 \text {. } \\
\text { Erlaubnis zum Kauf v. Staats- } \\
\text { gütern }\end{array}$ \\
\hline $1790-92$ & Leopold II., r.-dt. Kaiser & & \\
\hline
\end{tabular}




\begin{tabular}{|c|c|c|c|}
\hline & Politische Geschichte & $\begin{array}{l}\text { Innere Entwicklung, } \\
\text { Verwaltung } \\
\text { und Verfassung }\end{array}$ & $\begin{array}{l}\text { Gesetze und Verordnungen } \\
\text { Juden betr., insb. Heimatrecht } \\
\text { u. Staatsbürgerschaft }\end{array}$ \\
\hline 1790 & $\begin{array}{l}\text { Konvention v. Reichen- } \\
\text { bach: Verzicht auf türki- } \\
\text { sche Gebietserwerbungen } \\
\text { Vertrag von Haag: Gene- } \\
\text { ralamnestie und Souveräni- } \\
\text { tätsgarantie für die } \\
\text { "Vereinigten Staaten von } \\
\text { Belgien« (vorm. österr. } \\
\text { Niederlande) }\end{array}$ & $\begin{array}{l}\text { Leopoldinische Verwal- } \\
\text { tungsreform: Wiedererrich- } \\
\text { tung der "Böhmisch-öster- } \\
\text { reichischen Hofkanzlei« } \\
\text { +der siebenbürgischen Hof- } \\
\text { kanzlei (ital. HK. Niederl. } \\
\text { HK, galiz. HK 1795) }\end{array}$ & \\
\hline 1791 & $\begin{array}{l}\text { Friede v. Sistowa (4. Au- } \\
\text { gust) mit Bestätigung } \\
\text { des Friedens von Belgrad } \\
\text { v. } 1739 \text { mit zahlreichen } \\
\text { Übertrittbestimmungen } \\
\text { und Handelsprivilegien } \\
\text { (Meistbegünstigungsklau- } \\
\text { sel) }\end{array}$ & & $\begin{array}{l}\text { Möglichkeit des Übertritts } \\
\text { "türkischer Juden« in die } \\
\text { österreichische »Bothmäßig- } \\
\text { keit» (Naturalisation) }\end{array}$ \\
\hline $1792-1835$ & $\begin{array}{l}\text { Franz II. (I.), r.-dt. Kaiser, } \\
\text { ab } 1804 \text { Kaiser v. Öster- } \\
\text { reich }\end{array}$ & & \\
\hline $\begin{array}{r}1792-1795 / \\
97\end{array}$ & $\begin{array}{l}\text { Erster Koalitionskrieg ge- } \\
\text { gen Frankreich }\end{array}$ & & \\
\hline 1792 & $\begin{array}{l}\text { Demission Staatskanzler } \\
\text { Kaunitz }\end{array}$ & & $\begin{array}{l}\text { Wiedereinführung der Bollet- } \\
\text { tentaxe (Leibmaut) f. Juden. } \\
\text { Beschwerdeschrift der Wie- } \\
\text { ner Juden }\end{array}$ \\
\hline 1793 & Zweite Teilung Polens & & Einsetzung eines Judenamtes \\
\hline 1795 & $\begin{array}{l}\text { Dritte Teilung Polens } \\
\text { (Österreich erhält Westga- } \\
\text { lizien ) }\end{array}$ & & \\
\hline 1797 & $\begin{array}{l}\text { Friede v. Campo formio } \\
\text { (Campoformido): } \\
\text { Österreich verliert links- } \\
\text { rheinische Gebiete, die } \\
\text { Lombardei, Belgien u. } \\
\text { erhält Venetien, Istrien u. } \\
\text { Dalmatien }\end{array}$ & $\begin{array}{l}\text { Westgalizisches bürgerli- } \\
\text { ches Gesetzbuch (WGGB), } \\
\text { Patent v. 13.Februar }\end{array}$ & \\
\hline 1799-1802 & Zweiter Koalitionskrieg & & \\
\hline 1801 & $\begin{array}{l}\text { Friede von Lunéville (wie } \\
\text { Campo formio) }\end{array}$ & & \\
\hline 1802 & $\begin{array}{l}\text { Reichsdeputationshaupt- } \\
\text { schluß: Österreich verliert } \\
\text { Breisgau, Ortenau u. } \\
\text { erhält Trient + Brixen, Salz- } \\
\text { burg wird Kurfürstentum }\end{array}$ & $\begin{array}{l}\text { Vereinigte Hofkanzlei } \\
\text { (österr., böhm., galizische, } \\
\text { Italien.) } \\
\text { Ungarische Hofkanzlei, } \\
\text { Siebenbürgische Hof- } \\
\text { kanzlei }\end{array}$ & \\
\hline
\end{tabular}




\begin{tabular}{|c|c|c|c|}
\hline & Politische Geschichte & $\begin{array}{l}\text { Innere Entwicklung, } \\
\text { Verwaltung } \\
\text { und Verfassung }\end{array}$ & $\begin{array}{l}\text { Gesetze und Verordnungen } \\
\text { Juden betr., insb. Heimatrecht } \\
\text { u. Staatsbïrgerschaft }\end{array}$ \\
\hline 1804 & $\begin{array}{l}\text { Österreichisches Kaisertum } \\
\text { (Franz I., erbl. Kaiser v. } \\
\text { Österreich) }\end{array}$ & & \\
\hline 1805 & $\begin{array}{l}\text { Dritter Koalitionskrieg, } \\
\text { Friede v. Preßburg: Öster- } \\
\text { reich verliert Venetien, } \\
\text { Istrien, Dalmatien, Tirol, } \\
\text { Vorderösterreich, Brixen, } \\
\text { Passau, Trient; erhält } \\
\text { Salzburg }\end{array}$ & & \\
\hline 1806 & $\begin{array}{l}\text { Rheinbund; Ende des } \\
\text { »Heiligen Römischen } \\
\text { Reiches« } \\
\text { Vierter Koalitionskrieg } \\
\text { (ohne Österreich) }\end{array}$ & & \\
\hline 1809 & $\begin{array}{l}\text { Österr.-französischer Krieg. } \\
\text { Friede von Schönbrunn } \\
\text { (14. Oktober): Österreich } \\
\text { verliert das Innviertel, Salz- } \\
\text { burg, Westgalizien (Kra- } \\
\text { kau) u. "Illyrische Provin- } \\
\text { zen«. Nordtirol an Bayern, } \\
\text { Südtirol an Italien } \\
\text { Tiroler Freiheitskampf }\end{array}$ & & \\
\hline 1810 & $\begin{array}{l}\text { Metternich wird Außen- } \\
\text { minister }\end{array}$ & & \\
\hline 1811 & Staatsbankrott & $\begin{array}{l}\text { Allgemeines Bürgerliches } \\
\text { Gesetzbuch (ABGB), ( } \$ \$ \\
28-31 \text { Bestimmungen } \\
\text { über Erwerb u. Verlust der } \\
\text { österreichischen Staatsbür- } \\
\text { gerschaft) }\end{array}$ & \\
\hline 1812 & $\begin{array}{l}\text { Russlandfeldzug Napo- } \\
\text { leons }\end{array}$ & & \\
\hline 1813 & Völkerschlacht bei Leipzig & & \\
\hline 1814 & Abdankung Napoleons & & \\
\hline $1814-1815$ & $\begin{array}{l}\text { Wiener Kongress. } \\
\text { Kongressakte v. 9. Juni: } \\
\text { Österreich erhält Tirol, } \\
\text { Vorarlberg, Kärnten, Krain, } \\
\text { Triest, Galizien, Mailand, } \\
\text { Venedig, Salzburg u. das } \\
\text { Innviertel; Gründung des } \\
\text { Deutschen Bundes; Kon- } \\
\text { gresspolen (wird Russland } \\
\text { unterstellt), Krakau wird } \\
\text { Freistadt; Heilige Allianz }\end{array}$ & & $\begin{array}{l}\text { Bittschrift der Wiener Juden } \\
\text { an den Kaiser vom 11. April }\end{array}$ \\
\hline
\end{tabular}




\begin{tabular}{|c|c|c|c|}
\hline & Politische Geschichte & $\begin{array}{l}\text { Innere Entwicklung, } \\
\text { Verwaltung } \\
\text { und Verfassung }\end{array}$ & $\begin{array}{l}\text { Gesetze und Verordnungen } \\
\text { Juden betr., insb. Heimatrecht } \\
\text { u. Staatsbïrgerschaft }\end{array}$ \\
\hline 1817 & & & Enquete über Judenreform \\
\hline 1818 & Kongress von Aachen & & \\
\hline 1819 & Karlsbader Beschlüsse & & \\
\hline 1821 & $\begin{array}{l}\text { Metternich wird Staats- } \\
\text { kanzler }\end{array}$ & & \\
\hline 1830 & $\begin{array}{l}\text { Julirevolution in Frank- } \\
\text { reich }\end{array}$ & & \\
\hline 1831 & $\begin{array}{l}\text { Belgien wird unabhängiges } \\
\text { Königreich } \\
\text { Polnischer Aufstand nie- } \\
\text { dergeschlagen, Polen russi- } \\
\text { sche Provinz }\end{array}$ & & \\
\hline $0^{2}$ & & $\begin{array}{l}\text { Hofkanzleidekret v. } 1 . \\
\text { März: Staatsbürgerschaft } \\
\text { nur mehr nach Willenser- } \\
\text { klärung und Eidesleistung }\end{array}$ & \\
\hline $1835-48$ & $\begin{array}{l}\text { Regierungszeit Kaiser Fer- } \\
\text { dinand I. (ab 1836: Staats- } \\
\text { konferenz) }\end{array}$ & & \\
\hline \multirow[t]{2}{*}{1848} & $\begin{array}{l}\text { Märzrevolution (Met- } \\
\text { ternich tritt zurück) Mi- } \\
\text { nisterium Kolowrat (20. } \\
\text { März.-18. April) } \\
\text { Ministerium Ficquelmont } \\
\text { (18. April-7. Mai) } \\
\text { Ministerium Pillersdorf } \\
\text { (8. Mai-15. Mai./8. Juli) } \\
\text { Eröffnung der Paulskir- } \\
\text { chenversammlung in } \\
\text { Frankfurt am Main (Mai) } \\
\text { Erzherzog Johann Reichs- } \\
\text { verweser (29.Juni) }\end{array}$ & $\begin{array}{l}\text { Einsetzung eines verant- } \\
\text { wortlichen Ministerrates } \\
\text { und Errichtung der Mini- } \\
\text { sterien (Patent v. 15. März) } \\
\text { PillersdorfscheVerfassung } \\
\text { (»Aprilverfassung«), Patent } \\
\text { v. } 25 \text {. April } \\
\text { Patent über die Aufhebung } \\
\text { des Untertänigkeitsverban- } \\
\text { des und die Grundentla- } \\
\text { stung v. } 7 \text {. September }\end{array}$ & $\begin{array}{l}\text { Rede Adolf Fischhofs } \\
\text { 13.März } \\
\text { Petition um Emanzipation } \\
\text { 19. März }\end{array}$ \\
\hline & $\begin{array}{l}\text { Ministerium Wessenberg- } \\
\text { Doblhoff (18. Juli-21. } \\
\text { November) } \\
\text { Konstituierender Reichstag } \\
\text { in Wien eröffnet (22.Juli) } \\
\text { Sieg Radetzkys bei Cu- } \\
\text { stozza (25. Juli) } \\
\text { Oktoberrevolution in } \\
\text { Wien } \\
\text { Reichstag nach Kremsier } \\
\text { (22. Oktober) } \\
\text { Kaiser Ferdinand dankt ab. }\end{array}$ & & $\begin{array}{l}\text { Aufhebung der Judensteuer } \\
\text { (5. Oktober) }\end{array}$ \\
\hline
\end{tabular}




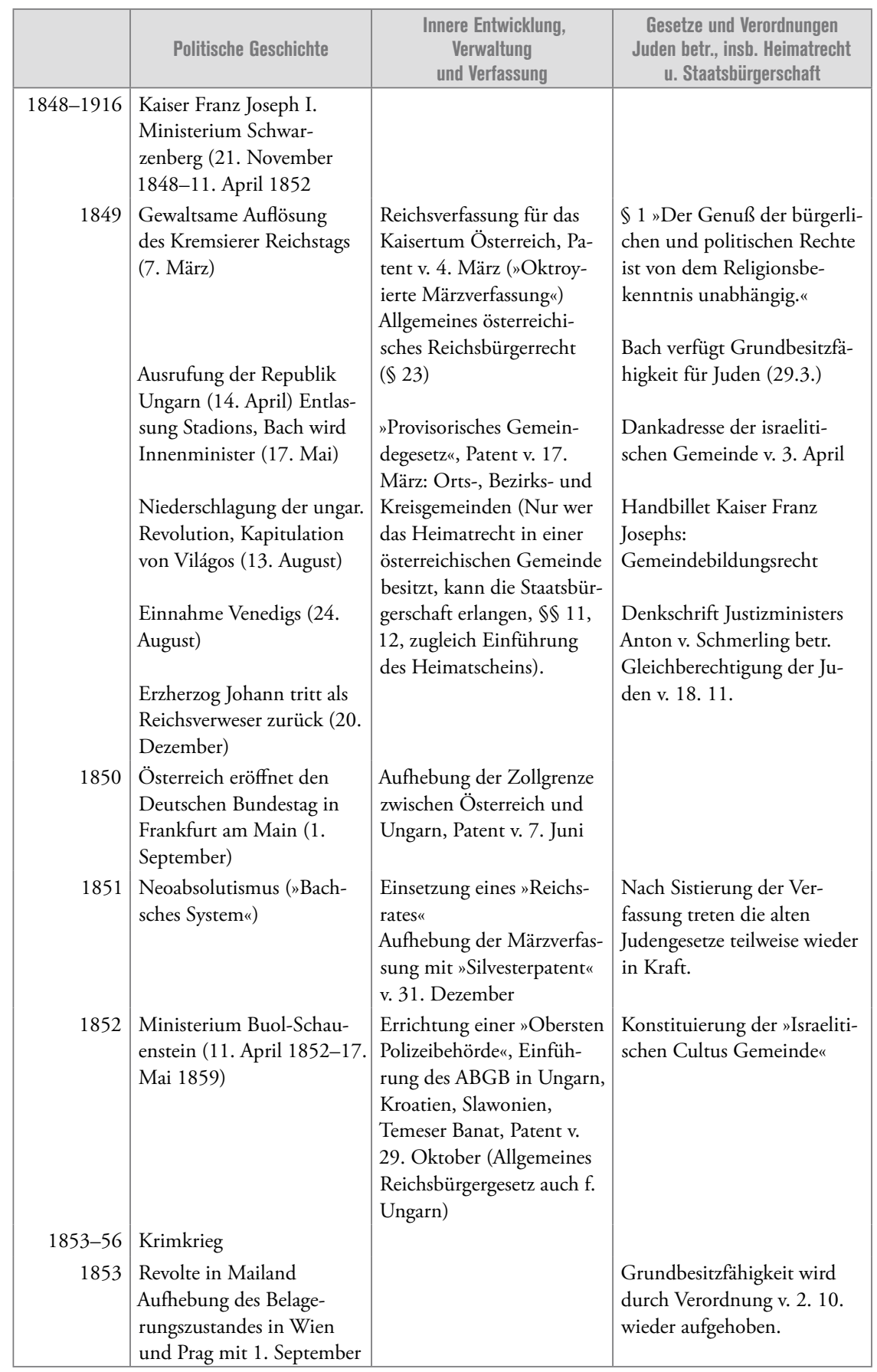




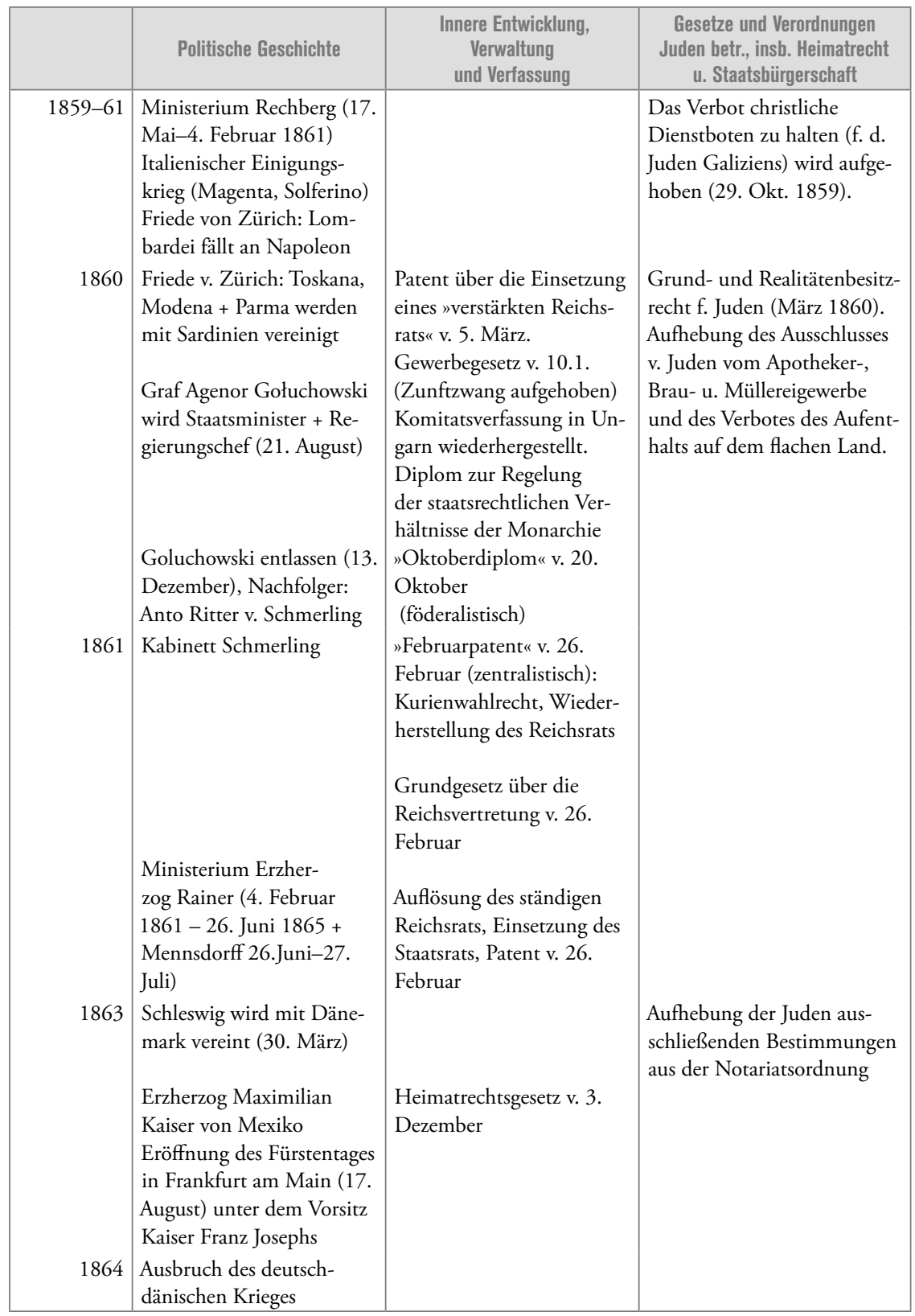




\begin{tabular}{|c|c|c|c|}
\hline & Politische Geschichte & $\begin{array}{l}\text { Innere Entwicklung, } \\
\text { Verwaltung } \\
\text { und Verfassung }\end{array}$ & $\begin{array}{l}\text { Gesetze und Verordnungen } \\
\text { Juden betr., insb. Heimatrecht } \\
\text { u. Staatsbïrgerschaft }\end{array}$ \\
\hline $1865-67$ & $\begin{array}{l}\text { Gasteiner Konvention (14. } \\
\text { August): Österreich verwal- } \\
\text { tet Holstein }\end{array}$ & $\begin{array}{l}\text { Sistierung des Grundge- } \\
\text { setzes über die Reichsver- } \\
\text { tretung, Patent v. 20. Sep- } \\
\text { tember und Ankündigung } \\
\text { einer neuen Verfassung } \\
\text { Aufhebung der Paßkontrol- } \\
\text { len an den Außengrenzen, } \\
\text { Verordnung v. 6. Novem- } \\
\text { ber }\end{array}$ & \\
\hline 1866 & $\begin{array}{l}\text { Krieg Preußens u. Italiens } \\
\text { gegen Österreich, König- } \\
\text { grätz (2. Juli) Friede von } \\
\text { Prag: Auflösung des Deut- } \\
\text { schen Bundes } \\
\text { Friede von Wien (3. Okt.): } \\
\text { Österreich tritt Venetien ab }\end{array}$ & & \\
\hline 1867 & $\begin{array}{l}\text { Ministerium Beust } \\
\text { Ausgleich mit Ungarn (15. } \\
\text { März) }\end{array}$ & $\begin{array}{l}\text { Staatsgrundgesetz über die } \\
\text { allgemeinen Rechte der } \\
\text { Staatsbürger v. 21. Dezem- } \\
\text { ber (Teil der Dezemberver- } \\
\text { fassung) } \\
\text { Ungarisches Verfassungs- } \\
\text { gesetz }\end{array}$ & $\begin{array}{l}\text { Staatsbürgerliche Gleichstel- } \\
\text { lung der Juden in Österreich } \\
\text { und Ungarn }\end{array}$ \\
\hline 1868 & $\begin{array}{l}\text { Ministerium Carlos Auers- } \\
\text { perg }\end{array}$ & $\begin{array}{l}\text { Interkonfessionelles Gesetz } \\
\text { v. } 25 . \text { Mai } \\
\text { Schule-Kirche-Gesetz }\end{array}$ & \\
\hline 1869 & & $\begin{array}{l}\text { Reichsvolksschulgesetz v. } \\
\text { 14. Mai }\end{array}$ & \\
\hline 1870 & $\begin{array}{l}\text { Beamtenkabinett Potocki } \\
\text { (12. April) }\end{array}$ & $\begin{array}{l}\text { Kündigung des Konkor- } \\
\text { dats }\end{array}$ & \\
\hline 1871 & $\begin{array}{l}\text { Ministerium Hohenwart } \\
(27.2 .-26.10 .)\end{array}$ & & \\
\hline 1873 & $\begin{array}{l}\text { Kabinett Auersperg II } \\
\text { Wiener Weltausstellung }\end{array}$ & $\begin{array}{l}\text { Wahlreform: direkt ge- } \\
\text { wählter Reichsrats durch } \\
\text { 10-Gulden-Männer (2.4.) }\end{array}$ & "Börsenkrach» (9.5.) \\
\hline 1878 & $\begin{array}{l}\text { Berliner Kongress zur } \\
\text { Bereinigung der "Orienta- } \\
\text { lischen Frage» } \\
\text { Okkupation Bosniens und } \\
\text { Herzegowinas }\end{array}$ & & \\
\hline 1879 & $\begin{array}{l}\text { Sturz der Reg. Auersperg } \\
\text { und Ende der deutschlibe- } \\
\text { ralen Ära. }\end{array}$ & $\begin{array}{l}\text { Ungarisches Staatsbürger- } \\
\text { schaftsgesetz }\end{array}$ & \\
\hline
\end{tabular}




\begin{tabular}{|c|c|c|c|}
\hline & Politische Geschichte & $\begin{array}{l}\text { Innere Entwicklung, } \\
\text { Verwaltung } \\
\text { und Verfassung }\end{array}$ & $\begin{array}{l}\text { Gesetze und Verordnungen } \\
\text { Juden betr., insb. Heimatrecht } \\
\text { u. Staatsbïrgerschaft }\end{array}$ \\
\hline & $\begin{array}{l}\text { Kabinett Eduard Taaffe } \\
\text { (kons.) } \\
\text { "Zweibund « mit Deut- } \\
\text { schem Reich (7.10.) }\end{array}$ & & \\
\hline 1882 & & $\begin{array}{l}\text { "Linzer Programm« der } \\
\text { Deutschnationalen }\end{array}$ & \\
\hline 1883 & & $\begin{array}{l}\text { Beginn einer Sozialgesetz- } \\
\text { gebung (Gewerbeinspek- } \\
\text { torate, } 11 \text { Stunden Tag, } \\
\text { Sonntagsruhe }\end{array}$ & \\
\hline 1885 & & $\begin{array}{l}\text { Reichsratswahlen: Liberale } \\
\text { geschwächt; Gewinner: } \\
\text { Lueger, Schönerer }\end{array}$ & \\
\hline 1889 & & & $\begin{array}{l}\text { Baron-Hirsch-Schulen in } \\
\text { Galizien }\end{array}$ \\
\hline 1893 & $\begin{array}{l}\text { Koalitionsministerium } \\
\text { Windischgrätz }\end{array}$ & & \\
\hline $1895-97$ & Regierung Badeni & $\begin{array}{l}\text { Wahlreform: } 5 \text {. Kurie } \\
\text { Wahlen zum Wiener } \\
\text { Gemeinderat bringen }\end{array}$ & \\
\hline $\begin{array}{l}1896 \\
1897\end{array}$ & . & $\begin{array}{l}\text { Zweidrittelmehrheit für } \\
\text { Christlichsoziale. } \\
\text { Heimatrechtsnovelle v. } \\
5.12 \text {. } \\
\text { Krise wegen Badenischer } \\
\text { Sprachenverordnungen für } \\
\text { Böhmen und Mähren }\end{array}$ & $\begin{array}{l}\text { Ausschreitungen gegen Juden } \\
\text { in Prag und Mähren infolge } \\
\text { der Badeni-Krise }\end{array}$ \\
\hline $1897-98$ & Regierung Gautsch & $\begin{array}{l}\text { Karl Lueger wird Bürger- } \\
\text { meister v. Wien }\end{array}$ & \\
\hline $1898-99$ & Regierung Thun & Erster Zionistenkongress & \\
\hline 1899 & $\begin{array}{l}\text { Regierung Clary (-Dez. } \\
99)\end{array}$ & $\begin{array}{l}\text { "Pfingstprogramm» der } \\
\text { deutschen Parteien }\end{array}$ & \\
\hline 1899-1904 & $\begin{array}{l}\text { Regierung Koerber (Dez. } \\
\text { 99-1904) }\end{array}$ & $\begin{array}{l}\text { Brünner Nationalitäten- } \\
\text { programm der Sozialdemo- } \\
\text { kratischen Partei }\end{array}$ & \\
\hline & & $\begin{array}{l}\text { Ausgleichsverhandlungen } \\
\text { mit Böhmen scheitern, } \\
\text { Förderung wirtschaftlicher } \\
\text { und technologischer Pro- } \\
\text { jekte zur Pazifizierung der } \\
\text { Nationalitätenfrage }\end{array}$ & \\
\hline 1903 & Ungarn: Istvan Tisza & $\begin{array}{l}\text { weitgehende Magyarisie- } \\
\text { rung in Ungarn }\end{array}$ & \\
\hline 1904 & $\begin{array}{l}\text { Regierung Gautsch (bis } \\
\text { Mai 1906) }\end{array}$ & & \\
\hline 1905 & & Mährischer Ausgleich & \\
\hline
\end{tabular}




\begin{tabular}{|c|c|c|c|}
\hline & Politische Geschichte & $\begin{array}{l}\text { Innere Entwicklung, } \\
\text { Verwaltung } \\
\text { und Verfassung }\end{array}$ & $\begin{array}{l}\text { Gesetze und Verordnungen } \\
\text { Juden betr., insb. Heimatrecht } \\
\text { u. Staatsbürgerschaft }\end{array}$ \\
\hline 1906 & $\begin{array}{l}\text { Regierung Hohenlohe- } \\
\text { Schillingfürst }\end{array}$ & $\begin{array}{l}\text { Allgemeines, gleiches Män- } \\
\text { nerwahlrecht }\end{array}$ & \\
\hline 1907 & Regierung Beck (bis 1908) & $\begin{array}{l}\text { Reichsratswahlen: Christ. } \\
\text { Soz. 96, Soz.Dem. } \\
\text { 87, Schönerer } 3\end{array}$ & \\
\hline 1908 & $\begin{array}{l}\text { Annexion Bosnien-Herze- } \\
\text { gowina } \\
\text { Kabinett Bienerth }(-1911)\end{array}$ & & \\
\hline 1911 & Kabinett Stürgkh (-1916) & $\begin{array}{l}\text { Notverordnungsrecht nach } \\
\$ 14\end{array}$ & \\
\hline 1912 & 1. Balkankrieg & & \\
\hline 1913 & 2. Balkankrieg & & \\
\hline 1914 & $\begin{array}{l}\text { Ermordung Erzherzog } \\
\text { Franz Ferdinands in Sara- } \\
\text { jevo (28.Juni) } \\
\text { Ultimatum an Serbien } \\
\text { (23.Juli) } \\
\text { Kriegserklärung Ö/U an } \\
\text { Serbien (28.Juli) }\end{array}$ & & \\
\hline $1914-18$ & Erster Weltkrieg & & \\
\hline 1916 & Tod Kaiser Franz Joseph I. & & \\
\hline 1918 & $\begin{array}{l}\text { Ausrufung der »Repub- } \\
\text { lik Deutschösterreich» } \\
\text { (12.11.) } \\
\text { 1. Prov.Regierung Karl } \\
\text { Renner }\end{array}$ & & $\begin{array}{l}\text { Gesetz v. } 5 \text {. Dezember } 1918 \\
\text { über das deutschösterreichi- } \\
\text { sche Staatsbürgerrecht }\end{array}$ \\
\hline 1919 & $\begin{array}{l}\text { 2.Prov. Regierung Karl } \\
\text { Renner } \\
(15.3 .-17.10 .1919) \\
\text { Staatsvertrag von St-Ger- } \\
\text { main (10.9.) } \\
\text { 3. Reg. Renner } \\
\text { (17.10.1919-16.6.1920 }\end{array}$ & $\begin{array}{l}\text { Allgemeines gleiches } \\
\text { direktes und geheimes } \\
\text { Wahlrecht für Männer und } \\
\text { Frauen } \\
\text { Wahl zur konstituierenden } \\
\text { Nationalversammlung } \\
\text { (16.2.) } \\
\text { rel. Mehrheit für Sozial- } \\
\text { demokraten }\end{array}$ & $\begin{array}{l}\text { "Sever-Erlaß« v. 9.9. (Auswei- } \\
\text { sung sog. "Ostjuden«) } \\
\text { Art. } 80 \text { des Staatsvertrags } \\
\text { v. St-Germain enthält Op- } \\
\text { tionsrecht "nach Rasse und } \\
\text { Sprache« } \\
\text { Gesetz v. 17.Oktober } 1919 \\
\text { über die Abänderung des Ge- } \\
\text { setzes über das deutschöster- } \\
\text { reichische Staatsbürgerrecht }\end{array}$ \\
\hline 1920 & $\begin{array}{l}\text { Koalitionsregierung Mayr } \\
(7.7 .1920-1.6 .1921) \\
\text { Staatsvertrag von Trianon } \\
\text { "Brünner Vertrag" v. 7.Juni } \\
\text { über Staatsbürgerschaft } \\
\text { und Minderheitenschutz }\end{array}$ & $\begin{array}{l}\text { Bundesverfassung vom } \\
1 . \text { Oktober } 1920 \\
\text { Nationalratswahl: (Christ- } \\
\text { lichsoziale relative Mehr- } \\
\text { heit) }\end{array}$ & $\begin{array}{l}\text { Artikel } 7 \text { des Bundesverfas- } \\
\text { sungsgesetzes } \\
\text { (Gleichheit vor dem Gesetz } \\
\text { unabhängig von Geschlecht, } \\
\text { Stand, Klasse, Konfession) } \\
\text { Vollzugsanweisung v. } 20.8 \text {. } \\
\text { über den Erwerb der österrei- }\end{array}$ \\
\hline
\end{tabular}




\begin{tabular}{|c|c|c|c|}
\hline & Politische Geschichte & $\begin{array}{l}\text { Innere Entwicklung, } \\
\text { Verwaltung } \\
\text { und Verfassung }\end{array}$ & $\begin{array}{l}\text { Gesetze und Verordnungen } \\
\text { Juden betr., insb. Heimatrecht } \\
\text { u. Staatsbïrgerschaft }\end{array}$ \\
\hline & & & $\begin{array}{l}\text { chischen Staatsangehörigkeit } \\
\text { durch Option }\end{array}$ \\
\hline 1921 & $\begin{array}{l}\text { "Bürgerblockregierung" } \\
\text { Schober } \\
(21.6 .1921-26.1 .1922) \\
\text { Aufnahme in den Völker- } \\
\text { bund }\end{array}$ & & $\begin{array}{l}\text { Erkenntnis des Verwaltungs- } \\
\text { gerichtshofs v. } 9.6 \text { im Fall } \\
\text { Moses Dym } \\
\text { „Wabersche Optionspraxis« }\end{array}$ \\
\hline \multirow[t]{3}{*}{1922} & $\begin{array}{l}\text { Reg. Schober II } \\
(27.1 .1922-24.5 .1922\end{array}$ & & \\
\hline & $\begin{array}{l}\text { Reg. Seipel I, II, III } \\
(31.5 .1922-16.4 .1923)\end{array}$ & $\begin{array}{l}\text { Nationalratswahl: Christ- } \\
\text { lichsoziale behalten rel. } \\
\text { Mehrheit }\end{array}$ & \\
\hline & $\begin{array}{l}\text { Unterzeichnung der Gen- } \\
\text { fer Protokolle } \\
\text { Völkerbundanleihe (4.10.) }\end{array}$ & & \\
\hline 1924 & $\begin{array}{l}\text { Reg. Ramek I, II } \\
\text { (20.11.1924 - 15.10.1926) } \\
\text { Schilling-Währung }\end{array}$ & & \\
\hline 1925 & & $\begin{array}{l}\text { Bundesgesetz v. 30.Juli } \\
1925 \text { über den Erwerb und } \\
\text { den Verlust der Landes- } \\
\text { und Bundesbürgerschaft } \\
\text { Bundesgesetz vom 30. Juli } \\
1925 \text { betr. die Abänderung }\end{array}$ & \\
\hline & & $\begin{array}{l}\text { und Ergänzung des Geset- } \\
\text { zes v. 3.Dezember } 1863 \\
\text { über die Regelung der Hei- } \\
\text { matrechtsverhältnisse }\end{array}$ & \\
\hline 1926 & $\begin{array}{l}\text { Reg. Seipel IV, V } \\
(20.10 .1926-3.4 .1929)\end{array}$ & & \\
\hline 1927 & & Justizpalastbrand (15.6.) & \\
\hline 1928 & & $\begin{array}{l}\text { Nationalratswahl: CS rel. } \\
\text { Mehrheit }\end{array}$ & \\
\hline 1929 & $\begin{array}{l}\text { Reg. Streeruwitz } \\
(4.5 .1929-25.9 .1929) \\
\text { Reg. Schober III } \\
(26.9 .1929-25.9 .1930)\end{array}$ & & \\
\hline 1930 & $\begin{array}{l}\text { Reg. Vaugoin (30.9.- } \\
29.11 .1930) \\
\text { Reg. Ender (4.12.1930- } \\
\text { 16.6.1931) }\end{array}$ & $\begin{array}{l}\text { Nationalratswahlen: Soz. } \\
\text { Dem. rel. Mehrheit }\end{array}$ & \\
\hline 1931 & $\begin{array}{l}\text { Zusammenbruch der Cre- } \\
\text { ditanstalt } \\
\text { Reg. Buresch I, II } \\
(20.6 .1931 \text {-27.1.1932) }\end{array}$ & $\begin{array}{l}\text { Landtagswahlen bringen } \\
\text { große Erfolge für National- } \\
\text { sozialisten }\end{array}$ & \\
\hline
\end{tabular}




\begin{tabular}{|c|c|c|c|}
\hline & Politische Geschichte & $\begin{array}{l}\text { Innere Entwicklung, } \\
\text { Verwaltung } \\
\text { und Verfassung }\end{array}$ & $\begin{array}{l}\text { Gesetze und Verordnungen } \\
\text { Juden betr., insb. Heimatrecht } \\
\text { u. Staatsbïrgerschaft }\end{array}$ \\
\hline 1932 & $\begin{array}{l}\text { Reg. Dollfuß I (20.5.1932- } \\
\text { 21.9.1933) }\end{array}$ & $\begin{array}{l}\text { Landtagswahlen im Juni } \\
\text { bringen starke Gewinne } \\
\text { der Nationalsozialisten }\end{array}$ & \\
\hline 1933 & $\begin{array}{l}\text { Ausschaltung des Parla- } \\
\text { ments (4.3.) } \\
\text { "Tausendmarksperre» } \\
\text { Reg. Dollfuß II } \\
(21.9 .1933-1.4 .1936)\end{array}$ & & \\
\hline 1934 & $\begin{array}{l}\text { Bürgerkrieg (Febr.) } \\
\text { Ermordung Dollfuß (25. } \\
\text { 7.) } \\
\text { Bundeskanzler Schusch- } \\
\text { nigg }\end{array}$ & $\begin{array}{l}\text { "Maiverfassung« des auto- } \\
\text { ritären Ständestaats }\end{array}$ & \\
\hline 1935 & & & \\
\hline 1936 & $\begin{array}{l}\text { Reg. Schuschnigg II, III, } \\
\text { IV } \\
(14.5 .1936-11.3 .1938)\end{array}$ & & \\
\hline 1937 & Juliabkommen & & \\
\hline 1938 & $\begin{array}{l}\text { Rücktritt Schuschniggs } \\
\text { nach Absage der Volksab- } \\
\text { stimmung (11.3.) } \\
\text { Reg. Seyß-Inquart } \\
(11.3 .1938-15.3 .1938)\end{array}$ & & \\
\hline & $\begin{array}{l}\text { Einmarsch deutscher } \\
\text { Truppen in Österreich (12. } \\
\text { März) } \\
\text { "Anschluss« Österreichs an } \\
\text { das Deutsche Reich (13.3.) } \\
\text { Konferenz von Evian, } \\
\text { 6.-14. Juli beschließt } \\
\text { Einwanderungsquoten für } \\
\text { jüdische Flüchtlinge } \\
\text { Münchner Abkommen (29. } \\
\text { September) }\end{array}$ & $\begin{array}{l}\text { Gesetz über die Wiederver- } \\
\text { einigung Österreichs mit } \\
\text { dem Deutschen Reich (18. } \\
\text { März). Eigenstaatlichkeit } \\
\text { erlischt. Österreich wird } \\
\text { zunächst „Land des Deut- } \\
\text { schen Reiches« (ab April } \\
1939 \text { „Ostmark») }\end{array}$ & $\begin{array}{l}\text { Einführung der Nürnberger } \\
\text { Gesetze in Österreich, Kund- } \\
\text { machung des Reichsstatthal- } \\
\text { ters v. 20. Mai, einschließlich } \\
\text { der Ersten Verordnung zum } \\
\text { Reichsbürgergesetz und zum } \\
\text { Gesetz zum Schutze des } \\
\text { deutschen Blutes und der } \\
\text { deutschen Ehre } \\
\text { (Juden können nicht Reichs- } \\
\text { bürger sein. Eheschließun- } \\
\text { gen zwischen Juden und } \\
\text { Nichtjuden werden verboten. } \\
\text { Weibliche Hausangestellte } \\
\text { dürfen in jüdischen Haus- } \\
\text { halten nicht mehr beschäftigt } \\
\text { werden). } \\
\text { Ausscheiden jüdischer Be- } \\
\text { amter aus dem Staatsdienst } \\
\text { nach der Verordnung zur } \\
\text { Neuordnung des österreichi- } \\
\text { schen Berufsbeamtentums v. } \\
\text { 31. Mai }\end{array}$ \\
\hline
\end{tabular}




\begin{tabular}{|c|c|c|c|}
\hline & Politische Geschichte & $\begin{array}{l}\text { Innere Entwicklung, } \\
\text { Verwaltung } \\
\text { und Verfassung }\end{array}$ & $\begin{array}{l}\text { Gesetze und Verordnungen } \\
\text { Juden betr., insb. Heimatrecht } \\
\text { u. Staatsbïrgerschaft }\end{array}$ \\
\hline . & 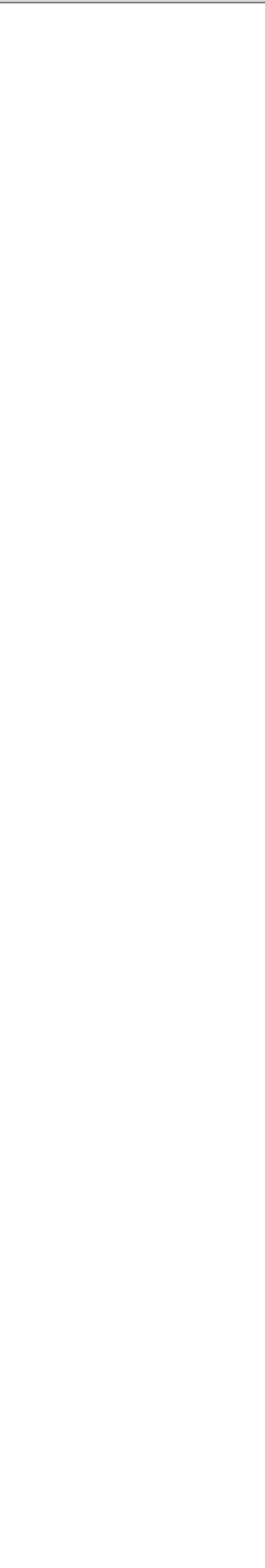 & $\begin{array}{l}\text { „Ostmarkgesetz« v. } 14 . \\
\text { April }\end{array}$ & $\begin{array}{l}\text { Erste Verordnung über die } \\
\text { deutsche Staatsangehörigkeit } \\
\text { im Lande Österreich, Kund- } \\
\text { machung v. 3. Juli (widerruft } \\
\text { Aus- und Einbürgerungen } \\
\text { des Ständestaates). } \\
\text { Vierte Verordnung zum } \\
\text { Reichsbürgergesetz, kundge- } \\
\text { macht am 25. Juli, schließt } \\
\text { Juden von der Ausübung des } \\
\text { Arztberufes aus. } \\
\text { Fünfte Verordnung zum } \\
\text { Reichsbürgergesetz, kundge- } \\
\text { macht am. 27. September, } \\
\text { schließt Juden aus der } \\
\text { Rechtsanwaltschaft aus } \\
\text { VO über das Kenntlich- } \\
\text { machen der Reisepässe } \\
\text { von Juden mit einem J (11. } \\
\text { Oktober). } \\
\text { Novemberpogrom (sog. } \\
\text { „Reichskristallnacht« (9.11.) } \\
\text { Verordnung v. 1.1. über } \\
\text { die Pflicht Zusatznamen } \\
\text { (Sara/Israel) zu führen } \\
\\
\text { Zweite Verordnung über die } \\
\text { deutsche Staatsangehörigkeit } \\
\text { im Lande Österreich, v. } 30 \text {. } \\
\text { Juni hebt StbG 1925 und } \\
\text { Heimatrecht auf und führt } \\
\text { Erwerbs- und Verlusttat- } \\
\text { bestände nach deutschem } \\
\text { Reichsangehörigkeitsgesetz } \\
\text { von } 1913 \text { ein. Alle Österrei- } \\
\text { cher/innen werden deutsche } \\
\text { Staatsangehörige } \\
\text { Verordnung über die Aber- } \\
\text { kennung der Staatsangehö- } \\
\text { rigkeit und den Widerruf des } \\
\text { Staatsangehörigkeitserwerbs } \\
\text { in der Ostmark, kundge- } \\
\text { macht am 11. Juli (ermög- } \\
\text { licht die Strafexpatriation } \\
\text { von Emigranten). }\end{array}$ \\
\hline $1939-45$ & Zweiter Weltkrieg & & \\
\hline
\end{tabular}




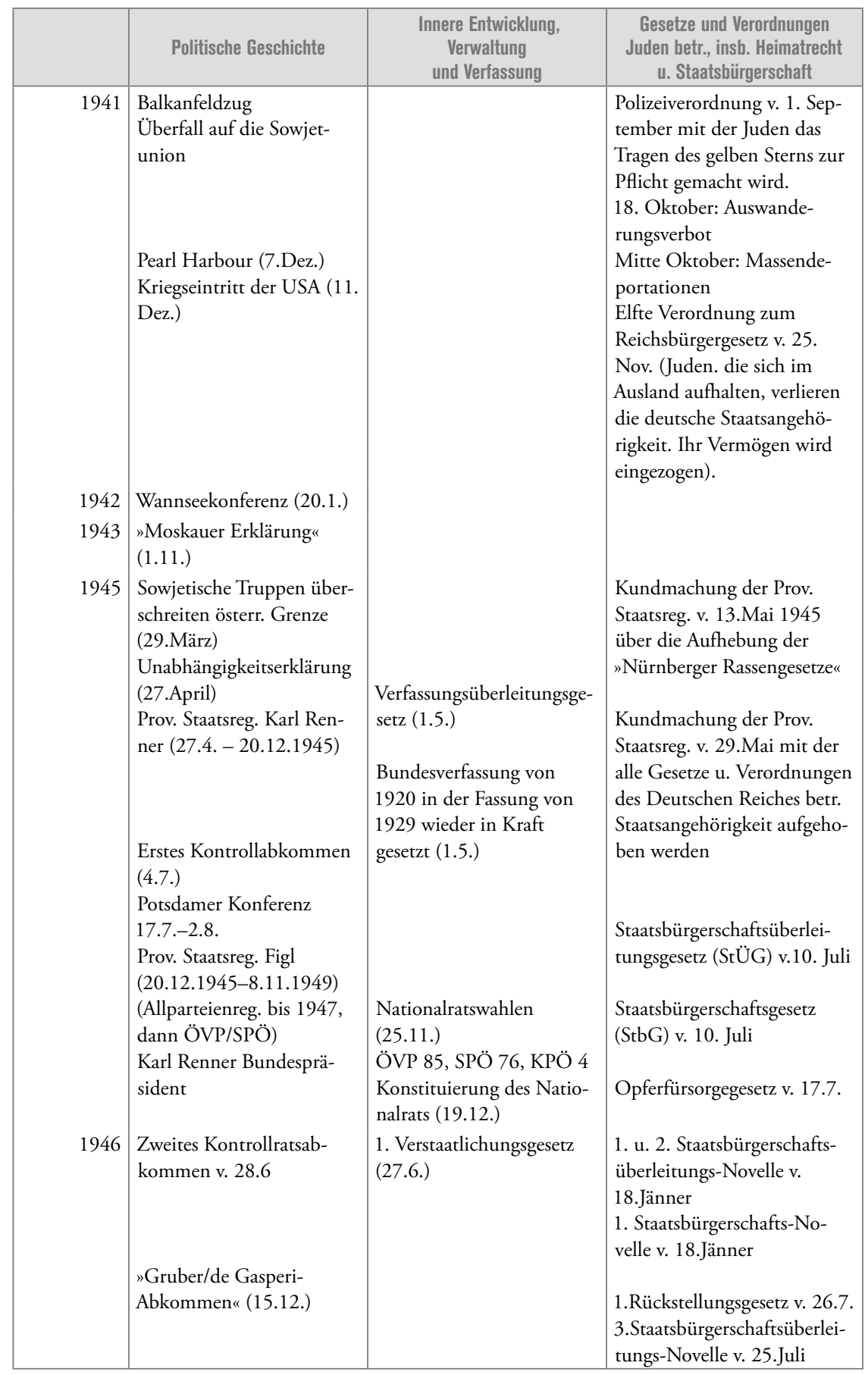




\begin{tabular}{|c|c|c|c|}
\hline & Politische Geschichte & $\begin{array}{l}\text { Innere Entwicklung, } \\
\text { Verwaltung } \\
\text { und Verfassung }\end{array}$ & $\begin{array}{l}\text { Gesetze und Verordnungen } \\
\text { Juden betr., insb. Heimatrecht } \\
\text { u. Staatsbürgerschaft }\end{array}$ \\
\hline 1947 & & $\begin{array}{l}\text { 2. Verstaatlichungsgesetz } \\
\text { (26.3.) }\end{array}$ & $\begin{array}{l}\text { Staatsbürgerschaftsrechtliche } \\
\text { Bestimmungen im Bundes- } \\
\text { verfassungsgesetz v. 6.2. betr. } \\
\text { die Behandlung der Natio- } \\
\text { nalsozialisten } \\
\text { 2. + 3. Rückstellungsgesetz } \\
\text { v. 6. 2. } \\
\text { 4. Rückstellungsgesetz v. } \\
\text { 21. Mai } \\
\text { Opferfürsorgegesetz v. 4.Juli }\end{array}$ \\
\hline 1948 & & & \\
\hline 1949 & $\begin{array}{l}\text { Reg. Figl II, III (ÖVP- } \\
\text { SPÖ-Koalition) } \\
(8.11 .1949-25.2 .1953)\end{array}$ & $\begin{array}{l}\text { Gründung des "Verbandes } \\
\text { der Unabhängigen« VdU } \\
\text { Nationalratswahl: ÖVP 77, } \\
\text { SPÖ 67, VdU 16, KPÖ } 5\end{array}$ & $\begin{array}{l}\text { 5. Rückstellungsgesetz v. } \\
\text { 22.6. } \\
\text { 6. Rückstellungsgesetz v. } \\
\text { 30.6. } \\
\text { 7. Rückstellungsgesetz v. } \\
\text { 14.7. } \\
\text { 3. Novelle zum Opferfürsor- } \\
\text { gegesetz v. 9. Februar (Ein- } \\
\text { beziehung von aus rassischen } \\
\text { Gründen verfolgten) } \\
\text { 4. Opferfürsorgegesetznovelle } \\
\text { v. 14. Juli } \\
\text { Wiederverlautbarung: } \\
\text { Staatsbürgerschafts-Überlei- } \\
\text { tungsgesetz v. 4. Nov. (StÜG } \\
\text { 1949) und des } \\
\text { Staatsbürgerschaftsgesetz v. } \\
\text { 4. Nov. (StbG 1949) }\end{array}$ \\
\hline 1950 & "Marshallplan« (2.7.) & Lohn/Preis-Abkommen & \\
\hline 1951 & $\begin{array}{l}\text { Bundespräsident Theodor } \\
\text { Körner }\end{array}$ & & \\
\hline 1952 & & & $\begin{array}{l}\text { Beginn der Verhandlungen } \\
\text { der Claims-Conference um } \\
\text { die Schaffung eines Fonds } \\
\text { aus »erblosem Vermögen» }\end{array}$ \\
\hline 1953 & $\begin{array}{l}\text { Reg. Raab I, II, III, IV } \\
\text { (ÖVP-SPÖ-Koalition) } \\
\text { (2.4.1953-11.4.1961) }\end{array}$ & $\begin{array}{l}\text { Nationalratswahlen: ÖVP } \\
74, \text { SPÖ } 73 \text {, VdU } 14 \text {, } \\
\text { KPÖ } 4\end{array}$ & \\
\hline 1955 & $\begin{array}{l}\text { Unterzeichnung des Staats- } \\
\text { vertrags (15.5.) } \\
\text { Aufnahme Österreichs in } \\
\text { die Vereinten Nationen } \\
(15.12 .)\end{array}$ & $\begin{array}{l}\text { Bundesverfassungsgesetz } \\
\text { über die Neutralität } \\
(26.10 .)\end{array}$ & \\
\hline 1956 & & $\begin{array}{l}\text { Nationalratswahlen: } \\
\text { ÖVP 82, SPÖ74, FPÖ 6, } \\
\text { KPÖ } 3\end{array}$ & \\
\hline
\end{tabular}




\begin{tabular}{|c|c|c|c|}
\hline & Politische Geschichte & $\begin{array}{l}\text { Innere Entwicklung, } \\
\text { Verwaltung } \\
\text { und Verfassung }\end{array}$ & $\begin{array}{l}\text { Gesetze und Verordnungen } \\
\text { Juden betr., insb. Heimatrecht } \\
\text { u. Staatsbürgerschaft }\end{array}$ \\
\hline 1957 & $\begin{array}{l}\text { Bundespräsident: Adolf } \\
\text { Schärf }\end{array}$ & $\begin{array}{l}\text { "Paritätische Kommission } \\
\text { für Lohn- und } \\
\text { Preisfragen" (Beginn der } \\
\text { Sozialpartnerschaft) }\end{array}$ & \\
\hline 1959 & & $\begin{array}{l}\text { Nationalratswahlen: ÖVP } \\
\text { 79, SPÖ 78, FPÖ } 8\end{array}$ & \\
\hline 1960 & EFTA-Beitritt Österreichs & & \\
\hline 1961 & $\begin{array}{l}\text { Reg. Gorbach I, II (ÖVP- } \\
\text { SPÖ-Koalition) } \\
(11.4 .1961-20.11 .1962)\end{array}$ & & \\
\hline 1962 & & $\begin{array}{l}\text { Nationalratswahlen: } \\
81 \text { ÖVP, } 76 \text { SPÖ, } 8 \text { FPÖ }\end{array}$ & \\
\hline 1963 & & & \\
\hline 1964 & $\begin{array}{l}\text { Reg. Klaus I, II (ÖVP- } \\
\text { SPÖ-Koalition) } \\
(2.4 .1964-3.3 .1970)\end{array}$ & & \\
\hline 1965 & $\begin{array}{l}\text { Bundespräsident Franz } \\
\text { Jonas }\end{array}$ & & $\begin{array}{l}\text { Bundesgesetz v. 15. Juli über } \\
\text { die österreichische Staatsbür- } \\
\text { gerschaft (StbG 1965) } \$ 58 \\
\text { ermöglicht Sondererwerb für } \\
\text { NS-Vertriebene ohne Pflicht } \\
\text { der Wohnsitzbegründung. } \\
\text { Aufgabe der bisherigen } \\
\text { Staatsbürgerschaft Bedin- } \\
\text { gung. }\end{array}$ \\
\hline 1966 & & $\begin{array}{l}\text { Nationalratswahlen: } \\
85 \text { ÖVP, } 74 \text { SPÖ, } 6 \text { FPÖ }\end{array}$ & \\
\hline 1967 & & & \\
\hline 1968 & & & \\
\hline 1969 & & & \\
\hline 1970 & $\begin{array}{l}\text { Minderheitsreg. Kreisky } \\
(21.4 .1970-19.10 .1971)\end{array}$ & $\begin{array}{l}\text { Nationalratswahlen: } \\
\text { SPÖ 81, ÖVP 78, FPÖ } 6\end{array}$ & \\
\hline 1971 & $\begin{array}{l}\text { Reg. Kreisky II (SPÖ- } \\
\text { Alleinreg.) } \\
4.11 .1971-8.10 .1975)\end{array}$ & $\begin{array}{l}\text { Nationalratswahlen (nach } \\
\text { Wahlreform): } \\
\text { SPÖ 93, ÖVP 80, FPÖ } 10\end{array}$ & \\
\hline 1972 & & & \\
\hline 1973 & & & $\begin{array}{l}\text { Staatsbürgerschaftsgesetz- } \\
\text { Novelle (StbG 1973) } \$ 58 \\
\text { c: Aufgabe der bisherigen } \\
\text { Staatsbürgerschaft bei Wie- } \\
\text { dererwerb der österreichi- } \\
\text { schen nicht mehr Bedingung, } \\
\text { dafür jedoch Wohnsitzan- } \\
\text { meldung. }\end{array}$ \\
\hline
\end{tabular}




\begin{tabular}{|c|c|c|c|}
\hline & Politische Geschichte & $\begin{array}{l}\text { Innere Entwicklung, } \\
\text { Verwaltung } \\
\text { und Verfassung }\end{array}$ & $\begin{array}{l}\text { Gesetze und Verordnungen } \\
\text { Juden betr., insb. Heimatrecht } \\
\text { u. Staatsbïrgerschaft }\end{array}$ \\
\hline 1974 & & & \\
\hline 1975 & $\begin{array}{l}\text { Bundespräsident Rudolf } \\
\text { Kirchschläger } \\
\text { Reg. Kreisky III } \\
(28.10 .1975-9.5 .1979)\end{array}$ & $\begin{array}{l}\text { Nationalratswahlen: } \\
\text { SPÖ 93, ÖVP 80, FPÖ } 10\end{array}$ & \\
\hline 1979 & $\begin{array}{l}\text { Reg. Kreisky IV } \\
(5.6 .1979-26.4 .1983)\end{array}$ & $\begin{array}{l}\text { Nationalratswahlen: } \\
\text { SPÖ 95, ÖVP 77, FPÖ } 11\end{array}$ & \\
\hline 1983 & $\begin{array}{l}\text { Reg. Sinowatz (SPÖ-FPÖ- } \\
\text { Koalition) } \\
(24.5 .1983-16.6 .1986)\end{array}$ & $\begin{array}{l}\text { Nationalratswahlen: } \\
\text { SPÖ 90, ÖVP 81, FPÖ } 12\end{array}$ & \\
\hline 1985 & & & $\begin{array}{l}\text { Staatsbürgerschaftsgesetz } \\
\text { (StbG 1985) }\end{array}$ \\
\hline 1986 & $\begin{array}{l}\text { Bundespräsident Kurt } \\
\text { Waldheim } \\
\text { „Waldheim-Affaire» } \\
\text { Reg. Vranitzky I, II, III, } \\
\text { IV,V (SPÖ-ÖVP-Koali- } \\
\text { tion) } \\
\text { (16.7.1986-20.1.1997) }\end{array}$ & $\begin{array}{l}\text { Nationalratswahlen (Nov. } \\
\text { 86): SPÖ } 80 \text {, ÖVP } 77 \text {, } \\
\text { FPÖ 18, Grüne } 8\end{array}$ & \\
\hline 1988 & $\begin{array}{l}\text { "Bedenkjahr» (50 Jahre } \\
\text { "Anschluss«) }\end{array}$ & & $\begin{array}{l}\text { Ehrengaben- und Hilfsfonds- } \\
\text { gesetz }\end{array}$ \\
\hline 1989 & $\begin{array}{l}\text { Fall des »Eisernen Vor- } \\
\text { hangs« }\end{array}$ & & \\
\hline 1990 & & $\begin{array}{l}\text { Nationalratswahlen: } \\
\text { SPÖ 80, ÖVP 52, FPÖ/F } \\
\text { 42, Gründe } 10\end{array}$ & \\
\hline 1991 & $\begin{array}{l}\text { Bundespräsident Thomas } \\
\text { Klestil } \\
\text { Bundeskanzler Vranitzky } \\
\text { bekennt sich zur österrei- } \\
\text { chischen Mitverantwor- } \\
\text { tung für Geschehnisse im } \\
\text { „Dritten Reich" (Juli-Rede) }\end{array}$ & & \\
\hline 1993 & & & $\begin{array}{l}\text { Staatsbürgerschaftsgesetz- } \\
\text { Novelle v. } 10.7 \text {. } \\
\text { Neufassung des } \$ 58 \text { c: Wie- } \\
\text { dererlangung der Staatsbür- } \\
\text { gerschaft für NS-Vertriebene } \\
\text { ohne Aufgabe der bisherigen } \\
\text { und ohne Wohnsitzbegrün- } \\
\text { dung möglich. }\end{array}$ \\
\hline
\end{tabular}




\begin{tabular}{|c|c|c|c|}
\hline & Politische Geschichte & $\begin{array}{l}\text { Innere Entwicklung, } \\
\text { Verwaltung } \\
\text { und Verfassung }\end{array}$ & $\begin{array}{l}\text { Gesetze und Verordnungen } \\
\text { Juden betr., insb. Heimatrecht } \\
\text { u. Staatsbïrgerschaft }\end{array}$ \\
\hline 1994 & & $\begin{array}{l}\text { Nationalratswahlen: } \\
\text { SPÖ 65, ÖVP 77, FPÖ/F } \\
\text { 18, Grüne 13, Liberales } \\
\text { Forum } 11\end{array}$ & \\
\hline 1995 & $\begin{array}{l}\text { Beitritt zur Europäischen } \\
\text { Union }\end{array}$ & $\begin{array}{l}\text { Nationalratswahlen: SPÖ } \\
\text { 71, ÖVP 52, FPÖ 41, } \\
\text { Grüne 9, Liberales Forum } \\
10\end{array}$ & $\begin{array}{l}\text { Bundesgesetz über Natio- } \\
\text { nalfonds für die Opfer des } \\
\text { Nationalsozialismus }\end{array}$ \\
\hline 1997 & $\begin{array}{l}\text { Reg. Klima (SPÖ-ÖVP- } \\
\text { Koalition) } \\
(28.1 .1997-J a ̈ n .2000)\end{array}$ & & \\
\hline 1998 & & & $\begin{array}{l}\text { Staatsbürgerschaftsgesetz- } \\
\text { Novelle v. } 14.8 \text { (StbGNov } \\
\text { 1998), \$10 Abs } 4 \text { Z } 2 \text { Er- } \\
\text { leichterte Einbürgerungen } \\
\text { bei "Altösterreichern" }\end{array}$ \\
\hline 1999 & & $\begin{array}{l}\text { Nationalratswahlen Nov. } \\
\text { 99: rel. Mehrheit Soz. } \\
\text { Dem., FPÖ wird zweit- } \\
\text { stärkste Partei } \\
\text { (SPÖ 65, ÖVP 52, FPÖ } \\
\text { 52, Grüne 14) }\end{array}$ & \\
\hline 2000 & $\begin{array}{l}\text { Regierung Schüssel/Riess- } \\
\text { Passer (4.2.) } \\
\text { "Sanktionen« der EU } 14 \\
\text { (4.2.) }\end{array}$ & $\begin{array}{l}\text { Zwangsarbeiterentschädi- } \\
\text { gungsgesetz }\end{array}$ & Versöhnungsfonds \\
\hline 2001 & Vertrag von Washington & & Entschädigungsfonds \\
\hline
\end{tabular}




\section{Register}

\section{Personen}

Adler, Alfred 205, 206

Adler, Friedrich 203

Adler, Viktor 111

Adorno, Theodor 194

Albrecht, Herzog 21, 245

Aly, Götz 156

Andersen, Hans Christian 179

Arditti, Nissim 188, 190

Arendt, Hannah 15, 99, 160, 165, 200, 208, 214

Arnstein, Franziska (Fanny) Freifrau von 47, 48

Arnstein, Nathan von 48, 55

Aron, Raymond 214

Auersperg, Carlos 104, 106, 253

Augenfeld, Dr. Moritz (Maurizio) 98

Bach, Alexander 60, 64, 66, 251

Badeni, Graf Casimir 93, 102, 118, 122, 254

Balk, Theodor 207

Baron, Salo 53

Barth-Barthenheim, Graf Johann 24, 39, 49, 53, 56, 71

Bartosch, Josef 128

Battenberg, Friedrich 10, 11

Bauer, Bruno 57, 58, 82

Bauer, Otto 126, 145, 199

Bayazid II., Sultan 188

Beck, Max Wladimir von 255

Beer, Adolf 108

Beller, Steven 112, 115

Berger, Ernst 106

Bernatzik, Edmund 63, 120, 121

Bettelheim, Bruno 154

Bettelheim, Caroline 91

Bettelheim, Daniel 85

Bettelheim, Helene 85

Beust, Friedrich Ferdinand von 253

Bienerth, Richard von 255
Bihalji-Merin, Otto 207

Billig, Dr. Josef 117

Birnbaum, Nathan 39, 58, 66, 126, 201

Bismarck, Otto von 82

Blau, Dr. Markus 89

Blaukopf, Herta 168

Blaukopf, Kurt 168

Bloch, Ernst 194

Bloch, Joseph 121, 122

Blümegen, Heinrich Cajetan Graf 26

Bobolc, Isaac 30

Bodin, Jean 217

Brand, Abraham 32

Brand, Jakob 32

Brecht, Bert 154, 206

Brix, Emil 124

Brod, Max 103

Broszat, Martin 156

Brown, Edward 23

Browning, Christopher 157, 163, 164

Bruck, Karl Ludwig 68, 69

Buber, Martin 200

Bucharin, Nikolai 207

Buol-Schauenstein, Graf Carl Ferdinand 64, 65,251

Bürckel, Josef 150

Buschmann, Gotthart von 218

Buschor, Hera 197

Calderon, Rachel 191, 192

Canetti, Abraham 188

Canetti, Elias 160-162, 187-200, 206, 208, 213

Canetti, Elias (Großvater) 188

Canetti, George 193

Canetti, Jacques 189

Canetti, Mathilde 189, 190

Canetti, Moisse 188 
Canetti, Veza 191-193, 195-197

Castells, Manuel 161

Celan, Paul 168

Chamberlain, Houston Stewart 118, 151

Charmatz, Richard 123

Chmelnitzkij, Bogdan 211

Christov-Bakargiev, Carolyn 215

Cohn, Camilla 77

Cohn, Salomon 77

Condere, Jean Pierre 211

Coschell, Moritz 35

Deutsch, Otto Erich 197

Diamant, Dr. Max 114, 126

Diner, Dan 220

Doderer, Heimito von 206

Dohm, Christian Wilhelm von 18

Dollfuß, Engelbert 142, 145, 193, 195, 257

Dostojewski, Fjodor Michailowitsch 203

Drach, Elias 42, 44

Dreyfus, Alfred 118, 122

Dym, Moses 138, 205, 256

Effenberger, Gustav 102

Eichmann, Adolf 150, 157, 159, 160

Einstein, Albert 206, 216

Ender, Otto 256

Engel, Emanuel 42

Engel, Mariana 42

Engel, Maximilian 42

Eötvös, Joseph 83

Ephrussi, Familie 89, 190, 213

Eskeles, Bernhard 47, 48, 55

Evan, Bernhard 176

Evan, Gershon 175, 176

Falkenflik, Cwetka (Niza) 174, 178, 181, 183

Falkenflik, Gena 173, 177-180, 182, 183

Falkenflik, Leon 173, 174, 176

Falkenflik, Leon Juda Leib 173, 176, 177, 179

Falkenflik, Martha 174, 175, 178-184

Ferdinand, Erzherzog Franz 255

Ferdinand, Kaiser 250

Ferdinand I., Kaiser 22, 70, 245, 250

Ferdinand II., Kaiser 23, 245

Fichte, Johann Gottlieb 15, 82, 117, 199

Figdor, Isac 42

Figl, Leopold 259, 260
Fischhof, Adolf 250

Fischhof, Adolph 59, 107, 108, 120

Fliegel, Dr. Julius 166

Flusser, Vilém 161

Foucault, Michel 25, 161

Frank, Anne 210

Frankl, Bernhard 32

Frankl, Ludwig August 59

Franz I. (II.), Kaiser 40, 45, 51, 55, 246, 248, 249

Franz Joseph I., Kaiser 64, 69, 70, 77, 123, 203, 204, 251, 255

Freud, Sigmund 106

Freundlich, Elisabeth 168

Fried, Erich 170

Friedrich II. (der Streitbare), Herzog 19, 245

Friedrich II., Kaiser 10, 19, 148, 245

Friedrich III., Kaiser 22

Fuchs, Albert 111

Gallenberg, Wenzel Robert Graf 36

Gammerl, Benno 14, 16, 79, 93, 95, 97, 133

Gaulle, Charles de 209

Gautsch, Paul von 254

Gellner, Ernest 118

Georg II., König 24

Gerlach, Christian 157-159, 162

Giskra, Karl 106

Glaser, Julius 106, 108

Globke, Hans 151, 221

Gobineau, Arthur de 118, 151

Goebbels, Joseph 156, 158, 159, 162

Goethe, Johann Wolfgang von 101

Goldmark, Joseph 59

Gorbach, Alfons 261

Gołuchowski, Graf Agenor 67, 252

Grab, Walter 62

Graf, Oskar Maria 142

Greiner, Hofrat von 41, 44

Grillparzer, Franz 101

Gropius, Walter 206

Grotius, Hugo 217

Habermas, Jürgen 215

Habsburg, Familie 13, 16, 21, 24, 34, 46, 52, $103,104,126,131,245$

Hakel, Hermann 168

Halban-Blumenstock, Heinrich Ritter von 122 
Hanuschek, Sven 188

Hartog, L.J. 157

Healy, Maureen 131

Hegel, Friedrich Wilhelm Georg 82

Hein, Franz von 69

Helmer, Oskar 169

Herder, Johann Gottfried 15, 82, 117

Hermann, Alois 108, 168

Herschmann, Bernhard 59

Hertz, Friedrich 154

Herz, Leopold von 55

Herzl, Amalie 90

Herzl, Theodor 58, 122

Heydrich, Reinhard 157, 159, 163, 175

Hilberg, Raul 155

Hilferding, Rudolf 154

Hilsner, Leopold 118, 123

Himmler, Heinrich 155, 156, 158-160, 163, 164

Hindenburg, Paul von 131

Hitler, Adolf 142, 145, 146, 148, 151, 155160, 162, 163, 194, 196, 208

Hoffmann, Eva 202

Hohenlohe-Schillingfürst, Chodwig zu 255

Hohenwart, Karl Sigmund von 253

Hollitscher, Walter 197

Homberg, Herz 36

Hönig, Israel, Edler von Hönigsberg 49, 51

Humboldt, Alexander von 54, 117

Humboldt, Wilhelm von 54, 82

Huxley, Aldous 216

Irving, David 156

Itzig, Daniel 47, 48

Jaques, Heinrich 64, 67, 68, 109

Jellinek, Hermann 59, 62

Johann, Erzherzog 250, 251

Jonas, Franz 261

Joppke, Christian 213

Joseph I., Kaiser 245

Joseph II., Kaiser 18, 26-29, 31, 36, 37, 39, 40, 45, 49-51, 148, 246, 247

Kafka, Franz 81, 100-103, 113, 123

Kafka, Hermann 102

Kampi, Franziska 94

Kanitz, Emanuel 91
Kant, Immanuel 13, 16, 18, 217

Kaposi, Jakob 84

Karavan, Dani 176

Karl VI., Kaiser 24, 29, 245

Karpeles, Josefa 48

Katzenelson, Jizchak 181, 182

Kaunitz, Wenzel Anton Fürst von 246, 248

Kesten, Hermann 209

Kewall, Benjamin 59, 62

Kirchschläger, Rudolf 262

Klaus, Josef 261

Kleist, Heinrich von 101

Klemperer, Wilhelm 160

Klestil, Thomas 262

Klima, Viktor 263

Koestler, Arthur 207, 210

Kohn, Salomon 91

Kokoschka, Oskar 170

Körner, Theodor 260

Kornfeld, Eduard 96

Koselleck, Reinhart 218

Kraus, Karl 144, 191, 193, 195, 196

Kreisky, Bruno 170, 261, 262

Kreissler, Felix 167, 176

Kübeck, Karl Friedrich von 63

Kun, Béla 207

Kuranda, Leopold 88

Kyogoku, Toshiaki 124

Landes, David 141

Lang, Ilse 206

Leopold I., Kaiser 23, 245

Leopold II., Kaiser 27, 38, 40, 247

Lessing, Gotthold Ephraim 45, 57, 82

Lie, Trygve 216

Locke, John 57

Lösener, Bernhard 151, 221

Löwenherz, Josef 142

Löwy, Rosa 33, 90

Lozowick, Yaakov 157

Lueger, Karl 74, 119, 122, 254

Lukács, Georg 206

Lyons, Löwy (Lions) 33

Mahler, Anna 144, 193, 197

Majo, de Familie 190

Malraux, André 209, 211

Mannheimer, Elisabeth 44 
Mannheimer, Isaak Noah 60-62

Maria Theresia, Königin, Erzherzogin 24, 25, 35, 39, 148, 245

Marie Louise, Erzherzogin 46

Marshall, Thomas H. 16, 215

Martini, Carl Anton von 16, 17, 217

Marx, Karl 57, 58, 82, 161

März, Eduard 168

Masaryk, Tomáš G. 123

Mathias, Erzherzog 23

Mathisen, Ralph W. 219

Maurer, Adolf 209

Maximilian, Kaiser von Mexiko 252

Maximilian I., Kaiser 20, 22, 245

Maximilian II., Kaiser 22

Mayer, Sigmund 85, 124, 125

McCagg, William 103

Mehring, Franz 142, 194

Mendelsburg, Albert 114

Mendelssohn, Moses 36, 47, 82, 104

Metternich, Clemens Lothar Wenzel 55, 249, 250

Mong Tse 199

Moreno, Familie 190

Moser, Leopold 83

Motesiczky, Marie-Louise von 197

Mozart, Wolfgang Amadeus 45, 49

Mühlen, Hermynia zur 142

Mühlfeld, Dr. 69

Münzenberg, Willi 206, 208, 209

Musil, Robert 101

Napoleon I. Kaiser 46, 51, 53, 249, 252

Nathans, Eli 79

Nekula, Marek 100

Ofner, Julius 91, 92, 136, 217

Onciul, Aurel von 126

Oommen, T. K. 216

Oppenheimer, Samuel 24, 245

Ornstein, Jakob 142

Ottokar II., König 20

Oxaal, Ivar 84

Pacholkiv, Svjatoslav 14, 34, 36, 38, 134, 136

Paris 11, 200, 207, 213

Passos, John dos 216

Paul, Wolfgang 185
Pereira, Henriette 48

Perek, Václav 124, 127

Pick, Dr. Alois 142

Pillersdorf, Franz von 56, 250

Platon 101

Polgar, Alfred 142, 194

Popper, Joachim 30

Popper, Karl 170

Potocki, Alfred Józef 253

Pressburger, Karl 42, 94

Pufendorff, Samuel 217

Raab, Julius 260

Radetzky, Wenzel von 250

Rainer, Erzherzog 69

Ramek, Rudolf 139, 256

Rauscher, Kardinal Joseph 23, 70

Raviv, Chaim 183

Raviv, Martha 172, 173, 178, 181, 183-186, 213

Rechberg, Johann Bernhard 67, 68, 148, 252

Reich, Wilhelm 206

Reinhardt, Max 142, 194

Reiter, Mirjam 207

Rembrandt van Rijn, Harmenszoon 196

Renner, Karl 119, 120, 126, 136, 137, 166, 255, 259

Reuchlin, Johannes 11

Richter, Josef 30

Riess-Passer, Susanne 263

Rintelen, Anton 142

Roosevelt, Franklin D. 158

Rosanes, Abraham ben Israel 189

Roschmann, Anton von 56

Rosenberg, Alfred 151, 163

Rosenberg, Samuel 84

Rosenfeld, Rabbiner Dr. 117

Roth, Joseph 138

Rothschild, Salomon 46, 141

Rousseau, Jean-Jacques 13, 18

Rozenblit, Marsha L. 84, 90, 112

Rudolf I., Kaiser 21

Rudolf II., Kaiser 22, 245

Rühle, Otto 206

Rühle-Gerstel, Alice 206

Ruppin, Arthur 80

Russell, Bertrand 216 
Safrian, Hans 157

Sahl, Hans 208

Sauer, Wenzel Graf 40

Saurau, Franz Graf 48

Schärf, Adolf 261

Schiller, Friedrich 101, 176, 213

Schimmer, Gustav 80

Schlegel, Dorothea 47

Schlegel, Friedrich 47

Schlesinger, Dr. Wilhelm 89

Schlesinger, Emma 89

Schmerling, Anton Ritter von 63, 64, 251, 252

Schmidl, Erwin 130

Schober, Johannes 256

Schönerer, Georg 79, 111, 122, 254, 255

Schorske, Carl 118

Schuschnigg, Kurt von 142, 146, 193, 194, 257

Schüssel, Wolfgang 263

Schwarzenberg, Fürst Felix 60, 61, 63, 64, 251

Sedlaczek, Franziska 94

Seipel, Ignaz 141, 256

Sever, Alfred 135, 204, 255

Seyß-Inquart, Arthur 155

Shakespeare, William 192

Shaw, Bernhard 216

Sigismund, Kaiser 21

Singer, Anna 94

Singer, Ascher 33

Singer, Julia 93, 94, 95

Singer, Michael 94, 95

Sinowatz, Fred 262

Sonnenfeld, Dr. Adolf 91

Sonnenfels, Joseph von 17, 37, 40, 218

Sophokles 101

Sperber, Dan 209

Sperber, David Mechel 203, 205

Sperber, Jenka 209, 211

Sperber, Jente 203

Sperber, Manès 187, 188, 200-213

Sperber, Mirjam 207

Spiel, Hilde 170

Spitzer, Gabriel 87, 88

Spitzer, Karl Heinrich 59

Stadion, Franz Graf 63

Stalin, Josef 162, 211

Stark, Gustav 93

Stark, Hugo 92, 93

Stein, Rabbiner Dr. A. 29
Steiner, Emanuel 92

Steiner, Rosa 92

Sternberg, Simon 173

Sternfeld, Albert 170, 171

Stift, Andreas von 56

Stourzh, Gerald 108, 124, 214

Strakosch, Alexander 89, 108

Straucher, Benno 126

Stránsky, Adolf 123

Stuckart, Wilhelm 151, 152, 155, 163, 164, 221

Stürgkh, Karl Graf 203, 255

Sulzer, Salomon 44

Šuman, Joseph 116

Swieceny, Friedrich 71, 73

Taaffe, Graf Eduard 111, 113, 119, 254

Tantner, Anton 23, 25

Taubes, Aron Moses 98, 130

Taubes, Chaim 98

Teitelbaum, Felix 98

Thun, Graf Leo 68, 70, 254

Tietze, Hans 18, 24, 25, 28, 39, 45, 55, 56, 81,85

Torberg, Friedrich 101

Ugarte, Graf Alois 31

Vaugoin, Carl 141, 256

Verkauf-Verlon, Willi 168

Verschleisser, Markus 97

Vesque von Püttlingen, Johann 53

Vranitzky, Franz 171, 184, 262

Waal, Edmund de 213

Waber, Leopold 139, 205

Waldheim, Kurt 262

Walter, Bruno 142, 194

Wassilko, Nikolai 126

Wastl, Dr. Joseph 175, 176

Wecker, Regina 198

Weigel, Helene 154

Weinberger, Aron 32, 33

Weissberg, Alex 206

Weitlof, Moritz 111

Weitzmann, Lea 84, 95, 96

Wendelin, Harald 170

Wertheim, Zacharias 43 
Wertheimer, Jacob 34

Wertheimer, Josef 77

Wertheimer, Joseph 67

Wertheimer, Samson 24

Wetzlar von Plankenstern, Carl Abraham 49

Wetzlar von Plankenstern, Raimund 49

Widmann, Karl von 55, 56

Wieland, Christoph Martin 16, 217

Wolf, Gershon 45

Wolf, Karl Hermann 122
Wrede, Carl Philipp Fürst von 55

Zadek, Walter 207

Zahra, Tara 124, 129

Zeiller, Franz von 17, 18, 52, 217

Zinzendorf, Ludwig Graf 39

Zuckmayer, Alice 143

Zuckmayer, Alice Henriette 154

Zuckmayer, Carl 143

Zweig, Stefan 101, 152, 153, 190

\section{Orte}

Adrianopel 188, 189

Alsergrund 112

Auschwitz-Birkenau 181

\section{Beirut 97}

Belgrad 75, 190, 245, 248

Bergen Belsen 180, 182

Berlin 11, 14, 15, 28, 52, 53, 58, 78, 80, 82, $101,103,117,122,131,151,152,155,156$, $159,160,161,164,166,187,201,206,210$, 215,221

Bernburg 177

Bełzec 163

Böhmen 20, 22, 24, 27, 29-31, 34, 67, 69, 75, $84,92,102,106,108,118,121-123,245$, 247, 254

Bösing/Pezinok/Bazin 83

Brody 35, 95, 96, 109, 110, 113

Brünn/Brno 31, 123, 133, 139

Buchenwald 175, 176, 177

Bucher/Puchér 92

Budapest 83, 87, 89, 124

Bukowina 35, 68, 69, 81, 83, 110, 114-119, $121,126,127,129,134,138,173,185,204$, 246

Bulgarien 188

Celle 180

Chemnitz 180

Custozza 250

Czernowitz/Černivci/Cernăuți 101, 114-116, 126

Dachau 150
Dallwitz/Dalovice 93

Dalmatien 69, 136, 248, 249

Dänemark 252

Darmstadt 9, 26, 210

Deutschkreuz 89

Dojcs/Dojč 94, 95

Drancy 181

Eger 93

Eibenschitz/Ivancice 111

Eisenstadt 10, 22, 28, 29, 84, 109, 114, 179

Elsass-Lothringen 122

England 21, 57, 190, 197, 213

Europa 13, 22, 24, 59, 86, 105, 122, 123, 127, 162, 187-189, 192, 198, 199, 210, 214-216

Europäische Union 210, 213, 263

Frankfurt am Main 53, 191, 217, 250, 251, 252

Frankreich 15, 16, 51, 53, 57, 64, 95, 118, 122, 178, 207-209, 211, 212, 216, 248, 250

Frauenkirchen 84

Friesach 20

Fuveau 208

Galizien 27, 28, 34-37, 56, 66-69, 80, 81, 83, $86,95,96,109,110,113-115,117,129$, 134-136, 138, 173, 175, 185, 202-205, 207, 246, 247, 249, 252, 254

Geiring 83

Görz/Gorizia 27, 39, 106

Grenoble 208

Großbritannien 79, 154, 216

Groß-Magendorf/Velký Mager 83

Gyömrö 87 
Haifa $178,181,182$

Halle 180

Hamburg 11, 16, 44, 57, 97, 120, 154, 155, $161,192,215,216$

Hannover 180

Hernals 94

Hildesheim 18, 180, 181

Hohenems 44

Holitsch/Holič 83

Honduras 181

Iglau/Jíhlava 33, 133

Indien 216

Innerösterreich 22, 23

Israel 29, 49, 51, 85, 172, 181-183, 185, 192, 210,258

Istrien 121, 136, 248, 249

Italien 67, 137, 188, 204, 248, 249, 253

Jamnitz/Jemnice 91 Jerusalem 76, 97, 160, 181, 209 Joka Korompa/Krompachy 83

Jugoslawien 207

Karlowitz 75, 190, 245

Karlsbad 92, 93

Kärnten 22, 69, 106, 245, 249

Kaunas 163

Kehl 181

Kiew 183

Kittsee 42, 84

Klosterneuburg 20, 21

Kobersdorf 84

Kolomea/Kołomyja 110, 202, 209

Königgrätz/Hradec Králové 253

Konstantinopel 97

Kopenhagen 24, 44

Krain 22, 69, 106, 249

Krakau/Kraków 246, 249

Krems 20, 21

Kremsier/Kromeříž 60-63, 105, 250

Kroatien 68, 251

Kuklov/Kukló 83, 94

Küstenland 69, 106

La Bourboule 182

Lackenbach 84, 90

Langenlois 21
Leipnik/Lipník 84, 128

Leipzig $10,18,38,60,63,85,120,122-124$, 180, 219, 249

Lemberg 110, 136

Lemberg/Lwów/L’viv 14, 98, 101, 109, 136

Leopoldstadt 23, 112, 203

Levante 96

Lilienfeld 93, 94

Linz 180

Lisko 205

Litauen 201

Łódź 164

Lomnitz/Lomince 30, 31

London 11, 15, 65, 111, 124, 129, 134, 144, 154, 159, 198, 215

Lourdes 182

Lublin 163

\section{Madagaskar 158}

Mähren 21, 22, 24, 29-34, 46, 48, 69, 75, 84, $91,102,117,118,122-125,127-129,203$, 245,254

Mainz 209

Manchester 190

Mantua 27

Mariahilf 77

Marrakesch 196, 197

Marseille 182, 208

Mattersburg 84

Minsk 164

Neu-Sandez/Novy Sacz 38

Niederlande 24, 248

Niederösterreich (Österreich unter der Enns) 22-24, 29, 38, 49, 56, 69, 71, 86, 90, 93, 95, 204, 245

Nikolsburg/Mikulov 48, 84

Oberösterreich (Österreich ob der Enns) 69

Odessa 89

Olmütz/Olomouc 27, 133

Osmanisches Reich 75, 76, 187, 188, 191, 192

Palästina 145, 168, 178, 181, 182

Paris 137

Passarowitz 75, 190, 245

Pearl Harbour 158, 259

Petah Tikva 172 
Philadelphia 33, 44

Polen 30, 34, 79, 114, 137, 173, 175, 184, 185, 186, 201, 204, 207, 208, 246, 248, 250

Polná 62, 123

Portugal 188

Pottornya Prekáska 92

Prag 22, 23, 29, 59, 92, 100-103, 112, 123, 124, 180, 207, 246, 251, 253, 254

Pressburg/Bratislava 59, 84, 85

Preußen 16, 53-55, 57, 79, 82, 216, 246, 253

Proßnitz/Prostějov 125

Pucho 84

Ringelsdorf 95

Rohrbach 93, 94

Römisches Reich 11, 17, 220

Rumänien 79, 137, 168, 186, 204

Russland 79, 81, 89, 179, 201, 207, 213, 249

Rustschuk/Russe 188, 189

Salzburg 69, 75, 142, 143, 248, 249

Sarajevo 192, 255

Schattendorf 206

Schlesien 31, 32, 33, 46, 69, 125, 246

Schönlind/Krásná Lípa 92

Schweiz 191, 198, 209

Sebes-Kellemes 89

Senitz 83

Sepharad (Spanien) 188

Shanghai 167, 234

Sistova/Sistowa 75, 190, 248

Slavonien 68

Slowakei 30, 32

Sniatyn 173

Sobotiz 83

Sowjetunion 159, 179, 207, 208, 211, 259

Spanien 75, 188, 197

Stanislau/Stanisławów/Stanyslav 173

Steiermark 20, 22, 69, 106, 245
St-Germain-en-Laye 133, 137-140, 173, 204, 255

Straßburg 181

Szilar-Balhás 77

Tel Aviv 172, 173, 185, 186

Tirol 68, 69, 245, 249

Tłuste 173, 184

Treblinka 209

Trianon 133, 139, 255

Triesch/Tř̀št 32, 33

Triest/Trieste/Trst 27, 39, 75, 98, 106, 178, 190, 245, 249

Tripolis 97

Tschechoslowakische Republik 103, 137, 204

Tulln 20, 21

Tunis 97

Türkei 75, 191, 192

Ukraine 173, 186, 204

Ungarn 16, 21, 22, 27, 30, 32, 42, 66-69, 77-79, 82-90, 92-96, 98, 119, 122, 219, 245, 247, 251-254

Unterer Werd 23, 245

USA $155,158,168,208,210,259$

Utrecht 24

Veszprém 77

Vittel 181, 182

Währing 84

Weimar 176

Wiener Neustadt 20

Zabłotow 202, 203, 209

Zagreb 207

Zürich 60, 122, 157, 158, 160, 192, 197, 198, 211,252

\section{SACHEN}

Ahasver 81, 210

Allgemeines bürgerliches Gesetzbuch (ABGB) $18,51,52,217,249$

Ämterfähigkeit 48, 56, 148
Anschluss 143, 146, 148, 150, 152-154, 166, $174,195,258$

Antisemitismus 22, 30, 68, 74, 82, 113, 114, $119,121-123,125,130,142,160,191,194$, 195,203 
Arisierung 146, 150, 174, 195

Aufklärung 146, 150, 174, 195

Ausbürgerung (Expatriation) 9, 11, 12, 78, 145, 152-155, 157, 164, 166, 169, 192, 258

Ausgleich 16, 77, 78, 82, 83, 85, 87, 92, 103, 114, 117, 119-121, 123-129, 219

Ausweisung (Austreibung) 21-24, 32, 62, 79, 86, 246

Mährischer Ausgleich 123, 124, 255

Badeni-Krise 93, 102, 118, 122, 254

Baron-Stiftung 202, 254

Bildung 15, 37, 39, 69, 82, 101, 103, 104, 106, 112, 122, 142, 202, 205

Bollette 40, 41, 43, 248

Bürgerliche Revolution 59

Bürger- und Meisterrecht 19, 28, 72

Chassidismus 37, 103

Cheder 38, 109, 115

christliche Dienstboten 20, 66, 67, 148, 252

Cisleithanien 80, 86, 87, 92, 95, 104, 106, 113, $117,119,120,129,134$

Cives Romani 11, 220

Conscription (Konskription) 37 Judenconscription 37

Depersonalisierung 155, 162, 164

Deportation 150, 154, 156, 160, 163-165, 172, 176, 178, 179, 209

Deutscher Schulverein 111

Displaced Persons 168, 182

Dreyfus-Affäre 118, 122

Dualismus 219

Eheconsens (Ehekonsens), -bewilligung 31, 36, 64

Ehefähigkeit 12

Emanzipation, Judenemanzipation 9, 12, 19, $28,54,57-60,62,63,66,82,83,105,147-$ 149,220

Endlösung 12, 155-162, 165, 209, 221

Erster Weltkrieg 16, 89, 97, 98, 114, 116, 120, $123,130-133,135,149,163,173,187,190$, 194, 198, 202, 203, 205

Ethnisierung 105, 117, 123, 220

Euthanasie 177
Familiantengesetze 24, 29, 245

Familienlisten 41, 42, 47, 48, 191

Familienstelle 11, 24, 29-34, 53, 71, 75, 84, 191

Frauen $13,18,19,21,61,72,90,104,132$, $171,182,195,209$

Freizügigkeit $66,75,83,85,220$

Fremde 10, 11, 18, 22, 28, 42, 46, 62, 70, 72, $85,87,92,98,99,151,170,171,173,190$, 197, 198, 203, 214

fremde Juden 24, 32, 33, 40, 41, 56, 74, 79, 85,190

Funktionalisten 156, 161

gelber Stern 147, 149, 165, 178, 179, 259

Gemeindegesetz 72, 73, 91, 128

Generalplan Ost 162

Geserah 21, 22, 245

Gestapo 150, 179, 207, 208

Gewerbefreiheit 12, 87

Gewerbeordnung 67, 68, 74

Ghetto 25, 164, 165, 209

Glaubens- und Gewissensfreiheitfreiheit 59, 60, $63,83,220$

Gleichberechtigung 54, 61, 64, 82, 85, 105, $106,117,118,126,141,142,219,220,251$

Gouvernementalität 11,39

Grundbesitz 19, 66, 85, 91, 167

Grundbesitzfähigkeit 12, 48, 52, 56, 63, 65, $68,73,251$

Grundbesitzrecht 39, 46, 49, 56, 65, 66, 73, $74,87,252$

Habsburg 16, 21, 24, 26, 34, 46, 135, 190, 191,202

Halacha 35

Haskala 104,110

Hebräisch 22, 26, 84, 112, 115, 188

Heiliges Römisches Reich 10, 19, 21

Heimatrecht (politisches Domicil) 9, 10, 13, 32, 34, 62, 70-74, 77, 84-93, 95, 97-99, 133-136, 139, 140, 144, 153, 184, 194, 198, 203-205, 213, 220, 245, 246, 252, 257, 259

Heimatschein 72-74, 94, 134, 173, 203, 204, 207

Heimwehr 142

Hilsner-Prozeß 118, 123

Hofbefreite (Hoffaktoren) 22, 23, 32 
Hofkanzlei 31, 34, 38, 41, 44-46, 48, 49, 55-57, 246-249

Hohe Pforte 74, 75, 190

Holocaust 22, 155-158, 171, 185

Incolat (Indigenat) 19, 219

Intentionalisten 156

ius sanguinis $16,184,216$

ius soli 16, 216

Jiddisch 36, 103, 110, 114, 115, 181, 201, 202, 220

Josephinismus, josephinisch 9, 15, 18, 26, 27, 29, 30, 36, 37, 39, 45, 70, 191, 218

Judenamt 40-44, 248

Judenfrage, jüdische Frage 53, 57, 58, 60, 82, $111,119,122,126,129,151,157,158,160$, 163

Judenordnungen (Regale, Patente, Schützungen) $10,19,20,24-27,35,38,66,73,148,245$, 247, 248

jüdische Kurie, jüdischer Kataster 104, 121, 124-126

Kahal, Kahalim 36

Kammerknechte 10, 19

Konfessionalisierung 47

Konversionen 47, 113, 145

Konzentrationslager 154, 165, 167, 168, 176, 177

Kremsierer Grundrechtskatalog 61, 63

Kultusgemeinde, israelitische 41, 53, 64, 85, 94, $96,110,128,135,141-145,190,193,251$

Laterankonzil 20

Leibmaut 28, 40, 85, 248

Lex Perek 124, 127

Maskilim 37

Mehrsprachigkeit 115, 116-118, 129

Menschenrecht 58,210, 214

Militärpflicht 12, 36, 38

Militärdienst 28, 38, 89, 247

Mischehen 113

Nationaljudentum 113

Nationalitätenschule (auch: Minoritätsschule) 109,128
Nationalsozialismus $160,172,175,176,184$ 221

Naturalisation 52, 75, 153, 194, 248

Naturrecht 17, 52, 184, 217

Neoabsolutismus 12, 15, 64, 67, 87, 251

Nobilitierung 47, 49, 50, 51

Notariat 69, 70, 87, 149

Notariatsordnung 64, 252

Novemberpogrom (»Reichskristallnacht") 136, $152,195,258$

Nürnberger Gesetze 20, 146, 147, 148, 150, $151,162,165,195,221,258$

öffentliche Ämter 20

öffentlicher Dienst 52, 72, 90, 104

oktroyierte Märzverfassung 61, 72, 73, 218, 251

Opferausweise 167

Opferfürsorge 167, 184

Opferfürsorgegesetze 167

Option 111, 122, 127, 137-140, 173, 187, 196, 204, 255, 256

orthodoxe Juden 12, 37, 38, 80, 98, 115, 130, 131,135

Österreichisch-Israelitische Union 122, 125

Ostjuden 35, 134-139, 162, 175, 191, 201, 202, 204, 205, 208, 256

Pillersdorfsche Verfassung 60, 250

Pogrome 21, 59, 79, 81, 82, 123, 131, 135, $136,150,152,158,185,195,204,211,258$

Protestanten 18, 24, 27, 39, 68, 247

Rabbiner (Oberrabbiner) 29, 36, 37, 43, 47, 98, $117,121,181$

Rasse $111,118,123,137,138,139,151,177$, 190, 204, 205, 256

Rassengesetzgebung 20, 143, 260

Reichsbürger 62, 146, 147

Reichsbürgerrecht 63, 147, 251

Reichsbürgergesetz 146, 147, 149, 163, 165, 166, 218, 220, 221, 251, 258

Elfte Verordnung zum Reichsbürgergesetz $12,154,164,165,259$

Reichsrat 60, 79, 80, 82, 87, 95, 125, 134, 204, 251-254

Remigration 84, 167, 168

Remigranten 85, 167

Reserveoffiziere 130, 132, 231 
Restitution 169, 170

Römisches Recht 11

Säkularisierung 26, 47

Scheva Kehillot (Sieben Heilige Gemeinden) 84

Schtetl 202, 209

Schub 70, 85, 92

Schutzgenossen 19, 76, 96, 97, 219

Sepharden (sephardische Juden) 12, 27, 76, 188, 190

Shoah 183

soziale Frage 91

staatenlos, Staatenlosigkeit 132, 152, 163, 165, $166,168,169,172,173,187,188,192-195$, 197, 200, 201, 206, 208, 210, 213, 214, 216

staatenlose Juden 13, 174-176, 195

Staatsgrundgesetz 19, 78, 82, 83, 85, 88, 89, 102, 104-106, 109, 119, 126, 130, 149, 219, 220, 253

Steuern 22, 23, 31, 60, 104, 191

Steuerpflicht 12

Talmud-Thoraschule 38, 115

Taoismus 199, 200

Taufe 20, 21, 46, 47, 48, 49, 75

Toleranz 11, 13, 26, 28, 34, 39, 41-44, 46, 53, $57,71,75,84,191$
Toleranzpatente 18, 27, 29, 30, 34, 36, 37, $40,45,49,148,149,191,247,248$

türkische Juden 27, 74-76, 96, 190, 191

Untertanen de facto 19, 96, 219

Utilitarismus 26

Vaterländische Front 144, 142

Vermögensentzug 164, 154

Vertreibung 12, 13, 22-24, 26, 152, 158, 162, $163,165,187$

Völkerbund 144, 187, 256

Vormärz 49, 53, 105, 117, 119

Wahlrecht 12, 60, 104, 125, 127, 132, 144, 215, 252, 255, 256

Waldheim-Krise 171, 263

Wannsee-Konferenz 159, 259

Wehrpflicht 107, 130, 214

Weltbürgerschaft 198, 215

Westgalizisches Gesetzbuch 16, 217, 248

Wiener Kongress 53-55, 57, 249

Zeugenfähigkeit 12

Zionismus 113, 126

Zionisten 12, 124-126

Zweiter Weltkrieg 12, 202, 208, 216, 259 


\section{STUDIEN ZU POLITIK UND VERWALTUNG}

HERAUSGEGEBEN VON CHRISTIAN BRÜNNER, WOLFGANG MANTL, MANFRIED WELAN

1 KORRUPTION UND KONTROLLE. HG. VON CHRISTIAN BRÜNNER. 1981. 726 S. MIT 8 TAB. BR. ISBN 3-205-08457-8 (VERGRIFFEN)

2 UNBEHAGEN IM PARTEIENSTAAT. JUGEND UND POLITIK IN ÖSTERREICH. VON FRITZ PLASSER UND PETER A. ULRAM. 1982. 208 S., BR. ISBN 3-205-08458-6 (VERGRIFFEN)

3 LANDESVERFASSUNGSREFORM. HG. VON REINHARD RACK. 1982. 255 S. BR. ISBN 3-205-08459-4 (VERGRIFFEN)

4 NATION ÖSTERREICH. KULTURELLES BEWUSSTSEIN UND GESELLSCHAFTLICH-POLITISCHE PROZESSE. VON ERNST BRUCKMÜLLER. 2. ERWEITERTE AUFLAGE 1996. 472 S., ZAHLR. GRAF. BR. ISBN 978-3-205-98000-1

5 KRISE DES FORTSCHRITTS. HG. VON GRETE KLINGENSTEIN. 1984. 172 S., BR. ISBN 3-205-08461-6 (VERGRIFFEN)

6 PARTEIENGESELLSCHAFT IM UMBRUCH. PARTIZIPATIONSPROBLEME VON GROSSPARTEIEN. VON ANTON KOFLER. 1985. 132 S., 58 TAB. BR. ISBN 3-205-08463-2 (VERGRIFFEN)

7 GRUNDRECHTSREFORM. HG. VON REINHARD RACK. 1985. 302 S. BR. ISBN 3-205-08462-4 (VERGRIFFEN)

8 AUFGABENPLANUNG. ANSÄTZE FÜR RATIONALE VERWALTUNGSREFORM. VON HELMUT SCHATTOVITS. 1988. 220 S. BR. ISBN 3-205-08464-O (VERGRIFFEN)

9 DEMOKRATIERITUALE. ZUR POLITISCHEN KULTUR DER INFORMATIONSGESELLSCHAFT. HG. VON FRITZ PLASSER, PETER A. ULRAM UND MANFRIED WELAN. 1985. 291 S., 91 TAB. BR. ISBN 978-3-205-08467-9

10 POLITIK IN ÖSTERREICH. DIE ZWEITE REPUBLIK: BESTAND UND WANDEL. HG. VON WOLFGANG MANTL. 1992. XV, 1084 S. GB. ISBN 978-3-205-05379-8 (VERGRIFFEN)

11 FLEXIBLE ARBEITSZEITEN. EINE FIXE IDEE. VON RUDOLF BRETSCHNEIDER, RUPERT DOLLINGER, JOACHIM LAMEL UND PETER A. ULRAM. 1985. 133 S., 33 TAB. BR. ISBN 3-205-08469-1 (VERGRIFFEN)

12 VERFASSUNGSPOLITIK. DOKUMENTATION STEIERMARK. VON CHRISTIAN BRÜNNER, WOLFGANG MANTL, DIETMAR PAUGER UND REINHARD RACK. 1985. 294 S. BR. ISBN 3-205-08465-9 (VERGRIFFEN) 


\section{STUDIEN ZU POLITIK UND VERWALTUNG}

HERAUSGEGEBEN VON CHRISTIAN BRÜNNER, WOLFGANG MANTL, MANFRIED WELAN

13 KRISEN. EINE SOZIOLOGISCHE UNTERSUCHUNG. VON MANFRED PRISCHING. 1986. 730 S., ZAHLR. TAB. UND GRAF. BR. ISBN 978-3-205-08468-6

14 SCHWEIZ - ÖSTERREICH. ÄHNLICHKEITEN UND KONTRASTE. HG. VON FRIEDRICH KOJA UND GERALD STOURZH. 1986. 279 S. BR. ISBN 3-205-08902-2 (VERGRIFFEN)

15 WAS DIE KANZLER SAGTEN. REGIERUNGSERKLÄRUNGEN DER ZWEITEN REPUBLIK 1945-1987. VON MAXIMILIAN GOTTSCHLICH, OSWALD PANAGL UND MANFRIED WELAN. 1989. VI, 325 S. BR. ISBN 3-205-08900-6 (VERGRIFFEN)

16 TECHNIKSKEPSIS UND NEUE PARTEIEN. POLITISCHE FOLGEN EINES „ALTERNATIVEN“ TECHNIKBILDES. VON ERICH REITER. 1987. 167 S. BR. ISBN 3-205-08904-9 (VERGRIFFEN)

17 DEMOKRATIE UND WIRTSCHAFT. HG. VON JOSEPH MARKO UND ARMIN STOLZ. 1987. 367 S. BR. ISBN 3-205-08905-7 (VERGRIFFEN)

18 SOCIETY, POLITICS AND CONSTITUTIONS. WESTERN AND EAST EUROPEAN VIEWS. VON ANTAL ADAM UND HANS G. HEINRICH. 1987. 212 S. BR. ISBN 3-205-08907-3 (VERGRIFFEN)

19 USA: VERFASSUNG UND POLITIK. VON FRANCIS H. HELLER. 1987. $120 \mathrm{~S}$. BR. ISBN 3-205-08906-5 (VERGRIFFEN)

20 UMWELTSCHUTZRECHT. VON BERNHARD RASCHAUER. 2. AUFL. 1988. 304 S. BR. ISBN 3-205-05143-2 (VERGRIFFEN)

21 VERFALL UND FORTSCHRITT IM DENKEN DER FRÜHEN RÖMISCHEN KAISERZEIT. STUDIEN ZUM ZEITGEFÜHL UND GESCHICHTSBEWUSSTSEIN DES JAHRHUNDERTS NACH AUGUSTUS. VON KARL DIETRICH BRACHER. 1987. 348 S. BR. ISBN 3-205-08909-X (VERGRIFFEN)

22 DAS ÖSTERREICHISCHE PARTEIENSYSTEM. HG. VON ANTON PELINKA UND FRITZ PLASSER. 1988. 800 S. BR. ISBN 978-3-205-08910-O (VERGRIFFEN)

23 PARTEIEN UNTER STRESS. ZUR DYNAMIK DER PARTEIENSYSTEME IN ÖSTERREICH, DER BUNDESREPUBLIK DEUTSCHLAND UND DEN VEREINIGTEN STAATEN. VON FRITZ PLASSER. 1987. 344 S. BR. ISBN 3-205-08911-1 (VERGRIFFEN) 


\section{STUDIEN ZU POLITIK UND VERWALTUNG}

HERAUSGEGEBEN VON CHRISTIAN BRÜNNER, WOLFGANG MANTL, MANFRIED WELAN

24 IDEOLOGIE UND AUFKLÄRUNG. WELTANSCHAUUNGSTHEORIE UND POLITIK. VON KURT SALAMUN. 1988. 142 S. BR. ISBN 3-20505126-2 (VERGRIFFEN)

25 DIE NEUE ARCHITEKTUR EUROPAS. REFLEXIONEN IN EINER BEDROHTEN WELT. HG. VON WOLFGANG MANTL. 1991. 332 S. GB. ISBN 978-3-205-05412-2

26 DIE GROSSE KRISE IN EINEM KLEINEN LAND. ÖSTERREICHISCHE FINANZ- UND WIRTSCHAFTSPOLITIK 1929-1938. VON DIETER STIEFEL. 1989. X, 428 S. BR. ISBN 3-205-05132-7 (VERGRIFFEN)

27 DAS RECHT DER MASSENMEDIEN. EIN LEHR- UND HANDBUCH FÜR STUDIUM UND PRAXIS. VON WALTER BERKA. 1989. II, 356 S. BR. ISBN 3-205-05194-7 (VERGRIFFEN)

28 STAAT UND WIRTSCHAFT. AM BEISPIEL DER ÖSTERREICHISCHEN FORSTGESETZGEBUNG VON 1950-1987. VON WERNER PLESCHBERGER. 1989. 579 S. BR. ISBN 3-205-05204-8 (VERGRIFFEN)

29 WEGE ZUR GRUNDRECHTSDEMOKRATIE. STUDIEN ZUR BEGRIFFS- UND INSTITUTIONEN-GESCHICHTE DES LIBERALEN VERFASSUNGSSTAATES. VON GERALD STOURZH. 1989. XXII, 427 S. BR. ISBN 978-3-205-05218-0 (VERGRIFFEN)

30 GEIST UND WISSENSCHAFT IM POLITISCHEN AUFBRUCH MITTELEUROPAS. BEITRÄGE ZUM ÖSTERREICHISCHEN WISSENSCHAFTSTAG 1990. HG. VON MEINRAD PETERLIK UND WERNER WALDHÄUSL. 1991. 268 S. BR. ISBN 978-3-205-05464-1

31 FINANZKRAFT UND FINANZBEDARF VON GEBIETSKÖRPERSCHAFTEN. ANALYSEN UND VORSCHLÄGE ZUM GEMEINDEFINANZAUSGLEICH IN ÖSTERREICH. HG. VON CHRISTIAN SMEKAL UND ENGELBERT THEURL. 1990. 307 S. BR. ISBN 3-205-05237-4 (VERGRIFFEN)

32 REGIONALE UNGLEICHHEIT. VON MICHAEL STEINER. 1990. 258 S. BR. ISBN 978-3-205-05281-4

33 BÜROKRATISCHE ANARCHIE. DER NIEDERGANG DES POLNISCHEN „REALSOZIALISMUS“. VON AUGUST PRADETTO. 1992. 156 S. BR. ISBN 978-3-205-05421-4 


\section{STUDIEN ZU POLITIK UND VERWALTUNG}

HERAUSGEGEBEN VON CHRISTIAN BRÜNNER,

WOLFGANG MANTL, MANFRIED WELAN

45 REGIMEWECHSEL. DEMOKRATISIERUNG UND POLITISCHE KULTUR IN OST-MITTELEUROPA. HG. VON PETER GERLICH, FRITZ PLASSER UND PETER A. ULRAM. 1992. 483 S., ZAHLR. TAB. U. GRAF. BR.

ISBN 978-3-205-98014-8

46 DIE WIENER JAHRHUNDERTWENDE. HG. VON JÜRGEN NAUTZ UND RICHARD VAHRENKAMP. 2. AUFL. 1996. 968 S., 32 S. SW-ABB. GB. ISBN 978-3-205-98536-5

47 AUSWEG EG? INNENPOLITISCHE MOTIVE EINER AUSSENPOLITISCHEN UMORIENTIERUNG. VON ANTON PELINKA, CHRISTIAN SCHALLER UND PAUL LUIF. 1994. 309 S. BR. ISBN 978-3-205-98051-3

48 DIE KLEINE KOALITION IN ÖSTERREICH: SPÖ - FPÖ (1983-1986). VON ANTON PELINKA. 1993. 129 S. BR. ISBN 3-205-98052-2 (VERGRIFFEN)

49 MANAGEMENT VERNETZTER UMWELTFORSCHUNG. WISSENSCHAFTSPOLITISCHES LEHRSTÜCK WALDSTERBEN. VON MAX KROTT. 1994. 325 S. BR. ISBN 978-3-205-98129-9 (VERGRIFFEN)

50 POLITIKANALYSEN. UNTERSUCHUNGEN ZUR PLURALISTISCHEN DEMOKRATIE. VON WOLFGANG MANTL. 2007. 345 S. BR. ISBN 978-3-205-98459-7

51 AUTONOMIE UND INTEGRATION. RECHTSINSTITUTE DES NATIONALITÄTENRECHTS IM FUNKTIONALEN VERGLEICH. VON JOSEPH MARKO. 1995. 632 S. BR. ISBN 978-3-205-98274-6

52 GRUNDZÜGE FREMDER PRIVATRECHTSSYSTEME. EIN STUDIENBUCH. VON WILLIBALD POSCH. 1995. XXVIII, 205 S. BR. ISBN 978-3-205-98387-3

53 IDENTITÄT UND NACHBARSCHAFT. DIE VIELFALT DER ALPEN-ADRIA-LÄNDER. HG. VON MANFRED PRISCHING. 1994. 424 S. BR. ISBN 978-3-205-98307-1 (VERGRIFFEN)

54 PARLAMENTARISCHE KONTROLLE. DAS INTERPELLATIONS-, RESOLUTIONSUND UNTERSUCHUNGSRECHT. EINE RECHTSDOGMATISCHE DARSTELLUNG MIT HISTORISCHEM ABRISS UND EMPIRISCHER ANALYSE. VON ANDREAS NÖDL. 1995. 198 S. BR. ISBN 978-3-205-98161-9

55 ALFRED MISSONG. CHRISTENTUM UND POLITIK IN ÖSTERREICH. AUSGEWÄHLTE SCHRIFTEN 1924-1950. HG. VON ALFRED MISSONG JR. IN VERBINDUNG MIT CORNELIA HOFFMANN UND GERALD STOURZH. 2006. 476 S. GB. ISBN 978-3-205-77385-6

BÖHLAU VERLAG, WIESINGERSTRASSE I, A-IOIO WIEN, T: +43 I 33024 27-O VERTRIEB@BOEHLAU.AT, WwW.BOEHLAU-VERLAG.COM 


\section{STUDIEN ZU POLITIK UND VERWALTUNG}

HERAUSGEGEBEN VON CHRISTIAN BRÜNNER, WOLFGANG MANTL, MANFRIED WELAN

45 REGIMEWECHSEL. DEMOKRATISIERUNG UND POLITISCHE KULTUR IN OST-MITTELEUROPA. HG. VON PETER GERLICH, FRITZ PLASSER UND PETER A. ULRAM. 1992. 483 S., ZAHLR. TAB. U. GRAF. BR.

ISBN 978-3-205-98014-8

46 DIE WIENER JAHRHUNDERTWENDE. HG. VON JÜRGEN NAUTZ UND RICHARD VAHRENKAMP. 2. AUFL. 1996. 968 S., 32 S. SW-ABB. GB. ISBN 978-3-205-98536-5

47 AUSWEG EG? INNENPOLITISCHE MOTIVE EINER AUSSENPOLITISCHEN UMORIENTIERUNG. VON ANTON PELINKA, CHRISTIAN SCHALLER UND PAUL LUIF. 1994. 309 S. BR. ISBN 978-3-205-98051-3

48 DIE KLEINE KOALITION IN ÖSTERREICH: SPÖ - FPÖ (1983-1986). VON ANTON PELINKA. 1993. 129 S. BR. ISBN 3-205-98052-2 (VERGRIFFEN)

49 MANAGEMENT VERNETZTER UMWELTFORSCHUNG. WISSENSCHAFTSPOLITISCHES LEHRSTÜCK WALDSTERBEN. VON MAX KROTT. 1994. 325 S. BR. ISBN 978-3-205-98129-9 (VERGRIFFEN)

50 POLITIKANALYSEN. UNTERSUCHUNGEN ZUR PLURALISTISCHEN DEMOKRATIE. VON WOLFGANG MANTL. 2007. 345 S. BR. ISBN 978-3-205-98459-7

51 AUTONOMIE UND INTEGRATION. RECHTSINSTITUTE DES NATIONALITÄTENRECHTS IM FUNKTIONALEN VERGLEICH. VON JOSEPH MARKO. 1995. 632 S. BR. ISBN 978-3-205-98274-6

52 GRUNDZÜGE FREMDER PRIVATRECHTSSYSTEME. EIN STUDIENBUCH. VON WILLIBALD POSCH. 1995. XXVIII, 205 S. BR. ISBN 978-3-205-98387-3

53 IDENTITÄT UND NACHBARSCHAFT. DIE VIELFALT DER ALPEN-ADRIA-LÄNDER. HG. VON MANFRED PRISCHING. 1994. 424 S. BR. ISBN 978-3-205-98307-1 (VERGRIFFEN)

54 PARLAMENTARISCHE KONTROLLE. DAS INTERPELLATIONS-, RESOLUTIONSUND UNTERSUCHUNGSRECHT. EINE RECHTSDOGMATISCHE DARSTELLUNG MIT HISTORISCHEM ABRISS UND EMPIRISCHER ANALYSE. VON ANDREAS NÖDL. 1995. 198 S. BR. ISBN 978-3-205-98161-9

55 ALFRED MISSONG. CHRISTENTUM UND POLITIK IN ÖSTERREICH. AUSGEWÄHLTE SCHRIFTEN 1924-1950. HG. VON ALFRED MISSONG JR. IN VERBINDUNG MIT CORNELIA HOFFMANN UND GERALD STOURZH. 2006. 476 S. GB. ISBN 978-3-205-77385-6

BÖHLAU VERLAG, WIESINGERSTRASSE I, A-IOIO WIEN, T: + 43 I 33024 27-O VERTRIEB@BOEHLAU.AT, WWW.BOEHLAU-VERLAG.COM 


\section{STUDIEN ZU POLITIK UND VERWALTUNG}

HERAUSGEGEBEN VON CHRISTIAN BRÜNNER,

WOLFGANG MANTL, MANFRIED WELAN

56 STAAT UND GESUNDHEITSWESEN. ANALYSEN HISTORISCHER FALLBEISPIELE AUS DER SICHT DER NEUEN INSTITUTIONELLEN ÖKONOMIK.

VON ENGELBERT THEURL. 1996. 302 S. BR. ISBN 978-3-205-98461-O

57 ELITEN IN ÖSTERREICH. 1848-1970. VON GERNOT STIMMER. 1997. 2 BDE., 1151 S. 38 SW-ABB. GB. ISBN 978-3-205-98587-7

58 FRANKREICH - ÖSTERREICH. WECHSELSEITIGE WAHRNEHMUNG UND WECHSELSEITIGER EINFLUSS SEIT 1918. HG. VON FRIEDRICH KOJA UND OTTO PFERSMANN. 1994. 307 S., 19 SW-ABB. BR. ISBN 978-3-205-98295-1

59 FAHNENWÖRTER DER POLITIK. KONTINUITÄTEN UND BRÜCHE. HG. VON OSWALD PANAGL. 1998. 351 S. BR. MIT SU. ISBN 978-3-205-98867-0

60 AVANTGARDE DES WIDERSTANDS. MODELLFÄLLE MILITÄRISCHER AUFLEHNUNG IN OSTMITTEL- UND OSTEUROPA IM 19. UND 2O. JAHRHUNDERT. VON RICHARD G. PLASCHKA. 1999. 2 BDE., 1062 S. 32 SW-ABB. GB. ISBN 978-3-205-98390-3

61 BERNARD BOLZANO. STAAT, NATION UND RELIGION ALS HERAUSFORDERUNG FÜR DIE PHILOSOPHIE IM KONTEXT VON SPÄTAUFKLÄRUNG, FRÜHNATIONALISMUS UND RESTAURATION. HG. VON HELMUT RUMPLER. 2000. 423 S. BR. ISBN 978-3-205-99327-8

62 UM EINHEIT UND FREIHEIT. STAATSVERTRAG, NEUTRALITÄT UND DAS ENDE DER OST-WEST-BESETZUNG ÖSTERREICHS 1945-1955. VON GERALD STOURZH. 5., DURCHGESEHENE AUFL. 2005. 848 S., 19 SW-ABB. GB. ISBN 978-3-205-77333-7 (VERGRIFFEN)

63 ÖSTERREICH UNTER ALLIIERTER BESATZUNG 1945-1955. HG. VON ALFRED ABLEITINGER, SIEGFRIED BEER UND EDUARD G. STAUDINGER. 1998. 600 S. ISBN 978-3-205-98588-4

64 EVALUATION IM ÖFFENTLICHEN SEKTOR. VON EVERT VEDUNG. 1999. XVIII, 274 S. 47 GRAFIKEN U. TABELLEN. BR. ISBN 978-3-205-98448-1

65 LIBERALISMUS. INTERPRETATIONEN UND PERSPEKTIVEN. HG. VON EMIL BRIX UND WOLFGANG MANTL. 1996. 320 S. GB. ISBN 978-3-205-98447-4 (VERGRIFFEN)

BÖHLAU VERLAG, WIESINGERSTRASSE I, A-IOIO WIEN, T: +43 I 33024 27-O VERTRIEB@BOEHLAU.AT, WwW.BOEHLAU-VERLAG.COM 


\section{STUDIEN ZU POLITIK UND VERWALTUNG}

HERAUSGEGEBEN VON CHRISTIAN BRÜNNER, WOLFGANG MANTL, MANFRIED WELAN

66 HERBERT STOURZH - GEGEN DEN STROM. AUSGWÄHLTE SCHRIFTEN GEGEN RASSISMUS, FASCHISMUS UND NATIONALSOZIALISMUS 1924-1938. HG. VON GERALD STOURZH. 2008. 186 S. BR. ISBN 978-3-205-77875-2

67 DIE UNIVERSITÄT ALS ORGANISATION. DIE KUNST, EXPERTEN ZU MANAGEN. VON ADA PELLERT. 1999. 346 S. 5 SW-ABB. BR. ISBN 978-3-205-99080-2

68 GEMEINDEN IN ÖSTERREICH IM SPANNUNGSFELD VON STAATLICHEM SYSTEM UND LOKALER LEBENSWELT. HG. VON DORIS WASTL-WALTER. 2000. 248 S. 18 GRAF. 17 KARTEN. 71 TAB. 1 FALTK. BR. ISBN 978-3-205-99212-7

69 NOCH EINMAL DICHTUNG UND POLITIK. VOM TEXT ZUM POLITISCH-SOZIALEN KONTEXT, UND ZURÜCK. HG. VON OSWALD PANAGL UND WALTER WEISS. 2000. 462 S. BR. ISBN 978-3-205-99289-9

70 POLITIK, STAAT UND RECHT IM ZEITENBRUCH. SYMPOSION AUS ANLASS DES 6O. GEBURTSTAGS VON WOLFGANG MANTL. HG. VON JOSEPH MARKO UND KLAUS POIER. 2001. 197 S. 3 SW-ABB. GB. ISBN 978-3-205-99259-2

71 QUALITÄTSSICHERUNG UND RECHENSCHAFTSLEGUNG AN UNIVERSITÄTEN. EVALUIERUNG UNIVERSITÄRER LEISTUNGEN AUS RECHTS- UND SOZIALWISSENSCHAFTLICHER SICHT. VON EVA PATRICIA STIFTER. 2002. 410 S. BR. ISBN 978-3-205-99317-9

72 KULTURGESCHICHTE DES HEILIGEN RÖMISCHEN REICHES 1648 BIS 1806. VERFASSUNG, RELIGION UND KULTUR. VON PETER CLAUS HARTMANN. 2001. 510 S. ZAHLR. SW-ABB. GB. ISBN 978-3-205-99308-7

73 MINDERHEITENFREUNDLICHES MEHRHEITSWAHLRECHT. RECHTS- UND POLITIKWISSENSCHAFTLICHE ÜBERLEGUNGEN ZU FRAGEN DES WAHLRECHTS UND DER WAHLSYSTEMATIK. VON KLAUS POIER. 2001. 379 S. 18 TAB. 8 GRAF. BR. ISBN 978-3-205-99338-4

74 RECHTSENTWICKLUNG IM BANNKREIS DER EUROPÄISCHEN INTEGRATION. VON HUBERT ISAK. BR. ISBN 3-205-99326-8. IN VORBEREITUNG.

BÖHLAU VERLAG, WIESINGERSTRASSE I, A-IOIO WIEN, T: +43 I 33024 27-O VERTRIEB@BOEHLAU.AT, WWW.BOEHLAU-VERLAG.COM 


\section{STUDIEN ZU POLITIK UND VERWALTUNG}

HERAUSGEGEBEN VON CHRISTIAN BRÜNNER,

WOLFGANG MANTL, MANFRIED WELAN

75 GIGATRENDS. ERKUNDUNGEN DER ZUKUNFT UNSERER LEBENSWELT. HG. VON FRANZ KREUZER, WOLFGANG MANTL UND MARIA SCHAUMAYER. 2003. XII + 339 S. 13 SW-ABB. UND 2 TAB. GB. ISBN 978-3-205-98962-2

76 AUTONOMIE IM BILDUNGSWESEN. ZUR TOPOGRAPHIE EINES BILDUNGSPOLITISCHEN SCHLÜSSELBEGRIFFS. VON WALTER BERKA. 2002. 213 S. BR. ISBN 978-3-205-99309-4

77 HOCHSCHULZUGANG IN EUROPA. EIN LÄNDERVERGLEICH ZWISCHEN ÖSTERREICH, DEUTSCHLAND, ENGLAND UND DER SCHWEIZ. VON ELISABETH HÖDL. 2002. 227 S. BR. ISBN 978-3-205-99421-3 (VERGRIFFEN)

78 FORSCHUNG UND LEHRE. DIE IDEE DER UNIVERSITÄT BEI HUMBOLDT, JASPERS, SCHELSKY UND MITTELSTRASS. VON HEDWIG KOPETZ. 2002. 137 S. 4 SW-ABB. BR. ISBN 978-3-205-99422-0

79 EUROPÄISCHE KULTURGESCHICHTE: GELEBT, GEDACHT, VERMITTELT. VON MANFRED WAGNER. 2009. 922 S. GB. ISBN 978-3-205-77754-O

80 KULTUR DER DEMOKRATIE. FESTSCHRIFT FÜR MANFRIED WELAN ZUM 65. GEBURTSTAG. HG. VON CHRISTIAN BRÜNNER, WOLFGANG MANTL, ALFRED J. NOLL UND WERNER PLESCHBERGER. 2002. 383 S. ZAHLR. TAB. UND 1 SW-ABB. GB. ISBN 978-3-205-77005-3

81 OKKUPATION UND REVOLUTION IN SLOWENIEN (1941-1946). EINE VÖLKERRECHTLICHE UNTERSUCHUNG. VON DIETER BLUMENWITZ. 2005. 162 S. BR. ISBN 978-3-205-77250-7

82 DER KONVENT ZUR ZUKUNFT DER EUROPÄISCHEN UNION. HG. VON WOLFGANG MANTL, SONJA PUNTSCHER RIEKMANN UND MICHAEL SCHWEITZER. 2005. 185 S. BR. ISBN 978-3-205-77127-2

83 ART GOES LAW. DIALOGE ZUM WECHSELSPIEL ZWISCHEN KUNST UND RECHT. HG. VON DIETMAR PAUGER. 2005. 269 S. 9 SW-ABB. BR. ISBN 978-3-205-77128-9 DIREKTE DEMOKRATIE. VON KLAUS POIER. IN VORBEREITUNG HOCHSCHULRECHT - HOCHSCHULMANAGEMENT - HOCHSCHULPOLITIK. SYMPOSION AUS ANLASS DES 6O. GEBURTSTAGES VON CHRISTIAN BRÜNNER. HG. VON GERHARD SCHNEDL UND SILVIA ULRICH. 2003. 258 S. 7 GRAF. UND 5 TAB. GB. ISBN 3-205-99468-X 


\section{STUDIEN ZU POLITIK UND VERWALTUNG}

HERAUSGEGEBEN VON CHRISTIAN BRÜNNER,

WOLFGANG MANTL, MANFRIED WELAN

86 DAS ZERRISSENE VOLK. SLOWENIEN 1941-1946. OKKUPATION, KOLLABORATION, BÜRGERKRIEG, REVOLUTION. VON TAMARA GRIESSER-PEČAR. 2003. 583 S. GB. ISBN 978-3-205-77062-6

87 ZUR QUALITÄT DER BRITISCHEN UND ÖSTERREICHISCHEN DEMOKRATIE. EMPIRISCHE BEFUNDE UND ANREGUNGEN FÜR DEMOKRATIEREFORM. VON E. ROBERT A. BECK UND CHRISTIAN SCHALLER. 2003. XXII + 620 S. ZAHLR. TAB. BR. ISBN 978-3-205-77071-8

88 DIE ÖSTERREICHISCHE AKADEMIE DER WISSENSCHAFTEN. AUFGABEN, RECHTSSTELLUNG, ORGANISATION. VON HEDWIG KOPETZ. 2006. $X X+$ 457 S. 8 SW-ABB. BR. ISBN 978-3-205-77534-8

89 RAUMFAHRT UND RECHT. FASZINATION WELTRAUM. REGELN ZWISCHEN HIMMEL UND ERDE. HG. VON CHRISTIAN BRÜNNER, ALEXANDER SOUCEK UND EDITH WALTER. 2007. 200 S. 66. FARB. ABB. BR.

ISBN 978-3-205-77627-7

90 SOZIOKULTURELLER WANDEL IM VERFASSUNGSSTAAT. PHÄNOMENE POLITISCHER TRANSFORMATION. FESTSCHRIFT FÜR WOLFGANG MANTL ZUM 65. GEBURTSTAG. HG. VON HEDWIG KOPETZ, JOSEPH MARKO UND KLAUS POIER. 2004. 2 BDE. IM SCHUBER. XXIV + 700 S., $X+1000$ S. ZAHLR. TAB., GRAF. UND ABB. GB.

ISBN 978-3-205-77211-8

91 NATIONALES WELTRAUMRECHT. NATIONAL SPACE LAW. DEVELOPMENT IN EUROPE - CHALLENGES FOR SMALL COUNTRIES. HG. VON CHRISTIAN BRÜNNER UND EDITH WALTER. 2008. 231 S. ZAHLREICHEN ABB. BR. ISBN 978-3-205-77760-1

93 KARL LUEGER (1844-1910). CHRISTLICHSOZIALE POLITIK ALS BERUF. VON JOHN W. BOYER. AUS DEM ENGLISCHEN ÜBERSETZT VON OTMAR BINDER. 2009. 595 S. 19 SW-ABB. GB. ISBN 978-3-205-78366-4

94 DER ÖSTERREICHISCHE MENSCH. KULTURGESCHICHTE DER EIGENART ÖSTERREICHS. VON WILLIAM M. JOHNSTON. BEARBEITET VON JOSEF SCHIFFER. 2009. 384 S. GB. ISBN 978-3-205-78298-8

95 FUNKTIONEN DES RECHTS IN DER PLURALISTISCHEN WISSENSGESELLSCHAFT. FESTSCHRIFT FÜR CHRISTIAN BRÜNNER ZUM 65. GEBURTSTAG. HG. VON SILVIA ULRICH, GERHARD SCHNEDL UND RENATE PIRSTNEREBNER. 2007. XXIV + 696 S. GB. ISBN 978-3-205-77513-3

BÖHLAU VERLAG, WIESINGERSTRASSE I, A-IOIO WIEN, T: + 43 I 33024 27-O VERTRIEB@BOEHLAU.AT, WWW.BOEHLAU-VERLAG.COM 


\section{STUDIEN ZU POLITIK UND VERWALTUNG}

HERAUSGEGEBEN VON CHRISTIAN BRÜNNER,

WOLFGANG MANTL, MANFRIED WELAN

97 DEMOKRATIE IM UMBRUCH. PERSPEKTIVEN EINER WAHLRECHTSREFORM. HG. VON KLAUS POIER. 2009. 329 S. MIT ZAHLREICHEN TAB. BR. ISBN 978-3-205-78434-O

98 DIE FREIHEIT DER POLITISCHEN MEINUNGSÄUSSERUNG. IHRE ENTWICKLUNG IM ÖSTERREICHISCHEN UND BRITISCHEN VERFASSUNGSRECHT UND IHRE STAATSPHILOSOPHISCHEN WURZELN. VON STEPHAN G. HINGHOFER-SZALKAY. 2011. 307 S. 2 TAB. UND 3 GRAFIKEN. BR.

ISBN 978-3-205-78622-1

99 DER UMFANG DER ÖSTERREICHISCHEN GESCHICHTE. AUSGEWÄHLTE STUDIEN 1990-2010. VON GERALD STOURZH 2011. 344 S. BR.

ISBN 978-3-205-78633-7

101 SKURRILE BEGEGNUNGEN. MOSAIKE ZUR ÖSTERREICHISCHEN GEISTESGESCHICHTE. MIT EINEM VORWORT VON WILLIAM M. JOHNSTON. VON NORBERT LESER. 2011. 254 S. 2 S/W-ABB. GB. MIT SU. ISBN 978-3-205-78658-O 102 SOFT LAW IN OUTER SPACE. THE FUNCTION OF NON-BINDING NORMS IN INTERNATIONAL SPACE LAW. HG. VON IRMGARD MARBOE. 2012. 407 S. FRANZ. BR. ISBN 978-3-205-78797-6

103 EUROPASPRACHEN. HERAUSGEGEBEN VON PETER CICHON UND MICHAEL MITTERAUER. 2011. 166 S. BR. MIT SU. ISBN 978-3-205-78608-5

105 LEBENSZEUGNISSE ÖSTERREICHISCHER VIZEKANZLER. DAS POLITISCHE SYSTEM ÖSTERREICHS IM EUROPÄISCHEN VERGLEICH. 2012. ISBN 978-3-205-77759-5

106 ÖSTERREICH AUF DEM WEG ZUR DEMOKRATIE? AUFMERKSAME BEOBACHTUNGEN AUS EINEM HALBEN JAHRHUNDERT. 2012. $358 \mathrm{~S}$. GB. MIT SU. ISBN 978-3-205-78853-9

107 JOSEPHINISCHE MANDARINE. BÜROKRATIE UND BEAMTE IN ÖSTERREICH BAND 2: 1848-1914. 2013. 332 S. GB. MIT SU. ISBN 978-3-205-78853-9

BÖHLAU VERLAG, WIESINGERSTRASSE I, A-IOIO WIEN, T: + 43 I 33024 27-O VERTRIEB@BOEHLAU.AT, WWW.BOEHLAU-VERLAG.COM 


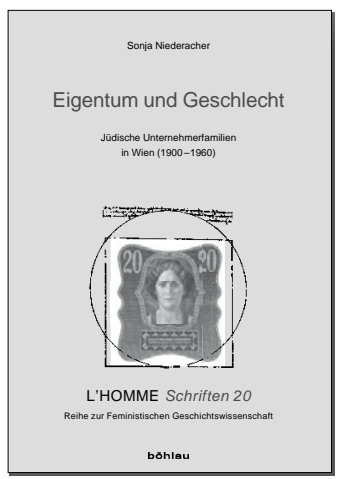

SONJA NIEDERACHER

EIGENTUM UND GESCHLECHT

JÜDISCHE UNTERNEHMERFAMILIEN IN WIEN (1900-1960)

L'HOMME SCHRIFTEN, BD. 20

Die Studie untersucht, wie Männer und Frauen aus jüdischen Mittelschichtsfamilien in Wien - durch Erbschaft, Heirat und unternehmerisches Handeln - Vermögen erwerben konnten. Dabei zeigt sich, dass das Geschlecht einer Person nicht nur die Höhe ihres Vermögens, sondern auch dessen Zusammensetzung beeinflusste. So hatten Männer mehr von ihrem Geld in Wertpapieren angelegt als Frauen, die eher Immobilien besaßen. Gefragt wird danach, welche Handlungsmöglichkeiten sich für Männer und Frauen aus ihrer Vermögenszusammensetzung ergeben konnten. Neben der Vermögensbildung selbst und dem Umgang mit Vermögen werden Eigentumsverluste durch die nationalsozialistische Verfolgung sowie Restitutions- und Entschädigungsmaßnahmen in der frühen Zweiten Republik mit Geschlecht als zentraler Kategorie analysiert.

2012. 256 S. FRANZ. BR. | ISBN 978-3-205-78751-8

BÖHLAU VERLAG, WIESINGERSTRASSE I, A-IOIO WIEN, T:+43 I 33024 27-O INFO@BOEHLAU-VERLAG.COM, WWW.BOEHLAU-VERLAG.COM | WIEN KÖLN WEIMAR 

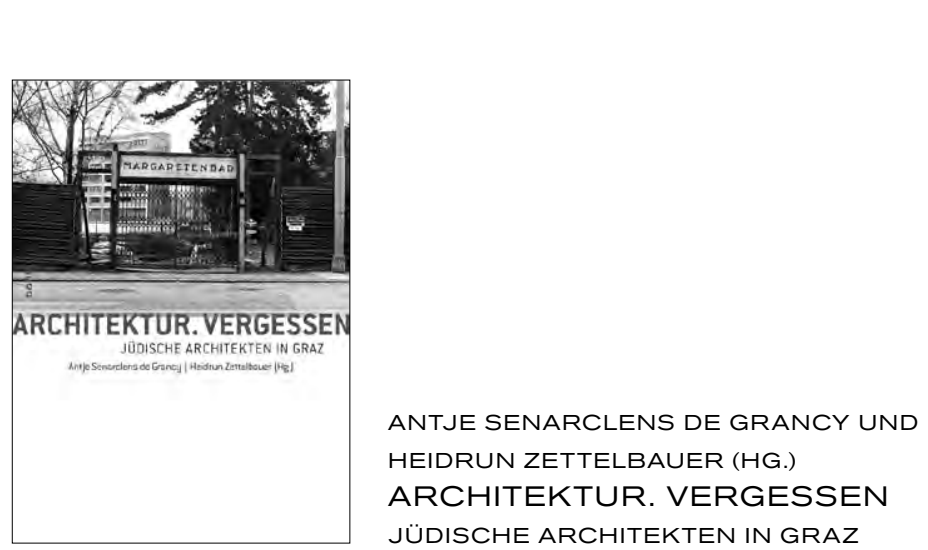

Fünf Grazer Bauten aus der Zeit von 1910 bis 1934 bilden den Ausgangspunkt für den Blick auf das Vergessen als kulturelle Praxis im Feld der Architektur. Die Autorinnen zeichnen ein Spannungsfeld zwischen alltäglichen Prozessen der Überbauung, Funktionsveränderung und räumlicher Neukonzeption sowie gewaltsamen Eingriffen wie politischer Neukodierung und Zerstörung nach.

Am Beispiel von Arbeitsamt, Freibad, Jüdischer Zeremonienhalle, Kinderheim und Stadtrandsiedlung werden vielschichtige Dimensionen des Vergessens freigelegt: Zufälliges, Intentionales, Privates, Öffentliches, Nicht-Erzähltes, Un-/Sichtbares.

Die Klammer, welche die vier Architekten und Baumeister zusammenhält, ergibt sich nicht aus ihrer jüdischen Herkunft oder Identität, sondern erst aus der nationalsozialistischen Verfolgungsgeschichte als einem Aspekt des Vergessens.

2010. BR. 300 S. 178 S/W-ABB. $170 \times 240$ MM.

ISBN 978-3-205-78472-2

BÖHLAU VERLAG, WIESINGERSTRASSE I, IOIO WIEN. T : + 43(o) I 33024 27-O BOEHLAU@BOEHLAU.AT, WWW.BOEHLAU-VERLAG.COM | WIEN KÖLN WEIMAR 


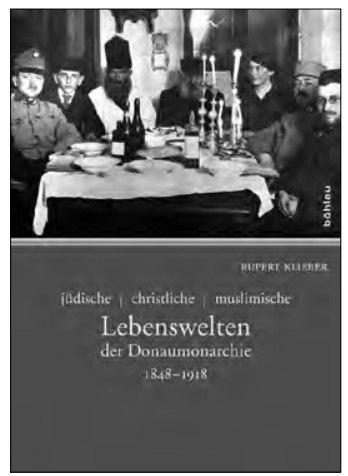

EIN PROJEKT DER
ÖSTERREICHISCHEN
FORSCHUNGSGEMEINSCHAFT

Die Habsburgermonarchie war nicht nur ein Vielvölkerstaat, sondern auch ein multireligiöses Reich. Das Buch betrachtet ihre fünf großen „Konfessionsfamilien“ (ostkirchliche, katholische und evangelische Christen, Juden und Muslime) erstmals vergleichend aus „lebensweltlicher" Perspektive: Wie stark haben ihre kulturellen und spirituellen Impulse den Alltag der Betroffenen geprägt? Inwieweit haben ihre Normen deren Lebens-Chancen gefördert oder beeinträchtigt? Die Religionsgemeinschaften der Monarchie standen auf einem starken Fundament aus volksreligiösen Vorstellungen und Praktiken, die in kreativer Wechselwirkung zu ihren offiziellen Positionen standen. Die zunehmend religionskritische Zeit zwang sie, neue Vorkehrungen für ein „Leben mit dem Glauben“ zu treffen: für Gottesdienste, religiöse Lebensgestaltung, soziale Hilfe, die Formung der Kinder zu sorgen. Sie kreierten dafür oft recht ähnliche Modelle. Die Monarchie hat mehr als andere Großmächte auf die „religiöse Karte“ gesetzt: Gezielte Förderung sollte die Konfessionen zu Stützen der Gesellschaft machen, was nur teilweise gelang. Sie blieben jedoch „Sinnprovinzen“: Ohne sie wären ihre Länder kulturell ärmer und sozial kälter gewesen; und sie hätten unter den überhitzten Nationalismen der Zeit wohl noch mehr gelitten, als dies ohnehin der Fall war.

2010. GB. MIT SU. 294 S. 58 S/W- \& 17 FARB. ABB.

$170 \times 240$ MM. | ISBN 978-3-205-78384-8

BÖHLAU VERLAG, WIESINGERSTRASSE I, IOIO WIEN. T : + 43(O) I 33024 27-O BOEHLAU@BOEHLAU.AT, WWW.BOEHLAU-VERLAG.COM | WIEN KÖLN WEIMAR 

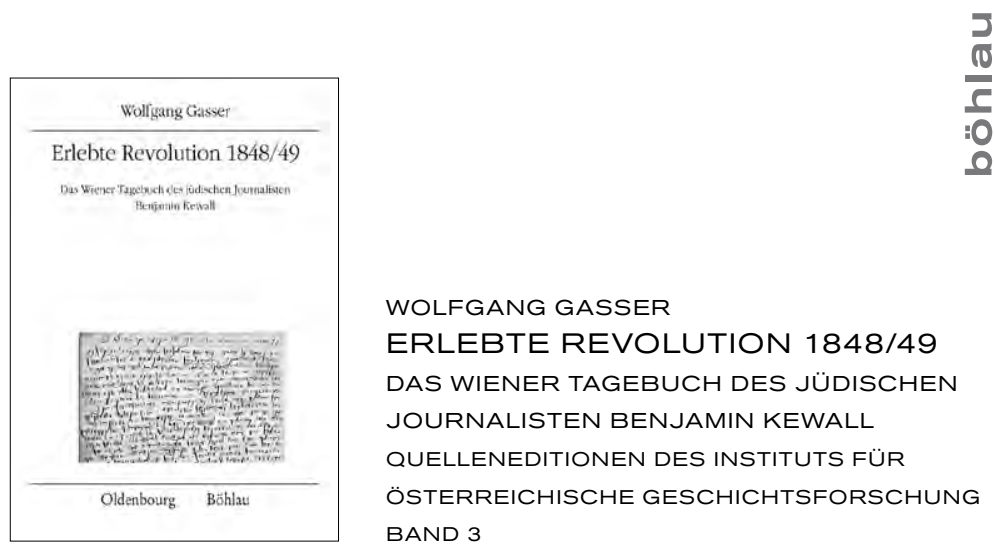

Dieses Buch beinhaltet eine besondere Kostbarkeit - das aus dem Müll gerettete Tagebuch des Hauslehrers und Journalisten Benjamin Kewall, das die Zeit vom 27. August 1848 bis zum 31. Mai 1850 umspannt. Seine Schilderungen betreffen die Wiener Revolution 1848/49 sowie zahlreiche Episoden aus dem nahen Umfeld des Tagebuchschreibers. Mit dieser Edition werden die im Original auf Deutsch mit hebräischen Lettern festgehaltene Aufzeichnungen nun in deutscher Schreibweise veröffentlicht, damit einem breiten Publikum zugänglich gemacht und Kewalls Lebenswelten ausführlich beleuchtet.

2010,545 S. BR. $170 \times 240 \mathrm{MM}$.

ISBN 978-3-205-78302-2

BÖHLAU VERLAG, WIESINGERSTRASSE I, IOIO WIEN. T : + 43(O) I 33024 27-O BOEHLAU@BOEHLAU.AT, WWW.BOEHLAU.AT | WIEN KÖLN WEIMAR 
Vor dem Hintergrund der Entrechtung und Ausbürgerung der österreichischen Juden während der NS-Zeit wird hier der umgekehrte Prozess der stufenweisen Inklusion von Juden in Heimatrecht und Staatsbürgerschaft der österreichischen Monarchie seit den josephinischen Toleranzedikten beschrieben. Dabei zeigt sich nicht nur die Bedeutung der Erlangung der vollen staatsbürgerlichen Rechte für den gesellschaftlichen, ökonomischen und kulturellen Aufstieg der Juden, sondern auch, wie sehr Heimatrecht und Staatsbürgerschaft - oder umgekehrt: Staatenlosigkeit - Leben und Identität von Menschen prägten, noch weit über die Monarchie hinaus. 